


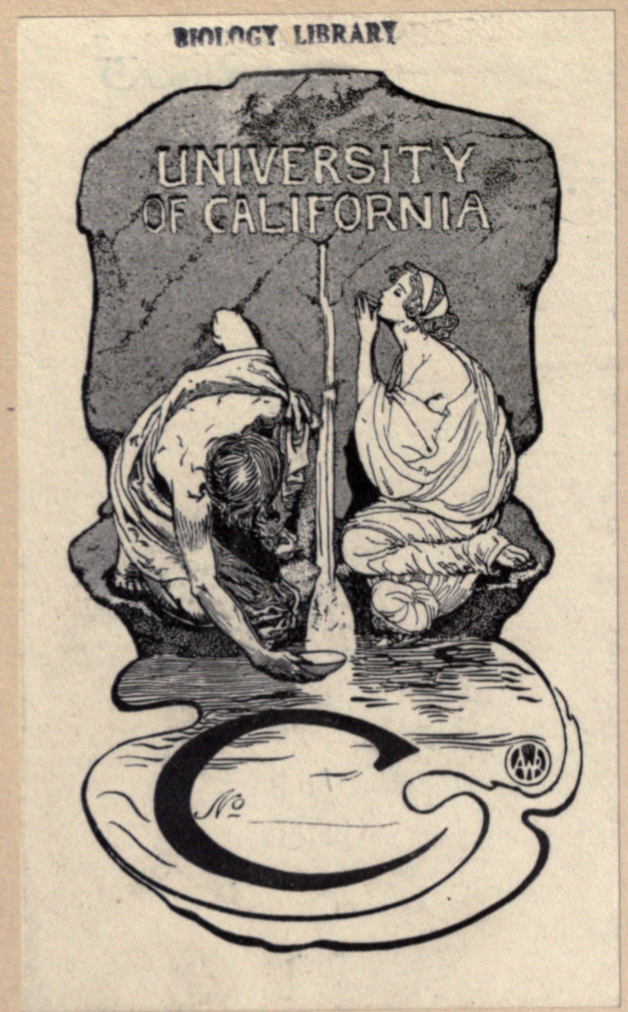










\section{VETER IN A R Y BACTERIOLOGY}

\section{A TREATISE ON THE}

BACTERIA, YEASTS, MOLDS, AND PROTOZOA PATHOGENIC FOR DOMESTIC ANIMALS

BY

\section{ROBERT EARLE BUCHANAN, Ph.D.}

PROFESSOR OF BACTERIOLOGY IN THE IOWA STATE COLLEGE OF AGRICULTURE AND MECHANIC ARTS, DIVISION OF VETERINARY MEDICINE; BACTERIOLOGIST OF THE IOWA AGRICULTURAL EXPERIMENT STATION

WITH 214 ILLUSTRATIONS

PHILADELPHIA AND LONDON

W. B. SAUNDERS COMPANY 1911 


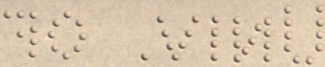

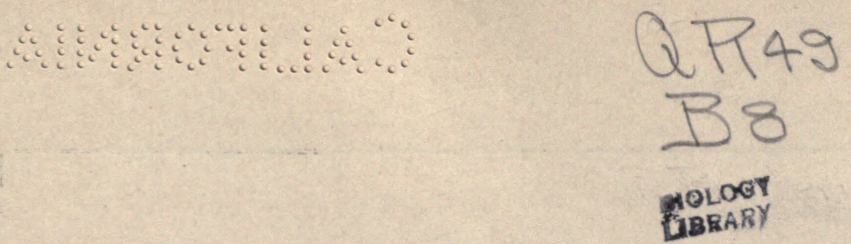

Copyright, r9r I, by W. B. Saunders Company

PRINTED IN AMERICA

PRESS OF

w. B. SAUNDERS COMPANY PHILADELPHIA 


\section{PREFACE}

THE present volume is a revision of the lectures on veterinary bacteriology given during the past six years to classes in the Division of Veterinary Medicine in the Iowa State College. It constitutes a serious attempt to put in usable form that fund of knowledge concerning bacteriology which the student of veterinary medicine should master. It is in no sense a text on pathology, and discussion of purely pathological subjects has been minimized as much as possible. The intention has been to confine attention as far as practicable to those topics that unquestionably lie in the province of bacteriology. This has been defined to include a discussion of immunity and of the pathogenic bacteria, yeasts, molds, and protozoa.

The book is not intended to serve as a manual of laboratory practice, hence detailed discussion of methods and technic has been omitted. Methods of significance in diagnosis or treatment are given in greater detail in the discussion of specific organisms.

Several organisms causing diseases of man not transmissible to lower animals have been included. In all cases they are closely related to organisms baving significance to the veterinarian, they cause diseases which are commonly confused with somewhat similar diseases of lower animals, or they are valuable as illustrations of methods of immunization, treatment, or diagnosis. Such organisms are relatively few in number.

A group system of discussion of the pathogenic bacteria has been adopted. The classification used has proved very helpful in my own classwork. The groupings used are not entirely satisfactory, in part due to the fact that some of the species have not been adequately described and differentiated in the literature. An effort has been made to point out the deficiencies in our present knowledge, both to give a better balanced presentation of the subject and to stimulate interest in the solution of the problems. 
The pathogenic protozoa constitute a group which is particularly difficult to treat adequately, largely due to the rapid growth of the subject. Relatively few of the forms, moreover, are of immediate interest to the North American student.

I wish gratefully to acknowledge the assistance of my wife in the preparation of illustrations and revision of manuscript, that of Mr. Chas. Murray in proof reading, and that of Dean Chas. C. Stange and Dr. Murphy, of the Division of Veterinary Medicine, for critical reading of the manuscript.

Iowa State College, Ames, Iowa.

R. E. Buchanan.

July, 1911 . 


\section{CONTENTS}

\section{SECTION I}

\section{MORPHOLOGY, PHYSIOLOGY, AND CLASSIFICATION OF BACTERIA}

Chapter I.-Introduction ............................

The Microscope and Its Influence, 18.-Nature and Classification of Microörganisms, 20.- Spontaneous Generation, 20.-Relation of Microörganisms to Fermentation and Decay, 21.-Relationship of Microörganisms to Disease, 21.Development of Laboratory Methods, 22. -Development of Theories of Immunity, 23.-Development of Sanitary Science and Preventive Medicine, 23.

\section{Chapter II.-Morphology and Relationships of Microörganisms}

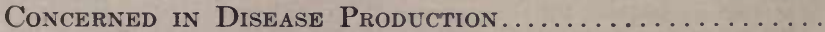

Position of Pathogenic Microörganisms, 25.-Differentiation of Animals and Plants, 25.-Subdivisions of the Thallophytes, 26.- Morphology of Bacteria, 27.Shape of Bacteria, 27. - Grouping of Bacterial Cells, 28. - Size of Bacteria, 30.Histology and Structure of Bacteria, 31.-Reproduction in Bacteria, 35.-Morphology of the Yeasts, Saccharomycetes, and Blastomycetes, 37.-Form, Size, and Grouping of Yeasts, 38. - Histology and Structure of the Yeast, 38. - Yeast Protoplasm and Cell Inclusions, 38. - Reproduction in Yeasts, 39.-Morphology of the Hyphomycetes or Molds, 40.-Form and Size of Hyphomycetes or Molds, 40. -Histology and Structure of Molds, 41.- Reproduction of Molds, 42. - Morphology of the Protozoa, 43. - Form and Size of Protozoa, 44.-Histology, 44. - Reproduction, 44.

Chapter III.-Physiology of Microörganisms ..............

Food Relationships of Microörganisms, 45.-Composition of the Cell, 45.-Sources and Kinds of Foods, 45.-Moisture Relationships of Microörganisms, 46.-Respiration of Micrö̈rganisms, 47.-Temperature Relationships of Microörganisms, 48.Optimum Temperature, 48.-Minimum Temperature, 48.-Maximum Growth Temperature, 48. -Growth Temperature Range, 48.- Thermal Death Point, 48. - Light Relationships of Microörganisms, 49.-Effect of Electricity on Bacteria, 50.-Relationships of Microörganisms to Chemicals, 50.-Chemotaxy, 50- - Tropisms, 51.- Influence of Reaction of Medium on Growth, 52.-Antisertics and Disinfectants, 52. - Disinfectants and Antiseptics in Common Use, 53.- Adjustment of Organisms to Osmotic Pressure, 55.- Symbiosis, Antibiosis, and Commensalism, 56.-Pigment Production by Microörganisms, 56. - Light Production by Microörganisms, 57.-Fermentation and Enzyme Production, 58.

\section{Chapter IV.-Changes of Economic Significance Brought About}

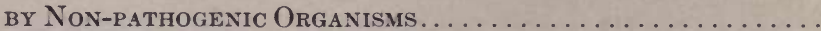

Production of Alcohol, 62.-Production of Acids, 62.-Decay and Putrefaction, 64. - Reduction Processes in Inorganic Compounds, 66.- Oxidation of Inorganic Compounds, 67.-Miscellaneous Changes, 74 .

Chapter V.-Classification of Microörganisms .............

Classification of Bacteria, 76.-Key to the Groups and Genera of Bacteria, 77.Streptococcus, 77.-Diplococcus, 78.-Micrococcus, 78.-Staphylococcus, 78.Bacillus, 78.-Spirillum, 79.- Spirochæta, 80.-Chlamydobacteriaceæ, 80.Beggiatoa, s1.-Classification of Yeasts, 82. - Classification of the Molds, 82. 


\section{SECTION II}

\section{LABORATORY METHODS AND TECHNIC}

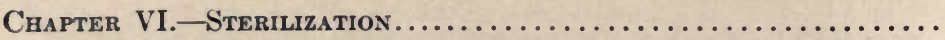

Sterilization by the Flame, 83. - Sterilization by Hot Air, 83. Sterilization by Streaming Steam, 84. - Sterilization by Steam under Pressure, 85. - Sterilization at Temperature Lower than Boiling-point, 87. - Sterilization by Addition of Chemicals, 87. - Sterilization by Filtration, 87.

Chapter Vil.-Culture-media and Their Preparation..........

Use of Normal Salt Solutions of Acid and Alkali and Methods of Expressing Reactions, 89. - Nature of Nutrients Required by Bacteria, 90. - Liquid Media, 91. - Bouillon or Beef Broth from Meat, 91. - Bouillon or Broth from Beef Extract, 91. - Sugar-free Broth, 91. - Sugar Broth, 92.-Glycerin Broth, 92. Serum Broth, 92.-Dunham's Solution, 92.- Beerwort, 92.-Milk, 92. - Synthetic Media, 92.Liquefiable Solid Media, 93.--Nutrient Gelatin, 93.- Other Gelatin Media, 93.Nutrient Agar, 93.- Other Agar Media, 93.-Non-liquefiable Media, 94.-Potato, 94. - Other Vegetable Media, 94.-Blood-serum, 94.-Egg Medium, 95.

Chapter Vili.-Biochemical Tests......................

Acid Production, 96.-Alkali Production, 96.-Gas Production, 96.-Reduction Processes, 97. - Indol Production, 98. - Thermal Death-point, 99.-Efficiency of Disinfectants, 99.

Chapter IX.-Microscopic Examination and Staining Methods..

Measuring Bacteria, 101.-Examining of Living Bacteria, 101.-Hanging Drops, 101. - Staining Methods, 102. - Mordants, 102.-Formulas of Some of the Commonly Used Stains, 102.-Preparation of a Stained Mount, 103. Spore Stain, 104. - Stain for Acid-fast (Acid-proof) Organisms, 104.-Flagella Stain, 105.Gram's Staining Method, 106.-Blood and Protozoan Stains, 106.

Chapter X.-Methods of Securing Pure Cultures of Bacteria....

Dilution Method, 107.-Isolation by Smearing, 107.-Direct Isolation, 107.Isolation by Plating, 108. - Isolation by the Use of Heat, 109.-Isolation by the Use of Differential Antiseptics or Disinfectants, 109.-Isolation by Animal Inoculation, 109.

Chapter Xi.-Study of Bacterial Cultures...............

Cultural Characters, 110.-Agar Stroke, 110 -Potato, 110-Blood-serum, 111 Gelatin Stab, 111. - Nutrient Broth, 111.-Milk, 111.-Litmus Milk, 112.Gelatin Plate Colonies, 112.-Colonies on Agar Plates, 113.-Physiological Characters, 115.

\section{SECTION III}

\section{BACTERIA AND THE RESISTANCE OF THE ANIMAL BODY TO DISEASE}

Cuapter XII.-Bacteria and Disease; General Considerations. . 116 Koch's Rules, 116.-Animal Inoculation, 117.-Interrelationships of the Organism and the Body, 119 .

Chapter Xili.-Immunity. General Discussion..............

Immunity, 121. - External Resistance to Infection, 121.-Variations of Individuals in Susceptibility to Disease. Predisposing Factors, 122. -Typcs of Immunity, 122.- Natural Inmunity, 122.-Acquired Immunity, 123.-Active Acquired Immunity, 123.-Acquired Passive Immunity, 125.- Theories of Immunity, 125. - Theory of Exhaustion, 125. - Noxious Retention Theory, 126 - Metchnikoff's Theory of Phagocytosis, 126.-Ehrlich's Humoral Theory, 126. -Duration of Immunity, 127. - Antigens and Antibodies, 127.-Antibodies as Factors in Acquired Immunity, 127. 
Antibodies of Ehrlich's First Order, 129.-Toxins, 129. - Antitoxins, 131.-Constitution of the Toxin, 134. - Constitution of Antitoxin, 134.-Diagrammatic Representation of Toxin and Antitoxins, 135.--Preferential Union of Toxins with Body-cells, 135. - Antitoxins of Commercial Importance, 136.-Manufacture of Diphtheria Toxin and Antitoxin, 136.-Preparation of Tetanus Toxin and Antitoxin, 143.-Preparation of Other Toxins and Antitoxins, 145.-Antienzymes, 145. -Other Antibodies Related to Antitoxins, 146.

Chapter XV.-Agglutination and Precipitation............. 147

Antibodies of Ehrlich's Second Order, 147.-Differentiation of Precipitation and Agglutination, 147.-Agglutination, 147.--Precipitins, 154.

Chapter XVi.-Cytolysins, Including Bacteriolysins, and Hemo-

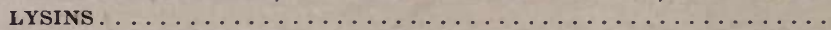

Antibodies of Ehrlich's Third Order, 157.-Cytolysins, 157.-Group Cytolysins, 160.-Bacteriolysins, 160.-Hemolysins, 162.-Fixation of Complement and Its Utilization, 163.-Cytotoxins, 165.

Chapter XVII.-Opsonins and Phagocytosis.............. 166

Opsonins, 167.-Opsonic Index, 169.-Autogenic Vaccines, 173.-Passive Opsonic Immunization, 175.

Chapter XVIII.-Anaphylaxis and Hypersusceptibility....... 176

Phenomenon of Arthus, 176. - Serum Sickness in Man, 176.-Theobald Smith Phenomenon, 177.-Antibodies in Anaphylaxis, 177.- Relationship of Anaphylaxis to Certain Body Reactions, 179.

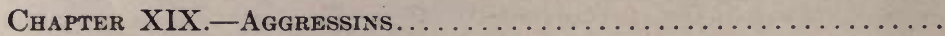

\section{SECTION IV}

\section{PATHOGENIC MICROÖRGANISMS EXCLUSIVE OF THE PROTOZOA}

Chapter XX.-Microörganisms as a Cause of Disease.......... 183

Infectious Diseases, 183.-Contagious Diseases, 183.-Bacteria Normally Present in the Body or on its Surface, 184. - Types of Disease Produced by Microörganisms, 186.- How Bacteria Produce Disease, 187.-Groups of Pathogenic Microorganisms Exclusive of Protozoa, 187.

Chapter XXI.-Non-specific Pyogenic Cocci................

Micrococcus Aureus, 192.-Micrococcus Albus, 196.-Micrococcus Citreus, 196.- Micrococci of Uncertain Significance, 196. - Streptococcus Pyogenes, 197.Streptococcus Lacticus, 204.

Chapter XXII.-Specific Infectious Diseases Produced by Cocci . . 207

Streptococcus Equi, 207.-Streptococcus Gallinarum, 210.-Streptococcus Sp., 211. - Streptococcus Sp., 213.- Other Streptococci of Uncertain Significance, 214.-Streptococcus Pneumonix, 215.-Micrococcus Meningitidis, 218.-Micrococcus Intracellularis Equi, 220.-Micrococcus Melitensis, 221.-Micrococcus Caprinus, 222.-Micrococcus Gonorrhœeæ, 224.-Micrococcus Ascoformans, 226.

Chapter XXIII.-Non-specific Pyogenic Bacilli.............

Bacillus Pyocyaneus, 228.-Bacillus Pyogenes Suis, 230.

Chapter XXIV.-Diphtheria Group

Bacillus Diphtheriæ, 231.-Bacillus Pseudodiphthericus, 236. 
Chapter XXV.-Bacillus Pseudotuberculosis Grodp........... 238

Bacillus Pseudotuberculosis, 238.-Bacillus Lymphangitidis Ulcerosa, 241.Bacillus Pyogenes Bovis, 242

Chapter XXVI.-Swine Erysipelas Group...............

Bacillus Rhusiopathiæ, 244.-Bacillus Murisepticus, 248.

Chapter XXViI.-Glanders Group..................

Bacillus Mallei, 250.-Bacilli of Selter, Babes, and Kutscher, 260.

Chapter XXViII.-Intestinal or Colon-typhoid Group. Water

AnALYSIS. . . . . . . . . . . . . . . . . .

Subgroup I-Colon Subgroup, 262.-Bacillus Coli, 262.-Bacillus Lactis Aërogenes, 266. - Bacillus Pneumoniæ, 267.-Subgroup II-Intermediate, Hog-cholera, or Enteritidis Subgroup, 268.-Bacillus Enteritidis, 268.-Bacillus Choleræ Suis, 271.-Bacillus Paratyphosus, 274. - Bacillus Psittacosis, 276.-Bacillus Typhi Murium, 276. - Bacillus Pullorum, 277.-Subgroup III-Typhoid-dysentery Suboroup, 278.-Bacillus Typhosus, 278.-Bacillus Dysenteriæ, 282.-Bacteria of Water and Water Purification, 284. - Quantitative Examination of Water, 285.Qualitative Examination of Water, 287.-Water Purification, 289.

Chapter XXIX.-Hemorrhagic Septicemia Group.............

Bacillus Avisepticus, 295.-Bacillus Suisepticus, 298.-Bacillus Bovisepticus, 302. - Other Hemorrhagic Septicemias of Animals, 303.- - Bacillus Pestis, 303.

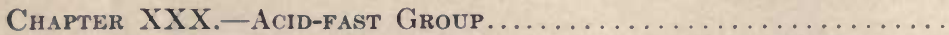

Bacillus Tuberculosis, 308.-Bacillus of Johnes' Disease, 326.-Bacillus Lepræ, 328. - Non-pathogenic Acid-fast Bacteria, 329.

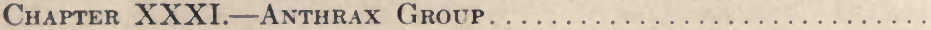

Bacillus Anthracis, 331.-Bacillus Iactimorbi, 338.

Chapter XXXil.-Abortion Bacilley Group..............

Bacillus Abortus, 341 .

Chapter XXXiII.-Bacillus Necrophorus Group............

Bacillus Necrophorus, 345.

Chapter XXXIV.-Group of Spore-bearing Anaërobes

Bacillus Tetani, 349.-Bacillus Chauvæi, 355.-Bacillus Gastromycosis Ovis, 359. -Bacillus Wdematis, 359.-Bacillus Welchii, 361.-Bacillus Botulinus, 364.

Chapter XXXV.-Vibrio or Cholera Spirillum Group..........

Spirillum Metchnikovi, 367.-Spirillum Choleræ, 369.-Non-pathogenic Spirilla, 371.

Chapter XXXVI.-Actinomyces Group.

Actinomyces Iovis, 375.-Actinomyces Nocardii, 378.-Actinomyces Capræ, 380.-Actinomyces Madurx, 381.-Actinomyces Eppingeri, 382. - Actinomyces of Other Infections, 382 .

Chapter XXXViI.-Blastomycetes.

Blastomyces Farciminosus, 384.- Blastomycetes Dermatitidis, 386.-Blastomyces Coccidioides, 389.

Chapter XXXVIII.-Mold or Hyphomycete Group

The Genus Aspervillus, 392.-Aspergillus Fumigatus, 395.-Aspergillus Flavus, 398. - Aspergillus Niger, 399. - Other Species of Aspergilli, 400. - The Genus Penicillium, 400.-The Genus Fusarium, 401.-Fusarium Equinum, 402. - The Genus Sporotrichum, 404. - Sporotrichum Beurmanni, 404.- The Genera Trichophyton and Microsporon, Achorion, and Ö̈dium, 408.- Trichophyton Tonsurans, 408. - Achorion Schoenleinii, 409. - Ordium Albicans, 410. 


\section{SECTION V}

\section{PATHOGENIC PROTOZOA}

Chapter XXXiX.-Structure, Relationships, and Classification

of the Protozoa......................... 412

Structure of the Protozoa, 412.-Classification of the Protozoa, 414.

Chapter Xl.-Pathogenic Protozoa of the Class Sarcodina

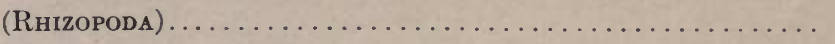

The Genus Entamaba, 416.-Staining Methods, 417.-Methods of Isolation and Cultivation, 417.-Entamcba Coli, 418. -Entamceba Histoly tica, 419. - Entamceba Tetragena, 422 .

Chapter Xli.-Pathogenic Protozoa of the Mastigophora (Ex-

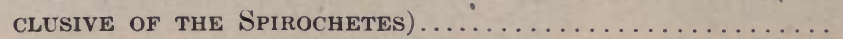

The Genus Trypanosoma, 423.-Morphology, 424.-Cultivation of Trypanosomes, 426. - Method of Disease Production, 426. - Examination and Staining Methods, 426. - Trypanosoma Equiperdum, 426.- Trypanosoma Evansi, 428.- Trypanosoma Brucei, 429. - Trypanosoma Equinum, 431. - Trypanosoma Dimorphon, 432 - Trypanosoma Congolense, 433.- - Trypanosoma Pecaudi, 433.- Trypanosoma Cazalboui, 434.- Trypanosoma Theileri, 435. - Trypanosoma Gambiense, 436.Trypanosoma Cruzi, 437. - Trypanosoma Calmettei, 437.- Trypanosomes in Birds, 437.- Trypanosoma Lewisi, 437.-The Genus Herpetomonas, 438. - Herpetomonas Donovani, 438. - Leishmannia (Herpetomonas?) Infantum, 439.Leishmannia Tropica, 439.

Chapter XliI.-Spirochete Group . . . . . . . . . . . . . .

Spirochæta Obermeieri, 444.-Spirochæta Duttoni, 446.-Spirochæta Kochi, 447. - Spirochæta Anserina or Gallinarum, 448. - Spirochæta Theileri, 450. Spirochæta Pallida, 451. - Spirochæta Pertenuis, 454. - Other Spirochetes, 454.

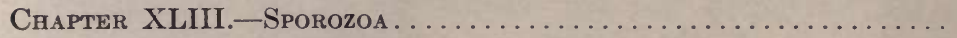

The Genus Piroplasma or Babesia, 456.-Piroplasma Bigeminum, 456.-Piroplasma Parvum, 458.-Piroplasma Mutans, 458.-Piroplasma Equi, 458.Piroplasma Ovis, 460.-Piroplasma Canis, 461.-Piroplasma Gibsoni, 462.Piroplasma Commune, 462. - The Genus Plasmodium, 462.-Plasmodium Vivax, 463. - Plasmodium Malariæ, 464.-Plasmodium Immaculatum and Falciparum, 465.-The Genera Proteosoma, Halteridium, and Hemoproteus, 465.-The Genus Anaplasma, 465.-Anaplasma Marginale, 465.-The Genus Leucocytozoön, 467.The Genus Sarcocystis, 468. - The Genus Coccidium, 469. - Coccidium Tenellum, 470. - Coccidium Cuniculi, 472.-Coccidium of Cattle, 473.-Coccidium of Sheep, 473.

Chapter Xliv.-Pathogenic Protozoa of the Infusoria.........

Balantidium Coli, 474.

\section{SECTION VI}

\section{INFECTIOUS DISEASES IN WHICH THE SPECIFIC CAUSE IS NOT CERTAINLY KNOWN}

\section{Chapter XlV.-Diseases Produced by Ultramicroscopic Organ-} ISMS.

Bacterial or Protozoan Relationships of Ultramicroscopic Organisms, 477.Virus of Pleuropneumonia, 478. - Virus of Foot-and-mouth Disease, 479.Virus of Rinderpest or Cattle Plague, 480.-Virus of Hog-cholera, 481. - Virus of Horse Sickness, 483. - Virus of Infectious Anemia of the Horse, 484. - Virus of Dog Distemper, 485. - Virus of Fowl Plague, 486. - Virus of Epithelioma Contagiosum, 487.- Virus of the Poxes, 488. - Virus of Yellow Fever, 488.-Virus of Epidemic Infantile Paralysis, 488. - Virus of Rabies, 489.

Bibliographical INdex. 



\title{
VETERINARY BACTERIOLOGY
}

\author{
SECTION I \\ MORPHOLOGY, PHYSIOLOGY, AND CLASSIFICATION \\ OF BACTERIA
}

\section{CHAPTER I}

\section{INTRODUCTION}

BACTERIOLOGY may be defined as that branch of science which treats of bacteria, their forms, and functions. Since the true bacteria are plants, this science may be considered as a subdivision of the great mother science of botany. Bacteria are the direct or indirect causes of many pathologic conditions in the bodies of animals, their study may accordingly be regarded also as one of the fundamental sciences underlying medicine.

Certain of the microscopic unicellular animals (protozoa) are likewise commonly considered in a discussion of bacteriology, for some of them are known to cause disease, and have been studied largely by means of the laboratory technic developed by the bacteriologist. There are several other reasons for this inclusion: the dividing line between bacteria and protozoa is far from distinct, and it is impossible to determine in many cases from a superficial examination of a new disease whether it is caused by the invasion of true bacteria or protozoa. Furthermore, the line of demarcation between the true bacteria and that group of plants known as fungi (including molds, mildews, smuts, rusts, toadstools, puff-balls, etc.) is very poorly defined. Several of the molds and yeasts are disease producing, and are generally included in a discussion of bacteriology. Certain worms, mites, 
insects, and other higher forms of animal life are likewise frequently parasitic, but are excluded from consideration here.

Medical bacteriology may be defined as that branch of bacteriology which treats of those microörganisms (including the true bacteria, molds, and protozoa) that produce disease in the animal body or are related directly or indirectly to the maintenance of health.

The history of veterinary bacteriology is closely linked with that of general medical bacteriology, for many of the diseases of man are transmissible to animals and vice versa. It should be remembered that both are merely subdivisions of a great science, concerning which it is important that the student should gain something of a perspective view, particularly with reference to its history and development. This development has been so rapid,

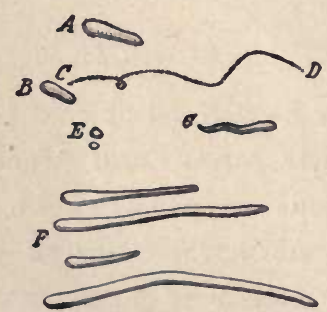

Fig. 1.-Leeuwenhoek's drawings of bacteria: $A, B$, Bacilli, probably; $C-D$, path of movement; $E$, cocci; $F$, Leptothrix, probably; $G$, spirillum.

and so many of the important discoveries have been made within recent years, that it is frequently difficult to determine their relative importance. However, certain facts and personalities stand out so conspicuously that they are deserving of brief consideration.

The Microscope and its Influence.-The existence of living plants or animals smaller than can be seen by the unaided eye was conjectured by several of the Greek philosophers and physicians who used such theories in their speculations on the origin and cause of fermentation and disease. Until the discovery of the microscope such speculations were without any basis in fact.

Leeuwenhoek (1632-1723), in the course of his examinations of a great variety of natural objects by means of the somewhat 
crude lenses of his own manufacture, chanced to observe the presence of motile and motionless microörganisms in the tartar from teeth and in various decaying organic materials. His correspondence with the Royal Society of London and the figures published leave no doubt but that he actually observed bacteria. These drawings are of such historic interest that they are here reproduced.

Each advance in the efficiency of the microscope was followed by an advance in our knowledge of the microörganisms, although speculation frequently outran the ability to see clearly. The compound microscope has proved to be indispensable in the study of these forms. Since the introduction of this instrument the degree of magnification, the clearness of definition, and the mechanic arrangements for accurate focusing have been gradually improved until at the present time the homogeneous oil immersion objective, the compensating ocular, and the Abbé condenser are in constant use in the laboratory, and enable us to secure readily magnification to 1500 diameters or more. During the last several decades there has been little increase in magnification, due to two reasons. The greater the magnification the more convex and consequently the smaller must be the lenses used in the objectives, and the more difficult becomes their grinding and adjustment. Furthermore, the physicist tells us that a clear view, with determination of the size and shape of microscopic objects, cannot be obtained when the objects examined are smaller than one-half the wave length of the rays of light in which they are examined. There is thus a seemingly insurmountable barrier set to an indefinite increase in magnification.

A recent advance has been made through the development of the ultramicroscope. This has made visible objects much smaller than those which had been previously observed. A bright gleam of light from an are or similar source is passed across the darkened field of the microscope, and the light is reflected to the eye from any particles that may be in suspension. These objects are seen in the same manner that minute particles of dust are made visible in a bright ray of light that enters a darkened room. The use of the ultramicroscope has not as yet added many facts of value to our knowledge of the bacteria. 
Nature and Classification of Microörganisms.-Leeuwenhoek, whom we have seen to be the first observer of bacteria, contributed very little to a knowledge of their essential nature. F. Müller (1786) worked out a simple classification, but did not differentiate between bacteria and protozoa. To him we owe several of the group names applied to bacteria, such as bacillus, vibrio, spirillum. Ehrenberg (1795-1875), with the improved microscope and lenses at his command, prepared the first logical classification of bacteria. He differentiated the true bacteria from the protozoa, and his arrangement is the basis for the classification used most extensively at present. Cohn (1828-1898) elaborated and modified Ehrenberg's classification. With the continued improvement in the microscope and laboratory technic, more careful studies of structure, form, and relationships have been rendered possible, and many classifications and groupings for bacteria have been suggested. The difficulty in finding morphologic characters that are accurate indices to true relationships has made the subject a troublesome one. The classification of bacteria most commonly in use at present is that of Migula, published in 1900 in Engler and Prantl's " Synopsis of the Genera of Plants." As will be seen from the discussion recorded in Chapter V, under the heading of Classification, even this system is not wholly satisfactory.

Spontaneous Generation.-In ancient times and even during the middle ages it was generally held by the philosophers and scientists that living things, animals, and plants, could arise de novo. Among the first observations that created doubt in man's mind as to the validity of this belief was that of Francisco Redi, who covered meat with gauze to protect it from flies, and found that maggots did not develop in it spontaneously, but arose from the eggs which the flies deposited on the screen. This pointed the path for other similar studies, and it was not long before the idea of spontaneous generation of the higher forms of life was abandoned. When the microscope revealed the presence of myriads of microörganisms in all decaying or putrefying materials, it was concluded that these organisms arose without progenitors of their own kind, but directly from the organic materials of their surroundings. Boiling was believed to certainly destroy all life, 
yet it was found that boiled decoctions would not always remain free from microörganisms. The theory of spontaneous generation of these bacteria was opposed by some and supported vigorously by others of the best scientists of the time. Experiments were carefully planned and a great variety of materials used, paving the way for the development later of the laboratory technic of the bacteriologist. The sterilizing action of heat, the antiseptic action of certain chemicals, and the value of the cotton plug as a bacterial filter were demonstrated. The theory of spontaneous generation as a topic of contention practically disappeared about 1860 . This was largely due to the efforts of Pasteur, who, by a long series of ingenious experiments, overthrew the last defense of the supporters of the theory. The dictum, omne vivum ex vivo (all life from life), is universally accepted at the present time, and the controversy has little but historic interest.

\section{Relationship of Microörganisms to Fermentation and Decay.-} As has been previously noted, some of the early philosophers hazarded the opinion that decay might be caused by invisible living beings of some kind. The causal relationship of microorganisms to decay and particularly to fermentation was first definitely established by the work of Louis Pasteur (1822-1895). $\mathrm{He}$ found the production of alcohol and carbon dioxid from sugar was due to a yeast, that milk soured because of the activity of bacteria, and that many of the familiar changes in organic substances were accomplished by microörganisms. His conclusions were strenuously opposed and ridiculed by the great German chemist, Liebig. Doubtless the necessity for meeting the attacks of the latter and of establishing his points beyond possibility of refutation led him to devise and develop many of the laboratory methods in common use at the present time. As a result of Pasteur's work the fundamental importance of bacteria in the transformation of nitrogen and carbon compounds in nature, the disposal of waste, the purification of water, the enriching of the soil, and many of the changes in the manufacture of foods have been established.

Relationship of Microörganisms to Disease.-The probable causal relationship of microörganisms of some kind to disease was argued as long ago as 1762 by Blencig, of Vienna. His 
theories were not generally accepted, and it was not until 1840 that Henle proposed what we have come to call the germ theory of disease. He never succeeded in proving his point satisfactorily because of the lack of proper methods and technic. Many other writers within the next few years discussed the theory and numerous facts were adduced in favor of it. The majority of medical practitioners, however, put very little faith in it. The argument that certain organisms were always present was met with the statement that these organisms were the result and not the cause of the disease. Davaine (1863) practically demonstrated by inoculation experiments the causal relationship of a bacillus he found in the blood of diseased animals to anthrax. Pasteur (1865) proved the cause of a silkworm disease to be a protozoan parasite. Koch and Pasteur later cultivated the anthrax organism in the laboratory and showed beyond a doubt its relationship to the specific disease. Improved laboratory technic cleared up the cause of many diseases within the next decade or two. The discovery of the Bacillus tuberculosis by Koch (1882) marks the real beginning of bacteriologic science. The knowledge of protozoa as a cause of disease lagged somewhat behind that of bacterial infections. Evans (1880) described the trypanosome of surra and transmitted the disease by inoculation experiments. In 1882 Laveran observed the Plasmodium malarix, the cause of malaria.

Development of Laboratory Methods.-Progress was delayed in the study of objects as minute as the bacteria because of the lack of proper methods for their isolation, observation, and identification. Culture-media in which the pathogenic microörganisms could be grown were used by Pasteur and Koch. To the latter we are indebted (1882) for our knowledge of the solid media which can be used for the isolation of organisms from mixed cultures. The importance of this contribution can hardly be overestimated, for the use of pure cultures lies at the very foundation of all modern bacteriologic investigation. This one discovery accounts in large measure for the rapid advance made during the next two decades in the identification of the organisms producing disease. The use of aniline dyes in rendering cells and their structure more plainly visible under the microscope we owe to Weigert, 
but the application to bacteriology was made by Koch. Since their introduction successive advances in staining technic have in every instance been followed by the discovery of new organisms related to disease. The microscope, liquefiable media, and anilin dyes constitute the trio of most important factors in the development of the science of bacteriology.

Development of Theories of Immunity.-Knowledge that one attack of certain diseases generally prevented a recurrence and that diseases could not be indiscriminately transferred to all species of animals has existed ever since the foundation of medicine. Many theories have been advanced to account for this phenomenon. A few of the names of investigators who have put the facts into logical form for presentation and study should be considered. Metchnikoff conceived that the white blood-corpuscles and some other body cells acted as scavengers and destroyed microörganisms in the blood. This theory in modified form furnishes to-day the logical basis for many of the operations of the practitioner. Von Behring (1890) published results of studies on the diphtheria bacillus in which he recounted the discovery of the specific toxin of this organism and a specific antitoxin. He laid the foundation for the present-day "humoral" theory of immunity, which supplements so well the phagocytic theories of Metchnikoff. Ehrlich has correlated and coördinated the various facts of the humoral theory and has made substantial additions to it. He has created a terminology which has been quite generally accepted and has proved most useful in discussion of the subject. So extensive have been researches in the field of immunity during the last two decades (since 1890) that it has assumed almost the rank of a coördinate science.

Development of Sanitary Science and Preventive Medicine.In 1858 Murchison formulated the so-called pythogenic theory of disease -i.e., that disease is caused by the emanations arising from decaying or putrefying organic matter, and by the consumption of such materials in water and food. This theory was quite commonly accepted, and its practical applications form the basis for our modern sanitary science. The disposal of sewage and refuse, the purification of drinking-water, and adequate systems of plumbing were advocated and adopted before the germ theory of disease 
had been well formulated and established. The rapid accumulation of evidence in favor of the germ theory gave rise to the art of preventive medicine. Lister (1875) advocated the use of antiseptics in the treatment of wounds and wound infection as a direct method of combating the activity of undesirable bacteria. The discovery of the means of transmission in most of the infectious diseases has enabled man to take measures for their eradication. Yellow fever, malaria, diphtheria, bubonic plague, and many other diseases are now kept in check by the use of preventive measures indicated by our knowledge of the manner in which they spread. It is probable that greater advance will be made within the next few years in the domain of preventive medicine, for mankind is fast coming to realize that prevention is better than cure. 


\section{CHAPTER II}

\section{MORPHOLOGY AND RELATIONSHIPS OF MICROÖRGANISMS CONCERNED IN DISEASE PRODUCTION}

\section{POSITION OF PATHOGENIC MICROÖRGANISMS}

Differentiation of Animals and Plants.-The distinctions we commonly recognize as differentiating plants from animals in large measure disappear among the microscopic forms of life. It is worth while, therefore, to discuss the factors that are taken into consideration in the assignment of a particular microörganism to the animal or the plant kingdom. The difficulty arises particularly in the differentiation of the bacteria and the protozoa. Bacteria, as will be shown later, probably have in all cases a cellwall which in function is closely related to that of plants. A cell-wall is frequently absent in protozoa, the limiting membrane usually consisting of the ectoplast (see below) alone. The composition of the cell-wall is in some cases like that of many animals (chitin), in others like plants (cellulose). In shape and habit of growth and reproduction the bacteria resemble very closely certain undoubted plants among the blue-green algæ and the mold fungi much more than they do animal forms. On the other hand, there are some types which intergrade with the protozoa, so that there is at present doubt as to their correct systematic position. In the matter of food supply and food utilization some bacteria resemble higher plants, others resemble animals. The possession of organs of motion by bacteria has no direct bearing on the subject, inasmuch as undoubted plants of the group of algæ and many of the protozoa have them. The evidence, on the whole, is much in favor of classification of the true bacteria with plants.

Before beginning a study of the morphology or structure of these microörganisms, their position and relationships to the other groups of plants and animals should be understood. Fol- 
lowing is a discussion of these various groups, with particular emphasis upon the groups or subgroups of significance in medical bacteriology.

The plant kingdom is generally divided into four great groups, the Spermatophytes, or seed-bearing plants, the Pteridophytes, or ferns and fern-like plants, the Bryophytes, or moss plants, and the Thallophytes, including all plants low in the scale of evolution, that have not become highly differentiated and that never have roots, stems, and leaves. All of the plant-like organisms to be considered belong to this lowest group, Thallophytes.

The animal kingdom may be divided into the Metazoa, or higher differentiated types, made up of many cells, and the Protozoa, or unicellular forms. To the latter group belong all the animal-like organisms to be considered.

Subdivisions of the Thallophytes.-Following is a key or outline of the principal subgroups of the Thallophyta:

A. Unicellular forms, multiplying only by splitting of the cells to form two equal daughter-cells. Never any sex cells.

I. Cells containing blue-green coloring-matter.

1. Schizophyceœ (Cyanophyceæ or blue-green algæ).

II. Cells not containing blue-green coloring-matter.

2. Schizomycetes (Bacteria).

B. Unicellular or multicellular, multiplication by some method other than simple fission. Frequently sexual reproduction occurs.

I. Cells containing green coloring-matter (chlorophyll).

3. Algce (sea-weeds, pond scums, etc.).

II. Cells without green coloring-matter (chlorophyll).

4. Fungi (yeasts, molds, mildews, rusts, smuts, toadstools, puffballs, mushrooms, etc.).

Of the last group (Fungi) only two subgroups are of especial pathogenic significance for the veterinarian, the yeasts and the molds. These two, with the bacteria, constitute the three types of microörganisms belonging to the plant kingdom that contain forms pathogenic for animals. 


\section{MORPHOLOGY OF BACTERIA}

Shape of Bacteria.-Bacteria may be classified according to shape into spheres, straight rods, bent or spiral rods, and filaments.

A spherical form is called a coccus (pl. cocci). Although the coccus is theoretically spherical, there are many that appear somewhat flattened or ovoid when in groups or chains.

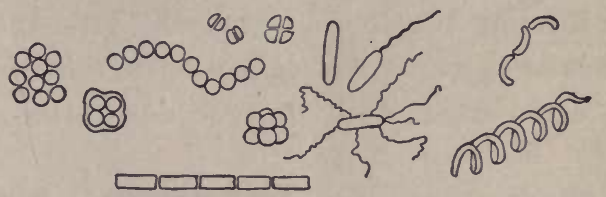

Fig. 2.-Types of bacteria: Cocci, bacilli, and spirilla (Jordan).

A straight rod is called a bacillus (pl. bacilli).

A curved or spiral rod is called a spirillum (pl. spirilla).

The filamentous bacteria are those in which the organism is greatly elongated. No specific name has been given to this form. Frequently the filamentous type exhibits branching and in other ways resembles the mycelium of the higher fungi or molds.
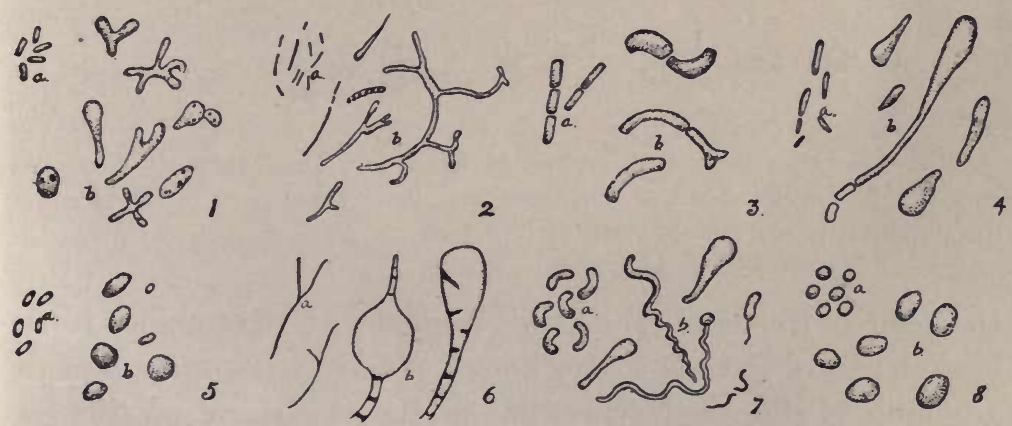

Fig. 3.--Involution forms of bacteria: 1, Bacillus radicicola-a, Normal rods; $b$, bacteroids. 2, Bacillus tuberculosis. 3, Bacillus subtilis. 4, Bacillus aceti. 5, Bacillus pestis. 6, Actinomyces sp. 7, Spirillum sp. 8, Micrococcus aureus- $a$, Normal forms; $b$, involution forms.

When grown under favorable conditions, as a result of the action of certain stimulation, many bacteria assume unusual and abnormal shapes. Cells of this type are called involution forms. Such cells are not necessarily incapable of continued growth and 
reproduction of the more usual or normal type when brought under favorable conditions. Frequently, however, these cells soon die and can no longer reproduce. Various bacteria differ considerably with respect to the ease with which they produce involution forms.

Grouping of Bacterial Cells.- The cells of bacteria are frequently surrounded by a gelatinous material (capsule, see below) which causes them to cling together in groups. This grouping in the various types is so constant that it is used to differentiate various genera from each other, and in some cases the species within

\section{- 10000000000000000000000 \\ 7}

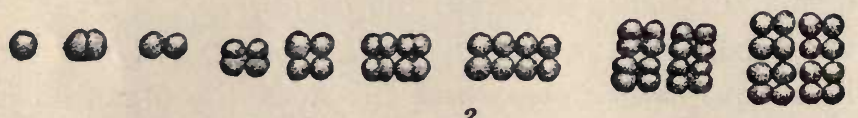

2

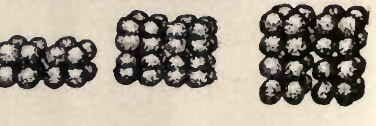

3

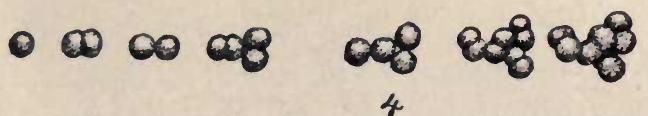

Fig. 4.-Development of groups of cocci: 1, Development of streptococcus; 2, development of micrococcus; 3, development of sarcina; 4, development of staphylococcus.

the genus. Bacterial cells divide normally at right angles to the longest axis of the cell. This allows of but little variation in the grouping of elongated types, but as the cocci have no "longest axis" they divide in various planes.

Some cocci divide constantly in the same plane or in a plane parallel to the first. This results in the formation of a chain of cocci. An organism showing this grouping is called a streptococcus (pl. streptococci).

Other cocei divide alternately in two planes at right angles to each other. Such an organism will be found in twos (diplococcus) or in fours (tetrad or tetracoccus). Diplococci may also 
be produced by the breaking up of chains of streptococci into pairs.

Cocci sometimes divide in three planes at right angles to each other. This results in the formation of cubes or packets of cocci. A packet of this kind is called a sarcina (pl. sarcince).
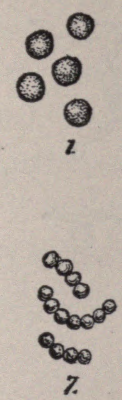
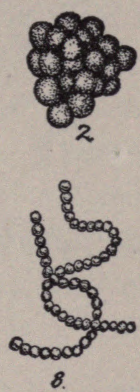
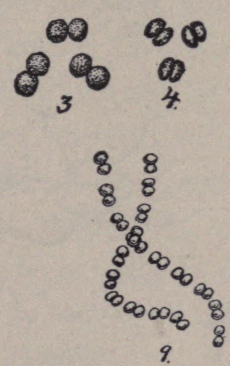

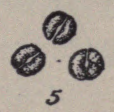

5

(2) (a)

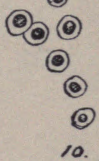

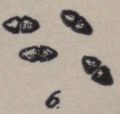

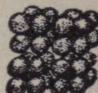

".

Fig. 5. - Shapes and groups of cocei: 1, Single coccus (micrococcus); 2, cocci in an irregular mass (staphylococcus); 3, spheric diplococci; 4, flattened diplococci; 5, coffee-bean-shaped diplococci; 6, lanceolate diplococci; 7 , streptococcus with short chains; 8 , streptococcus with long chains; 9 , a streptococcus made up of diplococcus elements; 10, capsulated micrococci; 11 , sarcina.

A staphylococcus (pl. staphylococci) is a coccus whose planes of division are not at right angles, or which divides at different intervals with a consequent irregular grouping of the cells much resembling grapes in a cluster.

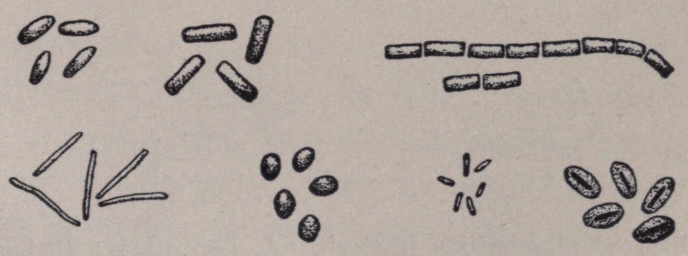

Fig. 6.-Types of bacilli.

Bacilli occur either singly or in chains. The latter are sometimes known as streptobacilli.

Spirilla usually occur singly, although short chains of two or three individuals are sometimes observed.

In a few bacteria the gelatinous envelop of the cell is greatly 
thickened, and the bacteria, either cocci or bacilli, are imbedded in a mass of gelatin. Such a mass of cells is called a zoöglea.

Size of Bacteria.-The unit of microscopic measurement is the micron (pl. micra or microns) and is indicated by the Greek
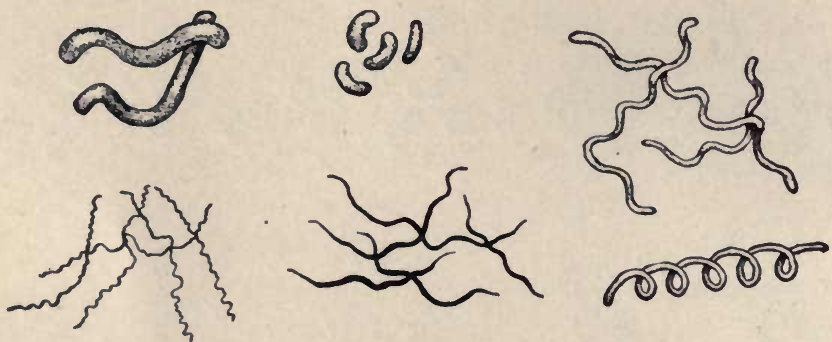

Fig. 7.-Types of spirilla.

letter $\mu$. It is the one-thousandth part of a millimeter or, approximately, the one twenty-five-thousandth part of an inch.

Bacteria vary considerably in size, from forms $0.1 \mu$ or less in diameter, barely visible under the microscope, to forms
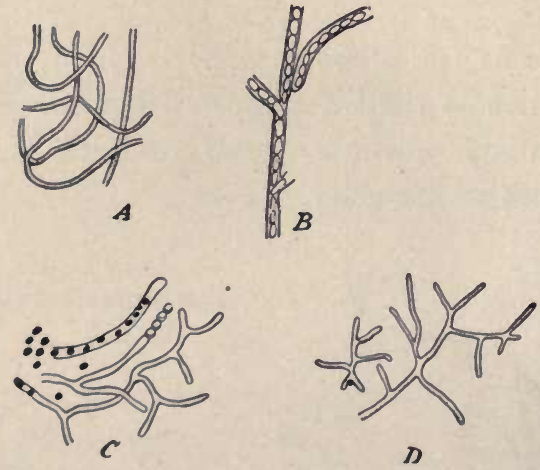

Fig. 8.-Types of filamentous bacteria: $A$, Leptothrix; $B$, Cladothrix; $C$, Nocardia; D, Actinomyces or Streptothrix.

$100 \mu$ or more in length. Most bacteria are between 0.5 and $5 \mu$ in diameter and $0.5 \mu$ and $10 \mu$ in length. Some bacteria are undoubtedly too small to be seen with the highest powers of our microscopes, hence less than $0.1 \mu$ in diameter. We know of the existence of these organisms by their effects. The organism caus- 
ing hog cholera, for example, is so small that it will pass through the pores of a fine porcelain filter, and will cause disease when injected into a healthy pig. Such an organism is frequently spoken of as ultramicroscopic, or as a filterable virus.

Histology and Structure of Bacteria.-This topic may be treated under four subheads, the cell wall with its related sheaths and capsules, the protoplasm, the cell inclusions, and the flagella.

Cell Wall.-The bacterial cell is in all cases surrounded by a definite membrane that morphologically resembles the cell wall of higher plants. When tested chemically with various reagents and examined microscopically, it is sometimes found to give the reactions characteristic of chitin, the material which makes up the hard outer shell of insects, and is found as a cell mem-
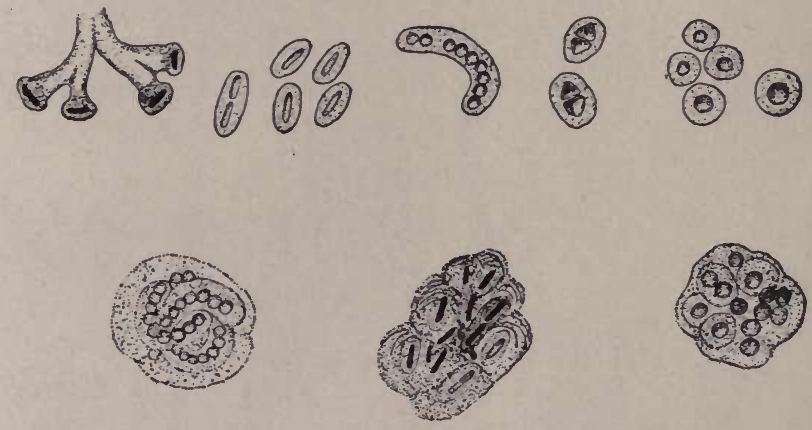

Fig. 9.-Capsulated bacteria.

brane in many animals. Chemically chitin is an amino-substitution product of a carbohydrate. The fact that the cell walls in bacteria so frequently resemble in composition those of certain animals has been used as an argument for the animal relationships of the bacteria. This is negatived, however, by the fact that in numerous molds and other fungi, undoubted plants, the cell walls are made up of a similar substance.

The cell wall in bacteria is usually covered by a layer of mucilaginous material, in most cases so thin that the most careful technic must be employed in its demonstration, in other cases a thick coating or capsule. The nature of this capsular substance has been a fertile subject for dispute. A few bacteriologists have claimed that it is composed of living protoplasm, the majority, 
with seeming justification, believe that this is either an excreted material or merely an outer swollen and differentiated portion of the cell wall. Chemically this material differs in the various capsulated bacteria. In some cases it is composed of mucin, a slimy material made up of a protein-like substance united with a carbohydrate, and resembling the mucus secreted by certain body cells. In other cases the capsule is made up of pure carbohydrates and is closely allied to certain of the vegetable gums, such as gum arabic and gum tragacanth. The capsule of some bacteria is partially or wholly soluble in water. When such an organism grows in suitable nutrient solution it renders the medium slimy or gelatinous. Slimy milk, bread and whey are caused by the luxuriant growth of such organisms.

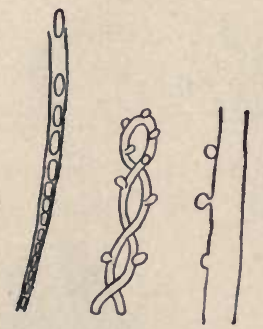

Fig. 10.-Bacteria showing sheaths.

Some of the filamentous bacteria produce a firm sheath or tube outside of the cell, this sheath usually inclosing an entire filament or chain of cells. In composition it probably closely resembles the cell wall. In some cases it is impregnated with iron oxid. It is possible that the sheath is a modified type of capsule.

Cell Protoplasm.-The living material within the cell wall is called the protoplasm. Structurally it may usually be differentiated into two layers, an outer thin layer lying closely appressed to the cell wall, and an inner portion. The outer layer or ectoplast performs one of the most important functions of the cell, as this is the membrane, and not the cell wall, that determines what materials in solution may enter and what may leave the cell; through it must pass by diffusion all the food that enters the cell. When certain bacteria, as the cholera spirillum, are placed in a strong solution of some salt which does not readily pass through 
this ectoplast, the water from the cell in part passes out, the protoplasm shrinks away from the cell wall, and the cell is said to be plasmolyzed (noun, plasmolysis). Such a plasmolyzed cell shows clearly the ectoplast separated from the cell wall. When a cell of certain species is placed in distilled water or a concentra-

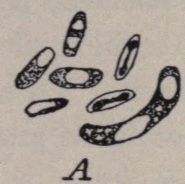

Fig. 11.-Plasmolysis and plasmoptysis of bacterial cells: $A$, Plasmolyzed bacterial cells; $B$, cells showing plasmoptysis, the protoplasm has burst the cell wall and is escaping. (Adapted from Fischer.)

tion of salt considerably less than that to which it has been accustomed, the cell takes up water, the cell wall bursts, and part of the protoplasm escapes. This phenomenon is called plasmoptysis. The protoplasm of the cell is commonly homogeneous in appearance, and stains best with the basic aniline dyes. Either a definite
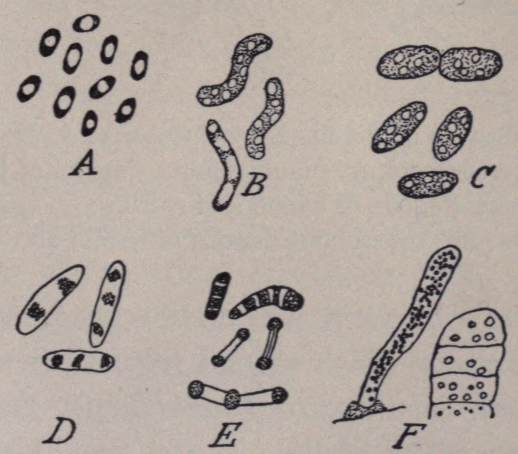

Fig. 12.-Bacterial cell inclusions: $A$, Vacuoles in the cell, polar staining rods; $B$, vacuolate spirilla; $C$, fat globules; $D$, glycogen granules; $E$, metachromatic granules; $F$, sulphur granules.

nucleus is not present, or the nuclear material is so scattered as to make the entire mass functionally a nucleus. Some bacteria have been described as possessing a primitive type of differentiated nucleus, but such structures cannot be discerned in others. 
Cell Inclusions.-Bacterial cells sometimes contain vacuoles, or spaces in the protoplasm filled with sap or some non-staining or non-refractive substance. A large vacuole near the center of the cell may crowd the protoplasm to the ends of the cell, and such organisms, when stained, are said to show polar staining. In other forms, as the diphtheria bacillus, granules are formed that stain much more intensely with the basic aniline dyes than does the remainder of the protoplasm. These are called metachromatic granules. The function of these granules is not clear. Certain species of bacteria living in water containing hydrogen sulphid are found to contain granules of free sulphur in their protoplasm. Still others have food materials in the form of oil globules or granules of glycogen.

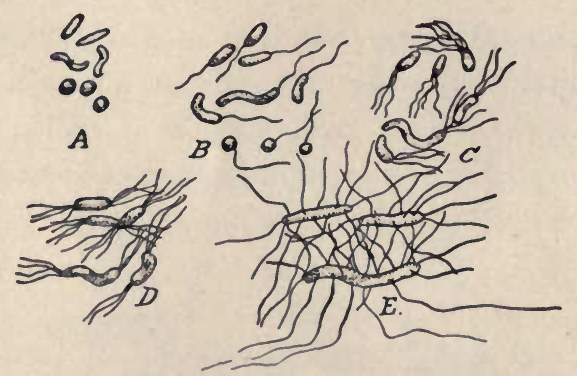

Fig. 13.-Distribution of the flagella of bacteria: $A$, Non-motile or atrichous bacilli, spirilla, and cocci; $B$, monotrichous flagella of bacilli, spirilla, and cocci; $C$, lophotrichous flagella of bacilli and spirilla; $D$, amphitrichous flagella of bacilli and spirilla; $E$, peritrichous flagella of bacilli and spirilla.

Flagella.-Many bacteria are motile by means of whip-like threads of protoplasm which extend from their surfaces. These threads are known as whips or flagella (sing. flagellum). These flagella are observed with difficulty in the living organism except with dark field illumination and require peculiar staining technic and careful treatment to make them visible in a stained mount. Comparatively few cocci, many of the bacilli, and most of the spirilla are flagellated. The distribution of flagella on the surface of the cell has been used as a basis for grouping. Atrichous bacteria have no flagella; monotrichous bacteria have a single flagellum at one end; lophotrichous, a group of flagella at one pole; amphitrichous, flagella at both ends; and 
peritrichous, flagella on all sides. Old cells and cells transferred from one medium to another are very apt to loose their flagella. A young culture is most suitable for determination of motility. True motility must not be confused with Brownian movement, which is a vibrating or oscillating motion of finely divided particles of almost any kind suspended in water, and visible when examined under the microscope. This motion has not been satisfactorily explained, but it is probably due to rapid changes in surface tension of the liquid at the point of contact with the particles.

Reproduction in Bacteria.-Multiplication in all bacteria is a simple process. The cell commonly elongates or enlarges, a cell wall develops across the middle, and the two cells separate. This operation may occur with considerable rapidity. Some organisms in favorable medium can grow to their full size and divide to form two individuals in the course of twenty minutes to an hour. If the organism could multiply in this geometric ratio for a short time the number of resultant organisms would be practically incalculable. For example, if a bacterium should divide every half-hour, at the end of two days the progeny would be represented by $2^{96}$, a number having twenty-eight figures. Such rapid multiplication is never long continued, for food supply is never long favorable, and waste products of the bacterial growth tend to accumulate and diminish the rate. Nevertheless, the rapidity of increase of bacteria accounts in a large measure for the considerable changes they bring about in a short time, as in the souring of milk or invasion of the body in disease.

Many bacteria also reproduce by means of spores. These are of two types: endospores, produced inside the bacterial cell, and arthrospores, consisting of entire differentiated cells. The former are produced by certain bacilli and spirilla, the latter by certain of the filamentous forms or trichobacteria.

Endospores are formed by many bacilli, and possibly by some spirilla. They are produced in response to some definite stimulus, such as unfavorable conditions of the environment, accumulation of waste products, or change in reaction of the medium. The spore is essentially a portion of the protoplasm of the cell which has expelled most. of its water and shrunken in 
size until it occupies a portion only of the space within the cell wall, and has then surrounded itself with a heavy wall, probably chitinous in nature. In practically all cases there is but one spore in a cell. The spore may be equatorial or polar in position, and of less or greater diameter than the cell which produces it. The term clostridium is sometimes used to indicate a spore-bearing

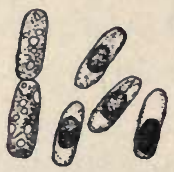

Fig. 14.-Development of endospores in a bacillus. (After Fischer.)

rod in which the spore is equatorial and of greater diameter than that of the cell, resulting in a spindle. Endospores contain only about 20 per cent. of water as compared with 80 to 90 per cent. in the cells which produced them. An organism without a spore is usually differentiated by the term vegetative rod or vegetative cell. Spores are much more resistant to desiccation, heat, light, and chemicals than the vegetative cells. They are of use in

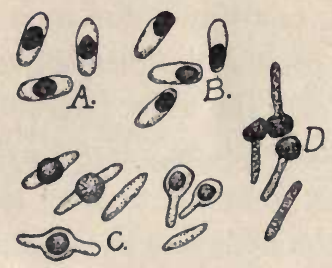

Fig. 15.-Bacterial spore types: $A$, Equatorial spores of a diameter less than the cell; $B$, polar spores of a diameter less than the cell; $C$, equatorial spores of a diameter greater than the cell (clostridium type); $D$, drumstick or polar spores of a diameter greater than the cell.

tiding the organism over unfavorable conditions. Spore-bearing bacteria are abundant in the soil, where they often are exposed to great ranges of moisture, temperature, and light. When a spore again comes under favorable conditions for growth, it germinates and produces a cell typical of its species. Germination is accomplisher either by stretching or bursting the spore wall. 
Arthrospores are bacterial cells set apart for purposes of reproduction, and are usually differentiated appreciably from the normal cell. Several investigators have claimed that they are produced by some of the cocci, but this has never been satisfactorily estab-

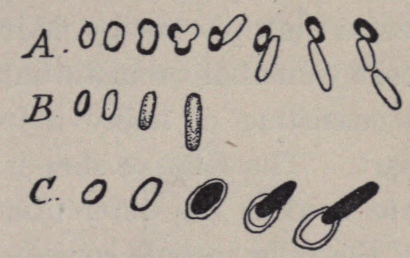

Fig. 16.-Germination of spores: A, Bacillus subtilis (Prazmowski); B, Bacillus anthracis (deBary); C, Clostridium sp. (deBary).

lished. The filamentous bacteria or trichobacteria produce - arthrospores or conidia, as they are sometimes called, by the disintegration of some of the filaments into short rods or spheres which are capable of reproducing the parent type or by a process

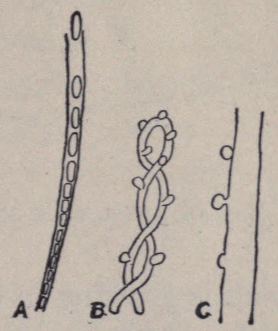

Fig. 17.-Arthrospores: A, Crenothrix polyspora (Cohn); B, Gallionella ferruginea, showing conidia formation (Ellis); C, Leptothrix ochracea (Ellis).

of budding. In many cases the threads which break up into the spores are somewhat differentiated from the normal cells of the plant, and are aërial, resembling closely some of the molds.

\section{MORPHOLOGY OF THE YEASTS, SACCHAROMYCETES, AND BLASTO- MYCETES}

Yeasts, from the standpoint of the systematic botanist, are placed at some distance from the bacteria, for there are many differences between typical yeasts and typical bacteria. On the other hand, there are forms which intergrade between the two, 
and are sometimes assigned to one group, sometimes to another. The yeasts and the molds also show intermediate types.

Form, Size, and Grouping of Yeasts.-Yeast cells are usually spherical, oval, ellipsoid, or cylindrical. For the most part they are larger than bacterial cells, although there are exceptions. The true yeasts multiply not by fission, but by a process of budding. The cells commonly remain united for a time, giving rise to masses consisting of many individuals. Sooner or later they break apart. The relative shape, size, and groupings of the yeast cells are used in the differentiation of species. In some species part of the cells become considerably elongated and form a kind of false mycelium resembling that of the molds. This character is not always constant in a given species, it may

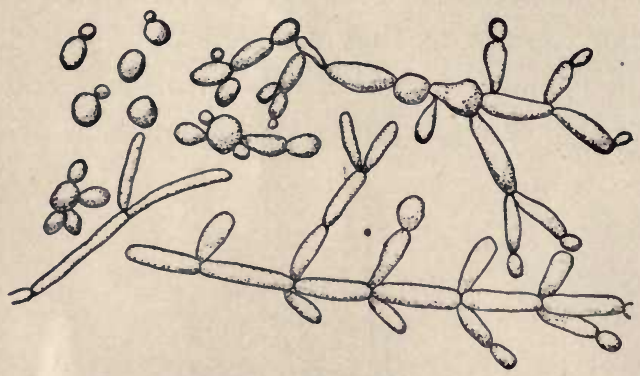

Fig. 18.- Types of yeast cells and groupings.

appear when the organism is growing in orfe kind of medium and not appear in another.

Histology and Structure of the Yeast.-The very young cell has no cell wall, but by the time it is one-third grown the wall appears as a delicate membrane. In old cells it is sometimes of considerable thickness. Its composition has not been certainly determined, probably it is a carbohydrate or related compound, and not chitinous, as are the walls of bacterial and mold cells. To this substance the name yeast cellulose has been given. It has not been prepared free from nitrogen, so that it is possible that it may be nitrogenous in nature. It is sometimes surrounded by a gelatinous excretion or capsule, as is the case with bacteria. -The yeasit cells are never motile.

Yeast Protoplasm and Cell Inclusions.-The contents of the 
yeast cell are more highly differentiated than are those of bacteria. The ectoplast, or limiting membrane of the protoplasm, is easily demonstrated by plasmolyzing the cell. This ectoplast (German Hautschicht) is the only membrane of the young cell, and the cell wall is probably secreted by it. The protoplasm is differentiated definitely into a nucleus and cytoplasm. The nucleus is not as easily demonstrated as in the higher plants and animals,

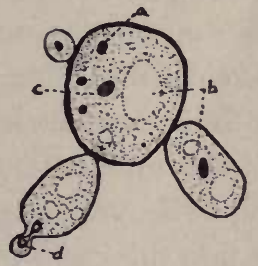

Fig: 19.-Diagram of budding yeast cells and their contents: $a$, Glycogen granules; $b$, vacuoles; $c$, nucleus; $d$, dividing nucleus in bud formation.

but may be shown by proper staining methods. The cytoplasm usually contains one or more vacuoles, spaces filled with cell sap and not taking the stain as does the cytoplasm. Older cells may also show oil globules or glycogen granules.

Reproduction in Yeasts.-Yeasts commonly multiply vegetatively by budding. A bit of the protoplasm protrudes on one side of the mother cell, the nucleus divides, and one part goes to
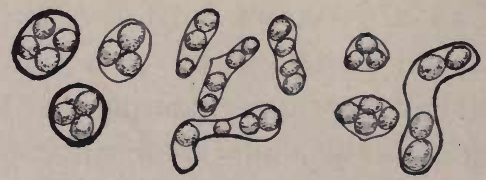

Fig. 20.-Spores (ascospores) of the yeast (Hansen).

the bud, the other remains within the cell, the bud enlarges, develops a cell wall, and is constricted off as a distinct individual. Many yeasts may also under favorable conditions produce spores. The development of the spores in the yeast cell differs considerably from that in the bacteria. The latter typically have but one spore developed within the cell, while a yeast cell usually produces two, four, six, or even eight spores. The nucleus divides several times to form a number of nuclei, each of which, together with the 
protoplasm lying in contact with it, becomes surrounded by a membrane. A cell of the yeast (and certain other fungi) when filled with spores is called the ascus (pl. asci) or sac. The spores are called ascospores (Fig. 20). This method of spore production relates the yeasts quite definitely to some of the higher fungi. In some cases there is a primitive type of sexual reproduction or fertilization associated with the development of the spores. The spores are more resistant to an unfavorable environment than the vegetative cells. When brought under favorable conditions they germinate and develop into the typical yeast plant. In old yeast cultures some cells develop heavy cell walls, are filled with granular reserve food materials, and become potentially spores. Such cells are likewise probably resistant to unfavorable conditions, and serve to tide the yeast over periods of desiccation or poor food supply. They resemble the chlamydospores produced by many molds.

\section{MORPHOLOGY OF THE HYPHOMYCETES OR MOLDS}

The molds or hyphomycetes do not constitute a homogeneous group in the eyes of the systematic botanist, but belong to various subdivisions of the group of fungi. Some are related to the algæ and are grouped under the Phycomycetes, others belong to the sac fungi or Ascomycetes, others are related to the smuts, rusts, and toadstools, or Basidiomycetes, and the largest number belong to the group of imperfect fungi or Fungi Imperfecti. From the viewpoint of the bacteriologist these botanic relationships are not significant; all the fungi, regardless of kinship, that agree in having the plant body made up of threads usually more or less branched, and forming more or less loose or cottony masses, in short, those that answer to the popular conception of molds, are grouped together as Hyphomycetes. Such a classification is scientifically justifiable only because of the great complexity of the various members of the family of fungi, and the fact that it is not the systematic position but the economic importance of the forms that is of significance.

Form and Size of Hyphomycetes or Molds.-A mold may be differentiated from the yeasts and bacteria in that it is multicellular, with the cells united to form more or less branched 
threads called hyphce (sing. hypha). The whole mass of threads or hyphæ which go to make up the plant of the mold is called the mycelium. In most molds certain threads are differentiated for the production of spores. The mycelium of the mold may extend over a considerable area, growing deep into the substratum for food or into the air to develop spores.

Histology and Structure of Molds.-The mycelium in some molds is continuous throughout its length, possessing no cross walls which might separate the cells from each other. In the majority of forms, and in all those of economic importance to the veterinarian, the hyphæ are divided by cross walls or septa

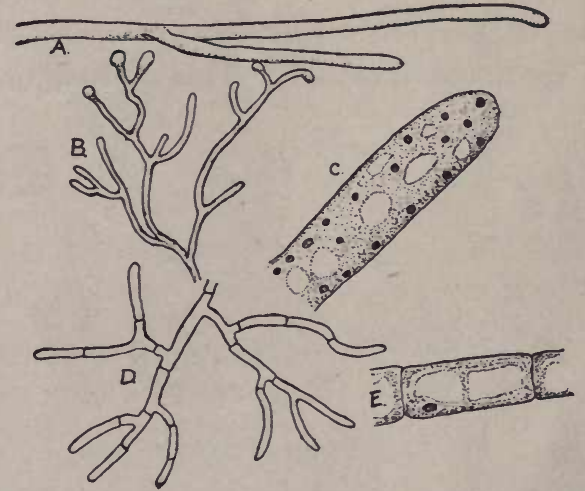

Fig. 21.-Mold hyphæ: $A, B$, Non-septate hyphæ of the Phycomycetes; $C$, tip of a non-septate hypha, showing numerous nuclei and vacuoles; $D$, septate branching hyphæ; $E$, a single cell of a septate hypha, showing nucleus and vacuoles.

(sing. septum). The cell wall is composed of true cellulose in a few molds, in the majority it is chitinous as in the bacteria. The almost universal presence of chitin in the cell walls of the fungi is frequently lost sight of by those who regard its presence in the cell walls of bacteria as evidence of animal affinities. The protoplasm of molds, as in the yeasts, is made up of cytoplasm and nucleus. The outer layer of the cytoplasm or ectoplast is readily demonstrated in most molds by plasmolysis. In the forms that do not have septa dividing the hyphæ into cells, the numerous nuclei are imbedded in the common cytoplasm. Functionally each nucleus with its bit of surrounding cytoplasm constitutes a 
cell, although the statement is often made that the entire mold filament in the non-septate type is a single cell.

Reproduction of Molds.- It is impracticable to go into detail concerning the reproduction of molds. Spores of many different types are produced (Fig. 22), sometimes three or four kinds by a single species. The spores exhibit every conceivable shape and coloring, are sometimes unicellular, at other times multiseptate. Hundreds of genera and thousands of species are known. The names applied to the different parts of the molds concerned in reproduction and the manner in which the spores are borne in some of the commoner molds may, however, be briefly discussed.

Molds may be divided, for convenience, into those which bear the spores enclosed in a spore case or sporangium and those in which they are not so inclosed. This sporangium is commonly

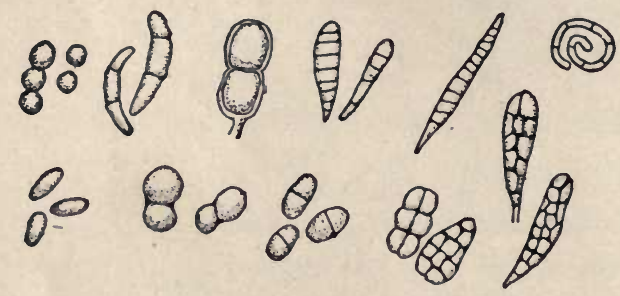

Fig. 22.-Types of mold spores.

borne at the tip of a hyphal thread differentiated for the purpose, called a sporangiophore. Spores not produced inside of a sporangium and not the result of fertilization (i. e., asexual spores) are termed conidia (sing. conidium). Conidia are usually developed at the tip of specialized branches called conidiophores. Sometimes they are formed by the breaking up of the mycelial threads or hyphæ, and are then called oïdia (sing. oïdium), in other cases they develop within the hyphæ and are surrounded by it as by a sheath. When one of the cells in a hypha becomes enlarged and surrounded with a heavy wall it is called a chlamydospore. Some molds develop spores as a result of the union of sex cells (sexual spores). These are called ascospores when produced in sacs (asci) and zygospores when formed by the union of two like cells as in certain Phycomycetes.

Spores of the molds are commonly born on hyphæ that extend 
into the air away from the moist surface of the medium in which they are growing. This facilitates their dispersal by the air

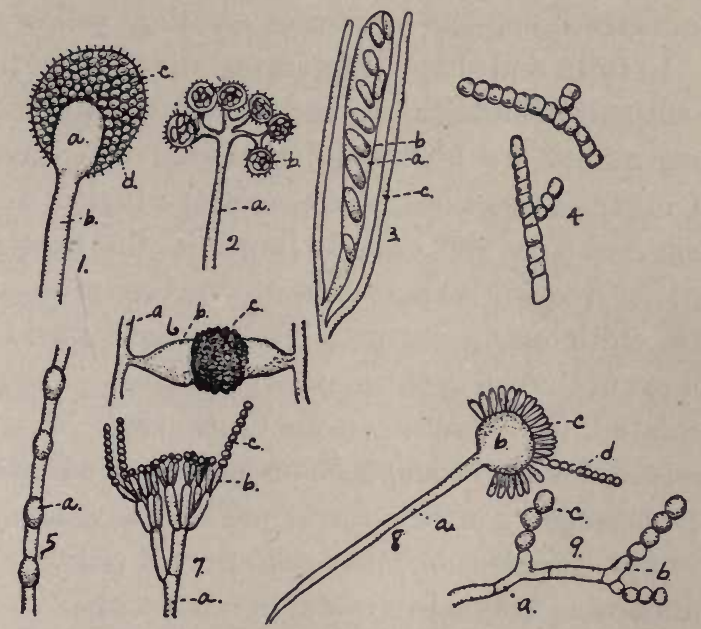

Fig. 23.-Types of the spores and the spore-bearing organs of the molds1, Sporangium of the Mucor: $a$, columella; $b$, sporangiophore; $c$, spores; $d$, sporangium wall. 2, Sporangia of Sporodinia: $a$, sporangiophore; $b$, sporangia containing spores. 3. Ascus of an ascomycete, Peziza: $a$, ascus or spore sac; $b$, spore; $c$, sterile threads or paraphyses. 4, Oidium spore formation; the hyphæ are segmenting to form spores or oïdia. 5, $a$, Chlamydospores formed in the hypha of a Chlamydomucor. 6, Zygospore of a Mucor: $a$, hypha; $b$, suspensor; c, zygospore. 7, Conidiophore and conidia of Penicillium: $a$, conidiophore; $b$, verticillate branches of the conidiophore; $c$, chains of spores or conidia. 8, Aspergillus: $a$, conidiophore; $b$, inflated tip of the conidiophore; sterigmata; $d$, chain of spores. $9, a$, Hypha; $b$, poorly differentiated conidiophore; $c$, chain of conidia.

currents. When they fall upon a suitable medium they germinate and soon develop the typical mold plant.

\section{MORPHOLOGY OF THE PROTOZOA}

The protozoa are unicellular and bear much the same relation to the higher animals or metazoa that the bacteria do to the higher plants. Notwithstanding that they are reckoned among the simplest forms of life, they are, nevertheless, greatly diversified in shape, size, and structure. Only the barest outline of their structure can be given here. For a more detailed account the student is referred to the section on Protozoa. 
Form and Size of Protozoa.-The pathogenic protozoa vary in size from those visible to the naked eye to those barely visible with the highest powers of the microscope. Some are undoubtedly ultramicroscopic, the organism causing yellow fever, for example. In form and shape the greatest diversity is to be noted. Some are without definite shape, and are apparently only lumps of protoplasm, others are highly differentiated and have as great variety of organs (organella) as some of the higher animals.

Histology.-A true cell wall, as found in the bacteria, yeasts, and fungi, is frequently not present in the protozoa. When found, it is chitinous in nature. The ectoplast forms the limiting membrane of the cell in the majority of cases. The protoplasm is differentiated into nucleus (sometimes two, a micronucleus and a macronucleus) and endoplasm or cytoplasm. Power of movement is possessed by many forms. This may be due to the development of pseudopodia, of flagella, or of cilia.

Reproduction.-Asexual reproduction is accomplished in many cases by a simple process of fission, in others the procedure is much more complex. Sexual reproduction is quite general, but here again the complexity is so great as to render brief treatment impracticable. The relationship and structure of these forms will be considered in greater detail under the heading of Pathogenic Protozoa in Section V. 


\section{CHAPTER III}

\section{PHYSIOLOGY OF MICROÖRGANISMS}

Physiology has been defined by Barnes to include " a study of the behavior of plants (and animals) of all sorts, and of the ways in which this is affected by external agents of every sort." In our discussion of the physiology of microörganisms we shall have to deal principally with the interrelationships existing between these microörganisms and their environment.

\section{FOOD RELATIONSHIPS OF MICROÖRGANISMS}

A food is any substance which a living organism may make a part of its living material or use as a source of growth energy. The term is frequently used very loosely to include all the substances of which an organism may make any use. For example, a distinction is sometimes made between green plants and animals on the basis of food used. The former are said to live on inorganic foods and the latter on organic. This distinction is erroneous. The difference is simply that green plants can manufacture their own foods out of inorganic material by the aid of the energy secured from the sun's rays through the green coloring-matter or chlorophyll, while animals make use of food already prepared. The materials of which some microörganisms make use are no more foods than the rays of the sun are a food for green plants.

Composition of the Cell.-The food utilized by any microorganism must contain the elements needed for the building up of the cell substance. The analysis of such cells shows them to be made up of the same elements as those of higher plants and animals, namely, carbon, oxygen, nitrogen, hydrogen, and smaller amounts of phosphorus, iron, magnesium, calcium, and some other elements. The foods utilized by organisms must, therefore, contain these elements likewise.

Sources and Kinds of Foods.- Some bacteria, like the green plants, are capable of manufacturing their own food. For this purpose a source of energy is necessary. Some species utilize the 
energy of the rays of sunlight in much the same manner probably as do green plants. The coloring-matter in these forms, however, is purple or red (bacteriopurpurin). Other forms living in water which contains hydrogen sulphid, as in the sulphur springs, oxidize the hydrogen sulfid to free sulphur and even sulphuric acid and gain energy for the manufacture of their foods from carbon dioxid, water, and other compounds by this process. Still other forms are believed to make use of iron, ammonia, nitrites, and other inorganic substances, and by their oxidation secure the necessary energy. Organisms which can manufacture their own food out of inorganic substances are said to be prototrophic. The prototrophic microörganisms so far as known are all bacteria or molds. Most microörganisms utilize organic matter in a dead or living condition for food. Those which utilize dead organic matter are called metatrophic, while those requiring living material or complex protein foods are called paratrophic. The latter are frequently disease producing. It must not be supposed that these division lines are strictly drawn. For example, certain bacteria seem to make use of the oxidation of carbohydrates and other organic substances to enable them to take up the nitrogen from the air and to convert it into usable form. Such are both prototrophic and metatrophic.

The peculiar food requirements of the different species must be kept in mind in the preparation of nutrient media for their growth. Some organisms will not grow in the presence of organic materials, while others require such specialized media as bloodserum or hemoglobin.

A second grouping of microörganisms commonly used is based upon the relationship to other living organisms. Those which do not require a living host (animal or plant) are called saprophytes if bacteria, yeasts, or molds, and saprozoites if protozoa; those which require a living host are called parasites. Those parasites which do not produce disease are termed commensals.

\section{MOISTURE RELATIONSHIPS OF MICROÖRGANISMS}

Microörganisms require considerable amounts of water for their development. The optimum condition for growth in most cases is saturation. There is great variation in ability to resist desiccation (drying). The spores of some bacteria and 
fungi and the encysted cells of some protozoa will live for years, while other forms are destroyed if allowed to become completely dried.

\section{RESPIRATION OF MICROÖRGANISMS}

Respiration is frequently defined as the taking up of oxygen and the elimination of carbon dioxid. This definition is entirely inadequate when we come to a discussion of microörganisms, if, indeed, it can be applied in any case even to higher animals and plants: Respiration seems fundamentally to be the process whereby energy is generated in the cell. Energy when evolved in the cell always originates from chemical changes in the compounds within the cell. Whether or not this energy may be gained by the oxidation of food materials when taken into the cell, or whether they must be first built up into protoplasm and this then broken down, is a matter of dispute at present among scientists. In any event the presence of free oxygen is certainly not necessary to this release of energy, for many bacteria as well as other plants and animals live in the absence of free oxygen. Organisms that grow only in the presence of oxygen are called aërobic; those which will grow only in the absence of free oxygen, anaërobic, and those which will grow either with or without free oxygen, facultative. It is probable that most of the so-called anaërobes grow better in the presence of minute quantities of oxygen. The end-products of respiration are found to differ with the type, aërobic bacteria usually produce carbon dioxid and water; anaërobic forms, less highly oxidized substances, such as alcohol and butyric acid.

The oxygen requirements of anaërobic bacteria must be recognized in the laboratory if they are to be successfully cultivated. The air of the culture-tube or flask may be removed by a stream of hydrogen, nitrogen, or some other inert gas, the oxygen may be absorbed by the use of alkaline sodium pyrogallate, the air may be exhausted by an air-pump, the oxygen may be excluded by covering the medium with oil or some similar material, or the organism may be mixed with some aërobic form which will use up the oxygen and allow growth of the anaërobe. Probably the latter is the common method whereby anaërobes are able to grow in nature. 


\section{TEMPERATURE RELATIONSHIPS OF MICROÖRGANISMS}

Optimum Temperature.-The optimum growth temperature is that which most favors the development of the microorganism. The optimum varies with the species. A few organisms found in the ocean, in cold waters, alpine regions, etc., prefer a low temperature, from $0^{\circ}$ to $15^{\circ}$. These are called psychrophilic. Those which prefer a somewhat higher temperature are called mesophilic. These latter may be again subdivided into those that prefer a "room" temperature of $18^{\circ}$ to $25^{\circ}$, and those that prefer blood heat $\left(\operatorname{man} 37.5^{\circ}\right)$ for the most parasitic forms. Temperatures such as are found in hot springs, interior of compost heaps $\left(50^{\circ}\right.$ to $\left.70^{\circ}\right)$ favor the development of thermophilic bacteria.

Minimum Temperature.-The lowest temperature at which an organism will continue growth is said to be its minimum. This temperature varies for different species. Some organisms will multiply in brine held at temperatures lower than the freezing-point of water.

Maximum Growth Temperature.-The highest temperature at which an organism will multiply is called its maximum. This must not be confused with the thermal death point (see below). The majority of bacteria cannot grow above $45^{\circ}$.

Growth Temperature Range.-The differences between the minimum and maximum growth temperatures vary within rather wide limits. Those organisms which exhibit considerable adaptability and are able to grow through a wide range of temperature are called eurythermic. Most of the saprophytic organisms belong here. The parasitic types which have minima and maxima varying but little from the optima are stenothermic.

Thermal Death Point.- The thermal death point of an organism is that temperature which under given conditions will certainly destroy all the cells. The following factors must be taken into consideration in the determination of any thermal death point:

1. The Absence or Presence of Spores. - Spores are much more resistant to high temperatures than the vegetative cells. Forms having spores, therefore, have two thermal death points, one for the vegetative cells and the other for the spores.

2. Presence or Absence of Moisture.-Bacteria are more resistant to dry than to moist heat. The thermal death point is probably 
the temperature at which incipient coagulation of the albuminous protoplasm occurs, resulting in an inability to function. Water is necessary for this coagulation. The following table from Frost and McCampbell illustrates this point:

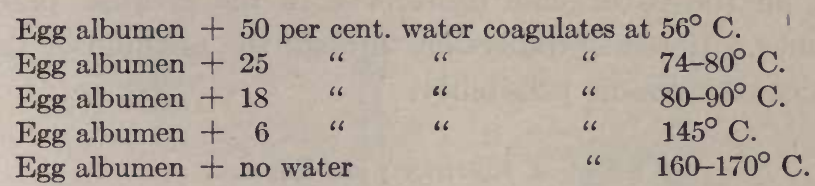

This fact is emphasized by the laboratory methods of sterilization. The autoclave, with live steam at temperature of $120^{\circ}$, will destroy in ten minutes the most resistant spores, while in the hot-air oven a temperature of $150^{\circ}$ to $170^{\circ}$ for an hour is necessary.

3. Reaction and Composition of Medium.-The reaction and composition of the medium has been found to exert a marked influence on the thermal death point. In comparative work, care must be exercised to use media of uniform reaction and composition.

4. Time of Exposure.-In general, the higher the temperature the shorter the period required to destroy life in the cells. Mathematic formulas have been developed giving the time as a function of temperature for some forms.

5. Specific Character of Organism.-Intrinsic variations in the character of protoplasm of different species make it necessary to determine the thermal death point for each species.

\section{LIGHT RELATIONSHIPS OF MICROÖRGANISMS}

A few bacteria possessing bacteriopurpurin require light for their development. For most other microörganisms, particularly the bacteria and the pathogenic protozoa, darkness is the optimum light condition. Light, particularly the direct rays of the sun, will destroy all but the most resistant bacteria if exposed for a sufficient length of time. Sunlight when passed through a prism is readily broken up into its constituent colors, the least refracted rays, or the reds and yellows, at one end, and the more highly refracted rays, the blues and the violets, at the other. Exposure of bacteria to these various colored rays has shown 
the blues and violets to be most powerful, while the reds and yellows of the other end have little or no effect. It will be remembered that the blue and violet rays are the ones which affect the photographic plate most intensely. The germicidal action of light on the pathogenic bacteria is of the greatest practical importance. It renders infection through the medium of the air in most cases a remote possibility.

\section{Effect of Electricity on Bacteria}

Strong direct currents of electricity passed through a solution containing bacteria will sterilize it. It is difficult, however, to dissociate the physical effect of the current directly upon the bacteria from the action of the chemicals produced by electrolysis. No practical use has been made of the destructive action of electricity upon microörganisms, as the method is difficult to apply and is inefficient at best. The Röntgen rays ( $x$-rays) do not destroy bacteria even when the latter are exposed for considerable periods.

\section{RELATIONSHIPS OF MICROÖRGANISMS TO CHEMICALS}

Microörganisms are profoundly affected both in growth and movement by the chemicals with which they come in contact. They may be attracted or repulsed, stimulated to increased growth, their development inhibited, or they may be destroyed when certain substances are present.

Chemotaxy.-Motile microörganisms are attracted or repulsed by certain chemicals. The first is known as positive chemotaxy, the latter as negative. Certain protozoa and bacteria are attracted by oxygen and may be observed to swim about air bubbles under the microscope. From their movements it is evident that different species prefer varying amounts of oxygen. This results in a grouping of the different kinds in concentric circles about the bubble. This type of chemotaxy is called aërotaxy (not aërotropism). The avidity of certain bacteria for oxygen has been used in the laboratory for their isolation from water, particularly the Asiatic cholera organisms. Peptones and meat extractives attract many kinds of bacteria. This phenomenon may be readily demonstrated by introducing the tip of a minute capillary tube 
filled with such a solution into water containing numerous bacteria. These will be found to congregate in great numbers about the mouth of the tube and to enter it. Probably chemotaxis accounts for the flocking of the leukocytes or white blood corpuscles to

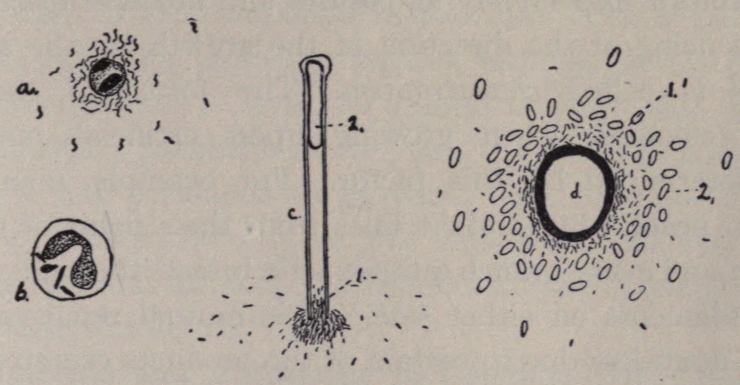

Fig. 24.-Chemotaxy: $a$, Spirilla attracted by a green algal cell which is giving off oxygen, aërotaxis; $b$, a leukocyte containing several bacteria which it has engulfed; $c$, capillary pipette containing a solution of beef extract, and at 2 an air bubble, placed in a drop of water containing motile bacteria. The latter are attracted in large numbers to the mouth of the tube; $d$, an air bubble surrounded by two concentric circles of organisms, the inner one bacteria, the outer protozoa. Each remains in the concentration of oxygen most favorable to its growth.

any part of the body attacked by certain bacteria. Microörganisms are not always attracted by food stuffs and repelled by harmful substances. A mixture of peptone and mercuric chlorid will attract bacteria and then destroy them.
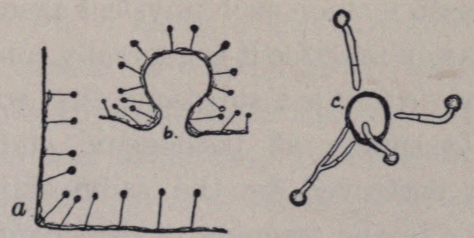

Fig. 25.-Chemotropism: $a, b$, Mold hyphæ and conidiophores, showing the negative hydrotropism of the latter; $c$, an air bubble in a medium with four germinating mold spores. The hyphæ are growing toward the air, showing positive aërotropism.

Tropisms.-Organisms which are not free to move in response to a chemotactic stimulus may nevertheless be influenced in their direction of growth. Such a response in the direction of growth 
to an external stimulus is called a tropism. Mold hyphæ will often grow toward a moist medium, while the conidiophores which they bear rise at right angles to its surface and seek to produce the spores as far as possible from a moist surface. These phenomena are known respectively as positive and negative hydrotropism. The influencing of the direction of the growth by the action of chemicals is called chemotropism. The forms of mold and bacterial colonies, when growing upon artificial media, are largely determined by this factor. For example, many molds radiate in practically straight lines from their point of origin in a medium, and every branch quite exactly bisects the angle between the two filaments on either side. This mutual repulsion of the hyphæ is doubtless due to certain of the products excreted by the cells. Heliotropism, or the influence of light on the direction of growth, is also observed in some forms. $J$

Influence of Reaction of Medium on Growth.-Many organisms are quite exacting in their requirements as to the reaction of the medium in which they are grown. Some forms grow best in a medium slightly acid, others refuse to develop except in one which is slightly alkaline. The majority of bacteria, however, grow well in a medium that is neutral to litmus.

\section{ANTISEPTICS AND DISINFECTANTS}

An antiseptic is anything that will inhibit the growth of microorganisms without necessarily destroying them. In the broadest sense, this term would include such physical agencies as the action of cold and heat, but in practice it is generally confined to chemical substances. A disinfectant is a substance that will destroy pathogenic bacteria. Inasmuch as pathogenic and non-pathogenic bacteria are both destroyed by the same substances, there is little real difference in the meaning of disinfectant and germicide (something that will destroy all bacteria). A deodorant is any substance that masks disagreeable odors or eliminates them entirely by removing their cause. A deodorant may or may not be a disinfectant or antiseptic. These latter terms are relative ones only, for any disinfectant if sufficiently diluted becomes an antiseptic.

Theories of Action of Antiseptics and Disinfectants.-Germicides may destroy microörganisms by forming compounds with 
the protoplasm, by dissolving or coagulating the protoplasm, or by oxidation and complete destruction of the cells. Our most efficient disinfectants are those which destroy in the manner first named. The activity and efficiency of many disinfectants depend upon the ionization of the compound in solution. This is particularly true with the salts of heavy metals, such as mercuric chlorid (corrosive sublimate). It is the ionized mercury that is poisonous to bacteria. Mercuric chlorid does not ionize in pure alcohol, hence it is not poisonous to bacteria when in solution in that substance. The addition of various other chemicals may increase or decrease the ionization of the disinfectant and enhance or diminish its destructive action.

Disinfectants and Antiseptics in Common Use.-Salts of the Heavy Metals.-The salts of gold, silver, copper, and mercury are all active disinfectants. Copper sulphate is sometimes used in an effort to free water reservoirs and other city supplies from growths of objectionable algæ. Mercury is the most efficient of the metals and its salts are most commonly used. It acts by forming a mercuric albuminate of the protoplasm. When used in any solution containing considerable quantities of protein or similar materials, as in feces, it must be used in excess and thoroughly mixed, for it is apt to form an insoluble coating over the surface of the solid particles and protect the bacteria in the interior from destruction. Mercuric chlorid is usually used in solutions of $1: 1000$ or $1: 2000$.

Lime, unslaked, is a fairly efficient disinfectant. It is particularly useful because in the form of whitewash it may be applied as a permanent coating to the walls of stables and outbuildings. Feces and urine may be disinfected by a mixture of equal parts of a 20 per cent. solution of freshly slaked lime with the material to be disinfected.

Phenol, or carbolic acid, $\mathrm{C}_{6} \mathrm{H}_{5} \mathrm{OH}$, and the methyl phenols or cresols, $\mathrm{C}_{8} \mathrm{H}_{4} \mathrm{CH}_{3} \mathrm{OH}$, either pure or in the trade mixtures, such as kreso, tricresol, creolin, etc., are among the most efficient and useful of disinfectants. They are most frequently used in 1 to 5 per cent. solutions, and will destroy bacteria even in the presence of quantities of organic matter.

Sulphur Dioxid and Sulphurous Acid.-When sulphur is 
burned it yields sulphur dioxid, a gas that has been much used in fumigation. It is powerless to destroy bacteria unless moisture is present, with which it may unite and form sulphurous acid. The latter is a very active bleaching and corrosive agent, hence it should not be used except where it can do no harm. One pound of water (about 1 pint) should be vaporized in a room for every 5 pounds of sulphur burned. This amount should efficiently disinfect 1000 cubic feet. Insects and other vermin are destroyed by the sulphur fumes.

Formaldehyd, HCHO.-Formaldehyd is the gas used most widely in fumigation and disinfection. It is very soluble in water and is commonly sold as formalin, a 40 per cent. solution of formaldehyd. Like sulphur dioxid, formaldehyd is efficacious only in the presence of moisture, but, unlike it, does not bleach fabrics or injure materials. Formaldehyd may be evolved in gaseous form for disinfection in a variety of ways. Incomplete combustion of methyl alcohol according to the reaction

$$
2 \mathrm{CH}_{3} \mathrm{OH}+\mathrm{O}_{2}=2 \mathrm{HCHO}+2 \mathrm{H}_{2} \mathrm{O}
$$

is utilized in a number of lamps upon the market. When properly carried out the method may be efficient, but it has several disadvantages, $i$. e., expense and presence of a fire in a closed room. Heating the formalin over an open flame will liberate a part of the formaldehyd readily, but under these conditions it polymerizes and some of the polymers (paraformaldehyd) are insoluble. If the evaporation is continued to dryness, all of these will again be broken up and given off as formaldehyd. The same result can be reached more quickly by the addition of glycerin or some salt which will raise the boiling-point of the solution above the dissociation temperature of the paraformaldehyd. An autoclave or closed vessel in which the solution is heated considerably above the boiling-point of water will serve the same purpose. Twelve ounces of formalin should be used for every 1000 cubic feet to be fumigated. A convenient method for fumigating small rooms is to pour formalin over crystals of potassium permanganate in an earthen vessel that is a poor conductor of heat. The permanganate is an active oxidizing agent and converts part of the formaldehyd into carbon dioxid and water, with the 
liberation of sufficient heat to vaporize a large portion of the remainder. The solid paraformaldehyd or paraform may be heated and is thereby converted into formaldehyd gas. On account of its cheapness and effectiveness formaldehyd is used much more commonly at present than any other of the gaseous disinfectants.

Adjustment of Organisms to Osmotic Pressure.-Any crystalloid in solution behaves within the limits of the solution like a gas, and the same laws of diffusion and diffusion pressures are applicable. Every organism when growing is surrounded by water containing substances in solution, and it also contains certain salts dissolved in the "cell sap" or water in the protoplasm. The ectoplast or limiting membrane of the protoplasm lying just within the cell wall is certainly in most, probably all, cases a semipermeable membrane, $i$. e., it will allow some substances to pass through readily, as water; others pass through slowly, and still others, although in true solution, cannot pass at all. This ectoplast, in short, serves as an osmotic membrane and determines what substances may enter and leave the cell. An active cell always maintains within its sap a greater concentration of solutes than the surrounding medium, the pressure on the inside of the membrane is greater than on the outside, and the cell is said to be in a state of turgor. When such a cell is placed in water containing a greater percentage of solutes than does the cell sap, water leaves the latter until the concentration on the inside and outside again becomes the same. This means a shrinking of the protoplasm; it withdraws from the cell wall and the cell is said to be plasmolyzed. After a time the cell may readjust the amount of solutes in the cell sap and regain its turgor. For every cell, however, there is a limit beyond which the organism cannot go. Some yeast cells have been found to develop slowly in a solution containing 35 per cent. of canesugar. A solution of this concentration exerts a pressure of more than 350 pounds per square inch. It is apparent that such a cell must be profoundly modified. The fact that concentration of solutes inhibits the growth of microörganisms is utilized in the preservation of many food stuffs. Such foods as syrups, jellies, and candied fruits are preserved by the high osmotic 
pressure of the solutes. The action of sugars, salts, etc., is in the nature of a physical antiseptic. Physiological salt solution is one having the same concentration of salt as do the body cells of the particular organism to be studied. It usually contains .85 per cent. of sodium chlorid.

\section{SYMBIOSIS, ANTIBIOSIS, AND COMMENSALISM}

Two organisms that live together and which are mutually beneficial are said to live in symbiosis. Each organism is called a symbion or symbiont. The symbionts are not necessarily closely related forms and may belong to the most widely separated groups of plants, as, for example, bacteria and members of the bean family of the flowering plants.

Antibiosis is that condition which obtains when organisms prove inimical to each other's development. The growth of one species of organism in a culture-medium may completely inhibit the development of some other type. For example, the organism (Streptococcus lacticus) which ordinarily sours milk prevents the development of most other species.

An organism which uses the by-products of another as food, in other words, is parasitic without producing disease, is called a commensal. Many of the bacteria found on the skin, in the mouth, and in the intestinal tract of man and animals are of this character.

All degrees of intergradation between symbiosis, true parasitism, and commensalism have been described for different species.

\section{PIGMENT PRODUCTION BY MiCROÖRgANISMS}

Molds, yeasts, and bacteria are frequently found to be chromogenic, that is, capable of producing pigments or coloring-matter. The colors produced range through all the colors and even shades of color of the spectrum. A few only of the pathogenic forms produce pigments. Many organisms, particularly molds and bacteria, excrete a pigment-forming substance which diffuses through the culture-medium and colors it. Such an organism is the Bacillus pyocyaneus, which produces a diffuse pigment, one that changes the medium first to a green, then to a brown. Some organisms produce pigment granules outside the cell, such are said to be chromoparous, for example, Bacillus prodigiosus, 
which produces a red pigment. The cell walls of some bacteria (such as B. violaceus) and of many of the molds are colored.

Pigments are generally produced only in the presence of free oxygen. Cultivation at high temperatures causes some organisms to lose the power of pigment production. Some pigments are soluble in water, others in alcohol, and others in ether and various fat solvents. They are of little economic importance, but are of value to the systematic bacteriologist in the separation and identification of species.

\section{LIGHT PRODUCTION BY MICROÖRGANISMS}

Several species of bacteria and fungi are known that give

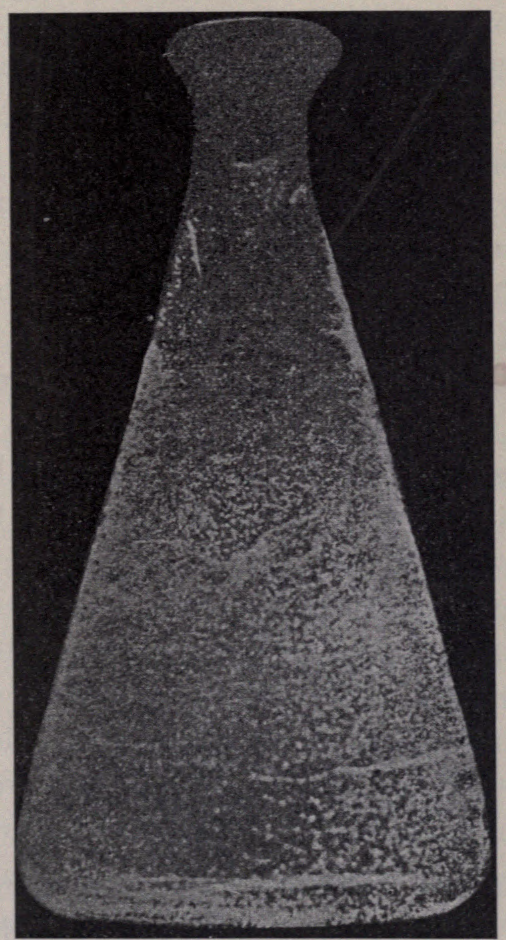

Fig. 26.-A bacterial lamp. The inner wall of the flask is coated with a medium on which there is growing Bacterium phosphoreum. Photographed by its own light (Moliseh).

off light. These are said to be photogenic. Bacteria of this type are found commonly in the water of the ocean, and are 
easily isolated from salt fish. When grown in a test-tube, they are sometimes sufficiently luminous, so that they may be photographed by their own light.

\section{FERMENTATION AND ENZYME PRODUCTION}

All microörganisms have their protoplasm bounded by the ectoplast, a semipermeable membrane, as previously shown. The cell wall, when present, seems to be a mechanical protection and support, and is readily permeable to most substances in solution, so may be disregarded in discussion. Whatever food or other materials are taken into the protoplasm must pass by diffusion through the ectoplast. This membrane, on the other hand, must prevent any valuable constituent of the cell from leaving by diffusion. Its action is, therefore, selective. Microörganisms do not always find the potential food materials with which they are surrounded suitable for food, for they may be in a solid form or, if in solution, of such a character that they cannot pass through the ectoplast. Many organisms find it necessary to so change this food and digest it that it may be assimilated. Once inside the cell, it usually is not of such a character that it can be built up directly into the protoplasm and further changes are necessary; or if the material is used simply as a source of energy and not incorporated into the cell substance, it is essential that the cell have some means of developing this energy. All cells accomplish these changes by means of enzymes (Gr. en, within, zyme, leaven). A distinction was once made between the so-called organized and unorganized ferments. The former was held to be living cells which could bring about a change or fermentation, the latter any cell secretion which could bring about such changes. In other words, organized ferments were supposed to owe their activity directly to the protoplasm, the unorganized, to substances secreted by the protoplasm. This distinction is no longer maintained, as it seems altogether probable that fermentative changes of whatever kind are brought about by the secreted enzymes or unorganized ferments. Enzymes may be intra- or extracellular. The intracellular enzymes are extracted from the protoplasm with difficulty, and during the life of the cell do not leave it. Such an enzyme is that of bread or brewer's yeast (the zymase), 
which converts dextrose into alcohol and carbon dioxid. Extracellular enzymes are usually digestive in their action. Different kinds attack different substances. Microörganisms are known which produce enzymes that will break down cellulose, starch, sugars, fats, and proteins into simpler substances. The action of an enzyme is said to be specific; a given enzyme will in general change only one type of material.

Enzymes are said to be organic catalysts (Gr. kata, down, lyo, to dissolve), that is, they bring about changes without themselves becoming part of the final product. Many inorganic catalysts, such as finely divided platinum, are known to the chemist. Although catalysts do not form a part of the final products, they certainly are a part of some of the intermediary products in many cases, but become free again when the action has been completed. Enzymes, then, are peculiar in that they are not used up in the using. Theoretically the amount of change that can be brought about by a given enzyme is limited only by the time and conditions under which it must act.

Most enzymes produce changes that are hydrolytic in nature, that is, they bring about the incorporation of water into the organic molecule with resultant disintegration. The digestion of gelatin by the bacterial enzyme gelatinase, the conversion of starch into maltose by ptyalin and diastase, the digestion of proteins by pepsin, the conversion of saccharose or cane-sugar into invert sugar by invertase, and the clotting of milk by rennet are a few examples of such hydrolytic changes. The following reaction illustrates the hydrolytic cleavage of saccharose by the invertase produced by yeast:

$$
\underset{\text { Saccharose. }}{\mathrm{C}_{12} \mathrm{H}_{22} \mathrm{O}_{11}}+\underset{\mathrm{H}_{2} \mathrm{O}}{\mathrm{H}}+\text { Invertase } \stackrel{\text { Dextrose. }}{\underset{\mathrm{C}}{\mathrm{C}} \mathrm{H}_{12} \mathrm{O}_{6}}+\underset{\text { Levulose. }}{\mathrm{C}_{6} \mathrm{H}_{12} \mathrm{O}_{6}}+\text { Invertase. }
$$

Other enzymes are active oxidizers. Changes of color in dead or injured plant and animal tissues are sometimes due to such oxidases. For example, potatoes turn black and apples become brown when the cells are bruised. Some other enzymes are said to be splitting. One of the best examples of these is the zymase of yeast, which converts dextrose into alcohol and carbon dioxid. 


$$
\underset{\substack{\mathrm{C}_{6} \mathrm{H}_{22} \mathrm{O}_{6} \\ \text { Dextrose. }}}{\mathrm{Zymase}_{\text {Alcohol. }}}=\underset{\substack{\text { Carbon } \\ \text { dioxid. }}}{2 \mathrm{C}_{2} \mathrm{H}_{5} \mathrm{OH}}+\text { Zymase. }
$$

Although alcohol and carbon dioxid represent the end-products, it is by no means certain that intermediate hydrolytic products are not formed, and this splitting action may be essentially hydrolytic. Reducing enzymes have also been demonstrated in plant and animal tissues and undoubtedly occur in microörganisms.

The autolytic (Gr. auto, self, lyo, dissolving) enzymes deserve particular mention. Enzymés are known to occur in most animal and plant cells that will, at least partially, digest the cells in which they occur. The rigor mortis or stiffening of the tissues of an animal after death is due to such an autolytic enzyme which coagulates the muscle protoplasm. The softening of the tissues which occurs later, the so-called " ripening " of meat, is due in part to the action of another proteolytic enzyme which carries the digestion somewhat further. Microörganisms contain such enzymes, and when the cells die, as in an old culture, they are then partially digested. This autolytic action we shall find to be of some practical significance in a discussion of disease production and immunity, as by it certain poisonous substances may be released from the cell. 


\section{CHAPTER IV}

\section{CHANGES OF ECONOMIC SIGNIFICANCE BROUGHT ABOUT BY NON-PATHOGENIC ORGANISMS}

Microörganisms bring about many changes, both analytic and synthetic, in the media in which they are cultivated. In any such medium growth products of many kinds will be found. These fermentative products may originate from the activity of extracellular enzymes, may consist of substances excreted from the cell as the product of intracellular enzymes, or as a result of the metabolic activity of the cell; they may be products of synthetic action (as the slimes and gums produced by a solution of the bacterial capsule), or they may be substances produced by the autolytic activity of intracellular enzymes after the death of the cell. Naturally, the products will vary greatly with the species of organism, the medium in which it is grown, and the character of the physical environment.

From the standpoint of the veterinarian, microörganisms are of most importance because many of them produce disease. It would, however, give a false impression of the place and function of microörganisms in nature to neglect at least a brief consideration of some of the other changes which they can bring about. In this chapter some of the more important will be considered.

The well-nigh universal distribution of bacteria and other microörganisms should be emphasized. They are to be found in the soil in great numbers, rich surface soil containing from 100,000 to $5,000,000$ bacteria to every dry gram. Their dried bodies and spores are constantly present free or attached to dust particles in the air. They are to be found in all surface waters in considerable numbers and are present even in the water from deep wells. They grow upon the surface of the skin of animals, and the mouth and digestive tract support a large and varied flora. It is apparent that whenever conditions are favorable for the growth of microörganisms they will be present to begin growth. 
The changes brought about by bacteria in nature are of such importance that but for their continuance plant and animal life on earth would quickly cease to exist. The fertility of the soil and the consequent production of all food stuffs is directly due to certain of the microörganisms present.

Production of Alcohol.-The various alcohols, but more particularly ethyl alcohol, are produced by certain bacteria, yeasts, and molds. It has been shown that in the yeast the ability to bring about this change is resident in the intracellular enzyme, zymase. Probably similar enzymes are present in the alcoholproducing bacteria and molds. The common bread or brewer's

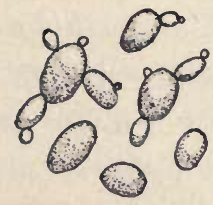

Fig. 27.-Brewer's yeast, Saccharomyces cerevisio.

yeast is the form most commonly used in the manufacture of alcoholic beverages, but certain molds have been found very useful in the production of alcohol for industrial purposes. Alcohol is commonly produced by the fermentation of one of the hexose monosaccharids, such as dextrose. The reaction may be given as follows:

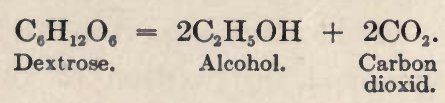

Yeast is utilized for its other product of fermentation, carbon dioxid, by the baker in bread making. Higher alcohols, such as butylic and amylic, are also formed. The yeasts which produce this change are quite widely distributed in nature, being particularly abundant on the surface of fruits and in saccharine liquids. Fruit juices and other solutions containing sugar if allowed to stand, therefore undergo "spontaneous" fermentation, with production of ciders, wines, and similar beverages.

Production of Acids. - Several of the organic acids are commonly produced by fermentative organisms. Three of these are 
of particular economic importance, namely lactic, acetic, and butyric. A great variety of others are occasionally produced, usually in small quantities only.

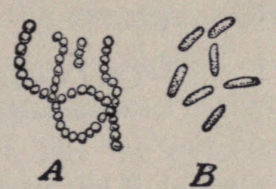

Fig. 28.-Lactic acid bacteria: $A$, Streptococcus lacticus; $B$, Bacillus bulgaricus.

Lactic Acid.-Dextrose and some other monosaccharids are converted into lactic acid by several common organisms. The reaction may be empirically represented as follows:

$$
\underset{\text { Dextrose. }}{\mathrm{C}_{6} \mathrm{H}_{12} \mathrm{O}_{6}}=\underset{\text { Lactic acid. }}{2 \mathrm{C}_{2} \mathrm{H}_{4} \cdot \mathrm{OH} \cdot \mathrm{COOH}}
$$

The reaction occuis most frequently in milk which is allowed to stand. In this case the lactose or milk-sugar is first broken down into the monosaccharids before being converted into lactic acid.

$$
\underset{\text { Lactose. }}{\mathrm{C}_{12} \mathrm{H}_{22} \mathrm{O}_{11}}+\underset{\text { Dextrose. }}{\mathrm{H}_{2} \mathrm{O}}=\underset{\text { Galactose. }}{\mathrm{C}_{6} \mathrm{H}_{12} \mathrm{O}_{6}}+\underset{\text { C. }}{\mathrm{C}_{6} \mathrm{H}_{12} \mathrm{O}_{6} .}
$$

The formation of lactic acid in milk is of the greatest economic importance, as the organisms which produce this acid are the ones

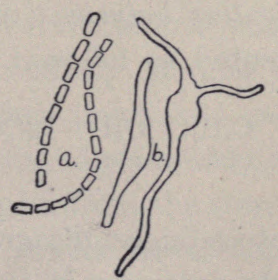

Fig. 29.-Acetic acid organism, Bacillus aceti: $a$, Normal individuals; $b$, involution forms. (Adapted from Hansen.)

which are necessary to the development of proper flavors and quality in butter and cheese. This acid is also produced in the manufacture of sauer-kraut and to some extent in silage. The lactic acid formed in milk is instrumental in preventing the growth of putrefactive and other undesirable bacteria. 
Acetic Acid.-Acetic acid is the most important and the characteristic constituent of vinegar. It is produced by several species of bacteria by the oxidation of ethyl alcohol according to the following reaction:

$$
\underset{\text { Alcohol. }}{\mathrm{C}_{2} \mathrm{H}_{5} \mathrm{OH}}+\mathrm{O}_{2}=\underset{\text { Acetic acid. }}{\mathrm{CH}_{3} \mathrm{COOH}}+\mathrm{H}_{2} \mathrm{O} \text {. }
$$

Any solution containing alcohol, if left in contact with free oxygen, will commonly undergo this fermentation spontaneously, as Bacillus aceti, the organism usually responsible, is ubiquitous. To insure rapid and efficient fermentation the cider or other alcoholic solution is sometimes inoculated with mother of vinegar, a mass of the organism which commonly forms a mat upon the surface of the fermenting liquid.

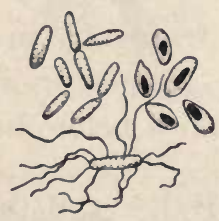

Fig. 30.-Butyric acid bacteria, Bacillus butyricus. (Adapted from Fischer.)

Butyric Acid.-Under anaërobic conditions saccharine solutions are apt to undergo butyric acid fermentation as a result of the development of the Bacillus butyricus or a related form. The reaction may be represented as follows:

$$
\begin{aligned}
& \mathrm{C}_{6} \mathrm{H}_{12} \mathrm{O}_{6}=\mathrm{C}_{3} \mathrm{H}_{7} \mathrm{COOH}+2 \mathrm{CO}_{2}+2 \mathrm{H}_{2} \text {. } \\
& \text { Dextrose. Butyric acid. }
\end{aligned}
$$

Butyric acid has an exceedingly disagreeable odor and taste, hence the growth of this organism in any saccharine or starchy food substance renders it unfit for use. Inasmuch as these organisms are all spore producers, they resist heat well, and as they are anaërobic they will grow when sealed in a can and all air excluded. Rancidity in butter is sometimes due, in part at least, to the development of butyric acid.

Decay and Putrefaction. - A distinction is sometimes made between the terms decay and putrefaction. The former is said to 
be decomposition of organic matter brought about by the aërobic bacteria, the latter by the anaërobic types. This distinction is not always acknowledged and adhered to, however. The substances produced by the decomposition by bacteria depend, of course, quite largely upon the nature of the material to be decomposed. The carbohydrates and fats break down into alcohols, acids, and carbon dioxid, but the proteins are split into a great -variety of substances. Other agents, as acids and alkalis, will break up the proteins in a similar manner and into many of the same substances as do bacteria. Chemists have in recent years demonstrated that proteins are made up of large numbers of molecules of the $\alpha$-amino acids linked together. An $\alpha$-amino acid is an organic acid that has the $\mathrm{NH}_{2}$ group in the alpha position, that is, next the carboxyl. For example, the amino acid corresponding to $\mathrm{C}_{2} \mathrm{H}_{5} \mathrm{CH}_{2} \mathrm{COOH}$, butyric acid, is $\mathrm{C}_{2} \mathrm{H}_{5} \mathrm{CHNH}_{2} \mathrm{COOH}$. When these constituent links of the protein molecule are forced apart, they usually appear in the form of one of about twenty compounds which have been grouped as primary protein derivatives. Some of these normal derivatives are further altered by bacteria. Among them have been found certain compounds called ptomains, some of which are known to be very poisonous. The splitting usually continues until much of the organic matter is reduced to comparatively simple compounds, such as $\mathrm{H}_{2} \mathrm{~S}, \mathrm{CO}_{2}, \mathrm{CH}_{4}$, and $\mathrm{NH}_{3}$. The process of protein disintegration is called proteolysis. It usually occurs in several distinct stages. The proteins are first broken down into relatively complex substances called proteoses, these then are broken down into peptones. This is called peptonization, as it is essentially the change that may be brought about by the enzyme pepsin from the stomach. The process continues and the peptones become amino acids and at last ammonia is liberated. From an economic point of view this liberation of ammonia has the greatest significance, for from this transformation comes all the nitrogenous material used by plants and indirectly by animals as food. This is the essential transformation that all organic nitrogenous fertilizers, such as barnyard manure and dried blood, will undergo before they can be of any use to higher plants. By such changes water contaminated by sewage purifies itself. 
Some of the nitrogenous products of bacterial decomposition are worthy of note, inasmuch as they are used in the laboratory in the differentiation of certain species. The most important of these are indol and skatol. They are organic compounds having the following formulas:<smiles>C1=CCCCC1</smiles>

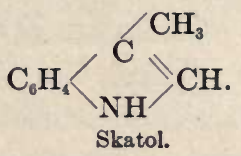

Indol is produced by certain bacteria when growing in a solution of peptone. It is identified by the addition of nitrous acid, with which it combines to form nitroso indol, a bright red compound. In making the test in the laboratory it is customary to add a

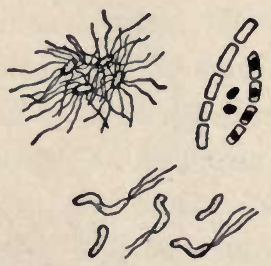

Fig. 31.-Some decay-producing and putrefactive bacteria.

few drops of concentrated sulphuric acid, followed by a dilute solution of nitrite. The sulphuric acid breaks up the nitrite, with the formation of free nitrous acid, which then unites with the indol. Indol and skatol are also formed in the intestines by the activity of certain of the bacteria found there and are of considerable physiological significance.

Reduction Processes in Inorganic Compounds.-Changes similar to those just discussed are sometimes brought about by bacteria in inorganic compounds. When nitrates are in solution together with organic substances and under anaërobic conditions, the bacteria present in many cases will reduce the nitrates to nitrites and the nitrites to free nitrogen, apparently in order to utilize the oxygen. This process is usually called denitrification because the medium loses nitrogen, but is more correctly a reduction or deoxidation. Sulphates are reduced to sulphites and even to sulphids under similar conditions. For example, the sewage from 
a city whose water supply contains a large percentage of sulphates will develop hydrogen sulphid in considerable quantities if it is put under anaërobic conditions. Other reductions of a similar nature have been described for chlorates.
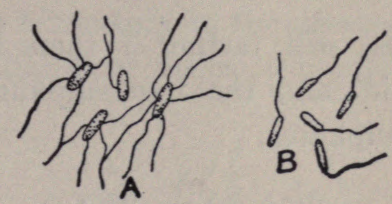

Fig. 32.-Denitrifying bacteria: A, Bacillus coli, which changes nitrates into nitrites; $B$, Bacillus denitrificans, which produces free nitrogen from nitrates.

Oxidation of Inorganic Compounds.-Bacteria and other microörganisms that live in the presence of oxygen are sometimes active oxidizers of inorganic compounds, securing in this manner the energy that is necessary for their various growth processes.

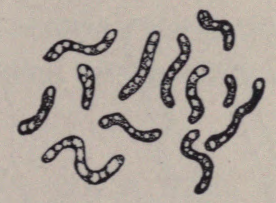

Fig. 33.-Sulphate-reducing spirillum, Spirillum desulfuricans.

Oxidation of Hydrogen Sulphid.-Waters containing hydrogen sulphid, as do many of the so-called mineral springs, usually contain bacteria which gain their energy for food manufacture
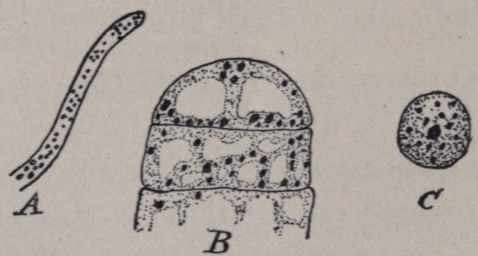

Fig. 34.-Microörganisms that oxidize hydrogen sulphid: $A, B$, Beggiatoa sp.; $C$, Thiophysa volutans (Hinze).

and growth from the oxidation of this substance. The slimy black and white deposit commonly found in such waters, when examined microscopically, will be seen to be made up of masses of 
Beggiatoa and similar organisms whose cells will be found packed with sulphur granules. Probably the following reaction accounts for this formation of free sulphur:

$$
2 \mathrm{H}_{2} \mathrm{~S}+\mathrm{O}_{2}=2 \mathrm{H}_{2} \mathrm{O}+\mathrm{S}_{2} .
$$

The process is carried still farther if there is any deficiency of the hydrogen sulphid, and the free sulphur is converted into sulphuric acid and sulphates.

$$
\begin{aligned}
\mathrm{S}_{2}+3 \mathrm{O}_{2} & =2 \mathrm{SO}_{3} \\
\mathrm{H}_{2} \mathrm{O}+\mathrm{SO}_{3} & =\mathrm{H}_{2} \mathrm{SO}_{4} .
\end{aligned}
$$

The sulphuric acid is, of course, at once neutralized by the bases present in the water.

Oxidation of Iron.-Many natural waters contain ferrous carbonate or some similar salt of iron. Certain bacteria oxidize
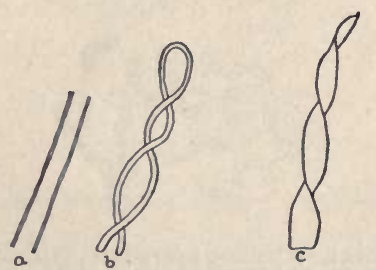

Fig. 35.-Microörganisms that oxidize ferrous to ferric iron: $a$, Leptothrix ochracea; b, Gallionella ferruginea; $c$, Spirophyllum ferrugineum. (Adapted from Ellis.)

this to ferric hydrate, and deposit this insoluble material in their sheaths. The reaction may be represented as follows:

$$
2 \mathrm{Fe}_{2} \mathrm{CO}_{3}+3 \mathrm{H}_{2} \mathrm{O}+\mathrm{O}=\mathrm{Fe}_{2}(\mathrm{OH})_{6}+2 \mathrm{CO}_{2} \text {. }
$$

Probably these organisms make use of the energy obtained by this reaction in the same manner that the sulphur bacteria do the oxidation of the sulphur, to secure energy for the formation of their foods and to gain the energy needed for growth and development. These organisms are particularly apt to occur in well water or spring water laden with iron, and have in some cases caused considerable trouble by clogging the water pipes with their growth. It is known that the bog iron ore of Sweden and probably the 
great iron beds of northern Minnesota have been deposited by the activity of such organisms.

Oxidation of Ammonia.-In most soils there are numerous bacteria that oxidize free ammonia to nitrous acid, and by neutralization with the soil bases form nitrites. These organisms do not develop well in the laboratory in the presence of organic matter. It seems evident that they utilize the energy secured from the

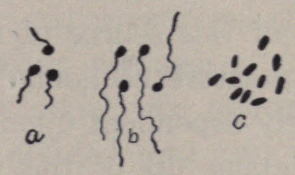

Fig. 36.-Bacteria that oxidize ammonia and nitrous acid to nitrous and nitric acid respectively: a, Nitrosomonas europea; $b, N$. javensis; $c$, Nitrobacter (Winogradsky).

oxidation of the ammonia to build up their protoplasm out of simple materials. They are among the best examples of the strictly prototrophic bacteria. Organisms capable of bringing about this change are called nitroso-bacteria. The reaction may be represented as follows:

$$
\mathrm{NH}_{3}+2 \mathrm{O}_{2}=\mathrm{HNO}_{3}+\mathrm{H}_{2} \mathrm{O} .
$$

This is the first of the two steps in the process called nitrification in the soil.

Oxidation of Nitrous Acid.-The nitrous acid formed in the soil and in water, etc., by the preceding group is further changed by another group of organisms called the nitrate bacteria. Like the preceding, they are widely distributed in water and soil, and complete the process called nitrification or, better, oxidation of nitrogen. The nitrates produced by their activity are the source of nitrogen for green plants. A few of the latter are able to make use of nitrogen in the form of ammonia compounds, but in nature this rarely occurs. The reaction may be represented as follows:

$$
2 \mathrm{HNO}_{2}+\mathrm{O}_{2}=2 \mathrm{HNO}_{3} .
$$

It is probable that the fertility of the average soil is more largely determined by the maintenance of conditions favorable to the 
development of these nitrifying organisms than by any other single factor. Their importance in nature as essentials for the growth of the higher plants and, therefore, of animals can scarcely be overestimated.

Nitrogen Fixation.-The free nitrogen of the air is so inert that very few living plants are capable of making use of it in the building up of their bodies. None of the green plants can bring this about of themselves. Certain molds and bacteria are able to make use of this source of nitrogen, however, and are, therefore, of the greatest economic importance. The fertility of the soil is largely dependent upon the fixed nitrogen that it contains, and the taking up of the free nitrogen by these organisms ultimately renders it available to other forms of plants. This does not mean that the bacteria take up the nitrogen from the
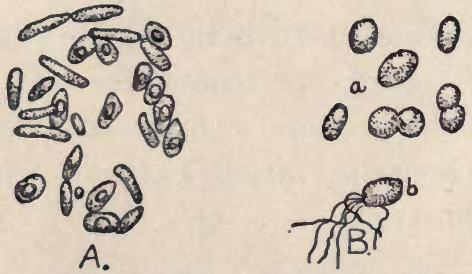

Fig. 37.-Free living or non-symbiotic nitrogen-fixing bacteria: $A$, Bacillus (Clostridium) pastorianum; B, Azotobacter; $a, A$. chroococcum; $b, A$. agilis. ( $A$ after Winogradsky, $B$ after Beyerinck.)

air and immediately transform it into nitrates for the use of the higher plants, but that it is built up into their protoplasm and ultimately is set free by the death and decomposition of the organisms. Microörganisms which make use of free nitrogen commonly utilize carbonaceous materials as a source of energy.

Organisms capable of fixing nitrogen are subdivided into two general groups, those which live free in soils and those which live in or on the roots of certain plants in a kind of symbiosis. The free living organisms which fix nitrogen belong to three general groups: first, certain anaërobic types belonging to the general group of butyric acid bacteria; second, certain aërobic species; third, a few molds. The anaërobic organism known to fix the nitrogen is Bacillus (Clostridium) pastorianum. Probably this organism is not of the greatest importance, as the conditions for 
its development do not often obtain. Bacteria of the nitrogenfixing aërobic type belong to the group called Azotobacter. These organisms are abundant in many soils and fix considerable quantities of nitrogen, gaining energy therefor by oxidizing the carbonaceous materials from dead plant tissues. The addition of straw, for example, to a soil will furnish sufficient food so that these bacteria will bring about an appreciable increase in the nitrogen content. The importance of the molds in this connection is not fully understood, but several species have been described which are capable of fixing nitrogen.

The microörganisms which fix nitrogen in symbiosis with higher plants may be divided into two groups, those bacteria which grow upon the roots of legumes and the molds which grow on the roots of certain other plants. All plants belonging

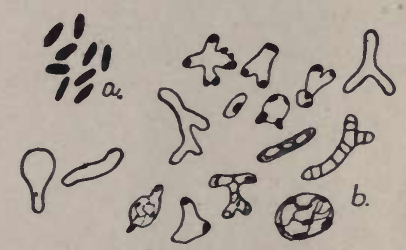

Fig. 38.-Bacillus radicicola: $a$, Normal bacillar form; $b$, bacteroids or involution forms.

to the legume or pulse family, such as clover, alfalfa, peas, beans, etc., usually bear upon their roots tubercles or nodules which, when opened, are found to be made up of cells tightly packed with bacteria. It has been shown experimentally that these organisms growing within the roots in some way take up free nitrogen from the air and eventually turn it over to the host plant, so that the legumes are not dependent for their development upon nitrogen which may be present in the soil, but can make use of the free nitrogen of the air as well. These plants are, therefore, very important in agriculture in the maintenance and increase of soil fertility. This organism, known as Bacillus radicicola (Fig. 38 ), enters the young growing root through a root hair and causes a kind of tumor formation in the tissues of the root, resulting in the development of the nodule. The organism is at first a straight rod, but later, when growing inside the cells of the host, it becomes 
much enlarged and shows many involution forms. The other organisms growing symbiotically within or upon the roots of plants are all molds. They develop either upon the surface of the root, forming a white, cottony, floccose covering, or they grow in the tissues just below the epidermis. They sometimes cause nodules to develop, as is the case with the Russian olive and the alder, or they produce no eharacteristic overgrowth of tissues

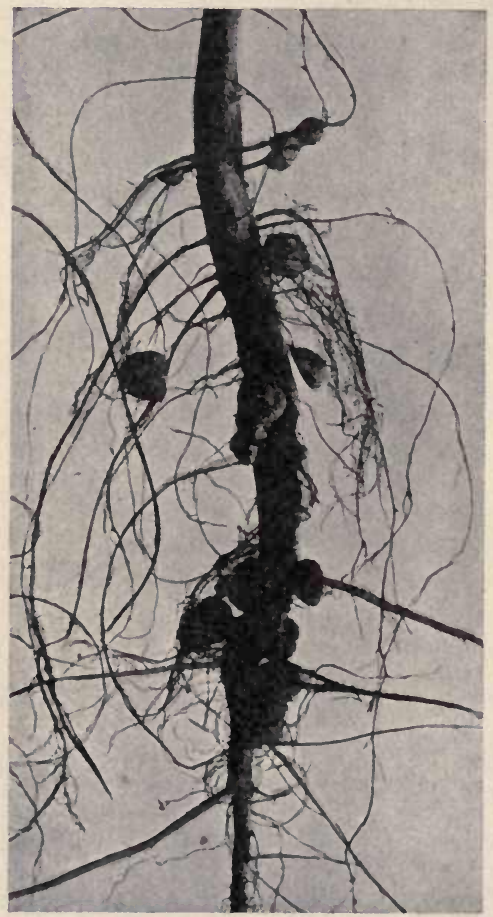

Fig. 39.-Nodules on the root of a legume, Soy bean. (Moore, U. S. Dept. Agr.)

at any one point, but are found quite uniformly present upon the young growing roots. Certain trees, such as the oak and the pine, particularly, when growing in nitrogen poor soils, show the development of this mycorrhiza (Gr. fungus and root). It has been shown that these molds are quite active in taking up free nitrogen from the air and are of benefit to the plant upon which they occur. 
The Nitrogen Cycle.-The relationship of microörganisms to nitrogen and its compounds has been noted in the preceding pages. These changes may be summarized as follows: Certain bacteria break down organic compounds containing nitrogen with the ultimate liberation of ammonia. Other species change the ammonia to nitrous acid and nitrites. Still other species transform the nitrites to nitrates, and these the higher plants take up from the soil and transform again into complex organic substances. These eventually again decay or are eaten by animals and converted into animal tissues. The nitrogen of both plant and animal tissues

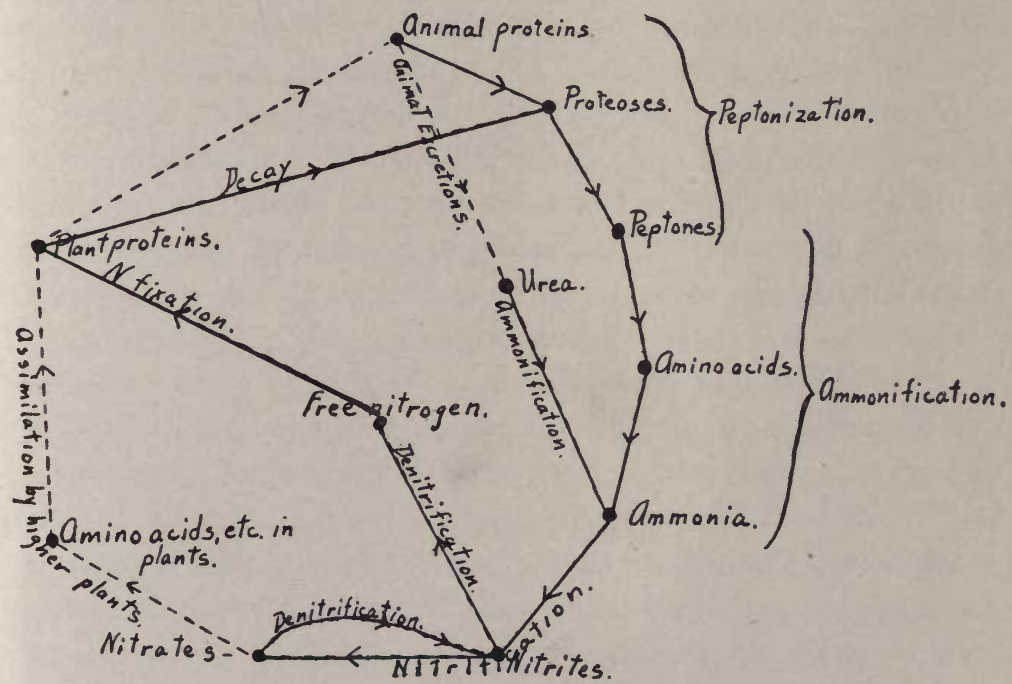

Fig. 40.-Nitrogen cycle. Changes brought about by bacteria indicated by solid lines, other changes by dotted lines.

ultimately undergoes the change first noted and the nitrogen again appears as ammonia. This series of changes is called the nitrogen cycle. It is to be noted in addition that some bacteria are found which decompose nitrates with the formation of nitrites and liberate free nitrogen in the so-called process of denitrification. Other species, either alone or in symbiosis with higher plants, take up and fix free nitrogen from the air and eventually convert it into a form available for higher plants. These changes may be better understood by reference to the accompanying diagram. 
Miscellaneous Changes.-Many changes are brought about by bacteria other than those which are here discussed. Microorganisms are of importance in tanning, curing of tobacco, the preservation of food-stuffs, such as silage and sauer-kraut, the retting of flax and hemp, the curing of the so-called burnt or heated hay, and in many other ways. It is to be remembered that probably in all cases these changes are brought about by the enzymes produced by the bacteria. 


\section{CHAPTER V}

\section{CLASSIFICATION OF MICROÖRGANISMS}

IT is necessary in a consideration of organisms belonging to either the plant or animal kingdoms to divide or separate them into groups, with their apparent relationships as the basis for the grouping. Microörganisms of pathogenic significance we have previously divided into the four groups-bacteria, yeasts, molds, and protozoa. A discussion of the classification of the last will be reserved to the chapter on Diseases Produced by Protozoa.

The classification of micro-örganisms is by no means in a satisfactory state. Many bacteriologists and others who have investigated diseases have failed to recognize the importance of simple classifications and have introduced many new names needlessly. It is a principle of nomenclature accepted since the time of Linnaeus that every plant and animal belonging to a distinct type or species shall receive a Latin name, this name to be made up of two words only. The second of these words is the species name, and is peculiar to the particular kind under consideration, the first is called the genus or generic name. For example, among higher plants we have the genus Quercus, or oak, which is subdivided into many species, such as white oak, red oak, swamp oak, etc. (Quercus alba, rubra, etc.). The generic name is applied to all those species which resemble each other, as do all of the oaks. Species of plants and animals are given names which are understood to serve as convenient terms for their designation. It is an established principle that the name first given to a plant or an animal is the one which should always be used whenever that name is in accordance with certain rules. Some bacteriologists have made the mistake of believing that a scientific name should be a description or even a descriptive term. It is no more necessary that the species name of a bacterium should describe that bacterium than that the given or Christian name of an individual should describe him. Disregard of this rule has resulted in some very unwieldy names being given to micro- 
organisms, for example, names such as the following have been applied to bacteria: Bacillus membranaceous amethystinus mobilis, Bacillus argenteus phosphorescens liquefaciens, and even the following, Bacillus saccharobutyricus fluorescens liquefaciens immobilis. Such names are given under the mistaken idea that the specific name should be a description of the species. This is not customary in naming any of the higher plants and animals, and it is certainly not more desirable in bacteria. The yeasts, molds, and protozoa have more commonly been studied by those who have had technical training in nomenclature than have the bacteria, consequently the classification of these forms is on a much more satisfactory basis. The only justification for a specific name made up of more than two words is that the two words taken together express but a single idea.

\section{Classification OF BACTERIA}

Many different classifications have been proposed for bacteria, but not one of these has come into general use. A careful examination of different texts in bacteriology, particularly those devoted to the pathogenic bacteria, will show that different systems and schemes of classifications are used in dealing with closely related organisms. Not only have the groups been frequently changed, but many different names have been applied to almost every one of the pathogenic bacteria. The consequence is that in studying any pathogenic organism it is necessary to give not only the name preferred by the author but also a list of the synonyms which have been used by others. It seems probable that a satisfactory system of nomenclature is yet to be devised. The system of bacterial classification which has been most generally adopted and has given the best general satisfaction is that of Migula, published in Engler and Prantl's Synopsis of Plant Genera. This classification has been somewhat modified by Frost and McCampbell and their regrouping is perhaps more in accord with the facts. It is perhaps more important that a distinct and satisfactory classification should be adhered to than that a single. classification should be used for all purposes. The following classification is the one which will be adopted in this text. It is based upon Frost and McCampbell's modifica- 
tion of Migula's scheme, but with some changes which seem to coördinate it better with practice. A key to the various groups and genera of the bacteria as here used will first be given, followed by a brief discussion of the characteristics of the more important genera. All of those groups of bacteria which are not of economic importance or which have no pathogenic members have been eliminated. This removes some fifteen or eighteen genera which have no common or economic representatives and are chiefly of systematic or botanical interest.

\section{KEY TO THE GROUPS AND GENERA OF BACTERIA}

I. Order Eubacteria, or true bacteria. Cells free from sulphur.

Family I. Coccaceæ. Bacterial cells globular when in a free state.

Non-motile.

Cell division occurring in parallel planes resulting in the formation of chains .............................. Streptococcus.

Cells dividing in two planes, forming plates of cells, or not remaining united, or dividing irregularly to form irregular masses. . Micrococcus. Cell division occurring in three planes, all at right angles, the cells remaining united after division and forming cubes or packets. . Sarcina. Motile.

Same as Micrococcus, but with organs of motion....... Planococcus.

Same as Sarcina, but with organs of motion........... Planosarcina.

Family II. Bacteriaceæ. Cells cylindric in shape and not bent. . Bacillus.

Family III. Spirillaceæ. Cells in the form of corkscrews or spirals, or segments of a spiral. Cells fairly rigid, usually motile by means of a flagellum or tuft of flagella at the end.............. Spirillum. Cells forming long, thin, and tenuous spirals. Flagella, if present, demonstrated only with difficulty. Probably protozoa in part and not true bacteria........................... Spirochata.

Family IV. Chlamydobacteriaceæ. Cells cylindric, united in threads, and surrounded by a sheath. Arthrospores sometimes present.

Filaments show no branching.................. Leptothrix.

Filaments show false branching.................. Cladothrix. Filaments show true branching.

Arthrospores or conidia produced.............. Nocardia.

No spores observed .....................Actinomyces.

II. Order Thiobacteria. Cells containing sulphur granules.

Filaments surrounded by a sheath ................ Thiothrix.

Filaments not surrounded by a sheath.............. Beggiatoa.

Streptococcus.-The term Streptococcus is applied to any spherical organism whose cells occur in chains. The method of development has already been discussed. Spores are not developed. In some forms the chains break up readily into pairs, to which 
the name Diplococcus is sometimes applied. This has been used by some writers as a genus name.

Micrococcus.-All spherical organisms the cells of which do not occur either in chains or packets are generally included under the genus name Micrococcus. As defined by Migula, the name strictly applies only to those organisms which divide alternately in two planes at right angles to each other, forming pairs and

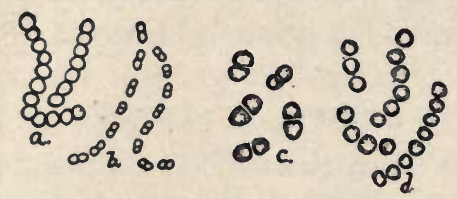

Fig. 41.-Types of Streptococci: $a, d$, Streptococci consisting of uniform elements; $b$, Streptococcus consisting of diplococcus elements; $c$, Diplococcus.

fours and eventually a plate. Very few bacteria develop in this manner. It has been assumed by some authors that division may occur in the two planes, but the cells may divide at such irregular intervals that irregular masses of the organisms may be formed. It is altogether probable that some of the cocci divide irregularly and not in planes strictly perpendicular or parallel to previous planes of division. This results in the forma-

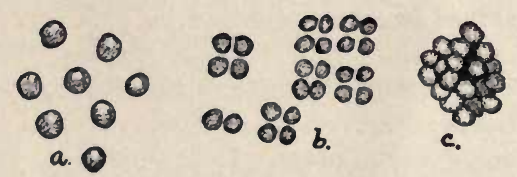

Fig. 42.-Types of Micrococcus: $a$, Micrococcus of isolated cells; $b$, Micrococcus showing tetrads, forming plates of cells or merismopedia; $c$, Micrococcus with cells in an irregular mass-Staphylococcus.

tion of irregular groups. When the organisms remain united, as frequently occurs, they form irregular bunches, to which the name Staphylococcus is sometimes given. As used in the following chapters, the term Staphylococcus is synonymous with Micrococcus.

Bacillus.-As used here, the term Bacillus includes all rodshaped organisms. Two other names are used by some authors, namely, Bacterium and Pseudomonas. Bacterium is defined by some authors as a non-motile bacillus, by others as a non-spore- 
bearing bacillus. Sometimes a non-motile organism is found to be physiologically, culturally, and morphologically closely related to some motile form, and it seems to be undesirable to separate these into different genera. The differentiation on the basis of spore formation has not been generally accepted by bacteriologists. The term Pseudomonas is sometimes used to indicate a motile

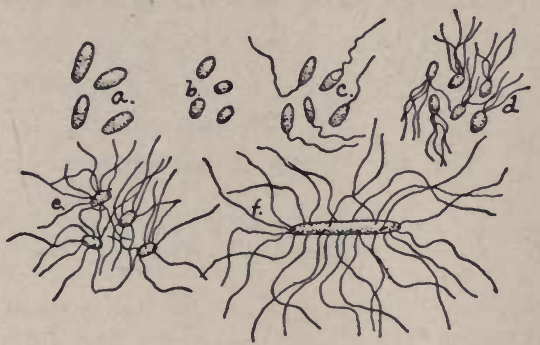

Fig. 43.-Types of bacilli: $a, b$, Non-motile bacilli (Bacterium); $c$, monotrichous bacillus (Pseudomonas); $d$, lophotrichous bacillus (Pseudomonas); $e, f$, peritrichous Bacillus.

bacillus having polar flagella, while the term Bacillus is limited to organisms having flagella over the entire surface of the body (peritrichous). The term Bacillus is here used to include both Bacterium and Pseudomonas.

Spirillum.-The family Spirillaceæ is divided by Migula into four genera: Spirosoma is non-motile. Microspira is a rigid,

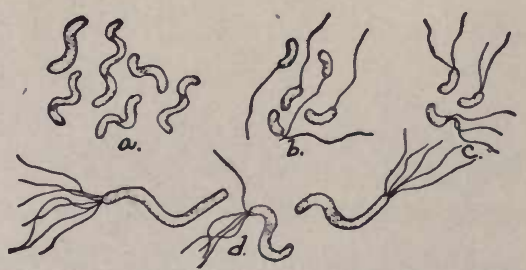

Fig. 44.-Types of spirilla: $a$, Non-motile spirillum (Spirosoma); $b$, monotrichous spirillum (Microspira, Vibrio); $c$, lophotrichous spirillum with 2 or 3 flagella (Microspira, Vibrio); $d$, lophotrichous spirillum (Spirillum).

short, comma-shaped organism with one, two, or three flagella. Vibrio is sometimes used as a synonym of microspira. Spirillum is used to indicate a long, rigid, spiral bacterium with a tuft of flagella at one or both ends. As used in this text, the term Spirillum will include Spirosoma, Microspira, Vibrio, and Spirillum. 
Spirochæta.-Spirochæta is defined as an organism with long, thin, flexible spirals on which flagella are demonstrated with difficulty, if at all. It is problematic whether the spirochætæ belong to the true bacteria or are a group intermediate between the bacteria and protozoa. Conclusive evidence on this subject

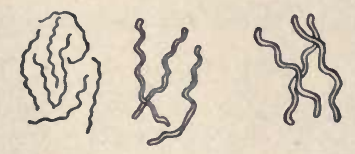

Fig. 45.-Types of spirochætæ.

is still lacking. These organisms will be discussed with the protozoa.

Chlamydobacteriaceæ.-The classification here given is that used by Jordan in his "General Bacteriology." Nomenclature of the forms belonging to this group is badly mixed, and the same terms have been used by different authors with reference to very

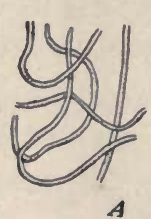

A

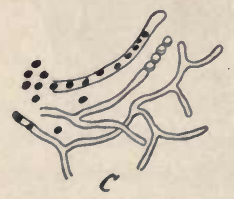

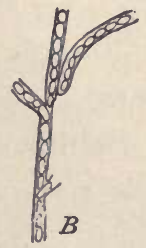

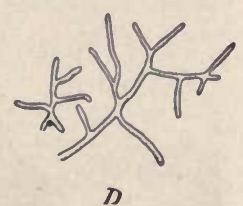

D

Fig. 46. - $A$, Leptothrix; $B$, Cladothrix; $C$, Nocardia; $D$, Actinomyces or Streptothrix.

different organisms. Leptothrix is a sheathed organism which shows no branching. Cladothrix is one which shows false branching. This false branching arises through one of the intercalary cells dividing and pushing the cells lying above it to one side, and developing thereafter as a terminal cell. Nocardia includes those forms in which there is true branching, and in which 
arthrospores have been observed. These are formed usually by aërial hyphæ which are thrown up from the surface of the medium upon which the organism is growing and break up into segments which resemble bacilli. The term Streptothrix is sometimes used as synonymous with both the terms Nocardia and Actinomyces, but not correctly, as the name Streptothrix was, as long ago as 1839 , used for a genus in a wholly unrelated group of fungi. Actinomyces includes those types which show true branching and in which spore formation has not been observed. Probably Nocardia and Actinomyces represent but a single genus. In addition to the forms here given, several other genera have been recognized by various writers, but are of no importance to the veterinarian.

Thiothrix includes all thread-like bacteria which possess no sheath and whose cells contain sulphur granules. Conidia or

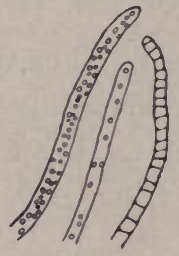

A

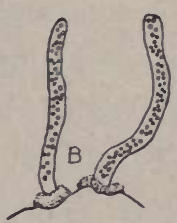

Fig. 47.- $A$, Beggiatoa (after Winogradsky); $B$, Thiothrix (after Ellis).

arthrospores are produced at the ends of the threads. This genus is of little importance.

Beggiatoa.-This includes all those forms in which the cells are surrounded by a sheath and contain sulphur granules.

In addition to the names of the genera given above, a large number of physiologic and pathologic names have been given. For example, Streptococcus pneumonice is frequently referred to as the pneumococcus. This is not in any sense a scientific name, but simply a convenient term for common designation. Other examples of similar type are gonococcus for the specific cause of gonorrhea, meningococcus for the organism causing epidemic cerebrospinal meningitis, and urobacillus for organisms causing certain ammoniacal fermentations in urine. Such examples might be multiplied indefinitely. 


\section{CLASSIFICATION OF YEASTS}

Mycologists recognize a number of different genera in the group of yeasts. It is probable that the yeasts do not constitute a homogeneous group. The genus Saccharomyces includes sûch forms as the common bread and brewer's yeast (Saccharomyces cerevisice) which produce spores and are active in alcoholic fermentation. The name Torula is sometimes given to similar yeasts that are not spore producing. This latter name, however, is incorrectly so applied, as it was previously and is now used to indicate a genus of molds. The name Blastomyces has been commonly accepted to indicate the yeasts pathogenic for man and animals. It is probable that there is little reason for separation of Saccharomyces and Blastomyces on the basis of their morphology, but such a separation on the basis of pathogenesis seems to be advisable.

\section{CLASSIFICATION OF THE MOLDS}

Several hundred genera and many thousands of species have been described. Of these, a few genera only contain species that are pathogenic for man and animals. For a discussion of classification the student is referred to Chapter XXXVIII. 


\section{SECTION II}

\section{LABORATORY METHODS AND TECHNIC}

\section{CHAPTER VI}

\section{STERILIZATION}

Sterilization is the process whereby glassware, media, or any of the materials or apparatus used in the laboratory are entirely freed from living organisms. It is evident that in the study of bacteria it is necessary that we deal with pure cultures, that is, that one kind of organism only be present in the material which we are studying. It is quite impossible to determine from mixed cultures which of the organisms present bring about observed changes. Bacteria are present upon the surface of all laboratory apparatus, in the dust, in soil, upon the handsthey are ubiquitous, hence the necessity for sterilization.

Sterilization may be accomplished by physical or chemical means. In practice the latter is generally called disinfection, and is rarely used in the laboratory. The term sterilization, therefore, as commonly used, indicates the destruction of microorganisms by physical processes.

Sterilization by the Flame.-The platinum wire used in the transfer of bacteria in the laboratory is sterilized by heating to a red or white heat in the flame of the Bunsen burner. Similar methods are sometimes used in the sterilization of other small pieces of laboratory apparatus, such as cover-glasses and slides.

Sterilization by Hot Air.-Glassware is commonly sterilized by subjecting it to a temperature of $150^{\circ}$ to $170^{\circ}$ in a hot-air oven for an hour. All bacteria will be destroyed at this temperature providing the material to be sterilized is of a nature such that the heat can penetrate readily to all parts. This method cannot be 
used, however, in the sterilization of liquids or of any organic material which might be decomposed at such a temperature.

Sterilization by Streaming Steam.-It is found in practice that live steam is the most efficient sterilizing agent for many of the media used in the laboratory. Steam under atmospheric pressure at sea-level has a temperature of about $100^{\circ}$. Some type of apparatus is used such that the live steam comes in direct contact with the material to be sterilized. One type of the apparatus is called the Arnold steam sterilizer (Fig. 49). It consists essentially of a pan with a double bottom opening into the sterilizing

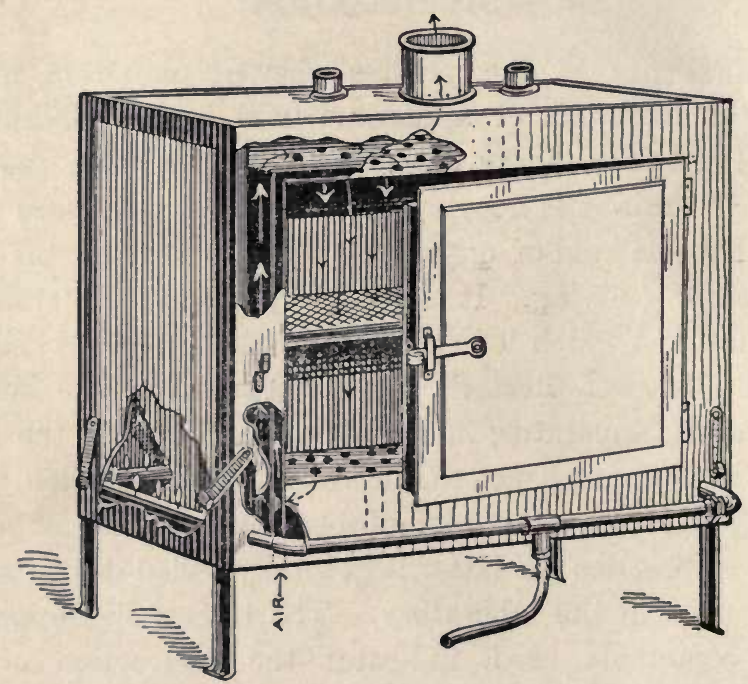

Fig. 48.- Oven for sterilization by hot air (Jordan).

chamber above. The water between the bottoms is quickly heated to boiling temperature and is automatically replaced from the supply on the exterior through small holes as rapidly as it boils away. A single exposure to live steam for fifteen minutes is sufficient to kill all vegetative bacteria, but spores are not thus destroyed. It is customary, therefore, to heat for fifteen minutes on one day, keep the medium for twenty-four hours at a temperature suitable for the germination and development of any spores present, then heat again for fifteen minutes in the same manner. Those spores which have germinated will 
be destroyed by this second heating. A third heating, twenty-four hours later, will quite certainly destroy all the bacteria which may have been present. This process is called intermittent sterilization. It finds its principal application in the sterilization of materials which would be changed or broken down by heating at a higher temperature. Among such materials are media containing sugars which undergo incipient caramelization when heated too hot.

Sterilization by Steam under Pressure.-This is generally accomplished in the autoclave or digester, which consists essentially

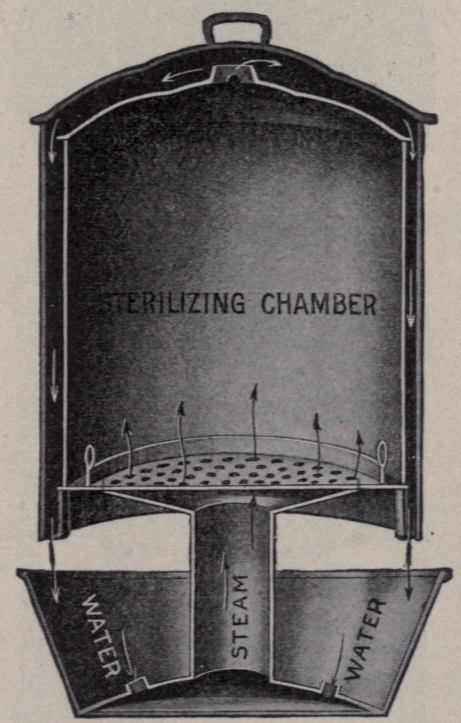

Fig. 49.-Arnold steam sterilizer (Fowler).

of a chamber into which steam under pressure can be introduced (Fig. 50). Many different types of these autoclaves have been put upon the market. Live steam under a given pressure unmixed with air has a constant temperature; therefore, if the pressure of the steam is known, one can determine easily the temperature as well. It is necessary, however, that all air be first eliminated. This is accomplished by allowing the stop-cock, which is always present upon the steam chamber in the autoclave, to remain open until all the air has escaped and the steam issues in a constant stream. This cock is then closed and the pressure caused to 
rise as quickly as possible to 15 pounds to the square inch, or one additional atmosphere. This gives a temperature of about $121^{\circ}$. Material to be sterilized should be allowed to remain fifteen minutes usually. If large bulks, such as flasks of media, are to be sterilized, a longer period must be allowed in order that

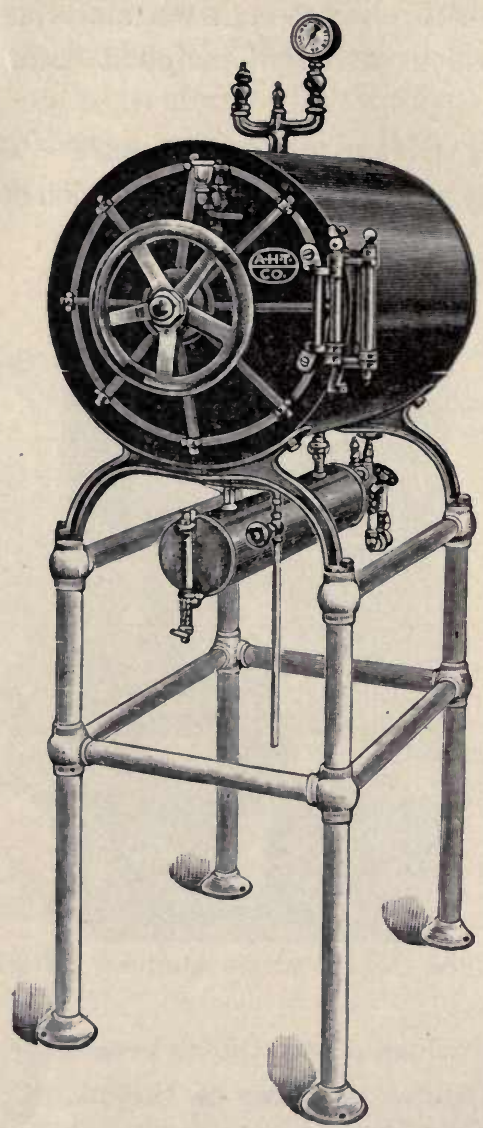

Fig. 50.-Autoclave for sterilizing by steam under pressure.

the media may be completely heated through. If very small quantities of material are being sterilized, a shorter period may be used. When properly earried out, sterilization by this method will certainly destroy all the bacteria present. Its principal disadvantage is that certain organic substances may be decomposed at this temperature. 
Sterilization at Temperatures Lower than Boiling-point.It is sometimes necessary to sterilize media, particularly bloodserum, at temperatures lower than the boiling-point of water. This is accomplished by placing the material to be sterilized in an apparatus where it may be heated to the desired temperature, usually $70^{\circ}-80^{\circ}$ for one to two hours on each of five or more successive days. If large numbers of spores of certain organisms, such as Bacillus subtilis, are present, it is almost impossible to sterilize efficiently by this method. However, if care is used in securing the blood-serum to prevent the introduction of such organisms, sterilization may be easily accomplished at this temperature.

Sterilization by Addition of Chemicals. - It is only under exceptional conditions that chemicals are used to sterilize media.

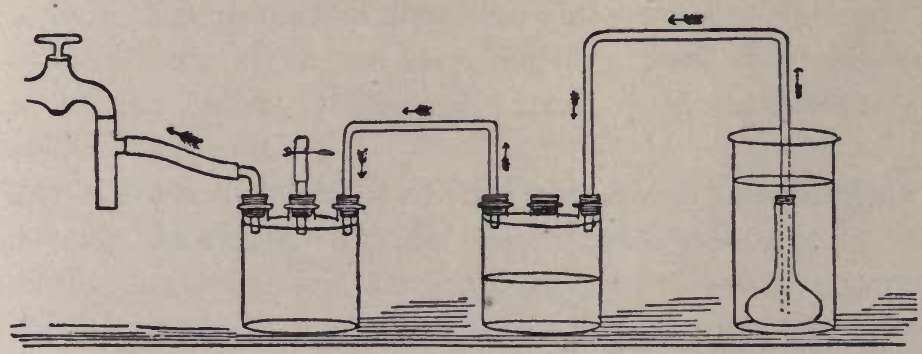

Fig. 51.-Apparatus for sterilization by filtration (McFarland).

It has been found that the addition of soluble materials, such as lactose, in considerable quantities to media containing pure cultures of certain bacteria will destroy the organisms so that they may be used as a vaccine. This method does away with the destruction of any of the characteristic metabolic products by heat.

Sterilization by Filtration.-Bacteria may be removed from a liquid by passing it through a filter with pores so fine that the organism cannot penetrate. Such filters are made up in a great variety of shapes and densities. Among the many used are the Berkefeld, the Pasteur, and the Chamberland. These are made of unglazed porcelain. In filtration through these it is necessary, of course, that all the apparatus used, particularly the vessel into which the filtrate runs and the filter itself, be sterilized before use. 
This method of sterilization is commonly used for the removal of bacteria from culture-media when it is desired to study their soluble metabolic products, and in the removal of bacteria from sera which contain antitoxins and other antibodies. It is not commonly used in the sterilization of media intended for the cultivation of bacteria. Filters of this character have been used extensively in the filtration of water for drinking purposes. When first installed, they are quite efficient, but it is found that the organisms rapidly penetrate, and in the course of time are found in the filtrate. Such filters must, therefore, be sterilized at intervals if they are to remain efficient. 


\section{CHAPTER VII}

\section{CULTURE-MEDIA AND THEIR PREPARATION}

Mrcroscopic examination alone is quite insufficient to differentiate species of bacteria. By the aid of a microscope one cannot readily recognize the differences, for example, between the organisms which cause typhoid fever and certain of the normal inhabitants of the intestinal tract. It is necessary, therefore, in a study and differentiation of species, that we make use of different kinds of culture-media in which the bacteria may be grown. By the term medium is meant any nutrient substance or mixture upon which or in which bacteria will multiply. The bacteria in their development on the various media show certain growth reactions which are very useful in their differentiation. Some produce acids, others gas, alkalis, and proteolytic and coagulative enzymes.

Use of Normal Solutions of Acid and Alkali and Methods of Expressing Reactions.-In the chapter on Physiology we have noted that many bacteria are extremely sensitive with respect to the acidity or alkalinity of the medium in which they are grown. Some organisms develop best in a medium which is approximately neutral; some refuse to develop unless there is a slight excess of alkali present. It is necessary, therefore, that some definite method of expression of these acidities and alkalinities be adopted. For this purpose it is customary to use normal solutions.

A normal solution of a chemical may be defined as one in which there is one gram of replaceable (acid) hydrogen or its equivalent per liter of solution. For example, if we wish to prepare a normal solution of $\mathrm{HCl}$, we must so dilute the acid that it contains one gram of hydrogen per liter of solution. This is best accomplished in any substance that can be readily weighed by dissolving the molecular weight expressed in grams in sufficient water to make a liter of solution. If there is more than one atom of replaceable hydrogen in the molecule, it is nęcessary to divide the amount used by the number of any such atoms. For example, the molecu- 
lar weight of $\mathrm{H}_{2} \mathrm{SO}_{4}$ is approximately 98 , but there are two replaceable acid hydrogen atoms. Therefore, half this molecular weight in grams, or 49 grams, of the $\mathrm{H}_{2} \mathrm{SO}_{4}$ is made up to a liter of solution and contains one gram of acid hydrogen. The same principle is adopted in the preparation of a normal solution of an alkali; in this case, however, it is necessary to divide the molecular weight by the number of atoms of the base present, which will replace hydrogen. For example, the molecular weight of $\mathrm{NaOH}$ is 40 . It contains one atom only of sodium, and a normal solution, therefore, contains 40 grams to the liter. Dry sodium carbonate $\left(\mathrm{Na}_{2} \mathrm{CO}_{2}\right)$ has a molecular weight of 106 . Two atoms of sodium are present; therefore it is necessary to divide by two, so that a normal solution of sodium carbonate contains 53 grams to the liter of solution. It is evident that a given volume of a normal solution of an acid will neutralize exactly an equal volume of a normal alkali.

It is customary to use indicators in the determination of the acidity or alkalinity of a solution. Those most commonly used are litmus, which is blue for alkaline and red for acid solutions, and phenolphthalein, which is colorless with acid and red with alkali. Phenolphthalein is so delicate an indicator that it is sensitive to the presence of $\mathrm{CO}_{2}$ in solution. It is, therefore, necessary, whenever this indicator is used, to heat the solution to boiling temperature in order to drive off any $\mathrm{CO}_{2}$ which may be present. It is customary to express the acidity or alkalinity of a solution in terms of the amount of normal acid or alkali present per 100 c.c. of solution. For example, if it is found that it requires 10 c.c. of the normal solution of alkali to neutralize 100 c.c. of a given solution, we know that there is present in that solution the equivalent of 10 c.c. of normal acid, and the reaction is expressed as +10 . If the reaction is alkaline, the negative sign is used.

Nature of Nutrients Required by Bacteria.-It is found that practically the same elements are necessary for the nutrition of bacteria as are essential for higher plants and animals, but they may be used in quite different proportions.

It is particularly important that the disease-producing bacteria be cultivated whenever possible. Cultivation outside the body is quite necessary to a satisfactory proof of pathogenicity, to differ- 
entiate species, and to secure the organism in quantities sufficient for preparation of vaccines, antitoxins, etc. A few standard media are commonly used in the laboratory for the growth of bacteria, and a great variety of special types have been devised for certain species that do not grow upon these. It is impracticable even to enumerate the many special media that have been employed.

\section{LIQUId MEdia}

Bouillon or Beef Broth from Meat.-This is the commonest of laboratory media and serves as a basis for the preparation of many others.

Place 500 gm. chopped lean beef in a liter of water and allow it to stand in a refrigerator over night. The juice is then pressed out with a meat press, boiled for half an hour, the coagulated albumins filtered out, the liquid made up to a liter with water, 10 gm. of peptone added, and heated sufficiently to dissolve. The reaction is adjusted to the proper point, usually +1 , by titration, or the medium is simply neutralized by addition of normal $\mathrm{NaOH}$, using phenolphthalein paper as an indicator if a high degree of accuracy is not required. The broth is then autoclaved at 15 pounds pressure or boiled for fifteen minutes, allowed to cool, and then filtered. The cooling throws down a precipitate of magnesium ammonium phosphate, which may then be removed. In many cases this is not objectionable and filtration may be carried out while the solution is still hot. The finished bouillon or broth is placed in test-tubes and flasks, and sterilized in the autoclave under a pressure of 15 pounds for 15 minutes.

Bouillon or Broth from Beef Extract.-It is customary, in much of the routine work of the laboratory, to substitute for the preceding a broth in which three grams of a beef extract, such as Liebig's, is substituted for the meat.

Sugar-free Broth.-There is generally present in the preceding media a small amount of carbohydrate, largely dextrose. In some cases a sugar-free medium is required. Theobald Smith has . devised a modification of the meat broth for this purpose which is commonly used. Several broth tubes containing vigorous twenty-four-hour cultures of Bacillus coli are added to the meat infusion and kept at $37^{\circ}$ for eighteen hours. In this time the 
bacteria will have used up all the sugar present. The broth is then prepared as above.

Sugar Broth.-Sugar-free broth is generally modified by the addition of carbohydrates, such as dextrose, saccharose, and lactose, making 1 per cent. solutions. Such media must be subjected to intermittent sterilization in flowing steam and not in the autoclave, as the carbohydrates readily decompose.

Glycerin Broth.-Five or 6 per cent. of glycerin added to broth makes it a much more favorable medium for many organisms.

Serum Broth.-Blood-serum secured under strict aseptic precautions may be added to sterile broth in various proportions. Tubes prepared in this manner should be incubated for a few days to determine whether or not the medium is sterile. Sterilization can be effected only by filtration, as heating would coagulate the serum.

Dunham's Solution.-This is a solution containing 1 per cent. peptone and 0.5 per cent. sodium chlorid in water. It is used in growing organisms for the determination of indol.

Beerwort.-Unhopped beerwort is frequently used for the growth of yeasts and molds.

Milk.-Fresh separated milk is tubed and subjected to intermittent sterilization. Commonly, litmus is added in sufficient quantities to make the milk a distinct blue.

Synthetic Media.-It is sometimes desirable to prepare a medium in which the exact chemical composition of every ingredient is known. The nature of all the changes brought about by bacteria can be studied chemically in such a medium, and the food requirements determined by changes in the composition. Most synthetic media contain as a basis an aqueous solution of certain salts, among them potassium phosphate and sodium chlorid. Special media of this kind are used extensively in the study of the soil bacteria; it is only occasionally that such a medium proves serviceable in the study of pathogenic forms. The most commonly used of the synthetic media is Uschinsky's solution.

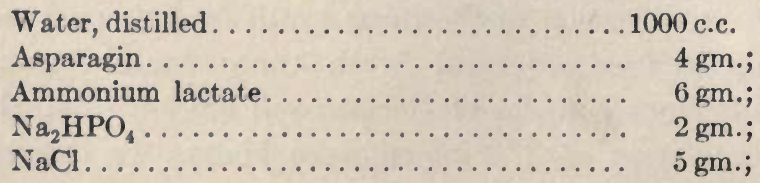




\section{LIQUEFIABLE SOLID MEDIA}

Nutrient Gelatin. - This is prepared by the addition of 10-15 per cent. of gelatin to bouillon as prepared above. The gelatin should be the best "gold label." Care must be used in heating the solution while dissolving the gelatin or the latter will stick to the bottom of the vessel and burn. It is best to use an asbestos pad, a double boiler, or a rice-cooker. The gelatin is itself acid, so that it is necessary to adjust the reaction after it has dissolved. The medium is then cooled to $60^{\circ}$, and the white of an egg thoroughly mixed with it. It is again heated to the boiling-point without stirring. The coagulation of the egg removes suspended dust-particles and makes filtration easier. The nutrient gelatin is tubed and sterilized in the autoclave at $120^{\circ}$ for ten minutes. It should be cooled at once after removal from the sterilizer. Care must be exercised not to heat the medium too long or it may fail to solidify when cooled.

Other Gelatin Media.-Any of the liquid media already discussed, with the exception of the milk and serum broth, may be made solid by the addition of 10 to 15 per cent. gelatin. Among the more commonly used are dextrose, lactose, and glycerin gelatin.

Nutrient Agar.-This is prepared by the addition of 1.5 per cent. of shredded or powdered agar-agar to bouillon. Agar-agar is a carbohydrate-like material, probably related to the vegetable gums, which is prepared from certain of the seaweeds of the Pacific and Indian Oceans. The mixture must be boiled vigorously for half an hour to insure thorough solution of the agar. This medium does not burn as readily as does gelatin, and longcontinued heating does not interfere with its solidification when cooled. The nutrient agar may be sterilized in the autoclave for fifteen minutes at $120^{\circ}$.

Other Agar Media.-Agar may be used as the solidifying agent for any of the liquid media described. It has the advantage over gelatin that it may be kept at blood heat, while gelatin under such conditions would liquefy. 


\section{NON-LIQUEFIABLE MEDIA}

Potato.-Cylinders are cut from potatoes by means of an applecorer or special potato borer. These are divided by a diagonal longitudinal cut such that each half has one long sloping surface. It is well to soak in running water for a few hours to prevent their turning dark when sterilized. They are placed with the sloping surface up in test-tubes with a bit of saturated absorbent cotton in the bottom, or in special potato tubes. The latter are tubes constricted a short distance from the bottom. The bulb thus formed is filled with water and the potato rests on the constriction above. This device enables one to keep the potatoes

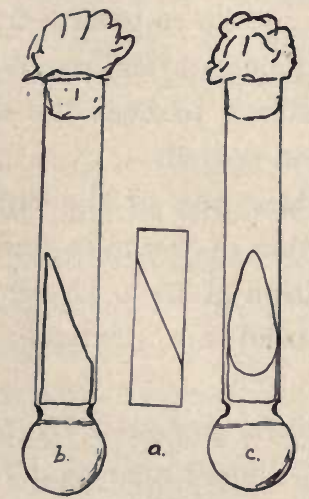

Fig. 52.-Preparation of potato tubes: $a$, Potato cylinder cut diagonally; $b$, side view in tube; $c$, front view.

moist for considerable periods. They are sterilized in the autoclave for fifteen minutes at $120^{\circ}$.

Other Vegetable Media.-Carrots and other vegetables may be prepared in the same manner as potato.

Blood-serum.- Solidified blood-serum has been found to be essential to the growth in the laboratory of certain of the pathogenic bacteria. It is best to avoid all the initial contamination of the serum possible, as it is difficult, by the methods used in sterilization, to rid the medium of all the spore producers when they are present in considerable numbers. The blood, usually from beef, is allowed to clot, and the clear, straw-colored serum removed. A clear, solidified serum may be prepared by heating 
the slanted tubes to $76^{\circ}$ for an hour or more on five or six consecutive days. An opaque medium is secured by heating to a temperature of $95^{\circ}$.

Loeffler's blood-serum is a mixture of three parts of the serum with one part of neutral 1 per cent. dextrose broth. It is solidified in the same manner as the simple serum.

Egg Medium.-This medium was developed by Dorset, of the U. S. Bureau of Animal Industry. It has come into common use for the growth of the Bacillus tuberculosis and has been used in recent years as a satisfactory substitute for blood-serum. Dorset's description of the method of preparation follows: "The egg shell is broken carefully, and the entire contents dropped into a wide-mouthed sterile flask. The yolk may be broken with a sterile platinum wire. Gentle shaking of the flask will serve to mix the white and yolk of the egg quite thoroughly. Care should be taken, however, not to shake the flask so that a foam will be produced, otherwise an uneven and unsatisfactory surface will be obtained when the medium is hardened. When the mixing is complete, the egg is poured into tubes, care being taken to avoid foaming, and the tubes containing about 10 c.c. of the medium are then inclined in a blood-serum oven and hardened at a temperature of $70^{\circ} \mathrm{C}$. This hardening will usually require two days, four or five hours each day. Sterilization will be accomplished at the same time. A higher temperature may be used and the medium . will be hardened more quickly. The growth of tubercle bacillus seems to be more vigorous when the egg is hardened at $70^{\circ}$ to $74^{\circ} \mathrm{C}$, and, in addition, the prolonged heating probably insures a more certain sterilization. The medium after hardening is opaque and yellowish in color, and usually dry, there being practically no water of condensation in the tube. The egg tubes should be kept in an ice-box to prevent further drying. Just before inoculation, three or four drops of sterile distilled water should be added to each tube to supply the moisture required for the satisfactory development of the tubercle bacillus." 


\section{CHAPTER VIII}

\section{BIOCHEMICAL TESTS}

THE physiological characteristics of bacteria are of considerable importance in the differentiation of species. A knowledge of such characteristics is of assistance in the isolation and recognition of certain species, as in the detection of sewage bacteria in water.

Acid Production.-Acids are most frequently and readily produced by bacteria in the presence of suitable carbohydrates. Litmus may be added to a sugar medium for the detection of acid. A quantitative determination of the acids produced in a liquid medium may be made by titrating against decinormal alkali. The ability of organisms to produce acid from various carbohydrates is used in the separation of the members of the intestinal group of bacteria from each other. A record of the changes in reaction from time to time has been found valuable in the differentiation of the organisms causing bovine and human tuberculosis.

Alkali Production.-The alkali most commonly produced by bacteria is free ammonia. It may be detected qualitatively by means of filter paper dipped in Nessler's solution and exposed above the medium. The ammonia gas turns the paper brown or black. The amounts of alkali produced may be determined by titration against normal acid.

Gas Production.-A few pathogenicabacteria produce gas from proteins, but most gas-producing species require the presence of a carbohydrate. The gases most commonly formed are carbon dioxid and hydrogen. One qr more species of cellulose-fermenting organisms can also produce methane, and some of the denitrifiers free nitrogen.

The ability to produce gas may be determined by inoculation of the organism into a dextrose agar or gelatin tube. Gas-bubbles will appear in the medium if the organisms can ferment dextrose. This sugar is generally used, as it is more easily fermented than most other carbohydrates. The fermentation tube is commonly used for the study of gas production. The closed arm is entirely 
filled, and the open arm partly filled, with broth containing the sugar to be tested. The gas found after inoculation collects in the closed arm and may be conveniently measured by means of a Frost gasometer. The approximate composition of the gas may be determined by filling the open arm with normal sodium hydrate and securely closing the opening with the thumb, mixing the gas with the alkaline solution by passing it several times from one arm to the other, finally returning it to the closed arm and removing the thumb. The liquid will then rise in the

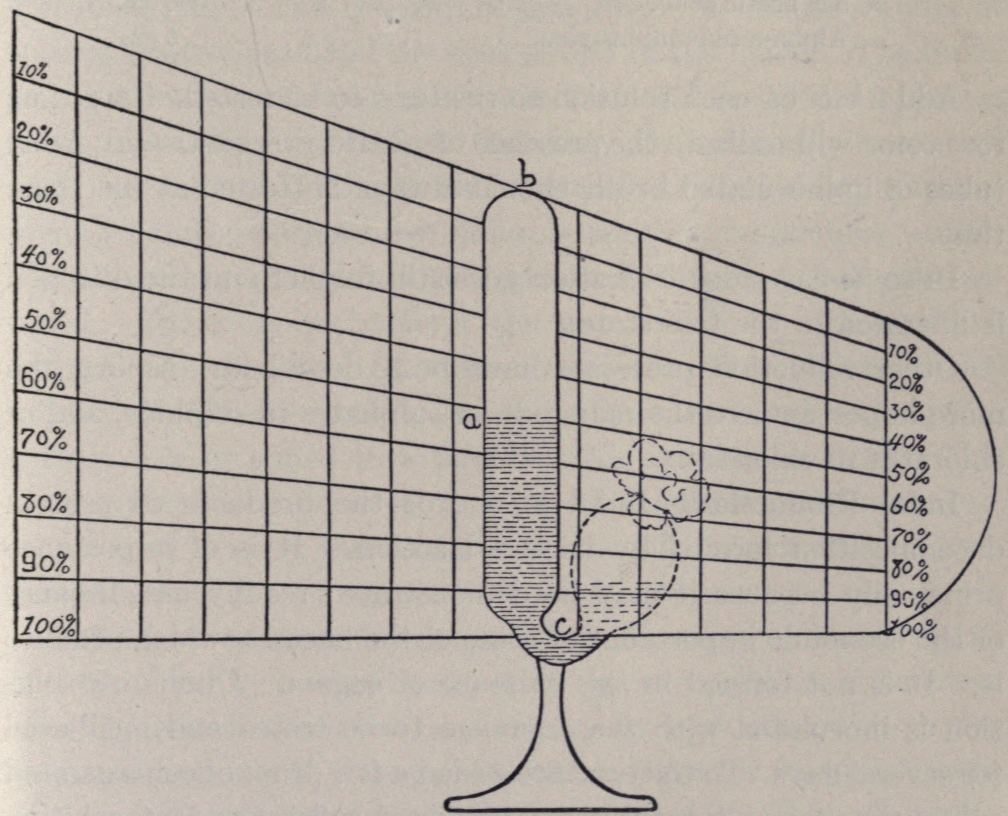

Fig. 53.-Fermentation tube and Frost gasometer (Heinemann).

closed arm to replace the carbon dioxid absorbed. The remaining gas may be transferred to the open arm and tested by the flame. Hydrogen is indicated by a slight explosion. The relative proportion of carbon dioxid and hydrogen is sometimes of importance in the differentiation of species. More important still is the ability of a species to ferment different kinds of carbohydrates. Some ferment dextrose, but not lactose or saccharose-some ferment two only, and some all three.

Reduction Processes.- Some bacteria, when living in the absence 
of free oxygen, can reduce certain chemicals, evidently securing oxygen for growth processes by this means. Litmus, methyleneblue, and other pigments may be decolorized. Nitrates are frequently reduced to nitrites. For this determination a broth made from 0.1 per cent. peptone and 0.02 per cent. potassium nitrate is inoculated and incubated for four days. It is then tested by the following reagent for the presence of nitrites:
a. $5 \mathrm{~N}$ acetic acid ..................... 1000 c.c.
Sulphanilic acid .................. $8 \mathrm{gm}$.
b. $5 \mathrm{~N}$ acetic acid ................... 1000 c.c.
Alpha-amidonaphthylene............. $5 \mathrm{gm}$.

Add 2 c.c. of each solution to the tube to be tested. A red or rose color will indicate the presence of nitrite. A control in check tubes of uninoculated broth should always be tested at the same time.

In some cases denitrification goes still further and the nitrogen is liberated in the free state.

Other reduction processes have been described. Among the more important are the reduction of sulphates to sulphids, and of chlorates to chlorites.

Indol Production.-Indol is one of the products of protein decomposition formed by bacterial action. It is of importance principally because it may be demonstrated readily and because of the economic importance of some of the bacteria which produce it. It is not formed in the presence of sugars. Dunham's solution is inoculated with the organism to be tested and incubated for several days. To the tube are added a few drops of concentrated sulphuric acid and a cubic centimeter of a 0.1 per cent. solution of sodium nitrite. The sulphuric acid decomposes the nitrite, freeing nitrous acid, which unites with the indol to form a bright red compound known as nitrosoindol. The appearance of this characteristic red color is evidence, therefore, of indol production. Indol is an organic compound of the empirical formula, $\mathrm{C}_{8} \mathrm{H}_{7} \mathrm{~N}$, and the structural formula<smiles>CCCCCC</smiles>

It is one of the products formed in intestinal putrefaction, and is the principal product which gives rise, under these conditions, to the characteristic "fecal" odor. 
Thermal Death-point. - The accurate determination of the exact temperature that is necessary to destroy various species of bacteria is frequently of great economic importance. Efficient sterilization and pasteurization can be accomplished only when these facts are known. Many methods have been suggested. In the laboratory the determination is frequently made by subjecting freshly inoculated tubes of broth to different temperatures in a water-bath for ten minutes each. For reliable results more accurate methods are needed. One of the commonest and best is the use of the Sternberg bulb. This is blown of thin glass. A definite amount of culture is introduced and the neck sealed in the flame. The bulbs are completely immersed in a water-bath and suspended by wires or by some other method, so that they do not come in contact with the walls of the bath, and heated. A number of bulbs are prepared and one heated five minutes, another ten minutes, at $50^{\circ}$. The temperature is raised two degrees and two more bulbs are exposed. For sporeless bacteria the test should be made to $70^{\circ}$, and still higher for those that produce spores. The bulbs are cooled quickly after their exposure, and their contents mixed with agar in a Petri dish, or added to a tube of other suitable medium. This is then incubated for several days. The minimum temperature required to destroy the bacteria can readily be determined by a comparison of the tubes.

Efficiency of Disinfectants.-The efficiency of disinfectants is determined by testing their action on pure cultures of bacteria. Koch's method, which has been commonly used, consists in drying the organism on silk threads, immersing them for varying lengths of time in the disinfectant to be tested, washing in sterile water, and placing them upon the surface of agar.

Hill's method is a modification of that of Koch, and is rather more accurate and relatively simple. Sterilized glass rods are coated at the tip with the bacteria to be tested by dipping them into a broth culture to a depth of an inch. These are placed in test-tubes and carefully dried in a thermostat. They may then be immersed to a somewhat greater depth in the disinfectant to be tested for definite periods of time, rinsed carefully in sterile water, and placed in tubes containing broth. 


\section{CHAPTER IX}

\section{MICROSCOPIC EXAMINATION AND STAINING METHODS}

OBJectives having a higher power than those commonly used in other work are required for the examination of bacteria. A $\frac{1}{12}$-inch or $1.8-2 \mathrm{~mm}$. oil-immersion objective is most commonly used. This lens differs from the low-power dry lenses in that it requires a layer of cedar oil between it and the object to be examined. This oil is used upon the lens for the following reasons. In general, the higher the power of the objective, the smaller the

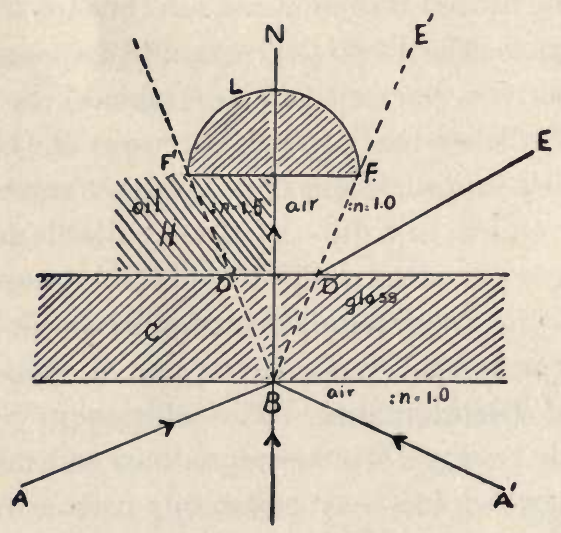

Fig. 54.-Diagram showing the function of an oil-immersion objective (adapted from Gage).

opening through which light may come to the eye. It is necessary, therefore, that all the light possible shall enter the lens in order that a well-illuminated field may result. The accompanying exaggerated diagrammatic representation of the objective and the stage of the microscope may be helpful in understanding the use of the oil.

Let $\mathrm{C}$ represent the microscopic slide, $\mathrm{H}$ the drop of oil having the same refractive index as glass, and $\mathrm{L}$ the tip of the objective 
with the opening $F^{\prime} F$. The rays of light are focused upon the object to be examined by the mirror or Abbé condenser. Those rays of light, such as $\mathrm{BN}$, that strike the glass perpendicularly pass through and enter the lens without any deflection. A ray of light, such as $A B$, striking the glass at a considerable angle, is refracted upward and toward the normal or in the direction of BD. Upon entering the air it would again be refracted and leave the glass in a direction parallel to the original ray, or DE, and would not enter the lens. If, on the other hand, a drop of oil having the same refractive index as the glass intervenes, there will be no refraction at $\mathrm{D}$, but the ray will pass through to the opening of the lens. This is represented by the ray $\mathrm{A}^{\prime} \mathrm{BD}^{\prime} \mathrm{F}^{\prime}$. The use of the oil, therefore, results in a more brilliantly illuminated field and a clearer definition of the objects to be examined.

Measuring Bacteria.-Bacteria may be measured under the microscope in one of several ways. A micrometer scale ruled on glass may be inserted in the ocular, and the distance between the lines determined by examination of a micrometer scale ruled upon the slide or cover-glass examined under the microscope. When the calibration has been effected, the ocular micrometer may be used to measure the bacteria directly. The unit of microscopic measure is the micron, the one-thousandth part of a millimeter.

Examination of Living Bacteria.-Hanging Drops.- The determination of the motility of bacteria can best be accomplished by the examination of the living cells under the microscope. A hanging-drop preparation is commonly used for the purpose. A loopful of broth culture of the organism to be tested is placed upon the center of a carefully cleansed and flamed cover-glass. Growth from an agar or other culture may be used by substituting a drop of physiological salt solution or sterile bouillon and introducing a minute quantity of the growth on a platinum needle. This drop is then carefully inverted over the cavity in a hollow ground slide, and sealed with a little vaselin. It may be examined with a high-power dry lens or with the oil-immersion objective. The drop may most easily be brought into focus at its margin. The light must be carefully regulated by means of the mirror and the iris diaphragm of the Abbé condenser to make the bacteria most clearly visible. 
Quite as effective an observation may be made in many cases by placing a drop of the culture upon a glass slide and dropping a cover-glass upon it, using care to include a few air-bubbles. A film of liquid sufficiently thick for the free movement of the bacteria will remain between the two glasses. The edges of the airbubbles furnish a convenient object upon which to focus.

\section{STAINING METHODS}

Bacteria as well as the pathogenic protozoa are generally so transparent when examined in a living condition that the details of their morphology can be made out only with difficulty. It is customary to stain these organisms with various anilin dyes which render them distinctly visible.

The stains used in biological work are, for the most part, known as anilin dyes, because they are derivatives of anilin, $\mathrm{C}_{6} \mathrm{H}_{5} \mathrm{NH}_{2}$. They are grouped as acid or basic, depending on whether the acid radical or the base possesses the tinctorial powers. Fuchsin, for example, is a basic stain, while ammonium picrate is an acid stain. The basic stains are the more useful in the study of bacteria; the acid stains are sometimes used as counterstains, particularly for tissues in which the organisms may be embedded. The anilin dyes are of all the colors of the rainbow. The most commonly used are gentian-violet, methylene-blue, thionin blue, fuchsin, and Bismarck-brown.

Mordants.-Anything which will cause a stain to penetrate an organism better or which causes it to set is termed a mordant. For example, carbolic acid or anilin added to certain stains makes them more intense. A solution of iodin in potassium iodid, a mixture of tannic acid and iron sulphate, and many other solutions are used under various conditions as mordants.

Formulas of Some of the Commonly Used Stains.- There are a few stains which find constant use in the laboratory. The formulas of these will be given. There are, in addition; a great many others which have special applications.

Löfler's methylene-blue:

Saturated alcoholic solution of methylene-blue. . . . . 15 c.c.

Solution of potassium hydrate $(1: 1000) \ldots \ldots \ldots \ldots . .50$ c.c. 


\section{Aqueous solution of gentian-violet:}

Saturated alcoholic solution of gentian-violet. . . . . 2.5 c.c.

Distilled water.

Anilin gentian-violet (Ehrlich's):

Saturated alcoholic solution of gentian-violet......6 c.c.

Absolute alcohol. ..................... 5 c.c.

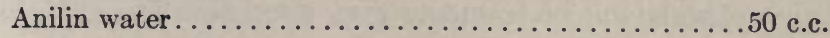

Anilin water is prepared by adding 2 c.c. of anilin to 98 c.c. of distilled water and shaking vigorously for several minutes. It should then be filtered until clear.

Carbol or phenol fuchsin (Ziehl's):

Saturated alcoholic solution of fuchsin......... 5 c.c.

Solution of phenol, 0.5 per cent. . . . . . .

Bismarck-brown: This is commonly used as a saturated aqueous solution.

Gabbett's methylene-blue:

Methylene-blue, dry....................

Sulphuric acid. . . . . . . . . . . . .

Distilled water............................

Preparation of a Stained Mount.-A drop of water about the size of a pinhead is placed upon a clean cover-glass. With a sterile platinum needle remove a small portion of the material to be examined and mix thoroughly in the drop of water. When the bacteria are in bouillon or other liquid media, the drop of water is unnecessary. This is then spread in a thin film over the surface of the glass and dried. The film is next fixed by passing the cover-glass, film up, through the flame of the Bunsen burner three times. The stain is placed upon the glass and allowed to act for a few seconds to ten minutes, depending upon the organism and the stain used. This is then washed in water until no more stain comes off. It is dried between filter-paper and placed film down upon a drop of water on a slide and examined under the microscope. If satisfactory, it may be floated off with water, dried, and placed film down on a drop of Canada balsam on the slide.

In many laboratories the use of the cover-glass is largely dispensed with, and certainly routine examinations of many kinds can be more conveniently made by means of films prepared 
directly upon the glass microscopic slides. The procedure is practically identical with that detailed above for cover-glass preparations except that the immersion oil may be placed directly upon the stained film and no cover-glass used.

Spore Stain.-Bacterial spores stain with difficulty, but once stained do not yield up the stain readily. Either one of the following methods will be found to give good results:

Hansen Method.-1. Prepare a film, fix, and stain with steaming hot carbol-fuchsin for five minutes.

2. Decolorize with 5 per cent. acetic acid until the film is a light pink, and wash in water.

3. Stain three minutes with Löffler's methylene-blue.

4. Examine.

Möller's Method.-1. Prepare films and fix in chloroform for two minutes.

2. Dry in air.

3. Cover with 5 per cent. solution of chromic acid for two minutes.

4. Wash in water.

5. Stain with hot carbol-fuchsin five minutes.

6. Decolorize with 1 per cent. sulphuric acid twenty-five to thirty seconds.

7. Wash and counterstain with methylene-blue ten to fifteen seconds.

8. Examine.

By either method the spores appear red and the cell body blue.

Stain for Acid-fast (Acid-proof) Organisms.-Certain bacteria are stained with difficulty, but when once stained, they resist decolorization with acids. The most important of these organisms is Bacillus tuberculosis.

Acid Alcohol Method.-1. Prepare film, fix in flame, and stain with hot carbol-fuchsin for two minutes.

2. Wash in 2 per cent. hydrochloric acid in 95 per cent. alcohol until there is no color visible in the thinner portions of the film.

3. Wash in water and stain with methylene-blue for contrast.

4. Wash and examine.

Gabbett's Method.-1. Prepare film and stain as above with carbol-fuchsin. 
2. Wash in water.

3. Stain with Gabbett's methylene-blue for one-half to one minute.

4. Wash and examine.

The acid-fast organisms will be red in a blue field.

Flagella Stain.-The flagella of bacteria are not visible in ordinary stained mounts, and can be demonstrated only by a special technic. Young, twelve- to eighteen-hour cultures of bacteria should be used for their demonstration. A tube containing a few cubic centimeters (5) is inoculated with sufficient quantity of the growth carefully removed from the agar surface to produce a slight turbidity. Incubate for an hour in the thermostat. Drop two or three drops without mixing or spreading on a clean cover-slip. Dry and then fix in the flame. Many methods of staining flagella have been suggested; the two following are probably the best:

Van Ermengem's Method.-1. Place the film for one hour in the following solution:

Osmic acid, 2 per cent. . . . . . . . . . . . . . . 1 part

Tannin, $10-25$ per cent. solution.............. parts

2. Wash in water, then absolute alcohol, then place in the following solution for a few seconds only:

Silver nitrate, 0.05 per cent. in distilled water.

3. Wash in the following solution for a few seconds:

Gallic acid ...................... 5 gm.

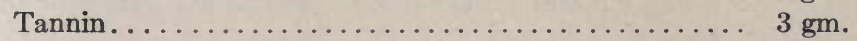

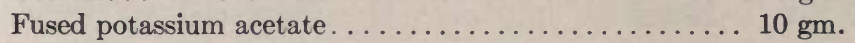

Distilled water..........................

4. Wash in silver nitrate solution until film turns black.

5. Wash in water and examine.

Löffler's Method.-1. Prepare film, fix, and apply the following mordant, heating for five minutes over a water-bath:

Tannic acid (25 per cent. aqueous solution)........10 parts

Saturated solution ferrous sulphate...........5 parts

Fuchsin (saturated alcoholic solution)......... 1 part 
2. Wash and blot with filter-paper.

3. Stain with hot anilin-gentian-violet or carbol-fuchsin over a water-bath for five minutes.

4. Wash and examine.

Gram's Staining Method.-This method was first used to demonstrate bacteria in tissues, the bacteria retaining and the tissues losing the stain. It was later found that not all bacteria could be stained by this method, and it has in consequence come into general use for separating bacteria into two groups, termed respectively gram-positive and gram-negative, the former retaining the stain and the latter losing it.

1. Prepare film, dry, and fix.

2. Stain one and one-half minutes in anilin-gentian-violet.

3. Treat with Gram's iodin solution one and one-half minutes. Iodin............................... 1 gm.

Potassium iodid....................... 2 gm.

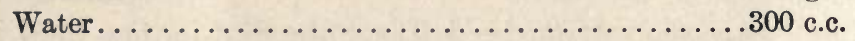

4. Decolorize with 95 per cent. alcohol for five minutes.

5. Wash, dry, and mount.

Blood and Protozoan Stains.-Many special stains have been devised for demonstrating the blood elements and protozoa in the blood and in tissues. The chief of these are the Romanowsky and Giemsa, each with numerous modifications. These may most profitably be purchased ready for use from a reliable dealer. The methods of use will be discussed in connection with specific microörganisms. 


\section{CHAPTER X}

\section{METHODS OF SECURING PURE CULTURES OF BACTERIA}

BACTERIa must be studied in pure culture if one is to determine with certainty their cultural, physiological, or pathogenic characters. One of the first efforts made in the study of a disease or any other process brought about by bacteria is to separate its causal organism from all others. Many methods have been devised for this purpose, not any one of them applicable to every case.

Dilution Method.-This method of securing pure cultures is of historic interest only. In the beginnings of the cultivation of microörganisms the culture-media commonly used were liquids, such as infusions from meat and vegetables, and beerwort. This method was used most commonly in securing pure cultures of yeasts. A long series of flasks was prepared with sterile media. The impure culture or mixture of organisms was mixed thoroughly with the contents of the first flask, and a definite amount transferred from this to another flask, from this to each of several others, from each of these into another group, and so on. The last dilution would, in general, remain sterile, but among some of the dilutions would be a group in which some flasks would show growth and others of the same dilution would not. The inference was that such a flask had been planted with but a single organism, and the flask contents, therefore, constituted a pure culture. This method is cumbersome, uncertain, and is rarely used.

Isolation by Smearing. - If a loopful of a mixed culture of microörganisms be drawn across the surface of a solid medium in parallel streaks, the first portion will generally show a solid line of mixed growth, but farther along the growth is discontinuous. Many of the isolated colonies here will be found upon examination to consist of pure cultures. This method is used for the isolation of bacteria from the mouth and throat in some cases.

Direct Isolation.-Barber has devised a capillary pipette method whereby it is possible to pick up a single bacterial cell and transfer it to a nutrient medium without any other organisms being carried 
over. This method has been found useful in the study of developmental and evolutionary problems, but is not practicable for routine laboratory isolations.

Isolation by Plating.-The development by Koch of the liquefiable media furnished a ready means for the isolation in pure

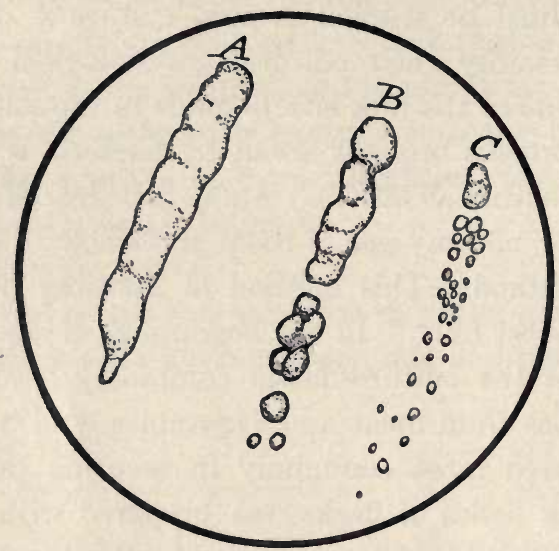

Fig. 55.-Isolation by successive streak cultures on an agar or gelatin plate: $A$, First streak solidly grown; $B$, second streak, discontinuous; $C$, third streak, having many isolated colonies.

culture of most species of bacteria. Nutrient agar or gelatin or one of their modifications may be used. The medium is liquefied by heat, then cooled in a water-bath to about $43^{\circ}$. The mixed culture of organisms from which it is desired to isolate pure cultures is inoculated into one of the tubes. From this

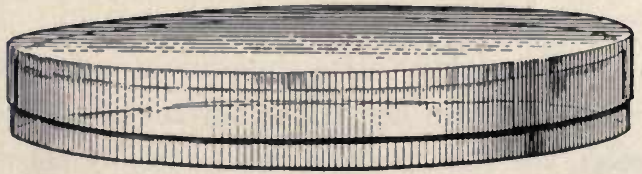

Fig. 56.-Petri dish (McFarland).

transfers are made by means of a sterile platinum loop to a second tube; this is thoroughly mixed and transfers made to a third tube, and from this even to a fourth. Each of these tubes of media is then poured into a sterile, flat, glass, covered dish called a Petri dish. These Petri dishes or "plates" are allowed to stand until the medium has solidified; they are then incubated and examined 
from time to time. The organisms are separated from each other by this process of dilution, and are held fast by the solidification of the medium. In most cases the conditions are favorable for growth, and development begins. Within a few days sufficient multiplication takes place, so that the mass of organisms that has developed from the single isolated individuals has reached a size that can be easily seen with the unaided eye. Such a mass of organisms is termed a colony. Transfers from such colonies will show only a single kind of organism present, and by making isolations from each type of colony, pure cultures may be secured of each species present.

Isolation by the Use of Heat.-When it is desired to isolate a spore-producing organism from non-sporulating forms, the culture may be heated to $80^{\circ}$ for fifteen minutes. This will not destroy the spores, but will eliminate all other cells. If one species of spore-forming organism only is present, this results in a pure culture at once; if more than one species, plating becomes necessary.

Isolation by the Use of Differential Antiseptics or Disinfectants.-Not all species of bacteria are affected alike by a given antiseptic or disinfectant, and it is sometimes possible to add a substance that will prevent the growth or kill one form without interfering seriously with the growth of others. A small amount of phenol added to bouillon will inhibit the growth of most bacteria, with the exception of certain members of the intestinal group. A still better example of such substance is antiformin, which, when mixed with sputum or other materials containing tubercle bacilli, destroys all other organisms than these, and enables one to secure a pure culture at once. This will be discussed in greater detail under the heading of Tuberculosis.

Isolation by Animal Inoculation.-Some species of pathogenic bacteria develop very slowly upon artificial media, or require a special medium for their growth. When these occur mixed with other organisms, it is sometimes difficult to secure them in pure culture. This difficulty may in some cases be overcome by animal inoculation. The injection of the organism into a suitable susceptible animal results in the destruction'by the body of the other bacteria injected at the same time, and the characteristic organism may later be isolated in pure cultures from the lesions of the disease. 


\section{CHAPTER XI}

\section{STUDY OF BACTERIAL CULTURES}

Species of bacteria are frequently separable from each other on the basis of differences in cultural characters alone. It is, therefore, important that careful descriptions should be kept of the cultural characteristics of each of the species. For assistance in such descriptions the Society of American Bacteriologists has adopted a standard descriptive chart from which the following are adapted:

\section{CUltural CHARACTERS}

Agar Stroke.-This is prepared by drawing an inoculated needle from the base to the top of the slanted surface of an agar tube that has solidified in the sloping position. In this culture are to
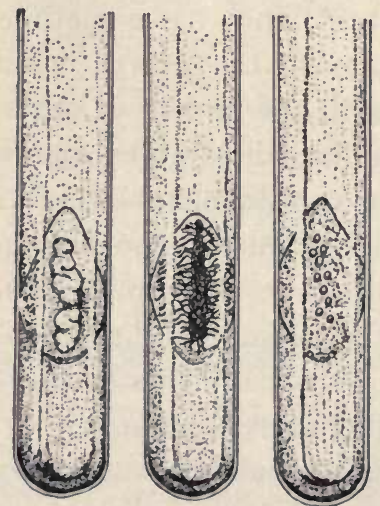

Fig. 57.-Types of growth on agar slants.

be noted the abundance, form, elevation, luster, surface, and optical characters of the growth, its pigment production, odor, consistency, and any changes that have occurred in the medium.

Potato.-The potato is inoculated and the growth characteristics studied in the same manner as the agar stroke. 
Blood-serum.-This is inoculated in the same manner as the agar slope, and the same characteristics are to be noted, with the addition of liquefaction or digestion of the medium.

Gelatin Stab.-This is prepared by running an inoculated platinum needle in a straight line from the surface of an erect tube of nutrient gelatin nearly to the bottom, and withdrawing it without cutting the medium by any lateral motion of the needle.
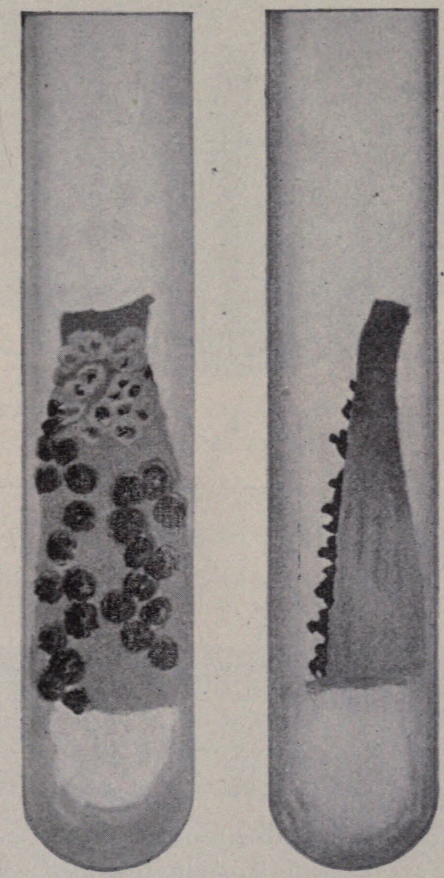

Fig. 58.-Potato slant culture (Page, Frothingham and Paige, in "Journal of Medical Research").

The characters to be noted are abundance and uniformity of growth along the line of the stab, the form of growth, liquefaction, and other changes in the medium.

Nutrient Broth.-This is inoculated by shaking an infected platinum needle in the medium. The characters to be noted are abundance and character of surface growth and character of sediment.

Milk.-Milk is inoculated in the same manner as the nutrient 
broth. The characters to be noted are presence or absence of coagulation, type of curd produced, whether or not whey is extruded, peptonization or digestion of the casein, acid production, consistency, and changes in color of the medium.

Litmus Milk.-In addition to the preceding, acid or alkali production and reduction of the litmus are to be noted.
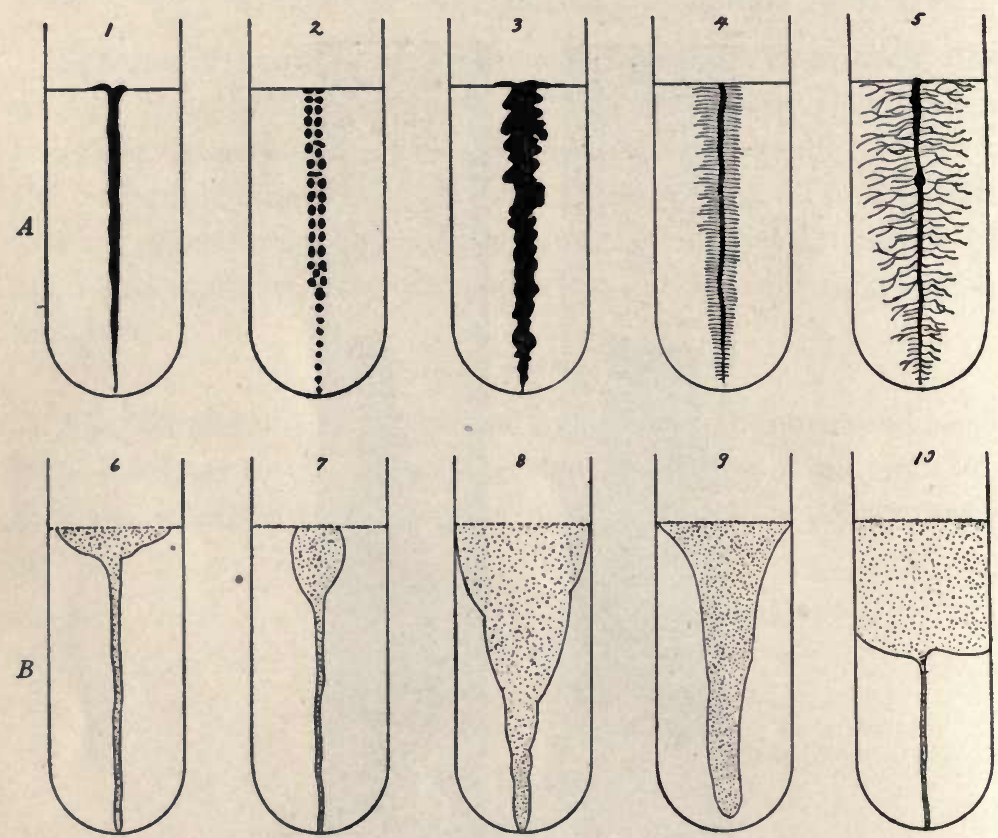

Fig. 59.-Types of growth in stab cultures: $A$, Non-liquefying: 1, Filiform (B. coli); 2, beaded (Str. pyogenes); 3, echinate (Bact. acidi lactici); 4, villous (Bact. murisepticum); 5, arborescent (B. mycoides). B, Liquefying: 6, Crateriform (B. vulgare, twenty-four hours); 7 , napiform (B. subtilis, fortyeight hours); 8, infundibuliform (B. prodigiosus); 9, saccate (Msp. Finkleri); 10, stratiform (Ps. fluorescens) (Frost).

Gelatin Plate Colonies.-Two or three tubes of gelatin are melted, cooled to $40^{\circ}$, and one inoculated with a small amount of the organism to be studied. The tube is rolled until the bacteria are thoroughly distributed, and with a platinum loop a transfer is made to a second tube, and from this to a third. The contents of each tube are then poured into a Petri dish and allowed 
to solidify. The plate showing a small number of colonies developing is the one chosen for examination. The characters to be

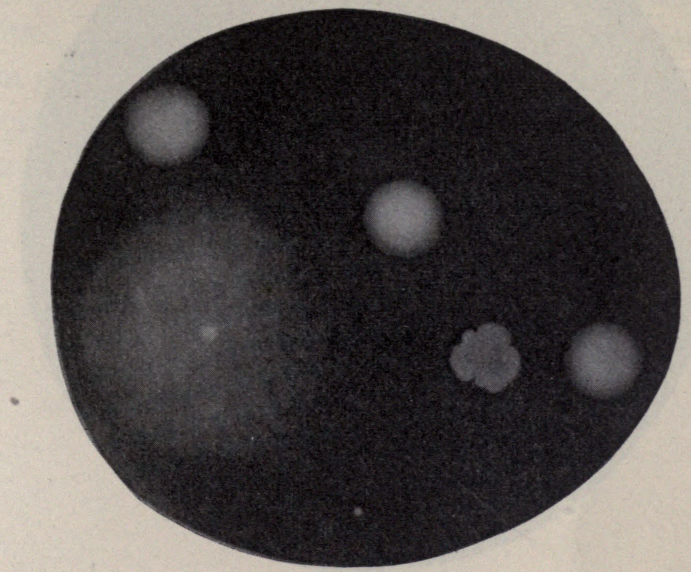

Fig. 60.-Portion of an agar plate culture showing a mold colony and five bacterial colonies.

noted are rapidity of growth, form, elevation, and edge of the colony and type of liquefaction if it occurs.

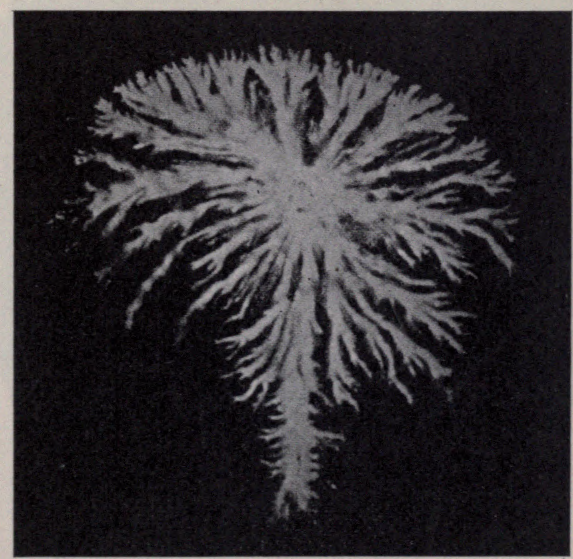

Fig. 61.-Ameboid colony on an agar plate (Lewton-Brain and Deerr).

Colonies on Agar Plates.-Plates containing nutrient agar are prepared in the same manner as the gelatin plates described. The 


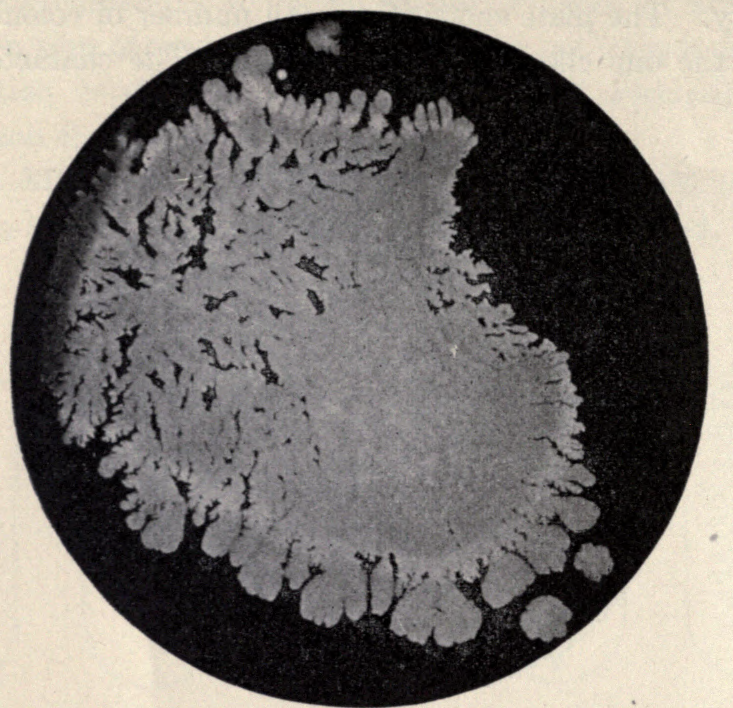

Fig. 62.-Spreading colony on an agar plate (Lewton-Brain and Deerr).

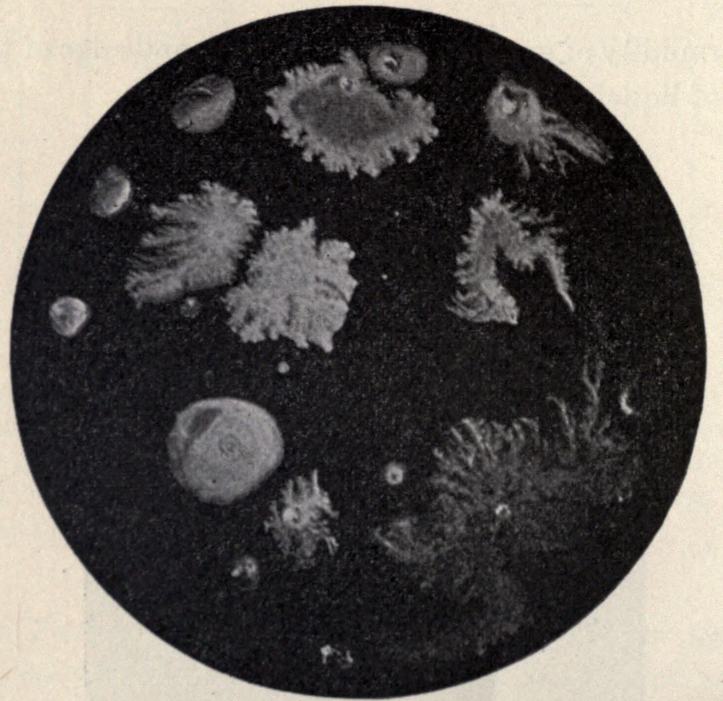

Fig. 63.-Colonies in an agar plate culture (Lewton-Brain and Deerr).

characters to be noted are rapidity of growth, form, surface elevation, edge, and internal structure of the colony. 


\section{PHySiological ChaRacters}

It is customary to determine gas and acid production in carbohydrate media, development of ammonia, reduction of nitrates to nitrites, indol production, temperature relations, including optimum growth temperature and thermal death-point, resistance to desiccation and disinfectants, and pathogenic characters. The methods of study of these characters have already been discussed. 


\section{SECTION III}

\section{BACTERIA AND THE RESISTANCE OF THE ANIMAL BODY TO DISEASE}

\section{CHAPTER XII}

\section{BACTERIA AND DISEASE; GENERAL CONSIDERATIONS}

Koch's Rules.- The proof of the germ theory of disease may be dated from 1876, when Koch succeeded in demonstrating the relationship of Bacillus anthracis to the disease anthrax. He later formulated the rules (which are known as Koch's rules) for the determination of the specific relationships of an organism to a disease. They may be stated as follows:

1. The suspected organism must be found in every case of the disease under consideration.

2. The organism must be isolated and grown in pure culture.

3. Inoculation of the organism into suitable animals should reproduce the disease.

4. The organism must again be isolated from such animals. Unfortunately, the proof of the cause is still lacking in a good many diseases, and is unsatisfactory in others. There are several reasons for this:

(a) The organisms in some cases have been shown to be ultramicroscopic and capable of passing through a porcelain filter, as, for example, those which cause rinderpest and hog-cholera.

(b) Some organisms, although evidently not ultramicroscopic, have never been satisfactorily demonstrated under the microscope, possibly from lack of proper staining methods.

(c) Some organisms are specific for man and do not reproduce disease of the same type when inoculated into animals. With some of these, accidental or intentional inoculation into man has supplied the needed evidence. 
(d) The organism may be demonstrated microscopically, but will not grow upon the culture-media of the laboratory. Such are some of the protozoa. With a few of these the proof has been perfected by the study of the growth of the organism in an intermediate host, for example, the malarial parasite in the mosquito.

Evidence of the relationship of an organism to a disease may frequently be secured by using the agglutination, precipitation, or some of the other tests discussed in the following chapters. Improvements in staining technic continually reveal new organisms.

Animal Inoculation.-Experimental inoculation and injections are made in the bacteriological laboratory for a number of reasons:

1. In determining the causal relationships of a specific organism to a disease in accordance with Koch's rules.

2. In the diagnosis of certain diseases. For example, one of the most satisfactory methods of diagnosing glanders is to inject some of the nasal, discharge from a suspected animal into a male guinea-pig and note the development of acute orchitis and subsequent general body reaction.

3. In the isolation of certain pathogenic bacteria. For example, if it is desired to isolate the organism causing tuberculosis from sputum or from milk, it may most readily be accomplished by inoculating the infected material into a suitable animal. All the non-pathogenic organisms will be destroyed and the specific organism may be isolated in pure culture from diseased tissue or lesions of the animal so infected. The animal body is used as a kind of filter for the removal of the non-pathogenic bacteria.

4. In determining the strength of concentration of certain biological products. As will be seen later, the only way that has been devised for the determination of the strength or potency of certain poisons, such as toxins, and for their antitoxins, is animal injection. The animal is used by the bacteriologist in much the same manner as an indicator is used by the chemist in determining the acidity or alkalinity of a solution.

5. In the production of certain so-called antibodies, such as antitoxins, and for the demonstration of certain characteristics of the blood-serum in immunity.

The animal most frequently used in experimental work is the 
guinea-pig or cavy; next in importance is the rabbit. Mice and rats, particularly the white varieties, are sometimes used. When birds are necessary, the pigeon and domestic fowl are generally utilized. Some of the larger animals, as the goat or horse, are used for the production of serum, where it is required in considerable quantities, as in the manufacture of antitoxins. The monkey has been used to some extent in the study of diseases peculiar to man. Heifers are utilized in the preparation of the vaccine against small-pox. Swine are used in the preparation of hog-cholera antiserum.

Methods of Inoculation.-Animals are commonly inoculated just beneath the skin or subcutaneously. The hair is shaved from the area selected, the skin is washed with an antiseptic, and a hypodermic needle inserted into the subcutaneous tissue. In the inocu-

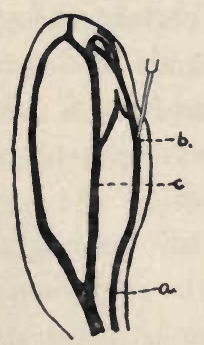

Fig. 64.-Ear veins of a rabbit: $a$, Posterior vein; $b$, point at which injections may be most easily made; $c$, median vein (adapted from Frost).

lation of a solid material a little incision may be made in the skin, the material inserted, and the flaps of skin pulled together. Usually stitches to hold the skin are unnecessary. Intravenous inoculation is accomplished by inserting the needle into a vein. Usually a rabbit is selected for this purpose. Reference to Fig. 64 will show the vein on the posterior edge of the ear, into which injections are usually made. The large median vein is not suitable, as it is situated in loose connective tissue and therefore difficult to enter. The posterior vein, on the other hand, is embedded in firm connective tissue and cartilage, so that it does not give before the needle-point.

Intraperitoneal injection is accomplished by thrusting the hypodermic needle through the abdominal wall. Some care must be used not to penetrate too rapidly, as there is danger of injuring 
the intestines. Intrathoracic inoculation is rarely practised. Injection directly into the heart (intracardiac) may be successfully practised if sufficient care is used. Inoculation by scarification is accomplished by scraping off the outer layers of skin without drawing blood and rubbing the organism on the surface moistened by the exuded serum. Intracranial injections may be made by the use of a trephine to penetrate the skull, when subdural inoculations are made with the hypodermic. Intra-ocular injections have sometimes been performed for the specific purpose of observing from day to day the development of lesions upon the iris or in other tissues of the eye. Inoculation by inhalation is accomplished by forcing the animal to breathe the organism in dust or as a fine spray. Infection by way of the digestive tract is accomplished by feeding or ingestion.

Interrelationships of the Organism and the Body.-Any organism which produces lesions or morbid changes of any kind in the body is said to be pathogenic, or disease producing. By virulence is meant the relative ability of organisms of different races to produce disease; for example, one culture of the diphtheria bacillus might produce a severe type of disease, while another might be wholly unable to produce an infection except under the most favorable conditions. The former is said to be more virulent than the latter.

Effects of Pathogenic Bacteria on the Body.-When bacteria infect the body, they may remain at or near the site of infection; they may spread through the tissues by direct growth, or be carried by the lymph and blood to other parts of the body; they may multiply in the blood or they may produce metastatic infections by becoming localized in other parts of the body. Disease may be produced by the action of poisons, either toxins or endotoxins, or possibly mechanically. The following classification adapted from Muir and Ritchie is useful in a consideration of the types of changes brought about in the body by microörganisms.

A. Tissue changes.

1. Produced in the immediate vicinity of the bacteria, either at the primary lesion or at secondary foci.

(a) Those changes resulting directly from damage, as degeneration and necrosis. 
(b) Those of a defensive or reparative nature, as production of new tissue and invasion of lesion by phagocytic leukocytes.

(1) Increased functional activity.

(2) Increased formative activity, cell growth, and division.

2. Produced at a distance from the bacteria, due directly or indirectly to poisonous substances produced by the bacteria.

(a) In special tissues.

(1) Changes resulting from damage.

(2) Changes of a reactive nature in blood-forming organs.

(b) General anatomical changes, effects of malnutrition or of increased waste.

B. Changes in metabolism, fever, etc. 


\section{CHAPTER XIII}

\section{IMMUNITY. GENERAL DISCUSSION}

Immunity.-Immunity is a term used to express relative resistance to disease. It is defined by Ricketts as follows: "By immunity we understand that condition in which an individual or a species of animals exhibits unusual or complete resistance to an infection for which other individuals or other species show a greater or less degree of susceptibility." The converse of immunity is susceptibility, or lack of resistance.

Resistance by the body to infection by microörganisms is due to a considerable number of factors. These may be grouped into two classes-the external resistance, due to body coverings and protective devices, and internal resistance, due to tissue and body humor reactions.

External resistance to infection is of the greatest practical importance. The skin covering the surface of the body is an excellent and effective barrier against bacterial invasion. The skin is constantly sloughing off at the surface and being replaced from below. Entrance to the tissues is sometimes effected by microorganisms through the hair-follicles and the sweat-glands; this is, however, exceptional. The subcutaneous tissues likewise obstruct the inward growth of organisms that have penetrated the skin. The mucous membranes constantly secrete mucus, which is as constantly removed, and the bacteria which have been caught go with it. The membranes which line the air-passages catch upon their moist surfaces practically all the bacteria that enter with the inspired air, and few ever reach the ultimate ramifications of the bronchioles, much less the alveoli. The gastric juice of the stomach is markedly germicidal. Many, though not all, bacteria which enter the body with the food are destroyed there. The intestinal juices, particularly the bile, are mildly antiseptic and inhibit the growth of many forms, although they are without effect on others, among them the so-called normal intestinal bacteria. 


\section{Variation of Individuals in Susceptibility to Disease. Pre-} disposing Factors.-The same individual varies greatly at times in his ability to resist infection by bacteria. Age frequently determines resistance to certain infections. For example, there are diseases, such as diphtheria and whooping-cough, which are much more common among children than among adults. Blackleg rarely attacks adult cattle. Advancing age seems to bring increased resistance to such infections. The mechanism of this kind of resistance to infection is not well understood. Hunger and thirst reduce the resistance of the body and predispose to infection. Exposure to excessive heat or the chilling of the body surfaces by cold will also reduce the body resistance so that organisms that ordinarily cannot produce disease gain a foothold. Fatigue has been demonstrated experimentally to render animals and man more susceptible to infection. The classic example of this diminution of resistance by fatigue is that of the white rat, which is normally immune to anthrax, but which, when exhausted by work in a treadmill, becomes susceptible to the disease and will succumb to infection.

Types of Immunity.--Immunity may be divided into two types, natural and acquired. The former may be subdivided again into racial or specific immunity and individual immunity. Acquired immunity may be either active or passive.

Natural immunity is congenital, that is, it is not acquired after birth. A racial immunity is one possessed by all the members of a group of individuals. Disease frequently cannot be transmitted from one species of animal to another, for example, man does not acquire many of the diseases of animals, such as hog-cholera and dog distemper, and, on the other hand, many diseases of man, such as measles, whooping-cough, and typhoid fever, cannot be transmitted to the lower animals. It is also said that the Algerian alone among the breeds of sheep is naturally immune to anthrax. In New York City it has been found that the Russian and Polish Jews are much more resistant to tuberculosis than are certain other races, particularly the Irish and the negroes - at least the deathrate among the former due to this disease is much lower. Individuals are also found who are naturally immune to disease. This resistance is perhaps more seeming than real in many cases, and has 
been induced by mild infections that have resulted in recovery without the development of definite symptoms of the disease. It is a well-known fact that frequently a small percentage of the hogs in a herd which becomes infected with hog-cholera do not contract the disease, and inoculation experiments show them to be relatively immune.

Acquired Immunity.-Immunity to a disease may be acquired in many different ways. An active acquired immunity is one brought about by the development in the tissues of the animal of certain antibodies which prevent the growth or destroy or neutralize the products of growth of the invading microörganisms. Passive acquired immunity is conferred upon the animal by the injection of antibodies which have been prepared in another animal. A passively immunized animal takes no part in the production of the antibodies to which it owes its immunity.

Active Acquired Immunity.-A development of antibodies and the consequent immunization of an animal may be brought about by the various methods illustrated in the following outline:

A. Injection of living microörganisms.

1. In quantities smaller than the amount needed to produce a fatal infection.

2. Attenuated in various ways-

(a) By growing upon artificial culture-media.

(b) By growing at unusual temperatures.

(c) By heating.

(d) By growing in the presence of substances inimical to growth, such as weak antiseptics.

(e) By animal passage.

B. By injection of dead organisms.

C. By injection of the products of autolytic digestion of organisms.

D. By injection of toxins.

Immunization by the injection of sublethal doses of pathogenic organisms has not been generally practised. With most pathogenic organisms it may be demonstrated experimentally that if the number of living cells injected be decreased below a certain minimum, they are no longer capable of producing disease. The method 
is dangerous because the minimum may vary with different individuals and the animal utilized may in some instances prove susceptible and succumb. Usually, however, increasing numbers of the organism may be given, and the animal will eventually become entirely immune. This method is of more theoretical than practical importance, and is rarely used.

As noted above, microörganisms may be attenuated, that is, their ability to produce disease lessened in several ways. Several species of bacteria are known gradually to lessen their virulence when cultivated for a time upon artificial media; for example, the Streptococcus pyogenes, which produces many suppurative infections, when cultivated upon artificial media, will finally lose so much of its virulence that it proves entirely non-pathogenic when inoculated into suitable animals. Inoculation of such nonvirulent types will increase the resistance of the body to the virulent forms. The converse of this is also true, for the continued growth and transfer of many organisms from one animal to another may greatly exalt the virulence. It is possible in a given species to secure in some cases every gradation from the wholly nonpathogenic type to forms that are exceptionally virulent.

Cultivation of some bacteria at a temperature higher than the growth optimum results in a diminution of virulence. The anthrax bacillus, whose optimum is $38^{\circ}$, may be cultivated at a temperature of $42^{\circ}$ for a time, when it loses much of its virulence. It may then be used in the form of injections to increase resistance to the disease anthrax in animals. The organism which causes blackleg in eattle is heated to a temperature just below its thermal death-point, and is found to lose many of its pathogenic properties, although it still causes the production of immune substances when injected into the body. A closely related method is to grow bacteria in the presence of mild antiseptics. The anthrax bacillus grown in the presence of carbolic acid (1:600) has been found to lose its virulence. The growth of certain microörganisms in the body of animals other than the species in which they normally produce disease in some cases results in a decrease of virulence for the first species. The small-pox organism, for example, is grown for a time in the bodies of cattle, and is found to lose much of its virulence for man by this means. The injection of dead 
microörganisms also results in conferring immunity in much the same manner, perhaps, as does the injection of non-virulent cultures. The injection of bacteria, whether dead or alive, in an effort to increase the immunity of the body, is known as vaccination. This is also defined as the production of an infection that will run a benign course. Bacterial cultures are sometimes allowed to stand until a considerable amount of digestion or autolysis has occurred. When the dead or living bacteria are filtered out by means of porcelain filters, the material remaining in solution or the filtrate may be used for animal injection in an effort to confer immunity. In other cases the bacteria are grown in solutions where they produce certain specific poisons called toxins. These latter are removed by filtration and used to inject animals to induce the development of an active immunity.

Acquired Passive Immunity.-Immunity may be conferred by the injection of serum that contains suitable antibodies. These may be, as will be seen later, in the nature of antitoxins, bacteriolysins, or opsonins. This method of conferring immunity should not be confused with vaccination. The animal passively immunized takes absolutely no part in the development of its immunity.

Theories of Immunity.-Four principal theories of immunity have been held since the acceptance of the germ theory of disease. The first two proposed are now of historic interest only, but the other two are well founded on fact and are generally accepted at the present time. When first proposed, these latter were supposed to be antagonistic, but as subsequently modified, they have been found to supplement each other, some facts being explained by the one and some by the other. These theories are worthy of brief consideration and comparison.

Theory of Exhaustion.- It was noted by early laboratory workers that bacteria, yeasts, and molds would grow rapidly when first planted upon a favorable medium, then the rate of growth would become slower, and finally cease. It was concluded naturally that growth stopped because all of certain of the nutrients needed were exhausted. This theory was applied to the growth of microörganisms in the body, and it was believed that immunity was established when certain requisite food materials were ex- 
hausted and the organism in consequence could grow no longer. This theory was soon disproved. It was shown, for example, that the Bacillus diphtherice would grow luxuriantly on sterilized blood taken from a person immune to diphtheria. Chemical analyses also showed that not all nutrients were exhausted from the medium in the culture tube when the organism ceased growing.

Noxious Retention Theory.-Further study revealed the fact that organisms ceased growing in a culture solution because they produced substances deleterious to themselves. The organism which sours milk, for example, produces acid until the concentration is so great that it can no longer develop. The same is true of yeasts in the production of alcohol, and of bacteria in the transformation of alcohol to acetic acid. The nature of the noxious material is known in very few cases. A logical explanation of immunity seemed to be that something of the same kind occurred in acquired immunity; that the organisms developed in the body until they produced so much material inimical to their own growth that multiplication would cease, and the individual would thereafter be immune. This theory was discredited by subsequent workers, who proved that the substances that prevented bacterial growth were produced by the body and not by the bacteria.

Metchnikoff's Theory of Phagocytosis.-The theory was advanced by Metchnikoff and his students that certain of the body-cells, particularly the leukocytes, would take up, digest, and destroy bacteria. Immunization accordingly consisted in a kind of stimulation or training of the leukocytes to destroy the pathogenic organisms. Cells capable of destroying microörganisms in this manner he called phagocytes (Gr. phagein, to eat; kytos, cell). Certain of Metchnikoff's ideas have not borne the test of time, but in the main his theory still is used to account for immunity of certain types.

Ehrlich's Humoral Theory.-Ehrlich has advanced the theory that immunity is due to substances present in the body humors which antagonize the growth and development of pathogenic organisms or are capable of neutralizing their products. Such substances capable of conferring immunity he calls antibodies. and to their production by the body-cells he attributes the devel- 
opment of immunity. This theory has been tested in a very great variety of ways, and seems to explain better than any other most of the facts known relative to immunity.

Duration of Immunity.-Recovery from certain diseases, such as small-pox, confers a lasting immunity; from others, such as pneumonia, a temporary immunity, and in still others the immunity disappears immediately upon recovery, as in influenza. In some cases recovery from an attack seems actually to predispose to a recurrence, as in erysipelas. This last probably means simply the complete or relatively complete disappearance of immunity from a peculiarly susceptible individual. The duration of immunity may depend in some cases upon the type of antibodies produced, although this is certainly not always the case. Probably the antibodies, particularly those introduced in passive immunization, are eliminated in some of the secretions and excretions, or they may, in some cases, be easily destroyed.

Antigens and Antibodies.-It has been found experimentally that injections of many substances besides bacteria and their products cause reactions on the part of the tissues, with consequent production of antibodies. These substances are called antigens. An antigen is, therefore, that substance which, when introduced into the body, stimulates the tissues to the production of antibodies. An antibody may be more accurately defined as any substance present in the serum which is capable of neutralizing, antagonizing, precipitating, agglutinating, or dissolving the substance (antigen) which has induced the formation of such antibody. For example, the toxin of the diphtheria bacillus, when injected in non-lethal doses, induces the production of antitoxin by the tissues: the is the antigen, the antitoxin, the antibody. Similarly, egg-white injected into an animal would be termed an antigen and the precipitating substance produced as a consequence in the blood-serum is termed the antibody.

Antibodies as Factors in Acquired Immunity.-The somatic reactions to the presence of antigens are now generally considered of primary importance in acquired immunity. Certain bacterial poisons called toxins cause the production by the animal tissues of the antibody called antitoxin, which will neutralize the toxin. The presence of certain bacteria in the body causes the production 
of bacteriolysins, substances which will dissolve or destroy bacteria. Opsonins (Gr. opsonein, to prepare for eating) are antibodies which will unite with the bacteria and enable the phagocytes to take them up and destroy them. Acquired immunity may, therefore, be said to be either antitoxic, bacteriolytic (antibacterial), or opsonic, or a combination of any or all of these types. Three other types of body reactions are also generally considered in a discussion of immunity. Although they probably in no instance actually account for immunity, they are found very useful in diagnosis, and their consideration is quite essential to a full discussion of theories of immunity. The blood-serum of individuals suffering from certain infections, particularly bacterial, acquires the property of agglutinating or clumping these organisms. The blood-serum from a horse having glanders when dropped into a culture of the glanders bacillus will cause the bacteria to clump together and settle out, leaving the medium clear. The phenomenon of agglutination is used in the diagnosis of this and other diseases. A somewhat similar body reaction is provoked by the injection of soluble proteins derived from some other species of animal (or plant) into the body of an animal. The serum of such an animal acquires the property of precipitating the corresponding protein when mixed with it in a test-tube. This phenomenon of precipitation is made use of in the differentiation of many kinds of proteins. The presence of certain substances in the blood, usually proteins derived from any foreign source, may result in the sensitization of the body to such, rather than immunity. This phenomenon is known as anaphylaxis (Gr. an, against; phylasco, to guard) and has led to an explanation of many otherwise obscure pathological and bacteriological facts. 


\section{CHAPTER XIV}

\section{ANTITOXINS AND RELATED ANTIBODIES}

\section{(Antibodies of Ehrlich's First Order)}

Toxins.-The word toxin has been used with a considerable variety of meanings. A substance is said to be toxic when it brings about an abnormal condition when introduced into the body. The discovery that certain microörganisms, particularly bacteria, produced their harmful effects by means of the poisons which they excreted led to the use of the term toxin to include all poisons produced by bacteria. Further study demonstrated that these bacterial poisons differed considerably in their method of action and in other characters. Ehrlich first clearly differentiated the bacterial poisons and used the name toxin to indicate a definite type. The name endotoxin is used to designate certain poisonous substances that are contained within the protoplasm of the cell, and are not excreted as are the true toxins. Some authors have included all these poisonous substances produced by bacteria under the name toxine, and recognize toxin as used in Ehrlich's sense.

Characteristics of a Toxin (Ehrlich).-According to Ehrlich, the toxins constitute a group of substances having the following - characteristics:

1. The true toxins are labile, that is, they are easily destroyed by heat, by acids, by exposure to light and air.

2. The chemical nature of the toxins, with one possible exception, is not understood. Beyond the fact that they are organic in origin and usually give some of the protein reactions, little is known of their chemistry.

3. Biological tests ( $i$. e., animal inoculations) have been found to be the only tests by which the toxins may be recognized and studied. These animal inoculations, as has been before stated, are quite as essential in determining the character and strength 
of a toxin as are indicators to the chemist in his study of endreactions.

4. Toxins act upon the body by combining chemically with definite cells and tissues. This union is not effected at once in all cases. The evidences of damage, with the clinical symptoms of poisoning, do not appear until after the lapse of a period of incubation. The length of this period varies with different toxins - with some of the snake venoms it is very short, in other toxins it is a matter of hours, or even days.

5. The injection of non-lethal doses of toxin into a suitable animal causes the tissues to react and to produce antitoxin, which will neutralize the toxin, and result in immunization.

Toxins may be differentiated from most other poisonous substances with which they may be confused by reference to the preceding. Poisonous alkaloids, such as strychnin, for example, do not cause the production of antibodies. Immunization against a toxin is, therefore, not to be confused with drug habituation.

Sources of Toxins.- Toxins have been found to be produced by a considerable number of plants and animals. Certain of the flowering plants form powerful toxins, such as ricin in the castoroil bean (Ricinus communis and $R$. zanzibarensis), abrin from the jequirity bean (Abrus precatorius), and robin from the bark of the locust (Robinia sp.). The pollen of certain plants, particularly certain of the grasses, the golden-rod and rag-weeds, is poisonous to some individuals, producing hay-fever, and as specific antitoxins have been prepared for them, the poison must be regarded as a true toxin. Among the fungi, certain poisonous mushrooms (or "toadstools"), as the Amanita, have been shown to contain toxins. Certain molds are stated to produce toxins, particularly Aspergillus. Toxins have been demonstrated in the animal kingdom in the venom of snakes, scorpions, and spiders, in the skin of certain reptiles, in the blood of the eel and of certain fish. A few species of bacteria have been shown to produce toxins, but in several cases the amount and character of the toxin are relatively unimportant. The bacteria which have been found to form appreciable amounts of toxin, and which produce lesions of the body tissues through the action of these toxins, are relatively few. The more important are the following: 
Bacillus diphtheria, the cause of diphtheria.

Bacillus tetani, the cause of tetanus or lockjaw.

Bacillus botulinus, the cause of certain cases of botulism or meat-poisoning.

Bacillus enteritidis, found in certain cases of meat-poisoning.

The organisms in which true toxins have been demonstrated, but in which the toxin production does not seem to account for the lesions of the disease, are-

Bacillus pyocyaneus, associated with suppurative processes.

Micrococcus aureus, associated with suppurative processes.

Micrococcus albus, associated with suppurative processes.

It should again be emphasized that the above list of bacteria does not include all those which may produce poisoning, but does include the most important known to produce true toxins. Many other species are known to produce endotoxins.

Specificity of Toxins.-Toxins must combine with the cells or tissues of the body in order to injure them. Toxins do not all attack the same tissue, but show a selective action. In some cases a number of tissues may be injured, in others the damage is limited quite strictly to one type. The toxin produced by the bacillus of tetanus attacks the cells of the central nervous system and is called a neurotoxin. One of the toxins commonly present in snake venom destroys red blood-cells (hemotoxin). Probably some animals owe their immunity to certain toxins to the fact that some of the less important or non-vital body-tissues will combine with the toxin and prevent its union with more vital portions.

Antitoxins.-Antitoxins are antibodies produced by the tissues of the body as a result of injection or presence of toxins. The fact of antitoxin production may be readily demonstrated by mixing the serum of an immune animal with toxin and injecting the mixture into a suitable animal. The normal toxic action will be found to be inhibited by the antitoxin of the serum. The most generally accepted and valuable of the explanations of the production of antitoxins by the body is that offered by Ehrlich, based upon his theory of cell nutrition, the lateral chain or sidechain theory of immunity.

Ehrlich's Theory of Cell Nutrition.-Several explanations have 
been offered by physiologists for the phenomenon of cell nutrition. Food substances carried to the cell by the blood must pass through the vessel and cell-walls and be anchored there if they are to be used in any of the processes of cell metabolism. According to Ehrlich, the protoplasm must be made up of molecules having an affinity for a great variety of food materials. These molecules he conceives to be made up of a central portion surrounded by atomic groups which unite with certain food molecules and bind them to the cell. These atomic groups have affinity for certain food substances, and, therefore, are differently constituted. These atomic groups he calls side-chains or, better, cell receptors. The character of these receptors may be illustrated by a chemical analogy. Benzene has the following formula:<smiles>c1ccccc1</smiles>

Any one of these hydrogens may be substituted by some element or group. Suppose one such to be replaced by the carboxyl group $(\mathrm{COOH})$, another by the amino group $\left(\mathrm{NH}_{2}\right)$, another by the aldehyd group ( $\mathrm{CHO}$ ), and still another by a hydroxyl group $(\mathrm{OH})$. Such a hypothetical compound might be illustrated as follows:<smiles>Nc1c(C=O)cccc1C(=O)O</smiles>

There are several possible ways in which such a compound might react. Should an alkali be brought into contact with it, the base would be taken up by the carboxyl atom group. Acids would be bound by the amino group. Other substances wouk be bound by other atom groups. The cell receptors must be con- 
sidered in this manner, as being of different types, each one capable of uniting with some food substance-probably only one. To take up the variety of substances necessary for cell life and activity, it is evidently necessary that there should be a multiplicity of these receptors, and their action must be considered as very specific.

It is found convenient to represent these cell receptors in a diagrammatic form. Such is scarcely necessary in a consideration of antitoxin, but will be found very helpful in a discussion of the more complex antibodies.

Ehrlich's Theory of Antitoxin Production.-As has been stated previously, toxins are believed to combine with the tissue-cells before the latter can be injured. This union of toxin with the cell takes place through the medium of the cell receptors, some of which are thus diverted from their normal functions. As a result, if the cell is not too seriously injured by the toxin, it or the neighboring cells produce an increased number of receptors of the type thus used. This is in accordance with the general hypothesis enunciated by Weigert, that injury or irritation always results in an overgrowth of tissue - a hypercompensation. For example, rubbing the skin will produce a callus, leaky heart valves cause hypertrophy of the heart, and the cicatricial tissue of a newly healed wound is generally greater in amount than the tissue it replaces. These receptors are, therefore, produced in great numbers, and many are eventually displaced and escape into the cell-plasma and finally into the blood-stream. These freed cell receptors still retain their affinity for the toxin and constitute the antitoxin molecules of the serum. For each of the statements just made there seems to be a good proof. That the toxin actually unites with the body-cells has been shown by experiment, for example, the brain tissue of an animal mixed with tetanus toxin will absorb the latter and remove it from the solution, so that it is without effect when injected into animals. That there is an actual increase in the number of cell receptors may be shown by injecting a small amount of toxin into an animal, and before antitoxins have appeared in the blood, injecting more toxin. The response to the second injection will be quicker than to the first, and the animal will succumb to what is not ordinarily a fatal dose. This indicates an increased power of fixation for the toxin, 
$i . e .$, an increase in the number of the receptors. The appearance and increase in the freed cell receptors or antitoxins in the blood shows that these receptors are thrown off in large numbers. The antitoxin in the serum unites with the toxin probably in much the same manner as an acid neutralizes an alkali. The principal difference is that in carrying out the test, animal inoculations must take the place of the indicator of the chemist. The union between the toxin and antitoxin has been shown to obey the general laws of chemical union.

Constitution of the Toxin.-Toxins are easily destroyed by heat, chemicals, light, and air. It will be shown later that the loss of toxicity does not result from a total destruction of the toxin molecule, for it still is able to unite with the antitoxin. It is evident that the toxin molecule is made up of two partsa thermostabile portion, which unites with cell receptors, either in the cell or free as antitoxins, called the haptophore, or binding group, and a thermolabile group, called the toxophore, which causes the cell injury after union by means of the haptophore has taken place. When the toxophore group of a toxin has been destroyed, that which remains is called a toxoid. That toxoids exist may be demonstrated in two ways. The injection of a toxin solution that has been heated to $56^{\circ}$ for half an hour into a suitable animal does not result in the development of symptoms of poisoning, but does cause the production of antitoxin; in other words, the toxoids retain the ability to unite with the cell receptors and to bring about their increase and elimination from the cell. An antitoxic serum may be mixed in suitable amounts with a solution of heated toxin (toxoid), and after a time mixed with virulent toxin, and the latter will be found to remain uncombined. The antitoxin is completely neutralized by the toxoid, and the toxin added subsequently finds no antitoxin free with which it ean unite.

Constitution of Antitoxin.-Antitoxin is more stable than the toxin in most cases. However, it is easily destroyed by a temperature of $60^{\circ}$ if sufficiently prolonged. There is no reason to suppose that it is made up of more than one group. Inasmuch as it has a binding group, this may be called a haptophore. It has not as yet proved possible to separate antitoxins from serum globulins; 
it is inferred, therefore, that they are similarly constituted. Further light is needed on this subject.

Diagrammatic Representation of Toxin and Antitoxins.-The preceding facts may in large part be recorded by diagrams. These are, of course, arbitrary in shape and appearance, but are helpful in an understanding of the reaction. The diagrams commonly used for this purpose are given in Fig. 65 .

Preferential Union of Toxins with Body-cells.-The union of antitoxin with toxin occurs apparently as readily within the

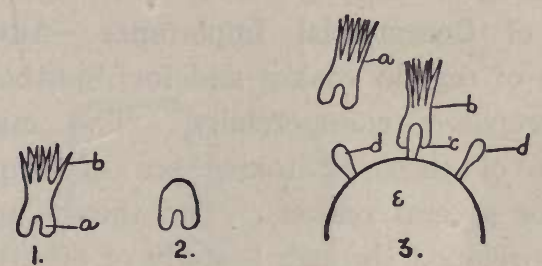

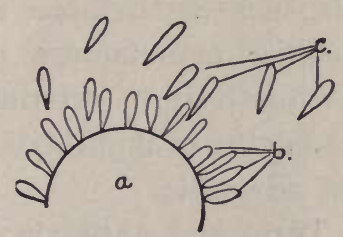

4.

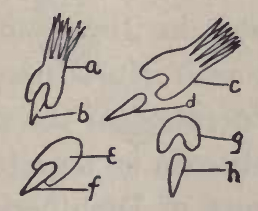

5.

Fig. 65.-Diagrammatic representation of toxins and of antitoxin production-1, Toxin molecule: $a$, Haptophore; $b$, toxophore. 2. Toxoid, a toxin molecule that has lost its toxophore. 3, Molecule of cell protoplasm showing the union of the toxin molecule: $a$, Free toxin; $b$, toxin attached to a cell receptor $c$; $d$, other cell receptors. 4 illustrates the overproduction of receptors by the cell and their elimination $(b)$ into the blood-stream as antitoxin molecules $(c)$. 5, Neutralization or union of antitoxin with toxoid and toxin.

body as without. When toxins are injected and antitoxins are present in the circulation, the latter will commonly unite with the former and prevent union with the body-cells. In some exeeptional conditions, however, this is shown not to occur; for some reason the affinity of cell receptors still united to the cell seems to be greater than those free (antitoxin). In other words, the tissues seem to become hypersensitive to the presence of the toxin, so that the antitoxin no longer protects. Tissue immunity 
is, therefore, not always the same as antitoxin immunity. This hypersensitiveness is of unusual occurrence. An animal that is being immunized against tetanus toxin by injections of increasing amounts may suddenly and unexpectedly show a marked reaction, or may even succumb, when additional amounts are injected, even though antitoxin may be demonstrated in considerable quantities in the blood. It is evident that, although this phenomenon is of infrequent occurrence, it is of some little importance. Possibly this may be related to the reactions to be described later under the heading of Anaphylaxis.

Antitoxins of Commercial Importance.-Antitoxins specific for the venom of certain snakes and for diphtheria and tetanus toxins are prepared commercially. The manufacture and standardization of these antitoxins are of importance to the veterinarian for several reasons. The theory of immunity has been largely developed through a study of diphtheria toxins and antitoxins. The larger animals, such as the horse and goat, are generally used in the commercial manufacture of antitoxin. The tetanus antitoxin is used extensively in veterinary practice. A brief consideration of the production of diphtheria and tetanus toxin and antitoxin is, therefore, advisable.

Manufacture of Diphtheria Toxin and Antitoxin.-Diphtheria toxin is prepared by growing the diphtheria bacillus in suitable broth. A sugar-free broth is prepared as described in Chapter VII. This is titrated and the reaction adjusted accurately to +0.5. It is then placed in flat-bottomed toxin flasks in a layer a few centimeters in thickness, and autoclaved. To each flask is then added sufficient sterile dextrose solution to make a 0.2 per cent. dextrose broth. It is found in experience that different strains of the diphtheria bacilli may vary considerably in toxin production. The strain used most frequently in the United States is the one known as the Park-Williams. The organism is grown in broth tubes, where it forms a film over the surface. Portions of this film are transferred carefully to the surface of the broth in the flasks and incubated at $37^{\circ}$ for eight days. Microscopic examination of the culture should show it to be uncontaminated. To destroy the bacteria and prevent possible infection of those handling the material 5 c.c. of phenol or similar antiseptic is then added to 
each liter. In some cases it is filtered through a porcelain filter, which will remove the bodies of the bacteria, but not the soluble toxins. The amount of toxin present in the solution must be next determined for two reasons: first, to insure the presence of toxins in sufficient concentration for efficient immunization, and, second, to determine the amount that may be injected into the horse without serious injury. The amount of toxin that, when injected subcutaneously, will kill a guinea-pig weighing $250 \mathrm{gm}$. in three days is called the minimum lethal dose for the guinea-pig (abbreviated M. L. D.). The broth should contain at least 1000

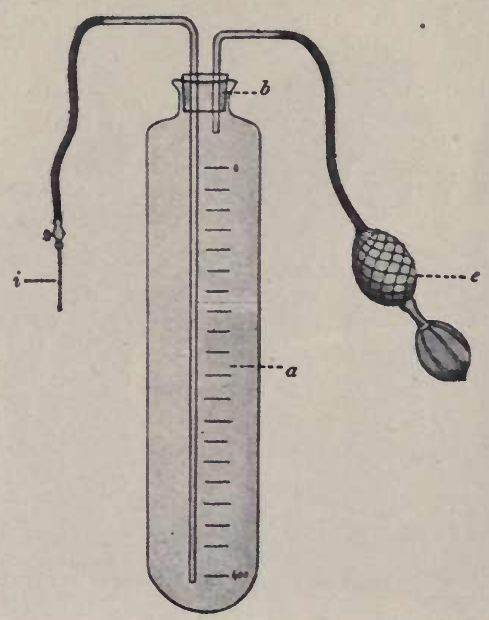

Fig. 66.-Apparatus for the injection of considerable quantities of toxin into the horse: $a$, Graduated cylinder closed by a rubber cork, $b$. Air is pumped into the constant pressure bulb $e$, and from this passes into the cylinder. The toxin is forced out through the needle at $i$ (Levaditi).

M. L. D. per cubic centimeter. The horse is most commonly employed for the production of the antitoxin. Care is used that the animal is fairly vigorous and entirely free from any infectious disease. Injections of 100 M. L. D. are made subcutaneously, or, better yet, larger amounts, neutralized by antitoxin already prepared, are first used. The animal responds by fever and swelling at point of injection and by other minor symptoms. After a lapse of several days, or when the horse has recovered, a 
second injection of a larger amount is given. Increasing doses of the toxin are injected at intervals until as much as 500 c.c. of the toxin may be administered at one time. Not all horses produce enough antitoxin in their blood to be commercially valuable; hence the antitoxin content is usually determined some time before the process of immunization is complete. When the animal's blood contains the maximum amount of antitoxin, it is drawn by a sterile trocar from the right jugular vein into wide-mouthed sterile jars (Fig. 68). Usually a little less than one liter of blood for every hundred pounds weight of the horse is removed, as this

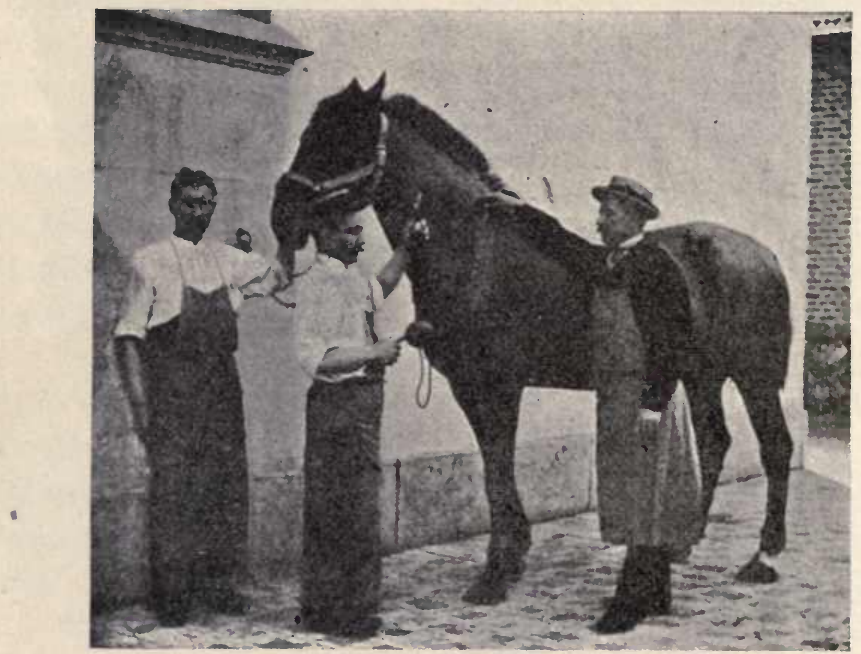

Fig. 67.-Injection of a horse with toxin (Levaditi).

amount may be withdrawn without appreciable injury. After a rest the horse may again be injected and bled.

The jars of blood are allowed to stand until the clot has shrunk and the clear, straw-colored serum has separated. This contains the antitoxin and is the serum antidiphtheriticum of the Pharmacopeia. It must now be standardized, that is, the amount of antitoxin per cubic centimeter determined. Several methods of determining the potency of the antitoxin have been proposed. Inasmuch as the unit formulated by Ehrlich has been generally adopted (except by the French) its development will be briefly traced. Behring first proposed as an antitoxic unit, 
the least amount of antitoxin which, when mixed with $100 \mathrm{M} . \mathrm{L}$. D. of the toxin, would prevent a 250 -gm. guinea-pig injected with the mixture from dying within four days. This implied the keeping of the toxin of a certain strength for the standardization of antitoxin. The toxin was found to be unstable, and the same toxin would at different times yield different results. Furthermore, antitoxins are neutralized by toxoids as well as toxins. The toxin cannot be.preserved for long periods without deterioration, as would be necessitated if used as a government standard. Ehrlich, therefore, made use of a toxin which he had studied in his laboratory to standardize a large quantity of serum. This serum he dried in a current of warm air in a partial vacuum. As a result,

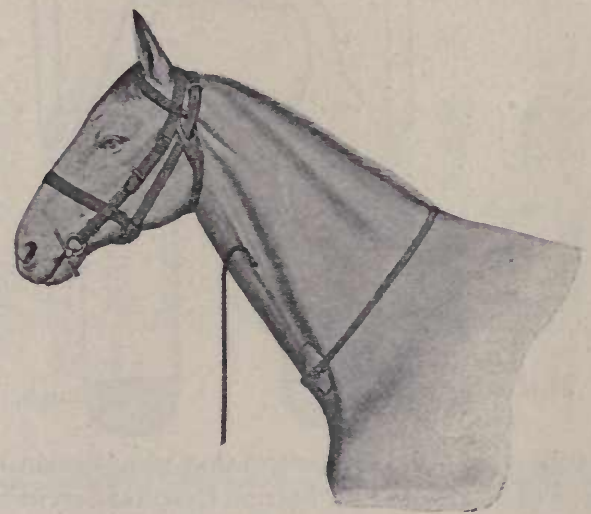

Fig. 68.-A trocar inserted into the jugular vein of the horse. The compressor causes a noticeable engorgement of the vessel (Kretz in Kraus and Levaditi).

he secured a considerable amount of serum in the form of dried scales. The number of immunity units (U. I.) per gram of this dried material was very accurately determined. Exactly equal amounts by weight of this standard serum were placed in each of a large number of special tubes. The serum was placed in one arm and phosphorus pentoxid $\left(\mathrm{P}_{2} \mathrm{O}_{5}\right)$, an active dehydrating agent, in the other. The air was then exhausted as completely as possible by an air-pump and the tubes sealed. They then were placed in a dark refrigerator, where a constant temperature was maintained. The antitoxin under these conditions was found to retain its potency undiminished for a long period. Ehrlich 
placed 1700 U. I. in each tube. Each month a tube is opened and its content of serum dissolved in 1700 c.c. of a mixture of water and glycerin. Each cubic centimeter, therefore, contains one immunity unit of antitoxin. A careful study of the toxin which Ehrlich had used in preparing this standard showed him that it contained, in addition to the 100 M. L. D. of toxin, an equal amount of toxoid. Theoretically, therefore, this immunity unit prepared by him contains sufficient antitoxin to neutralize 200 M. L. D. of a pure toxin. In view of the fact that all antitoxin

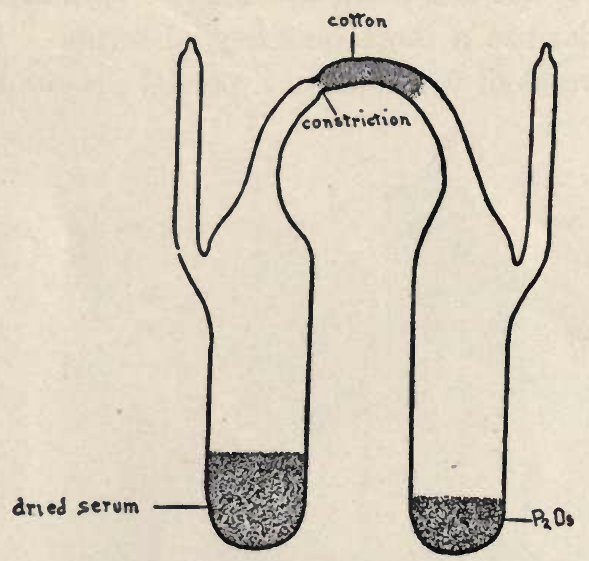

Fig. 69.-A tube used for the preservation of antitoxin by the Hygienic Laboratory of the Public Health and Marine Hospital Service: $a$, Serum scales, or antitoxin; $b$, phosphorus pentoxid, an active dehydrating agent (M. J. Rosenau, Bulletin No. 21, Hygienic Laboratory).

in this country is now standardized with reference to this U. I. of Ehrlich, the immunity unit for diphtheria antitoxin has been redefined as an amount of antitoxin equivalent to that contained in 1 c.c. of solution when the contents of the tubes prepared by Ehrlich are dissolved in 1700 c.c. of water. In the United States a similar set of tubes (Fig. 69) has been prepared by the Hygienic Laboratory of the Public Health and Marine Hospital Service, and the standard serum is sent from that laboratory to the manufacturers.

The old antitoxin cannot be used directly to determine the potency of new antitoxin, but a lot of toxin must first be standardized. It is necessary to express the strength of the toxin in terms 
of the standard antitoxin. Toxin is used which has been preserved until the first rapid transformation of toxin to toxoid has ceased, and it has, therefore, become relatively stable. A series of syringe tubes is prepared (Fig. 70), each one containing one standard immunity unit of antitoxin, and to these are added varying amounts of the toxin to be tested; each is then injected into a 250 -gm. guinea-pig. The amount of antitoxin will be more than sufficient to neutralize the toxin in some cases, and the animals injected will show no ill effects; in other cases the toxin will be in excess, and the animals will die. The amount of toxin which, when thus mixed with 1 U. I., will kill a 250-gm. guineapig in just four days is called the $\mathrm{L}+$ dose. The amount of the

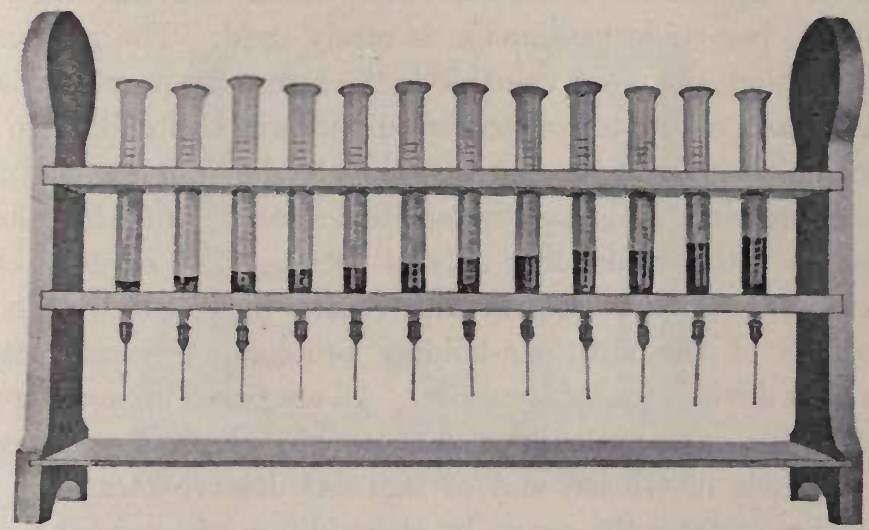

Fig. 70.-Battery of syringe tubes for testing the potency of toxin and antitoxin (Madsen).

toxin solution just necessary to neutralize an immunity unit, as evidenced by the almost complete lack of tissue reaction at the site of injection, is called the L0 (limit zero) dose. In a solution containing toxins only (no toxoids) the difference between the $\mathrm{L}+$ and the $\mathrm{L} 0$ dose would be $1 \mathrm{M}$. L. D. of the toxin, but such toxoidfree solutions cannot be obtained; hence the difference between the two is greater. The only reason that the $\mathrm{L} 0$ dose is determined in practice is that a toxin solution, in which the $\mathrm{L}+$ and $\mathrm{L} 0$ doses differ widely, is not suitable for carrying out the test and should be discarded. When the $\mathrm{L}+$ dose of the toxin has been satisfactorily determined, it may then be used to determine the potency 
of fresh antitoxin. A series of syringe tubes, each containing one $\mathrm{L}+$ dose of the toxin, is arranged, and the varying amounts of the antitoxin serum to be tested are added. The amount of serum which will prevent a 250 -gm. guinea-pig from dying in less than four days contains 1 immunity unit.

According to Ehrlich, diphtheria toxin is in reality made up of two poisons - the true toxin and toxone. The latter he holds to account for the paralyses that are frequent sequelæ in diphtheria. The same antitoxin neutralizes both the toxin and the toxone. This toxone is of some theoretic and practical importance in the standardization of the toxin and the antitoxin.

The amount of antitoxin present varies greatly in the serum produced by different horses. One which contains less than 250 U. I. per cubic centimeter is rarely used. The greater the concentration, the more valuable is the serum for prophylaxis and cure. Many efforts to concentrate diphtheria antitoxin have been made, all based upon the fact that the blood-serum is a mixture of various proteins, and that the antitoxin seems to be inseparably bound up with certain ones only of these. The removal of the proteins having no antitoxic value results in a considerable concentration of the antitoxin-holding proteins. Several methods have been devised for this purpose. All are based upon differences in solubility or coagulability of the various serum constituents. The methods of Gibson and of Banzhaf deserve mention. The former precipitates the serum by the addition of an equal amount of a saturated solution of ammonium sulphate. This precipitates the antitoxic and some other fractions of the serum, but does not precipitate certain of the non-antitoxic albumins. These are filtered out, the precipitate is dissolved in water to its original volume, and is again precipitated by ammonium sulphate. This precipitate, when filtered, is relatively free from albumins. It is then stirred into a saturated solution of sodium chlorid, which dissolves the pseudoglobulins with the antitoxin. The insoluble portions are filtered out and the clear filtrate acidified by the addition of 0.25 per cent. of 80 per cent. acetic acid. The precipitate which is thrown down is collected over hard filters, partially dried by pressure with bibulous filter-paper, and placed in a parchment bag for dialysis in running water. The acid is neu- 
tralized by the addition of sodium carbonate, and dialysis is continued until the soluble salts have practically disappeared. If care is used, the antitoxin will be found to be dissolved in a much smaller quantity of water than originally present in the serum. The concentration may be from two to three and one-half times the original.

Banzhaf makes use of the various coagulation temperatures of the serum constituents in effecting their separation. The albumins and part of the non-antitoxic globulins are precipitated by heating for twenty-four hours at $58^{\circ}$. Sodium chlorid crystals are added to saturation, and much of the remaining globulin, transformed by heat, is precipitated, leaving the pseudoglobulins

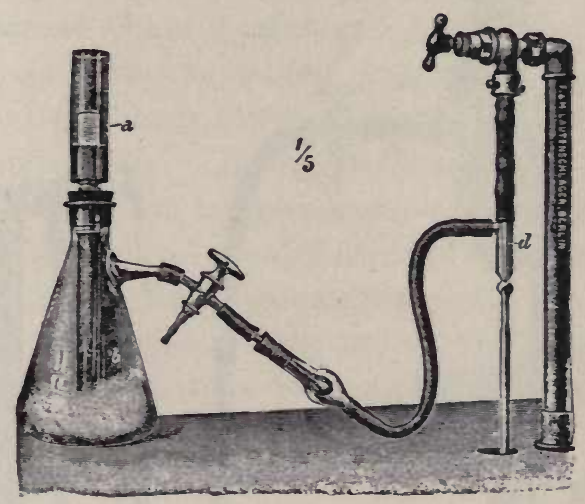

Fig. 71. - One type of filtration apparatus used for serum: $a$, Filter; $b$, test-tube within a filter flask from which the air is partially exhausted by the vacuum pump at $d$ (Weidanz).

and the associated antitoxin in solution. The clear filtrate is acidified with acetic acid, and the precipitate prepared as in the preceding method. By this method a concentration of ten times the original has been obtained.

The antitoxic serum is in all cases filtered through sterile unglazed porcelain, and, after the addition of a small amount of preservative, placed in sterile containers and sealed.

Preparation of Tetanus Toxin and Antitoxin.-The tetanus toxin is prepared by growing Bacillus tetani in broth under anaërobic conditions. This may be accomplished by the use of a hydrogen 
atmosphere, but more easily by covering the medium by a layer of paraffin or other neutral oil. The methods of preparing the toxin for use and of manufacture of the antitoxin do not differ materially from those used in the production of diphtheria antitoxin.

Unlike diphtheria toxin, the tetanus toxin may be dried and preserved indefinitely without deterioration. It is, therefore, the toxin and not the antitoxin which is sent out from the Hygienic

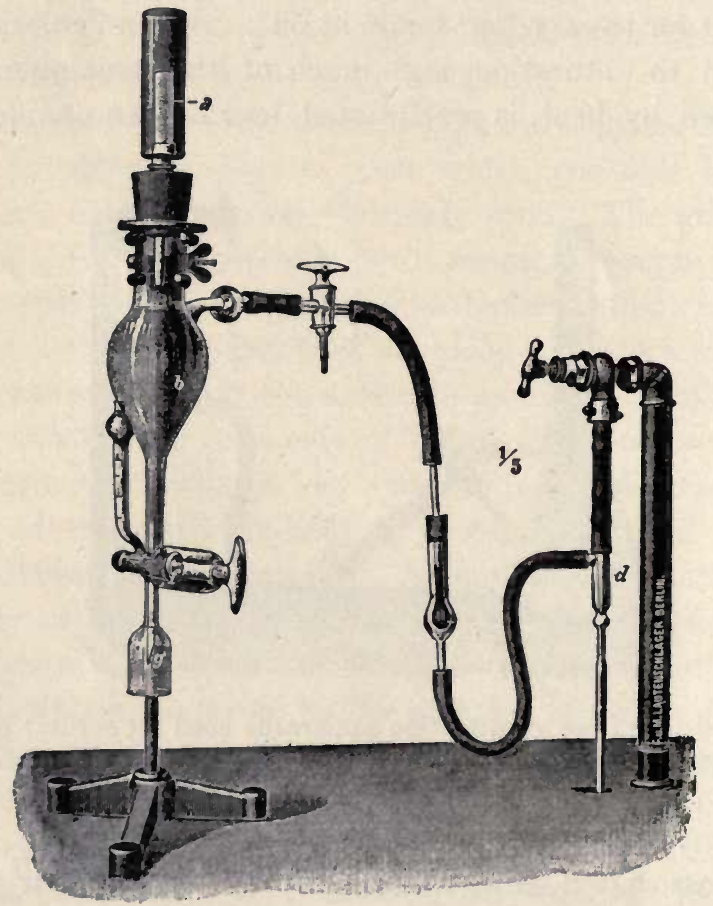

Fig. 72.-A filtration apparatus after Uhlenhuth and Weidanz.

Laboratory to the serum laboratories for the purpose of standardization. A standard toxin has been prepared at this laboratory, and its M. L. D. for a 350-gm. guinea-pig carefully determined. This is sent out in dried form, and is diluted before use, so that each cubic centimeter contains $100 \mathrm{M}$. L. D. of the toxin for a $350 \mathrm{-gm}$. guinea-pig. The immunity unit is defined as follows: "The immunity unit for measuring the strength of tetanus antitoxin 
shall be ten times the least quantity of antitetanic serum necessary to save the life of a 350 -gm. guinea-pig for ninety-six hours, against the official test-dose of a standard toxin furnished by the Hygienic Laboratory of the Public Health and Marine Hospital Service." 1

Another statement is that one-tenth of a unit, mixed with 100 M. L. D. of the standard toxin, contains " just enough free poison in the mixture to kill the guinea-pig in four days after subcutaneous injection." The amount of toxoid has not been accurately determined in this test-toxin used; therefore, the standardization test must in all cases be in terms of the Hygienic Laboratory toxin, no other sample of toxin being suitable. The test-dose is called the $\mathrm{L}+$ dose, as in the diphtheria toxin.

Preparation of Other Toxins and Antitoxins.-As has before been stated, antitoxins have been prepared for a large number of toxins. The two already discussed are by far of the greatest importance commercially. In the development of theories of immunity considerable use has been made of antiricin and antiabrin. An antitoxin for pollen (called pollantin) has been used to some extent in hay-fever. Antitoxins against snake venom may be purchased upon the market. They are of considerable importance in certain tropical countries, particularly India, where poisonous snakes abound.

Antienzymes.-A study of enzymes and their actions has shown them to resemble toxins in some respects. Although an enzyme does not form a part of the final product of its activity, it nevertheless seems evident that it first unites with the compound which it transforms, and later is split off. Enzymes are believed to possess two groups, resembling the toxins-one a binding group, or haptophore, and the other a fermenting group, or zymophore. The injection of an enzyme into the animal body will usually result in the production of an antienzyme, which will permanently combine with the enzyme and effectually prevent its action. These antienzymes are probably developed in exactly the same manner as are the antitoxins, and have the same general constitution. They are likewise very specific: the action of pepsin is inhibited by an antipepsin, and not by an antirennet.

$$
1 \text { Treasury Dept., Circular No. 61, Oct. 25, } 1907 .
$$


Enzymes, like toxins, are thermolabile. The zymophore may be destroyed without injuring the haptophore.

It is probable that there are certain antiferments constantly present in body tissues which prevent the activity of the autolytic and other enzymes during life.

Other Antibodies Related to Antitoxins.-Antibodies of the same type as the antitoxin have been produced for agglutinins, amboceptors, complements, and other bodies. These will be considered with their specific antigens. 


\section{CHAPTER XV}

\section{AGGLUTINATION AND PRECIPITATION}

\section{(Antibodies of Ehrlich's Second Order)}

GRUBER, in 1896, discovered that the blood of animals immunized against Bacillus typhosus, and the blood of patients having the disease, when added to a liquid culture of the organism, caused the bacteria to cease moving and to clump together. This phenomenon has been named agglutination. Later it was found that the use of protein substances as antigens caused the production in the body of substances which, when mixed with the protein in solution, would form a precipitate. This is known as the precipitation phenomenon. The antibody responsible for agglutination is called an agglutinin; for precipitation, a precipitin.

Differentiation of Precipitation and Agglutination.-The distinction between agglutination and precipitation may be stated as follows: Agglutination occurs when the antigen is in suspension in the form of individual cells or finely divided particles. Precipitation occurs when the antigen is a colloid in solution.

Agglutination.-Agglutinins may be grouped into two classes, normal and immune. A normal agglutinin is one present in the body without any infection or systematic immunization. An immune agglutinin is one that is developed as a result of the presence of an organism or its products in the body. There is no reason to suppose that the normal and immune agglutinins differ from each other in any essential particular. It is possible that all normal agglutinins are in reality produced as a result of an undetected infection or to the presence of the so-called group agglutinins to be considered later.

The agglutination reaction is said to be specific; that is, the agglutinin will agglutinate, in general, only the homologous organism. The term homologous is used to indicate the relation- 
ship between an antigen and its specific antibody. The serum of a glandered animal is homologous for the glanders bacillus, but is heterologous for the typhoid bacillus.

Agglutinins are formed by the body for most foreign cells which may enter or be injected. Red blood-cells, other body-cells, protozoa or bacteria, may be the antigens which provoke agglutinin production. Under the right conditions the clumping will occur whether the cells be living or dead, motile or non-motile.

Agglutinogen.-The antigen which causes the body to react and produce agglutinins is called an agglutinogen. It is evident that the agglutinogen is not the cell used for injection, but some substance produced by it. A culture of Bacillus typhosus in broth may be passed through a porcelain filter, and the sterile filtrate will still cause agglutinin production when injected into the animal body. The agglutinogen is either something thrown off by the antigenic cell in the process of growth, or formed as a result of autolytic disintegration and digestion. Evidently some constituent of the cell excites the production of the antibodies or agglutinins, and these, therefore, unite with the corresponding material in the bacterial or other cell.

Ehrlich's Theory of Agglutinin Production.-According to Ehrlich, the agglutinogen unites with the receptors of the bodycells, which are diverted in this way from their normal function. As a result, there is an overproduction of the receptors and they are freed as agglutinins. These freed receptors or agglutinins differ in several ways from the antitoxins, for they not only combine with the antigen, but they bring about certain changes in it. Such receptors, to differentiate them from antitoxins and similar antibodies (receptors of the first order), are termed receptors of the second order.

Constitution of the Agglutinin.-The agglutinin may be shown to consist of two portions - a binding group and an agglutinating group. The presence of the binding group, or haptophore, may be shown by mixing bacteria with a serum containing the specific agglutinin, and centrifuging. The supernatant liquid will be found to have lost its agglutinating power - that is, the agglutinins will all have united with the bacteria first added, and will be removed thereby from solution. The agglutinating group of the agglutinin 
is called the agglutinophore, the zymophore, or the zymotoxic group. This group is unstable, and may be destroyed by heating to a temperature of $60^{\circ}$ to $75^{\circ}$ and by acids and alkalis. It changes with age slowly. An agglutinin which has lost its zymotoxic group is called an agglutinoid. The agglutinoid still retains the capacity to unite with the antigen, but has lost the ability to act upon it. The presence of agglutinoids may be demonstrated by mixing a serum containing them with the homologous organism, and allowing the mixture to stand for a time. No agglutination will take place, nor will it occur when fresh agglutinin is added. The
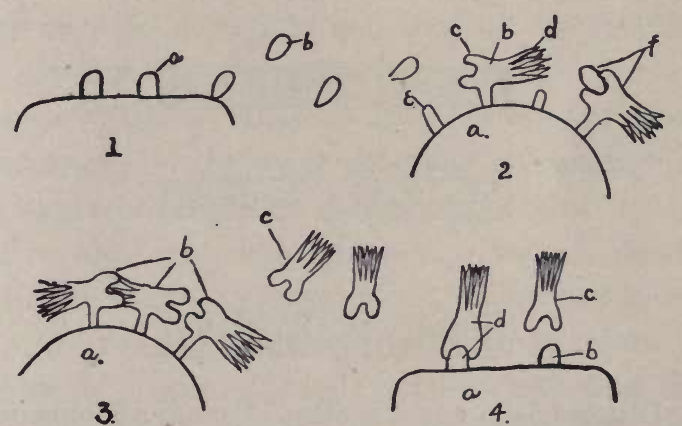

Fig. 73.-Agglutination and formation of agglutinins: 1, Diagrammatic representation of bacterial or other antigenic cells with fixed $(a)$ and freed $(b)$ agglutinogen groups. 2, Union of agglutinogen with cell receptors of the second order: $a$, Molecule of the cell protoplasm, with a cell receptor of the first order $(e)$ and of the second order $(b)$, showing its haptophore $(c)$ and its agglutinophore or zymophore $(d) ; f$, an agglutinogen group united to the cell receptor. 3 , Overproduction of cell receptors $b$ and freed receptors or agglutinin molecules at $c . \quad 4$, Union of agglutinin with the bacterial or other cell.

agglutinoid unites with the cell and blocks the union of the agglutinin. Certain investigators have claimed to have produced antiagglutinins by the use of agglutinins as an antigen, inoculating them into another species of animal. These antiagglutinins, when mixed with the agglutinins, unite with them and prevent them from uniting with the homologous antigen when it is added.

Body or Somatic and Flagellar Agglutinins.-It is probable that agglutinogen in motile organisms may originate in two ways-from the flagella or from the cell-bodies. Agglutinins have been differentiated in such cases into those that bring about agglutination 
by combining with the flagella (flagellar agglutinins) and those which unite with the cell-body (somatic or body agglutinins).

Method of Agglutinin Action.-Common salt must be present in any serum which agglutinates. Its function is not thoroughly understood, nor is the general phenomenon of agglutination itself susceptible of a simple explanation. The older theories of the change whereby the organisms are made glutinous by the union of the agglutinin are to be discarded, and the true explanation is doubtless to be found somewhere in the field of colloid chemistry. Concerning the exact nature of the change in the cell we know little or nothing. The cells are certainly not seriously injured;

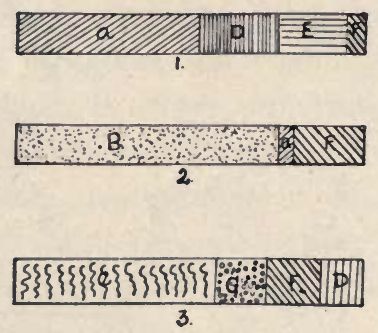

Fig. 74.-Diagrammatic representation of group agglutination: Let 1, 2, and 3 represent the agglutinogen given off by three related species of microorganisms. The organisms 1 and 2 have agglutinogens $a$ and $F$ in common, but in quite different proportions. No. 3 likewise has $F$ in common with both of the others, and $D$ in common with 1 . If the area covered in the diagrams represents the relative proportions of agglutinogen of each kind, the readiness with which one species may be agglutinated by a heterologous serum may be understood.

in fact, an organism may grow luxuriantly in a serum which agglutinates it. One of the delicate tests for agglutinability is to grow the organism in such a serum, and note the production of long threads (Pfaundler's reaction).

Group Agglutinins. - The statement has been made that agglutinins are specific. This must be somewhat modified. It has been shown that the serum homologous for a certain organism may clump to a less degree some other species or closely related forms, and in rare instances forms quite unrelated. This seems to be due to the fact that not all the agglutinogen given off by a particular organism is of one type; the agglutinins produced, 
therefore, are likewise of different types. It is entirely probable that closely related organisms should throw off some identical agglutinogen, and, therefore, have some common agglutinins. Agglutination of an organism by a heterologous serum is termed group agglutination. The agglutinins which are specific for the organism are called its chief agglutinins, and those common to two or more organisms are termed coagglutinins. It may sometimes be shown that differences exist between the agglutinins produced by different strains of the same organism. The importance is apparent, therefore, of using care in testing the agglutinating power of any serum to dilute to such an extent that the action of the coagglutinins may be negligible and that of the specific or chief agglutinins, recognized.

Agglutination Tests in Disease Diagnosis.-The fact that an organism developing in the body generally excites the production of a specific agglutinin has led to the wide use of the fact in the diagnosis of certain infectious diseases. Not all diseases cause an appreciable production of agglutinin. The test is carried out by mixing serum from the suspect with the organism. If agglutination occurs in proper dilution, it is evident that the specific organism is or has been present in the patient. The test is frequently reversed, and serum from an animal showing high agglutinating power is used to differentiate between different species and races of bacteria. The principal disease organisms which cause the production of appreciable amounts of agglutinin are as follows: Bacillus typhosus (typhoid fever), Bacillus paratyphus (paratyphoid), Bacillus enteritidis (meat-poisoning), Bacillus dysenterice (bacillary dysentery), Bacillus coli, Bacillus pyocyaneus, Bacillus mallei (glanders), Bacillus pestis (bubonic plague), Bacillus tuberculosis (tuberculosis), Micrococcus melitensis (Malta fever), Streptococcus pyogenes, and some other pyogenic cocci, Micrococcus meningitidis (epidemic cerebrospinal meningitis), Spirillum cholerce (Asiatic cholera), and others. The test is not commonly used in practice for the recognition of all of them-some are of experimental interest only.

The diagnosis of disease by agglutination is commonly called the "Gruber-Widal," or simply the "Widal " test. The test may be made either by observation of a hanging drop or microscopically, 
or it may be made by naked-eye observation of the reaction in the test-tube, or macroscopically.

Microscopic Widal, or Agglutination Test.-Dilutions of the serum are generally made $1: 10,1: 20$, and $1: 40$, or even more. To prepare a 1:40 dilution for a hanging drop, place 19 loops of physiological salt solution, separately, upon a clean microscopic slide, then add one loopful of serum to be tested, and mix thoroughly with the diluent. Place one loopful of a suspension of the organism (broth culture or suspension from the surface of an agar slant in physiological salt solution) upon each of two clean cover-glasses; to one add one loopful of the serum dilution, to the other a loopful of sterile physiological salt solution. Invert over the cavity of a

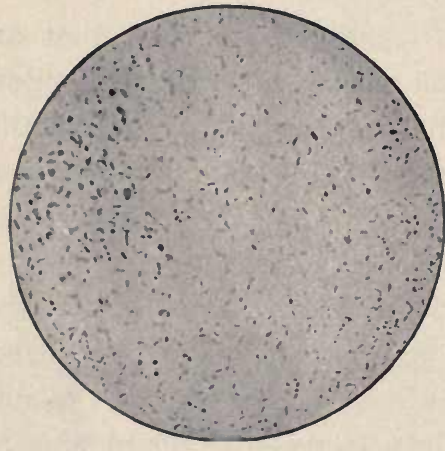

A

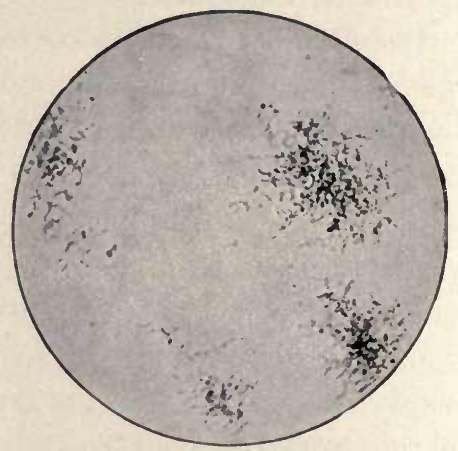

B

Fig. 75. - The Widal or agglutination test of the typhoid bacillus, using serum from a typhoid patient: A, Check showing the uniform distribution of the bacilli; B, clumps of bacteria in the positive test (Jordan).

hollow-ground slide and examine microscopically. The check should show the organisms uniformly distributed over the field, and moving about actively, if the organism is motile. The organisms in the other may show no change, but if the serum has come from a patient infected with the organism, the bacteria will soon begin to clump together, and in the course of a few minutes to an hour practically all of the organisms will be found so clumped, very few or none remaining isolated in the field. Motility is lost in motile forms. The test is a very delicate one, as is evidenced by the fact that the agglutination may sometimes be secured in dilutions as great as $1: 100,000$. The higher the dilution 
at which agglutination occurs, the greater is the specificity of the reaction. As has been seen, the dilution must be great enough in every case to escape the activity of the normal and the common group agglutinins. Serum from an animal that has been immunized against a specific organism may be used in the recognition of that organism. Typhoid serum in this way can be used in the detection of the typhoid bacillus. Such a test also enables one to differentiate between closely related forms, as the varieties of the dysentery and of the paratyphoid bacilli.

Macroscopic Widal, or Agglutination Test.-A series of small test-tubes is prepared, each tube containing a definite amount of a suspension of the organism. To these are added varying quantities of serum, making dilutions of $1: 10,1: 50,1: 100,1: 200$, and higher. A positive reaction is indicated by the appearance of small flocculi of bacteria, which soon settle to the bottom, leaving the supernatant liquid clear. The reaction may not be complete for several hours, and the tubes should be allowed to stand for twenty-four hours before making final observations. Check tubes should always be kept as controls, in which the liquid should remain uniformly turbid. Advantage is taken by certain manufacturers of the fact that dead bacteria, as well as the living, may be agglutinated. They make "agglutinometers." containing all the apparatus and materials for making a complete test. The bacterial suspension supplied will keep for a long period.

Significance of Agglutinins in Immunity.-Agglutination takes place in the body as well as without. Clumps of typhoid bacilli may be found in various capillaries in cases of typhoid. It is uncertain what significance is to be attached to the phenomenon. It can scarcely be of advantage, except possibly that it prevents to some degree the distribution of the bacteria through the blood.

Hemagglutinins. - Certain bacteria, and certain toxic materials from plants and animals, contain substances which agglutinate red blood-cells. Such agglutinins are termed hemagglutinins. When this agglutination occurs in the blood, it results in the formation of emboli of the red blood-cells. These emboli are of considerable significance in some diseases. Hemagglutinins may also be formed by the injection of the red blood-cells of one species into another. 
Precipitins.-The precipitins are quite analogous to the agglutinins. They are formed as a result of the injection of a great variety of proteins or protein derivatives. An antigen which induces the development of precipitins is known as a precipitogen. The precipitogen is doubtless the protein molecule itself. It consists essentially of a binding or haptophore group only. The precipitin seems to be formed in a manner similar to that already described for agglutinins. It may be shown to consist of a zymophore or precipitating group, and a haptophore or binding group. The zymophore is easily destroyed by heat, but the haptophore is thermostabile. A precipitin that has lost its zymophore is known as a precipitoid. The precipitins are quite specific, but group precipitation will take place when related proteins are treated with a serum homologous to one of them. The bloodsera of various ruminants, for example, exhibit group precipitation. An antiserum homologous to human serum will precipitate the serum of anthropoid apes.

The work of Nuttall has showed quite definitely the limits of group agglutination. He tested 900 kinds of blood, using in all 30 antisera, and made a total of about 16,000 combinations. He showed that, on the whole, the closer the relationship, the greater the amount of common or group agglutination. For example, he determined that the blood of apes of the old world would yield a heavier precipitate with human antiserum than would that of apes of the new world. Another exception to specificity has been found in the protein of the crystalline lens: an antiserum for the lens protein of man or the ox will produce a precipitate in solution containing the lens protein from other animals not at all closely related. It has been suggested that the cataract of the eye may be due to the formation of an autoprecipitin for the protein of the lens and its consequent partial coagulation or precipitation in situ.

The mechanism of precipitation is not well understood, but it is probably to be explained on the basis of certain facts of colloid chemistry. The test is so delicate that a positive reaction has been secured with a dilution of $1: 100,000$ of egg-white, while the ordinary protein tests of the ehemist fail to show 1: 1000 .

Uses Made of the Precipitation Phenomenon.-Several practical 
applications have been made of precipitation in the differentiation of proteins. These are the recognition of blood-stains, the differentiation of meats from different species of animals, particularly horse-flesh from beef, and the diagnosis of many other proteincontaining substances, including bacteria and their products.

Recognition of Blood-stains.-It is sometimes necessary in murder trials to determine with certainty the origin of a blood-stain. The fact that the stain has been produced by blood may be easily demonstrated by the chemist, but he has no ready means of telling with certainty whether the blood is of animal or human origin. Uhlenhuth was the first to call attention to the value of this test in legal medicine. The precipitation test, when properly carried out, enables the determination to be made with a high degree of certainty. An antiserum specific for human blood must be secured first by injections of human serum into a rabbit, at intervals of a few days, for a period of several weeks. A bit of the material with the blood-stain is placed in a watch-glass and 5 c.c. of sterile physiological salt solution is added. This is allowed to stand until some of the blood proteins have been dissolved. This may be shown by blowing into the liquid through a capillary tube, when a fairly permanent foam will be produced. If any dirt or sediment appears in the solution, it is removed by filtration. An effort is made to secure a dilution of the serum of about 1:1000. The diluted serum is placed in a series of test-tubes, and the specific antiserum is added. If the blood-stain is from human blood, the precipitate will make itself apparent as a clouding in the course of a few minutes. The reliability of the test has been recognized by the German courts, and the results have been accepted as evidence. By varying the procedure, the same method may be used in differentiating animal bloods.

Differentiation of Meats.-Meat inspection, particularly in certain European countries, includes the differentiation of meats. In certain localities large quantities of horse-flesh are used for food, but the law forbids that horse-flesh be sold as beef. There are certain chemical differences between the two,- - differences in the composition of the fat and possibly in the abundance of glycogen,--but these differences require careful chemical analysis and examination for their recognition. The precipitation test furnishes an easier 
and more reliable method for reaching the same end. Furthermore, the testing may be extended to an examination of mixed meats, as sausages, and the various kinds of meat present determined. Specific antisera must be prepared for each of the meats which it is desired to recognize by mincing the meat and soaking it in physiological salt solution. This material is then used in the immunization of a rabbit by repeated injections during several weeks. The flesh to be tested is likewise extracted with physiological salt solution, the solution filtered and tested as in the blood diagnosis with the various specific antisera. It will give a most prominent precipitate with its homologous antiserum, and the differentiation may thus be made.

Differentiation of Bacteria.-It has been found that the injection of the bacteria-free filtrates of liquid cultures of bacteria will induce the production of an antiserum specific for the filtrate from that particular type of organism. This method is not as reliable as the agglutination method of differentiating bacteria, but it may be used, and is just as specific.

Similar tests have been made to differentiate from each other the proteins derived from certain plants and plant-seeds. It may be stated that, in general, the injection of any protein in absolutely pure condition will cause the production of the homologous specific antiserum in the animal injected. 


\section{CHAPTER XVI}

\section{CYTOLYSINS, INCLUDING BACTERIOLYSINS, AND HEMOLYSINS}

\section{(Antibodies of Ehrlich's Third Order)}

THE use of animal, plant, or bacterial cells as antigens has been found usually to cause the development, by the tissues, of specific antibodies, which have the power of destroying these cells, and in many cases of actually dissolving or digesting them. These antibodies are termed cytotoxins. In most cases the action is lytic or dissolving; the antibodies are cytolysins. Cytolysins are frequently subdivided with reference to their antigens, as bacteriolysins, hemolysins, nephrolysins, etc. Any substance which destroys bacterial cells is said to be bactericidal, and this expression is used when the method of cell destruction is not specified. Cytolysins are produced by certain bacteria, and are also found in certain snake venoms.

Bacteriolysins were first noted by Pfeiffer. He found that when cholera spirilla were injected into the peritoneal cavity of the immune guinea-pig, the serous exudate rapidly dissolved and destroyed them. This lytic action of the blood-serum is called Pfeiffer's phenomenon. Later, it was discovered that this reaction would take place just as well in a test-tube (in vitro) as in the animal body.

Cytolysins. - Cytolysins have been shown to be made up of two elements. When a cytolytic serum is heated to $56^{\circ}$ for half an hour, or is allowed to stand for a time, it loses its lytic property. This is regained, however, when a little fresh normal serum is added. The normal serum is said to reactivate the immune serum. The normal serum alone is not lytic, nor is the immune serum, but when mixed, they will destroy cells. It is evident, therefore, that the cytolysin is made up of two constituents, neither of which can act without the other. The thermostabile constituent of the im- 
mune serum is termed amboceptor; ${ }^{1}$ the thermolabile constituent of normal serum is termed complement. ${ }^{2}$

Action of Amboceptor.-It may be shown that the amboceptor unites with the antigenic cell with which it comes in contact. This may be demonstrated by the following experiment: A heated immune serum ( $i$. e., one containing amboceptor only) is added to the homologous cell, allowed to stand for a time, then, by means of repeated centrifugation and washings with physiological salt solution, the serum may be completely removed. To the washed cells normal fresh serum (i. e., containing complement) is added, when cytolysis may be observed. This seems to show that the amboceptor unites with the cell and cannot be removed by washing, but cannot, on the other hand, destroy the cell until the complement is added.

Action of Complement.-Normal serum containing complement only shows no cytolytic activity. An experiment reciprocal to the preceding, the addition of complement containing serum to a suspension of cells, followed by centrifugation and washing, and the addition of amboceptor, will not result in cytolysis. The complement is evidently not bound to the cell, and can only be attached through the amboceptor. The amboceptor may be considered as a structure which links or binds the complement to the cell and enables it to destroy such cell.

Specificity of Amboceptors and Complements.-The amboceptor is formed usually as the result of immunization, and is specific for its antigen. The amboceptor for the red blood-cells of one species of animal will not unite with those of an unrelated species. Inasmuch as normal serum will activate many different amboceptors, it has been argued that all complement is of a single type, but Ehrlich has succeeded in demonstrating that there are many complements, and the general activating power of certain fresh sera for many amboceptors is due to the multiplicity of the complements which they contain.

Structure of Amboceptor.- There is reason for believing that the

${ }^{1}$ Synonyms of amboceptor are immune body, Immunkörper, Zwischenkörper, substance sensibilisatrice, copula, desmon, philocytase, fixateur, preparator, Hilfkőrper:

${ }^{2}$ Synonyms of complement are addiment, alexin, cytase. 
amboceptor is made up of two haptophore groups, one uniting with the specific cell, and called the cytophilous haptophore, the other uniting with the complement, and called the complementophilous haptophore. The injection of a serum containing amboceptors into a different species of animal has been claimed to cause the production of anti-amboceptors. That these anti-amboceptors are formed was held because, by adding the serum produced by immunization with amboceptors to a solution of the amboceptors, the solution will be found to have lost all cytolytic power when the complement is added. The fact that the amboceptor has the two haptophore groups would make it seem probable that two kinds of anti-amboceptors may be formed, one of which unites with the complementophilous, the other with the cytophilous, haptophore. That such are actually present may be demonstrated by carefully planned experiments. Add the anti-amboceptor solution to the solution of amboceptor, then add the specific cell antigen, wash the cells repeatedly with physiological salt solution by means of centrifugation, and add the complement. No cytolysis will take place, but, on the addition of fresh amboceptor, cytolysis will occur. It is evident that, in the first instance, the amboceptor has been prevented from uniting with the cell by the cytophilous antiamboceptor. The anti-amboceptor for the complementophilous haptophore may be demonstrated by adding amboceptor to the antigenic cell; to a portion add anti-amboceptor. To each portion then add complement, and it will be found that no cytolysis occurs when anti-amboceptor has been used, while it does occur in the other tube. The anti-amboceptor in this case has prevented the complement from attaching itself to the amboceptor, and consequently prevented cytolysis. Some doubt has been thrown upon the sufficiency of the above explanation, for it has been shown that the anti-amboceptor for goat anticholera serum will inhibit likewise the action of the goat typhoid serum.

Structure of the Complement.-The complement is believed to consist of two groups - a haptophore, which unites with the amboceptor, and an active or lytic group, the zymophore. Careful heating of complement is found to destroy the zymophore without injuring the haptophore. Such a changed complement is called a complementoid. It has been claimed that immunization of one 
species of animal with the complement of another results in the formation of anticomplement, but more recent investigations have thrown some doubt upon the sufficiency of the explanation offered.

Ehrlich's Conception of Formation of Amboceptor and Complement.-Ehrlich calls an amboceptor a freed cell receptor of the third order. Such a receptor he believes exists in the form of a double haptophore, and unites first with food or other materials, then, by means of the other haptophore, with complement which is present in the serum. The latter doubtless normally brings

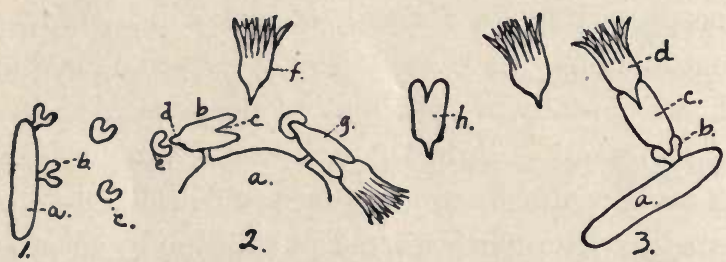

Fig. 76.-Formation and action of cytolysins: 1, Bacterial or other cell, $a$, with receptors, $b$, which are thrown off as antigens, $c$; 2 , protoplasmic molecule of the body $a$, with a receptor of the third order, $b$. This receptor, by means of its cytophilous haptophore, $d$, can unite with the antigen, $e$, and by means of its complementophilous haptophore, $c$, it can unite with the complement $f$. At $g$ is shown a receptor with both haptophores occupied. At $h$ is a freed cell receptor or amboceptor; 3 , a bacterial or other cell, $a$, to which an amboceptor has united by means of the receptor $b$, and with a complement united to $c$. This completes the lytic system, and the cell may be destroyed by the complement.

about changes of a digestive nature which enable the cell protoplasm to make use of the food. The antigens used in immunization unite with such receptors and divert them from their normal function. Possibly the cell is injured; it is, at any rate, stimulated to an overproduction of these receptors, and they are thrown free in the blood as amboceptors.

Group Cytolysins.- It may be shown that related cells contain some similar antigens, and that the cytolysins for one species of cell may dissolve in low dilutions the cells of another species. This phenomenon is similar to that of group agglutination, and seems to be based upon the same general facts.

Bacteriolysins.--Bacteriolysins are normally present for certain 
bacteria in the blood of some animals, as bacteriolysins for the anthrax organism in dog's blood. They may be developed for many organisms by systematic immunization, or they may appear during the course of an infection. Their presence may be demonstrated in two ways - either by direct microscopic examination or by plating methods. In the first method the organisms are mixed with the serum and examined microscopically. They can be found, by actual observation, gradually to disintegrate and disappear. The second method offers certain advantages. The serum is mixed with the bacteria, and from time to time portions of the mixture are plated out, and the rapidity of the destruction determined by the relative number of colonies that develop. Neisser and Wichsberg have developed a technic which enables them to differentiate dead and living cells by the fact that leukobases are formed from methylene-blue during life and not after death.

Bacteriolytic Sera Used in Practice.-By no means all bacteria will induce the production of bacteriolysins in any quantity in the body, as, for example, the pyogenic organisms and the pneumococcus. The members of the intestinal group and the spirilla are readily destroyed thus. Antisera have been prepared and used for several of the latter. In the manufacture of the antisera, either living or dead organisms may be used. Methods of titration, whereby the actual bacteriolytic content of the serum used may be known, have not thus far been developed. The antisera generally have other antibodies developed in addition to the bacteriolysins. Plague serum and that of swine erysipelas contain some bacteriolysins, and probably the same is true of the sera used in immunizing against hog-cholera and against rinderpest.

Bacteriolytic sera for passive immunization are prepared by the methodical introduction of the organism into the animal body. Either the first injections must be made with dead organisms or an animal which has recovered from an attack of the disease must be chosen. The animal is hyperimmunized by increasing doses of the virulent organism after the first establishment of immunity. This results in the accumulation of considerable quantities of immune substances (amboceptors) in the blood. This serum may then be used in passive immunization. Vaccina- 
tion, or the injection of dead or living bacteria into the body, with the resultant development of an active immunity, owes its efficiency, in some cases at least, to the production, by the body, of the bacteriolysins specific for the organism.

Bacteriolytic sera for passive immunization are not employed against many diseases. Some organisms, as has been stated, cause the production of little or no bacteriolysin. The bacteriolysin developed in the blood of one species is not always suitable for the passive immunization of another. There have been various reasons advanced for this fact: the injection of the foreign serum may cause the production of anti-amboceptors, or of anticomplements, or of some other antibody which would inhibit the lytic action of the injected serum. Complement soon disappears from an immune serum; therefore the amboceptors are dependent for their activation upon the normal complement of the blood. This complement may not in all cases be suitable for combination with the particular amboceptor used, and the lytic activity be thus inhibited. When the antiserum to be used for passive immunization comes from the same species of animal, as is the case in immunization against hog-cholera and rinderpest, these objections do not seem to obtain.

Hemolysins.-Hemolysins for the red blood-cells of one animal usually may be obtained by injection of these into another. They are divided into three types, the classification being made upon the basis of relationship. Heterolysins are developed by the injection of the red blood-cells of one species into another; isolysins by the red blood-cells of one animal into another animal of the same species, and autolysins by an individual for his own red blood-cells. The last two, particularly the autolysins, are not easily produced or demonstrated.

The study of hemolysis has proved of great value in two ways: First, hemolysis is a phenomenon that may be easily observed, and it has been used, therefore, more than any other, in the study of the nature and activity of cytolysins. Hemolysis is readily detected, because the hemoglobin escapes into the solution and it remains permanently red, while unhemolyzed red blood-corpuscles soon sink to the bottom, leaving the blood-serum clear and colorless. Second, they are made of indirect use in the diagnosis of 
certain diseases, and in the recognition of certain organic substances. This second use is called variously absorption or fixation of complement, or, after the name of its discoverers, the BordetGengou phenomenon.

Fixation of Complement and Its Utilization.-The method of complement fixation is one that enables us to determine the presence or absence of cytotoxic, cytolytic, or similar antibodies in a serum. Inasmuch as such substances are generally present in the serum of a diseased individual, the determination of their presence may constitute in such cases a diagnosis of the disease. A specific example, the demonstration of fixation of complement by use of antityphoid serum, will first be discussed. Five different solutions are always needed in carrying out a test of this kind.

1. Suspension of Bacillus typhosus (antigen).

2. Heated serum of rabbit immunized against 1 (amboceptor).

3. Normal sèrum, usually taken from guinea-pig (complement).

4. Red blood-cells. Those of sheep generally used (antigen).

5. Heated serum of rabbit immunized against 4 (amboceptor).

Suppose that 1 and 2 are mixed, and a small amount of 3 added. Evidently the complete bacteriolytic system is present and bacteriolysis should occur. This is difficult to demonstrate microscopically, however, and would not be demonstrated at all in that manner if an excess of the first antigen or suspension of bacilli is used. It is evident that the complement added will be used up or "bound" by the combination of bacillus and amboceptor. No. 4 and 5 are next added. They unite with each other, but, as all the complement has been used up, there can be no hemolysis. The fact that hemolysis does not occur is proof, therefore, that the complement has been removed. Suppose that, instead of the blood of a rabbit that has been intentionally immunized to the disease, the serum from a patient suspected of having the disease is used. If hemolysis does not occur, then amboceptors for B. typhosus are present in the patient's blood, and the diagnosis of the disease would be positive. If hemolysis does occur, evidently the patient's serum lacks amboceptor specific for typhoid, and the diagnosis would be negative. The test may be reversed also, and some organism suspected of being Bacillus typhosus may be substituted for No. 1, and the same technic carried through. A lack of hemo- 
lysis would indicate that the organism had bound the amboceptor and complement, and, therefore, was Bacillus typhosus in fact, while hemolysis would indicate the reverse. The accompanying. figure will make this clearer. In carrying out a test of this kind it is necessary to arrange a very complete series of checks. When properly managed, the method is very accurate and has yielded results of value in many cases.

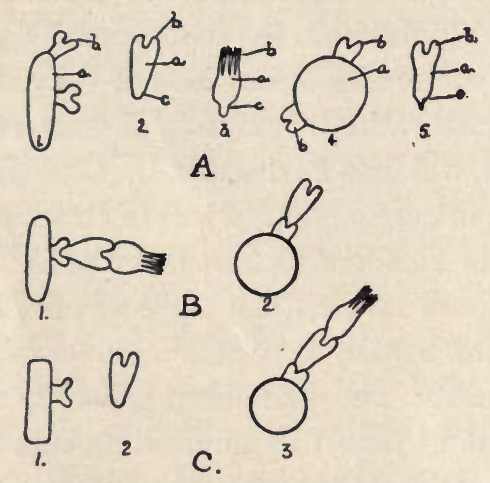

Fig. 77.-Fixation or absorption of complement: A, Diagrammatic representation of -1 , Bacterial cell, $a$ (B. typhosus in text), with antigen $b ; 2$, amboceptor for the antigen of (1) (the antityphoid serum); 3, normal complement of the guinea-pig's blood with the haptophore $c$ and the zymophore $b$. 4 , red blood-cell (sheep) with the antigenic receptors $b ; 5$, amboceptor from the blood of the rabbit immunized against 4. B, 1, Bacterial cell + amboceptor + complement makes a complete lytic series; bacteriolysis occurs, and the complement is removed from solution; 2 , the red blood-cell + its amboceptor; no hemolysis, as the complement has been used by the other series. C, 1 , Bacterial cell not B. typhosus, to which amboceptor (2) cannot unite, hence the complement is not removed from the serum, and when the red blood-cells and their specific amboceptor are added, a complete hemolytic system (3) is formed and hemolysis occurs.

This test has been most used in the diagnosis of syphilis, the antigen being secured from a macerated syphilitic fetus and the amboceptor from the blood of the suspect. This is known as the Wassermann syphilis test. A similar test may be used for diagnosis in other diseases. The same method may be used also in the differentiation of proteins. In this case the antigen used is the protein, and the first amboceptor is in the serum of an animal immunized against this protein. The method is even more reliable than the precipitation tests already discussed, but is more difficult 
to carry out, hence is less frequently used. It may be used for the identification of blood-stains.

Cytotoxins.-Antisera have been prepared for a number of different body-cells, as epithelial cells, spermatozoa, and leukocytes. Within limits they seem to be specific. It is believed that some pathological conditions in the body are produced by autocytotoxins, substances produced by the body poisonous for its own tissues. 


\section{CHAPTER XVII}

\section{OPSONINS AND PHAGOCYTOSIS}

IT was observed by Parum as early as 1874 that decay-producing bacteria quickly disappeared when introduced into the body, and could not be demonstrated in the blood or other tissues. To Metchnikoff, however, must be given the credit of elaborating the theory of phagocytosis. By the term phagocytes (Gr. phagein, to eat) is meant any body-cell which is capable of taking up and destroying other cells, usually those of foreign origin. These phagocytes are in some cases fixed body-cells, but, for the most part, are leukocytes or white blood-cells of different kinds. Upon the phagocytic activity of the body-cells Metchnikoff established his theory of immunity. It may be stated briefly as follows: If an animal is either naturally or artificially immune to a disease, it means that the invasion of the body by organisms is followed by a struggle between the organisms and the phagocytes. These phagocytes ingest the organisms and render them harmless. Metchnikoff subdivides the phagocytes in two ways-first, on the basis of their morphological and functional behavior, and, second, on the basis of their relationship to the surrounding tissue, i. e., some are mobile, others are fixed. The leukocytes in the blood are in part the free-moving phagocytes. The small lymphocytes are not known to have any phagocytic power, and it is probable they are not endowed with active motion. Most cells have not been shown to be phagocytic. The polymorphonuclear and the large mononuclear leukocytes are the phagocytes par excellence. Certain fixed cells of the lymph-nodes and the spleen are likewise active phagocytes.

Metchnikoff terms the polymorphonuclear leukocytes the microphages (Gr. micros, small; phagein, to eat), and the large mononuclear, the macrophages (Gr. macros, large; phagein, to eat), 
and believes that they perform somewhat different functions in the body.

Wright and Douglas, in 1902, published observations that threw much needed light on the theory of phagocytosis. They showed that, in most cases, at least, the bacteria would not be destroyed by the white blood-cells or phagocytes in the absence of blood-serum. They showed that the serum contained something that rendered the bacteria positively chemotactic or attractive for the phagocytes, and they accordingly named this something opsonin (Gr. opsonein, to prepare a meal).

Opsonins.-Opsonins may be shown to be present in certain sera by the following experiment: Blood of a suitable animal is drawn into citrate solution and centrifuged, thus throwing the
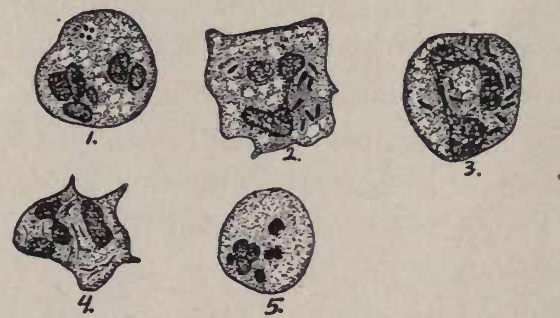

Fig. 78.-Phagocytosis by human leukocytes: 1, Micrococcus aureus; 2, Bacillus dysenteria; 3, B.typhosus; 4, B.tuberculosis; 5, Micrococcus meningitidis $(1,2$, and 3 adapted from Levaditi and Inman, 4 from Freeman, and 5 from Councilman).

cellular elements to the bottom. The top layer of corpuscles, or " cream," containing a large proportion of leukocytes, is pipetted off, and mixed with physiological salt solution and again centffuged. A second washing and centrifugation removes all traces of adherent serum. The corpuscles are then mixed with a suspension of the bacteria and incubated for fifteen minutes. At the end of that period mounts are prepared, stained with a suitable bloodstain, such as Jenner's or Wright's, and examined. The bacteria will not, in general, be engulfed by the phagocytes. A similar series carried through, but with the addition of a little immune serum, would exhibit marked phagocytosis, and considerable numbers of the microörganisms would be found within the leuko- 
cytes. Evidently the presence of the serum, or rather the opsonin which it contains, induces phagocytosis. Opsonins are believed so to change or alter the bacteria as to make them positively chemotactic for the phagocytes. This does not mean that the bacteria are destroyed, for there is no evidence that they are in any way injured. That it is an alteration of the organisms, and not a mere stimulation of the phagocytic cell, may be shown as follows: A suspension of washed corpuscles prepared as before is treated with immune serum, allowed to stand, and then washed. When mixed with the bacterial suspension, no phagocytosis occurs; evidently the opsonin is not bound to the phagocytes, nor does it stimulate them when they are brought in contact with the bacterial cells. The converse of this experiment may be tried, the bacteria added to the immune serum, and then centrifuged out and washed free from all the serum with salt solution. When these organisms are added to a suspension of the washed leukocytes, active phagocytosis occurs. The opsonin is bound to the bacterial cell, and makes it in a sense attractive to the leukocytes. The negative chemotaxis is converted by this union into a positive chemotaxis. The action of the opsonin has been likened to that of an amboceptor, for it links up the bacteria and the white bloodcells. The opsonins are, however, not identical with bacteriolytic amboceptors.

Opsonins for some organisms are quite constantly present in the blood. For example, human blood contains opsonins for the organisms producing bubonic plague, Malta fever, pneumonia, dysentery, Asiatic cholera, and for the pyogenic organisms. These are called normal opsonins. Immune opsonins are those produced as a result of infection or immunization. It is also probable that some species of bacteria may be taken up by phagocytes in total absence of opsonins. On the other hand, it is believed that certain bacteria, when they invade the body, may develop a resistance to phagocytosis. The appearance of the capsule about the anthrax bacillus in the blood has been thought to be a protective agency of this character. Whether the immune and the normal opsonins are identical is a moot question. Probably they may differ, it being contended that the normal opsonin is simply the normal complement of the serum, for it has 
been found to be thermolabile $\left(58^{\circ}\right.$ to $60^{\circ}$ destroys). The immune or specific opsonin is, on the other hand, relatively thermostabile.

Opsonic Index.- It is sometimes advisable to compare the opsonic content of the serum of a diseased animal with that of a healthy individual. The ratio between the two sera may be determined by the relative effect they have on the rapidity of phagocytic action. It is customary, though not in all cases necessary, to use the leukocytes of the species of animal under investigation. The technic of the operation is as follows:

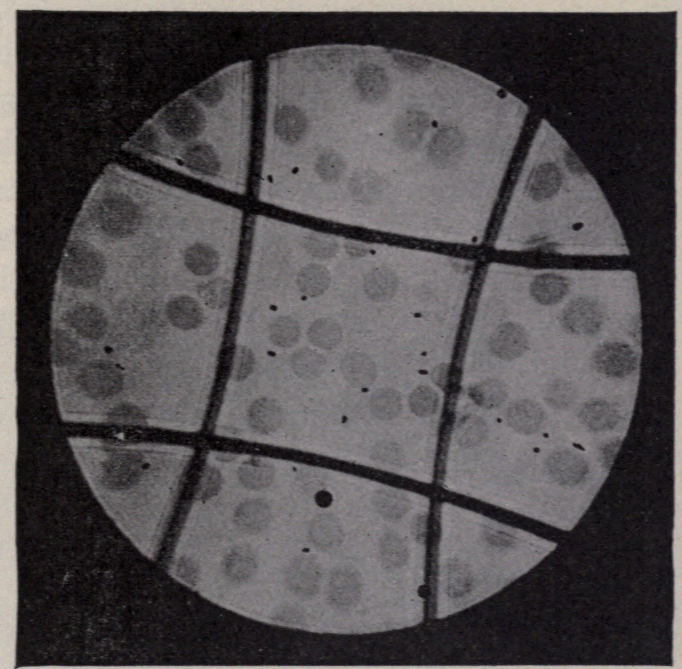

Fig. 79. - Standardization of bacterial emulsion. A photomicrograph showing the bacteria and the red blood-cells mixed (Miller).

Preparation of Leukocytes.-These may be secured by bleeding into citrate solution (1 per cent. in physiological salt solution) and centrifuging. Pipette off the serum and citratesolution, add physiological salt solution, mix, and again centrifuge; repeat the washing and centrifuging to remove the last traces of serum. Carefully pipette off the upper layer of corpuscles, rich in leukocytes, and keep in a small test-tube. Sometimes the defibrinated whole blood is used. In other cases, particularly with small experimental animals, an intraperitoneal injection of bouillon is made, and the leukocyte-rich exudate removed from the peritoneal cavity in the course of a few hours. 
Preparation of Bacterial Emulsion.-The organisms must be present in a perfectly homogeneous suspension. With most

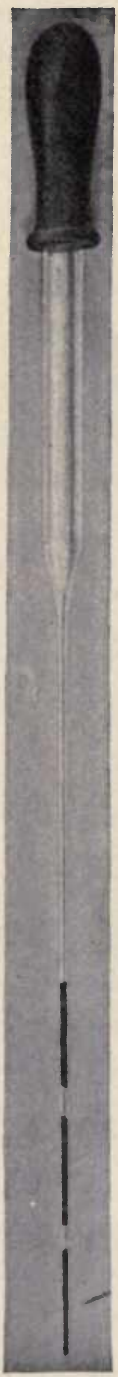

Fig. 80.-Opsonizing pipette containing the leukocytes, bacteria, and serum (Miller). organisms a twenty-four-hour slant agar culture may be used, the growth scraped off into sterile physiological salt solution, triturated, and diluted until it shows only a faint opalescence. Filtration is sometimes necessary. This technic must be varied somewhat for different organisms.

Preparation of Serum.-Both normal serum and serum from the animal to be tested are secured by bleeding, allowing the blood to clot, centrifuging, and taking off the serum with a pipette and transferring to a small tube. Before use, the serum is sometimes diluted-usually ten times.

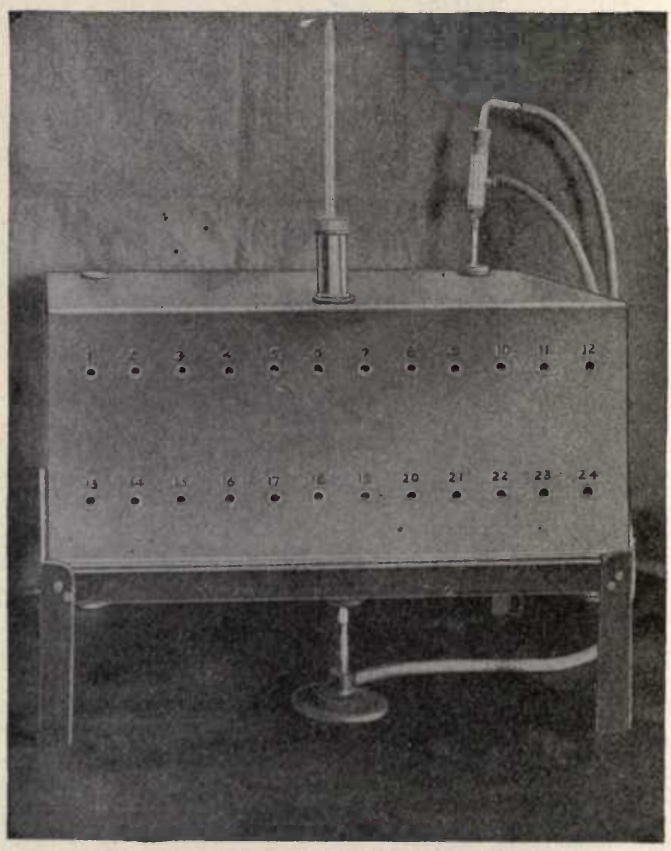

Fig. 81.-Opsonic incubator (Miller).

Technic of Test.-A capillary pipette with a fine bore is prepared from glass tubing, and a mark is made a short distance, usually 
about $2 \mathrm{~cm}$., from the end. The suspension of leukocytes is then drawn up to the mark, then an air-bubble is admitted, then the serum to be tested to the same mark, a second air-bubble, and finally an equal amount of the bacterial suspension. The contents of the tube are blown out upon a glass plate or into a watch-glass and thoroughly mixed. This mixture is again drawn some distance into the capillary pipette and the end sealed in the flame. It is then kept at $37^{\circ}$ for fifteen minutes, preferably in an opsonic incubator, where it may be rotated frequently to secure thorough mixture. The end is then broken from the pipette, and smears are made and stained with some good blood-stain, such as Wright's or Jenner's modification of the Romanowsky, which will stain bacteria. Special staining methods must sometimes be used, as in the examination of the tubercle bacillus.

Determination of the Opsonic Index.-The total number of bacteria ingested by 100 polymorphonuclear leukocytes is counted. This number is determined both with normal serum and the serum to be tested. The ratio between the number of organisms ingested by the leukocytes, when treated with the specific serum and when treated with normal serum, is called the opsonic index. Let $\frac{a}{b}$ equal opsonic index where $a$ is average number of bacteria ingested per leukocyte when treated with a specific serum; $b$ is average number of bacteria ingested per leukocyte with normal serum. In general, the opsonic index is found to be low (less than unity) in chronic bacterial infections.

McCampbell's Modification of Opsonic Test.-McCampbell has considerably shortened the technic in veterinary practice as follows: The bacterial suspension containing 0.8 per cent. sodium citrate is drawn to the 0.5 mark on the leukocyte pipette of a hemocytometer, the specific blood to be tested is drawn to the same mark, then all drawn into the bulb, mixed, replaced in the capillary tube, and the whole wrapped with a rubber band and incubated. The same procedure is carried through with normal blood. The disadvantages of this method are the presence of sodium citrate, which interferes to a slight degree with action of opsonins, and the use of two lots of leukocytes from two animals, one diseased and the other normal. Smears and examinations 
are made as in the preceding. It is possible there may sometimes be intrinsic differences in these leukocytes, which render direct comparison between their activity somewhat misleading. These difficulties are more than outweighed by the increased ease of manipulation, and good results are commonly secured.

The variation in the opsonic content of a patient's blood gives valuable information relative to the development of resistance. As stated above, in many chronic infections the opsonic index is below unity. In the treatment of tuberculosis in the human, by means of minute injections of tuberculin, the determination of the opsonic index has given much information of practical nature. The injection of bacterial vaccines or bacterins which have been carefully studied is followed at first by an initial lowering of the index. This is called the negative phase. Later, the index should rise above unity, when the positive phase is said to be established. If the index can be kept above unity, the prognosis is generally regarded as favorable.

Methods of Opsonic Immunization.-Immunization due to increased opsonin is generally brought about by the introduction of bacteria or their products into the body. Such an immunity is, therefore, active. There is good reason to believe that injection of an opsonic serum in some cases confers some passive immunity. The most commonly practised method of increasing the opsonin content of the blood is by vaccination. This may be defined as the injection or inoculation with organisms or their products in such a way that the disease produced will run a benign course. Such a procedure in many cases induces the production of bacteriolysins, in others opsonins, and in still others both. Vaccines may consist of either living or dead organisms. If the former, they may be either virulent or attenuated. Vaccination with virulent organisms is not frequently practised. Some organisms do not produce typical and serious diseases unless they enter the body by a certain channel. The injection of the Asiatic cholera organism subcutaneously is not followed by any serious results, but, when the alimentary tract is the infection atrium, the characteristic symptoms of the disease are produced. This fact has been used as the basis for practical vaccination against this disease. Usually vaccines consist of attenuated organisms. Atten- 
uation or weakening or decrease of virulence is accomplished in several ways: in some cases by growing at high temperatures, as for anthrax, heating to temperatures just below the thermal death-point, as in blackleg, by animal passage, as in small-pox, or by growth on artificial media, as with members of the hemorrhagic septicemia group.

Vaccines consisting of dead organisms are called bacterins. These are prepared and sold commercially under various trade names. They usually consist of pyogenic organisms which have been killed by heat. The injection of these bacterins has been shown to increase the opsonic index for specific organisms when properly administered. It has been found, however, that there are many strains of some of the pyogenic bacterial species, for example, of Streptococcus pyogenes, and that vaccination against one strain does not always protect against another. Vaccines are, therefore, prepared containing organisms isolated from as many sources as possible and containing many races or strains. Such a vaccine is called polyvalent, a vaccine containing but one strain, univalent.

Autogenic Vaccines.-Inasmuch as it cannot be readily determined to what strain a particular organism causing a chronic bacterial infection, such as suppuration in a fistula, belongs, it is sometimes desirable to prepare a vaccine of this particular organism for this single case. A vaccine prepared in this manner, to be used in the animal from which the organism was isolated, is said to be autogenic. The use of autogenic vaccines, carefully prepared and standardized, has proved successful in many cases in the treatment of stubborn and chronic suppurative conditions. The technic of preparation and use follows.

Isolation of Organism.--In many instances a slant agar culture, made directly by securing material on a sterile platinum loop from the deeper parts of the wound or abscess, will prove to contain only the causal organism. In most cases, however, it will be found advisable to plate directly in agar and incubate at blood-heat. An examination of the colonies will reveal the causal organism (or organisms in a mixed infection).

Preparation of Vaccine (McCampbell). - Into each of two flat flasks or bottles, 100 c.c. of nutrient agar is placed, sterilized, and 
slanted. Streaks of the organism are made the full length of the slant and incubated twenty-four hours at blood-heat. The water of condensation is removed without disturbing the growth, and 100 c.c. of sterile physiological salt solution added. The growth is carefully scraped from the surface with a long sterile glass rod; the suspension is placed in a sterile flask and shaken thoroughly.

Standardization of the Vaccine.-Before injections are made, the number of bacteria present per given volume of the suspension must be known in order that accurate dosage may be determined. The standardization may be effected by direct count or by use of the nephelometer. In the first method, equal parts of the bacterial suspension and of defibrinated human blood are thoroughly mixed, a smear prepared, and stained with a blood-stain or carbolthionin. The number of red blood-cells on several fields and the number of bacteria on these fields are counted (see Fig. 79). The number of red blood-cells may be taken as 5,000,000 per cubic millimeter. The number of bacteria per cubic millimeter will be found by the following proportion:

$5,000,000: x::$ number red blood-cells per field : number bacteria per field.

Suppose 20 red blood-cells per field, and 50 bacteria, the ratio becomes-

$5,000,000: x:: 20: 50$ or $x$ (number of bacteria per cubic centimeter) $=$ $\cdot 12,500,000$.

To convert the number of bacteria per cubic centimeter, multiply by 1000 , which in this case would give $12,500,000,000$. It is customary to dilute the bacterial suspension so that each cubic centimeter will contain a number of bacteria that is readily reckoned, usually 50,000,000 per cubic centimeter.

The nephelometer is an instrument described by McFarland, in which tubes containing varying amounts of barium sulphate in suspension in water are observed side by side with tubes of equal. size containing the bacteria. After the tubes containing barium sulphate have been compared as to opacity with tubes containing known numbers of bacteria per cubic centimeter, they may be used in determining the number present in other bacterial suspensions. 
Passive Opsonic Immunization.- - It is probable that some antibacterial sera, as the antimeningococcic serum, owe in part their immunizing and their curative powers to the presence of opsonins. The part that these opsonins may play in passive immunization is not thoroughly understood. 


\section{CHAPTER XVIII}

\section{ANAPHYLAXIS AND HYPERSUSCEPTIBILITY}

The body normally takes its food through the intestinal tract, or by enteral introduction. Any foreign proteins introduced in this manner are generally changed by digestion, so that they may be used by the body-cells or assimilated. When introduced by parenteral injection (outside the alimentary canal, as subcutaneously, intravenously, etc.) antibodies of different kinds are produced. Thus far we have considered three antibodies which antagonize bacteria or other antigens which are introduced, but there exists still another type of body reaction, sensitization toward, rather than immunization against, an antigen. This phenomenon is exhibited only under certain eonditions, and the body is then said to show anaphylaxis or hypersensitiveness to the antigen. The significance ean best be understood by a study of specific examples. A number of these have been noted independently and are deserving of mention.

Phenomenon of Arthus.-Arthus injected rabbits subcutaneously with horse serum at six-day intervals. The first three injections were readily absorbed by the tissues, the fourth was followed by some edema at the site of injection, and, after the sixth or seventh injection, the skin at the site became gangrenous, and a deep abscess scar was finally formed. If the sensitized animal be injected intravenously with the serum, it appears restless, lies on its belly, and respiration frequently inereases; it defecates frequently, finally falls upon its side, and commonly dies, all within the space of two or three minutes.

Serum Sickness in Man.-Many observers have noted that the injection of antitoxic sera into man sometimes is followed by a fever, the appearance of a rash or urticaria, pains in the joints, etc. In some individuals the reaction is shown after the first injection, in most cases only after a second injection, given some time after 
the first. Evidently there may be an inborn or a developed sensitiveness in man to serum injection.

Theobald Smith Phenomenon.-Theobald Smith made the observation that when guinea-pigs are injected with horse serum, and a second injection is given after the space of ten days or more, the pig will show signs of hypersensitiveness, and if a sufficient quantity, 5 or 6 c.c., is injected intraperitoneally, death will result in a few minutes. The first injection serves to sensitize against the second. This phenomenon in the guinea-pig is so striking that it has been used by many investigators in a study of the reaction. The general phenomenon was given the name of anaphylaxis. This will be discussed, and its utilization in diagnosis and in explanation of certain hitherto obscure body reactions reviewed.

Antibodies in Anaphylaxis.-Many of the factors determining anaphylaxis are at present imperfectly understood. Enough is known, however, to enable us. to account for many hitherto obscure body reactions. Various species of animals show different types of anaphylactic reaction, but the differences are, according to Anderson and Frost, mainly quantitative - the nature is the same, although the manifestations are different.

Sensibilisinogen.-The antigen used in developing anaphylaxis is known as the sensibilisinogen. In experimental work upon guinea-pigs practically all proteins have been found to sensitize, among them, blood-serum of many animals, egg-white, milk, extracts from body organs and cells, plant proteins, bacterial proteins, yeast proteins, and even some of the peptones formed by the peptic digestion of proteins. Experiments have shown that the sensibilisinogen is thermostabile; in many cases it will still sensitize after heating to a temperature above boiling.

Allergin.-The injection of the specific protein or sensibilisinogen has been shown to cause the production in the blood of the guinea-pig of an antibody which has been variously termed allergin, sensibilisin, immune body, and anaphylactin. Either of the first two names is to be preferred to the others. That some kind of an antibody is formed may be shown by injecting the serum of a sensitized animal into a normal animal, which will then show the anaphylactic reaction when injected with the proper sensibilisinogen. Evidently a sensitizing substance (the allergin) 
has been transferred in the serum. An animal sensitized by the injection of a foreign protein or sensibilisinogen is said to show active anaphylaxis, one which is sensitized by the serum or allergin of another sensitized animal is said to show passive anaphylaxis. This allergin is specific, that is, an animal sensitized to egg-white will not show anaphylactic reaction when injected with horse serum. This fact might be utilized in testing for proteins of different kinds, were it not for the much simpler technic of the precipitation reaction. It is made use of, as will be noted later, in certain disease diagnoses. How this allergin is formed is uncertain. Probably the primary injection of the protein stimulates the cells of the body to increase their normal power of assimilation. This is accomplished by certain receptors, which break up the protein (proteolysis), or so change it that it can be rapidly utilized by the cell. These receptors increase in numbers, and are thrown off into the serum, where they are as capable of transforming the protein when injected as when still attached to the protoplasm. The allergin retains its activity after heating to temperatures of $56^{\circ}$ to $58^{\circ}$; it is, therefore, regarded by Anderson and Frost as thermostabile. These authors believe that " anaphylactic shock is due to disturbance of metabolic activities of vital cells rather than to the specific (permanent) intoxication of the cells." In other words, there is no proof that the substances produced from the homologous protein (sensibilisinogen) are poisonous; the shock of anaphylaxis comes from the disturbance of metabolism of the body-cells due to the sudden flood of readily assimilable materials. Antianaphylaxis.-An animal which has just recovered from an anaphylactic shock does not show the same symptoms when a second injection is made soon after. Again, if a small injection be made into a sensitized pig, a large dose a few hours later will fail to show the reaction. The possible explanation for this phenomenon has been offered, to the effect that the allergin is in each case all used up by the first injections, and the second injection, therefore; is transformed too slowly to allow any reaction to become apparent. Such an animal is said to be in a state of antianaphylaxis.

Immunity.-Continued injections of the antigen (sensibilisinogen) result usually in the development of an immunity in the 
experimental animal. Allergin may be demonstrated in the bloodserum of such immunized animals. Immunity must, therefore, be accounted for on a basis other than antianaphylaxis. It may be that the cells no longer unite with the products of the action of the allergin upon the antigen, or that another antibody has been developed which inhibits the action of the allergin. The immune animal is only relatively susceptible, and may be shown still to be somewhat susceptible by appropriate experimentation. Anderson and Frost state " anaphylaxis is a step toward immunity, which is conceived as an increased capacity for safely and rapidly eliminating the specific antigen proteid."

Relationship of Anaphylaxis to Certain Body Reactions.The anaphylactic explanation of serum sickness in man has already been discussed. Several cases are on record where injection of diphtheria antitoxin has resulted in death within a few minutes. Rosenau and Anderson have recorded cases in which the prophylactic injection of antitoxic serum into normal individuals resulted in explosive manifestations of anaphylaxis, such as a prickling sensation in chest and neck, labored breathing, paralysis, convulsions, and death within five minutes after injection. It seems evident that the individual was naturally hypersensitive. Fortunately, such cases are extremely rare. The prophylactic and curative value of diphtheria antitoxin far outweigh its dangers.

Rosenau and Anderson have also recorded some evidence that certain of the toxemias of pregnancy, particularly puerperal eclampsia, are to be accounted for by a sensitization of the body by the cells of the placenta. It was found that guinea-pigs might be sensitized with the placenta of the same species by a single injection, and a second injection later gave a typical anaphylactic reaction.

Bacterial Anaphylaxis.-It has been shown by several investigators that proteins from bacteria may be used in sensitizing animals against a second injection; in other words, they resemble proteins from other sources in this respect. Extracts from Bacillus coli, B. anthracis, B. tuberculosis, B. typhosus, and others have been shown to sensitize. This fact has been deemed of considerable practical importance in disease diagnosis. There is reason to suppose that infection with certain bacteria will sensitize the body 
to the injection of the bacterial proteins or extracts or to the dead bodies of the organism. It has been found, for example, if the dead organisms, or extracts from them, be rubbed into the skin of an infected individual, an inflammation, marked by some edema, redness, and frequently the formation of papules, will occur. This is true in tuberculosis and some other diseases. That this is one of the manifestations of anaphylaxis seems probable. The injection of tuberculin, consisting of dead tubercle bacilli and their products of growth, into an animal having tuberculosis will cause a characteristic rise in temperature, and is, therefore, of great diagnostic value. This reaction resembles the anaphylactic reaction in many ways. For example, a second injection following soon after the first will give no reaction; probably the body is in a state of antianaphylaxis. Furthermore, advanced cases of the disease do not respond-perhaps they are either constantly antianaphylactic or show anaphylactic immunity due to the constant presence of large numbers of organisms in the body. On the other hand, there are some unexplained differences between this reaction and that typical of anaphylaxis produced by other proteins. Many points remain still to be explained. That it is, however, of a similar nature seems to be altogether probable. A similar reaction may be secured with the emulsion of dead Bacillus mallei (mallein) in glanders. 


\section{CHAPTER XIX}

\section{AGGRESSINS}

THE term virulence, as applied to microörganisms, is not readily defined. The reaction of an organism in the body cannot be predicted by its behavior in culture-media. The most virulent, diphtheria bacillus, for example, is not necessarily the one that produces the largest amounts of toxin in culture-media. Concerning this mechanism of virulence there have been much discussion and speculation.

Bail has developed what he has termed an aggressin hypothesis to account for these variations in virulence. He has defined an aggressin as a substance which is secreted by pathogenic organisms, when growing in the animal body, which will neutralize the efforts of the tissues to destroy the organism. The work on this subject has been done principally by Bail and his students, although many substantiating facts have been developed by other investigators. The theory is of practical importance, inasmuch as it is claimed that the injection of bacteria-free aggressins into an animal results in the ultimate development of antiaggressin and of an active immunity.

Bail divides bacteria into three groups-true parasites, half parasites, and saprophytes. The true parasites include such forms as the anthrax bacillus, in which the injection of a very small number results fatally through a rapid multiplication of the organisms. The half parasites are those having a lower degree of virulence - such that relatively large injections must be made to produce infection. The third group includes those totally devoid of pathogenic properties. The difference between these forms is a difference in the ability to produce aggressin.

Aggressin production is demonstrated by Bail as follows: A guinea-pig is injected intraperitoneally with many times a fatal dose of culture of Bacillus typhosus or Spirillum cholerce. The 
peritoneal exudate is removed after the death of the animal and centrifuged to remove the cellular elements as well as most of the bacteria. The organisms remaining in the supernatant liquid are destroyed by a chemical disinfectant. If a small quantity of this is injected into a guinea-pig, together with a quantity of the specific organisms that would usually be non-lethal, the animal will die ${ }^{\circ}$ with an acute infection. The injected exudate apparently makes the organisms more virulent. The aggressins are contained in this exudate, and convert a mild infection into one that is fatal. The repeated injection of sterile aggressin causes the development in the animal body of an active immunity. According to Bail, antiaggressins can be demonstrated in the blood-serum of such animals. One of the strongest links of corroborative evidence is the fact that the bacteriolytic power of a serum in vitro is not an index of the ability of the animal from which it was taken to resist infection. The modus operandi of the aggressin is to be sought in the inhibition of phagocytosis. Bail found that when the typhoid bacillus is injected intraperitoneally, there is a marked increase in the number of phagocytes in the exudate within a few hours, but when they are injected with aggressin, there is no such increasethe phagocytes are evidently not attracted.

This theory has not been accepted in its entirety by many bacteriologists. The facts given by Bail are largely accepted, but the theory is not well established. Some authors claim to have shown that the so-called aggressin is simply endotoxin released in the body by the lysis of the bacterial cells. It is also claimed that there is no demonstrable difference between the endotoxins produced in culture-media and the aggressins formed in the body. Peritoneal exudate containing aggressin, according to Bail, has been filtered through porcelain, and found to be toxic for guinea-pigs after filtration. Bail has attempted to develop practicable methods of immunization in several diseases by an application of the theory. None of his methods have come into general use. 


\section{SECTION IV}

\section{PATHOGENIC MICROÖRGANISMS, EXCLUSIVE OF THE PROTOZOA}

\section{CHAPTER XX}

\section{MICROÖRGANISMS AS A CAUSE OF DISEASE}

Infectious Diseases.-An infectious disease is one caused by a microörganism. In general, the presence of microörganisms in the body does not constitute infection unless proliferation and multiplication occurs and there are pathological changes in tissues. An individual harboring such an organism is called the host, and is said to be infected. The latter expression is commonly used also to describe any object, such as a surgical instrument, which may introduce pathogenic organisms into the body; a better term for such, however, is infective. An infective object, such as the clothing of a diphtheritic patient or the manger of a glandered horse, is sometimes called a fomite. An organism which will produce disease is sometimes spoken of as a virus; it is customary to speak of the cause of a disease where the infecting agent is not known by this name. By no means all diseases are infectious. Among the non-infectious diseases may be named azoturia, diabetes, Bright's disease, etc.

Contagious Diseases.-Any disease in which the causal organism may be readily transferred from one individual to another by direct or indirect contact is said to be contagious. The terms infectious and contagious have been used very loosely, particularly in veterinary writings, sometimes even interchangeably. The best usage, however, is strictly to limit the terms as here defined. Infectious has to do with the cause of a disease, and contagious with its ease and method of transmission. All infectious diseases, 
therefore, which are readily transmitted by contact, direct or indirect, are said to be contagious. All contagious diseases are necessarily infectious, but the reverse is not true; for example, malaria in man and Texas fever in cattle cannot be regarded as contagious, as they are transmitted only through the bite of certain insects.

Bacteria Normally Present in the Body or on its Surface.Many microörganisms are found in the healthy body. In some cases they are harmless commensals; in others, they merely await a favorable opportunity to invade the tissues. The care used in surgical operations is made necessary by the presence of these organisms.

Bacteria of the Skin. - Some bacteria are found quite constantly upon the skin and hair, others may be isolated only occasionally. Staphylococci and streptococci are generally present, and many of them are capable of causing pus infection when introduced under the skin. Certain organisms, such as the Bacillus smegmatis, are found commonly in the axillæ, where the skin is moist and frequently greasy.

Bacteria of the Mouth.-Microörganisms to the number of sixtytwo species were found by Miller in the human mouth. Of these he found ten quite constantly present. The flora of the mouth in domestic animals has not been accurately determined, but large numbers of bacteria are always present. Some of these are pyogenic cocci.

Bacteria of the Stomach. - The acidity of the gastric juice in man destroys many of the microörganisms which enter the stomach. In cases where the normal acidity is absent many bacteria will multiply. The flora of the stomach in animals is not well understood. Bloat is due to the development of gas-producing bacteria in the ingested carbohydrate-rich food. The organisms responsible are probably those normal to the intestinal tract.

Bacteria of the Small Intestine and Colon.-The flora of the intestines in man has been studied at length by bacteriologists, but that of animals is not so well understood. The organisms most common are those belonging to the so-called intestinal group, such as Bacillus coli and Bacillus lactis aërogenes. Streptococci are generally present in feces. Certain putrefactive 
anaërobes, such as Bacillus putrificus, are sometimes found in large numbers. Amebæ and certain other protozoan types are frequently found. The intestinal juices, particularly the bile, inhibit the growth of some species, but the normal inhabitants of the digestive tract will grow and multiply in pure bile. The number of bacteria increases from the stomach on, the greatest numbers being found in the colon. Here the living bacterial cells are frequently present by hundreds of millions to the gram. It has been estimated that human feces sometimes contain as much as 38 per cent. of their bulk in bacteria. The bulk in herbivorous animals is certainly much lower. Some of these bacteria are harmless commensals, but a few are believed sometimes to assume pathogenic rôles. It has been claimed that in the case of herbivora certain of these bacterial cells secrete cellulase and assist materially in the digestion of cellulose. This has not been satisfactorily demonstrated, but is not improbable. Whether or not bacteria in the intestines are essential to the maintenance of health is a mooted question. Experimental evidence is conflicting. Practically, infection of the intestinal tract occurs very early in life. Metchnikoff and his school have claimed that in man some of the symptoms of old age, such as arteriosclerosis, are due to the absorption of poisonous products of bacterial putrefaction, and has sought to establish an intestinal flora consisting of non-putrefactive types.

Bacteria of the Organs of Respiration.-Air entering the nose is rapidly freed from dust and bacteria by contact with the moist surfaces of the lining membranes, consequently the nose may have many types of organisms present. It is a most efficient filtering device, so that very few bacteria gain entrance to the trachea and the lungs, and these are generally quickly eliminated.

Bacteria of the Genito-urinary Organs.-The secretions of the vagina seem effectually to prevent bacterial growth. The uterus is normally bacteria free, as is also the bladder. The urethra contains few organisms.

Avenues of Infection.-The avenue through which an organism gains entrance to the body is called its portal of entry or its infection atrium. An infection arising from contact with infective external objects is termed exogenous; one caused by organisms 
constantly or normally present in the body or on it is termed endogenous. Traumatic infection frequently occurs through a break in the continuity of the skin or mucous surfaces. Wounds caused by weapons, instruments, and similar objects, the bites of animals and sucking insects such as the mosquito, flea, tick, or bed-bug, may introduce a pathogenic organism. Ordinarily, the skin is an efficient barrier against infection. Microörganisms may occasionally enter through the glands or hair follicles. Some bacteria apparently may injure the unbroken mucous surface, as, for example, the diphtheria bacillus. Certain disease organisms enter through the digestive tract. Bacteria have been shown to pass unharmed through the intestinal walls and to enter the lymphvessels and the thoracic duct. To what extent this is the common source of infection in certain diseases, such as tuberculosis, is at present a matter of dispute.

The lungs constitute the infection atrium in pneumonia, probably in many cases of tuberculosis and aspergillosis, and possibly in certain diseases whose cause has not been determined, such as small-pox.

The genital organs are the common infection atria in the so-called venereal diseases, such as syphilis, chancroid, and gonorrhea in man, dourine in the horse, and contagious abortion in cattle. Disease organisms rarely pass from the blood of the mother through the placenta to the blood of the fetus. There are comparatively few diseases, therefore, that are inheritable. Syphilis and small-pox are exceptions.

Types of Disease Produced by Microörganisms.-The characteristics of the disease produced by various microörganisms, and the pathological changes they bring about, vary as much as do the morphological and cultural characters of the organisms themselves. It is possible, however, to group related types together and find a general basis for classification.

Specific and Non-specific Infections.-A specific infectious disease is one caused in every case by a single species of organism, and characterized by definite clinical characters or symptomcomplex and pathological lesions. A non-specific infection is one which may be caused by one of several organisms, and does not possess the definite characters which enable the determination of 
the specific cause by clinical examination or from the general character of the lesions produced. Such infections as those produced by the common pyogenic bacteria are non-specific.

Primary, Secondary, and Mixed Infections.-Any disease caused by a single organism may be termed a primary infection. One organism may break down the body defenses and make infection with another and second species easy. The occurrence of pneumonia as a sequel to measles in man, for example, would be termed a secondary infection. Two or more organisms associated in bringing about changes are said to cause a mixed infection, as is frequently the case in wound suppuration.

Classification of Disease Types.-Certain disease organisms do not frequently enter the general circulation, but proliferate in a more or less circumscribed area. In some cases such an organism produces toxins, which are absorbed into the blood-stream and cause injury to remote tissues, as in diphtheria and tetanus. Such a disease is called a toxemia. When, on the other hand, no appreciable amount of toxin is produced, it is known as a phlogistic disease or infection, such as wound suppuration and gonorrhea. A general invasion of the blood-stream is called a bacteremia. The term septicemia has come to be used synonymously with bacteremia, although more correctly applied to those types produced by pyogenic organisms. Sapremia is produced by the absorption of poisonous putrefactive products or the destruction of necrotic tissues by saprophytic bacteria. Pyemia is a metastatic pyogenic infection. Diseases characterized by skin eruptions of certain types are called exanthemata (sing. exanthema). For the most part, the causes of these, such as small-pox, chicken-pox, sheep-pox, scarlet fever, etc., have not been certainly determined.

How Bacteria Produce Disease.-A few bacteria produce the specific toxins which have already been discussed. Intracellular poisons, called endotoxins, are produced by other forms, and are freed only by the dissolution of the cell. Possibly, disease may sometimes be produced by mechanical means. The mechanism in other cases is imperfectly understood.

Groups of Pathogenic Microörganisms, Exclusive of Protozoa. - The disease-producing organisms can best be studied after a classification of the related forms into groups. The characters 
belonging in common to all the organisms of a group are more easily remembered than when learned separately for each species. A classification may be based upon the character of the disease produced; that is, be pathologic. Such a classification is open to the objection that very different types of infection may be produced under different conditions by the same or closely related organisms. Certain pus cocci, for example, may produce erysipelas, wound suppuration, septicemia, pyemia, or local infection, and inflammation of almost any organ of the body. On the other hand, infections having similar clinical characters may be produced by very different organisms. A bacteriologic classification is based upon resemblances in morphologic, physiologic, and cultural characters.

The following classification, in the main bacteriologic, will be used in the differentiation of the various groups of known microorganisms, exclusive of the protozoa, that are of pathogenic veterinary interest.

\section{Principal Groups of Pathogenic Microörganisms}

I. True bacteria.

A. Cells spherical, cocci.

1. Non-specific pyogenic organisms. Non-specific pyogenic coccus group (1).

2. Causing specific infections. Specific coccus group (2).

B. Cells rod-shaped. Bacilli.

1. Non-specific pyogenic forms. Non-specific pyogenic bacillus group (3).

2. Usually associated with specific infections.

a. Aërobic or facultative anaërobic.

(1) Non-spore producing.

(a) Not acid fast.

+ Gram positive.

1. Diphtheria group (4).

2. Bacillus pseudotuberculosis group (5).

3. Swine erysipelas group (6).

++ Gram negative.

1. Glanders group (7).

2. Intestinal group (8).

3. Hemorrhagic septicemia group (9).

4. Fowl diphtheria group (10).

(b) Acid fast. Acid fast group (11).

(2). Spore producing. Anthrax group (12). 
b. Anaërobic or microaërophilic.

(1) Non-spore producing. Short bacillus type. Abortion bacillus group (13).

Long slender beaded rods. Necrosis bacillus group (14).

(2) Spore producing. Anaërobic spore-producing group (15).

C. Cells spiral. Spirilla.

1. Spirillum or Asiatic cholera group (16).

2. Spirochæte group (17). ${ }^{1}$

D. Cells elongate, forming threads, branched. Actinomyces group (18).

II. Yeasts or yeast-like forms. Blastomyces group (19).

III. Molds or mold-like forms. Hyphomycete group (20).

1 The spirochætes, on account of their protozoan resemblances, are grouped with the protozoa and not the bacteria. 


\section{CHAPTER XXI}

\section{NON-SPECIFIC PYOGENIC COCCI}

THE non-specific pyogenic cocci are characteristic of wound infections, suppuration, non-specific inflammations, and their sequelæ. A considerable number of microörganisms have been described belonging to this group. They are found quite commonly upon the surface of the skin. In pathogenicity, they vary from non-virulent strains to those which will kill experimental animals promptly when introduced in minute doses. Even the same organism may be made to vary its virulence by proper cultural methods.

An organism which is capable of causing suppuration or pus production is said to be pyogenic. A long list of organisms are known which can bring about this tissue reaction, but the coccal forms to be studied are by far the most common in suppurative processes in man and animals. Whenever these organisms invade the tissues, or are introduced through a wound, they begin to multiply and to destroy, and seemingly, to some extent, to disintegrate the tissues with which they are in contact. The body reacts, in general, by an inflammation of the surrounding tissues, the blood-vessels become dilated, there is more or less extravasation of blood-serum. Most important of all, the phagocytic white blood-cells, particularly the polymorphonuclear leukocytes, pass out of the capillaries in great numbers, so that the tissues become packed full and the lesion is surrounded by a phagocytic wall, which usually effectually prevents the bacteria from spreading. The leukocytes also invade the diseased tissue and eventually destroy the bacteria. This can, of course, be accomplished only in the presence of opsonins. Nor is it brought about without a struggle, for many of the leukocytes themselves are destroyed by the bacteria, possibly through the leukocytotoxic substances 
produced by them. The mixture of blood-serum, white bloodcells, bacteria, and disintegrated tissue is called pus.

Until recent times it was supposed that no wound could heal normally and naturally without pus being produced; it was regarded as a more or less essential step in the healing process. When it was discovered that pus production was the result of infection, and that healing by first intention (without pus formation) was desirable, every effort was made to disinfect the wounds made in surgical operations. This antiseptic surgery was unquestionably an advance over that previously practised, but the use of the strong disinfecting solutions irritated the tissues. At present the surgeon uses every precaution to prevent the entrance of extraneous bacteria into the wound, and dependence is placed upon the natural resistance of the body and its immunizing agencies to prevent the development of those organisms which cannot be removed from the skin. This has been termed aseptic surgery.

While these organisms are usually associated with local inflammation and suppuration, they may gain entrance to the bloodstream and produce septicemia, pyemia, and metastatic infections in many organs and tissues.

Organisms Belonging to this Group.-The organisms belonging to this group may be subdivided into the Micrococci (Staphylococci) and Streptococci. The following species will be discussed: Micrococcus aureus, M. albus, M. citreus, M. bovis, M. mastitidis, M. ovis, M. epidermidis albus, M. cereus albus, M. cereus flavus, Streptococcus pyogenes, and the closely related Streptococcus lacticus. The student must expect to find in bacteriologic and pathologic literature the greatest diversity of treatment of these forms. It is important that the various synonyms of the names of the more important organisms should be learned, that they may be recognized hereafter. For example, the term Staphylococcus will be found in literature quite as commonly as the form Micrococcus, which is here used. It will be well before beginning the study of the specific bacteria to read again the chapter on Classification of Microörganisms.

Common Characters.-The organisms belonging to this group resemble each other in being cocci, without spores, non-motile, 
and gram-positive. They are all aërobic and facultative anaërobic, and all grow, though in some cases poorly, upon most of the common laboratory media.

\section{Micrococcus aureus}

Synonyms.-Micrococcus pyogenes aureus; Staphylococcus pyogenes aureus; Staphylococcus aureus.

Micrococci were definitely described as present in pus by Ogston (1881). Three years later Rosenbach (1884) cultivated them upon artificial media and differentiated several species, among them the one under consideration. Other investigators have frequently.

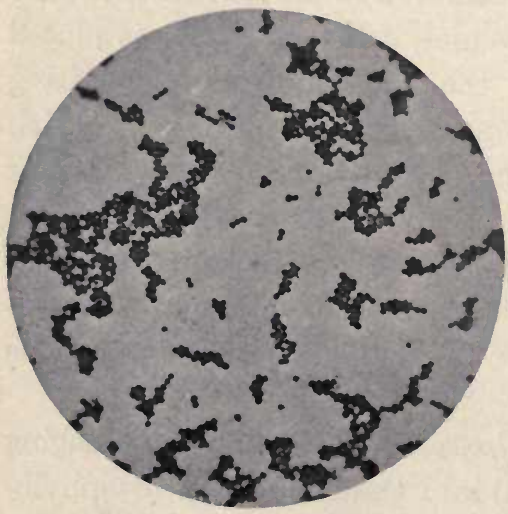

Fig. 82.-Stained mount of the Micrococcus aureus from agar (Günther).

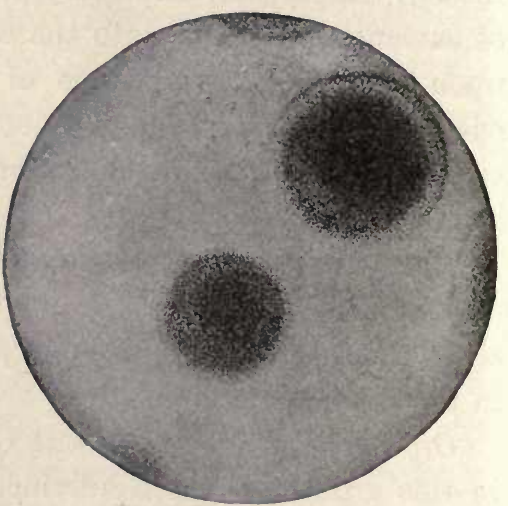

Fig. 83.-Colony of Micrococcus aureus on agar (Heim).

isolated this organism from pus in man and practically all domestic animals.

Distribution in Nature.-Micrococcus aureus occurs quite constantly upon the skin and hair of man and animals, in the nose and mouth of man, occasionally in human feces, and frequently in milk. It is often carried about in atmospheric dust, and is not uncommon in water, especially when contaminated with sewage.

Morphology and Staining Characters.-The organism is spherical, sometimes slightly flattened where two are appressed, and in pus and in the blood is usually in masses like grape-elusters (whence the name, Staphylococcus); in culture-media the cells are 
grouped irregularly. The diameter of the cells is about 0.7 to $0.9 \mu$, rarely larger. It stains well with ordinary anilin dyes and is gram-positive.

Isolation and Culture.-Micrococcus aureus may be frequently secured in pure culture by making cultures directly from a fistula or other suppurating focus, first cleansing the outer portion and securing material on a sterile platinum needle. In general it is best, however, to plate out the drop of pus obtained in this way. This is not only important in preventing contamination, but in order to diagnose mixed infections, especially in isolations made for the purpose of preparing autogenic vaccines. The organism grows well in all the common laboratory media. The colonies upon gelatin appear as disks with smooth, definite edges, and with granular, dark interior. Within a few days the colony sinks in a cup of liquid. The liquid is cloudy, with a golden-yellow sediment. The growth on agar is abundant, shining, and well circumscribed. Upon the potato the growth is luxuriant, and the orange pigment is produced here in greatest abundance. Bouillon is clouded. Milk is curdled with a slight acid reaction, and the curd is eventually digested.

Physiology.-A study of the physiologic characters of this organism makes it apparent that there are many races of which account must be taken. It has not been satisfactorily demonstrated, however, that there is any relationship between these variations and pathogenicity.

Pigment Production.-An orange-yellow pigment is produced.

Fermentation.-A slight power to produce acid in milk has been noted. No gas is produced. Nitrates are reduced to nitrites. A proteolytic enzyme which digests casein is produced in milk. Gelatinase is found in gelatin. Rennin and maltase have been demonstrated.

Relation to Oxygen.-The organism is aerobic and facultative anaërobic.

Vitality. - There is a marked resistance to desiccation, although it is not probable that the organism can remain alive for very long periods in this condition. Cultures upon media will remain alive for months. The optimum growth temperature is blood-heat, although growth is good at room-temperatures and below. The 
various isolated strains have shown great variation in heat resistance. Usually a temperature of $60^{\circ}$ for half an hour suffices to destroy all the cells, but some require $80^{\circ}$ for the same length of time. The cells are easily destroyed by common disinfectants.

Pathogenesis.-Mechanism of Disease Production.-Staphylococci have been shown to produce a leukocytotoxin called leukocidin. A stained mount of pus will frequently show that many of the leukocytes have been destroyed, and that the cells are beginning to disintegrate. Staphylolysin, a hemolytic toxin, is also produced, particularly by the virulent strains. It seems to have been demonstrated, however, that these two toxins do not explain the pathogenic nature of the organism satisfactorily. Possibly anaphylaxis will explain some of the reactions secured, but there seems to be some poisonous property, possibly an endotoxin, which is not at present understood. We have no satisfactory explanation for its mechanism of disease production.

Experimental Evidence of Pathogenesis. - The causal relationship of this organism to pus-production and wound infection has been amply demonstrated. One-tenth c.c. of a twenty-four-hour culture of a moderately virulent strain will kill a rabbit, when injected intravenously, in four to eight days, and, upon postmortem examination, abscesses containing the same organism will be found in many of the internal organs.

Types of Natural Infection.-As has been stated previously, Micrococcus aureus is most frequently found associated with wound infections, and is also the common cause of abscesses, carbuncles, boils, acne, and furuncles in man and animals, of poll-evil and fistula in the horse, and similar lesions in other animals. The organism may gain entrance to the circulation and produce septicemia or pyemia in man, rarely in animals. It has also been found in man as the cause of certain metastatic infections, particularly of the bone-marrow (osteomyelitis), and ulcerative endocarditis. These have also been produced experimentally in the laboratory animals. Inflammation of the udder in cows (mastitis) is occasionally caused by this organism.

Immunity.-The production of two specific toxins, the hemolytic staphylolysin and the leukocidin, has already been noted, as also the probable importance of an endotoxin. Antitoxins 
for the two first mentioned have been produced, but do not seem to confer immunity. Agglutinins have been demonstrated in normal as well as infected animals; they seem, however, to be of no diagnostic value. The precipitation reaction has likewise been obtained with the bacterial filtrate. Bail has claimed that the production of aggressins accounts for pathogenicity, but his results are inconclusive. Bacteriolysins for Micrococcus aureus are not produced in appreciable quantities, and are probably not of any immunizing value. Opsonins may be demonstrated in both normal and immune blood, and seem to be the most important serum component in determining immunity.

Immunization.-Bacterins and vaccines, both univalent and polyvalent, have been prepared, and have been extensively tested in cases of chronic suppuration. The results of repeated injections have been encouraging in many cases. A check has been kept on the development of immunity in man by repeated determinations of the opsonic index. Care is used to eliminate the negative phase as far as possible in making the injections. Autogenic vaccines have proved even more successful in

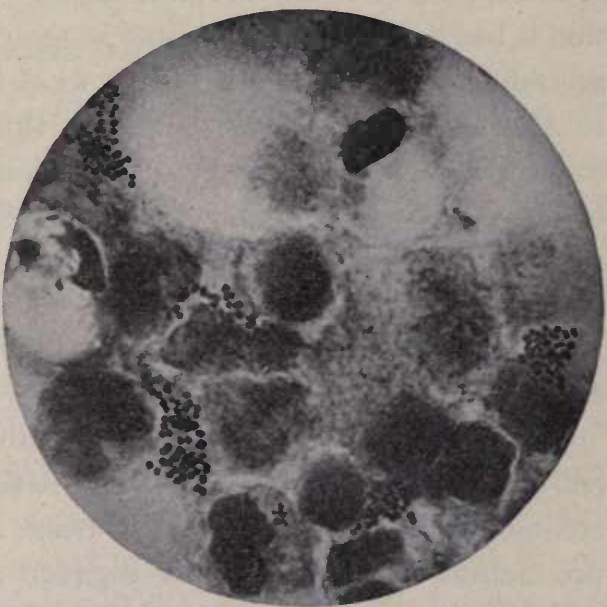

Fig. 84.-Micrococcus aureus in pus (Fränkel and Pfeiffer). both man and animals. The methods of preparation of such a vaccine have already been discussed. It seems altogether likely that the use of bacterins and of autogenic vaccines has found a permanent place in veterinary treatment.

Bacteriologic Diagnosis.-A mount of pus stained by Gram's method reveals the organism distinctly, if present. Its characteristic morphology will, in general, render its recognition easy. This method has proved to be of particular value in differentiating 
this organism from certain other pyogenic forms, such as the gonococcus. Frequently a stained mount will reveal but a few bacteria, and cultures are then necessary. These must be made in any event where it is desired to make a positive diagnosis.

Transmission and Prophylaxis. - The fact that the organism is constantly present on the skin and hair makes it partieularly difficult to prevent its entrance into wounds. The common practices of aseptic surgery are the best preventives of infection.

\section{Micrococcus albus}

Synonyms.-Micrococcus pyogenes albus; Staphylococcus pyogenes albus.

This organism differs from Micrococcus aureus by being devoid of color, and by being less pathogenic. In a few cases of suppuration it has been found alone, and in many cases associated with the preceding. In all other respects what has been said with respect to Micrococcus aureus will apply to this form. It is believed by some investigators that these two organisms are simply varieties of one single form which they term Micrococcus (Staphylococcus) pyogenes.

\section{Micrococcus citreus}

Synonyms.-Micrococcus pyogenes citreus; Staphylococcus pyogenes citreus; Staphylococcus citreus.

This organism was originally described by Rosenbach as present on the skin. It is doubtfully pathogenic and relatively uncommon. It differs principally from Micrococcus aureus in the production of a lemon-yellow pigment on agar and potatoes and its lack of power to liquefy gelatin. In other respects it resembles the two preceding forms, and is possibly but'a variety of them.

\section{Micrococci of Uncertain Significance}

Micrococcus (pyogenes) bovis (Synonym, Staphylococcus pyogenes bovis).-This organism is somewhat smaller than Micrococcus aureus, and does not liquefy gelatin. It has been claimed to be more commonly the cause of suppuration in cattle than the typical Micrococcus aureus. It is doubtful whether there is a valid specific difference between the two.

Micrococcus mastitidis. - A mierococcus was isolated by Kitt 
from mastitis in cows, which differed from typical Micrococcus albus principally in its lack of power to liquefy gelatin. It probably represents a variety merely.

Micrococcus ovis.-An organism resembling Micrococcus albus was described by Nocard as the cause of gangrenous mastitis in sheep. With the exception of its specialized pathogenesis, it differs but little from typical Micrococcus albus.

Micrococcus epidermidis albus.-This is probably a variety of the Micrococcus albus found in the deeper layers of the skin, and the common cause of "stitch abscesses."

Micrococcus cereus (albus and flavus).-These organisms differ from the micrococci heretofore described in producing a waxy growth upon artificial media, hence the name cereus (wax).

\section{Streptococcus pyogenes}

Synonyms.-Streptococcus erysipelatos; Str. puerperalis; Str. articulorum; Str. pyogenes malignis; Str. septicus; Str. scarlatinosus.

Pasteur first recognized the Streptococcus in pus, but Ogsten, between 1880 and 1884, first definitely isolated and described it. Fehleisen, in 1883, found the organism in erysipelas, and Rosenbach described it in detail and gave it its present name.

The student will find no more puzzling group of organisms than the Streptococci. They have been found in connection with all types of inflammatory processes. Some strains are exceedingly virulent, others wholly lack the power of disease production. Differences have been recorded in the cultural characters of isolations from different sources, and the species split into several on the basis of these variations. None of these classifications has proved to be wholly satisfactory, and, for the present, it is probably best to treat all the forms as varieties merely of one rather polymorphic species.

Distribution.-Streptococcus pyogenes does not adapt itself as readily to a saprophytic mode of existence as do the staphylococci. It is commonly present upon the skin of man and animals, and has been isolated from a great number of different inflammatory and suppurative processes in both.

Morphology and Staining Characters.-This organism is a 
coccus about $1 \mu$ in diameter, occurring in chains of greater or less length. Sometimes there is a tendency toward diplococcus formation, and the threads may be made up of many such diplococci. Where two organisms approximate, they are more or less flattened. The organism is non-motile, does not produce spores, is easily stained by the common anilin dyes, and is gram-positive. The length and character of the chains is variable in different media and under varying growth conditions, and likewise in strains isolated from different sources. This latter fact has been made use of by some investigators in an effort to perfect a classification.

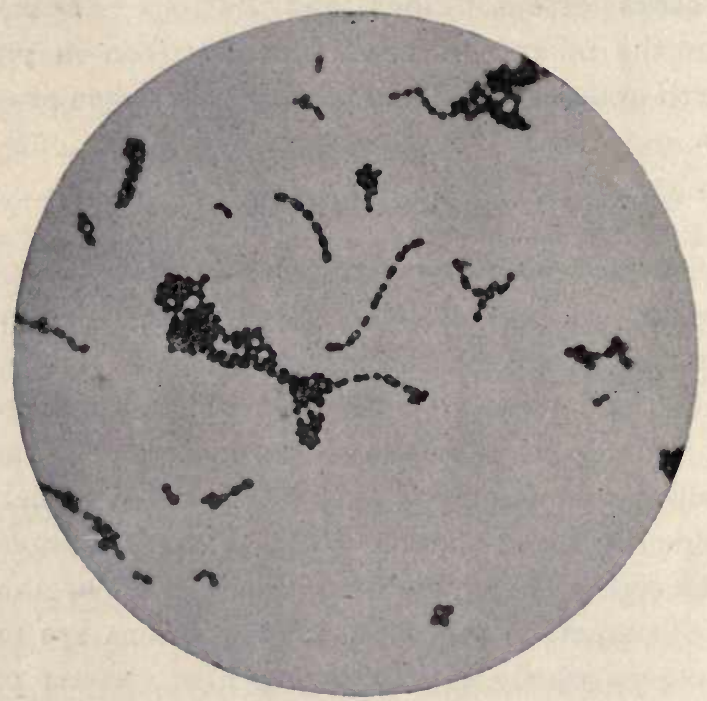

Fig. 85.-Streptococcus pyogenes in lactose broth (Heinemann in "Journal of Infectious Diseases").

The typical form does not produce capsules, although capsulated varieties have been described.

Isolation and Culture.-The organism may frequently be isolated in pure culture directly from the wound, but it is generally necessary to pour plates and isolate from the colonies. Care must be used in this latter method not to overlook the colonies, for many strains produce minute colonies only, and in mixed infections they may be missed. Inasmuch as most strains ferment lactose, with the production of acid, the use of 
litmus-lactose-agar plates is sometimes helpful, the colony appearing surrounded by a zone of red.

Growth occurs in most of the laboratory media, particularly upon the addition of a sugar, such as dextrose. The colonies upon agar and gelatin are small,-rarely larger than a pinhead, -at first transparent, and almost dew-drop-like. Later they may become somewhat opaque. The gelatin is not usually liquefied, although saprophytic strains are known which possess this property. Whether these latter are typical Streptococcus pyogenes is uncertain. Upon agar slants this organism tends to grow in the form of discrete colonies. Bouillon is sometimes clouded by a uniform distribution of short chains; in other cases it remains clear, the organism growing in masses of long, tangled threads which remain as a sediment at the bottom. Blood-serum is unusually favorable as a medium. A growth is frequently produced upon the potato, though many strains refuse to develop on this medium. Milk is usually coagulated, with acid production and no digestion of the curd.

Physiology.-Streptococcus pyogenes is aërobic and facultative anaërobic. Its optimum temperature is about $37^{\circ}$, but growth will usually take place at roomtemperatures. The thermal death-point differs in various strains-usually about $60^{\circ}$ for fifteen minutes is sufficient to destroy.

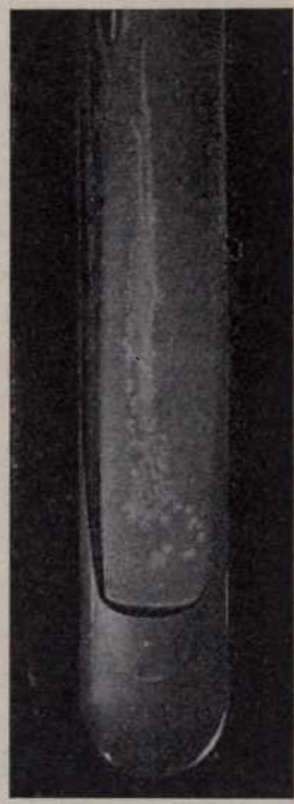

Fig. 86.-Streptococcus pyogenes on a slant agar culture (Fränkel and Pfeiffer).

Antiseptics and disinfectants are efficient in destruction. No pigment is produced. No coagulating or proteolytic enzymes are developed in the typical strains, although, as indicated above, gelatinase has been reported in some saprophytic types. No indol is produced. No gas is developed in any medium. Acid is produced by most strains from many sugars, particularly dextrose and lactose. Efforts have been made to classify the various types of Streptococcus on the basis of their acid-production 
in various sugars. This seems to be helpful in determining the origin of intestinal types in some cases.

Pathogenesis.- Unexplained differences and variations in pathogenesis may be noted in the various strains which have been studied. Virulence for a given species of animal may be increased by passage through that species.

Mechanism of Disease Production.-Little more is known of the mechanism of disease production with this organism than with the staphylococci. Neither the hemolytic streptolysin nor the endotoxins, which have been described, seem adequately to explain its pathogenesis. Changes are usually brought about in tissues which are in more or less intimate contact with the organism. No class of infections shows better the necessity of virulence of an organism and lack of resistance on the part of the tissues in order to bring about pathologic changes.

Experimental Evidence of Pathogenesis.-Inoculation experiments of animals have duplicated practically every infection with which this organism has been found associated in man and animals. The causal relationship of the organism to many infections has been abundantly demonstrated. All laboratory animals may be infected with strains exhibiting sufficient virulence.

Disease and Lesions Produced.-Streptococcus pyogenes is associated as primary cause with a long list of affections in both man and animals. As a secondary invader it is of great importance in many other diseases. Mixed infections with Micrococcus aureus and other organisms are common. Some of the more important are worthy of note.

Wound Infection and Suppuration.-Streptococcus pyogenes is not as common in surgical wounds and other traumata as the Micrococcus aureus and M. albus. Karlinski, in 1890, examined suppurative processes in man, animals, and birds, and found that Streptococcus was present in about 22 per cent. of the cases in man, 27 per cent. in lower animals, and 15 per cent. in birds. Staphylococci were present in about 70 per cent., 54 per cent., and 55 per cent. respectively. Lucet found Streptococci alone in 9 cases, and associated with other organisms in 10 cases, out of a total of 52 examinations of abscesses in cattle. Both Strepto- 
cocci and Micrococci are commonly present in fistulas and in pollevil in horses.

Septicemia and Pyemia.-When an unusually virulent Streptococcus gains entrance to the blood-stream it may cause septicemia (blood-poisoning). Direct growth through a blood-vessel wall may result in the formation of an infected blood-clot, and later, when broken up, it produces thrombi and may lead to embolism. Abscess formation proceeds at the new foci of infection. Multiple metastatic abscess formation of this character is known as pyemia.

Erysipelas.-This infection in man is characterized by a severe inflammation of the skin, in which this organism is present in large numbers in the lymph-spaces of the subcutaneous tissue. Erysipelas seems to be due to an invasion with a peculiarly pathogenic organism and to a lack of resistance on the part of these tissues. Somewhat similar lesions have been noted upon lower animals. The erysipelas of swine must not be confused with this disease, as it is caused by a totally different organism.

Infection of Mucous Surfaces.-Tonsillitis in man, enteritis in children, non-diphtheritic anginas, and similar inflammations of mucous surfaces are commonly caused by Streptococcus. Puerperal fever, an infection of a mucous surface following childbirth and its consequent septicemia, has been demonstrated in many cases to be due to Streptococcus infection, not infrequently contracted from a case of erysipelas. Less is known of the relationship of Streptococcus to related diseases in animals, though doubtless it plays an important part.

Peritonitis following an enterotomy is usually due to infection of the peritoneum with Streptococcus pyogenes, although other organisms are equally capable of giving rise to this condition.

Pneumonia, particularly the traumatic pneumonia of the horse, may be caused by this organism. The so-called contagious pleuropneumonia of the horse is believed by many investigators to be due to an organism which has not been shown to differ materially from Streptococcus pyogenes, except for its exceptional virulence and mode of attack. The disease is contagious, and in this respect differs from most types of streptococcic infection.

Ulcerative Endocarditis.-This affection is produced most commonly by Streptococcus, although Micrococcus is found in 
some cases. Cauliflower-like excrescences of the heart-valves, with consequent valvular insufficiency and embolism, due to the breaking off of these particles, are the characteristic lesions.

Arthritis.-Inflammation of the bone covering (periostitis), infections of the bone-marrow (osteomyelitis), and of the joints (arthritis) are generally the result of streptococcic invasion. In all new-born animals there is danger of infection through the navel, and consequent production of " navel ill " (omphalophlebitis). The umbilical vein, according to Moore, becomes heavily infected with bacteria, which invade the joints by metastasis. The selective action of the organisms in infecting certain tissues at one time and others at another is not well understood. Rheumatic fever in man (acute articular), and probably in animals, has been shown to be sometimes due to Streptococcus pyogenes. The infection atrium in man appears to be the tonsils.

Suppurative Cellulitis.- Under this heading Moore has described the streptococcic infections of the subcutaneous tissues, particularly of the lower extremities. In sheep it is called locally "foot-rot."

Mastitis.-Mastitis is commonly caused by Streptococcus. Here again the particular strain selects a particular organ, and may be transferred from one animal to another by the hands of the milker. Several different species of the Streptococcus have been described as associated with garget or infectious mastitis, but there does not seem to be any good reason for believing them to be anything but specialized strains of the Streptococcus pyogenes. As will be seen later, the presence of Streptococcus in milk does not necessarily predicate mastitis, for non-pathogenic forms are common.

Immunity.-A hemolytic toxin, streptolysin, may be demonstrated in some strains of Streptococcus pyogenes. For this an antitoxin has been produced. It seems probable that there is also a toxin which injures or destroys leukocytes. These toxins vary in amount, however, in cultures of different strains, and seem to vary independently of the virulence. They certainly do not account for the pathogenic nature of the organism. Agglutinins may occasionally be demonstrated, but are not of diagnostic importance. Endotoxins are produced by both virulent and non- 
virulent strains. Bacteriolysins are probably not important. Opsonins, normal and immune, and the phagocytosis induced by them, probably explain any immunity which is exhibited by the body. This immunity, like others produced by opsonins, is not lasting; in fact, it is so transient that it may be said that an attack of erysipelas, for example, renders one even more subject to recurrence.

Treatment by the use of bacterins, and particularly autogenic vaccines, has been found successful in chronic suppurations in both man and animals. In acute attacks it is of little or no value. It seems to be the consensus of opinion among investigators that the use of a polyvalent vaccine is more efficacious than a univalent when it is not autogenic.

Antistreptococcic sera are produced for. use by both the veterinarian and the physician. The serum of Marmorek is prepared by the use of a culture having such virulence for rabbits that $\frac{1}{1,000,000}$ c.c. proves fatal. Horses are immunized by repeated injections of such broth

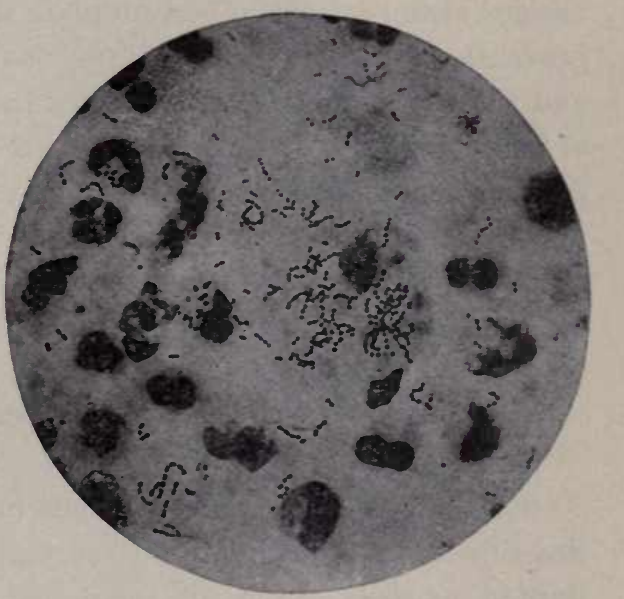

Fig. 87.-Streptococcus pyogenes in pus (Fränkel and Pfeiffer).

cultures and their serum used. This seems to be of distinct benefit in immunizing passively an animal against the same strain, but does not protect against others. Polyvalent sera are prepared by immunizing horses against a considerable number of strains of the Streptococcus. The results from the use of such sera have not proved as successful as hoped, though some have reported excellent results. Such a serum doubtless owes its protective influence to its opsonic content, but Hektoen and Ruediger have shown that in some antistreptococcic sera on the market the opsonin content was below normal. The advisability of the use of antistreptococcic serum in general streptococcic 
infections in veterinary practice cannot be determined at present from the data available. It is possible that in some diseases, particularly of equines, a serum, either curative or prophylactic, prepared from a homologous organism, may prove practicable and helpful.

Diagnosis.-Smears of pus stained with methylene-blue or by Gram's method will usually reveal the organism if present in any numbers. Sometimes the pus seems to be practically sterile upon microscopic examination, but cultures prepared from it will reveal the presence of the Streptococcus.

Transmission and Prophylaxis.-The constant presence of various strains of this organism upon the hair and skin makes the prevention of its entrance into wounds difficult. Cleanliness and the use of mild antiseptics are the only practicable methods of inhibiting its growth. In those infections which are characterized by a specialized organism, and which are more or less contagious, isolation of infected animals and quarantine of those exposed, with disinfection of barns, particularly stalls and mangers, are the methods which must be used in checking the spread.

\section{Streptococcus lacticus}

Synonyms.-Bacillus lactici acidi.

Strangely enough, the organisms first isolated from milk, and described as the cause of its souring, are not the ones now regarded as most commonly associated with this change. These were members of the intestinal group, or bacilli that produce both acid and gas in milk. Leishman, in 1899, gave the name Bacillus lactici acidi to an organism which he isolated from soured milk, and regarded as the common cause of this fermentation. Kruse later showed that Leishman had been mistaken in regarding it as a bacillus, and renamed the organism Streptococcus lacticus. Since then experimental data have accumulated, which seem to demonstrate quite conclusively that normal souring of milk is brought about in the vast majority of cases by this organism. The work of Heinemann in this country served materially to clear up the relationship between this and other forms.

Distribution.-Streptococcus lacticus is found generally in milk, butter, and cheese, upon the skin and hair of cattle, and in feces. 
Isolation, Morphology, and Culture.-This organism may be most easily isolated from milk by plating in litmus-lactose gelatin. The characteristic non-liquefying colonies surrounded by red may be easily recognized. Its morphologic characters differ in no marked degree from Streptococcus pyogenes. Culturally, many strains of this latter organism appear to be identical with Str. lacticus. In fact, the resemblance is so close that there is a good reason to believe that Str. lacticus is a strain of Str. pyogenes which has adapted itself to a saprophytic life.

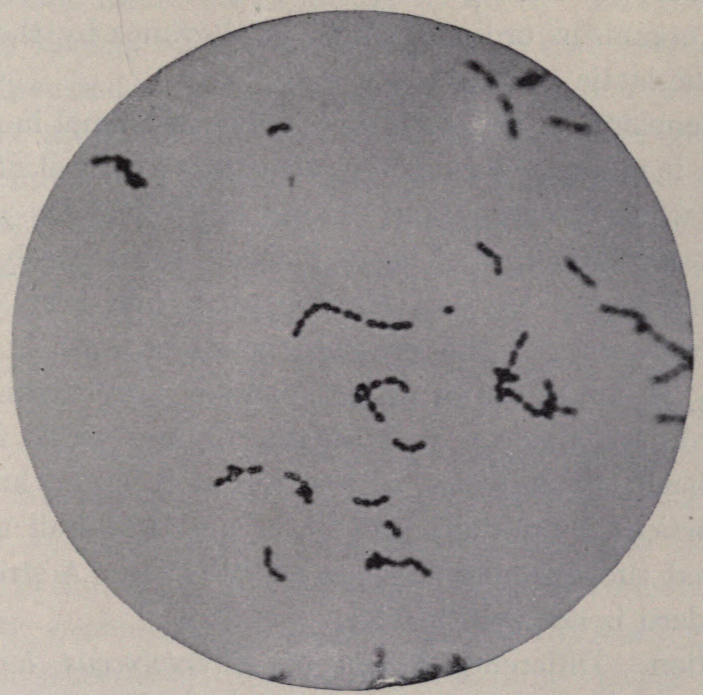

Fig. 88.-Streptococcus lacticus (Heinemann, in " Journal of Infectious Diseases").

Physiology.-Its physiologic characters differ in no noteworthy degree from the preceding. Acid is produced from dextrose and lactose. According to Heinemann, the dextro acid is produced by this organism and the levo by the $B$. lactis aërogenes and other members of the intestinal group.

The heat resistance of Str. lacticus is of particular importance in connection with pasteurization of milk. It has been generally regarded that pasteurization would certainly kill all organisms of this type, and it has been believed that pasteurized milk would contain only the spores of putrefactive bacteria, and if improperly 
handled, would "rot." Ayers and Johnson have shown recently the falsity of this assumption. There are practically always present in any given sample of raw milk one or more strains of the lactic-acid organism, which will resist the temperature of the pasteurizer, and will bring about normal souring in the milk pasteurized.

The production of lactic acid in milk is of considerable importance in preventing the growth of undesirable bacteria. Milk entirely freed from these forms, as by heating to the boiling-point, does not sour, but undergoes a putrefactive fermentation, brought about by organisms ordinarily held in abeyance by the development of the lactic acid.

- Pathogenesis.-Heinemann, by a series of animal inoculations, has shown it possible to exalt the virulence of typical Str. lacticus so that it would kill rabbits as quickly as virulent Str. pyogenes.

The close relationship of the two forms can scarcely be questioned. Before the work of Heinemann it had been concluded by many workers that the presence of streptococci in milk was necessarily an indication of udder infection, and examination for streptococci was made a part of the routine work of certain board of health laboratories. Inasmuch as it is now known that the Str. lacticus is normally present in practically all milk, it is evident that such examinations are of little use. A streptococcic milk standard is not practicable.

Utilization.-Different strains of Streptococcus lacticus are used in pure cultures as starters in the dairy. The flavor of butter is largely dependent upon the development of a peculiar flavor and aroma, largely through the agency of the lactic-acid bacteria present. It is customary, therefore, to pasteurize cream to destroy undesirable organisms and to add to it the starter, which is allowed to increase and produce the desired aroma and flavor. The Str. lacticus is likewise of importance in the manufacture of cheese; the change of the lactose present to lactic acid is an essential preliminary in most cases to the ripening process. 


\section{CHAPTER XXII}

\section{SPECIFIC INFECTIOUS DISEASES PRODUCED BY COCCI}

No hard-and-fast lines can be drawn between the specific and non-specific infections produced by cocci. The relationship and possible identity of some of the organisms here discussed, with the forms discussed in the preceding chapter, will be made evident. Some of the infections here classed as specific should possibly be considered under the general heading of Streptococcus pyogenes. The diseases described are, however, recognized as clinical entities, and are, therefore, worthy of somewhat more lengthy consideration.

Several of the diseases here discussed are caused by Streptococci: strangles in horses (Streptococcus equi), apoplectiform septicemia in chickens (Str. gallinarum), verrucose vaginitis of cattle (Str. sp.), abortion in mares (Str. sp.); the remainder are caused by Micrococci: pneumonia (Micrococcus pneumonia or lanceolatus), epidemic cerebrospinal meningitis in man (M. meningitidis) and in horses ( $M$. intracellularis equi), Malta fever in goats and man (M. melitensis), takosis in goats (M. caprinus), gonorrhea in man ( $M$. gonorrhœe $)$, and botryomycosis in various domestic animals (M. ascoformans).

The Streptococci of this group all closely resemble the Streptococcus pyogenes, and possibly are specialized varieties of that organism. Many of the Micrococci are characteristically grouped as diplococci, particularly in the tissues.

\section{Streptococcus equi}

Synonyms.-Streptococcus coryzœe contagiosce equorum.

Disease Produced.-Strangles or distemper in equines.

The disease strangles in horses has a long recorded history. It was described by Solleysel in 1664, and its contagious nature determined by Lafosse in 1790. Schütz (1888) first isolated and 
described the organism now generally considered to be the specific cause.

Distribution.-The disease is quite widely distributed, both in Europe and America. It generally attacks young animals.

Morphology and Staining Characters.-The organism is a grampositive Streptococcus, resembling the Str. pyogenes in both morphologic and staining characters. Some authors state that the organism is gram-negative, for it is decolorized if the alcohol remains too long in contact. The chains are usually long and twisted.

Isolation and Cultural Characters.-The organism may be isolated in pure culture, in most cases from the deeper portion of the characteristic abscesses, by the same methods used for Str. pyogenes. No specific differences in cultural characters have been shown. Bureschello claims that in many cases strangles is a mixed infection of Staphylococcus aureus and Streptococcus equi. In such cases plating would be necessary to differentiate the species of organisms present.

Physiology. - A temperature of $60^{\circ}$ will destroy the organism in an hour, and $80^{\circ}$ in thirty minutes. It is destroyed readily by direct sunlight and by disinfectants. It grows well at roomtemperature, although its optimum is blood-heat.

Pathogenesis.-Enough has already been said to make doubtful the standing of strangles as a specific disease caused by a specific organism.

Mechanism of Disease Production.-Little is known of the factors that determine the pathogenicity of the organism. Probably they differ little, if at all, from those of Str. pyogenes.

Experimental Evidence of Pathogenesis.-Pus from abscesses in strangles kills white mice, with evidence of acute septicemia in two to four days. An abscess generally develops at the point of inoculation. Rabbits and guinea-pigs succumb to the injection of large quantities of the organism, but are not readily infected. Other animals are very resistant. Subcutaneous inoculations of the horse will usually provoke abscess formation at the point of inoculation. Typical strangles in horses was caused by Schütz by use of pure cultures. It seems evident, however, that there must be some predisposing factor to the disease in most cases. 
Inoculations upon the nasal mucous membrane frequently fail to infect. Some authors are inclined to believe that the true cause has not been discovered, and that Str. equi is a secondary invader. Age is a predisposing factor: young animals are most commonly infected. Other predisposing causes are fatigue and exposure to cold, hard work, or any other factor that lowers the vitality. Variations in virulence wholly unexplained probably account for the epidemic character of the disease.

Disease and Lesions Produced.-The infection atria are probably the upper air-passages. The disease may be produced in simple or malignant form. A catarrhal discharge, with inflammation of the nasal mucous membranes, is generally first noted, followed quickly by a swelling of the adjacent lymphatic glands and of the submaxillary and pharyngeal lymph-nodes. These generally develop into abscesses. The infection spreads through the lymph-channels, but generally remains localized in the tissues adjacent to the point of infection. Metastatic infections may occur in practically any of the organs of the body, and in the chronic types of the disease great variations in localization will be found. Fatal termination is rare ( 0 to 3 per cent.), but sometimes occurs, due to septicemia, pyemia, or pneumonia.

Immunity.-Toxins and antitoxins, agglutinins, and bacteriolysins have not been satisfactorily demonstrated for this organism. Immunity is conferred by an attack of the disease, but is transitory, and the same animal may suffer from the disease a second time. Animals over five years old are quite generally immune. Probably immunity can be best accounted for by increased opsonin content of the blood and consequent stimulation of phagocytosis.

Immunization by vaccination with living and with dead cultures has not given wholly satisfactory results. Possibly the injection of autogenic cultures may have a protective influence. Todd has prepared a vaccine by growing the organism on blood-serum for twenty-four hours, then large flasks, containing 10 per cent. serum broth, are inoculated and incubated a month. Six per cent. of sterile glycerin is added, and the material concentrated at $60^{\circ}$ for two days over unslaked lime. The organism is destroyed, and the material evaporated to a thick paste. This is diluted and used as a vaccine. He has reported favorable results. The 
use of the serum of animals recovered from the disease and hyperimmunized by repeated injections has been followed by even better results. Certain French veterinarians have secured unusually good results by the prophylactic injection of such a serum. The immunity conferred is not permanent. The curative effect seems sufficient to warrant its use in many cases.

Diagnosis.-Bacteriologic diagnosis may be made by identification of a gram-positive Streptococcus from the lesions characteristic of the disease.

Transmission.- Transmission probably occurs most frequently by the use of common drinking troughs and by ingestion of infective food; more rarely, by direct contact and inhalation. It is probable that the organism may remain in the glands and follicles of the nasal mucosa after recovery of some animals, and such might easily infect others.

\section{Streptococcus gallinarum}

Synonyms.-Streptococcus of Nörgaard and Mohler. Streptococcus capsulatus gallinarum (?).

Disease Produced.-Apoplectiform and other septicemias in chickens.

This disease was first described, and its cause isolated, by Nörgaard and Mohler in 1902 . The same disease was studied by Moore and Mack in 1905. Damman and Manengold (1906) recorded an epidemic of "fowl sleeping sickness," due to a Streptococcus, and later, in 1908, noted a similar outbreak.

Distribution.-The disease has been reported from the original outbreak in Virginia, from northern New York, from Sweden, and a similar, if not identical, disease from Germany.

Morphology.-The organism is a typical Streptococcus with chains of variable length, cells $0.6-0.8 \mu$ in diameter, stains readily by the ordinary anilin dyes, and is positive to Gram's stain. With the exception of the doubtful difference in diameter, there appear to be no morphologic characters which differentiate it from Str. pyogenes. The German type is described as forming capsules in the blood, and may be entirely distinet.

Isolation and Culture.-The organism may be isolated from the blood and internal organs of affected fowls. It does not produce 
sufficient acid to coagulate milk, but differs culturally otherwise in no marked degree from Str. pyogenes.

Pathogenesis.-Experimental Evidence.-Inoculations of pure cultures into fowls, rabbits, mice, and swine are fatal, while those into the guinea-pig, sheep, and dog are not.

Disease and Lesions Produced.-The disease is a typical septicemia, marked by parenchymatous degenerations and hemorrhage. Nörgaard and Mohler state that fowls frequently die in twelve to twenty-four hours after the first symptoms.

Immunity.- Little is known relative to the causal organism and its products. Probably they differ little, if at all, from those of Str. pyogenes. The discoverers state that active immunity may be conferred by the injection of bouillon culture filtrates and by vaccination with killed cultures, and passive immunity by the injection of the blood-serum of an immunized animal.

Bacteriologic Diagnosis. - The organism may be identified as a gram-positive organism in smears from the blood and internal organs and by culture.

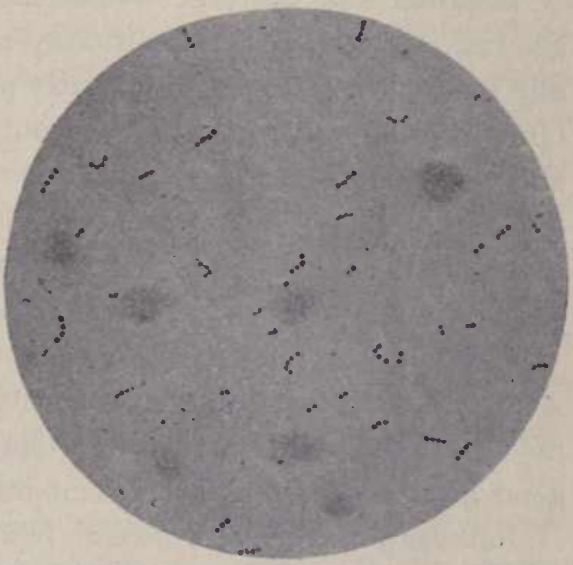

Fig. 89.-Streptococcus gallinarum (Magnusson).

Transmission.-According to the German authorities, the disease is not very contagious, but its appearance in considerable numbers of fowls at one time remains unexplained.

\section{Streptococcus Sp.}

Synonym.- Streptococcus of Ostertag.

Disease Produced.-Contagious granular or verrucose vaginitis in cattle.

Ostertag, in 1898, isolated and cultivated a Streptococcus from the purulent discharge and from the deeper layers of the mucous membrane in cases of infectious vaginal catarrh. His 
findings have been confirmed by the work of Hecker, Raebiger, and Hess. The latter edited a report of the Swiss Veterinary Surgeons Society in 1903, which gives a very complete summary of the knowledge of the disease and its cause.

Distribution.-The disease has been reported from all parts of Europe, and is wide-spread in North America.

Morphology. - The organism occurs in short chains of six to nine individuals, held together by a delicate capsule. It stains readily with common anilin dyes, and is decolorized by Gram's method. This latter differentiates it sharply from the Str. pyogenes.

Isolation and Culture.-Isolation may be made upon agar or gelatin. Plate cultures are usually necessary, as there are generally many other bacteria constantly present in the infected vagina. Growth occurs on gelatin (without liquefaction), blood-serum, and agar, particularly glycerinized. It produces a diffuse clouding of bouillon. Acid production is so weak that milk is not coagulated. It will be noted that the latter is also a character which differentiates it from the Str. pyogenes.

Physiology. - The organism is aërobic and facultative anaërobic. Acids are produced in small quantities, if at all, in carbohydrate media. The optimum growth temperature is blood-heat, but good growth occurs at room-temperature.

Pathogenesis.-Experimental Evidence.-This organism is not pathogenic for any of the laboratory animals, nor can it produce disease in horses, hogs, sheep, or dogs when inoculated into the vagina. Inoculations of pure cultures into the vagina of heifers has been found to reproduce the disease, so that there seems to be little doubt of its etiologic relation to the disease. It seems to be an example of extreme specialization, such as is found in the organism causing gonorrhea in man.

Disease and Lesions Produced.-The disease in an acute form produces a swelling of the labia of the vulva, with increased secretion from the mucous membranes of the vagina. Later the discharge becomes purulent, then granules from the size of a pinhead to a rape-seed develop. These are the enlarged lymph-follicles of the mucous membrane. The acute stage lasts usually for several weeks, the discharge becomes less prominent, and 
finally the chronic stage sets in, and may persist indefinitely or gradually disappear. The organism may be isolated from the pus in the acute stage, or from the deeper layers of the mucosa in the later stages. In the bull the glans penis may show granules similar to those of the vagina, or there may be a purulent catarrh of the prepuce. In the cow the disease may involve the uterus and possibly produce abortion and even sterility.

Immunity.-Recovery from the disease presumably results from the development of an active immunity, probably opsonic in nature. No means of artificial immunization have been employed.

Bacteriologic Diagnosis.-The presence of a gram-negative Streptococcus in the depths of the mucous membranes should be diagnostic of the disease. Identification in the discharges would necessitate cultures.

Transmission.- The disease is probably most commonly transmitted by coition or by immediate contact with soiled litter and fodder.

\section{Streptococcus Sp.}

Disease Produced.-Contagious abortion in mares. Ostertag in 1900 described a Streptococcus as the cause of abortion in mares.

Distribution.--Recorded only from Europe.

Morphology.-This organism somewhat resembles the preceding morphologically. It is a coccus, occurring in short chains, stains easily with anilin dyes, but is gram-negative.

Isolation and Culture.-Ostertag succeeded in isolating the organism upon blood-serum in pure cultures from the uterine mucous membranes and from the blood and internal organs of an aborted fetus. This Streptococcus does not grow readily upon most artificial media, but shows much better development upon the addition of blood-serum. Serum bouillon shows initial clouding, with subsequent sedimentation. Upon the solid serum media the growth is poor, being scarcely visible to the naked eye. Milk is not changed. It will be noted that both this organism and the preceding may be differentiated, both morphologically and culturally from the Str. pyogenes.

Physiology.-The organism quickly dies on artificial media, 
frequent transplantations being necessary to maintain it. It is easily destroyed by disinfectants.

Pathogenesis.-Ostertag succeeded in producing abortion in a pregnant mare by an intravenous injection. The organism is not pathogenic to the common laboratory animals. Like the preceding, it seems to be a case of specialized parasitism. Not enough critical work has been done upon the disease to satisfactorily establish the causal relationships of this organism.

Immunity.-No work is recorded relative to immunity to this disease. Transmission is probably through coitus.

\section{Other Streptococci of Uncertain Significance}

Streptococcus mastitidis sporadicæ.-(Str. agalactice contagiosa, Str. der infektiösen Induration des Euters).

Organisms of mammitis or mastitis in cattle have been found in all parts of the world, frequently associated with the disease in epidemic form. This organism was originally reported as gramnegative, but the Str. mastitidis, gram-positive, is reported by the local government board in England as the commoner type. There are no good differential characters other than pathogenesis to separate this latter form from Str. pyogenes and Str. lacticus. On account of the general occurrence of this latter species in milk, direct microscopic examination of the milk is often insufficient for the purpose of determining the condition of the udder, i. e., whether or not it is infected with garget.

Streptococcus Sp.-Epizoötic pleuropneumonia in equines. Stable pneumonia.

A number of investigators have demonstrated a Streptococcus present in the lesions of certain pneumonias in the horse. The organisms isolated by different investigators have not always the same cultural, morphologic, and physiologic characteristics. By some the organism is regarded as identical with Str. equi, by others as a specific type, and by still others it is believed that the specific organism is still unknown, and the Streptococci described are but secondary invaders. An organism resembling the human pneumococcus, if not identical with it, has been isolated from some cases of equine pneumonia, and will be considered in connection with that organism. 


\section{Streptococcus pneumoniæ}

Synonyms.-Pneumococcus; Diplococcus pneumonice; Diplococcus lanceolatus; Streptococcus pneumonic; Micrococcus pneumonice; Micrococcus lanceolatus.

Disease Produced.-Pneumonia in man, and probably some animals, particularly the horse.

Sternberg, in 1880, described this organism from normal sputum, but Fränkel, in 1885, first definitely associated the organism with croupous pneumonia. Considerable difficulty early arose, due to the confusion of two distinct organisms; namely, the form under consideration with the pneumobacillus of Friedländer. A somewhat similar organism, possibly a gram-negative variety of this form, has been found by Mayer associated with pneumonia in the horse.

Distribution. - Throughout the world, in diseased and healthy individuals.

Morphology and Staining.Usually occurs in twos, more rarely in chains of four or six, spherical or more generally flattened at the point of contact, and with opposite side somewhat elongated and pointed, whence the name, lanceolatus.

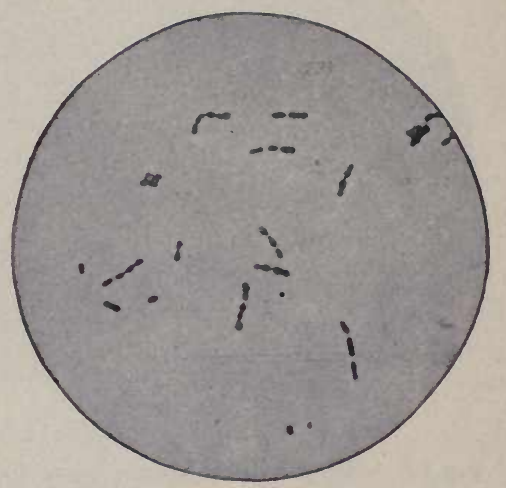

Fig. 90.-Streptococcus pneumonice in pure culture (Weichselbaum) (Kolle and Wassermann). Capsules may be demonstrated in the body, but do not appear in culture-media except in serum broth. It stains readily with ordinary anilin dyes, and is gram-positive. There is some doubt as to whether the organism is a Micrococcus or a Streptococcus. The occurrence of chainformation and lack of any other grouping would make the latter more probable.

Isolation and Cultural Characters. - The organism may in some cases be isolated from the blood directly in pure cultures. It is most readily obtained from the sputum by animal passage. Growth occurs on most laboratory media except potato. Growth is never luxuriant, the organism developing as discrete, transparent, 
dewdrop-like colonies upon the surface of the medium. Bouillon is slightly clouded. Milk is acidified and coagulated. The addition of glycerin, and particularly blood-serum, stimulates growth in most media.

Physiology.-The optimum temperature is $37^{\circ}$; little or no growth will occur at lower temperatures. Desiccation for several months, particularly in sputum, does not always kill the organism. Twelve hours' exposure to direct sunlight is fatal. Acids are produced from many carbohydrates.

Pathogenesis.-The pneumococcus produces acute septicemia

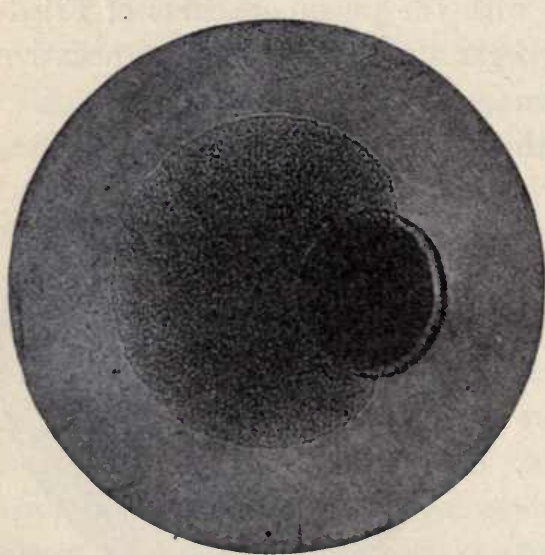

Fig. 91.-Streptococcus pneumonice colony on agar plate $(\times 100)$ (Fränkel and Pfeiffer). when injected into the mouse, guinea-pig, or rabbit. The production of typical pneumonia is attended with difficulty, if, indeed, it has been satisfactorily demonstrated. Its principal claim to recognition as the etiologic factor in the disease rests upon its presence in the lesions and its general pathogenic relationship to animals. The fact that it is quite commonly present in the sputum of normal individuals seems to indicate that there are great differences in disease-producing power among different strains. Whether or not the organism isolated by Mayer from pneumonia in the horse is identical with this organism cannot at present be determined, nor can its relationship to "Brustseuche" be said to be satisfactorily proved.

The tissues of the lung invaded by the organism become congested, and blood-plasma is poured into the alveoli. The fibrinogen coagulates, and the lung becomes "hepatized," that is, liver-like in consisteney. Frequently there is more or less hemorrhage, largely by diapedesis, and the lung becomes reddened. Later leukocytes, particularly the polymorphonuclear type, invade, and the tissues become gray. Autolytic digestion 
of the fibrin and other exudates supervenes, and the material passes off through the air-passages or is resorbed.

Metastatic infections with the pneumococcus are common in man. Inflammations of the endocardium, the pericardium, the pleura, and the meninges have been found to be due to this organism in a small percentage of cases. Otitis media is sometimes the initial infection, and may be followed by meningitis.

Immunity.-No toxin has been demonstrated in this organism. Endotoxins may be demonstrated, but whether they account for

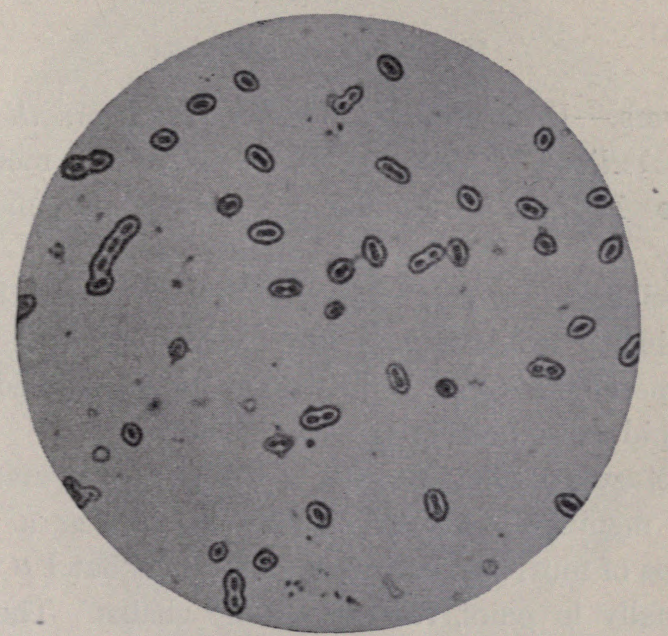

Fig. 92.-Streptococcus pneumonice. Stained preparations showing capsules (Buerger, in "Journal of Infectious Diseases").

its pathogenicity is uncertain. Agglutination of the pneumococcus occurs with the blood-serum of an infected individual, but not usually in greater dilutions than 1:50. Opsonins, both normal and immune, have been demonstrated, and likewise there has been isolated from virulent Streptococci a substance that inhibits phagocytosis.

Immunity to pneumonia is transient; relapses frequently occur, possibly due to decrease in immunity during convalescence. Recovery in some cases seems to be followed by increased susceptibility. The immunity developed is evidently opsonic in 
nature. No practicable method of immunization, either by the use of vaccines or antisera, has been developed.

Bacteriologic Diagnosis. - The most conclusive method of bacteriologic diagnosis is by isolation and eultivation of the organism. A demonstration of the characteristic lanceolate, capsulated, gram-positive diplococci is often diagnostic. The agglutination test is not conclusive.

The relationship of this organism to pleuropneumonia and contagious pneumonia in equines is uncertain, and further work needs to be done before the connection can be made clear.

\section{Micrococcus meningitidis}

Synonyms.-Diplococcus intracellularis meningitidis; Micrococcus weichselbaumii; Streptococcus meningitidis; meningococcus.

Disease Produced.-Epidemic cerebrospinal meningitis in man.

Weichselbaum, in 1887, first adequately described this organism from meningeal exudate, and proved its pathogenic nature by animal experimentation. It has since been observed repeatedly in many epidemics, both in Europe and America.

Morphology and Staining.-Micrococcus meningitidis in stained smears of meningeal exudate usually appears as a diplococcus, or in groups of four. In culture-media it is about $1 \mu$ in diameter, and is usually in pairs, rarely in short chains. The latter fact would seem to indicate that this organism should be classed as a Streptococcus, but the tetrad formation sometimes seen seems, on the contrary, to show that cell division may be in two planes, hence the use of the generic name, Micrococcus. No capsules are produced. It stains readily with the ordinary anilin dyes, but is gram-negative.

Isolation and Culture.-The organism may be obtained by a lumbar puncture with a sterile hypodermic needle, and transferred directly to artificial media. It is best to use a medium containing serum for the first isolation, for this bacterium frequently does not grow well on artificial media at the first. Upon blood-serum at $37^{\circ}$ white, viscid, coherent colonies develop. Serum may be added to agar or bouillon and will be found to favor the growth. 
Milk is not changed. Frequent transfers are necessary to the preservation of cultures in artificial media.

Physiology.-The meningococcus is killed almost immediately by desiccation. In culture-media autolysis rapidly occurs, and the organism soon disappears. No acids are produced in carbohydrate media. Proteolytic enzymes are not produced.

Pathogenesis.-The meningococcus does not readily infect common laboratory animals unless intraperitoneal injections of comparatively large amounts of the culture be used. Even in

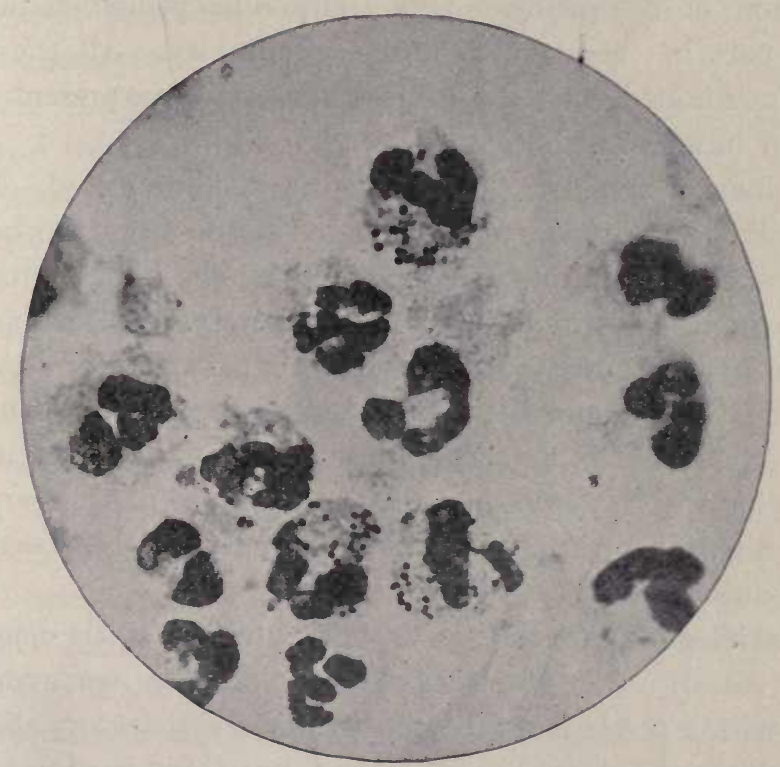

Fig. 93.-Micrococcus meningitidis in a preparation of pus from a brain abscess. Note that the organism is generally intracellular (Flexner).

this case the result seems to arise from the absorption of the toxic products, rather than from an invasion of the tissues. Injection of pure cultures into the spinal cavity of the goat has been found to produce meningitis, and inoculation into the monkey has resulted practically in a duplication of the disease as it occurs in man. The relationship of the organism to the disease is, therefore, well demonstrated.

The disease is an acute inflammation of the meninges, accompanied by a purulent exudate. The organism sometimes, though 
rarely, enters the blood. Metastatic involvement of the lungs and other organs occurs in a few cases.

Immunity.- No true toxins have been demonstrated; endotoxins are probably produced, and released through the autolytic disintegration of the organism. Agglutinins are developed in sufficient quantity, so that the blood of a patient frequently agglutinates in a dilution of $1: 50$. Although no distinct bacteriolysins have been demonstrated, specific amboceptors for the organism may be shown to be present in the blood by the hemolytic absorption of complement test. Opsonins probably play the largest part in the development of immunity. All these antibodies mentioned have been determined to be present in the serum of immunized horses.

Vaccination against the disease is not practised. Flexner and Jobling have prepared an immune serum from the horse by the injection of dead bacteria, followed by the injection of living bacteria and the products of their autolytic digestion. The serum is injected directly into the spinal canal after the withdrawal of an equal amount of the purulent exudate. It comes in direct contact, therefore, with the organisms, and probably stimulates phagocytosis by its opsonin content. The use of this serum has proved highly successful; by its means mortality has been materially reduced.

Bacteriologic Diagnosis.-Lumbar puncture, with demonstration in smears of a gram-negative diplococcus, occurring principally within the leukocytes, constitutes a satisfactory diagnosis. The agglutination test may be applied, but is not used in practice.

Transmission and Prophylaxis.-How the organism gains entrance to the spinal and brain cavities is not certainly known. It is found in the early stages of the disease upon the nasal mucous membranes. It is spread probably by the use of infected handkerchiefs or by the inhalation of infectious droplets.

\section{Micrococcus intracellularis equi}

Synonym.-Diplococcus intracellularis equi.

An organism in no important particular differing from the meningococcus has been reported by Johne, Ostertag, and others in epizoötic or cerebrospinal meningitis in horses. Ostertag 
succeeded in producing the disease in horses by subdural injections of pure cultures. Other organisms have been found in similar outbreaks by other investigators. Careful study of the relationship of these organisms to the diseases must be made before conclusions as to their importance as an etiologic factor would be justified. This epizoötic infection should not be confused with the far more common type of so-called meningitis produced by forage poisoning.

\section{Micrococcus melitensis}

Diseases Produced.-Malta fever in the goat and in man; Mediterranean fever.

Bruce, in 1887, discovered a microörganism in the spleen of men dead from Malta or Mediterranean fever. Since that time it has been studied carefully by numerous investigators, and its relationship to the disease is well established.

Distribution.-The disease is known to occur in all the countries bordering on the Mediterranean, in southern Asia, South Africa, the Philippines, and some of the islands of the West Indies.

Morphology and Staining.-The organism is a small coccus, about $0.4 \mu$ in diameter, usually in pairs, occasionally in short chains. Possibly it should be classed as a Streptococcus. Rarely, forms longer than broad may be observed, especially in cultures kept at temperatures below the optimum. These are probably involution forms. The organism stains well with ordinary anilin dyes, but is gram-negative.

Isolation and Culture.-It may be isolated from the spleen during life or after death in pure culture, or by plating. The individual colonies on agar in three days are small and dew-droplike, and continue to increase in size for some time. There is no marked peculiarity of growth upon any of the artificial media, although the organism may be cultivated readily on any of them. Milk is not changed.

Physiology.-The $M$. melitensis does not produce acid from any of the carbohydrates. Desiccation does not destroy it quickly, for the organism has been found to remain alive and virulent when dried for a considerable time. Pasteurization is fatal.

Pathogenesis.-The disease is a true bacteremia. Inoculation of pure cultures reproduces the disease in the goat, cow, and mon- 
key. Accidental laboratory infections have proved its power of producing disease in man. Infection probably usually arises through ingestion. The disease is characterized by its low mortality, its long duration in man, and the accompanying articular rheumatism. It is a disease primarily of the goat, though it is possible that cattle may sometimes harbor and transmit it.

Immunity.-No toxins have been demonstrated. Agglutinins are present in the blood in infected individuals, so that agglutination may sometimes be secured with high dilutions-occasionally as high as 1:6000. This test is one of the readiest methods of diagnosing the disease.

Bacteriologic Diagnosis.-Diagnosis may be made by isolation

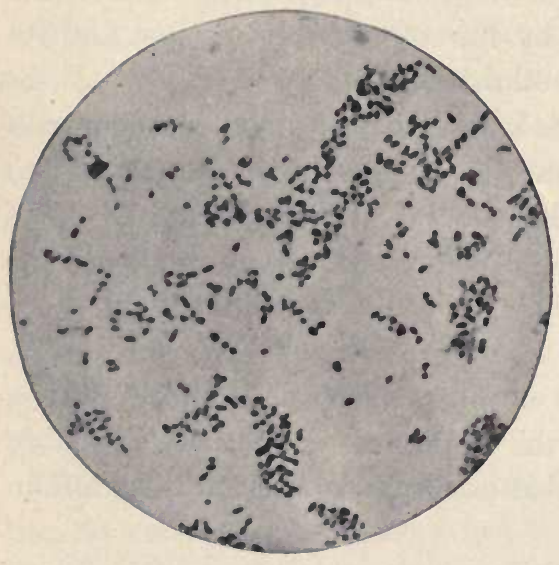

Fig. 94. -Micrococcus melitensis $(\times 1200)$ (Jordan). of the organism by a puncture of the spleen, or by demonstrating the presence of specific agglutinins in the serum in dilutions of 1: 50 or greater.

\section{Transmission and Pro-} phylaxis.-The organism is excreted in the feces, urine, and milk from infected animals. Most cases in the human are acquired by drinking the milk of infected animals. The disease infects, in either the acute or chronic form, so

large a proportion of the animals in some countries that the use of unheated milk is always attended with danger. The disease has no foothold at present in the United States, but is occasionally reported.

\section{Micrococcus caprinus}

Disease Produced.-Takosis, or wasting disease, of Angora goats.

Mohler and Washburn, in 1903, deseribed the organism believed to be the specific cause of this disease of Angora goats. 
Their published investigations still remain practically the only discussion of the etiology to the present time.

Distribution.-The disease is certainly known only from the United States, where it has been reported from many localities, particularly in the northern States. It is probably to be found in other countries, and is believed to be endemic in Asia Minor.

Morphology and Staining.-The $M$. caprinus occurs in pairs in the blood, and usually shows the same grouping in culture-media, rarely in chains of three or four cells. When in pairs, the cells are somewhat compressed longitudinally. Rarely in the blood they assume the lancet shape characteristic of Str. pneumonice. No capsules are produced. The organism does not stain well with methylene-blue, but heavily with carbol-fuchsin and gentianviolet. It is gram-positive.

Isolation and Culture.- The organism has been isolated directly from the blood upon artificial media. In broth there is first turbidity, followed by sedimentation and clearing up of the medium. Upon agar slants a white, ceraceous or granular mass of confluent colonies is produced. Colonies on agar reach a diameter of 8 to $10 \mathrm{~mm}$., and appear smooth, white, flatly convex, and waxy. When first isolated, liquefaction of gelatin does not occur, but later transfers liquefy the gelatin, beginning at the fourth day. Good growth is obtained upon blood-

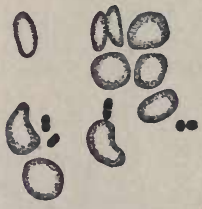

Fig. 95.-Micrococcus caprinus in a bloodsmear (Mohler and Washburn). serum and potato. Milk is coagulated, with development of acids and ultimate peptonization. Many of the characters noted relate the organism closely to $M$. albus.

Physiology.-The organism is aërobic and facultative anaërobic. Blood-heat is the optimum temperature, but development takes place at room-temperature also. Acids are produced in many carbohydrate media. No indol is produced, but phenol may be demonstrated. The thermal death-point is $58^{\circ}$ for ten minutes. The organism is readily destroyed by desiccation and light and by the action of disinfectants.

Pathogenesis.-The exact mechanism of disease production is not understood. It certainly is not by the development of toxins. 
Experimental Evidence of Pathogenesis.-The organisms produce a fatal disease in mice, guinea-pigs, and sometimes rabbits, but the white and brown rat, dog, and sheep are found to be immune. Inoculation into the goat revealed the fact that the disease could be produced only with difficulty, yet enough evidence was secured to make the demonstration of the organism as the etiologie factor satisfactory.

Disease Produced.-The disease produced in the Angora goat is characterized by symptoms of diarrhea, by pneumonia, great emaciation, and weakness. It is generally fatal. The visible mucous membranes are anemic. The anemia is even more marked on postmortem examination. The lungs show inflammatory changes; the exterior is frequently mottled, showing much the appearance of pneumonia in process of resolution. Degenerative changes are also to be observed in the heart and the kidneys.

Immunity.-There is no evidence of toxin production. Attempts at immunization by injection of broth filtrates into guineapigs revealed the development of some increased resistance. Efforts at practical immunization were unsuccessful. Nothing is known of the agglutinins, opsonins, or bactericidal properties of the immune serum.

Bacteriologic Diagnosis.-Cultures from the blood, or stained mounts from this source, should reveal the characteristic organism.

Transmission.-Methods of transmission are not certainly known.

\section{Micrococcus gonorrhœæ}

Synonyms.-Diplococcus gonorrhœœ, gonococcus; diplococcus of Neisser.

Diseases Produced.-Gonorrhea and its sequelæ in man.

Neisser, in 1879 , noted the occurrence of a characteristic coccus in gonorrheal pus. Bumm, in 1885, succeeded in obtaining the organism in pure cultures, and determined by inoculations into human subjects the causal relationship of the organism to the disease.

Distribution.-Gonorrhea is a common disease in all classes of men, particularly in civilized countries.

Morphology and Staining.-The gonococcus closely resembles the meningococcus. In stained preparations of gonorrheal pus 
the organisms occur generally in pairs inside the polymorphonuclear leukocytes. The cells are usually coffee-bean shaped. The individual cells measure about 1.6 by $0.8 \mu$. There is little or no tendency to chain formation, the cells being arranged in irregular masses in culture-media. The organism stains readily with the ordinary anilin dyes and is gram-negative. This latter fact is important, as it renders differential diagnosis between the common streptococci and the gonococcus possible.

Isolation and Cultural Characters.-The organism may be isolated directly from gonorrheal pus, care being exercised to secure pus not contaminated with organisms from the skin. Considerable difficulty is sometimes experienced in securing cultures. Usually no growth will occur on ordinary agar or gelatin, although, when considerable quantities of pus are spread over the surface, some colonies will develop. Wertheim's medium, composed of one part of human serum to two parts of nutrient agar, is commonly found to be the one on which growth is most readily secured. The organism gradually adapts itself to growth on artificial media, and after a few transfers develops more luxuriantly. The

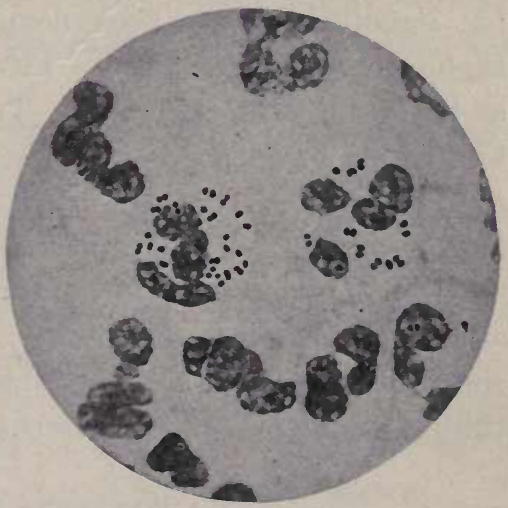

Fig. 96.-Micrococcus gonorrhœe in pus (Günther).

colonies resemble those of the Str. pyogenes, being small, discrete, and transparent.

Physiology.-The organism is aërobic. It is easily destroyed by desiccation, although when dried in pus it may retain its vitality for weeks. It must be transferred from one culturemedium to another every two days if kept at thermostat temperatures, less frequently in the refrigerator, to keep it alive.

Pathogenesis.-Evidence of Pathogenesis.-That the gonococcus causes gonorrhea is evident from the fact of its universal occurrence in gonorrheal pus, and from inoculation experiments 
upon man. The laboratory animals do not contract the disease upon inoculation.

Character of Disease and Lesions. - The organism ordinarily causes an acute urethritis in both sexes. It may also produce gonorrheal ophthalmia, particularly in the new-born. The urethritis may become chronic and lead to stricture. Secondary involvement of the Fallopian tubes, ovaries, and peritoneum in the female, and of the epididymis and bladder in the male, frequently occurs. Metastatic infections of the joints, causing gonorrheal rheumatism, of the heart valves, causing endocarditis, of the brain and cord, causing meningitis, are not uncommon. The organism may persist for a long period in a dormant state.

Immunity.- No true toxins are produced by the gonococcus, but endotoxins have been demonstrated, as have also specific agglutinins and precipitins. Little or no immunity is developed as the result of an infection. The presence of specific amboceptors in the blood has been shown by the method of deviation of complement. Vaccination with the autolytic products of the organism, and with cultures killed by heat, and by mixture with strong solutions of lactose or other sugars, have been used with a moderate degree of success. Porrey has prepared an antigonococcus serum from the rabbit by immunization with living cultures, and claims to have secured favorable results from its use.

\section{Micrococcus ascoformans}

Synonyms.-Micrococcus botryogenus; Botryococcus ascoformans; Botryomyces ascoformans; Zoögløa pulmonis equi.

Disease Produced.-Botryomycosis.

The organism associated with botryomycosis was discovered in 1870, and later investigated independently by Revolta and Micellone in 1879, by Johne in 1885, and by Rabe in 1886 .

Distribution.- This infection has been reported several times from Europe, and there is evidence of its presence in the United States.

Morphology. - The micrococci in the tissues are comparatively large -1 to $1.5 \mu$ in diameter. They are embedded in the thick capsules of the organism, forming a gelatinous mass of considerable size - zoöglea. Upon culture-media the capsule formation 
is not very evident, if present, and the cells are usually in pairs or tetrads. There is some evidence that this organism should be grouped as a Sarcina, rather than as a Micrococcus, while in many respects it resembles the Micrococcus aureus. It stains readily with anilin dyes, and is gram-positive.

Isolation and Culture. $-M$. ascoformans may be isolated in pure culture from the characteristic lesions, or in mixed infections it may be secured by plating. In most of its cultural characters it resembles a weakened strain of $M$. aureus. Gelatin colonies are small, and cause slight liquefaction and cupping of the medium when at the surface. In gelatin stab the growth is filiform and white, followed by a slow, crateriform liquefaction. The colonies on agar are scarcely visible in most strains, although more vigorous types have been described. On potato the growth is yellowish and has an aromatic odor.

Physiology. - This organism produces a small amount of gelatinase, as evidenced by the liquefaction of the gelatin.

Pathogenesis.-Experimental Evidence-Guinea-pigs injected with $M$. ascoformans generally succumb to septicemia. Mice are not susceptible. Sheep and goats develop ulcers at the point of inoculation. Injection into the horse usually results in suppuration, but occasionally the typical botryomycomata are developed. Whether or not this is a variety of $M$. aureus is unsettled, but it seems probable that it is a distinct species.

Character of Disease and Lesions Produced.-The lesions resemble superficially certain fibromata and other neoplasms. The infection usually takes place where the surface of the skin has been abraded, as by harness, through wounds at castration, on the udder, and elsewhere on the body. The tissues involved become grayish-red, then lardaceous, and eventually form a mass resembling a fibroma. These sometimes reach considerable size. Metastatic infection through the lymph-channels may result in the involvement of considerable areas and infection of the internal organs, particularly the lungs.

Immunity.-Methods of developing immunity have not been devised. It is possible that autogenic vaccination might be of value.

Transmission.-As noted above, infection generally occurs through wounds or abrasions of the skin. 


\section{CHAPTER XXIII}

\section{NON-SPECIFIC PYOGENIC BACILLI}

MANY bacilli have been isolated from suppurative infections. Some of these undoubtedly have no causal relationship to the pusproduction and are purely saprophytic; others, as the colon bacillus, are normally non-pathogenic, but under certain conditions may cause pus-infection; others, as the typhoid bacillus, normally cause specific diseases, but occasionally produce a secondary pyogenic infection, while others are known only from their association with suppurative processes, and may be termed true pyogenic bacilli. Two organisms belonging to the latter class are worthy of specific mention-Bacillus pyocyaneus and B. pyogenes suis. They are grouped here solely because of their pyogenic properties, and not on account of any relationships existing between them. Their only common characteristics are their shape and ability to incite suppuration. Our knowledge of the $B$. pyogenes suis is unsatisfactory. It probably should be grouped with some other forms, possibly with the Bacillus pseudotuberculosis.

\section{Bacillus pyocyaneus}

Synonyms.-Pseudomonas pyocyanea; Ps. aeruginosa; bacillus of green or blue-green pus in man and animals.

Gessard, in 1882, described the Bacillus pyocyaneus from bluegreen pus. Since that time it has been isolated and studied by numerous investigators, both in Europe and America.

Distribution.-This organism has been isolated from the feces of man and animals, from sewage and surface waters, from the soil, and from air and dust. It is usually saprophytic or commensal in its growth, and is only rarely pathogenic.

Morphology and Staining.-B. pyocyaneus is a slender rod with rounded ends, about 0.6 by $2.6 \mu$ or smaller, usually single, rarely in chains of 2 to 6 individuals. It is motile by means of a single terminal flagellum. No spores or capsules are produced. It stains readily by the ordinary anilin dyes, and is gram-negative. 
Isolation and Culture.-This organism is readily isolated by plating out pus which contains it, as the colonies are quite characteristic on account of the green pigment which they diffuse. It grows readily on all the common laboratory media. Upon agar and gelatin plates the thin, poorly defined colonies are characterized by the fluorescent pigment surrounding them. Upon slant agar the color diffuses until the whole of the medium is a light green, then a darker blue-green, and finally a brown or brownred. Gelatin is rapidly liquefied. Bouillon is clouded, a pellicle forms, and the fluorescent pigment diffuses from the top downward. Potatoes support a slimy growth and turn green, then brown. Milk is coagulated by a rennetlike enzyme, and the curd peptonized.

Physiology.-This organism is preferably an aërobe, and grows most luxuriantly in the presence of oxygen, but growth will continue under anaërobic conditions. Proteolytic ferments which will digest gelatin, fibrin, and casein are produced. Two pigments are usually

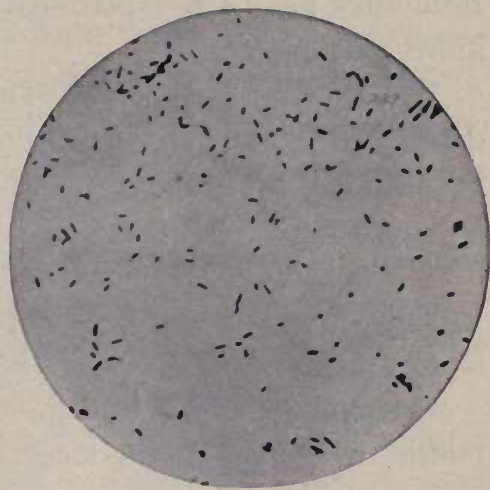

Fig. 97.-Bacillus pyocyaneus (Kolle and Wassermann).

formed - one green and fluorescent (fluorescin), the other (pyocyanin) bluish. Pigment is not produced in the absence of oxygen. In old cultures the pigments become yellow or brown. Autolytic disintegration of the cells takes place in old cultures. Mucin, a compound made up of a protein and a carbohydrate, has been found present in cultures. To this may be ascribed its slimy consistency on agar or even in bouillon. The organism is resistant to desiccation.

Pathogenesis.-Experimental Evidence.-Injection of cultures of $B$. pyocyaneus subcutaneously into the guinea-pig or rabbit causes rapidly spreading edema, suppuration, septicemia, and death within a day or two. Not all cultures are equally pathogenic.

Character of Infection Produced.-The B. pyocyaneus is usually a secondary invader, although in man it has been found causing 
primary infections. It has not yet been proved ever to cause suppuration alone in any of the domestic animals, but is not uncommon in pus, to which it gives a green or blue-green color. In man it has been found in purulent otitis media, meningitis, bronchopneumonia, infantile diarrhea, and generalized infections.

Immunity.-A true toxin is produced by virulent cultures. Wassermann found 0.2 to 0.5 c.c. of this fatal for the guinea-pig. An antitoxin has been prepared for this pyocyaneus toxin. An endotoxin has also been demonstrated. A leukocytic poison, leukocidin, and a hemolytic toxin, hemotoxin, have been differentiated. Immunity has been experimentally produced by the injection of killed cultures.

Bacteriologic Diagnosis.-The organisms may be most readily determined by plating. The presence of a gram-negative bacillus in pus in a stained mount constitutes presumptive evidence.

\section{Bacillus pyogenes suis}

This organism has been several times described from inflammatory suppurative processes in the hog.

Morphology and Staining.-The organism is a slender, nonmotile bacillus. It produces neither spores nor capsules. It stains readily with the ordinary anilin dyes. It is gram-negative.

Isolation and Culture.-The organism may be readily isolated in pure cultures immediately from the pus. It grows readily on artificial media, particularly on coagulated blood-serum. On this latter medium the small dry colonies form a slight area of liquefaction immediately about them.

Physiology.- Growth occurs best at $37^{\circ}$. No gas is produced from dextrose.

Pathogenesis.-The organism has been found associated commonly with suppurative processes in the hog, particularly those affecting the serous membranes lining the body-cavities. These abscesses are generally encapsulated. 'Evidently they may arise as metastatic infections, for they are sometimes distributed throughout the body. The organism is pathogenic to rabbits and mice, and may set up inflammatory processes in these animals closely resembling those of the hog. 


\section{CHAPTER XXIV}

\section{DIPHTHERIA GROUP}

Two organisms will be considered under this heading, the Bacillus diphtherice and B. pseudodiphthericus. The former is of importance in human medicine as the cause of the disease diphtheria, and to the veterinarian, because of the use of horses and other animals in the manufacture of antitoxin, and because of the use that has been made of the toxin in the development of the theories of immunity. The B. pseudodiphthericus is important because of its resemblance to the diphtheria bacillus.

The characters which particularly differentiate this group are the polar or banded staining of the organisms (presence of metachromatic granules) and the production of the characteristic toxin by the diphtheria bacillus.

The term diphtheria is used in a pathologic sense to denote a type of inflammation characterized by more or less extensive necrosis, and the formation of false membranes of fibrin, which are rather intimately joined to the tissue which produces them. Many organisms can bring about diphtheritic inflammation in the tissues of man and animals. These organisms belong to such varied genera as Streptococcus, Bacillus, and Actinomyces; a pathologic grouping would, therefore, bring together unrelated forms, hence the inclusion of but the one organism under this group. By diphtheria is meant the specific disease of man caused by the Bacillus diphtheria, and diseases of animals resembling it clinically, as fowl diphtheria, are not to be confused with it.

\section{Bacillus diphtherix}

Synonyms.-Klebs-Löffler bacillus; Bacterium diphtheria; Corynebacterium diphtheria; Mycobacterium diphtheria.

Disease Produced.-Diphtheria in man, rarely in some animals.

Klebs, in 1883, described an organism present in the false mem- 
brane of diphtheria, which Löffler, in 1884, secured in pure culture and showed to be pathogenic. A similar organism was isolated by him from a healthy child, so that he was reluctant to conclude that he had found the true cause of the disease. Roux and Yersin, in 1888-1890, showed that the various pathologic conditions most characteristic of diphtheria could be duplicated in animals by injection of the broth filtrate containing the toxin.

Distribution.-Occurs in epidemies, particularly among the young, in Europe and America.

Morphology and Staining.-Bacillus diphtherio is so variable in its morphology that many writers do not consider it a Bacillus

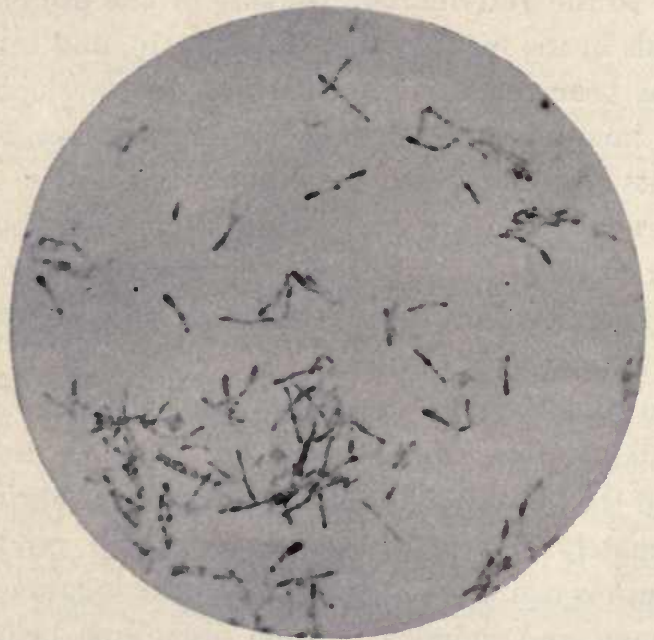

Fig. 98.-Bacillus diphtherice (Epstein in Journal of Infectious Diseases).

at all, but to be more closely related to some of the higher bacteria or even the fungi. It stains readily with the common anilin dyes, and is gram-positive. When stained with methylene-blue a smear, prepared directly from an infected mucous membrane, will show rods varying from 0.4 to $1 \mu$ in diameter and 1.5 to $3.5 \mu$ in length, frequently slightly curved, sometimes pointed or club-shaped, sometimes staining uniformly, but usually containing metachromatic granules, which stain more deeply than the remainder of the cell, and give a barred or granular appearance to the cell contents. These same variations may be observed in the organism taken from suitable culture-media, particularly Löffler's blood- 
serum. Occasionally branched forms may be observed. Demmy has shown that the Bacillus diphtherio varies almost from hour to hour in its morphology when grown upon blood-serum. In five hours after the culture is made the cells take the stain uniformly; in eight hours some cells show vacuolization; in twelve hours the organism is larger and stains unevenly, and within forty-eight hours irregular and clubbed forms are abundant. Wesbrook has constructed a chart which is in common use in laboratories in the designation of the different types of bacilli to be observed. Upon media where growth occurs more slowly than upon serum the organism remains smaller and stains more
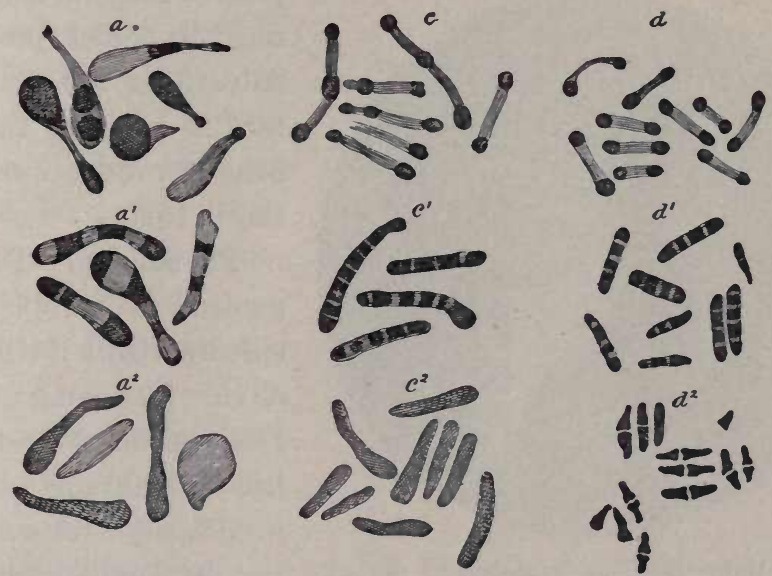

Fig. 99.-Bacillus diphtheria, Wesbrook's types: $a, c, d$, Granular types; $a^{1}, c^{1}$, $d^{1}$, barred types; $a^{2}, c^{2}, d^{2}$, solid types ( $\left.\times 1500\right)$ (McFarland).

uniformly. Whether or not the morphologic types of Wesbrook represent true varieties or differ in their pathogenic properties is a matter of dispute. Wesbrook claims the types which develop rapidly upon blood-serum and show distinct granulation are virulent, while the slower growing solid types are relatively nonvirulent. It is claimed by others that the latter simply represent the B. pseudodiphthericus, the organism next to be considered. No spores or capsules are produced. The organism is non-motile.

Isolation and Culture.-Bacillus diphtherice may usually be isolated directly from the throat of a diphtheritic patient in pure culture upon agar or, better, upon blood-serum. In mixed infec- 
tions glycerin-agar plates may be poured from the growth on blood-serum. It grows well upon most of the laboratory media. Upon Löffler's blood-serum distinct colonies are sometimes visible within twelve hours as minute, pin-point, translucent dots; these enlarge, and within twenty-four hours show as small, opaque, gray colonies, usually discrete. The organism develops somewhat less luxuriantly upon agar and gelatin, although repeated transfers tend to increase the luxuriance. Growth occurs in milk, with but little or no observable change in the medium. Broth may be clouded. A delicate film or pellicle forms on the surface after a time, and if transfers of this are made to fresh broth, the

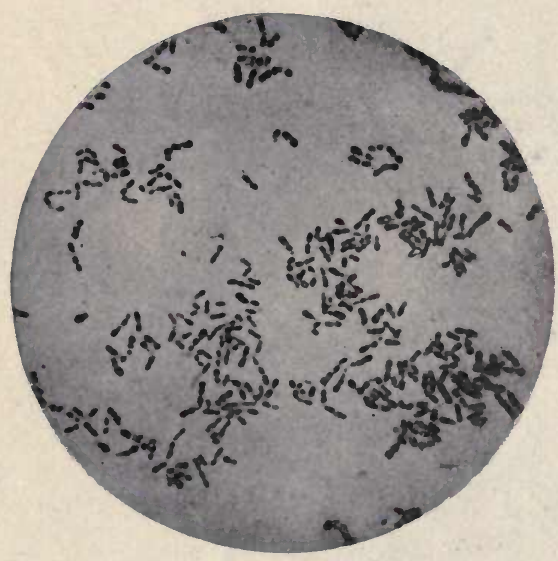

Fig. 100.-Bacillus diphtheria, mount from blood-serum showing the characteristic metachromatic granules (Fränkel and Pfeiffer).

for thirty minutes, destroys it. In the dried condition it is more resistant. Dextrose is fermented by virulent forms in general, with the production of acid, but no gas. Lactose is not fermented. The non-virulent types are believed to show less power of acid production. Nitrates are reduced to nitrites. No indol is produced. Proteolytic enzymes are not formed; gelatin is not liquefied.

Pathogenesis.-Mechanism of Disease Production.-Diphtheria is one of the best examples of a toxemia, as the organism remains upon the surface of the mucous membranes and in the necrotic 
tissue, rarely, if ever, entering the blood-stream, and brings about the characteristic lesions of the disease by means of the toxins which it produces. These are absorbed into the blood and bring about changes in many of the organs of the body. Death is sometimes due directly to asphyxiation by the false membranes occluding the air-passages.

Experimental Evidence of Pathogenesis. - The typical diphtheritic inflammation of the mucous membranes may be reproduced in young animals by direct inoculation in the trachea, and in older animals as well if the membranes are-injured previously. The histologic lesions of the body organs can be produced by injections of the toxin of the organism. Paralysis due to toxone poisoning may be developed under certain conditions. That this organism is the specific cause of diphtheria is, therefore, definitely established.

Character of Disease and Lesions Produced. - The pharynx is most commonly affected; the larynx and the nasal mucous membranes are sometimes involved. There may also be diphtheritic conjunctiv-

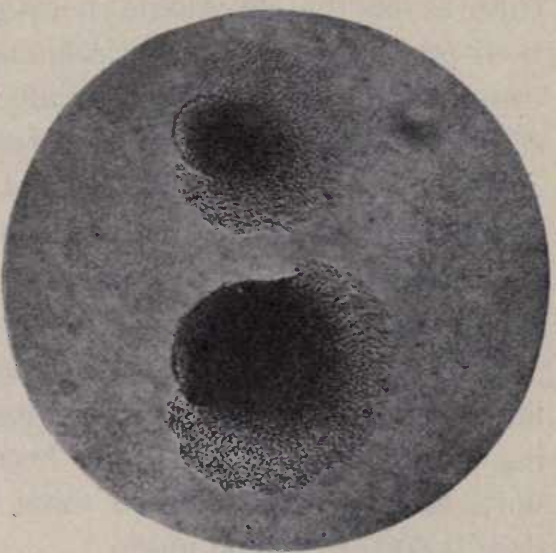

Fig. 101.-Bacillus diphtheria, twentyfour-hour colony on agar $(\times 100)$ (Fränkel and Pfeiffer).

itis, diphtheritic infections of the middle ear and of the mucous membranes of the genital organs. The organisms remain localized, rarely entering the blood-stream, cause necrosis and degeneration of the epithelial cells and the deeper tissues as well. Bloodserum and fibrin are exuded from the vessels, and, together with fragments of the necrosed tissue, form the diphtheritic membrane. Acute interstitial nephritis, fatty degeneration of the myocardium, and sometimes of the nerve tissues, are due to the absorption of the toxins. There is no constant ratio between the extent of the diphtheritic process in the throat or elsewhere and the severity of the symptoms and lesions produced by the toxin. 
Immunity. - The diphtheria bacillus, according to Ehrlich, produces two types of poison, the true toxin and the toxone. The first is responsible for the acute symptoms of poisoning, the latter for the paralysis that frequently occurs during convalescence. The haptophores of both toxin and toxone are believed to be identical, and to be neutralized by the same antitoxin. A consideration of the production of diphtheria antitoxin has been taken up in the chapter on Toxins and Antitoxins, under the heading of Immunity. Agglutinins may develop in the blood, but are not constant, and are of no practical value in diagnosis. They may be produced in experimental animals by the injection of killed cultures of the diphtheria bacillus. Precipitins have likewise been produced by artificial immunization, but usually cannot be demonstrated in the blood of infected individuals. Bactericidal sera may be prepared by repeated injections of killed, washed cultures of diphtheria bacilli, and favorable results have been reported in the use of such a serum in freeing the throat of convalescents from the bacteria. Its clinical value can scarcely be said to be proved. Opsonins have not been demonstrated.

The value of diphtheria antitoxin for prophylactic and curative injections is well established. It has resulted in materially lessening mortality whenever it has been used. As much as 100,000 units have been injected in some cases, but the usual curative dose is 8000 to 15,000 units.

Bacteriologic Diagnosis. - Sterile swabs are used to swab out the throat and nose of the suspect, and are smeared over the surface of blood-serum. Mounts made in five to eighteen hours thereafter, stained with Löffler's methylene-blue, should show the characteristic organism with its metachromatic granules. Diagnosis may sometimes be made directly from smears taken from the throat.

Transmission.-The organism doubtless sometimes gains entrance into the body by the inhalation of infective droplets, but more commonly by the use of common drinking vessels and through fomites.

\section{Bacillus pseudodiphthericus}

Synonyms.-Bacterium pseudodiphthericum; Mycobacterium pseudodiphthericum; bacillus of Hoffman; Bacillus clavatus; Corynebacterium pseudodiphthericum. 
Löffler, in 1887, found an organism in diphtheritic membranes that resembled the true diphtheria bacillus closely. Hoffman, a little later, made a series of similar observations. These organisms have since been found repeatedly in normal throats, as well as associated with the true diphtheria bacillus in disease.

Distribution.--It has been estimated that about one-sixth of all healthy individuals have the pseudodiphtheria bacilli present in the mouth and throat.

Morphology.-Morphologically, some races have been discovered that are practically indistinguishable from the $B$. diphtherice. In general, however, the pseudodiphtheria organism is somewhat shorter and plumper, and does not ordinarily show granules when treated with the Neisser stain. Some investigators claim to have observed transformations of the one type into the other, but these statements need verification, for other careful workers have failed.

Pathogenesis.-The principal differential character is the lack of pathogenesis and toxin-production by the Hoffman type. Transformation of the non-virulent into the virulent type has not been satisfactorily demonstrated. The organism is of importance only in that it may lead to a mistaken diagnosis of diphtheria. 


\section{CHAPTER XXV}

\section{BACILLUS PSEUDOTUBERCULOSIS GROUP}

THE term "pseudotuberculosis bacillus" is applied to any organism that produces a disease in which nodules resembling those of tuberculosis are formed. The name does not refer to any relationship of the organism to the Bacillus tuberculosis, but simply to the similarity of the lesions produced. These organisms are not acid fast. They all resemble each other in being the cause of chronic caseations and suppurations, particularly of the lymphnodes.

This group of organisms, including the B. pseudotuberculosis, B. lymphangitidis ulcerosa, and B. pyogenes bovis, is in need of careful revision, for the species limits are not well understood. These organisms all resemble the diphtheria bacillus somewhat, particularly in pleomorphism, shape, and staining characters. None, however, are known to produce any toxins.

\section{Bacillus pseudotuberculosis}

Synonyms.-Bacillus pseudotuberculosis ovis; Mycobacterium pseudotuberculosis; Bacillus tuberculosis murium; bacillus of Preisz.

Diseases Produced.-Caseous lymphadenitis in sheep, and similar infections in the mouse and rarely in cattle.

Organisms differing morphologically from the tubercle bacillus, but causing somewhat similar lesions in the body, were first noted by Malassez and Vignal in 1883. Charrin and Roger, in 1888, described nodules in the liver and spleen of guinea-pigs, caused by organisms that were not acid fast. Nocard, in 1889, studied an epizoötic among rabbits caused by a similar organism. Preisz and Guinard, in 1891, reported pseudotuberculosis in sheep, and in 1894 Preisz published an extended account of the disease. In the United States Nörgaard, in 1899, published an account of 
the disease and its organism, which showed it to be of considerable economic importance in sheep and to be quite generally distributed. This organism is not to be confused with the pseudotuberculosis bacillus of Pfeiffer infecting guinea-pigs. The latter is wholly different, and belongs to another group entirely.

Distribution.-The disease in sheep has been reported from Europe, South America, and North America, particularly in aged sheep.

Morphology.-Bacillus pseudotuberculosis is a short, straight rod, with rounded ends, quite variable in size, about $0.4 \mu$ by 1.3 to $1.6 \mu$ or longer. Sometimes clubbed types are observed, the enlarged portion staining more intensely than the remainder,

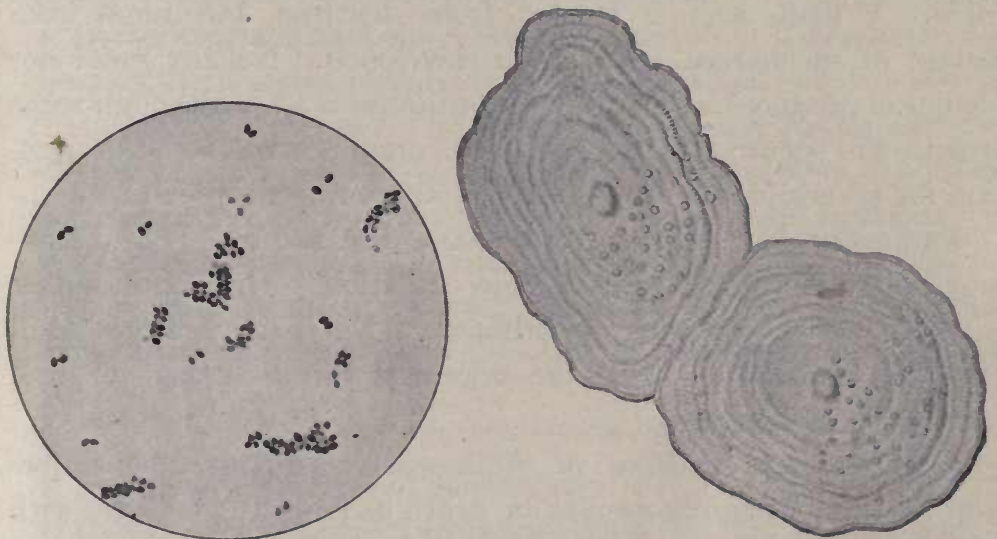

Fig. 102.-Bacillus pseudotuberculosis, colony and mount (Nörgaard and Mohler in Report of Bureau of Animal Industry).

reminding one of somewhat similar types in the $B$. diphtherice. Chain formation rarely occurs; the organisms are usually found in pairs. It is non-motile, and produces no spores or capsules. It stains readily with the ordinary anilin dyes, and is grampositive.

Isolation and Culture.-Cultures may be obtained in pure condition by opening a caseous nodule and making smears upon agar. Growth is scant at first, but becomes better after a time, as the organism adapts itself to growth on artificial media. The discrete colonies produced by the initial inoculation grow in twelve days to a diameter of 4 to $6 \mathrm{~mm}$.; they are rounded, thick, graywhite in color, with a waxy and granular surface, and with con- 
centric rings and a papillate center. In subsequent transfers the colonies are confluent, dry, and cohesive. Glycerin agar is not so favorable as the plain agar. Bouillon becomes turbid, then clears by sedimentation, and a white, "greasy," brittle pellicle forms. Gelatin is not a suitable medium, as little growth occurs at room-temperatures. Blood-serum is favorable, the colonies frequently becoming creamy yellow in color. Growth occurs on potato and in milk. In the latter the appearance is unchanged. The organism described by Preisz is recorded as showing some minor differences in cultural characters from the one studied by Nörgaard.

Physiology.-The organism is aërobic and facultative anaërobic. A little acid is formed from dextrose, but none from lactose or saccharose. No gas is developed. Neither indol nor phenol is produced. The growth optimum is $37^{\circ}$, although some growth will occur at $16^{\circ}$ to $18^{\circ}$. The organism will resist desiccation for several days. It is easily destroyed by disinfectants.

Pathogenesis.-Mechanism of Disease Production.-The disease may be characterized as a chronic caseation of the lymph-nodes, without general systemic disturbances. No toxins are produced, and the means by which the organism brings about its local reaction is unknown.

Experimental Evidence of Pathogenesis.-Intravenous injection of the guinea-pig results in death in four to ten days, with foci of caseation in various internal organs, particularly the lungs and the liver. Subcutaneous injection is followed by enlargement and caseation or suppuration of the lymph-glands, resulting fatally in from fifteen to twenty-eight days. Feeding experiments have been successful in causing infection. Similar results may be reached by the use of the rabbit, the mouse, but not pigeons and fowls. Experimental inoculation of sheep has reproduced the disease.

Character of Disease and Lesions Produced.-The organism has been reported chiefly as a cause of ovine caseous lymphadenitis, but an organism probably identical with this form has been reported from similar lesions in the lungs of cattle. It is possible that it likewise is identical with the type next to be described. The disease of sheep is found chiefly in breeding ewes. The 
disease progresses slowly, and is frequently not recognized until the animal is slaughtered. The lymphatic glands are most frequently affected. These glands enlarge, caseate, and are often encapsulated. In more advanced cases the internal organs are also infected, nodules appearing in the lungs, spleen, and liver, and sometimes in the kidneys. The lesions are not commonly found in young animals, probably because the disease has not had time to develop sufficiently to cause the enlarged glands to be noted in inspection.

Immunity.-The organism does not produce a toxin. Agglutinin, bacteriolysin, and opsonin production, as well as methods of immunization, have not been investigated.

Bacteriologic Diagnosis.-Mounts from pus or the caseated contents of the nodules, stained by Gram's method, should show the characteristic bacillus. The use of the acid-fast staining method will differentiate from $B$. tuberculosis. Isolation upon agar slants may sometimes be necessary to complete the identification.

Transmission.-The normal infection atrium in the sheep is not certainly known. Probably the organism may gain entrance through skin abrasions, and possibly by inhalation and ingestion.

\section{Bacillus lymphangitidis ulcerosa}

Synonym.-Bacillus of pseudofarcy.

Disease Produced.-Ulcerative lymphangitis, pseudofarcy, or pseudoglanders in equines.

Nocard, in 1892, described an organism which he believed to be the etiologic factor in an outbreak of pseudofarcy in horses. Later (1897) he concluded that his organism was identical with the Bacillus pseudotuberculosis just described. Sufficient differences in the organism have been pointed out to justify the retention of a separate name for this organism until further investigations have been made. The probabilities are much in favor of the identity of the two forms, and the name B. pseudotuberculosis might then be used to include both.

Morphology and Staining.-This organism resembles the preceding morphologically. It is gram-positive.

Isolation and Culture.-The organism may be obtained in pure culture directly from infected lymph-glands. Upon agar discrete, 
white, opaque colonies are formed. These generally become confluent. The whole mass of the growth may be detached from the surface of the medium. In bouillon, clouding occurs, then the medium clears by sedimentation, with or without a pellicle. Upon serum the organism produces outgrowths into the medium, and resembles the $B$. pseudotuberculosis closely. Milk is not changed.

Physiology. - The organism is aërobic. Neither acid nor gas is developed from carbohydrates. The thermal death-point is about $65^{\circ}$ with an exposure of fifteen minutes.

Pathogenesis.-Experimental Evidence.-Subcutaneous inoculations of the guinea-pig result in abscess formation and extension along the lymph-channels. Introduced intraperitoneally into a male guinea-pig, it commonly produces an orchitis which cannot be readily differentiated from that produced by the glanders bacillus. Nocard reproduced the disease in the horse by the inoculation of pure cultures.

Character of Lesions and Disease Produced.-The subcutaneous lymph-nodes are chiefly affected. They enlarge, and break through to the surface, producing an abscess characterized by suppuration. The clinical spicture closely resembles that of farcy. Involvement of the deeper glands and of the internal organs occurs later in the progress of infection.

Bacteriologic Diagnosis.-This organism may be differentiated from the true glanders bacillus by the fact that it is gram-positive, while the latter is gram-negative. The production of an orchitis in the male guinea-pig when injected makes it necessary that mounts stained by Gram's method be used to differentiate from $B$. mallei. In doubtful cases, pure cultures should be grown upon the potato.

Immunity.- Nothing is known of the metabolic products of the growth of the organism nor of methods of immunization or of the body reactions to its presence.

Transmission.-The disease is probably transmitted through skin lesions, possibly by inhalation or ingestion.

\section{Bacillus pyogenes bovis}

Synonyms.-Bacillus renalis bovis; B. pyelonephritidis bovis.

Infection Produced.-Pyelonephritis, caseation of lymphglands, and chronic pneumonia in cattle. 
It is probable that this organism is identical with the Bacillus pseudotuberculosis discussed above or at least closely related to it. It has been isolated from cattle by several investigators.

Distribution.-This organism has been reported both from this country and Europe.

Morphology and Staining.-This organism resembles the Bacillus pseudotuberculosis in many respects, but is somewhat larger0.7 by 2 to $3.8 \mu$. It is sometimes granular, and produces clubbed or even branched forms. It is quite commonly bent. It is nonmotile, does not produce spores or capsules. It stains readily with the common anilin dyes, and is gram-positive.

Isolation and Culture.-The organism may be isolated in pure culture from infected lymph-nodes or other lesions directly upon agar. Agar slants show discrete, grayish-white colonies that never become large. From the periphery of some of these colonies short filaments radiate into the agar. Bouillon remains clear, and a distinct sediment forms.

Physiology. - This organism tends to die out quickly in artificial media. It is aërobic. No acids nor gas are produced from carbohydrates.

Pathogenesis.- Our knowledge of the pathogenesis of this organism is not in a satisfactory state. It has been isolated from chronic bronchopneumonia in cattle and from various other secondary and metastatic infections. It has also been found associated with pyelonephritis. This latter infection is marked by enlargement of the kidneys and a purulent inflammation of the lining mucous membranes of the ureters and bladder. The inflammation may cause necrosis of the tissues. When injected into guinea-pigs or mice, suppuration may be induced.

Immunity. - Nothing is known relative to the metabolic products of the organism or of methods of either passive or active immunization.

Bacteriologic Diagnosis. - The presence of the organism may be demonstrated by the use of Gram's stain and by pure culture methods.

Transmission.- The infection atria are probably the respiratory tract in lung infection and the genito-urinary organs, particularly in the female following parturition. 


\section{CHAPTER XXVI}

\section{SWINE ERYSIPELAS GROUP}

Two organisms have been described as belonging to this group-the Bacillus rhusiopathice and B. murisepticus. As will be noted later, there is good reason to believe that these organisms are identical. The group may be characterized as made up of very minute, slender, non-motile, non-spore-producing, gram-positive rods.

\section{Bacillus rhusiopathixe}

Synonyms.-Bacillus rhusiopathice suis; Bacillus erysipelatis suis.

Disease Produced.-Swine erysipelas, red fever of swine, rouget, Rotlauf.

Löffler in 1885 first described the organism present in swine erysipelas. The disease had previously been differentiated from anthrax by Pasteur and Thuiller.

Distribution.-The disease has been reported from most of the European countries, and an organism resembling the Bacillus rhusiopathice has several times been reported from the United States, although there has been no satisfactory demonstration of the presence of the disease in this country. In Europe the disease is of considerable economic importance.

Morphology and Staining.-Bacillus rhusiopathice is a slender rod, variously given as 0.2 to $0.4 \mu$ by 1 to $2 \mu$, usually straight, but sometimes somewhat curved, single or in chains. It is nonmotile, does not produce spores or capsules. It stains readily with the anilin dyes and is gram-positive.

Isolation and Culture.-The organism may be secured in pure culture by plating the blood or pulp from some of the internal organs, the spleen in particular. The colonies in the gelatin plate appear on the second or third day, and are quite character- 
istic. Each colony is found to be surrounded by a zone of muchbranched threads. They permeate the medium, and are not found upon the surface, as is the case with anthrax and other forms which produce colonies with filamentous edges.

Gelatin stab cultures develop only below the surface of the medium, showing the micro-aërophilic or semi-anaërobic growth characters of the organism. The mature stab has the appearance of a test-tube brush, streaks and disks of growth radiating from the center. Streak cultures do not develop well upon agar or bloodserum except by growth under anaërobic conditions, preferably by absorption of the oxygen by the alkaline pyrogallate method. Bouillon is clouded and produces a grayishwhite sediment. Ordinarily no growth occurs upon potatoes, even under anaërobic conditions.

Physiology.-The B. rhusiopathice grows better anaërobically than aërobically. It is unusually resistant for a non-spore-producing form. Desiccation frequently fails to destroy the organism in several weeks. The thermal death-point is recorded by some authors as low as $52^{\circ}$ for fifteen minutes, by others as high as $70^{\circ}$. The optimum growth temperature is $37^{\circ}$, but growth occurs well at roomtemperatures. Gelatin is not com-

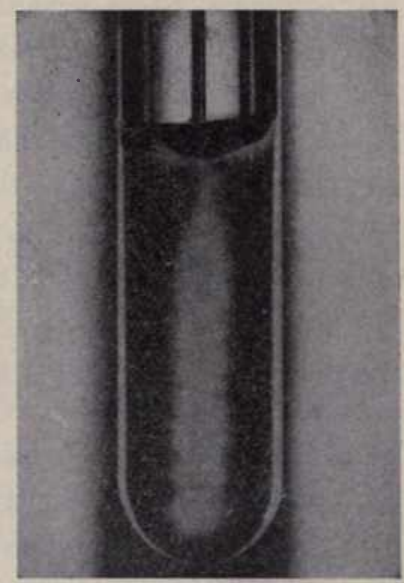

Fig. 103.-Bacillus rhusiopathice, stab culture in gelatin -four days (Fränkel and Pfeiffer). pletely liquefied, but generally softened.

Pathogenesis.-Experimental Evidence.-Mice die of septicemia when inoculated with pure cultures. Death occurs usually within four days, frequently within forty-eight hours. Field-mice are immune, as are guinea-pigs, cattle, horses and other equines, dogs, cats, chickens, and geese. Rabbits inoculated subcutaneously develop an edema and redness at the point of inoculation, and this erysipelas-like lesion spreads to other parts of the body and the animal dies. Intravenous injection is quickly fatal through the development of a septicemia. The white rat, 
the sparrow, and the pigeon are likewise susceptible. The typical disease may be produced in swine by inoculation of pure cultures. There is no doubt but that the Bacillus rhusiopathice is the cause of the disease. There is some evidence that the infection in a mild urticarial form is occasionally transmitted to the human.

Character of Disease and Lesions Produced.-Small numbers of bacteria can generally be demonstrated in the blood, and abundantly in various of the body organs, particularly the spleen and the lungs. In the acute type of the disease the mucous membrane of the alimentary tract is reddened, and shows petechial hemorrhages. The spleen and the lymph-nodes are somewhat enlarged, and the lungs are usually congested. The most characteristic lesions are those of the skin, where numerous congested areas and local hemorrhages give rise to the spotted appearance. In chronic cases there is generally a verrucose or ulcerous endocarditis which is quite characteristic.

Immunity.- No true toxin has been demonstrated for the Bacillus rhusiopathice. The presence of specific amboceptors in immune serum may be shown by the method of complement absorption, but just what part these play in immunity has not been satisfactorily demonstrated. Opsonins are present, and probably account in part for the immunity.

Very young animals-under three months - and those over one year rarely contract the disease. Animals that recover from the disease are thereafter immune.

Active Immunization.-It has been shown by the researches of Pasteur, later by Kitt and others, that passage of strains through certain animals, particularly the rabbit or the pigeon, leads to an attenuation such that the material may be used for vaccination of the hog. It is also known that continued cultivation usually reduces the virulence of the organism for mice. The virulence is subject to great and inexplicable variations. The Pasteur vaccine consists of an attenuated bouillon culture of the B. rhusiopathice. The material is sent out in two packages, labeled Vaccine I. and Vaccine II. These are injected fifteen days apart. Immunity is established in two to three weeks after the second injection. The injected animals sometimes show the characteristic 
urticaria of the disease. The use of this method has led to varied results in different countries. Voges and Schütz have modified the Pasteur vaccine method by doing away with the Vaccine II., as they found the blood still contained bacilli at the time of the second injection, and concluded the latter, therefore, useless. It seems that a satisfactory immunization of the hog against the disease cannot be accomplished by injections of the killed organisms.

Passive Immunization.-Emmerlich and Mastbaum, in 1891, described a method of preparing an immune serum which would protect animals against the disease. Their method was impractical in some respects, and was superseded by the method of Lorenz, and this by those of Leclainche, Voges and Schütz, and Lange. The antiserum is prepared by the intravenous injection of virulent bouillon cultures into the horse. Usually 100 c.c. constitutes the initial injection, and is followed at intervals by larger amounts - up to 500 c.c. The injection produces a rise in temperature, and other reactions that disappear in twenty-four to forty-eight hours. The immune blood is drawn, and the serum used for passive immunization of swine. It is prepared on a large scale in several institutes in Europe, and is used extensively. Cattle and even buffalo are sometimes used instead of the horse in the preparation of the serum. Prettner claims that the use of cattle immune serum confers a more lasting immunity than that of the horse. Schreuber and Schubert studied the question of multiplicity of amboceptors, and came to the conclusion that a mixture of immune sera from horses and cattle would give a greater variety of amboceptors specific for the organism. A mixture of this kind is termed "double serum" (German, Rotlauf Doppelserum). The double serum has not proved in practice to be of any greater value than the serum from the horse alone. The immune serum is usually standardized by the use of the mouse, commonly by the method of Lorenz. A serum suitable for use should immunize a mouse in doses of 0.01 gm. per $10 \mathrm{gm}$. of weight, against injection with $0.01 \mathrm{gm}$. of a virulent culture. Lorenz used mice weighing uniformly $15 \mathrm{gm}$. as a standard, and such a serum is said to have a titer of $0.015 \mathrm{gm}$. (mouse). Marx has modified the technic of Lorenz somewhat, but the principle is the same. Leclainche has advised the use of 
the pigeon, rather than the mouse, as a test-animal. The serum may be used curatively or prophylactically. Amounts up to 30 c.c. are used in curing the disease. In cases not too far advanced it arrests the disease, and has been shown to reduce the mortality materially. The injection of the serum prophylactically results in temporary immunity only, hence it is customary to establish an active immunity by injection of the specific organism, the culture and the serum being mixed together or injected separately at the same time. This method of immunization has proved of such value that it is extensively used in Europe. The active immunity developed as a result of the combined method lasts for periods of six months to a year or even longer.

Bacteriologic Diagnosis.-Smears from the spleen, sometimes from the blood, will show the characteristic slender, gram-positive bacillus. Isolation in gelatin plates gives a characteristic type of colony. The stab culture in gelatin is also diagnostic.

Transmission.-The specific organism may be demonstrated in the feces of an infected individual. It may gain entrance directly through the skin, but probably, in most instances, the infection atrium is the alimentary tract. Typical virulent bacilli and non-virulent forms have been repeatedly isolated from healthy animals. It is evident that the interrelationships of this organism and the body are quite complex.

\section{Bacillus murisepticus}

Disease Produced.-Mouse septicemia.

Koch, in 1878, ealled attention to the fact that the injection of putrid meat infusion into a mouse resulted in a septicemia due to a non-motile, minute rod. It is of importance chiefly because of its resemblance to the Bacillus rhusiopathice. It has been isolated from a variety of sources in nature, and has been known to cause epidemics in mice kept for experimental purposes. There are no marked cultural characters which may be used to differentiate the two organisms, and morphologically they are likewise very similar. It is claimed by some that the $B$. murisepticus is somewhat more slender than the $B$. rhusiopathice. It has been found possible to immunize the rabbit against the latter by injections of the former. However, it has not been found possible to 
produce typical swine erysipelas by the injection of $B$. murisepticus. It is undoubtedly true that the two organisms are closely

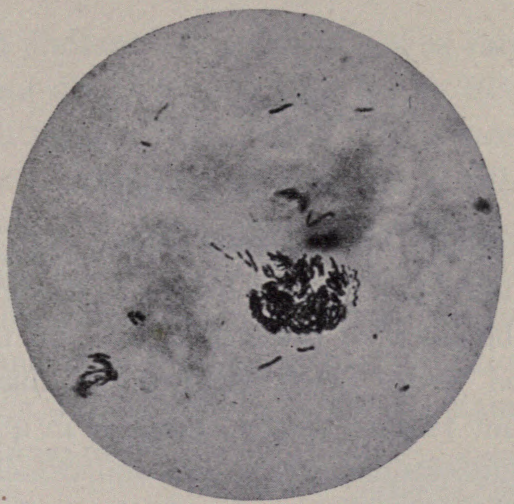

Fig. 104.-Bacillus murisepticus, stained mount (Günther).

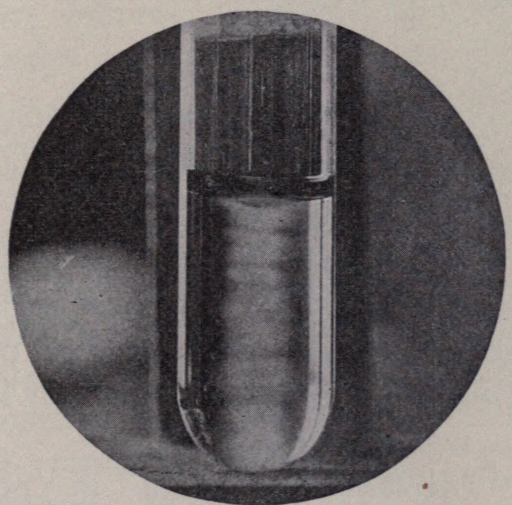

Fig. 105.-Bacillus murisepticus, stab culture in gelatin (Günther).

related. Whether they are varieties of one species, differing in virulence, is not known. 


\section{CHAPTER XXVII}

\section{GLANDERS GROUP}

ONE organism only, the Bacillus mallei, the cause of glanders and farcy in equines, is known to belong to this group. It should be noted that the so-called pseudoglanders and the causal organisms are treated under other chapter headings. These latter organisms are not related to the organism in question except in that they produce lesions which are sometimes confused with glanders clinically. Some of the pseudoglanders organisms belong to such disease groups as the bacteria, the blastomycetes, and the hyphomycetes.

\section{Bacillus mallei}

Synonyms.-Bacterium mallei; Mycobacterium mallei.

Diseases Produced.-Glanders and farcy in equines; Rotz; morve.

Löffler and Schütz, in 1882, demonstrated the presence of a characteristic rod (B. mallei) in the nasal discharge of a horse affected with glanders. Kitt, in 1883 , and Weichselbaum, in 1885 , confirmed these results and added to our knowledge of the organism.

Distribution.-Glanders is known in practically every civilized country.

Morphology and Staining.-Bacillus mallei is a short rod, usually straight, but sometimes somewhat curved. The ends are rounded. It is usually single, more rarely in pairs or short chains. Involution forms are frequently produced; enlarged cells, clubbed forms, filaments, and even branching have been observed. This last fact has led to the grouping of this form with the higher fungi by some authors. The normal rods vary from 0.25 to 0.4 by 1.5 to $5 \mu$. The organism is non-motile, and does not produce spores or capsules. It stains with the ordinary anilin dyes, and still better with stains containing a mordant, such as carbol-fuchsin. 
It sometimes shows some granular differentiation of the cytoplasm, resembling the diphtheria bacillus. It is not acid fast and is gram-negative.

Isolation and Culture.-Bacillus mallei is rarely in pure cultures in the nasal discharges, so that for its isolation from such sources a special technic is necessary. It is customary to inject intraperitoneally a male guinea-pig with a small quantity of the discharge from an ulcer, mixed with a little bouillon or physiologic salt solution. Within two to four days the testicles swell and give evidence of acute inflammation. The animal is then killed, a testis removed and opened under aseptic conditions, and the contents of one of the small abscesses or foci of inflammation removed on a sterile platinum needle to suitable media.

\section{Bacillus mallei grows} upon the ordinary culturemedia, particularly upon those that contain glycerin, upon blood-serum, and potato. The colonies upon agar and glycerin-agar plates are whitish or yellowish, glistening, usually circular. Upon the slanted medium the colonies are coalescent and form a moist, shining layer. In

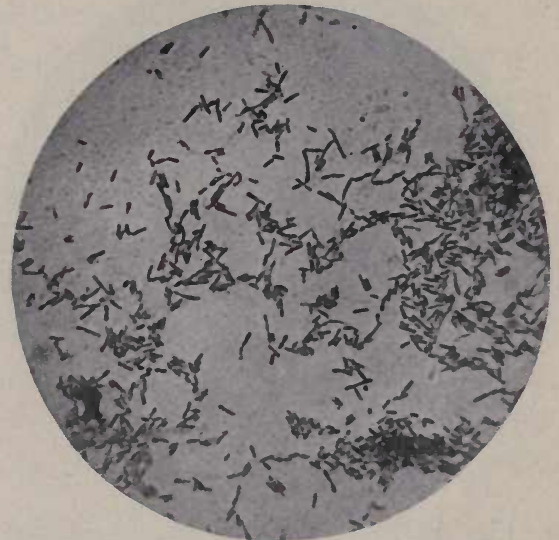

Fig. 106.-Bacillus mallei from glycerin agar ( $\times 1000[$ (Fränkel and Pfeiffer). bouillon and glycerin bouillon B. mallei produces an initial turbidity, followed by sedimentation; a shining white pellicle is likewise formed when the medium is not shaken. On bloodserum the colonies are first discrete, clear, yellowish, viscous, hemispheric drops which coalesce to form ${ }^{-}$a transparent layer over the surface; this later becomes gray and opaque. Gelatin is not liquefied. The growth upon potato is perhaps the most characteristic. It may be described as forming within fortyeight hours a yellow, honey-like, semitransparent growth that gradually becomes brownish or amber in tint. The potato itself is tintd greeenish or greenish brown. This reaction is not charac- 
teristic if potatoes having too acid a reaction are used. They may be neutralized previously to inoculation by soaking in dilute sodium carbonate.

Physiology.-B. mallei is aërobic and facultative anaërobic. Its optimum growth temperature is $37^{\circ}$, but its growth limits, at least in freshly isolated cultures, are about $25^{\circ}$ and $42^{\circ}$. Its thermal death-point is $55^{\circ}$, with five minutes' exposure.

Pathogenesis.-Experimental Evidence.-There is an abundance of evidence to prove that $B$. malle $i$ is the cause of glanders. All the lesions of the disease may be duplicated by the experimental inoculation of pure cultures into laboratory animals and

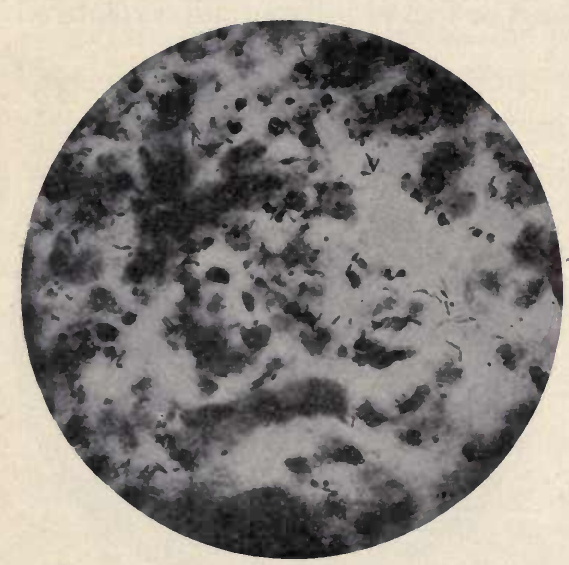

Fig. 107.-Bacillus mallei, in section from the spleen of a field-mouse (Fränkel and Pfeiffer). the horse. The guinea-pig is very susceptible. A subcutaneous inoculation is followed within a few days by local swelling and induration, which soon ulcerates and discharges to the surface. The disease spreads largely through the lymph-channels, and the lymph-nodes enlarge and suppurate. Various metastatic infections of the joints, the lungs, and other organs occur. Death seems to be due to exhaustion. Infection may similarly be transmitted to the rabbit. The horse may be readily infected, as may sheep, goats, the cat, and the dog. Cattle and the house-rat do not contract the disease. It occurs in man through infection from glandered animals and through working with pure cultures in the laboratory.

Character of Disease and Lesions Produced.-The disease as found in equines may be either of an acute or a chronic type. The former is commoner in the ass and mule, and the latter in the horse. The acute type of disease is commonly ushered in with a chill, there is a mucopurulent discharge, and death usually occurs in from one to four weeks. The chronic type shows no marked 
characteristics in its early stages; the lymph-nodes in various parts of the body become infected and enlarge. This may exist for a long period in an animal, and may terminate finally in an acute attack. The lesions in the chronic type are generally present on the nasal mucosa, in the lungs, and in the lymph-glands. The nodular glanders of the nasal mucosa is the most frequent type. The nodules, small at first, enlarge to the size of a pea, then break down, suppurate, and form chronic ulcers. When healing of the deeper ulcers occurs, the scar resulting is quite characteristic. In the lungs lesions are almost invariably to be found; these may be nodular, or consist of infiltration of considerable areas of tissue. In farcy or cutaneous glanders the nodules form in the skin; the lymph-vessels become swollen and feel like a string of beads or a knotted cord. These nodules usually break through to the surface and ulcerate. In man the organism commonly gains entrance through abrasions or wounds in the skin, or by inhalation, and the infection produced is practically always fatal.

Immunity.-No toxins have been demonstrated for Bacillus mallei, although endotoxins are produced. Agglutinins are present in the blood-serum of normal animals, but in much greater concentration in the blood of infected animals. Precipitins may also be demonstrated. Of the bactericidal and opsonic nature of sera less is known.

Active Immunization.-Immunization by the use of suspensions of dead bacteria or their products (mallein) has been attempted both in prophylaxis and cure. Although some favorable results have been reached, the subject needs further study. No method of vaccination or active immunization has as yet been shown to be practical and successful.

Passive Immunization.-The blood-serum of animals, such as the ox, naturally immune to glanders has been claimed to possess immunizing power when injected into smaller laboratory animals, as the rabbit. No practical utilization has been made of this, and the fact itself is in need of further study.

Bacteriologic Diagnosis.-A presumptive bacteriologic diagnosis may be made by an examination of properly stained pus or sections of tissue, and a more positive diagnosis by the meth- 
ods of animal inoculation, agglutination, precipitation, absorption of complement, and by the use of mallein.

Examination of Pus and Tissues.-The discovery of a gramnegative bacillus (in the pus or in tissues) having the general characters of the glanders bacillus is presumptive evidence of its presence, as there are few organisms with which it might be confused. Inasmuch as the organism decolorizes easily and is gramnegative it is difficult to demonstrate satisfactorily in tissues. The method of Kühne is recommended as giving good results. Carbol-methylene-blue (methylene-blue, 1.5 gm.; alcohol, 10 c.c., and 5 per cent. aqueous phenol or carbolic acid, 100 c.c.) is used to stain the sections one-half hour; they are then washed in water, then in very dilute hydrochloric acid ( 10 drops to 500 c.c. of water), and quickly transferred to a solution of lithium carbonate (8 drops of a saturated solution to 10 c.c. of water), then to distilled water, dehydrated in absolute alcohol containing a little methylene-blue, then cleared in anilin oil. The bacteria should show plainly.

Diagnosis by Animal Inoculation.-A male guinea-pig is inoculated intraperitoneally with a small amount of the suspected material. This should be secured as free as possible from other organisms to obviate the possibility of the animal dying prematurely of peritonitis or septicemia. In from two to four days the testes become enlarged and tender, the skin above them is reddened and shiny. The animal, in case of a positive reaction, should be killed and the contents of the testes examined microscopically to determine the presence of a gram-negative characteristic bacillus. Other organisms may give the orchitic reaction, but they are gram-positive, with the exception of Bacillus pyocyaneus. A culture should always be made from the pus in the scrotum to make diagnosis certain. This reaction is sometimes known as Strauss' biologic test.

Agglutination Test for Glanders.-The serum of a normal horse will frequently agglutinate the $B$. malle $i$ when in dilutions of $1: 100$, 1: 500 , rarely more. The serum from infected animals will in general give a reaction in dilutions of $1: 500$, and usually much higher. The organisms used in the agglutination test may be either living or dead. The latter are commonly used, as it does away largely with danger of infection to man. The bacterial 
suspension is prepared by removing the growth from a young culture on agar and suspending it in physiologic salt solution containing 0.5 per cent. phenol. This is heated at $70^{\circ}$ for two to four hours; this kills the bacteria, but does not interfere with the agglutination reaction. Equal amounts of this suspension are placed in a series of small test-tubes, and to these are added equal amounts of different dilutions of the serum to be tested, and the final dilutions of the serum determined. Dilutions are usually prepared 1:100,1:200,1:400,1:500,1:800,1:1000, and up to 1: 8000 or more. The tubes are kept at $37^{\circ}$ for from twenty-four to thirty-six hours. A positive reaction is indicated by a film covering the entire bottom of the tube, a negative by no precipitate or a little sediment in the bottom of the convexity, not forming a film. Normal blood frequently gives the reaction in dilutions as high as 1:500, and usually in dilutions of 1:100 or less. The serum of injected animals will commonly agglutinate in dilutions of $1: 800,1: 1000$, and much higher. A positive reaction in dilutions of over 1: 1000 may be considered diagnostic. Whether or not a positive reaction is accompanied by a complete clearing of the test fluid depends upon the concentration of the suspension and the dilution and potency of the serum used. The fluid may remain somewhat cloudy in a positive reaction in the higher dilutions, not all the organisms being agglutinated. The suspensions of killed organisms may be secured ready for use from some pharmaceutical houses, together with tubes and materials for preparing the proper dilutions. The suspension when properly prepared and preserved in the dark will keep for a considerable time. The microscopic test for agglutination has not proved practicable, as normal serum agglutinates microscopically in high dilutions. When properly carried out, the macroscopic test is claimed by some to be an even better diagnostic than mallein.

Konew's Precipitation Test or the Ring Test.-A solution of glanders bacillus prepared by adding 10 c.c. of an 8 per cent. antiformin ${ }^{1}$ solution to the bacilli washed from the surface of a forty-eight-hour slant agar culture. The bacteria will go into

${ }^{1}$ The composition of antiformin is given on p. 312. It is a patented disinfecting solution, and may be purchased upon the market. 
solution within two hours. It is well to add even more of the organism if it appears to dissolve rapidly, as it is desirable to get as concentrated a solution as is possible. The solution must then be carefully neutralized, preferably by the use of 5 per cent. sulphuric acid. This is then filtered through paper, then through a Berkefeld filter, to remove all undissolved bacteria. The filtered solution is termed " mallease." A test-tube is filled to a depth of $3 \mathrm{~cm}$. with mallease, and blood-serum from a suspected case is introduced by means of a pipette. The end of the pipette should be passed through the layer of mallease and should rest against the bottom of the tube before the serum is allowed to flow. A quantity of serum about equal to the mallease is introduced. The pipette is withdrawn quickly and carefully to prevent any mixture of the two liquids. The serum has a higher specific gravity and remains at the bottom, with the mallease as a distinct superficial layer. If the serum is from an animal free from the disease, there will be no reaction. A positive diagnosis of glanders is indicated by a white cloudiness that appears along the line separating the two liquids. This is due apparently to precipitation by the specific precipitins formed in the serum. In acute or well-marked cases the reaction occurs almost immediately, and usually in all cases within fifteen minutes. The test is too recent to speak authoritatively of its reliability, but the reports thus far seem to indicate that it is far more reliable and more easily carried out than any of the other glanders tests.

Fixation of Complement Test.-Schütz and Schubert ${ }^{1}$ have described a satisfactory method of adapting Wassermann's syphilis test by fixation of complement to the diagnosis of glanders. Mohler and Eichhorn ${ }^{2}$ have tested out the method and found it highly satisfactory. They prepare hemolytic amboceptor for sheep erythrocytes by injecting the washed red blood-cells intraperitoneally into a rabbit. The corpuscles are suspended in an equal bulk of physiologic salt solution, and 14, 20, and 24 cubic centimeters are injected at intervals of seven days. The serum from the blood of the rabbit may be used in five or six days after the last injection. It must be inactivated by heating to $56^{\circ}$ for thirty

${ }^{1}$ Arch. f. Wiss. u. prakt. Tierheilkunde, Band 35, pp. 44-83, 1909.

${ }^{2}$ Bull. 136, Bureau An. Ind. U. S. Dept. of Agriculture. 
minutes before it can be used. Fresh guinea-pig serum is used as complement. The antigen used is an extract of glanders bacilli prepared from the growth on slant glycerin-agar tubes. The growth is washed off with physiologic salt solution and heated to $60^{\circ}$ for four hours to kill the bacteria. The suspension of organisms is then placed in flasks and shaken in a shaking apparatus for four days. It is then centrifuged, the clear liquid removed, and 10 per cent. of a 5 per cent. solution of phenol added. This antigen may be preserved without material deterioration for several months if kept in a cool, dark place.

It is necessary to titrate the rabbit serum and likewise the antigen in order to determine the amounts most suitable for carrying out the test. For each set of determinations of diagnosis fresh guinea-pig serum must be used. Blood-serum from the animal that is suspected of having glanders must be inactivated by heating to $58^{\circ}$ for thirty minutes. The materials necessary for the test are-

1. Washed sheep corpuscles, 5 per cent. suspension (antigen 1).

2. Inactivated serum from rabbit immunized against 1 (amboceptor 1).

3. Fresh guinea-pig serum (complement).

4. Extract of glanders bacilli (antigen 2).

5. Inactivated serum from suspected animal (amboceptor 2).

The test is carried out in test-tubes. In tubes 1 and 2 there is placed 0.1 c.c. of the serum (No. 5, above), and in tubes 3 and 4 , 0.2 c.c. of the same. One c.c. of the established dilution of glanders bacilli (No. 4, above) is then added to tubes 1 and 3 . To each tube is then added 1 c.c. of the dilution of fresh guinea-pig serum that has been established by preliminary test. Each tube is now made up to 3 c.c. with physiologic salt solution. They are then placed in the thermostat at $37^{\circ}$ for an hour. They are then removed and to each tube is added 1 c.c. of the previously standardized rabbit serum (No. 2, above) and 1 c.c. of the sheep corpuscles (No. 1, above). The tubes are shaken and incubated for ten hours. A positive diagnosis is indicated by lack of hemolysis in tubes 1 and 3 and complete hemolysis in tubes 2 and 4 . Checks must be made to determine the hemolytic activity of each of the above constituents independently. 
This method is essentially a laboratory one and quite impracticable for field work. There seems to be no reason why blood samples or, better, serum samples from suspected cases should not be sent to properly equipped laboratories for diagnosis and report. The method apparently is capable of giving good results, and seems to be more accurate than the mallein test.

Mallein Test for Glanders.-Mallein is a suspension of killed B. mallei, together with the products of its autolytic disintegration. What the active principles in bringing about the characteristic reaction in a glandered horse may be is not known. Probably they are the soluble bacterial proteins, possibly true endotoxins. The various laboratories use different methods of preparing mallein. The most important of these are worthy of note.

The mallein of Roux is prepared by the Pasteur Institute as follows: The virulence of the $B$. mallei used is increased by passage through rabbits, and is such that mice and rabbits are killed in less than thirty hours by intravenous injections. Flasks containing 250 c.c. of glycerin bouillon are inoculated and incubated a month at $35^{\circ}$. The cultures are killed by exposure to a temperature of $100^{\circ}$ for thirty minutes in an autoclave, then evaporated to one-tenth the volume, and filtered through filterpaper ("papier Chardin"). The final product is a dark-brown, syrupy liquid, containing 50 per cent. glycerin. For use this is mixed with nine times its volume of 0.5 per cent. carbolic acid. The diagnostic dose is 2.5 c.c. of this dilution.

The mallein of Vladimiroff, used in the Russian Empire, is prepared by inoculating a considerable number of flasks, each containing 600 to 800 c.c. of beef broth, with a vigorous culture of $B$. mallei, and incubating for eight months at $37^{\circ}$. The flasks are shaken from time to time to cause the shiny, gray-white pellicle which forms to sink to the bottom. The culture is then examined for purity, sterilized in the autoclave at $110^{\circ}$, and filtered. This is concentrated and again diluted until the diagnostic dose for the horse is 1 c.c.

The mallein or morvin of Babes is prepared by inoculating potato paste with $B$. mallei, and incubating six weeks. It then is heated at $68^{\circ}$ for three and one-half hours, emulsified with water, filtered through a Witt filter, and precipitated with alcohol. This 
precipitate is washed in alcohol, then in ether, and dried. The diagnostic dose is 0.02 to $0.03 \mathrm{gm}$. It is prepared for injection by dissolving in a mixture of glycerin and water.

The malleinum siccum, or dried mallein, of Foth is prepared by growing $B$. mallei in 4.5 per cent. glycerin broth. The cultures used are rendered virulent by passage through cats, guinea-pigs, and field-mice. The material is incubated at $37.7^{\circ}$ for three weeks. It is concentrated, and the organism killed by evaporation at a constant temperature of $76^{\circ}$ to $80^{\circ}$ to one-tenth of its former volume. This is filtered and poured into absolute alcohol, in which a precipitate immediately forms. This precipitate is washed in alcohol and dried in a desiccator. The final product is a white powder which readily dissolves in water. The diagnostic dose for the horse is 0.045 to $0.05 \mathrm{gm}$.

The mallein prepared in the laboratories of the Bureau of Animal Industry consists of glycerinated broth in which the $B$. mallei has grown four to five months, has been heated, concentrated, and filtered. It is diluted by the addition of one-half its volume of glycerin and one and one-half times its volume of 1 per cent. phenol. The diagnostic dose is 1 c.c.

No practicable method of standardizing mallein has been worked out other than trial upon a considerable number of healthy and infected animals. The variations in the methods of production of mallein given above are due to a desire to secure a very uniform product.

Mallein, when injected in the correct diagnostic dose, sometimes causes in a healthy animal a slight fever reaction of short duration, with frequently a transitory swelling at the point of injection. When injected into a glandered animal, the temperature begins to rise in six to eight hours. At the site of injection there is developed a swelling, painful, hot, and of considerable size, and extending along the lymphatics for some distance. It persists several days, and disappears in a week or ten days. Constitutional symptoms of the reaction, such as dejection of the patient, lusterless coat, anxious expression, impaired appetite, and hurried respiration are usually valuable aids in recognizing a reaction.

When properly carried out, the mallein test is valuable as a diagnostic method for glanders. 
Transmission.- The disease is transmitted from one animal to another through infected food, mangers, drinking troughs, etc.; rarely through wounds or skin abrasions. Veterinarians and horsemen sometimes become infected through the skin, rarely by inhalation.

Bacilli of Selter, Babes, and Kutscher*

Organisms morphologically similar to the preceding have been isolated from pus by Selter and by Babes, and from the nostrils of a healthy horse by Kutscher. They may be differentiated readily by their lack of pathogenesis, and would rarely, if ever, lead to mistakes in diagnosis. 


\section{CHAPTER XXVIII}

\section{INTESTINAL OR COLON-TYPHOID GROUP. WATER ANALYSIS}

THE organisms belonging to this group may be characterized as plump, gram-negative rods, frequently though not always motile; they produce no spores, do not liquefy gelatin, and in most cases ferment certain sugars, with acid- and sometimes gasproduction. The group contains many undoubted species that may be easily differentiated, but there are many intergrading types and forms showing similar morphologic and cultural characters, but differing considerably in kind and in degree of virulence. These latter make a systematic presentation of the group as a whole difficult. Exactly what amount of difference is necessary to constitute a distinct species is always a difficult problem, but nowhere more so than with these forms. The group name is given because of their prominence in the intestinal flora in disease and health in both man and animals. They are, therefore, abundant in sewage and water contaminated thereby, and in soil, particularly that which has received additions of barn-yard manure. They are uncommon in virgin soil and in uncontaminated water.

The members of this group are divided, for convenience in study, into three subgroups. This arrangement seems to represent evident relationships. The fermentative powers of the organisms are used as a basis upon which to make the groupings. The first of these is known as the colon bacillus subgroup, the second as the intermediate, hog-cholera, or enteritidis subgroup, and the third as the typhoid-dysentery subgroup. The principal points of difference between these subgroups may be summarized in the following chart, giving the fermentation reactions in dextrose and lactose broth.

Subgroup $I$.

Colon subgroup.
Subgroup II.

Intermediate subgroup. Typhoid-dysentery subgroup.

Subgroup III.

Acid. Gas.

Acid. Gas.

Acid. Gas.

Dextrose..... + + Dextrose..... + + Dextrose..... \pm -

Lactose..... + + Lactose..... - - Lactose..... - - 
The differences may be summarized as follows: the organisms of subgroup I. ferment both dextrose and lactose, with formation of both acid and gas; those of subgroup II. form acid and gas from dextrose, but not from lactose; and those of subgroup III. may or may not form acid from dextrose, but never from lactose, and gas from neither of the sugars.

The fermentations of other carbohydrates and related compounds are used to differentiate species and varieties from each other. A few can be satisfactorily differentiated only by the agglutination reaction. For a study of the fermentative power of the organisms 1 per cent. solutions of the sugars to be studied are made in sugar-free broth and placed in fermentation tubes, and sterilized by the discontinuous process to prevent decomposition. Those organisms which produce gas grow in both the open and closed arm, as do those which produce acid, and those which do not ferment the sugar are usually confined to the open arm. The composition of the gas, that is, the relative proportion of $\mathrm{CO}_{2}$ and $\mathrm{H}_{2}$, is also of diagnostic value.

The organisms to be considered belonging to the colon subgroup are Bacillus coli, B. lactis aërogenes, and B. pneumoniae. Those of the intermediate group, Bacillus enteritidis, B. cholera suis, B. psittacosis, B. paratyphosus, B. typhi murium, bacillus of Danysz, and B. pullorum. The most important forms of the third subgroup are Bacillus typhosus, B. dysenteria, and $B$. faccalis alkaligenes.

The growth reactions of the various members of the intestinal group, and more particularly of the colon subgroup, are of considerable sanitary significance, as they furnish our most efficient means of securing evidence of the suitability of water for drinking purposes, and of its contamination by sewage. The topics of water analysis, sewage disposal, and water purification are so intimately connected with the discussion of the members of the intestinal group that they are included in the same chapter.

\section{SUBGROUP I-COLON SUBGROUP}

\section{Bacillus coli}

Synonyms.-Bacillus coli communis; $B$. neapolitanus; $B$. pyogenes fotidus; Bacterium coli (commune); colon bacillus. 
Emmerich, in 1885, isolated an organism, which he named Bacillus neapolitanus, from the feces of patients suffering from Asiatic cholera. Escherich, in 1886, isolated a similar organism, which he termed Bacterium coli commune, from normal feces. Since that time the organism has been found to be constantly present in the intestines of man, most animals, and even some birds. The question of its occurrence in nature independent of fecal contamination is a moot one. That it may maintain a saprophytic existence outside the body for some time seems to be well established, but the evidence that it does not usually long so maintain itself is increasing. Examination of water for the presence of $B$. coli to determine its potability is quite universally practised, and when properly interpreted, has led to valuable results. The presence of $B$. coli in water in any considerable numbers is sufficient to condemn it for drinking purposes, not because of a pathogenic property of this organism, but simply because it indicates contamination with surface wash or with sewage.

\section{Morphology and Staining.-} The $B$. coli is a rod, varying from 0.4 to 0.7 by 2 to $4 \mu$, sometimes shorter and almost

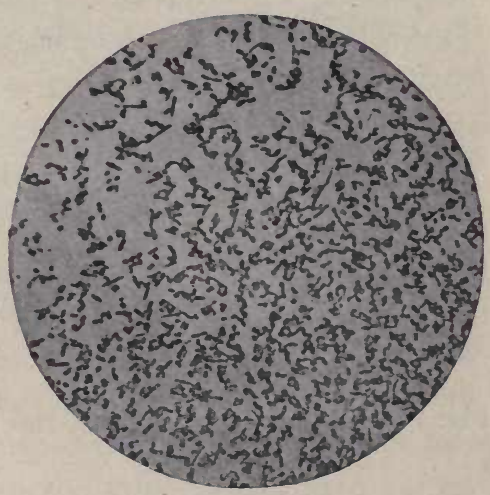

Fig. 108.-Bacillus coli, stained preparation from a twenty-four-hour agar slant $(\times 650)$ (Heim). coccus-like, with rounded ends, usually single, but occasionally in short chains. It does not produce spores or capsules. It is rather sluggishly motile, at least in young cultures, usually with 2 to 8 flagella, rarely more. It stains readily with the ordinary anilin dyes, sometimes showing some vacuolization and polar granules. It is gram-negative.

Isolation and Culture. $-B$. coli may be readily isolated from feces or sewage by plating the material in various dilutions in litmus-lactose agar, and incubating at blood-heat. The colonies of $B$. coli appear surrounded by a zone of red, due to the formation of acids from the lactose. The colonies must be differentiated from those of the organism next to be described. Upon gelatin 
plates the colonies are moist, grayish white, opaque, becoming darker and more coarsely granular. Gelatin is not liquefied. Stab cultures in gelatin show a filiform growth along the line of puncture, and a spreading growth at the surface. The agar cultures resemble those on gelatin. Bouillon is quickly clouded, sometimes with formation of a pellicle. On potato a moist, spreading growth occurs, and the potato is darkened. Milk is

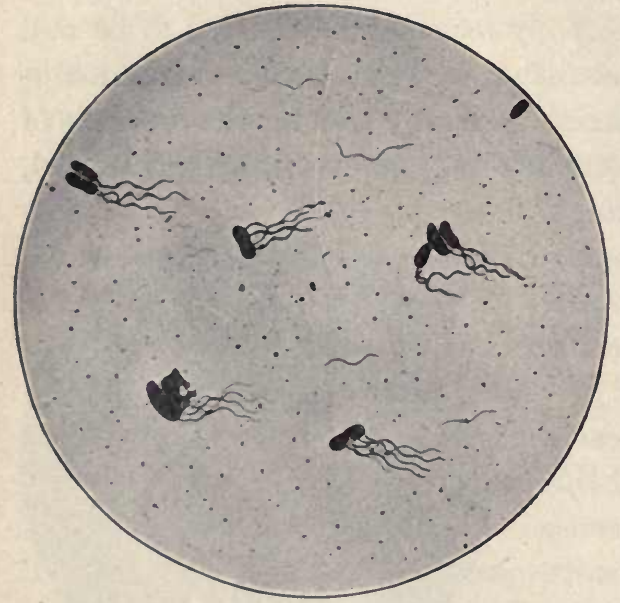

Fig. 109.-Bacillus coli showing the flagella (Migula). coagulated by the formation of acids; the curd shrinks, but is not digested.

Physiology.-B. coli is aërobic and facultative anaërobic. Its optimum growth temperature is $37^{\circ}$, but growth is luxuriant at room-temperature and even below. The thermal death-point is $60^{\circ}$ for fifteen minutes. Many carbohydrates are fermented, with production of acid and gas. Among these are dextrose, lactose, and maltose, and, in about half the strains isolated, saccharose. The gas formula from dextrose is approximately $\frac{\mathrm{H}_{2}}{\mathrm{CO}_{2}}=\frac{2}{1}$. Indol is produced in Dunham's solution. Peptonizing and proteolytic enzymes have not been demonstrated.

Pathogenesis.-The following quotation from Jordan epitomizes our present estimate of the pathogenicity of $B$. coli: "The common occurrence of agonal or postmortem invasion of the body by the colon bacillus tends to diminish the value of the supposed evidence derived from finding the colon bacillus in the internal organs after death, and there ean be no doubt that the rôle in human pathology assigned to the colon bacillus by some investigators, notably certain French bacteriologists, has been greatly 
exaggerated. Failure to distinguish between the true colon group and the group of meat-poisoning bacilli is doubtless responsible for some of the statements attributing pronounced pathogenic properties to $B$. coli. The frequent ascription of various inflammatory processes, particularly those occurring in the appendix and peritoneum, to the unaided activities of B. coli, appears to be without sufficient justification. Many of the cases reported rest on the evidence derived from simple aerrobic cultivation, and the possible concurrence of anaërobic or other organisms not growing by ordinary methods has not been excluded." The preceding was written with pathogenesis for the human body in mind, but the conclusions are even more true with reference to its pathogenesis for animals. Many diseases in domestic animals have been ascribed to infection with varieties of $B$. coli from insufficient evidence. It has been shown that even in the normal body colon bacilli sometimes escape from the intestines, and are to be found in the mesenteric lymph-nodes, and occasionally in some of the other internal organs.

Experimental Evidence of Pathogenesis.-The intraperitoneal injection of broth cultures of $B$. coli into the guinea-pig results in the death of the animal, usually within three days. Animal experimentation has demonstrated quite conclusively that there are considerable differences in virulence of the colon bacillus isolated from different animals or from the same animal at different times.

Character of Lesions and Disease Produced.-B. coli has been isolated from suppurations in pure culture. In man it is known occasionally to invade the gall-bladder, and is a common cause of cholecystitis. It may serve as a nucleus for gall-stones, and is probably instrumental in their formation by the precipitation of cholesterin. Inflammation of the ureters and of the urinary bladder is commonly caused in man by organisms that cannot be differentiated from typical $B$. coli. It has been reported as the cause of calf diarrhea or white scours, and from malignant catarrh in cattle. It is possible that these organisms are more closely related to the $B$. enteritidis. Usually the colon bacillus does not give rise to putrefactive products, and must be regarded as a harmless or even useful commensal. 
White scours, or diarrhea in calves, is the most important of the diseases of animals that have been attributed to B. coli. Different strains showing differences in agglutination have been isolated from various outbreaks. Moore and Nocard believe that the organism enters the body soon after birth through the ruptured umbilical cord coming in contact with fecal material. Investigators are by no means in accord in attributing this disease to B. coli. The etiologic relationship of this organism cannot be considered as settled.

Immunity.-A considerable degree of immunity to $B$. coli may be induced by injections of cultures, killed or living. Agglutinins are present in normal serum, but may be greatly increased by systematic immunization. Specific precipitins for the bacterial proteins are present in the immune serum. Opsonins are present in normal serum. The body has naturally a high degree of immunity against the $B$. coli. This may be accounted for by the presence of $B$. coli in the intestines and the continued opportunity for infection.

Bacteriologic Diagnosis.-The isolation of the characteristic colonies upon litmus-lactose agar is the simplest and quickest method of determining the presence of $B$. coli. Methods of recognition and isolation from water will be discussed at greater length under that heading.

\section{Bacillus lactis aërogenes}

Synonyms.-Bacterium aërogenes; Bacillus pyogenes.

Escherich, in 1885, described an organism which he isolated from sour milk as $B$. lactis aërogenes. It has since been found repeatedly in the intestinal contents of man and animals. It is sometimes more abundant than Bacillus coli itself.

Morphology and Staining.-Bacillus lactis aërogenes differs morphologically from the $B$. coli principally by the lack of flagella and in the ability to produce capsules when grown in milk.

Isolation and Culture.-This organism may be isolated in the same manner as B. coli upon litmus-lactose agar. The colonies upon agar and gelatin are larger, thicker, and more slimy than those of the colon bacillus. Milk is curdled more rapidly. In gelatin stabs the growth along the streaks is filiform; that at the surface is 
thick, convex, and circumscribed. The whole stab culture is frequently described as " nail like."

Physiology.-In most respects this organism resembles B. coli. It ferments dextrose, lactose, and saccharose, with production of both acid and gas. It also ferments starch, notably by the transformation of the starch into dextrose by an amylolytic enzyme. Indol is produced in Dunham's solution.

Pathogenesis.-This organism is not known to possess pathogenic powers. It is of interest principally because of its close relationship to $B$. coli. and association with it. In making water examinations no distinction is ordinarily made between $B$. coli and $B$. lactis aërogenes, inasmuch as they resemble each other so closely and come from the same sources.

\section{Bacillus pneumonix}

Synonyms.-Bacterium pneumoniœ; B. capsulatus mucosus; pneumobacillus; pneumococcus of Friedländer.

Friedländer, in 1883, discovered this organism in the sputum from a case of croupous pneumonia, and it was believed by him to be the cause of the disease. He failed to discover the real cause of pneumonia because the pneumococcus of Fränkel does not grow readily upon plate cultures prepared by the method used. It has since been found repeatedly in normal saliva, and is still believed to be an occasional cause of pneumonia. It sometimes is found in the feces and in sewage.

\section{Morphology and Staining}

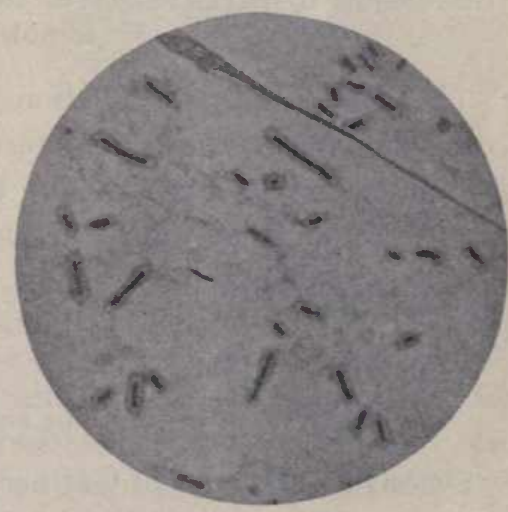

Fig. 110.-Bacillus pneumonia, showing capsules (Günther). - The organism as it occurs in the sputum is sometimes so short as to resemble a coccus. Usually it is single, rarely in chains. It is surrounded by a capsule in sputum and in milk. It is non-motile. It resembles the preceding organism closely in all other respects. 
Isolation and Culture.-Isolation is accomplished by plating upon gelatin. Growth upon most media resembles that of the $B$. lactis aërogenes. Milk is not coagulated, although litmus milk is reddened.

Physiology. - The organism shows markedly less fermentative power than $B$. lactis aërogenes, but otherwise closely resembles it. Dextrose, lactose, and saccharose are all fermented, but usually not vigorously. Growth occurs at blood-heat, but the organism develops well at room-temperature. The thermal death-point is about $56^{\circ}$. Indol is produced.

Pathogenesis. - B. pneumonice has a very low virulence only exceptionally will it infect any of the lower animals. It has been isolated in pure culture from the vegetations upon the heart valve in endocarditis, from otitis media, and occasionally it is believed to cause catarrhal or lobular pneumonia. It is noted here simply because of the possibility of isolation in various infections, and because of its obvious relationship to the preceding organisms of the group.

\section{SUBGROUP II-INTERMEDIATE, HOG-CHOLERA, OR ENTERITIDIS SUBGROUP}

The classification and relationships of the organisms belonging to this subgroup are much confused at present. Whether or not the various forms described are all distinct species is doubtful. The most important will be discussed under the names by which they are commonly known, but this uncertainty as to correct grouping must constantly be borne in mind.

\section{Bacillus enteritidis}

Synonym.-Bacillus of Gärtner.

Diseases Produced.-Meat-poisoning and enteritis in man and in cattle.

Gärtner, in 1888, studied an outbreak of meat-poisoning in a village in Saxony, and isolated from a fatal case and from the uncooked flesh of a cow the organism now known as Bacillus enteritidis. This organism has since that time been found in similar outbreaks of meat-poisoning and associated with certain 
infections in cattle. The organism has been found in meat or so-called ptomain-poisoning in the United States.

Morphology and Staining.-Bacillus enteritidis resembles $B$. coli morphologically. The organism is short and thick, sometimes with a thin capsule, motile by means of numerous or few flagella. It does not produce spores. It stains well or irregularly with the anilin dyes, and is gram-negative.

Isolation and Culture.- The organism has been isolated directly from the blood-stream and the spleen, and from the intestinal contents by plate cultures. The cultural characters as reported vary with different authors, probably because different strains were studied. Colonies upon gelatin and agar resemble those of B. coli. Bouillon is clouded, a delicate pellicle may form, and in a few days a whitish sediment collects. A yellowish, glistening layer forms on potato, frequently turning brownish with age. Growth in milk seems to vary with the organism studied. Some have been described as coagulating milk, but the typical form does not, although a slow proteolysis may take place without coagulation.

Physiology. - B. enteritidis is

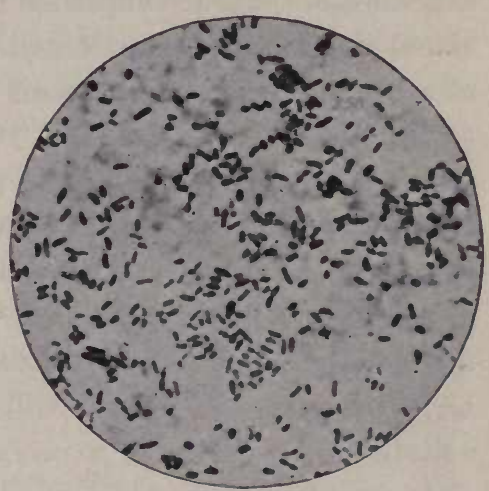

Fig. 111.-Bacillus enteritidis (Kolle and Wassermann).

aërobic and facultative anaërobic. Its optimum growth temperature is between $30^{\circ}$ and $40^{\circ}$, but it grows well at room-temperature also. The thermal death-point, as determined by Mohler and Buckley, is $58^{\circ}$ for twelve minutes. Dextrose is fermented, with production of acid and gas. Lactose is not fermented by the typical strains, although some strains have been reported by a few investigators to ferment this sugar, and the statement is commonly current in texts. Indol is not produced. Gelatin is not liquefied.

Pathogenesis.-Experimental Evidence.-B. enteritidis is pathogenic for the guinea-pig, mouse, and pigeon, but not for the cat. The guinea-pig may be fatally infected by intraperitoneal or subcutaneous injections and by ingestion. The same is true 
of the rabbit. Mohler and Buckley produced a fatal infection in young house-rats, while other authors report the rat as immune. The same is true of the dog, though this animal is relatively resistant. Chickens are immune. Sheep are readily infected. The hog succumbs to intravenous injection, as well as through feeding.

Type of Disease and Lesions Produced.-In man the infection is marked by a severe enteritis and enlargement of the lymphfollicles and Peyer's patches, and by small hemorrhages. The mortality in infections is low-probably less than 5 per cent.

The infection in cattle, as observed by Mohler and Buckley, was characterized by degeneration of the heart muscle (frequently fatty) and hemorrhages therein; in the liver parenchymatous degeneration was accompanied by localized hemorrhagic extravasations; the spleen was enlarged and hemorrhagic and the lesions of acute enteritis, with necrosis of the epithelium, were evident.

Immunity.-The so-called "toxin" of the B. enteritidis is probably an unusually soluble and potent endotoxin. It differs from true toxins in being exceptionally heat resistant. Meat which has been quite thoroughly cooked is sometimes found capable of giving rise to toxic symptoms when ingested. The bacteria-free filtrates from bouillon cultures and cultures in which the organisms have been killed by heat will kill guinea-pigs when injected in suitable quantities. It is probable that this endotoxin is responsible for the quick development of symptoms in those who are poisoned by eating infected food. Specific agglutinins are developed in the blood of infected individuals, as are also coagglutinins for other members of the intestinal group. Some differences in agglutinability of the different strains isolated have been noted. It has been proposed that meat may be tested for the presence of $B$. enteritidis by expressing the juice and determining its agglutinating power. This has not been proved practicable. It is probable that the bacilli already present in the meat would in some cases fix all the agglutinins present, if stored for any length of time. Practicable methods of prophylactic or curative immunization have not been demonstrated.

Bacteriologic Diagnosis.-The organism may be demonstrated by plate cultures from infected flesh. In man the disease may be diagnosed by the agglutination test, although with difficulty, for, 
as has been noted above, the various strains agglutinate differently, and blood from a typhoid or a paratyphoid patient may show a marked capacity to agglutinate $B$. enteritidis.

Transmission and Prophylaxis.-Probably a large proportion of the cases of so-called ptomain-poisoning is due to infection with Bacillus enteritidis and to its toxic products of metabolism. Such infection undoubtedly occurs frequently enough to justify rigorous measures for its prevention. Meat or milk from animals showing severe gastro-intestinal disturbances should never be used, as the infection in the human has in several well-authenticated instances been traced directly to such practices. Probably most cases of meat-poisoning originate from use of flesh of diseased animals, but the possibility of infection with the organism after the animal has been slaughtered should not be ignored. Experiments have shown that when fresh meat is inoculated upon the surface with a culture of $B$. enteritidis, the organism rapidly penetrates the tissues, even at low temperatures. Such infection might easily occur in unsanitary abattoirs, through flies and careless handling.

It should be noted that certain types of the paratyphoid bacillus are very similar to this form, if not identical with it, and doubtless are the cause of meat-poisoning as well.

\section{Bacillus cholerx suis}

Synonyms.-Bacillus suipestifer; B. salmoni; Salmonella.

Salmon and Smith, in 1885, described what is known as the Bacillus cholero suis as the cause of the disease called by them swine plague. In the following year Smith discovered another organism associated with a different disease of swine. This led to a revision of terminology, which has since come into common use, and the organism first described is now known as the hog-cholera bacillus. Smith recovered this organism from the spleens of about 500 hogs affected with hog-cholera. It was quite generally accepted as the cause of the disease, until de Schweinitz and Dorset reported an outbreak of hog-cholera in which the B. cholerce suis was not the primary cause. This was shown by the transmission of the disease by blood filtered through fine-grained porcelain bougies, a procedure which removed the bacillus completely, as 
shown by the fact that the filtrate was quite incapable of infecting culture-media. By the subsequent work of Dorset, Bolton, and McBryde it was shown quite conclusively that the $B$. cholerœ suis is not the cause of hog-cholera in the Mississippi Valley, and but a secondary invader at most. Hog-cholera and its virus will be considered, therefore, under the heading of Diseases Caused by Ultramicroscopic Organisms. The Bacillus cholerce suis, however, doubtless plays some part in the disease as a secondary invader, and is, therefore, worthy of consideration.

Morphology and Staining.-This organism differs morphologically in no essential character from $B$. enteritidis.

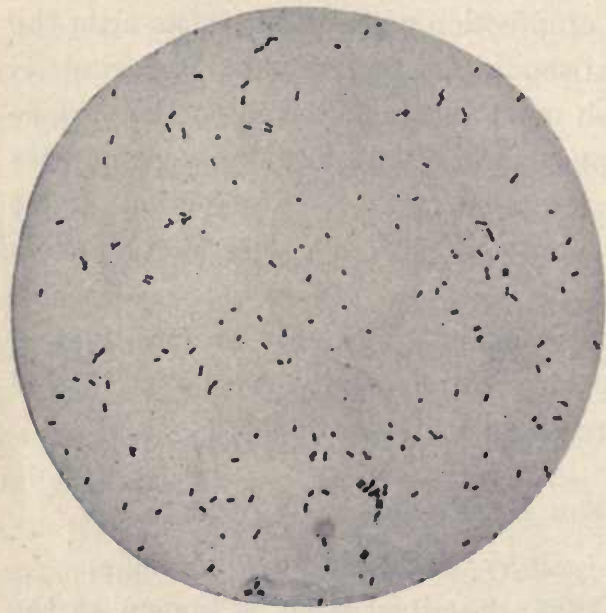

Fig. 112.-Bacillus cholerœ suis, organisms from a young culture (deSchweinitz, Bureau Animal Industry).

Isolation and Culture. $-B$. cholera suis may frequently be isolated at once in pure culture from the organs of infected animals, particularly from the spleen. It has likewise been isolated by plating the intestinal contents of normal and infected animals. The organism grows upon agar and gelatin, forming a grayish, glistening, non-viscid growth, which is not particularly characteristic. No growth occurs upon potatoes having a decided acid reaction, but upon those which are neutral or alkaline a thin, glistening, usually yellowish, layer is formed. Bouillon is uniformly clouded; a slight pellicle may appear in time. A grayish, friable sediment is formed. Milk shows a slight initial acidity, but soon becomes alkaline, and gradually becomes opalescent and finally translucent. It will be noted that there are no marked cultural differences between $B$. enteritidis and $B$. cholera suis.

Physiology.-B. choleræe suis is aërobic and facultative anaërobic. 
The optimum growth temperature is about $37^{\circ}$; it grows also, but more slowly, at room-temperature. The thermal deathpoint is $58^{\circ}$, with ten minutes exposure. The organism will remain viable for several days when dried. Gas and acid are produced in dextrose broth. The gas formula is $\frac{\mathrm{H}_{2}}{\mathrm{CO}_{2}}=\frac{1}{2}$, the reverse of that of $B$. coli. Lactose and saccharose are not fermented, and no growth occurs in the closed arm of the fermentation tube containing these sugars. Indol is not ordinarily produced.

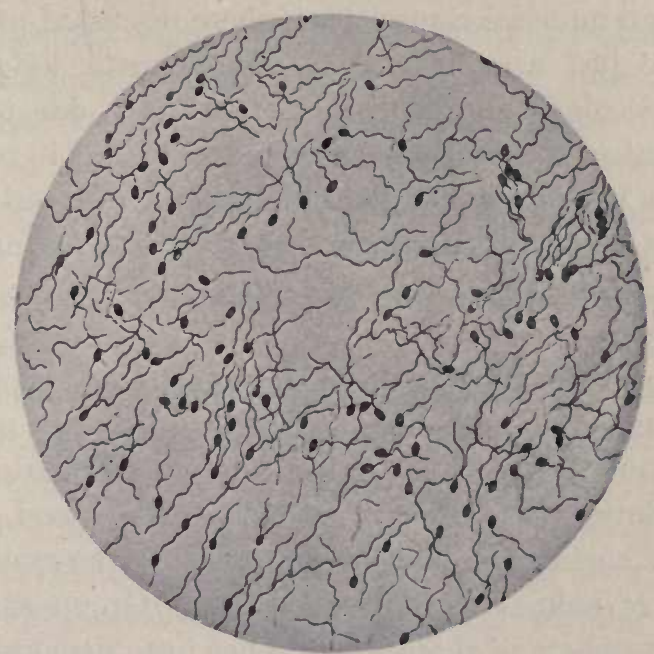

Fig. 113.-Bacillus cholerce suis, showing flagella (deSchweinitz, Bureau Animal Industry).

It will be noted that there are no physiologic differences between the $B$. enteritidis and $B$. cholerce suis.

Pathogenesis.-It should again be emphasized that the $B$. cholerce suis is not the primary cause of hog-cholera, but that it is a secondary invader of importance, and may be occasionally the primary cause of disease in hogs, but this disease probably would possess, according to Dorset, Bolton, and McBryde, a low degree of contagiousness.

Experimental Evidence of Pathogenesis.-Some differences in virulence have been observed in cultures obtained from different sources. Rabbits succumb to septicemia in five to eight days 
when inoculated with $\frac{1}{10}$ c.c. of a virulent bouillon culture. Guineapigs are more refractory, and die after seven to twelve days. Subcutaneous and intravenous injections and feeding experiments rarely produce death in the hog. The animal may sometimes show fever and depression, particularly after the intravenous inoculation, but the infection is rarely fatal unless 1 or 2 c.c. or more of culture are used. Feeding with large quantities of culture or long-continued feeding sometimes proves fatal.

Character of Disease and Lesions Produced.-An examination of a rabbit killed by injections of $B$. choleræe suis shows lesions differing in no material respect from those discussed under $B$. enteritidis. To just what extent the characteristic lesions in hogcholera, particularly in the chronic types, are due to infection by this organism is uncertain. It is probable that in many cases, at least, it is responsible for the development of intestinal ulcers. Inasmuch as it is sometimes found in the blood of animals infected by hog-cholera, it is probable that death may be due directly to their activity.

Immunity. - The topic of immunity against hog-cholera will be considered under that heading. The $B$. choler $x$ suis produces no true toxin, but there is some evidence of the formation of endotoxin. Agglutinins are present normally in the blood of the hog, and immune agglutinins may be produced by the systematic immunization of animals by killed cultures. Group agglutination with other members of this subgroup has been demonstrated. It has also been shown that immunization of the hog against true hog-cholera results in a considerable increase of agglutinins for $B$. choleræ suis in the blood. Opsonins for B. cholerøe suis have been shown to be present in normal serum. Since the discovery of the filterable virus, efforts at immunization by the use of vaccines and sera prepared by the use of B. cholerce suis have been practically abandoned.

\section{Bacillus paratyphosus}

Synonym.-Paratyphoid or paracolon bacillus.

Disease Produced.-Paratyphoid in man, possibly similar infections in animals.

Gwyn, in 1898, isolated from a clinical typhoid case an organism which belonged to the intermediate subgroup of intestinal 
organisms, rather than to the typhoid-dysentery group. Similar organisms have been isolated repeatedly since that time-in some instances from typical typhoid cases, in others from cases that had all the clinical symptoms of typhoid, but that did not give the agglutination reaction.

Morphology and Staining.-This organism corresponds closely in morphologic and staining characters to the Bacillus enteritidis and the Bacillus cholerce suis.

Isolation and Culture.-The organism has been isolated in pure culture directly, from the blood, and by plate cultures from the internal organs in disease, and particularly from the intestinal contents of man and of the lower animals. In general cultural characters the organism resembles the $B$. enteritidis. It has been found in practice that two varieties may be differentiated, termed $\mathrm{A}$ and $\mathrm{B}$, respectively. Type $\mathrm{A}$ does not produce a terminal alkalinity in milk and dissolve the casein, and in that respect differs from B. enteritidis, while type B corresponds exactly.

Physiology.-Not markedly different from B. choleræ suis.

Pathogenesis.-Paratyphoid fever in man has been attended by a low mortality; in consequence few autopsies have been reported. In both animals and man infection partakes more of the nature of an acute enteritis than does typhoid fever; the lymphatics are not generally invaded as in typhoid, and the Peyer's patches are not swollen and ulcerated.

Immunity.-Probably an endotoxin, less soluble, but in some respects similar to that of $B$. enteritidis, is produced by these organisms. Agglutinins are produced in infected individuals. The agglutination reactions of types $\mathrm{A}$ and $\mathrm{B}$ differ markedly. It was this difference which first suggested the existence of the two types. No method of practical immunization against the disease is known.

Bacteriologic Diagnosis.-The differentiation of paratyphoid may be made clinically by the specific agglutination tests. The absence of a test in a case of clinical typhoid calls for a repetition with the two types of paratyphoid bacilli.

Transmission.-It is probable that certain gastro-intestinal infections in cattle may be caused by organisms of this type, and 
that meat and milk may become contaminated from these sources. Milk and meat are probably the most common sources of infection, although water has been clearly shown, in some instances, to be the source of epidemics.

\section{Bacillus psittacosis}

Nocard, in 1892, isolated an organism belonging to the intermediate group from cases of psittacosis (Latin, psittacus, parrot), a type of pneumonia supposed to be contracted from infected parrots. The same organism has since that time been isolated from other outbreaks. In cultural, morphologic, and physiologic characters it is scarcely to be differentiated from the $B$. enteritidis. Some differences have been found in agglutinating properties of the specific sera, and this organism is believed, on these grounds, by some authors to constitute a distinct species. The disease is uncommon, and is of little importance.

\section{Bacillus typhi murium}

Löffler, in 1889, described an organism as the cause of an epidemic among the mice kept for experimental purposes. Danysz,

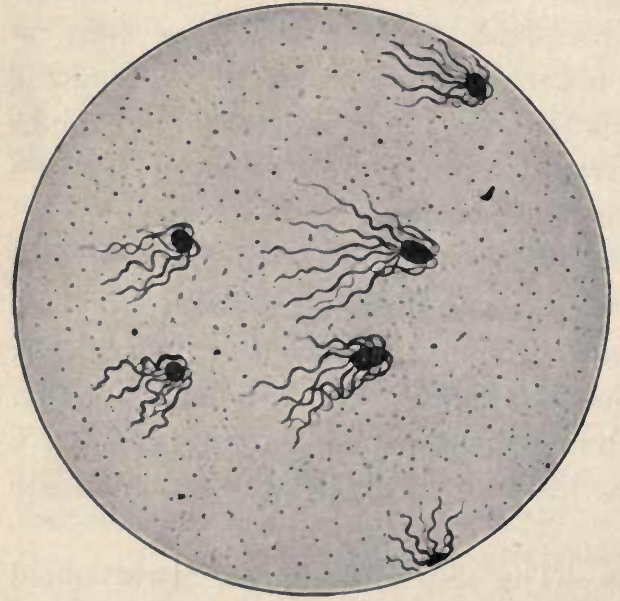

Fig. 114.-Bacillus typhi murium (Migula). in 1900, described a similar, probably identical, organism, and recommended its use in the destruction of rats. These forms have all the morphologic and cultural characteristics of the enteritidis group, but show some differences in pathogenicity and in formation of specific agglutinins. Cultures of these organisms have been widely exploited as specific for mice and rats, producing a rapidly fatal disease, but as harmless to the higher animals. Reports as to their efficacy when fed to the vermin are conflicting; the results seem in some cases to have 
been favorable. It evidently is true that the virulence of the organism is subject to considerable variations, for the careful work of Rosenau showed the culture which he possessed to be worthless in the extermination of rats. On the other hand, there is some evidence that the organism is not so free from harmful effect on the human as has been supposed. Fatal infections in man have been reported from Japan.

\section{Bacillus pullorum}

Disease Produced.-White diarrhea of chicks.

Rettger and Harvey have described the Bacillus pullorum as the specific cause of a white diarrhea in young chicks. Its etiologic relation to the disease has been called seriously into question by Morse, Hadley, and others, who believe that it is either a commensal or a secondary invader, and that the disease is in reality a coccidiosis. The evidence is somewhat conflicting on this point. The importance of the B. pullorum, even as a secondary invader, renders a description pertinent.

Morphology and Staining.-Bacillus pullorum is a rod, 0.3 to 0.5 by 1 to $2.5 \mu$, with rounded ends. It occurs singly or very rarely in chains. It is non-motile, does not produce capsules or spores. It stains readily and uniformly with ordinary aqueous anilin dyes, and is gram-negative.

Isolation and Culture.-The organism may be isolated from the infected chicks by opening the body with aseptic precautions, and making streaks upon the surface of agar slants with blood or the pulp of the spleen or liver. Upon the agar slant the colonies are discrete, and at first resemble the pin-point, translucent colonies of the Streptococcus. They enlarge later. Upon gelatin the colonies resemble those of the typhoid bacillus. Little growth occurs upon potato. Milk is a suitable medium, but there is little change, no coagulation, and no proteolysis.

Physiology. - The organism is aerrobic and facultative anaërobic. The optimum growth temperature is about $37^{\circ}$. Dextrose and mannite are fermented, with the production of both acid and gas. Maltose, lactose, and saccharose are not fermented. Indol is not produced.

Pathogenesis.-Experimental Evidence.-Rettger has isolated 
the specific organism in several outbreaks of the disease from the internal organs, particularly the livers, of chicks that had died of the disease or were showing symptoms. He also isolated it from abnormal egg-yolks in the ovaries of hens, from freshly laid eggs, and from the yolk-sacs of fully developed chicks within the shell. He also succeeded in infecting chicks by feeding, but the disease was not always contracted. Subcutaneous injections always proved fatal. Hadley, Kirkpatrick, and others have been unsuccessful in transferring the disease by feeding.

Characteristics of Disease and Lesions.-The most noticeable antemortem characteristics are emaciation and wasting of the chick, and the white diarrhea. The lesions are confined principally to the intestines, and particularly the cecum. The liver is sometimes congested in areas.

Immunity.-Practicable methods of immunization have not been evolved.

Bacteriologic Diagnosis. - The organism may be isolated in pure culture from the internal organs, particularly the liver. Work on the normal intestinal flora of the chicken is needed.

Transmission and Prophylaxis.-Rettger claims that the disease is sometimes present before hatching, the organism being present in the ovaries and oviduct, and that contamination of the food likewise results in infection.

\section{SUBGROUP III-TYPHOID-DYSENTERY SUBGROUP}

The three important organisms belonging to this subgroupBacillus typhosus, B. dysenteria, and B. focalis alkaligenes-are not ordinarily pathogenic for the lower animals. They are, however, pathogenic for man, and since many of our diagnostic methods for other diseases have been discovered through their study, they are discussed briefly.

\section{Bacillus typhosus}

Synonyms.-Bacillus typhi; B. typhi abdominalis; Eberth or Eberth-Gaffky bacillus.

Disease Produced.-Typhoid fever in man.

Eberth, in 1880, discovered the B. typhosus in the spleen and other internal organs of the body of persons who had diect of typhoid fever. Gaffky, in 1884, cultivated the organism. It 
is now generally conceded to be the cause of typhoid fever, although the experimental animals cannot ordinarily be infected.

Distribution.- Typhoid fever is widely distributed throughout temperate and tropical countries. It is constantly present, frequently in epidemic form, in the United States.

Morphology.-Bacillus typhosus is a short, plump rod, usually varying between 0.5 and $0.8 \mu$ in diameter, and 1 to $3 \mu$ in length. It is motile by means of numerous flagella. It does not produce capsules or spores. It stains readily with aqueous anilin dyes. Granular staining is sometimes observed, although the cells usually stain uniformly. It is gram-negative.

Isolation and Culture.The desirability of isolating $B$. typhosus from contaminated water has led to the development of many media in an effort to accomplish this. A quantitative estimation of the typhoid bacillus from such sources does not seem to be practicable, but the qualitative determination of presence may be

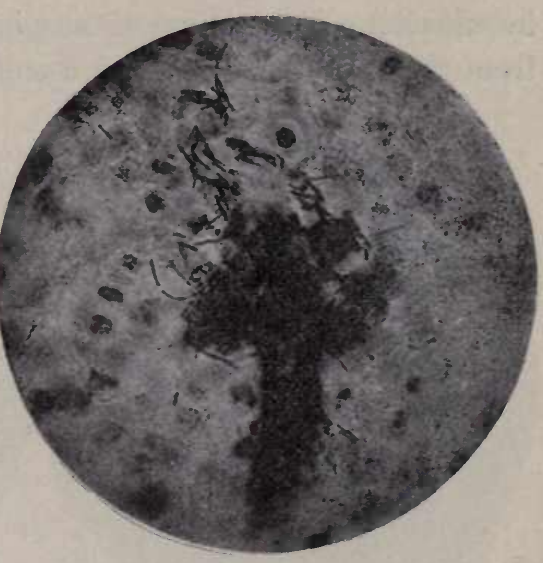

Fig. 115.-Bacillus typhosus, clump in a section of a spleen (Fränkel and Pfeiffer).

carried out. The methods

used are to inhibit the growth of the purely saprophytic organisms present by the use of antiseptic substances, such as malachite green, caffeine, and crystal violet, and to incubate such media at blood-heat. These media do not inhibit, in general, the growth of either B. typhosus or B. coli, and dependence is placed upon differences in colony characters and media reactions to separate them in subsequent plating.

The colonies upon gelatin are somewhat smaller and more delicate than those of the $B$. coli. This organism was originally described as producing a thin, "invisible growth" upon potato. This is true upon potato with an acid reaction, but upon alkaline or neutral potato the growth is relatively abundant. 
Physiology. $-B$. typhosus develops best at a temperature of $37^{\circ}$, but will grow at room-temperature. It is an aërobe and facultative anaërobe. No indol is produced. Acid, but no gas, is formed from dextrose. Neither acid nor gas is produced from lactose or saccharose. There may be slight initial acidity in milk, but there is never coagulation of the casein. Proteolytic enzymes are not developed in cultures.

Pathogenesis.-Experimental Evidence.-The lesions typical of typhoid in man are not produced either by injection or feeding experiments upon the laboratory animals. The symptoms after intraperitoneal injection of a guinea-pig do not differ greatly from those produced by the Bacillus coli. Feeding experiments

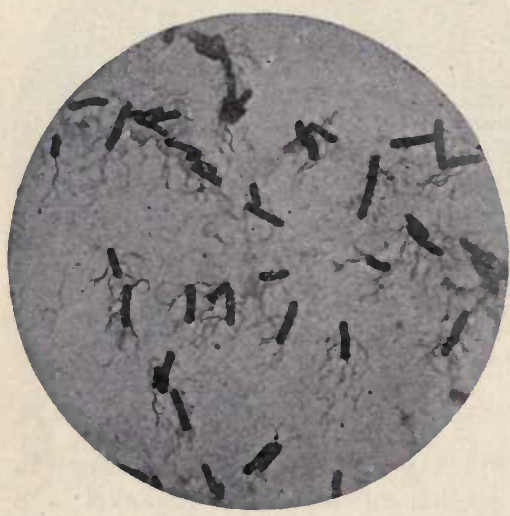

Fig. 116.-Bacillus typhosus, showing flagella (Günther).

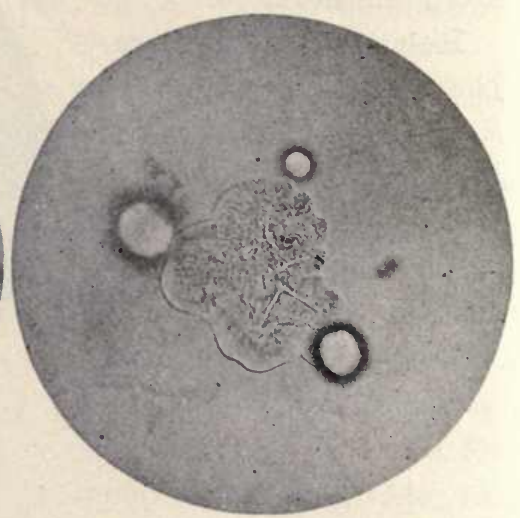

Fig. 117.-Bacillus typhosus, colony on agar (Günther).

with anthropoid apes within recent years have shown the possibility of producing the typical lesions of the disease in these animals. Infection with typhoid bacilli in laboratory workers has several times occurred following the accidental ingestion of pure cultures of the organism.

Character of Lesions and Disease Produced.-Clinical diagnosis of typhoid is frequently difficult, as the characteristics of the disease are often not well marked. The organism invades the intestinal lymph-system, and particularly the Peyer's patches. The latter become ulcerated, and perforation of the intestinal wall is a not uncommon result. The spleen is swollen. The bacteria 
are usually found in the blood, though not commonly in large numbers, but are abundant in the spleen. Cystitis, cholecystitis, and bone metastases are not uncommon sequelæ to the infection.

Immunity.- No true toxin has been demonstrated for $B$. typhosus, but an endotoxin is present. Agglutinins and precipitins specific for the organism are likewise produced. Bacteriolysins may be demonstrated in the blood of animals that have been artificially immunized by injections of the typhoid bacillus. There is developed in the body of an individual that has recovered from typhoid a certain degree of immunity, but this disappears, so that it is not unusual for a person to have several attacks of the disease. This immunity is probably both bacteriolytic and opsonic in nature.

The use of antisera in passive immunization against typhoid and in curing the disease has not proved successful. The injection of such sera has not been shown to have either an immunizing or a curative effect in man. Active immunization by the injection of dead or living bacteria or their products has, on the contrary, been quite successful. Usually the organisms are scraped from the surface of agar cultures, suspended in physiologic salt solution, and killed by heat, or a broth culture may be used. Such injections are, of course, only prophylactic.

Bacteriologic Diagnosis. - The Widal or agglutination test is commonly used in the diagnosis of typhoid. A dilution of 1:40 and higher is generally made to minimize the effect of the normal agglutinins which may be present in the blood. Both microscopic and macroscopic tests are used; the former is the more delicate, but the latter somewhat more reliable. The agglutinins often appear early in the course of the disease-usually by the fifth day or rarely later. Blood or serum for making the test may be either liquid or dried. It is received in the latter condition by many of the state and municipal bacteriological laboratories. The bacteria may be cultivated directly from the blood of a patient. Frequently the organisms can be found in the blood somewhat before the serum exhibits a marked agglutinating power. Isolation of the organisms directly from the feces is sometimes resorted to in an effort to determine the occurrence of the so-called "bacillus carriers." 
Transmission.- Typhoid fever is contracted from contaminated drinking-water, milk and other foods, and by contact, the frequency being in about the order named. Flies probably are commonly instrumental in carrying the organism from dejecta of typhoid-fever patients to food materials. The term bacillus carrier, or germ-carrier, is used to designate an individual who still harbors a pathogenic organism in the body after convalescence. Such germ-carriers are particularly dangerous, as they may give rise to an epidemic that is almost impossible to trace to its source. The danger of milk infection is probably the greatest from individuals that are employed in dairies. Several epidemics have been traced to this origin.

\section{Bacillus dysenterix}

Synonyms.-Bacillus of Shiga; bacillus of Flexner.

Disease Produced.-Bacillary dysentery.

Shiga, in 1898, discovered in the feces of patients suffering from dysentery a bacillus which he believed to be the specific cause of

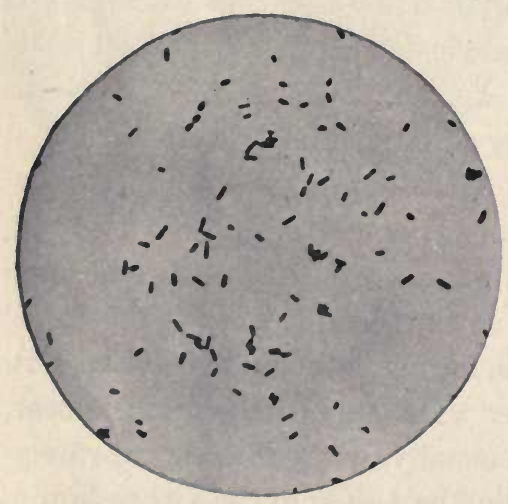

Fig. 118.-Bacillus dysenteric (Kolle and Wassermann). the disease. Previous to this it had been shown that amebæ may cause dysentery, and it was when examining stools for these protozoa that Shiga discovered this organism. In 1900 Flexner published the results of work in Manila and described another type of organism. Since that time many epidemics have been studied, and it is generally believed that the type described by Shiga is the more common, but that the bacillus of Flexner occurs in a certain proportion of the outbreaks, more particularly in the tropical countries. Other authors, Hiss in particular, have differentiated even more groups.

Morphology. $-B$. dysenterice and $B$. typhosus are practically indistinguishable under the microscope in stained mounts. The 
B. dysenteria, however, is non-motile. Spores and capsules are not produced. It stains uniformly and is gram-negative.

Isolation and Culture.-The organism may be isolated directly from the dejecta by plating. The cultural characters in general closely resemble those of $B$. typhosus. Milk is rendered permanently alkaline, however. ${ }^{1}$

Physiology.-The physiologic characters of $B$. dysenterice closely resemble those of $B$. typhosus. The ability to produce acid in solutions of various carbohydrates and of the related alcohols is used as a means of differentiation of the varieties. Otho listed some fifteen different types by this means. A more conservative and valuable classification is that of Hiss, as modified by Shiga:

\section{Variety}

B. dysenterice.

I. Shiga, type I. . . . . . . .

II. Park-Hiss type..........

III. Flexner-Strong type........

IV. Harris-Wollstein type.......

V. Shiga, type II .......... 1
Acid Prodtced from Maltose. Saccharose. Dextrose.

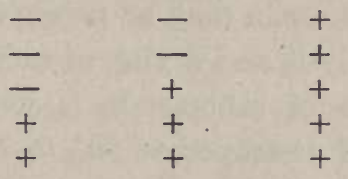

It is believed that type I. is the most virulent. Types III. and IV. are found frequently in summer diarrhea of infants.

Pathogenesis.-Experimental Evidence.-The belief that the varieties of $B$. dysenterix are the more important etiologic factors in the disease is based upon the following facts:

1. This .organism in some one of its varieties has been shown to be present with great constancy in the patients' excreta.

2. Injections of the organisms and their products kill laboratory animals, particularly rabbits, although typical dysentery is not readily induced by feeding experiments.

3. The blood-serum of a patient will, in general, agglutinate in high dilution the strain isolated from the feces.

4. An antiserum has been successfully used in the prevention and cure of the disease.

Character of Disease and Lesions Produced.-The intestine, particularly the colon, is inflamed and is sometimes ulcerated, and may even show diphtheritic necrosis. With the exception of this there is little that is characteristic of the disease. Unlike the ${ }^{1}$ Initial acidity followed by permanent alkalinity. 
typhoid bacillus, it does not commonly invade the blood or the internal organs, with the exception of the mesenteric glands. The disease is rather a toxemia than a bacteremia.

Immunity.-A soluble toxin has been demonstrated for the Shiga type, but repeated efforts have failed to show that any such is produced by the Flexner type. This poison was at first believed to be an unusually potent endotoxin. Conradi first demonstrated the toxin by growing the organism upon agar, then suspending it in physiologic salt solution, and allowing the bacteria to undergo autolysis. Later, Rosenthal and others showed that toxin will be produced in considerable quantities in an alkaline bouillon, but not in one that is neutral or acid. This bouillon is either filtered through porcelain filters, or 0.5 per cent. phenol is added and allowed to stand, and then filtered through paper until clear. The toxin may be precipitated by ammonium sulphate, and after dialysis and drying of such, 1 to $2 \mathrm{gm}$. may be a lethal dose for a kilo of rabbit. It is weakened by prolonged heating at $70^{\circ}$, and destroyed at $80^{\circ}$ to $100^{\circ}$. The rabbit is very susceptible to the injection of the toxin, while the guinea-pig is relatively resistant. The effect upon the rabbit may be characterized as a hemorrhagic necrotic enteritis.

Shiga first used antisera in the treatment of dysentery. He regarded its curative properties as wholly bactericidal. Todd, Koram, Doerr, and others have, by systematic immunization of a horse, secured a serum that neutralizes the toxin actively. This has been used with very favorable results in the treatment of dysentery caused by the Shiga bacillus.

Bacteriologic Diagnosis. - The disease may be recognized by the Widal or agglutination test, and the several types of organisms differentiated in the same manner. The organism may likewise be isolated directly from the stools by plating.

Transmission.-Dysentery is spread in much the same manner as typhoid, and the same preventive measures must be used.

\section{BACTERIA OF WATER AND WATER PURIFICATION}

Diseases of man and animals, particularly those of the alimentary tract, are frequently transmitted through contaminated or impure water. The impurity, so called, arises from the presence 
of sewage or surface wash. This does not mean that every water containing sewage is necessarily harmful, but that the presence of the sewage is an indication of the possible and probable occasional presence of pathogenic forms.

Bacteriologic examination of water is important, for several reasons. Much smaller quantities of contaminating organic matter may be determined by bacteriologic than by chemical means. Its methods may be used in the determination of the potability of water-supplies, in tracing a typhoid or similar epidemic to its source, in determining the efficiency of filters for water-supplies and of different types of sewage-disposal systems.

Water may be examined bacteriologically, either quantitatively or qualitatively. In the former a determination of the total number of bacteria present in the water is made; in the latter, the tests are designed to determine the abundance of certain specific bacteria. The qualitative examination may be again divided into determination of normal sewage bacteria, particularly B. coli, and of specific disease-producing bacteria, as B.typhosus. The former is the most useful examination made in determining the potability of a water; the latter is rarely used.

Quantitative Examination of Water.-In general, the greater the quantity of organic and decomposing matter present in water; the greater will be the number of bacteria present. However, it must be noted that changes in the environment, such as temperature, may cause great variations in bacterial content, even though the original water be uncontaminated. For example, water from a source quite above suspicion may have less than 100 bacteria to the cubic centimeter. This same water, carefully sampled in a sterile bottle and allowed to stand at room-temperature, may show in twenty-four to forty-eight hours hundreds of thousands to the cubic centimeter. It is important, therefore, that the sample taken for examination shall be typical, and that it be examined immediately, to prevent multiplication of the bacteria present.

Media Used.-Either nutrient gelatin or agar may be used. It should be prepared according to the methods outlined by the American Public Health Association. The gelatin will, in general, give a somewhat higher count than the agar, but, when many 
liquefying species are present, the count on the gelatin must be made before all the slower-growing species have had a chance to develop.

Methods.-Various dilutions of the water to be tested are placed in a series of sterile Petri dishes, and the melted medium to be used is poured in and thoroughly mixed. After the medium has solidified, the plates may be kept at room-temperature, or, better, placed in a thermostat which maintains a temperature of about $20^{\circ}$ to $22^{\circ}$. The number of colonies developing upon a given plate, multiplied by the dilution introduced, will give approximately the number present per cubic centimeter in the original sample. The final count should be made only after the lapse of several days or a week. Discrepancies will usually be detected between the numbers, as determined from the plates containing the lesser and the greater dilutions. It is customary to use the plate having the nearest to 200 colonies in making the final estimation. Where more than this number of colonies are present, it is probable that many more have failed to develop at all, or to a size that can be readily detected, on account of the overcrowding. The numbers of bacteria can, of course, be determined only approximately by the higher dilution; it is, therefore, customary to follow the mode of expression suggested by the committee on standard methods of the American Public Health Association:

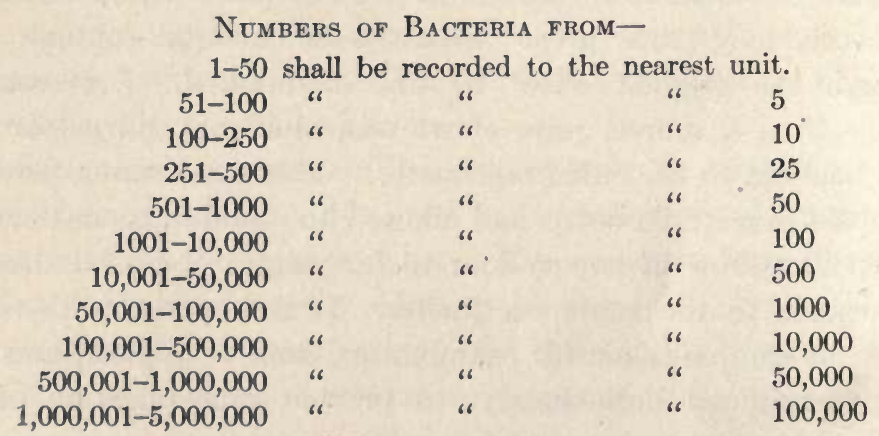

Interpretation of Results.-No standard for the number of bacteria that may be present in potable water can be set because of the various factors which may determine a high count. Sternberg, however, has suggested a standard that is in general ap- 
plicable; water containing less than 100 bacteria per cubic centimeter is probably pure; one containing 500 bacteria is suspicious, and one with 1000 bacteria is quite certainly bad. The number of bacteria normally present in unpolluted supplies of various kinds differs considerably; for example, that in the deep wells of a region from those of its lakes, and standards must, therefore, be established for each. Determination of numbers is probably most useful in systematic examination of the efficiency of filtration of public water-supplies. In some countries these tests are made daily, and the maximum bacterial content of the filtered water that may be used has even been fixed by law.

When gelatin is used, a separate count should be made of the colonies which develop that are capable of liquefying the medium. Such organisms are particularly characteristic of the surface soil, and usually belong to the Bacillus subtilis group. The presence of such in large numbers is an index to the extent of the surface-wash, and not in general of the extent of sewage pollution. This determination is frequently of value in the examination of shallow wells.

Agar plates may be incubated at blood-heat. The typical water bacteria develop very slowly, if at all, at this temperature. A count made in forty-eight hours of such a plate is a fair index of the amount of sewage contamination usually, as the organisms from this source thrive best at this temperature. This determination, however, is largely displaced by the use of the litmus-lactoseagar plates, as discussed under Qualitative Analysis.

Qualitative Examination of Water.-As has before been stated, water may be examined for the specific pathogens it may contain, or for the presence of sewage and intestinal bacteria, particularly B. coli.

Isolation of Specific Pathogens.-B. typhosus is the organism for which examinations have been most frequently made. It has been actually isolated from water in a few instances only. Frequently only a very small percentage of the colonies which develop from direct plating of typhoid stools are typhoid colonies. The chances of direct isolation by plating sewage or water from a supply is, therefore, remote, even though this organism be present in numbers such as to cause an epidemic of the disease among the consumers. 
Usually the search for the specific organism in the water-supply is not begun until there is an outbreak of the disease, and the probabilities are that the organism by that time has disappeared from the supply. Many methods for isolation have been devised, but are not commonly used. For the most part, they are dependent upon enrichment by placing the suspected water in broth containing antiseptics which will inhibit the growth of other bacteria, but not of the intestinal forms. This material is then plated, and the typhoid-like colonies are fished out and tested one at a time, the crucial test usually applied being the ability to agglutinate with high dilution of typhoid antiserum.

The specific organism of Asiatic cholera may be more readily isolated than that of typhoid. Flasks of peptone salt solution are inoculated with the suspected water, and incubated at blood-heat for twenty-four hours or less, and transfers made to fresh flasks from the surface layer. The cholera spirillum has a considerable avidity for free oxygen, and swarms just below the surface in much greater numbers than elsewhere in the medium. Plates made from this surface film should show the characteristic colonies.

Isolation of B. coli.-Advantage may be taken of the physiologic and cultural characteristics of the $B$. coli to isolate it from water. In examination of large numbers of samples it is often found useful to make what is termed a preliminary or presumptive test for the presence of the colon bacillus. Fermentation tubes containing 1 per cent. dextrose (glucose) broth are inoculated with varying amounts of the water to be tested. If gas is not produced in any of the tubes, it is evident that $B$. coli is not present; at least in any considerable numbers. A negative result is, therefore, good evidence of the purity of the water examined. A positive test makes it probable that the water contains the colon bacillus, although further tests are necessary to establish the fact; hence the name, presumptive test. The evidence that $B$. coli is present is much strengthened if gas to the amount of 30 per cent. or more, and having a composition of $\frac{\mathrm{H}_{2}}{\mathrm{CO}_{2}}=\frac{2}{1}$, is produced. An approximation of the number of colon bacilli present may sometimes be made by observing the dilutions of the water in which gas is produced. For example, if gas is produced in dilutions of $1: 0,1: 10$, and $1: 100$, 
but not in higher dilutions, it may be inferred that there are between 100 and $1000 \mathrm{~B}$. coli present per cubic centimeter in the original sample.

A more accurate determination of the number of $B$. coli present in a given sample may be secured by plating different dilutions in agar containing 1 per cent. lactose, colored blue by litmus solution, and incubating twenty-four to forty-eight hours at $37^{\circ}$. Organisms which can ferment lactose with acid production are surrounded by a red discoloration of the litmus. Such organisms are the B. coli, B. lactisaërogenes, and Streptococcus. The first two may be considered together, as they come from the same source and indicate the same facts. The colonies of these may usually be readily differentiated from those of Streptococcus by their large size, their shiny appearance, and the frequent gas-bubble accompanying the colony if it lies below the surface. The Streptococcus colonies, on the other hand, are small, rarely larger than a pinhead, and never have gas-bubbles. It is sometimes necessary to make transfers from colonies and carry them through the various media to complete the identification. A highly contaminated water will usually reveal the acid colonies directly upon plating, but in careful work it is sometimes necessary to enrich the suspension. Plates may be poured from fermentation tubes that show gas-production.

$B$. coli is not uncommon in nature; its constant presence in the feces of most animals makes it widely distributed. It is entirely probable that the presence of small numbers of $B$. coli in water may, therefore, be without significance from the standpoint of potability. It is generally regarded in America that if $B$. coli can be constantly demonstrated in 1 c.c. samples of the water, this is an indication of recent sewage contamination. When its presence may be demonstrated only by the use of larger samples than 1 c.c., the evidence must be regarded as inconclusive.

\section{Water Purification}

Self-purification of Natural Waters. - Natural waters, both running and impounded (as in lakes and reservoirs), gradually free themselves from organic and bacterial contamination. The rapidity and efficiency of this cleansing process depend upon many factors. 
Sedimentation is probably the most potent factor in freeing a contaminated water from bacteria. The bacteria themselves have a slightly greater specific gravity than water, and tend to go to the bottom under the influence of gravity. This occurs more rapidly when other and larger solid particles are in suspension; flocculation and more rapid sedimentation then frequently occur. Advantage is taken of this fact in the artificial purification of -water, and coagulants of different kinds are added, which carry down the bacteria, together with other suspended material. Diminution of food-supply with consequent disappearance of many bacteria is likewise important. Probably light destroys some organisms, and others are ingested by protozoa. Some species do not develop in the presence of certain other forms, that is, they exhibit antibiosis. Water-plants, algo, and natural obstructions of all kinds to water-flow exert a filtering action. Changes in temperature may inhibit the growth and even destroy some bacteria. A contaminated stream is constantly diluted by the influx of ground-water and of tributaries.

Purification of Drinking-water.-For domestic purposes, water may be effectually purified by heating to the boiling-point for a few minutes. All the pathogenic bacteria are quite effectually eliminated by this method. Berkefeld porcelain filters, if properly constructed, are also efficient. They must be cleaned and steriliized at short intervals, otherwise the organisms will grow through the pores of the filter, and the water passing through will be as contaminated as the original supply. Where a city-supply must be purified, it is commonly pumped into reservoirs and allowed to settle, with or without the addition of coagulants. It is then passed through filters of various types, usually sand. Passage through a properly constructed filter of this type has been shown to be exceptionally efficient. Such a system requires careful supervision. An efficient system will remove over 99 per cent. of the bacteria originally present. Some city supplies are pumped under pressure through sand-filters. This does not seem to be as efficient a means of ridding the water of bacteria as the other, as a filter, in any case, to retain its highest efficiency, must remain for some time undisturbed, and filters of the latter type require frequent cleaning and washing. The installation of filtration plants 
for purification of city supplies has in many cases resulted in a great diminution of the death-rate from typhoid and other intestinal diseases.

Sewage Disposal.-The question of proper disposal of sewage is closely related to the topic of pure water for domestic purposes. Usually sewage is allowed to flow into a suitable stream, and is purified as it passes down-stream. There is no valid objection to this, providing there is a sufficient and constant flow of water in the stream to insure dilution, and the water of this stream is not used as a city supply further down. Unfortunately, too little attention has been paid to this subject, and the high typhoid death-rates in some cities are due directly to the use of such sewage polluted water. Berlin and Paris purify their sewage by using it in the irrigation of large tracts of land, and recollecting the water in underdrains. Such a system is highly efficient, but, as it requires a particular type of soil, large areas, and suitable conditions, it is not often practicable. For sewage disposal in small cities and towns, and even private residences or farms, some of the numerous modifications of the septic tank and filter-bed have been shown to be most efficient. The sewage is first carried to a septic tank, so called-a large tank, usually of brick or concrete, and commonly covered. This tank is planned so that the sewage flow of twelve to twenty-four hours will fill it, or, in other words, that a given portion of sewage will require that time to pass through. Here much of the solid material settles out. The dissolved oxygen, if any be present in the raw sewage, is quickly used up, and anaërobic conditions are established. Under such treatment the decomposition of the organic matter occurs rapidly. Most of the sediment of the septic tank is soon dissolved by bacterial action. Gases, particularly $\mathrm{H}_{2} \mathrm{~S}, \mathrm{CH}_{4}, \mathrm{H}_{2}$, and $\mathrm{NH}_{3}$, are produced. These rise to the top, and are there intercepted by the heavy scum which forms, and oxidized to $\mathrm{H}_{2} \mathrm{SO}_{4}$, or free $\mathrm{S}_{2}, \mathrm{CO}_{2}$, $\mathrm{H}_{2} \mathrm{O}$, and $\mathrm{HNO}_{3}$; hence there is but little disagreeable odor to be noted about such a plant. The organic material is, for the most part, broken down into soluble, easily oxidizable substances. The sewage must not be held under these conditions for too long a period, otherwise the decomposition will go too far. The sewage then usually passes to a dosing chamber. This is simply a chamber 
which automatically discharges through one or more siphons whenever it becomes filled. The sewage passes from here either into contact beds or into filter-beds. The former consist of beds of crushed rock, usually with water-tight walls. The sewage may be sprinkled over the surface constantly and allowed to trickle through (the so-called trickling filter), or it may be poured onto the bed in bulk, and held in contact with the crushed stone for a time and then discharged. In either case the sewage becomes thoroughly aërated, and the aërobic bacteria rapidly oxidize the organic matter present. A filter-bed, on the other hand, is constructed of sand underlaid with gravel and stone. The sewage is spread out over the surface and is allowed to seep through. Opportunity for thorough aëration of the sand and gravel is given by the time elapsing between the discharges from the dosing chamber. Frequently several beds are used, and the sewage is discharged first upon one then upon another. The organic material is retained, probably by absorption, and, as the sewage passes through, the bacteria are largely filtered out, and the organic material is, for the most part, quite completely oxidized. The water leaving the drains under these filter-beds is relatively pure, in some cases quite as pure as water from the average shallow well. As has been stated, there are many modifications of the type of disposal plant. It has been adapted to use for the farm-house as well as the city. 


\section{CHAPTER XXIX}

\section{HEMORRHAGIC SEPTICEMIA GROUP}

HUEPPE, in 1886, united a number of organisms causing somewhat similar diseases in different species of animals under the name of Bacillus septicemia hæmorrhagica. He included chicken cholera, septicemia of rabbits, swine plague, hemorrhagic septicemia of cattle and of various wild animals, and a number of other diseases. Trevisan grouped these organisms in a new genus, which he named Pasteurella. The diseases produced by such organisms are, therefore, sometimes termed pasteurelloses (sing., pasteurellosis). Lignières, in 1901, classified the pasteurelloses, or hemorrhagic septicemias, and his classification has been generally adopted by the French bacteriologists, and is the outline followed by Nocard and Leclainche in their "Maladies microbienne des Animaux." The name Bacillus pleurisepticus is sometimes used to designate the organisms of this group as a whole.

There is probably no group of organisms which is in greater need of thorough study and revision than this. Non-pathogenic organisms having the morphologic and cultural characters of this group have been isolated from many sources. At least one disease, dog distemper, originally described as caused by a Pasteurella, has been shown to be due to an ultramicroscopic virus. It is possible that in some other diseases placed in this group the organism described as the etiologic factor is but a secondary invader. The discovery that hog-cholera is not caused by B. cholerce suis makes it appear highly probable that still other of these diseases may be found to be due to a filterable virus. Furthermore, there has not been sufficient care used in the differentiation of the various members of the group. It is not to be concluded that our knowledge of none of these diseases rests upon a secure foundation; there is little doubt, for example, that the Bacillus pestis is the cause of bubonic plague. 
The bacteria belonging to this group are closely related in their morphologic, physiologic, and cultural characters. A description for one will answer in general for the remaining. They are small, plump, short bacilli, with rounded ends, usually about 0.5 to 0.8 by 1 to $2 \mu$, non-motile, and without spores. Capsules may be demonstrated in the blood with some species. The organisms stain readily with aqueous anilin dyes, but are gram-negative. The outstanding morphologic character is the tendency toward bipolar staining, particularly in tissues. The ends stain deeply, the central portion not at all, giving the appearance of diplococci. The organisms grow readily upon the common cultural media, with the exception of potato, upon which they usually develop scantily, if at all, at blood-heat. Gelatin is not liquefied. Some acid is produced from dextrose; milk is usually not coagulated. The organisms are not particularly resistant, and are easily destroyed by heat, desiccation, and sunlight. Not only the organisms, but the diseases produced by them in various animals, resemble each other. All the species of the group are pathogenic for the rabbit, and usually for other laboratory animals. On the other hand, some of them possess a high degree of specificity, such that only that form isolated from the lesions of a certain species is pathogenic for that species. The disease is, in most cases, a true septicemia, characterized by hemorrhages in various organs. In some cases it may be localized in the lungs, the lymphglands, or the intestines.

As has been stated, it is at present not possible to differentiate the organisms associated with the various diseases from each other by any of their biologic characters. It is, therefore, necessary to adopt tentatively a pathologic classification, and group them with reference to the animals naturally infected and the diseases produced. The following list includes only the more important types that have been described, and is not complete:

A. Hemorrhagic septicemias of lower animals only.

1. Of birds, Bacillus avisepticus.

2. Of swine, Bacillus suisepticus.

3. Of cattle, Bacillus bovisepticus.

4. Of equines, Bacillus equisepticus,

5. Of rabbits, Bacillus cuniculicida. 
B. Hemorrhagic septicemia of rodents transmissible to man: Bacillus pestis.

\section{Bacillus avisepticus}

Synonyms.-Bacillus choleræe gallinarum; B. choleræ; Bacterium avicidum.

Disease Produced.-Fowl or chicken cholera in domestic fowls and other birds.

Perroncito, in 1878, first observed this organism in an outbreak of chicken cholera. Pasteur, in 1880, cultivated the organism and studied it quite at length. It was with this organism that he performed his first experiments upon vaccination and the preparation of attenuated cultures. It is, therefore, of considerable historic interest, as marking the beginning of the experimental study of immunity.

Distribution.-The disease is known to occur in various European countries, and has been reported from Canada and the United States.

\section{Morphology and Staining.} $-B$. avisepticus is a typical member of the hemorrhagic septicemia group; the characters given under the introductory heading will serve for this form.

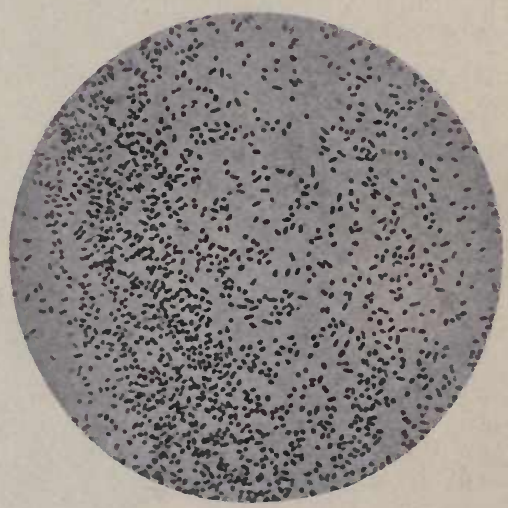

Fig. 119.-Bacillus avisepticus, from an agar slant $(X 1000)$ (Günther).

Isolation and Culture.-The organism may be isolated in pure culture from the blood and internal organs of infected birds. The colonies upon gelatin plates are small, white, usually irregular dots, without marked or distinctive characters. In gelatin stab, growth occurs along the line of inoculation in the form of numerous tiny, discrete colonies, and upon the surface a thick mass generally forms, rather circumscribed, giving to the whole the appearance of a nail. Agar and blood-serum slants show a moderately luxuriant, white, glistening growth. Bouillon is slightly clouded.

Physiologic Characters. $-B$. avisepticus is aërobic and facultative anaërobic. It grows best at blood-heat, but will develop 
readily in culture-media at room-temperatures. Acid is produced from saccharose and dextrose, but not from lactose; gas is never formed. No proteolytic enzymes are produced. Indol and phenol are formed in Dunham's solution.

Pathogenesis.-Experimental Evidence.-The B. avisepticus is pathogenic for chickens, geese, pigeons, and other birds, mice, and rabbits, producing a rapidly fatal septicemia when introduced subcutaneously. When fed, it will also produce disease in these animals. Guinea-pigs appear to be relatively immune,

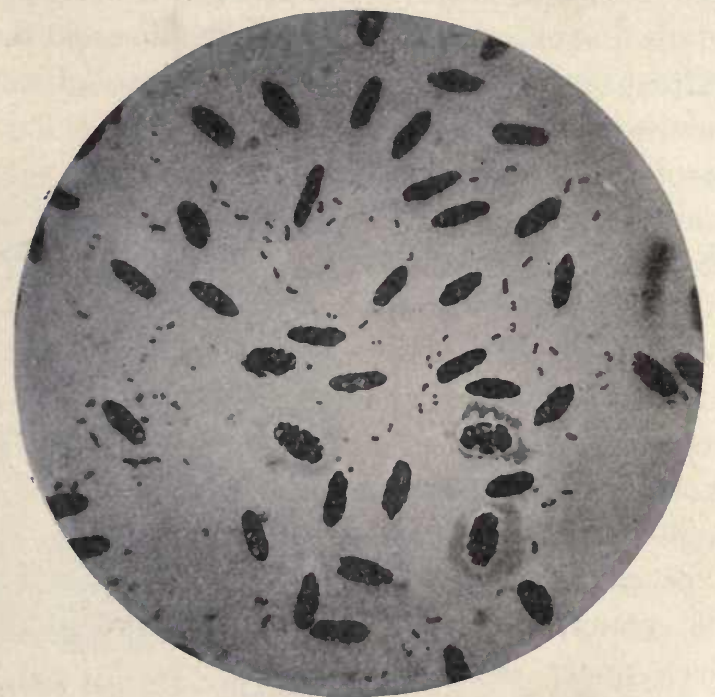

Fig. 120.-Bacillus avisepticus, in pigeon's blood (Fränkel and Pfeiffer).

except when injected with very large doses. It is not known to produce disease in man.

Character of Disease and Lesions Produced.-When introduced subcutaneously, there is an extensive edema at the site of inoculation, generally accompanied by more or less hemorrhage. The spleen and liver are swollen and congested, the lungs have congested areas, and the intestines show an inflamed mucosa, with occasional ulcer formation. Minute hemorrhages are found in various organs, particularly the lungs, the walls of the intestines, and the heart. Feeding experiments result in a localization of the lesions in the intestines. Areas of necrosis are frequently found in the liver. 
Immunity. - No true toxin has been demonstrated for the B. avisepticus. Endotoxins are produced. One attack of the disease with recovery confers immunity. Agglutination in dilutions of 1:6000 has been shown with blood of animals artificially immunized. The nature of this immunity is not certainly known, although opsonins have been demonstrated.

Pasteur, in 1880, worked out a method of prophylaxis by the use of vaccines prepared from attenuated cultures. He attenuated the organism by long-continued cultivation upon artificial media. Broth cultures were allowed to stand from three to ten months. Under these conditions the virulence is gradually lost, and inoculation into the fowl is followed by a mild local reaction only. This immunizes against subsequent injections of the virulent form. Pasteur believed that the attenuating factor was the abundant presence of oxygen, for cultures which he sealed from the free entrance of air he found to retain their virulence even after ten months. He also found that various strains showed great differences in their rate of attenuation. The Pasteur method of vaccination has never come into general use. Tests have shown that the use of the vaccine sent out by the Pasteur Institute was apt to produce typical cholera in some fowls. It has been shown that some degree of immunity is conferred by the injection of killed cultures of the organism.

It has also been found that immunization against one of the members of the hemorrhagic septicemia group immunizes likewise against others. Injections of the Bacillus bovisepticus, for instance, will protect against subsequent injection with Bacillus avisepticus. Lignière has prepared a polyvalent vaccine by growing at $42^{\circ}$ to $43^{\circ}$ organisms isolated from sheep, cattle, horses, dogs, hogs, and fowls in bouillon. When allowed to grow for five days, it constitutes the Vaccine I.; for two days only, Vaccine II. One-eighth c.c. of I. is injected, and twelve to fifteen days later the same amount of Vaccine II. By this means he claims to be able to immunize against all types of hemorrhagic septicemia in animals other than fowls. This method has not been utilized in practice, although a few recorded tests have been favorable. In summary, therefore, it may be stated that no practicable method of vaccination against fowl cholera has been evolved. 
Kitt and Mayr, in 1897, showed that it is possible to secure a protective serum from the horse and other animals, as goat and swine, by injections of living fowl-cholera organisms, and this serum, when injected in suitable quantities into susceptible animals, will protect them from injections of virulent bacilli. Schreiber, in 1899, elaborated upon an observation of the preceding investigation that animals immunized against swine-plague bacilli (B. suisepticus) were likewise immune to fowl cholera. In 1902 he gave the name "septicidin" to a polyvalent serum which he prepared by immunization with $B$. suisepticus, B. avisepticus, and $B$. cholerce suis. The reports relative to the efficiency of this serum are conflicting. It has not come into general use. Hertel, in 1902 , reported that by intravencus injections of dead bacteria followed by living bacteria into an ass he secured a serum which in injections of 0.5 c.c. protected pigeons against 10,000 times the normal lethal dose of the organism. Lignière and Spitz have also prepared a polyvalent serum, using the Lignière vaccine noted above. There is no record of a practical utilization of this method. Kitt and others, in 1904, have described sera which protect fowls experimentally inoculated with $B$. avisepticus, but, like the others described, these have not come into general use. It may be concluded, therefore, that while immunization against fowl cholera, either by vaccination or the use of antisera, has been shown to be possible, it has not been proved practicable.

Bacteriologic Diagnosis.-Stained mounts of the blood which reveal the presence of gram-negative bacilli showing prominent bipolar staining are diagnostic. The bacillus may be readily isolated in artificial media. Whether or not serum reactions, particularly agglutination, might be utilized in diagnosis is not known.

Transmission. - The disease is supposed to be transmitted from bird to bird by ingestion of food or water fouled with excretions containing the specific organism.

\section{Bacillus surisepticus}

Synonym.-Bacillus suicida.

Disease Produced.- Swine plague; Schweineseuche.

Löffler and Schütz, in 1886, published results which established the identity of swine plague as a specific disease by the discovery 
of the causal organism. In the same year Smith isolated what proved to be the same organism from hogs in the United States. Since that time it has been isolated from animals in many parts of Europe and the United States. From the beginning the close relationship between the swine-plague and fowl-cholera bacilli was recognized. In the early literature of swine diseases in America there is much confusion relative to the use of the terms swine plague and hog-cholera. The discovery that hog-cholera is caused primarily by an ultramicroscopic organism has made necessary a very careful retraversing of the knowledge relative to swine plague, and it has been urged that probably the $B$. suisepticus is a secondary invader merely, as is the hog-cholera bacillus, and that the two diseases differ not at all in their primary cause. The evidence at present seems to point, however, to a specific disease caused by $B$. suisepticus, and entirely distinct from hog-cholera. The question cannot be said to be satisfactorily settled at the present

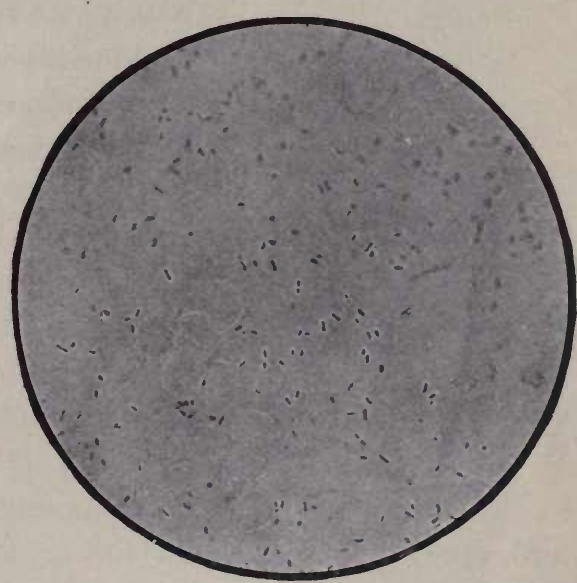

Fig. 121.-Bacillus suisepticus (after deSchweinitz and McFarland). time. In the United States it seems probable that swine plague, if such really exists, is relatively unimportant in comparison with hog-cholera.

Distribution.-Swine plague is known to occur in Germany and in parts of the United States. It has been reported from practically all the States, but the evidence is in most cases quite inconclusive, as the final criterion must be the isolation of the specific organism.

Morphology and Staining.-The morphologic characters are practically identical with those of $B$. avisepticus, as are also the staining characteristics.

Isolation and Culture.-B. suisepticus may be isolated in pure 
culture from the lungs, from the blood, and from various internal organs of the body, without difficulty. The cultural characters do not differ from those described for B. avisepticus.

Physiology. - The physiologic characters do not differ from those of the group.

Pathogenesis.-Experimental Evidence.-Inoculation of the mouse, rabbit, and fowl lead to the same results as with the bacillus of fowl cholera. Hogs die of septicemia after subcutaneous injection. It has not proved generally possible to infect the hog by feeding. That the organism is, under proper conditions, pathogenic for the hog appears to be well

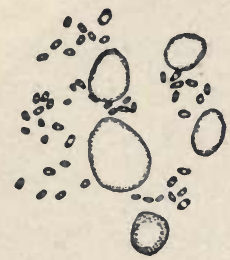

Fig. 122.-Bacillus suisepticus in blood (after deSchweinitz, Report Bureau of Animal Industry). demonstrated, but that it can produce an epizoötic naturally among animals is by no means so well established.

Character of Disease and Lesions Produced.-The characteristic lesions of this disease are generally to be found in the lungs, although the intestines may exhibit some changes and may closely simulate the conditions found in hogcholera. The disease may, therefore, be denominated a pneumoenteritis. It may also appear in septicemia form. Punctiform hemorrhages are generally to be observed, particularly in the kidneys.

Immunity.-As with the fowl-cholera bacillus, no true toxins have been demonstrated. Both active and passive immunization against the $B$. suisepticus have been accomplished. Active immunization has been attempted in many different ways. The use of killed and living cultures has not, in general, proved satisfactory in immunizing the hog, although they have been successfully used in the preparation of antisera from the horse and other animals. Weil has elaborated the following technic, making use of the so-called "natural aggressins" for the establishment of immunity. A rabbit is injected intraperitoneally with 5 c.c. of bouillon containing a drop of twenty-four-hour culture of a highly virulent strain of the organism. The animal should die within the next twenty-four hours. The exudate, varying in amount from 1 to 20 c.c., is pipetted off and sterilized by the addition of 0.5 
per cent. of phenol, then heated to $44^{\circ}$ for three hours, then its sterility determined by transfers to broth. If the broth shows no growth, the material is sterile and is ready for use. This may be used to inject laboratory animals and thereby establish immunity. The animal immediately after injection becomes more susceptible to the disease, presumably due to the presence of aggressin in the blood, but later a relatively permanent active immunity is produced. In practice it is found that in the immunization of hogs it is necessary that the exudate containing the aggressin be obtained from other hogs rather than rabbits. Wassermann and Citron have developed a somewhat similar method of immunization by the use of so-called "artificial aggressins" or bacterial extracts. These methods of immunization are of much more theoretic than practical importance.

Passive immunization by means of antisera has been studied by several investigators. A rabbit may be actively immunized by one of the preceding methods, and its serum may protect a mouse in doses of less than 0.1 c.c. against a fatal injection of a highly virulent organism. Wassermann and Ostertag and their pupils have shown that an antiserum specific for one strain of $B$. suisepticus is not always effective for others. They, therefore, prepare serum by the systematic immunization of a horse against several strains of the organism until a serum of high potency is produced. Its strength is determined by injections into mice. Experiments upon young pigs with this serum are claimed to have been highly successful, but the method has not come into general use. Simultaneous injections of immune sera and of $B$. suisepticus have also been advocated.

In summary it may be said that immunization against swine plague is still in the experimental stage, and that no completely satisfactory method has been evolved.

Bacteriologic Diagnosis.-The identification of the causal organism by actual isolation is the only practicable method of bacteriologic diagnosis.

Transmission.- The means by which the disease spreads naturally are not fully understood. It is possible that it is by ingestion, probably sometimes by inhalation. 


\section{Bacillus bovisepticus}

Synonyms.-Bacterium bovisepticum; Bacterium bipolare multicidum; Bacillus bovicida.

Disease Produced.-Hemorrhagic septicemia in cattle, buffalo, and related wild animals; Rinderseuche; Wildseuche.

The early descriptions of this disease refer to it as attacking cattle, wild animals, and swine. Bollinger, in 1878, first described it as Wild- and Rinderseuche, attacking wild boars and deer. Kitt, in 1885, isolated an organism belonging to the hemorrhagic septicemia group. Since that time numerous investigators have reported epidemics of the disease in many countries. Fernmore, in 1898, first noted its presence in the United States. Wilson and Bumhall, in 1901, and Reynolds, in 1903, studied several epidemics in the State of Minnesota.

Morphology and Staining.-It does not differ from the $B$. avisepticus and B. suisepticus.

Isolation and Culture.-The specific organism may be isolated from the blood and the internal organs of infected animals. The cultural characters are practically identical with the preceding forms.

Physiology. - Same as B. avisepticus and B. suisepticus.

Pathogenesis.-Experimental Evidence.-The organism is pathogenic for the mouse, rabbit, and pigeon. Inoculation of virulent cultures into cattle have been successful in causing the disease.

Character of Disease and Lesions Produced.-The presence of small hemorrhages in many of the body organs, and particularly upon the serous surfaces, is characteristic. Hemorrhages are quite uniformly present also in the subcutaneous tissues. In some cases these are quite extensive and involve a considerable portion of the body surface. The heart is usually petechiated.

Immunity. - It is entirely probable that the facts relative to immunity given under the discussion of fowl cholera and swine plague will hold good in bovine hemorrhagic septicemia. However, no practical method of immunization is known and little work has been done on this topic.

Bacteriologic Diagnosis.- Stained mounts from the blood and the internal organs will show the gram-negative, polar-staining bacillus. It may be isolated upon culture-media. Diagnosis 
by agglutination may be practicable, but further work is needed before its usefulness can be ascertained.

Transmission.- The means by which the organism spreads from one animal to another, and by which it gains entrance to the body, is not well understood.

\section{Other Hemorrhagic Septicemias of Animals}

Organisms belonging to this group have been isolated from a considerable number of other animal diseases in addition to the ones which have already been described. Rabbit septicemia or rabbit plague (Bacillus cuniculicida), pneumoenteritis, or hemorrhagic septicemia of sheep and of the horse, infectious pneumonia of goats, Büffelseuche or pasteurellosis of the buffalo, dog typhoid or dog pasteurellosis, hemorrhagic septicemia of elephants, of geese, wild birds, and many other animals have been ascribed to Bacillus septicemice homorrhagica. As has been before stated, the evidence in some of these cases seems to be inconclusive.

\section{Bacillus pestis}

Synonyms.-Bacterium pestis; B. pestis bubonica.

Disease Produced.-Bubonic plague in man and rodents.

Yersin and Kitasato, in 1894, independently described the organism which causes bubonic plague. Since that time it has been isolated and described by many observers in numerous outbreaks.

Distribution.-The disease is endemic in parts of China and India. At various times it has spread as an epidemic over the entire civilized world. Cases have been reported within recent years in most of the civilized countries, but it has not gained a foothold and spread in any countries except those of southern Asia and China.

Morphology and Staining.-The Bacillus pestis morphologically resembles the other members of this group. It is smallusually about 0.5 to 0.75 by 1.5 to $2 \mu$. It sometimes occurs in short chains, but is usually single. Involution forms are produced so readily upon appropriate culture-media, such as partially desiccated agar and salt agar, that their development has been regarded as diagnostic. Capsules may sometimes be demonstrated on culture-media, but not in tissues. The bipolar staining of 
the organism is particularly evident in smears from tissues or blood.

Isolation and Culture.-The organism may be isolated directly from infected lymph-glands in pure culture. It has been obtained from the blood, but this is not usual. Growth occurs readily on most culture-media. The colonies on agar are delicate, drop-like, with center somewhat granular and thicker than the uneven, slightly granular margin. Growth on other media does not differ markedly from that described for other members of this group. Growth occurs scantily or not at all on potato. One character that has been described and has been found useful in

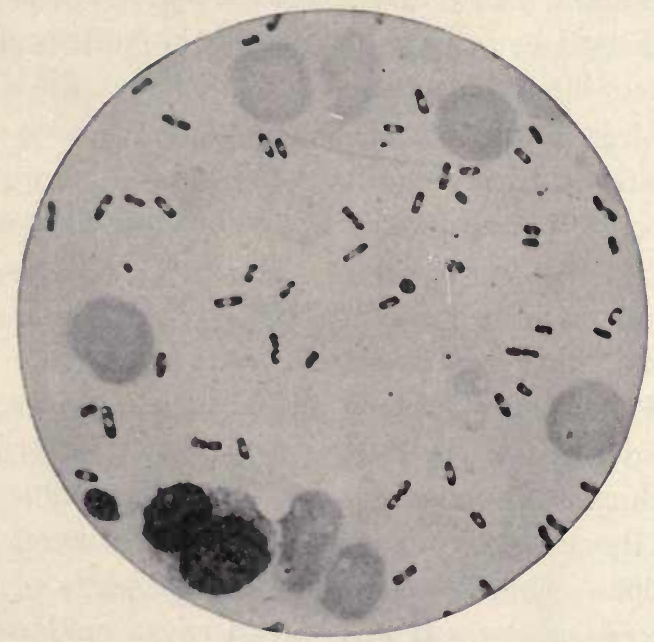

Fig. 123.-Bacillus pestis (Wherry).

diagnosis is the "stalactite" formation in broth covered with oil and allowed to remain without being disturbed. Under these conditions long delicate threads are produced which hang from the oil and resemble the stalactites found in caves.

Physiology. - The organism is aërobic and facultative anaërobic. The optimum growth temperature is between $25^{\circ}$ and $30^{\circ}$, but growth occurs both above and below these temperatures. It is easily destroyed by desiccation, heat, light, and disinfectants. Dextrose broth is acidified, but no gas is produced. Indol is not formed. 
Pathogenesis.-Experimental Evidence.-The organism readily infects mice, rats, guinea-pigs, rabbits, dogs, cats, and monkeys, when they are experimentally inoculated. The symptoms and lesions produced are entirely typical of bubonic plague in man. Accidental infection of man resulting in four cases of plague occurred in a Vienna laboratory at a time when bubonic plague did not exist elsewhere in Europe. The causal relationship of the organism to the disease may be held to be fully established.

Character of Disease and Lesions Produced.-The disease in experimental animals may be a rapidly fatal septicemia, or in those animals which are somewhat resistant, as the rat, typical buboes (enlarged and suppurating lymph-nodes) or abscesses

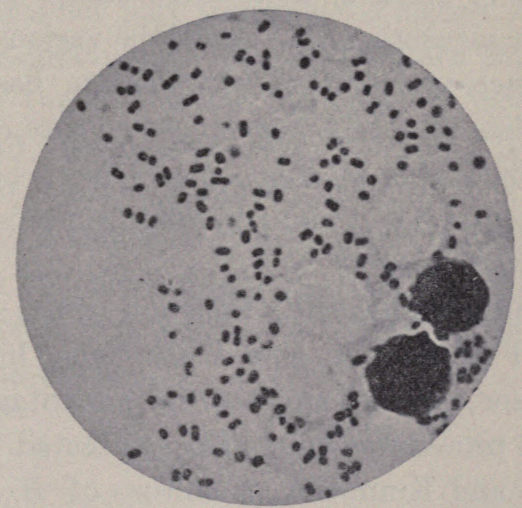

Fig. 124.-Bacillus pestis, bacilli from a bubo (Günther).

in the spleen or liver are produced. The disease in man may be of one of three types - septicemic, usually rapidly fatal with the organisms generally distributed through the blood and various tissues of the body; the pneumonic, also rapidly fatal; and the bubonic, the most common, in which the lymph-nodes are infected, become enlarged, and ulcerate. The bubonic type is less fatal, recovery taking place in a small percentage of cases. The septicemic type of the disease is often accompanied by extensive subcutaneous hemorrhages, which gave the name "black death" to the epidemics of mediæval Europe.

Immunity.- No true toxin has been demonstrated for B. pestis, although endotoxins have been shown to be present. Agglutinins 
for this organism may be found in the blood of advanced cases and of convalescents, but they appear too late to be of any diagnostic value. The reaction is rather doubtfully specific. The reaction occurs only in low dilutions-rarely above 1:20. Agglutination in much higher dilutions may be secured with immune serum-sometimes as high as 1:1000 has been observed. Precipitins have also been noted in laboratory experimentation. Opsonins for $B$. pestis have been demonstrated in normal human serum and in immune serum. Bactericidal substances are present in the serum of artificially immunized animals.

Active immunization of man against bubonic plague has been quite extensively practised. The procedure consists in every case of injection of killed or attenuated bacilli or their products as a prophylactic measure. The use of the various substances has proved quite successful. Haffkine's vaccine has been used in India. It consists of a killed six-weeks culture of plague bacilli in broth. Modifications of this method have been utilized by many investigators. The immunity established is probably both opsonic and bactericidal.

Passive immunization by the injection of the serum of horses hyperimmunized against $B$. pestis has been highly successful according to some, and of no material advantage according to others. Several procedures have been advocated. The following is that of Kolle and Kumbein: A culture of B. pestis is passed through rats to exalt its virulence. This is planted upon agar and incubated forty-eight hours at $30^{\circ}$, the growth washed off and suspended in physiological salt solution. The suspension is killed by heating to $70^{\circ}$ for an hour and its sterility determined. The horse is injected at intervals of a few days with gradually increasing doses of the dead bacteria, until after seven or eight injections the bacteria from six or more culture-tubes are injected at one time. Injections of minute quantities of the living organism are then begun and finally after repeated injections the living organisms from 16 cultures are used. The interval between injections is governed by the reaction of the animal. Usually it is from five to eight days. The animal is then bled, and the serum preserved by the addition of 0.5 per cent. phenol.

Bacteriologic Diagnosis.-The organism may be recognized 
in stained mounts from the pus from a bubo as a small gramnegative bacillus, with characteristic bipolar staining. It may also be isolated upon culture-media and identified by its growth characteristics.

Transmission.-The pneumonic form of the disease may be transmitted by the inhalation of infectious droplets. Plague is not known to occur in the human following ingestion of the organism. The bubonic or most common type is probably transmitted to man by the bite of fleas (or from their excretions scratched into the skin), which have left rats dead of the disease. An epidemic of plague in the human is commonly preceded by an epizootic among the rats of the community. It has been shown experimentally that a flea may transmit the disease from an infected to a non-infected individual. It is also known that the cannibalistic tendency of the rats to eat their dead is in part responsible for the spread of the disease among vermin. The annihilation of the rat is the best prophylaxis known. The disease has in certain places, as about San Francisco, been found to spread to such rodents as the ground-squirrels and wood-rats. When a region once becomes thoroughly infected, it is, therefore, difficult to stamp out the disease. 


\section{CHAPTER XXX}

\section{ACID-FAST GROUP}

The Bacillus tuberculosis, B. leproe, the bacillus of Johnes' disease, and certain common non-pathogenic bacteria isolated from hay, dung, milk, butter, and other sources, have common morphological and staining characters which associate them as the acid-fast group. The crucial test for these forms is their ability to retain stains when treated with strong acids. They do not stain readily with the common anilin dyes, but when once stained they are "acid-fast." Hot carbol-fuchsin is commonly used in determining this character.

The members of the acid-fast group of bacteria are all slender, non-motile rods, without capsules or spores, gram-positive, and acid-fast. Slight variations in morphology and eultural characters and considerable differences in pathogenesis serve to differentiate the various species. All the species may occasionally produce branched cells and threads, and it has been concluded by some investigators that they belong rather with the fungi, or at least with the higher bacteria than with the lower bacteria.

Care should be used not to confuse the term pseudotuberculosis, and particularly the bacteria associated with that disease, with the true tubercle bacilli and related forms. As has before been stated, the term pseudotuberculosis is purely pathological, and refers to the type of lesions produced in the body, and not to any resemblance of the organisms causing the disease to those of tuberculosis. The pseudotubercle bacilli are more closely related to the diphtheria group, and have already been discussed.

\section{Bacillus tuberculosis}

Synonyms.-Bacterium tuberculosis; Mycobacterium tuberculosis.

Disease Produced.-Tuberculosis in mammals and birds. 
The disease in its various forms in man and animals has been known since ancient times. Villemin, in 1865, showed that the disease could be transferred from one animal to another by injection of the crushed nodules. He did not succeed in discovering the specific organism, however. In 1884 Dr. Robert Koch presented the results of his studies of the disease and described the organism which he had proved to be its etiological factor. This work will always stand as a model of scientific research in bacteriology carried out under the most difficult circumstances. Staining methods and culture-media were both devised before the organism could be seen or grown. Koch succeeded in demonstrating its presence in the characteristic lesions, in growing it upon artificial media, and in reproducing the disease in animals by the inoculation of pure cultures. It was assumed in the beginning that tuberculosis in all animals was caused by the same organism, but in 1896 Theobald Smith called attention to the fact that certain differences in cultural, morphological, and pathogenic characters could be distinguished in the organisms isolated from human and bovine tuberculosis. Koch, in 1901, declared the two organisms to be distinct, and that the probability of human infection with bovine tuberculosis was remote indeed. Since that time the subject has been studied with varied results by many investigators. Probably more has been written on this one disease than any ten or more other diseases. Journals devoted exclusively to tuberculosis are issued. Many points even yet are not fully understood, but the subject is upon a moderately sound basis at present. It seems best to differentiate three varieties of the tubercle bacillus - the human, the bovine, and the avian. These possess many points in common, and it is by no means certain that they cannot be transformed the one into the other, but they may, in general, be readily differentiated by specific morphological and physiological characters. They will be discussed together.

Distribution.-Tuberculosis in man is known throughout the civilized world. In the United States over 110,000 deaths occur annually from this disease. It usually leads all other diseases in total number of deaths produced. The disease in cattle is nearly as widely distributed. It is found throughout Europe and America. Isolated localities free from the disease, however, are known. 
In the United States it is rarely encountered on the western ranges, but is relatively common in dairy and beef herds in other parts of the country. Whenever swine are allowed to follow tuberculous cattle, they commonly become infected. The same is also true when they are fed upon unpasteurized milk from tuberculous animals. Tuberculosis occurs rarely in the horse. Sheep have been reported as tuberculous, but the disease is certainly rare; it is probably frequently confused with pseudotuberculosis or caseous lymphadenitis in this animal. Tuberculosis in domestic fowls is known to occur in many European localities, and in the United States has been reported from Oregon, California, and New York.

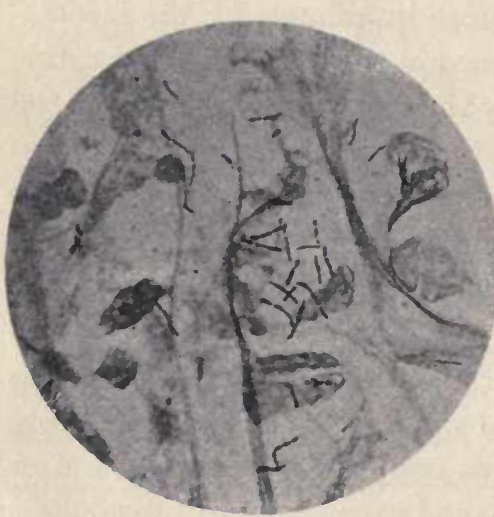

Fig. 125.-Bacillus tuberculosis in human sputum. Note the slender beaded character of the rods ( $X$ 1000) (Günther).

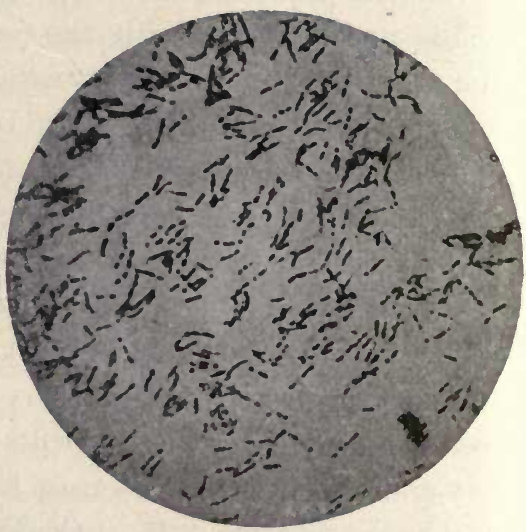

Fig. 126.-Bacillus tuberculosis, human, mount from glycerin agar (Fränkel and Pfeiffer).

Morphology and Staining.-B. tuberculosis is a slender rod, frequently somewhat bent, with rounded ends. It varies from 0.2 to 0.5 by 1.5 to $3.5 \mu$, and sometimes longer. Frequently the protoplasm takes the stain irregularly and gives a beaded appearance to the cell. No spores or capsules are produced. The organism is non-motile. Branched and elongated forms resembling somewhat the actinomyces are sometimes observed. It is probable that these are involution forms, although some authors claim them to be developmental forms instead. The organism stains with difficulty, but when once stained, is acid-fast. It is possible that 
under certain conditions, in the animal tissues in particular, this acid-fast property may be temporarily lost. The acid-fast character is apparently due to the presence of a wax-like substance in the bacterial cell. The cells from which this has been removed by ether and benzol are no longer acid-fast.

There are certain morphological differences commonly to be observed between bovine and human tubercle bacilli. The former are shorter, straighter, and thicker than the latter. They are also less apt to show the irregular or granular staining noted above. These characters are, of course, not sufficient to differentiate isolated bacteria of the two types, but cultures can usually be identified readily by an experienced observer. Whether or not one type may be transformed into the other type by animal inoculation or by cultural methods is a moot question. Some investigators claim to have isolated typical human bacilli from animals that have been inoculated with bovine bacilli, others hold that there is no evidence of the transformation of the one type to the other. However this may ultimately be

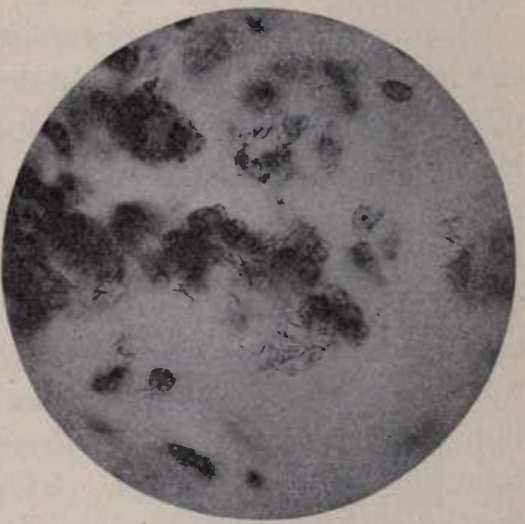

Fig. 127.-Bacillus tuberculosis, bovine, in a section of the peritoneum (Fränkel and Pfeiffer). decided, it is certain that each

type retains its characters with a considerable degree of constancy. The existence of two well-marked varieties is unquestioned. The bacillus of avian tuberculosis resembles the bovine type closely in its morphology and staining reactions.

Isolation.-The isolation of $B$. tuberculosis from lesions is attended with considerable difficulty. This is even more pronounced when an attempt is made to secure the organism from the sputum or the feces where it exists in mixed culture.

It may be isolated from infected organs by securing bits of the tissue and rubbing over the surface of inspissated blood-serum or other suitable medium. The method worked out by Theobald 
Smith has given excellent results in the hands of numerous investigators. A dog is bled, using all aseptic precautions, from the femoral artery into a sterile vessel and the blood allowed to clot. The serum is removed by sterile pipettes to sterile test-tubes. These are slanted and heated to a temperature of $75^{\circ}$ to $76^{\circ}$ for about three hours, or until the serum is coagulated. The heating must be done in a saturated atmosphere and the medium stored so that there is no loss by evaporation. Bits of infected tissue are placed upon the surface and kept in a thermostat for several weeks. If no growth appears, the tissue is moved about and incubated again. A constant temperature of $37^{\circ}$ and a saturated atmosphere must be maintained.

A procedure somewhat simpler than the preceding has been described by Dorset and is found to give good'results. The shell of fresh eggs is carefully broken, and the white and yolk dropped into a sterile flask, the yolk broken with a sterile rod or wire, and the contents of the flask shaken until the two are thoroughly mixed. Foaming is to be avoided. The mixture is placed in tubes, slanted, and heated at a temperature of about $70^{\circ}$ for from four to five hours on two days. This coagulates and sterilizes the medium. The tubes should be stored where they will not lose water by evaporation. Several drops of distilled sterile water should be added to a tube just before incubation. The isolation upon this medium is carried out as outlined above. A growth may generally be observed within ten days after inoculation with fresh tissue.

Isolations from sputum or feces, milk, or other substances in which the organisms occur mixed with other forms, is attended with some difficulty. It is usually accomplished by injecting the material or the sediment yielded by centrifugation directly into a guineapig. The bacilli may later be isolated in pure culture from the nodules produced. Within recent years the use of "antiformin" and similar substances has considerably simplified this procedure. Antiformin is the trade-name given a disinfectant mixture having the following composition:

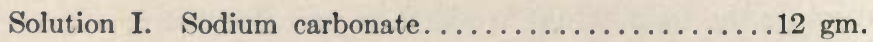

Chlorinated lime.............. 8 gm.

Distilled water.................. $80 \mathrm{gm}$.

Solution II. Sodium hydroxid..............

Distilled water................... 85 gm. 
Equal quantities of the two solutions are mixed for use. The sputum or other material containing the tubercle bacilli is placed in a centrifuge tube, and antiformin to about 20 per cent. of its bulk, added. The tube is then corked, thoroughly shaken, and allowed to remain in a dark place for twenty-four hours. It is then centrifuged, the clear, supernatant liquid pipetted off, the tube filled with sterile physiological salt solution, centrifuged, washed a second time, and the sediment smeared over the surface of serum slants. The antiformin destroys all other non-acid-fast bacteria present and dissolves the mucus and most of the cell elements, but when properly used, seems to have little effect upon the tubercle bacilli, as they retain their vitality unimpaired. This is probably because of their chemical composition and waxy covering.

Cultural Characters. $-B$. tuberculosis does not grow readily when first isolated upon culture-media, and will grow only upon certain substances. After a few transfers it seems to become habituated to growth under these conditions and will develop through a much greater range of temperature and on other media. Development occurs best on media containing blood-serum, egg, or similar proteins, or to which glycerin has been added.

The colonies upon blood-serum or glycerin agar appear in the course of ten days or two weeks as tiny grains barely visible to the naked eye. They gradually enlarge, and in subcultures become confluent and cover the surface of the medium with a dry, rather mealy, wrinkled growth; the colonies direct from lesions do not coalesce usually. The growth is white and lusterless, or rarely in old cultures cream or brown. In glycerin bouillon the growth generally occurs as a more or less continuous, heavy, wrinkled, white pellicle that breaks into pieces and sinks to the bottom when the medium is shaken. Similar growths occur upon other media which contain glycerin. In no other case is the growth so rapid.

Cultural characters which may be used in the certain differentiation of the human, bovine, and avian tubercle bacilli are not readily found. The organisms isolated from the human and from the bird adapt themselves much more readily to artificial media and grow more luxuriantly than does the bovine type.

Physiology.-The B. tuberculosis is aërobic. Its optimum growth temperature is about $37.5^{\circ}$ for the human and the bovine 
types and somewhat higher for the avian. The thermal deathpoint is $60^{\circ}$ for twenty minutes. This is, therefore, the minimum

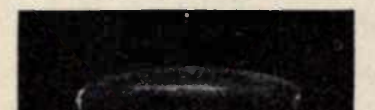
time and temperature for the efficient pasteurization of milk. Sunlight destroys the organism quickly, but it is moderately resistant to desiccation. Most of the physiological characters, such as acid, gas, pigment, ${ }^{\circ}$ and indol production, are negative.

Theobald Smith has called attention to what appears to be a very constant differential character between human and bovine tubercle bacilli. He found that in glycerin bouillon ( 2 per cent.) acid to phenolphthalein the human bacillus causes a permanent acid reaction, while with the bacillus of bovine origin the acidity diminishes and the reaction becomes alkaline if the growth environment of the culture is suitable. The tuberculin prepared from the human bacillus is acid, and from the bovine bacillus alkaline. This difference has been noted by other investigators since its first description, and seems to be one of the best methods of differential diagnosis.

Pathogenesis.-Tuberculosis is characteristically a chronic disease. Even in experimental animals months are often required for it to run its course. As stated by Moore, "It does not destroy life by acute toxemia, but by a chronic and long-continued systemic poisoning

Fig. 128. - Bacillus tuberculosis, glycerin agar slant (Curtis). and by the morbid changes brought about through the localization of these lesions in the organs necessary to life."

Experimental Evidence of Pathogenesis. - The laboratory animals 
are generally susceptible to infection with $B$. tuberculosis. The constant presence of the organism in the lesions of the disease and its ability to reproduce the disease are sufficient evidence that it is the true etiologic factor.

Important differences in pathogenesis are to be noted among the three varieties. The bovine bacillus is most pathogenic for laboratory animals, the human next, and the avian least (except
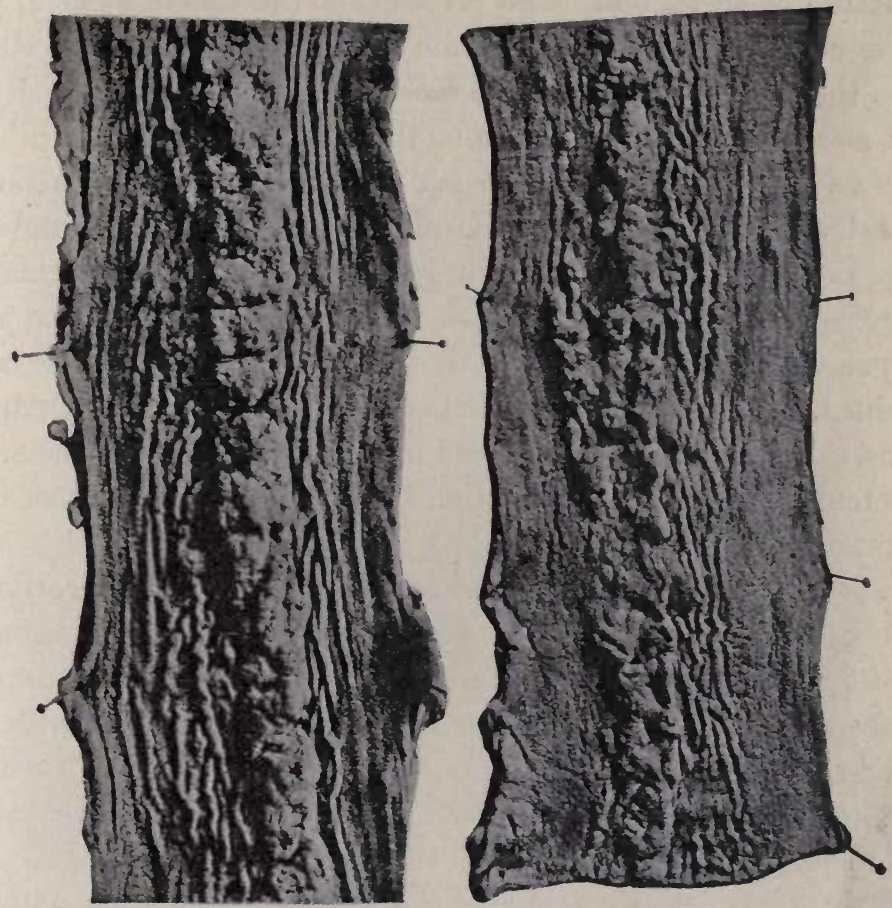

Fig. 129.-Tubercular hypertrophy of the intestinal wall in the bovine (Chaussé).

for birds). Guinea-pigs inoculated subcutaneously with bovine bacilli generally succumb in less than fifty days; those inoculated with human bacilli generally live more than fifty days. Intraperitoneal injection of the bovine type is fatal in seven to eighteen days, of the human type in from ten to thirty-eight days. The difference upon intravenous injection of the rabbit is even more marked-with bovine bacilli death occurs within three weeks, with human bacilli the animals usually live for several months 
and may even recover. The avian type ordinarily does not produce fatal infection in guinea-pigs, although rabbits succumb and fowls and pigeons contract the disease readily.

Character of Disease and Lesions Produced.-Almost any part of the body may be affected with tuberculosis. The disease, wherever found, generally involves the lymphatics. It is characterized by the development of nodules having an essentially similar structure in all tissues. The presence of the tubercle bacilli in a tissue causes a proliferation of the fixed connective-tissue cells to form the beginning of a miliary tubercle. Lymphocytes are generally attracted and are present in the surrounding tissues in considerable numbers. A more or less definite layer of "epithelioid" cells forms the boundary of the tubercle. Typical giant-cells with peripheral nuclei are found near the center. Coagulation necrosis proceeds and the interior caseates. Encapsulation with fibrous tissue may occur, and the whole may eventually become calcified. These calcareous grains persist in healed tuberculous areas. Tubercles frequently are formed in masses. In the cow tubercular lymph-glands sometimes become as large or larger than an orange.

The arrangement of the nodules frequently shows clearly the path of the spread of the bacilli through lymphatic metastases. Direct growth through tissues with invasion of new areas probably rarely occurs. The organisms are not commonly found in the blood-stream, although they may sometimes be carried to other parts of the body by this means. Infection of the bones, joints, and meninges probably occurs in this manner.

The organs most commonly the seat of lesions vary with the species of animal and the mode of infection. In the human, pulmonary infection (consumption) is most common, although intestinal tuberculosis, infection of the lymphatics of the neck (scrofula), of the bones and joints (tubercular osteitis and arthritis), of the meninges, and of the liver, spleen, kidneys, and other organs of the body and the serous membranes lining the cavities, are not uncommon. Lupus or tuberculosis of the skin is of frequent occurrence in certain European countries. Cattle generally show nodules in the mesentery and in the peritoneum (Perlsucht or pearl disease). The lungs and the accompanying lymph-glands 
and the intestines commonly show lesions. In a certain small percentage of tuberculous cows, variously estimated from a fraction of 1 to 5 per cent., tuberculous lesions may be found in the udder. Any and all of the organs of the body may be infected. Swine are most commonly infected in the lymph-glands of the neck (swine scrofula), and in the abdominal organs and the lungs. Avian tuberculosis most frequently attacks the abdominal organs, particularly the liver and spleen, more rarely the lungs.

Immunity.-No true toxin has been demonstrated for the tubercle bacillus. Endotoxins are produced. These are liberated

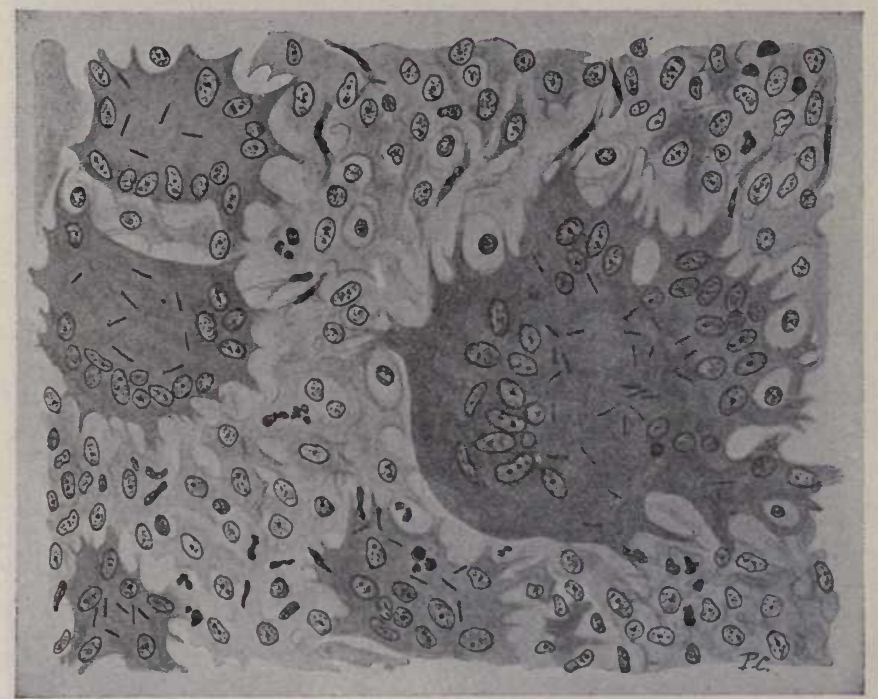

Fig. 130.- Section of a tubercular intestinal wall showing the bacilli and giantcells (Chaussé).

from the cell with difficulty because of its composition and slow dissolution. Specific agglutinins and precipitins have been demonstrated in the blood of infected individuals and in immune serum. Opsonins, both normal and immune, have been shown to occur. The development of bacteriolysins has not been satisfactorily demonstrated.

Methods of active immunization are all dependent upon the use of killed or attenuated bacteria or their products. The name tuberculin is given to any suspension of dead tubercle bacilli or a solu- 
tion of their products. As will be noted later, tuberculin is not only of therapeutic significance, but of great diagnostic value. Many types have been prepared by various workers. Some of the more important will be described before a discussion of their use in immunization and in diagnosis is undertaken.

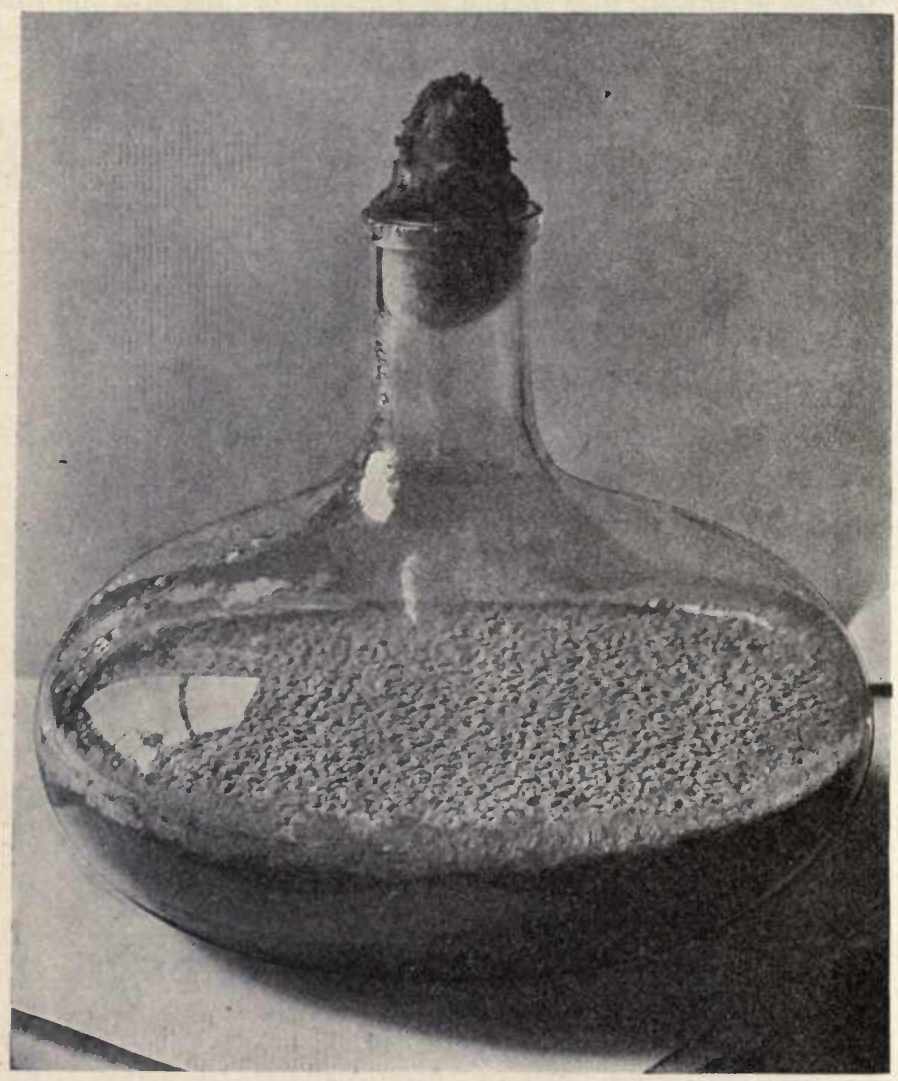

Fig. 131.-Tuberculin flask, showing the growth of Bacillus tuberculosis (McFarland).

Koch's Old Tuberculin (Alt Tuberculin).-Flat-bottomed flasks containing 4 per cent. glycerin broth to a depth of 2 to $3 \mathrm{~cm}$. are inoculated with $B$. tuberculosis. The inoculated material is carefully placed on the glass at the surface of the liquid in order that it may spread out at once as a film over the surface. Unless the organism is at the surface, little or no growth will occur. In 
the course of four weeks at blood-heat the surface of the broth is covered with a heavy, wrinkled pellicle. By the end of eight weeks it is ready for the preparation of the tuberculin. The contents of several flasks are then united and placed in a porcelain evaporating dish on a water-bath. The material is concentrated to about one-tenth of its original bulk, when the glycerin content becomes about 40 per cent. This constitutes the tuberculin commonly used.

Tuberculin of Denys.- This investigator believed that the efficiency of the tuberculin was impaired by the heat used in concentration. He filtered unheated broth cultures through porcelain and utilized the filtrate.

The tuberculol of Landmann, the tuberculocidin or antiphthisin (A. P.) of Klebs, the oxytuberculin of Hirschfelder are all tuberculins prepared by various modifications of the original Koch method, such as repeated extraction of bacilli at different temperatures, treatment with $\mathrm{H}_{2} \mathrm{O}_{2}$, etc.

Koch's purified tuberculin is prepared by adding $1 \frac{1}{2}$ volumes of absolute alcohol to the crude tuberculin and allowing the mixture to stand twenty-four hours, collecting the precipitate on a filter and washing in 60 per cent. alcohol, and finally drying in a desiccator at $100^{\circ}$. This material is diluted in water or glycerin before use, being soluble in these.

Tuberculin R. or T. R. of Koch.-Young virulent cultures of tubercle bacilli are dried in a vacuum, then ground in an agate mortar or ball mill for a considerable period. The resultant powder is next suspended in water, shaken, and centrifuged for half to three-quarters of an hour at a speed of 4000 revolutions per minute. The bacterial fragments are thrown to the bottom. The portion of the tubercle bacilli that remain in solution Koch termed Tuberculinum O. (T. O.); the portion which is precipitated was called Tuberculinum R. (T. R.). Koch dried this T. R., reground it, suspended and centrifuged to get rid of all the T. O. The T. $R$. was originally planned for use in immunization. This residual material was found to be largely free from the toxic action of other tuberculin and of the T. O. This preparation has not come into use, inasmuch as there is always a possibility that living virulent organisms may survive the treatment and produce disease when injected. 
New Tuberculin or Bacillus Emulsion of Koch.-The cultures are prepared, dried, and ground as for the manufacture of T. R. They are then suspended in glycerinated physiologic salt solution. Some preservative, as phenol, is added.

This by no means completes the list of preparations of the tubercle bacillus. Most of them are of laboratory significance only, the ones of any considerable practical importance being the old tuberculin and the purified product.

The use of tuberculin as a prophylactic or cure has not proved successful with the lower animals, nor has it in man when used in large doses. Within recent years it has come into common use in the treatment of human tuberculosis, minute injections being given and care taken that no febrile reaction shall follow. Determinations of the opsonic index from time to time have been used with success in the determination of the proper spacing of the injections. This method is intended to stimulate opsonin production and thus aid the body in ridding itself of the bacilli.

The use of attenuated cultures, and particularly of cultures of the $B$. tuberculosis from the human, has been advocated by von Behring and others as a practicable vaccination method against tuberculosis in cattle. This method seemed to promise good results at first, but has failed when tried on an extensive scale.

Antisera have been prepared by repeated injections of various animals with tuberculin T. R. and other products of the tubercle bacillus. None of them has proved successful in conferring passive immunity on other individuals.

In summary it may be stated that up to the present time no practicable method of immunization against tuberculosis in cattle has been developed, although in man the use of carefully regulated injections of tuberculin is promising.

Bacteriologic Diagnosis.-Tuberculosis may be diagnosed bacteriologically by staining methods, animal inoculation, agglutination, and the tuberculin reaction.

Diagnosis by Staining Methods.-Tubercle bacilli may be readily recognized by their acid-fast character when examined microscopically. The presence of the characteristic acid-fast bacteria in the tissues or sputum is generally sufficient to establish diagnosis. This is not the case, however, with feces, milk, or 
other substances which may become contaminated with nonpathogenic acid-fast forms common in dust, in soil, etc. Resort must then be had to animal inoculation followed by isolation of the characteristic bacillus, or to isolation by the use of antiformin. The discovery of the bacilli in milk, sputum, and other body secretions may frequently be greatly facilitated by centrifugation and by the preparation of mounts from the sediment. Antiformin mixed with the material to be examined greatly aids in its sedimentation without interfering in any way with its staining properties, providing care is used in the washing as described under "isolation."

Diagnosis by Animal Inoculation.-This is the most delicate method of determining the presence of tubercle bacilli. Intraperitoneal injections of the suspected material into a guinea-pig will result in the development of the disease within a few weeks. Non-pathogenic acid-fast bacteria may give some of the pathological appearances of true tuberculosis, so that it is well to make certain of the diagnosis by isolation and cultivation of the organism from the inoculated animal. An injection of tuberculin may be used to shorten the period of time necessary to diagnosis in the inoculated guinea-pig.

Diagnosis by the Agglutination Test.-Although specific agglutinins for the tubercle bacillus may be demonstrated in the blood of those having the disease, the diagnosis by this method has not proved practicable. Great care is necessary to secure a homogeneous suspension of the bacteria, and the agglutinins are rarely present in quantity.

Diagnosis by the Tuberculin Tests.-Subcutaneous injection of tuberculin into an infected animal causes a characteristic reaction. The nature of this reaction varies to a considerable extent with the manner and site of the injection or application. Subcutaneous injections are usually used in cattle; in man the dermo-, cuti-, or ophthalmo-reactions are commonly employed.

The test of cattle is made by injecting a standard dose of tuberculin. This is about the equivalent of 0.25 c.c. of Koch's Old Tuberculin. The normal temperature of the animal should be ascertained before injection. This is most accurately determined by taking the temperature every two hours on the day preceding 
the test, but in practice frequently but one or two preliminary determinations are made. After six or eight hours the temperature is again to be taken every two hours for the remainder of the twenty-four hours after injection. Care must be exercised that the animals are kept under normal conditions during the test, and that they remain quiet. Animals in heat or advanced in pregnancy or suffering from other diseases should not be tested. A positive test should show an increase of at least $1.5^{\circ}$ above the previous maximum recorded temperature. The temperature usually begins to rise in about eight hours, and reaches its maximum in from ten to eighteen hours after injection, then gradually subsides. There are many theories of the mechanism of the tuberculin reaction, but it is now believed to be explained best on the basis of anaphylaxis. The fact that the amount of tuberculin used in the test is not appreciably poisonous to a healthy animal indicates that the infected animal has become sensitized against the bacterial constituents, probably proteins The presence of a specific allergin has not been satisfactorily demonstrated, but something of that nature is probably present and renders the tissues sensitive, principally about the lesions. That this sensitiveness extends to other tissues also is shown by the ophthalmic and other reactions to be described presently. It is a well-known fact that one injection of tuberculin will prevent a reaction to a second injection made shortly after. This fact is made use of by dishonest cattlemen in vitiating the tuberculin test. The probable explanation of this fact is that the body is in a condition of anti-anaphylaxis, that the allergin has been exhausted by the preceding dose, and there has been insufficient time for the accumulation of a new supply. There is no evidence that the use of tuberculin as ordinarily practised ever results in the sensitization of the animal. This is an important point, as the test can be used repeatedly in a herd of cattle, and the results may be relied upon. Animals $\mathrm{n}$ advanced stages of the disease frequently fail to react. In such cases it is probable that the body is in a state of immunity to the proteins of the tubercle bacillus. As was stated in the discussion of anaphylaxis, the mechanism of this immunity is not well understood. This immunity to injections of tuberculin must not be confused with immunity to the disease, for it seems that these 
rest upon quite different factors. The diagnosis of tuberculosis in the human is generally accomplished by other means than injection, on account of the severity of the reactions. In cattle it may be relied upon quite implicitly if the test is carried out properly.

Von Pirquet has described a cutaneous tuberculin reaction that is of diagnostic value in man, particularly in young children. The inner side of the forearm is washed with ether. One drop of old tuberculin is applied, and another at a distance of about $10 \mathrm{~cm}$. The skin is slightly scarified and the drops rubbed with a bit of cotton. A positive diagnosis is evidenced by the development of a papule resembling that of vaccinia. The reaction is quite local, showing that the tissues of the body distant from the tuberculous lesions have been sensitized. The method has been extensively tested and has been found quite accurate. Von Pirquet secured positive reactions in 87 per cent. of the clinically tubercular, in 20 per cent. of clinically tubercular free. The reaction was found to be far more accurate during the first year of life than later. Lignières modified this method by shaving the skin and avoiding scarification. Six drops of undiluted old tuberculin are applied and rubbed with a bit of absorbent cotton. The reaction is similar to the preceding. It has been termed the antituberculin reaction. The intradermal method has yielded satisfactory results when used upon cattle by some investigators; others find it less reliable than subcutaneous injection.

The ophthalmo-reaction of Calmette and the conjunctival reaction of Wolff-Eisner have likewise found extensive use in recent years in human diagnosis. A tuberculin specially prepared free from glycerin and other irritants is dropped into the conjunctival sac. A positive reaction consists in the appearance of a pronounced conjunctivitis, which shows itself in five or six hours and disappears in two or three days. This reaction may be used upon cattle, but it is not as specific as the subcutaneous injection.

Transmission and Prophylaxis.-Channels Through Which the Organisms Leave the Body.-These are determined largely in both man and animals by the localization of the lesions. The organism is to be found in the sputum in man and animals affected by pulmonary tuberculosis. The infectious droplets thrown out 
in coughing and the contamination of drinking-vessels are common sources of infection. Material coughed up from the lungs by cattle is commonly swallowed, and both pulmonary and intestinal tuberculosis in these animals results in large numbers of organisms being thrown off with the feces. This is probably the most important channel of exit in the cow. Tuberculosis in swine following cattle is undoubtedly due to the ingestion of bacteria voided in this manner. Contamination of milk with tubercle bacilli is almost inevitable when they are constantly present in the feces. Milk is also found to contain tubercle bacilli when lesions are present in the udder. Whether or not they may be present when the udder is not tuberculous is a mooted question, but as the bacilli can rarely if ever be demonstrated in the blood, it is not probable that they can enter the milk direct when the udder lesions are absent. The urine may occasionally contain the bacteria.

The disease is probably never inherited, the offspring being infected only when the disease infects the uterus and the placenta. This fact is of importance, for upon it the Danish veterinarian, Bang, has outlined a practicable method of building up herds free from tuberculosis. The calves are separated from their tuberculous mothers soon after birth and are fed only upon pasteurized milk. Those animals known to be tuberculous are separated from the others and a quarantine strict enough to prevent the transfer of the disease from infected to non-infected animals is established.

Infection Atria in Tuberculosis. - The portals of entry of Bacillus tuberculosis have been investigated at length in recent years, but there are still discrepancies in the results of investigators that are unexplained. One group of tuberculous infections, particularly the pulmonary type in man, is probably due to inhalation of the organisms. This was at one time universally conceded, but the work of Calmette and others has shown that primary pulmonary tuberculosis may result from ingestion of the organisms. Certain investigators believe this to be far more common than infection by inhalation. It has been shown that the tubercle bacilli may be demonstrated in the thoracic duct of a dog fed upon the organisms within a few hours after their ingestion, and without any apparent lesion of the intestinal wall. The alimentary tract is undoubtedly the infection atrium in most cases of intestinal 
tuberculosis and of infection of the other abdominal organs, the mesentery, and the peritoneum. The tonsils are believed with good reason to permit the infection of the neighboring lymphglands and the consequent production of scrofula. Cutaneous lesions following abrasions or cuts of the skin have been observed, particularly in butchers, and in a few instances in veterinarians.

Intertransmissibility of Human, Bovine, and Avian Tuberculosis. -Human tubercle bacilli do not readily infect cattle. When injected, they may cause local, but rarely general, infection. The fact that the human and bovine types of bacilli may be differentiated has already been emphasized. Both types of bacilli produce fatal infection in the monkey. Instances of probable cutaneous infections of man from cattle are on record.

Park and Krumweide have outlined the factors which must be taken into consideration for differentiation of the bovine and human type of tubercle bacilli. In their own isolations of the tubercle bacilli from the human they have used the following criteria: "All cultures showing maximum luxuriance on glycerin egg in primary cultures are certainly human. All cultures not showing maximum luxuriance should then be transferred to glycerin egg, potato, and glycerin egg with bouillon added. Cultures which have failed on glycerin egg should also be transferred on plain egg, as glycerin egg may again fail. All cultures showing maximum luxuriance are quite certainly human." The forms which show a very sparse growth are as quite certainly bovine. Intermediate forms are tested upon rabbits, and, if necessary, upon calves.

Swine readily contract bovine tuberculosis. They have also been known to become infected with avian tuberculosis through the consumption of birds dead from the disease.

Birds contract the disease from each other by ingestion of excreted bacteria. Whether or not the disease may start from ingestion of bovine or human tubercle bacilli is not certainly known.

It is evident that while each of the types of tubercle bacilli are generally associated with a specific host, on the other hand, each may, under appropriate conditions of infection and susceptibility, produce infection in other hosts. 
The following table, adapted from a paper by Park and Krumweide, summarizes 1042 cases of human tuberculosis reported in which the bovine or human character of the organism was determined. The age groupings are particularly interesting.

\begin{tabular}{|c|c|c|c|c|c|c|}
\hline \multirow{2}{*}{ Diagnosis. } & \multicolumn{2}{|c|}{$\begin{array}{l}\text { Adults } \\
16 \text { yrs. and over. }\end{array}$} & \multicolumn{2}{|c|}{$\begin{array}{l}\text { Children } \\
5-16 \text { yrs. }\end{array}$} & \multicolumn{2}{|c|}{$\begin{array}{l}\text { ChiLdren } \\
\text { Under } 5 \text { yrs. }\end{array}$} \\
\hline & Human & Bovine & Human & Bovine & Human & Bovine \\
\hline Pulmonary tuberculosis. & 568 & $1(?)$ & 11 & .. & 12 & \\
\hline 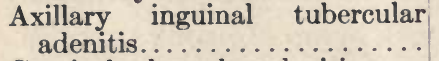 & 2 & & 4 & & 2 & \\
\hline Cervical tubercular adenitis.... & 22 & 1 & 33 & 20 & $1 \overline{5}$ & 20 \\
\hline Abdominal tuberculosis......... & 15 & 3 & 7 & 7 & 6 & 13 \\
\hline $\begin{array}{l}\text { Generalized tuberculosis of ali- } \\
\text { mentary origin } \ldots \ldots \ldots \ldots \ldots\end{array}$ & 6 & 1 & 2 & 3 & 13 & 10 \\
\hline Generalized tuberculosis.......... & 28 & .. & 4 & 1 & 28 & 5 \\
\hline Generalized tuberculosis and & & .. & 1 & & 3 & 8 \\
\hline $\begin{array}{l}\text { Generalized tuberculosis and } \\
\text { meningitis } \ldots \ldots \ldots \ldots \ldots \ldots \ldots\end{array}$ & 4 & 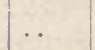 & 7 & & 45 & 1 \\
\hline Meningitis . . . . . . . . . . & & & 2 & & 14 & 2 \\
\hline $\begin{array}{l}\text { Tuberculosis of bones and joints. } \\
\text { Other types................... }\end{array}$ & 18 & 1 & 26 & 1 & 21 & \\
\hline $\begin{array}{r}\text { Other types } \ldots \ldots \ldots \ldots \ldots \ldots \ldots \\
\text { Totals. } \ldots \ldots \ldots \ldots \ldots \ldots\end{array}$ & 14 & 2 & 2 & 1 & 2 & \\
\hline Totals........ & 677 & 9 & 99 & 33 & 161 & 59 \\
\hline
\end{tabular}

There seems to be no reasonable doubt but that the bovine tubercle bacillus may infect the human. The above table shows it to be common enough in children under sixteen years to justify all reasonable precautions against the ingestion of infected meat and milk. The danger to the adult would appear to be almost negligible.

\section{Bacillus of Johnes' Disease}

Disease Produced.-Chronic enteritis or para-tubercular dysentery of cattle.

Johnes and Frothingham, in 1895, described an acid-fast organism as the probable cause of chronic dysentery in cattle. They believed the organism to be identical with the avian tubercle bacillus, but this has been disproved by subsequent investigations. It has not received a specific name.

Distribution.-The disease has been noted in various parts of Europe and in the United States. Cases have been reported from Wisconsin, Minnesota, and Iowa. 
Morphology and Staining.-The organism closely resembles the Bacillus tuberculosis morphologically. It is a slender rod, usually 1 to $2 \mu$ in length, rarely longer. It is non-motile. Neither spores nor capsules have been observed. It does not stain readily with the aqueous anilin dyes unless mordanted. When once stained, it is acid-fast. The same staining technic may be used as with the tubercle bacillus.

Isolation and Culture.-Bugge and Albein claim to have isolated the organisms, but details are lacking. It has not been cultivated by other investigators.

Pathogenesis.-Experimental Evidence.-The disease has not been transmitted to any of the laboratory experimental animals. The belief that it is the etiologic factor in the disease rests upon its constant presence in the lesions.

Character of Disease and Lesions Produced.-The disease is characterized by progressive emaciation and persistent chronic diarrhea, with commonly fatal termination. The lesions are confined to the intestines, small intestines primarily, and the colon secondarily. The mucosa shows thickening and wrinkling, but there is little evidence of conges-

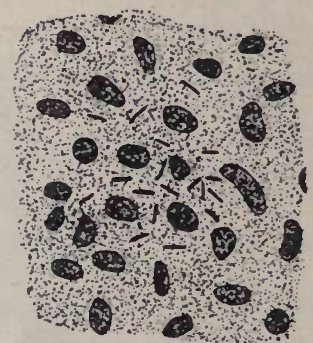

Fig. 132.-Bacillus of Johnes' disease in section of intestinal wall. tion. The lesions are not sharply limited, there is no necrosis, although some of the villi may be denuded of epithelium. Giantcells may rarely be demonstrated, but tubercle formation does not occur.

Immunity.-Nothing is known relative to immunity to this disease.

Bacteriologic Diagnosis.-No practicable method of bacteriological antemortem diagnosis has been developed. The presence of acid-fast organisms in large numbers in the thickened mucosa in the absence of nodule formation is diagnostic on postmortem.

Transmission.- The disease is doubtless transmitted by ingestion, but this has not been experimentally demonstrated. 


\section{Bacillus lepræ}

Synonyms.-Bacterium lepra; Mycobacterium lepre.

Disease Produced.-Leprosy in man.

Hansen, in 1872, discovered the bacillus of leprosy in the lesions of the disease. It was studied more at length by Neisser and Hansen, who published their report in 1880 .

Distribution.-Leprosy is common in Asia, northern Europe, in certain Pacific Islands, and is found occasionally in various parts of the United States. A similar, though probably not identical, disease has been noted by Wherry and others in rats.

Morphology and Staining.-B. leprce resembles the B. tuberculosis. It is a slender rod, frequently as much as $6 \mu$ in length. The

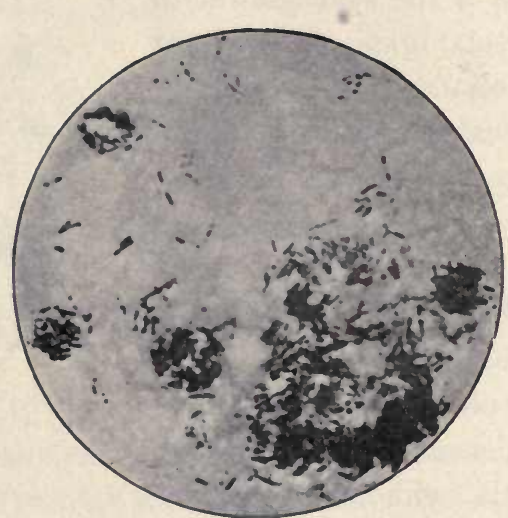

Fig. 133.-Bacillus leproe (Kolle and Wasserman).

rods are usually straight, non-motile, do not produce spores or capsules. They stain somewhat more readily than the $B$. tuberculosis, but are distinctly acid-fast.

Isolation and Culture.-Several investigators claim to have cultivated the leprosy bacillus, but the results in every case need confirmation. It is not certainly known that it has ever been successfully grown upon artificial media.

Physiology.- Until the organism can be secured in pure cultures, little or nothing can be determined as to its physiology.

Pathogenesis.-Experimental Evidence.-Lower animals, with the possible exception of the monkey, cannot be successfully infected with the Bacillus leproe. Arning succeeded in infecting 
a criminal in the Hawaian Islands by subcutaneous implantation of leprous tissue. The belief in the pathogenicity of this organism rests principally upon its presence in great numbers in the. leprous tissues.

Character of Disease and Lesions Produced.-The organisms may proliferate in the nerves, causing anesthetic leprosy; or in the subcutaneous tissues, producing nodules resembling superficially those of tuberculosis. The disease progresses slowly, the infected individual surviving for years or even several decades.

Immunity.-Methods of immunization are unknown.

Bacteriologic Diagnosis. - The disease may be diagnosed bacteriologically by scraping a nodule and preparing a smear from the serum so obtained. The characteristic acid-fast organism may be demonstrated. In the hands of some investigators the complement binding reaction (using extracts from leprous organs as the antigen) has proved of diagnostic value.

Transmission.-The method of the spread of leprosy is not understood.

\section{Non-pathogenic Acid-fast Bacteria}

Many species of non-pathogenic acid-fast bacteria have been described, and from a variety of sources. Some are normal inhabitants of the skin, others occur in dung and in soil. The presence of these organisms upon the body, in milk, etc., frequently renders a differential diagnosis necessary between them and the Bacillus tuberculosis. A few of the more important types will be briefly described.

Bacillus smegmatis.-This organism has been repeatedly observed in the smegma from the genitals of man and animals and from the skin of the axillæ. Morphologically it resembles the tubercle bacillus. Its isolation is accomplished with considerable difficulty and only upon media containing blood-serum. The $B$. smegmatis is non-pathogenic. It is of importance principally because of the possibility of confusion with $B$. tuberculosis when it occurs in the urine. Although the smegma bacillus is acid fast, it may be decolorized by alcohol according to most authors.

Dung Bacillus, Grass Bacillus of Moeller, Butter Bacillus, etc. -Acid-fast bacteria not unlike the $B$. tuberculosis in morphology have been isolated from a great variety of sources. They may in 
general be easily differentiated from the tubercle bacillus, as they do not produce a generalized tuberculosis when inoculated into experimental animals. However, nodules resembling those of tuberculosis are found as a result of the injection of some species. The organisms when isolated upon culture-media, however, are found to develop luxuriantly even at room-temperatures. It is

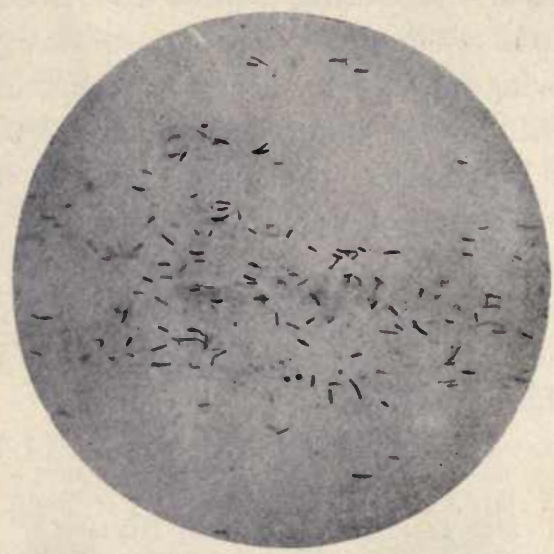

Fig. 134.-Bacillus smegmatis, in a stained smear of preputial smegma (Fränkel and Pfeiffer).

interesting to note that isolation of such bacteria from soil has been accomplished by the use of antiformin. The differential diagnosis of these forms from $B$. tuberculosis must always be accomplished by both animal inoculation and isolation upon culture-media. In making a diagnosis of tuberculosis from stained mounts the possible presence of these forms must constantly be borne in mind. 


\section{CHAPTER XXXI}

\section{ANTHRAX GROUP}

THE organisms Bacillus anthracis and Bacillus lactimorbi are included in this group. It is possible that the latter organism might better constitute the type of another group, but it resembles the $B$. anthracis in a sufficient number of its morphological characters to render a tentative association of the two forms justifiable.

The organisms belonging to this group are aërobic bacilli which form spores, are gram-positive, and liquefy gelatin. These two bacilli are the only pathogenic aërobic spore producers which have been described.

This group is in reality a subdivision of the much larger Bacillus subtilis, or hay-bacillus group of bacteria. Organisms closely related morphologically and culturally to the Bacillus anthracis are ubiquitous; they are found by tens of thousands in every gram of most surface soils. A dozen or more species of these soil organisms have been described, some of them so similar to the anthrax bacillus that they can practically be differentiated only by suitable animal inoculations. These bacteria are among the most active in nature in bringing about the decomposition of organic substances in the soil, particularly in the series of changes grouped together under the heading of Ammonification.

\section{Bacillus anthracis}

Synonym.-Bacterium anthracis.

Diseases Produced.-Anthrax, splenic fever, Milzbrand, charbon in cattle, sheep, and rarely other animals; malignant carbuncle, woolsorters' disease, in man.

Pollender, in 1849, observed $B$. anthracis as minute rods in the blood of cattle which had died of anthrax. Davaine also observed and described it in the following year. The complete proof that this organism causes the disease was furnished by the 
work of Dr. Robert Koch, published in 1876. Methods of vaccination were developed by Toussaint in 1880, and by Pasteur in 1881.

Distribution.-Anthrax has been recorded in Europe since ancient times. It is known also from Africa, Asia, Australia, and South America. It has been reported from about one-third of the States of the United States, and probably occurs sporadically in most of them. The disease in this country is not common, except in a few thoroughly infected localities.

Morphology and Staining.-Bacillus anthracis is a large rod, straight, usually with truncate ends, 1 to 1.25 by 4.5 to $10 \mu$, in short chains when examined in tissues or blood and in long chains

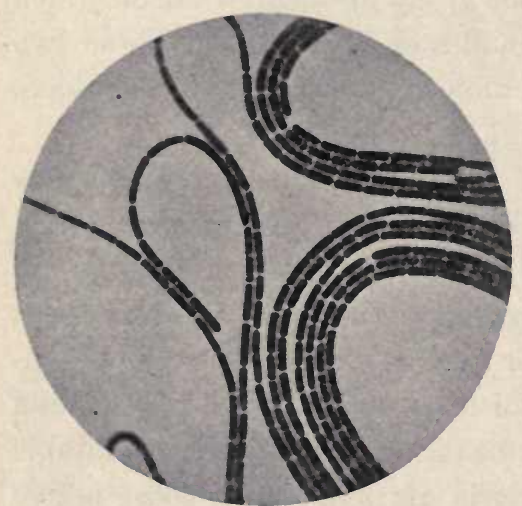

Fig. 135.-Bacillus anthracis, rods without spores (Günther). in culture-media. It is nonmotile. Capsules may be demonstrated in smears from blood and other tissues. Spores are produced only when the organism is grown in the presence of free oxygen. They do not, therefore, occur in the bacillus as found in the blood and the tissues. The single spore produced by a cell is oval or spherical, occupies the middle of the cell, and is of almost the same diameter. The spores are much more refractive than the protoplasm of the non-sporulating cells. The spores germinate on being brought under favorable growth conditions by breaking through the spore-wall at the pole. They may be demonstrated by a contrast spore stain. The vegetative rod stains readily with the aqueous anilin dyes and is gram-positive. Metachromatic granules may rarely be demonstrated.

Isolation and Culture. $-B$. anthracis may be readily isolated in pure culture, upon any of the common laboratory media by direct inoculation from the blood of an infected animal or from the internal organs, particularly the spleen or liver. Plate cul- 
tures in agar or gelatin are sometimes necessary when the organism is mixed with other forms. The colonies microscopically are found to consist of long chains of bacilli, which, under the low power, resemble tufts of curled hair. This appearance is quite characteristic, but is closely duplicated by certain soil organisms of the Bacillus subtilis group. In gelatin stabs a "spiking" occurs, $i$. e., filaments radiate from the line of puncture and give the appearance of an inverted fir tree. The gelatin is liquefied slowly. The growth on potato is creamy in color and rather dry in consistency. Blood-serum is slowly liquefied. Milk is rendered slightly acid, curdled by a lab ferment, and the casein digested.

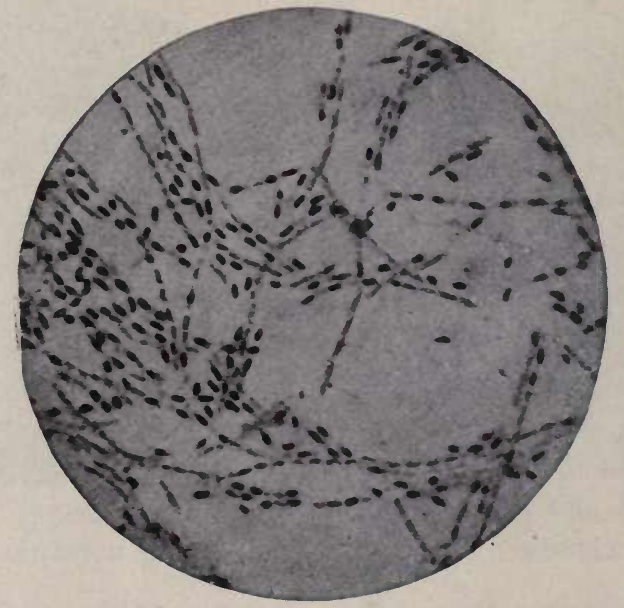

Fig. 136.-Bacillus anthracis, with spores (Fränkel and Pfeiffer).

In bouillon the organism frequently forms a pellicle which readily settles to the bottom. Clouding of the medium does not occur.

Physiology.-Bacillus anthracis grows best in the presence of oxygen. The optimum growth temperature is about $37^{\circ}$. It will grow at temperatures as high as $45^{\circ}$, and also at room-temperature. The vegetative rods are easily destroyed by heat, but the spores must be heated to $100^{\circ}$ for five minutes before they are certainly killed. The spores likewise exhibit great resistance to desiccation. Dried upon threads, they have been known to retain their vitality for years. Five per cent. phenol destroys 
the spores only after prolonged contact. A rennet-like enzyme and ferments which digest casein, gelatin, and blood-serum are produced. Acids and gas are not formed.

Pathogenesis.-Experimental Evidence.-Guinea-pigs, mice, and rabbits are very susceptible to experimental inoculation. The subcutaneous injection of anthrax bacilli results in the development of a quickly fatal septicemia having the characters of the disease as it occurs in the larger animals. The carnivora are relatively immune. Birds show a high degree of immunity. Inoculation of cattle, sheep, swine, and other susceptible domestic animals with pure cultures of the organism invariably produces

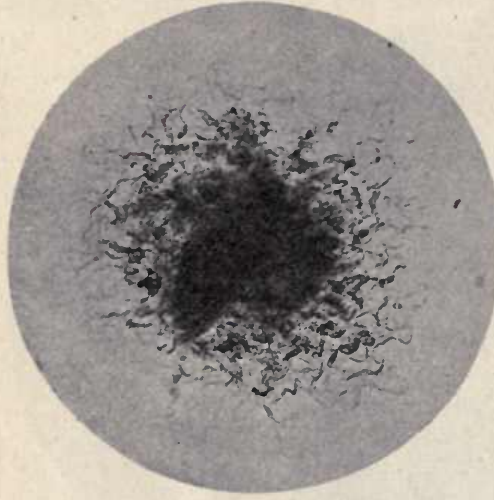

Fig. 137.-Bacillus anthracis colony (Günther).

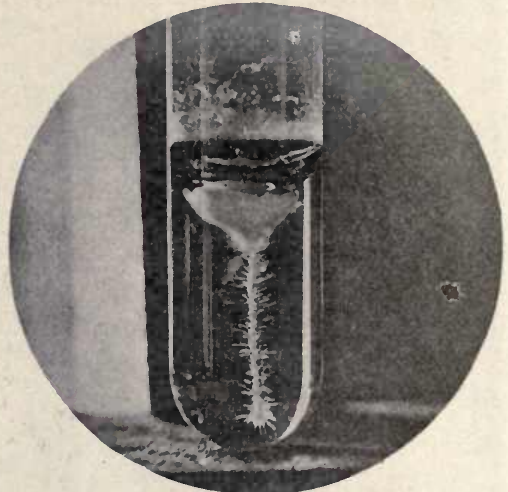

Fig. 138.-Bacillus anthracis, stab culture in gelatin (Günther).

the disease, so that there is no question of the causal relationship of this organism.

Character of Disease and Lesions Produced.-As it occurs in animals the disease is usually a distinct and rapidly fatal septicemia. Hemorrhagic and serous infiltration of the subcutaneous and other connective tissues and subepidermal hemorrhages are characteristic. The spleen is much enlarged, often several times its normal size. The liver, kidneys, and lungs are usually congested and ecchymotic. The organism is to be found in great numbers everywhere in the blood-stream. Cutaneous infections in horses and man, rarely in cattle, develop as carbuncles from which the organism may not invade the general circulation, and healing may occur. Commonly, however, this infection terminates 
fatally. Pulmonary infection resulting in a pneumonia with quickly fatal termination may occur from inhalation.

Immunity.-No true toxin has been demonstrated for the anthrax bacillus, in fact, it is difficult to account for the pathogenicity of the organism on the basis of specific poison formation. Immune serum is claimed by some investigators to have a considerable specific agglutinative power, but others have failed to demonstrate this. It seems that this reaction is inconstant and may be entirely absent, even though the serum have a high immunizing value. Certain normal bloods, as from the dog, show bacteriolytic power, but specific bacteriolysins cannot be demonstrated in most immune sera. Opsonins, both normal and im-
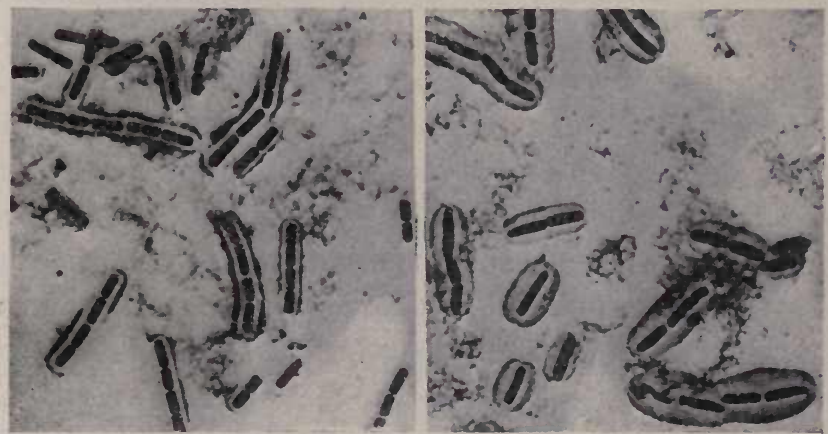

Fig. 139.-Bacillus anthracis, stained mount of blood, showing the capsules of the bacilli (Preisz).

mune, have been demonstrated. Aggressins, according to Bail, account for its pathogenicity. Many theories of immunity in anthrax have been developed, but none of them has been generally accepted as solving the problem wholly.

Active immunization by vaccination has been extensively practised. The organism may be attenuated in a variety of ways. The first developed was that of Pasteur, and it is still the one most commonly used. The organism is grown at a temperature of $42^{\circ}$ to $43^{\circ}$ for varying lengths of time. The pathogenicity gradually decreases until injections no longer kill the rabbit; longer growth attenuates it until the guinea-pig is not susceptible, and finally even the mouse will not succumb. The exact length of time required for attenuation in each instance can be determined 
only by experimentation, as there are many unknown or uncontrolled factors involved. Chamberland and Roux found that atten-

- uation could likewise be accomplished by the use of small amounts of certain antiseptics in the culture-medium. One part in 600 : 800 of phenol, and one part in $2000: 5000$ of potassium bichromate were found to reduce the virulence so that ten days' exposure rendered the organism non-virulent for the sheep. Numerous other methods of attenuation have been proposed, such as heating to a temperature just below the thermal death-point, and injection into resistant animals, such as the frog and white rat. These latter have no practical significance. Before use the virulence of cultures grown from sixteen to eighteen hours at $37^{\circ}$ must be determined. Rabbits, guinea-pigs, and mice are inoculated with varying amountsusually from $\frac{1}{10}$ to $\frac{1}{1000}$ of a standard loopful of the culture is injected subcutaneously. An exposure to a temperature of $42.5^{\circ}$ for eleven days renders the organism non-virulent for the rabbit, but an exposure of twenty days is required before it shows diminished virulence for the guinea-pig, and of ten weeks before it becomes non-virulent for the mouse. Experiments have shown that the organisms once attenuated do not regain at once their virulence when cultivated at $37^{\circ}$. Pasteur believed that the attenuated forms lost their power of spore production, but avirulent types have since been shown to be sporogenous and not to be differentiated morphologically from the fully virulent form. Slight cultural differences have been described. Pasteur prepared vaccine of two grades of virulence. The "Premier vaccine" (vaccine 1.) killed white mice with certainty, was irregular in pathogenicity for guinea-pigs and åvirulent for rabbits. The "Deuxieme vaccine" (vaccine II.) killed guinea-pigs and was somewhat virulent for the rabbit. About 0.25 c.c. of vaccine $I$. is used for cattle, half the amount for sheep. Twelve days later a similar injection of vaccine II. is made. The use of the Pasteur vaccination method has been attended with highly satisfactory results in European countries, although not so good in the United States. Variations in the virulence of vaccine II. and also differences in susceptibility in the vaccinated animals lead to a loss among such animals which averages about 1 per cent. in cattle and somewhat more in sheep as a direct result of the vaccination. Many modifications of the 
original Pasteur method have been suggested, but in only slightly modified form it is the one still most commonly used.

Attempts to used killed cultures of anthrax bacilli or their sterile products in producing immunity have failed to yield satisfactory results in practice. Bail claims that an active immunity may be established by the use of aggressins. The material used is the serous fluid from animals dead from anthrax; this is sterilized by phenol and injected into an animal to be immunized. The aggressin should preferably be secured from the same species of animal as the one to be immunized. The immunity is not established until after the lapse of ten days or more. When established, it is claimed that the animal will resist infection with fully virulent cultures. This method of immunization with aggressins has not been thoroughly tested out.

Passive immunization by means of antisera has been tried by numerous investigators. Cattle, the horse, ass, and sheep have been used in the production of such sera. The animals are first immunized by Pasteur's method of vaccination, and in ten days or two weeks from $\frac{1}{1000}$ to $\frac{1}{200}$ of a loop of a fully virulent culture is injected. This is generally followed by a strong reaction. Two or three weeks later a somewhat larger dose is given, and the dosage is gradually increased until many loopfuls - then entire culturesare injected. In three to four months an immunity is developed such that the subcutaneous injection of several cultures from agar slants may be made without noteworthy reactions. The blood is drawn about two weeks after the last injection. The animal may then, after the lapse of two weeks, be again injected and again bled. The serum is pipetted off and preserved with 0.5 per cent. phenol. Exact methods of standardization such as are used with antitoxins cannot be employed. An approximation of the potency can be reached by the intravenous injections of varying amounts of serum into rabbits, and five to ten minutes later inoculating each subcutaneously with $\frac{1}{1000}$ of a loop of a virulent culture. A serum is regarded as usable if two out of five animals injected with $2,3,4,5$, and 6 c.c. of the serum survive, and the remainder live longer than control animals. As noted above, the immune serum contains agglutinins, some bacteriolysins, and opsonins specific for the anthrax bacilli. The serum may be used, both in prophy- 
laxis and cure. It is of therapeutic value in man, also. Ten c.c. is a prophylactic dose for sheep. The serum is of greatest use where it is necessary to immunize large numbers of animals quickly, as in a herd of sheep in which anthrax has made its appearance. The serum has not been used extensively enough to warrant definite statements of its value, although many favorable reports have been recorded.

Simultaneous injection of antisera and virulent cultures has been advocated by Sobernheim. Its value has not been satisfactorily demonstrated.

Bacteriologic Diagnosis. - Smears from the blood or tissues of an animal show short chains of large, gram-positive rods, with blunt ends. Capsules may be demonstrated in the blood. A stab culture in gelatin will give the characteristic spiking. Animal inoculations may be used where the organism is not in pure culture.

Transmission.-Anthrax is usually transmitted from one animal to another by ingestion, more rarely through skin lesions. Cutaneous infection and infection by inhalation are most common in man. The organism does not sporulate within the body. Dead animals should be burned or buried deeply. The excretions from an infected animal, the feces in particular, contain many bacteria which can form spores on leaving the body. Pastures once infected may remain so for many years, as the spores are not readily destroyed by desiccation and may persist in the soil for a long time. Blood-sucking flies sometimes spread the disease from one animal to another by direct inoculation. Care should always be used in dealing with infected animals, as the disease is fatal to man as well.

\section{Bacillus lactimorbi}

Diseases Produced.-Trembles of cattle; milk sickness of man; "alkali-poisoning" in the southwestern United States.

Jordan and Harris, in 1909, described the Bacillus lactimorbi as the probable cause of trembles in cattle and of milk sickness in man. The organism was first isolated in an outbreak in New Mexico.

Distribution.-The disease has been reported from Ohio, Tennessee, Carolina, Kentucky, Illinois, Indiana, and the southwestern states and territories. 
Morphology and Staining.-The Bacillus lactimorbi is a rod somewhat smaller than the anthrax bacillus, usually single or in pairs, occasionally in filaments. It is motile by means of 10 to 15 peritrichous flagella. Capsules have not been observed. Spores are produced in the ends of the rods, and are slightly greater in diameter than the rod itself. The young rods stain unevenly with methylene-blue, and show very distinct metachromatic granules. The organism is gram-positive.

Isolation and Culture.-Jordan and Harris isolated the organism directly upon agar plates from the intestinal contents-bile,

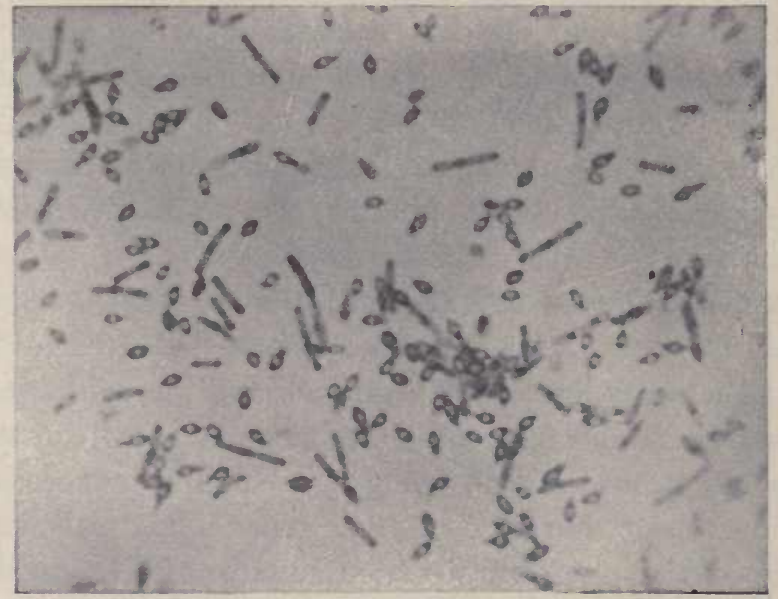

Fig. 140.-Bacillus lactimorbi, showing rods and spores (X 1100) (Jordan and Harris in "Journal of Infectious Diseases").

spleen, liver, and pericardial fluid. The agar colonies are small and Streptococcus-like. The growth on agar slants is moderate at first, later more luxuriant, but without distinct differential characters. Gelatin stabs show incipient liquefaction in about ten days. Bouillon is somewhat clouded, and a well-defined pellicle forms. Milk is not coagulated. In litmus milk the reaction is observed to become more alkaline, and there may be some development of opalescence due to the great increase in alkalinity. There is no growth upon potatoes. Blood-serum is not liquefied.

Physiology. - The optimum growth temperature is probably about $37^{\circ}$, although good development takes place at room-temper- 
atures. The thermal death-point for non-sporulating rods is $55^{\circ}$ for five minutes, and for the sporulating rods, $100^{\circ}$ for fifteen minutes. The organism is aërobic. Neither gas nor acids are produced from carbohydrates. Gelatinase is produced, but not enzymes that will proteolize milk or blood-serum.

Pathogenesis.-Experimental Evidence.-The proof that this organism stands in an etiologic relation to the disease does not seem to be entirely satisfactory. An organism not distinguishable from this has been isolated from soil, dung, and hay in localities from which the disease has not been reported. Intraperitoneal injection of the heart blood from a case of trembles into a rabbit resulted in death, and the organism was recovered from various internal organs. Subsequent efforts at infection with pure cultures failed. Inoculations into the guinea-pig were unsuccessful. Feeding experiments upon dogs and cats were more successful, and a disease corresponding to milk sickness was produced when the organisms were fed in large quantities.

Character of Disease and Lesions.--Jordan and Harris give the following characterization of the disease. "The course of the disease in cattle is marked by lassitude and muscular weakness, sometimes, but not invariably, accompanied by constipation. There is often muscular twitching or trembling, and occasionally signs of nervous excitement. In man there is, as a rule, excessive vomiting, and obstinate constipation accompanied by great weakness. The temperature is normal or subnormal." In cattle, the principal lesion observed is fatty degeneration of the liver. Ecchymoses in the heart-wall, the liver, and spleen have been noted.

Immunity.- Experiments relative to the agglutinating power of serum have not yielded consistent results. Nothing is known of methods of conferring immunity.

Bacteriologic Diagnosis. - The organism may be isolated in pure culture from the infected organs and may be identified by its characteristic morphology. 


\section{CHAPTER XXXII}

\section{ABORTION BACILLUS GROUP}

ONE organism only, the Bacillus abortus of Bang, is placed in this group. It should be noted that other organisms besides the one here discussed are doubtless occasionally responsible for abortion in cattle and other animals.

\section{Bacillus abortus}

Synonyms.-Abortion bacillus of Bang; Bacterium abortum.

Disease Produced. - Contagious abortion in the cow.

Bang, in 1897, described a Bacillus as the probable cause of contagious abortion in the cow. The specific organism was isolated with difficulty. It has been isolated since that time in Europe several times, and, more recently, in the United States. Several investigators in the United States have described members of the colon group and of other groups as present in contagious abortion, but it is doubtful whether in many cases appropriate cultural methods have been utilized for the isolation of this organism.

Distribution.-Contagious abortion has been reported from many localities on the continent of Europe and in Great Britain. It is known to occur in all sections of the United States.

Morphology and Staining.-Bacillus abortus is very small, and, according to Nowak, resembles the bacillus of chicken cholera. Nowak, on the basis of its morphology, groups it with the Pasteurellas or hemorrhagic septicemia bacilli. It is polymorphic in culture-media. Involution forms occur as branched and clubbed types. It is non-motile, and neither capsules nor spores have been demonstrated. It stains readily by the aqueous anilin dyes, frequently showing polar granules. It is gram-negative.

Isolation and Culture. - The isolation and cultivation of Bacillus abortus are attended with peculiar difficulties. The organism may be frequently obtained at once in pure culture from the 
heart blood or the intestines of an aborted fetus. Bang used a medium consisting of nutrient agar, to which he added liquid gelatin and sterile liquid blood-serum. These tubes were inoculated with suspected material, mixed well, and kept at blood-heat. In the course of three days numerous colonies developed in a definite stratum a few millimeters below the surface. As will be noted under the discussion of physiology, the organism has an unusual relationship to oxygen, and the amount of oxygen needed for its development is to be found at the depth at which the colonies form. These colonies are compact, rounded, or somewhat irregular, sometimes showing a dense nucleus surrounded by a

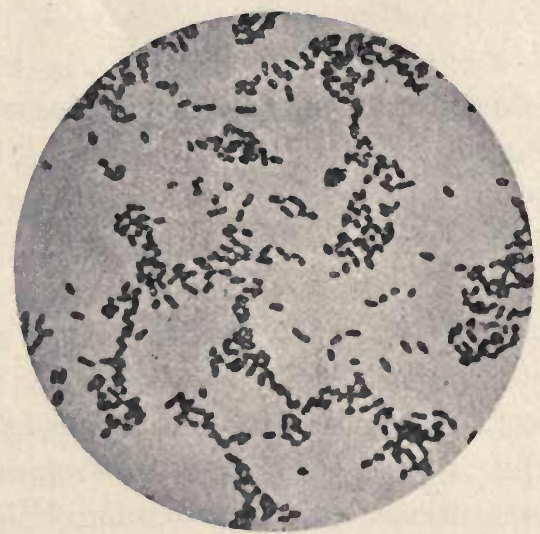

Fig. 141.-Bacillus abortus ' (Nowak).

lighter zone. When the organism is present in impure culture, as in the vagina of the cow, other methods are necessary for its isolation. Nowak has described a procedure which has proved satisfactory in the hands of several investigators. Probably simpler methods will be devised in time, but this appears to be the best thus far developed. The material is smeared over the surface of successive tubes of serum agar or over the surface of this medium in Petri dishes. These are allowed to stand for several days, and the colonies which develop are marked, as they are not B. abortus. The plates are then placed in a desiccator, whose cubic content of air has been determined, and plates of agar thickly seeded with Bacillus subtilis are introduced, so that about $16 \mathrm{sq}$. $\mathrm{cm}$. of surface 
is present per every 240 c.c. of space. It has been found experimentally that this will diminish the oxygen pressure to a point where the Bacillus abortus will develop. After three days the plates are examined and search made for the B. abortus in the spaces between other colonies on the original plates. This same device, of reducing oxygen pressure by means of cultures of Bacillus subtilis, may be used in the study of growth-characters on other media. The organism will grow in agar without addition of serum, particularly at the surface, but the addition of serum is decidedly beneficial. The colonies develop at the surface in about three days at $37^{\circ}$ as small, usually discrete, transparent dots. In shake cultures in serum agar they appear in about four days in a well-defined stratum about 10 to $20 \mathrm{~mm}$. below the surface. The individual colonies may reach a diameter of $1 \mathrm{~mm}$. when well separated from each other. Growth in gelatin at room-temperature is slow. Bouillon cultures show development some millimeters below the surface, the medium above this remaining clear. Milk is not coagulated. Little or no growth takes place on potato.

Physiology.-The optimum growth temperature is $37^{\circ}$, although the organism is found to multiply slowly at room-temperature. The relationship to oxygen, which has already been discussed, classifies the $B$. abortus as a micro-aërophile rather than a strict anaërobe. Strangely enough, Bang reports that the organism will also grow in an atmosphere of pure oxygen; two oxygen optima are, therefore, evident. It is relatively resistant to desiccation. It will remain alive for months in a retained mummied fetus, and for a year or more in a culture-medium. Acids and gas are not produced from carbohydrates.

Pathogenesis.-Experimental Evidence.-Bang demonstrated the etiologic relationship of the organism to the disease by intravenous injection, and by injection into the vagina and uterus of pregnant cows. Preisz did not succeed in transmitting the disease 
by vaginal injections into the cow, guinea-pig, or rabbit. Nowak succeeded in producing typical abortion of dead feti in guineapigs and rabbits by intraperitoneal and intravenous injections. He did not succeed by intravaginal injections.

Character of Disease and Lesions.-There are few symptoms either preceding or following the expulsion of the fetus. The infection seems to result in the death of the fetus, and the organism can be readily isolated in pure culture from such. Bang regards the disease as a specific uterine catarrh.

Immunity. - It is known that cows that have aborted one or more times may become immunized against the disease. Vaccina-

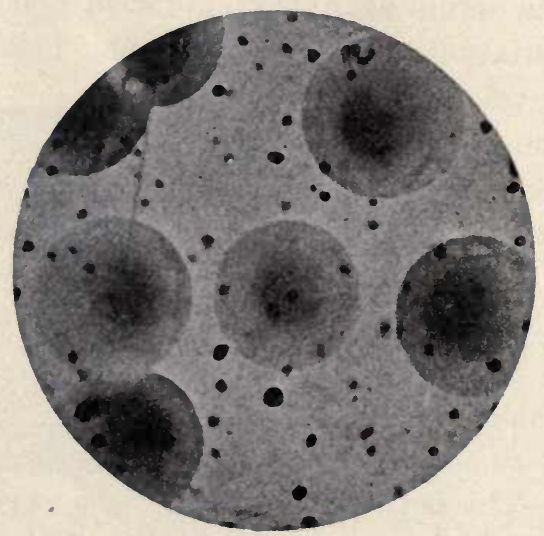

Fig. 143.-Bacillus abortus, colonies on serum agar (Nowak).

tion and serum treatments have been attempted, but their worth has not been thoroughly proved.

Bacteriologic Diagnosis.-Bacteriologic diagnosis may be made certain by the isolation of the specific organism in culture as outlined above. A tentative diagnosis may be made by preparing stained mounts, and demonstrating the presence of a short, gram-negative bacillus in the uterine exudate and in the blood and tissues of the fetus.

Transmission.- The disease is probably most frequently transmitted by the bull. Infection may also occur from other cows, from infected stables, and bedding. 


\section{CHAPTER XXXIII}

\section{BACILLUS NECROPHORUS GROUP}

THIs group is at present represented by a single species, according to most investigators. There is a real question as to the proper placing of this form, whether among the true bacteria or in the group of Actinomyces. As will be observed from the discussion of the morphology, the organism resembles the latter rather more than true bacilli. There has, however, been no satisfactory demonstration of branching, although some of the forms seen in culture-media suggest that such may occur.

\section{Bacillus necrophorus}

Synonyms.-Bacillus diphtheriæe vitulorum; B. filiformis; Streptothrix cuniculi; Actinomyces cuniculi; B. necroseos; Streptothrix necrophora.

Disease Produced.-A large number of diphtheritic and necrotic pathologic conditions in animals.

Löffler, in 1894, described this organism from calf diphtheria. Later, Schütz found it associated with the intestinal ulcerations of hog-cholera. It is now known to produce disease in birds and in both domestic and wild animals.

Distribution.-Bang succeeded in demonstrating the presence of this organism in the feces of normal hogs, but not in the intestinal contents of the cow. It is probably rather widely distributed in some localities. The infection has been described from various sections of Europe and America.

Morphology and Staining.-The organism is a long, slender rod, usually bent more or less, although coccus-like forms and filaments may be observed. It is about 0.7 to $1.5 \mu$ in diameter. In the tissues and colonies the filaments are matted together, but definite branching has not been satisfactorily demonstrated. The stained rods are usually beaded. Involution forms, as long 
clubs, frequently occur. The organism is non-motile, and does not produce spores or capsules. It stains readily with the common anilin dyes, but is gram-negative.

The peculiarities of staining, the possession of easily stained granules, or of a vacuolate protoplasm, have caused some authors to group this germ with the diphtheria bacillus, but these appearances are even more characteristic of certain of the Actinomyces, particularly those isolated from soil.

Isolation and Culture.-Bacillus necrophorus is most easily isolated in pure culture by inoculating infected tissue into rabbits

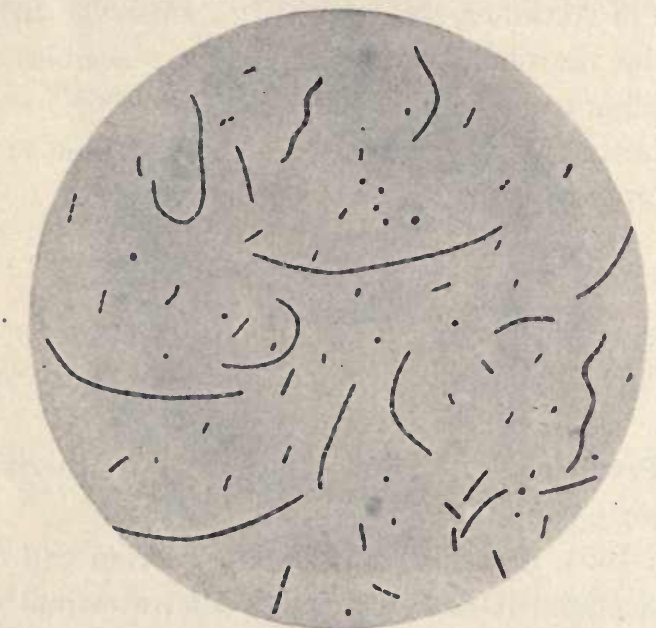

Fig. 144.-Bacillus necrophorus (Mohler, Bureau of Animal Industry, Circuiar No. 160).

or white mice. The pure culture may then be secured from the infected organs. The cultural characters are all modified by the fact that the organism is a strict anaërobe.

Colonies may develop upon the surface of agar plates if the oxygen is removed by the alkaline pyrogallate method, but not, according to Mohler and Morse, in an atmosphere of hydrogen or in a vacuum. They appear in forty-eight hours as minute, dirty white, round, opaque colonies, with gas-bubbles developing below the surface. In seventy-two hours the colony appears wooly, and the central portion, upon microscopic examination, is shown to be a felted mass of threads with a border of long, wavy 
filaments. Bouillon becomes turbid, and then gradually clears, with subsidence of the organism. Gelatin is not liquefied.

Phyșiology. $-B$. necrophorus is an obligate anaërobe. Its temperature growth limits are between $30^{\circ}$ and $40^{\circ}$, with an optimum at about $35^{\circ}$. The organism is readily destroyed by disinfectants. No pigment is produced. A very characteristic odor, " between the odor of cheese and of glue," may be noted in both cultures and lesions. No enzymes capable of liquefying gelatin or blood-serum are produced. Gas is formed in bouillon. Milk is not coagulated, nor are acids formed. Indol is produced.

Pathogenesis.-Experimental Evidence.-Rabbits may be readily infected with the $B$. necrophorus. A subcutaneous injection of a small amount of necrosed tissue results in the death of the rabbit in about a week. The inoculated area is necrotic to some depth, and to a distance along the surface of half to one inch from the point of injection. The necrosis is complete, and the tissues wholly disintegrated. In some cases gas-bubbles may be observed. The inoculation of pure cultures results in death more slowly; frequently two weeks are required. The animal dies suddenly after a series of convulsions. Mice are readily infected. Guineapigs are much more refractory, but occasionally die as a result of inoculation. There seems to be abundant experimental evidence to connect the $B$. necrophorus with many types of necrosis in animals. There is no evidence that the organism enters the normal healthy unbroken skin. It is usually a secondary invader.

Character of Disease and Lesions Produced.-Mohler and Washburn have given an excellent résumé of the conditions under which this organism has been found. In many of these conditions it has not been satisfactorily established that this organism is the sole cause, for pyogenic cocci and other organisms may produce the same changes. More work is needed upon these infections. The possible presence of this organism in necrotic infections of all kinds must be borne in mind. The organism has been reported from the following infections, and probably in most cases is responsible for the accompanying necrosis: necrotic dermatitis, necrotic scratches in the horse, necrotic pox in horses, cattle, goats, and hogs, several types of necrosis in rabbits, necrosis of the hoof in the horse, necrosis of the mouth and esophagus, ulcerative 
and necrotic vulvitis, vaginitis, and metritis, foot-rot of cattle, lip and leg ulceration of sheep, necrotic omphalophlebitis and joint ill in young animals, necrosis in the alimentary tract and other viscera in many animals, and possibly even avian diphtheria. It is sometimes of considerable economic significance, particularly in the so-called lip and leg ulceration of sheep. Some of the affections, particularly this latter, are known to be contagious. Much work still remains to be done, however, on the different infections and possible variations in virulence.

The lesions produced in all tissues have many common characters. They are essentially coagulation necroses with caseation. Metastatic infection is very apt to occur. The local lesion is described by Mohler and Morse as a "sharply circumscribed patch of yellowish or dull brown, sometimes greenish white, homogeneous, structureless, dry, crumbly tissue débris of soft, cheesy consistence, resembling compressed yeast, and manifesting a characteristic stench. The line of demarcation between the living tissue and the dead mass is a narrow hyperemic zone." A false membrane is formed over the surface as a " result of coagulation necrosis of the inflammatory exudate and entanglement in its meshes of the hyaline degenerated tissue-cells and leukocytes."

Immunity.- It has been supposed that the organism produces a true toxin because of its intense local destruction of tissue, and because of the death of laboratory animals with many of the symptoms of a toxemia. The toxin has not been isolated, however. It is stated that intravenous injections of the organism into the goat confer an immunity. No practicable method of immunization has been developed.

Bacteriological Diagnosis.- The organism may be observed in mounts prepared from the tissue just surrounding the necrosed area. Its appearance is characteristic enough to differentiate it from other forms that may be present. Animal inoculations, preferably into the rabbit, are generally necessary to secure pure cultures.

Transmission.- It is improbable that the organism ever gains entrance through the unbroken skin or mucous membrane. Scratches, wounds, abrasions, or injuries of other types supply an infection atrium. The disease must be regarded as mildly contagious, however. 


\section{CHAPTER XXXIV}

\section{GROUP OF SPORE-BEARING ANAËROBES}

THE six organisms belonging to this group are Bacillus tetani, causing tetanus; B. chauvaei, of blackleg; B. gastromycosis ovis, of bradsot; $B$. oedematis, of malignant edema; $B$. welchii, of emphysematous edema; and the $B$. botulinus, of meat-poisoning.

The organisms of this group are united because of their lack of tolerance of free oxygen. They will develop in the presence of small amounts of oxygen, but not with an oxygen pressure as great as that of the atmosphere. Morphologically, these organisms are not unlike. All are bacilli producing spores. Other characters, such as retention of Gram's stain and motility, are inconstant. The members of this group may be differentiated from each other in most cases by their morphological and cultural characters, although, for the separation of some, animal experimentation is necessary.

\section{Bacillus tetani}

Synonym.-Bacillus of Nicolaier.

Disease Produced.-Tetanus or lockjaw in man and animals.

Nicolaier, in 1889, observed the Bacillus tetani in pus from laboratory animals that had died, following subcutaneous inoculation with small amounts of garden-soil. He cultivated the organism, but did not succeed in securing it in pure cultures. Kitasato, in 1889 , succeeded in growing the organism in pure culture, and in transmitting the disease experimentally. Kitasato and Veyl, in 1890 , described the production of the tetanus toxin.

Distribution.-The organism is found in all parts of the world. It is particularly common in street-dust and fertilized garden-soil, and is found quite constantly in the alimentary tract of herbivorous animals. It seems probable that it may for a time maintain a saprophytic existence and multiply in the soil. 
Morphology and Staining. $-B$. tetani is a rather long, slender rod, 0.5 by 2 to $5 \mu$, with rounded ends, usually single, rarely in short chains. It is motile by means of numerous peritrichic flagella. Capsules are not produced. Spores are formed abundantly. Their size and position are so characteristic as to be practically diagnostic. They are spherical, two or three times the diameter of the rod, and terminal, giving the organism the appearance of a drumstick. The organism stains readily with the ordinary anilin dyes and is gram-positive.

Isolation and Culture.-The isolation in pure culture of $B$. tetani is attended with considerable difficulty, largely on account of its being an obligate anaërobe. Kitasato first succeeded in

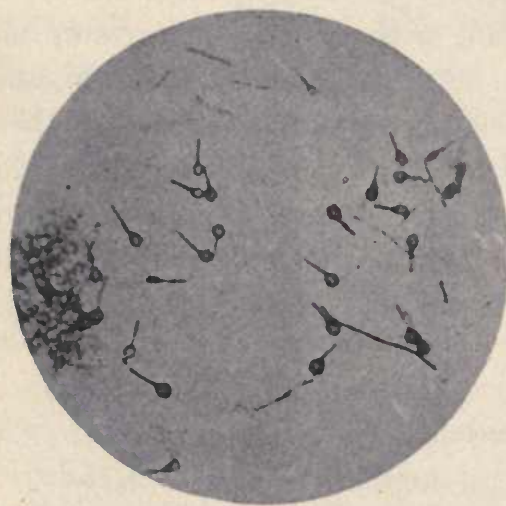

Fig. 145.-Bacillus tetani, rods and spores (Günther). isolating it by producing tetanus in experimental animals, then inoculating broth, and, after growth had taken place, heating to a temperature of $80^{\circ}$ for half an hour. This temperature should destroy all but spores. The broth may then be inoculated into agar or gelatin and kept under anaërobic conditions. If spores of other anaërobes are present, it may be necessary to make several consecutive animal inoculations and isolations.

The colonies of the tetanus bacillus upon gelatin plates show minute radiating lines of growth from a central nucleus, resembling somewhat those of $B$. subtilis. Gelatin stabs show an arborescent growth. The gelatin is slowly liquefied. Radiating filaments are also produced in glucose agar stabs. Bouillon is clouded, and a sediment forms. Blood-serum is liquefied. Milk is coagulated, with production of acid.

Physiology. - The optimum growth temperature is $37.5^{\circ}$, but the organism multiplies rapidly at room-temperatures. It is an obligate anaërobe, and in pure culture requires practically complete exclusion of oxygen. It will develop, however, under aërobic 
conditions when in mixed cultures with aërobes. The spores resist desiccation indefinitely. They are also much more than usually resistant to the action of disinfectants. Likewise, resistance to heat is so marked that Theobald Smith found in one case that exposure to live steam for seventy minutes failed to destroy the organism, although usually a shorter period suffices.

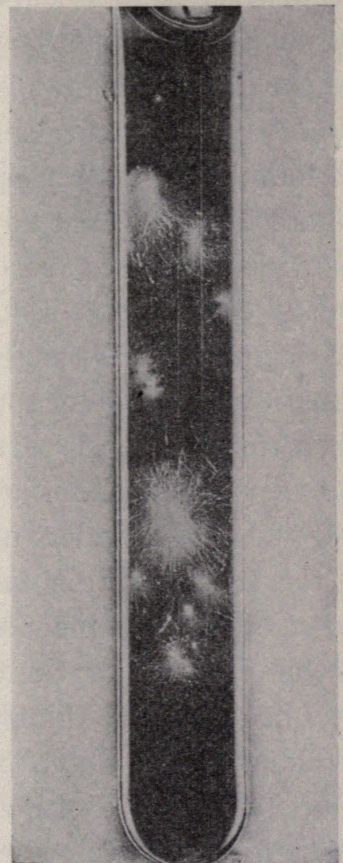

Fig. 146.-Bacillus tetani, colonies in dextrose gelatin (Fränkel and Pfeiffer).

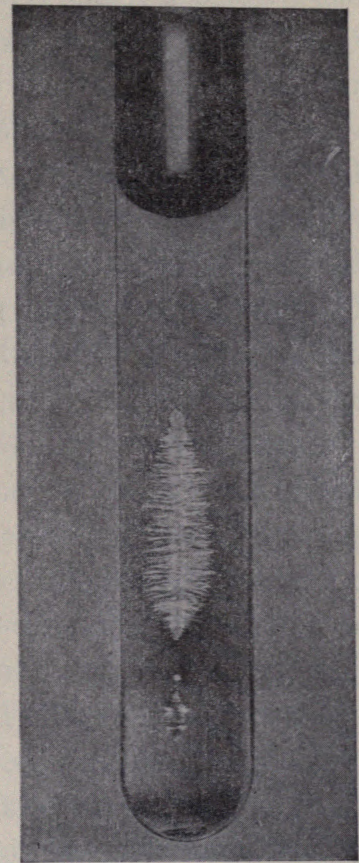

Fig. 147.-Bacillus tetani, deep stab culture in dextrose gelatin (Fränkel and Pfeiffer).

Acids are produced from carbohydrates, and a small amount of gas from dextrose. Enzymes which liquefy gelatin and bloodserum have been demonstrated.

Pathogenesis.-Experimental Evidence.-Injection of pure cultures of $B$. tetani into experimental animals causes the development of a typical tetanus. The white mouse is among the most susceptible of animals to inoculation. Infection of this animal is within one to three days followed by tetanic convulsions and death. Birds are not ordinarily susceptible to infection. The 
disease is most common in man and in the horse, although no mammalia are immune. The disease is not transmitted by ingestion. The injection of the characteristic toxin is followed by the symptoms of the disease.

Character of Disease and Lesions Produced.-The disease is a typical toxemia. There is rarely, if ever, a general invasion of the tissues. The organism remains localized at the seat of inoculation, and produces the toxin which brings about the characteristic symptoms. The entrance of the organism into a wound is not always followed by the development of tetanus, for anaërobic conditions must obtain, and it has been found that tetanus spores entirely freed from toxin cannot germinate when introduced into the tissues in moderate numbers. It is evident that the organism has little initial pathogenic power. Usually considerable amounts of dirt are introduced into the wound simultaneously with the organism, and produce proper conditions for rapid development. The tetanus toxin produced is absorbed, for the most part, by the end-organs of the motor nerves, and travels to the nerve-cells of the central nervous system by way of the axis-cylinders of the peripheral nerves. Possibly a part of the toxin may be carried to the central ganglion-cells by the blood-stream. The inoculation period noted is believed to be due to the time required for the toxin to pass along the nerves. That the toxin has a special affinity for nervous tissue, and may be bound by it, has already been noted in the discussion of toxins and antitoxins. The period of incubation in man averages about nine or ten days. In the horse it varies from four to twenty days. Under exceptional conditions this period may be much longer. Mortality is over 90 per cent. when there is a short period of incubation, and over 50 per cent. where the period is prolonged. The characteristic symptom in all animals is a tetanus or stiffening of the muscles. The muscles at the site of inoculation are generally the first, and, in mild cases, they may be the only ones, affected. In the horse the appearance of the tetanus or lockjaw, the retraction of the eyes and protrusion of the nictitating membrane, spasmodic contraction of other muscles of the head, and those of other parts of the body, are diagnostic. A postmortem examination usually shows absence of gross lesions. Certain degenerative changes in the motor cells of the cord may 
be observed in stained sections. Hemorrhages in different organs are an inconstant accompaniment of the disease.

Immunity. - The toxin of the tetanus bacillus is produced in artificial media as well as within the body. For the preparation of antitoxin the organism is grown in bouillon, under anaërobic conditions, in an atmosphere of hydrogen, with surfaces of the medium covered with paraffin or paraffin oil or with oxygen excluded in some other manner. After incubation for a period of one or two weeks the broth is filtered through porcelain. The toxin may be prepared in dried form by precipitation with an excess of ammonium sulphate. After standing overnight the brown scum is removed and dried, first between hardened filter-papers, then in a desiccator, pulverized, and preserved in a darkened refrigerator. Various methods of purification have been devised, such that a dried toxin may be prepared of which $0.00000025 \mathrm{gm}$. will prove quickly fatal to a white mouse. As has been said, this toxin has a peculiar affinity for the cells of the central nervous system. Two poisonous constituents of the toxin have been differentiatedtetanolysin, which lakes the red blood-cells, and tetanospasmin, which gives rise to the characteristic tetanus symptoms.

In the preparation of antitoxin the unprecipitated broth is used. The smallest amount of toxin that will certainly kill a $350 \mathrm{gm}$. guinea-pig in three to four days is taken as the unit of toxicity. Increasing amounts of the toxin are injected at intervals into a horse. The blood-serum of the immunized horse contains the specific antitoxin. Many methods of standardization of the antitoxin have been used. In the United States it is titrated by guinea-pig injections against a standard toxin, sent out by the Hygienic Laboratory of the Public Health and Marine Hospital Service. It is used in both human and veterinary medicine, principally as a prophylactic. The tetanus antitoxin has not taken the place in the treatment of tetanus that is occupied by the antitoxin specific for diphtheria in the treatment of that disease. It seems that the symptoms of the disease are noted only after the union of the toxin with nerve-cells; that is, after much of the damage has already been accomplished. The injection of antitoxin then will doubtless neutralize any toxin present in the blood, but cannot remove the toxin already bound to the nerve-cells. 
The antitoxin is generally injected subcutaneously, but in severe cases intravenous, intraneural, and intraspinal injections are made to insure the contact of antitoxin with the toxin present. Its use is doubtless indicated in all cases. As a prophylactic, it has been found quite certainly to prevent the development of tetanus when injected before the appearance of symptoms. In human medicine it is customary to make injections following severe wounds, into which dust and dirt have gained entrance, such as Fourth-of-July wounds. The same may be said with reference to severe wounds, nail-punctures, and similar traumata in the horse.

Bacteriological Diagnosis.-The organism may frequently be recognized in stained mounts of the pus from the wound. The drumstick shape of the sporulating organism is quite characteristic. Isolation in pure culture and animal inoculation may also be used. The symptoms of tetanus are so distinctive, however, that these methods are rarely called into use.

Transmission.-Tetanus is one of the best examples of a noncontagious, infectious disease. Infection occurs practically invariably directly through the skin. The almost universal presence of the organism about stables renders infection easy. Nailpunctures are particularly apt to result in tetanus, as they introduce the organism deep into the tissues; superficial healing and exclusion of air quickly take place, and conditions are then right for rapid multiplication. It should again be emphasized that it seems very difficult for the tetanus bacillus to gain a foothold and proliferate, except in tissues that have been injured. The constant presence of these organisms in the intestines does not produce disease. So-called cryptic infections are not of uncommon occurrence, particularly in the horse. In these the point at which the organism gains entrance to the body is not known. Usually this comes either from the wound having healed superficially, so as to be indistinguishable, or from the wound having been originally so insignificant as to have escaped notice. Some investigators believe that the organism may occasionally gain entrance to the blood-stream from the intestines, but is unable to produce an infection, except when it lodges in tissue traumatically or otherwise injured, such as a broken bone or a bruise. 


\section{Bacillus chauvæi}

Synonyms.-Bacillus feseri; B. chauvei; B. chauveaui; $B$. anthracis symptomatici.

Diseases Produced.-Blackleg, symptomatic anthrax, quarter evil, quarter ill, Rauschbrand, charbon symptomatique in cattle and rarely in sheep and goats.

Arloing, Cornevin, and Thomas, in 1880, described the $B$. chauvæi as the cause of blackleg, and proved its etiological relation to the disease. Kitasato first grew the organism in pure culture. Grassberger and Schattenfroh have shown that this organism, as well as the organism of malignant edema still to be considered, is a member of the ubiquitous group of anaërobic butyric acid bacilli.

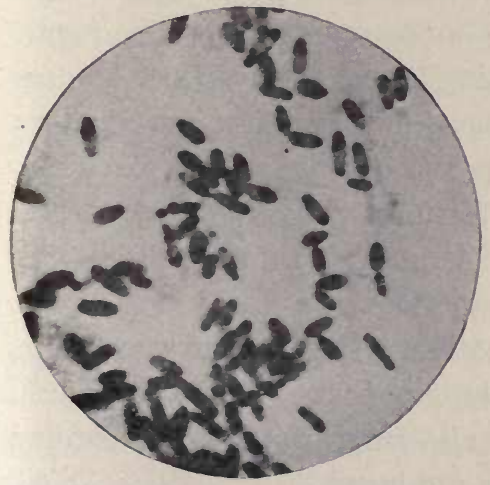

Fig. 148.-Bacillus chauvei (Kolle and Wassermann).

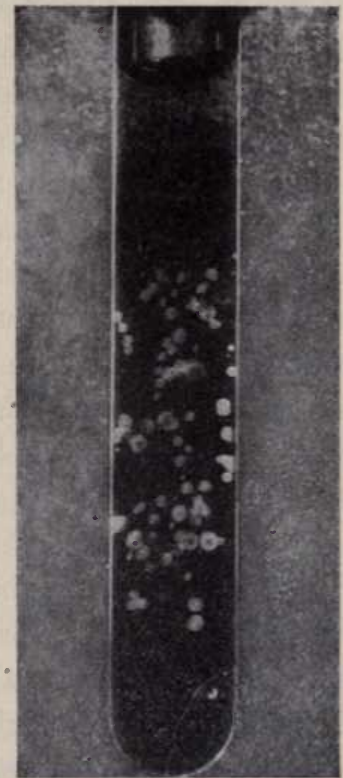

Fig. 149.-Bacillus chauvi, colonies in a dextrose gelatin shake culture (Fränkel and Pfeiffer).

Morphology and Staining.-B. chauvai is a large bacillus with rounded ends, usually single, but occasionally in pairs, 0.5 to 0.6 by 3 to $5 \mu$. It is motile by means of peritrichic flagella. Involution forms, consisting of greatly enlarged rods, are frequently encountered, particularly in old cultures. Capsules have not been demonstrated. Spores are produced, sometimes central, but more frequently near a pole, rarely quite terminal. They are oval in shape, and are not generally more than twice the diameter of the 
rod. These characters enable one readily to differentiate it from the $B$. tetani. When the spores are central, the spindle-shaped swollen cell is called a clostridium. The organism is easily stained by the common aqueous anilin dyes, but is gram-negative. This reaction to Gram's stain is a little uncertain, some cultures retaining the stain to some degree.

Isolation and Culture.-The organism may be readily isolated in pure cultures from the tissues infected. Plates may be poured and kept under anaërobic conditions. The colonies are spherical, or somewhat irregular, with microscopic radiations. Dextrose gelatin is an exceptionally favorable medium. In a shake culture the colonies appear in the lower portion of the tube, each usually with its gas-bubble, and surrounded by a liquefied area. Bouillon is clouded, gas is produced, and a flaky white deposit forms. The reaction in milk is somewhat variable; according to most authorities, it produces acid, coagulates, and later proteolyzes the casein.

Physiology. - The optimum growth temperature is about bloodheat, but good growth occurs at room-temperatures. The organism is a strict anaërobe. Concerning its other physiological characters, there is considerable disagreement among investigators. This may be due to the fact that there are strains which react very differently, and may constitute distinct varieties. Grassberger and Schattenfroh claim that the organism shows considerable variability, and that certain characters are easily lost. The spores are quite resistant to desiccation. Heating for some hours at $100^{\circ}$ is necessary certainly to destroy them. Gas is produced from carbohydrates, and probably also from proteins. According to some authorities, butyric acid is produced.

Pathogenesis.-Experimental Evidence.-Inoculation of pure cultures into laboratory animals results in death, with production of many of the characteristic symptoms of blackleg, particularly the edema about the point of inoculation. The disease may also be produced in cattle, so that there is no doubt as to the etiological relationship of this organism to the disease.

Character of Disease and Lesions Produced.-Blackleg in cattle is characterized by a swelling, edema, and emphysema of the muscles and the subcutaneous tissues of the infected part. Infection appears most commonly in the shoulder or hindquarter. 
The swelling increases rapidly in size, and the emphysema soon manifests itself by the crackling sound produced when the thumb is drawn firmly across the part. After death the organisms continue to grow and the body becomes distended with gas. The subcutaneous tissues of the infected part are edematous, even gelatinous, with blood and gas-bubbles. The underlying muscles are dark brown or even blackish, whence the name, blackleg. The disease usually results fatally in cattle in from one to three days after the first appearance of the lesions.

Immunity.-The production of true toxins by Bacillus chauvoi is not well understood. According to some authors, no toxin can be demonstrated. Others believe that there is a relatively thermostabile toxin produced which will endure a temperature of even $115^{\circ}$. Grassberger and Schattenfroh, who have made the most careful study of this problem, have succeeded in producing broth cultures containing a toxin that, in doses as small as those employed with diphtheria toxin, will kill laboratory animals. This toxin is produced by certain strains of the organism only, but these they believe are the more pathogenic. This toxin they have shown to be thermolabile. They have worked out methods of standardization closely resembling those of Ehrlich for diphtheria. Antitoxin may be produced by the injection of increasing doses into suitable animals, particularly cattle, and this antitoxin has a protective influence when injected into other animals. This method of immunization has never come into general use.

Animals that have recovered from an attack of the disease acquire immunity to a recurrence. Very young cattle and aged cattle have a considerable degree of natural immunity. To what the immunity developed may be due is not well understood. Probably it is in part opsonic.

Active immunization of animals is extensively practised. Various methods of attenuation of the organism for the vaccine have been developed. That in common use in the United States is the one adopted by the Bureau of Animal Industry, and is essentially that developed by Kitt. Fresh material is secured by macerating in a mortar the muscle tissue from a blackleg tumor and squeezing the fluid through a linen cloth. This is spread in a thin layer, and dried to a brown scale at a temperature 
at about blood-heat. This dried virus retains its virulence for several years, at least. The vaccine is prepared by mixing one part of this material with two parts of water and placing in a hot-air oven at a temperature of $95^{\circ}$ to $99^{\circ}$ for six hours. This dries the material and attenuates the organism. It is then pulverized and put up in packages containing a definite number of doses. Before use, a cubic centimeter of water for each dose is added, and the material mixed and then filtered. The injection then is made with 1 c.c. The dried material, pressed into the form of tablets, is sometimes inserted under the skin without suspending it in water. Vaccination has proved quite satisfactory.

Bacteriological Diagnosis.-A presumptive determination of the organisms may be made by smear preparations from the infected tissues. Anaërobic cultures will demonstrate the specific organism in pure culture if inoculated with a bit of the tissue before decomposition has begun and putrefactive bacilli have gained entrance. Animal inoculation, particularly subcutaneous inoculation into the guinea-pig, may prove useful. Usually the symptoms of the disease are so characteristic that a bacteriological test is wholly unnecessary.

Transmission.- It is believed that $B$. chauvai is widely distributed in nature. The disease occurs only in certain localities. There are districts which are never affected. Attempts have been made to correlate the topography of the country, such as character of soil, presence of marsh land, etc., with the prevalence of the disease, but without much success. Organisms closely related to B. chauvai may be found widely in the soil, but, for the most part, they do not possess the peculiar pathogenic characters of this form. Infection is believed to occur through wounds. The disease is rarely, if ever, contracted directly by one animal from another. It is a non-contagious infectious disease. It is not always possible to locate the point at which the organisms gained entrance-in fact, these cryptic infections constitute a considerable proportion of the cases. It is possible that the explanation sometimes offered for similar infections in tetanus will hold good here also; that is, that the organisms may occasionally gain entrance to the blood from the intestinal tract, and that they cannot produce disease except when they lodge in some tissue that has been injured, as from a bruise. 


\section{Bacillus gastromycosis ovis}

Disease Produced.-Bradsot or braxy in sheep.

An organism morphologically quite identical with the Bacillus chauvæi has been isolated and claimed to be the cause of braxy or bradsot in sheep. The disease is known principally from northern Europe and the British Isles. There are certain chemical and pathogenic characters of this organism which seem to separate it from the Bacillus chauvai. Careful comparative studies of these organisms are needed.

\section{Bacillus codematis}

Synonyms.-Vibrion septique; Bacillus œdematis maligni.

Diseases Produced.-Malignant edema; Malignes CEdem, cedeme malin, septicemie gangreneuse, in various animals and in man.

Pasteur, in 1877 , found that the injection of putrid flesh into a rabbit was followed by an edema at the point of inoculation, and ultimately by the death of the animal, with changes in many of the internal organs. That these changes were due to a specific organism, and not to the poisons of the putrid flesh alone, was shown by transfers from one animal to another, and by the isolation of an anaërobic bacterium. Koch later (in 1881) studied the disease.

Morphology and Staining.-The Bacillus odematis closely resembles the $B$. chauvai morphologically, and

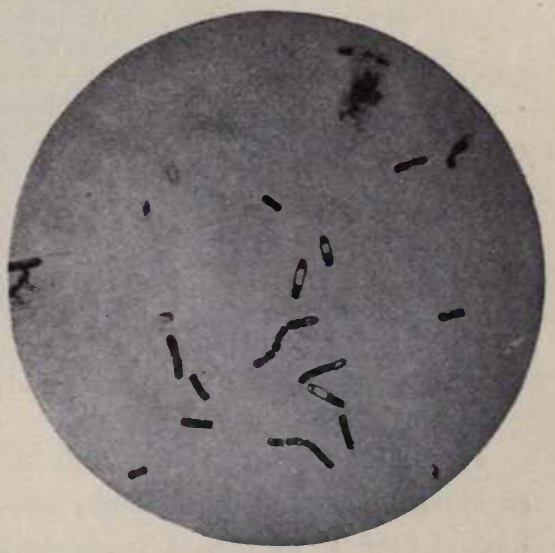

Fig. 150.-Bacillus adematis, spores and rods from an agar culture (Fränkel and Pfeiffer). is apparently closely related to it. Some investigators believe that the two organisms are simply two varieties of the same species. The organism is a rod, 0.8 to 1 by 2 to $10 \mu$, with rounded ends, single or in chains. Many of the cells are long and filamentous. It is motile, with numerous peritrichic flagella. Capsules have not been demonstrated. Spores are produced, 
usually equatorial, but sometimes polar. The rod is not greatly distended by the spore, although the snowshoe or clostridium shape is usually evident. The organism is gram-negative, and stains readily with the common anilin dyes.

Isolation and Culture.-The organism may be secured in pure cultures without difficulty, under anaërobic conditions, from the edematous tissues of the infected animal. It may usually be isolated from garden-soil by inoculation of a guinea-pig or a rabbit. Its cultural characters do not differ from those deseribed for Bacillus chauvai. Gelatin and blood-serum are digested, milk is curdled, and the casein digested.

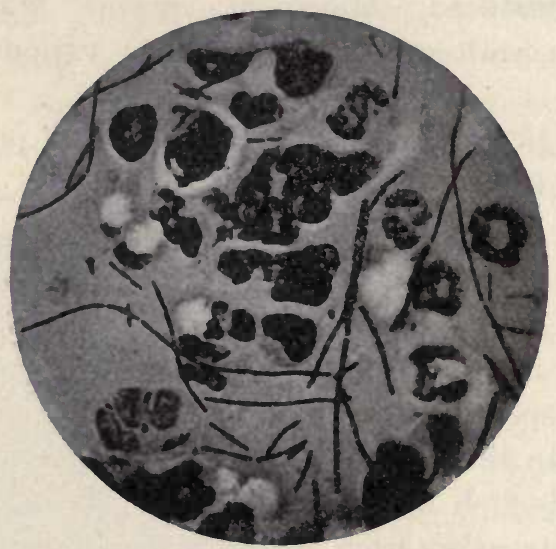

Fig. 151.-Bacillus adematis, tissue smear showing rods without spores (Fränkel and Pfeiffer).

Physiology.-Growth is luxuriant at room-temperatures, as well as at blood-heat. The spores are resistant to desiccation and to heat. Gas is produced from dextrose, probably also from proteins. Enzymes that liquefy gelatin, blood-serum, and easein are present.

Pathogenesis.-Experimental Evidence.-Inoculation of pure cultures of the organism into the laboratory animals, and also into the horse and other domestic animals, will produce a typical infection.

Character of Disease and Lesions Produced.-The tissues at the point of invasion are distended with gas-bubbles and are infiltrated with yellow or red serum. The muscle becomes dark 
and brittle. Hemorrhages are generally to be found in the subcutaneous tissues. The disease has been noted in man, and is not uncommon in the horse and the sheep. It occurs more rarely in cattle. It is a typical wound infection.

Immunity.-Animals which recover from an infection are found to be thereafter immune. The organism is also known to produce a leukocidin, which destroys white blood-cells. Aside from these facts, little is known relative to the factors determining immunity in this disease.

Transmission.- The organism usually gains entrance through wounds, although the possibility of a cryptic infection, such as is claimed to occur in tetanus, should not be ignored. In man the disease has been known to occur following injections in which an

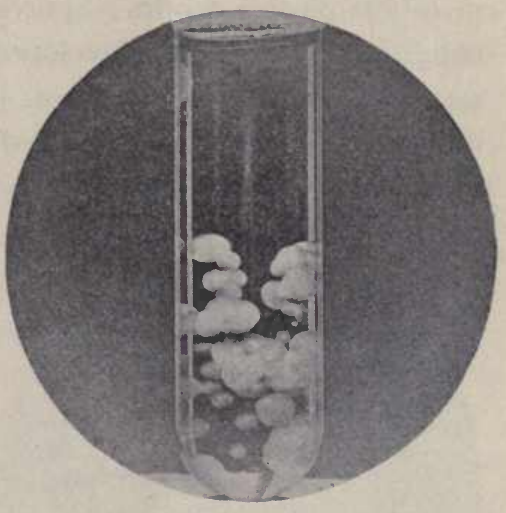

Fig. 152.-Bacillus œdematis, dextrose gelatin culture (Günther).

unclean hypodermic syringe was used, and a case has been reported in which the organisms were believed to have gained entrance to the body through the intestinal ulcers of typhoid fever. Infection may follow delivery, castration, shearing of sheep, use of unclean syringes or instruments, or dirty wounds of any kind.

\section{Bacillus welchii}

Synonyms.-Bacillus aërogenes capsulatus; B. phlegmones emphysematosæ; B. enteritidis sporogenes; Bacterium welchii; $B$. perfringens; Granulobacillus saccharobutyricus immobilis; B. anaërobicus cryptobutyricus; $B$. cadaveris butyricus; $B$. emphysematis vagino.

Disease Produced.-Gaseous edema in man.

Welch, in 1892, described Bacillus aërogenes capsulatus from the body of a man who died from an aortic aneurysm. The internal organs and subcutaneous tissues showed considerable emphysema. Since that time it has been repeatedly isolated in Europe and America. 
Distribution.-The organism is common in garden-soil, particularly that contaminated with excreta.

Morphology and Staining.-B. welchii is a rod, 1 by 3 to $6 \mu$, with rounded ends when single or truncate when in chains. It frequently occurs in chains, but may be found in pairs and small groups. It is non-motile. In this respect it differs from the other members of this group. Spores are produced only under certain conditions. They are developed best upon the surface of bloodserum in anaërobic cultures. They are central, and the cells develop as clostridia. Capsules may be demonstrated in the body fluids and in some artificial media. The organism stains readily

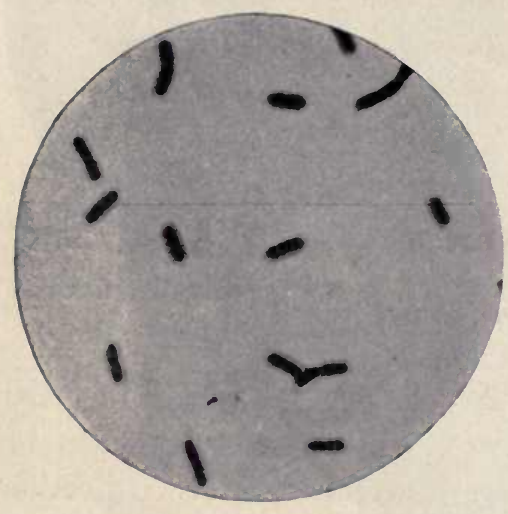

Fig. 153.-Bacillus welchii (Jordan). with the common anilin dyes and is gram-positive. Involution forms are frequent in artificial media.

\section{Isolation and Culture.-} McCampbell has described a modification of Welch's method of isolation as follows: " $1 \mathrm{gm}$. of soil is shaken in sterile $\mathrm{NaCl}$ solution ( 0.85 per cent.), and inoculated into sterile neutral litmus milk tubes, which are covered with $25 \mathrm{~mm}$. of neutral paraffin oil, for the purpose of securing anaërobiosis, and then incubated for twenty-four hours at $37^{\circ}$. At the end of this time the milk in the tubes is coagulated and shows acids and gas. A subculture is made in a second litmus milk tube under oil, and incubated for twelve hours in order to prevent the possible overgrowth of other bacteria. At the end of this time the milk usually shows coagulation, acid- and gas-production, as in the first instance ("stormy fermentation"); 0.5 c.c. of the whey in the subculture is then injected into the posterior auricular vein of a rabbit. In three or four minutes the animal is killed by a blow on the head, and the body is incubated at $37^{\circ}$ for eight to ten hours, at the end of which time the abdomen is markedly distended with gas. When ignited, this explodes and burns with a hydrogen flame. The thorax of the 
animal is carefully opened, and cultures made from the heart blood in dextrose broth, covered by neutral paraffin oil. In from eight to twenty-four hours the culture tubes show a marked cloudiness, abundant gas-production, and, in most instances, an odor of butyric acid."

The colonies upon agar and gelatin plates are round, grayish, semitranslucent; they are usually nucleated, and resemble those of $B$. tetani. Upon agar slants a thin, coalescent, yellowish-white growth occurs. Gelatin may or may not be slowly liquefied. Bouillon is clouded with a heavy precipitate. Little or no growth occurs on potato. Upon blood-serum the growth resembles that upon agar. There is some liquefaction along the line of inoculation. Milk is quickly coagulated, with gas- and acid-production.

- Physiology.-Growth occurs best at $37^{\circ}$. The thermal deathpoint for non-sporulating culture is $50^{\circ}$ for ten minutes, for spores $100^{\circ}$ for fifteen minutes. Gas is produced from dextrose, lactose, and saccharose, but not from mannite. Probably some differences are to be found in various strains. Gas is likewise produced from pure proteins, such as recrystallized egg-white. The gas formula is approximately $\frac{\mathrm{H}_{2}}{\mathrm{CO}_{2}}=\frac{2-3}{1}$. Butyric, lactic, and acetic acids have been detected.

Pathogenesis.-Experimental Evidence.-Intravenous injection of the rabbit frequently, though not always, causes death, but subcutaneous inoculations are without effect. Guinea-pigs are susceptible, as are also pigeons.

Character of Disease and Lesions Produced.-Infections with B. welchii among the lower animals have been noted in few instances only, and then only in the rabbit and in the dog, as a result of severe injuries. However, it may quickly invade tissues after death, and give opportunity for mistaken diagnosis. It has not been shown satisfactorily that it ever invades the tissues generally before death. It is a secondary invader in practically every instance of natural infection. It has been found in emphysema of many organs in the human body. Herter believes that the presence of large numbers of this organism or its varieties in the intestines is responsible for the production of primary pernicious anemia, particularly in children. 
From the veterinary standpoint, the organism is of principal interest, not so much because of its slight pathogenic power, as the fact that it may be confused upon isolation with other sporebearing anaërobes.

Immunity.-McCampbell has found that the filtrates of B. welchii grown in dextrose bouillon are toxic, but showed the toxicity to be due to the butyric acid produced. No true toxin nor endotoxin could be demonstrated. The acids are also hemolytic and leukocytotoxic. Opsonins are present in normal and in increased quantities in immune sera, as are also specific bactericidal substances. No method of systematic immunization has been developed, nor does the slight pathogenicity of the organism make this advisable.

Bacteriological Diagnosis.-The organism can be recognized certainly from tissues only by isolation and morphological examination. Its gram-positive staining characters, lack of motility, and the diffieulty with which spores may be demonstrated are characteristic.

Transmission.- The organism probably gains entrance to the body through wounds or invades the tissues after death from the intestines.

\section{Bacillus botulinus}

Disease Produced.-Meat- or sausage-poisoning in man, botulism (botulus $=$ sausage).

Van Ermengem, in 1896, isolated an organism from sausage, which he believed to be the cause of poisoning. The organism has sinee that time been several times isolated, and is, therefore, of some hygienic importance, particularly in meat inspection and in meat hygiene. This disease or poisoning should not be confused with that produced by the Bacillus enteritidis, which has already been diseussed.

Distribution.-Only a few well-authenticated reports of the isolation of the organism are on record, and these principally from European countries.

Morphology and Staining.-Bacillus botulinus is a large bacillus, with usually rounded ends, 0.9 to 1.2 by 4 to $6 \mu$. It is commonly single or in pairs, sometimes in short chains. Involution forms frequently oceur. It is motile by means of four to eight 
peritrichic flagella. Capsules have not been demonstrated. Oval spores, somewhat greater in diameter than the bacillus, are produced at the poles. The organism stains readily with the anilin dyes and is gram-positive.

Isolation and Culture.-The colonies on dextrose gelatin are at first circular, transparent, light yellow, and soon liquefy the gelatin. Under the low power of the microscope they appear to consist of granules in constant motion. Later the colonies become brown and opaque. Milk is not curdled.

Physiology.-The organism is an obligate anaërobe. Its optimum-growth temperature is $18^{\circ}$ to $20^{\circ}$. It grows little, if at all, at blood-heat, and when developing at this temperature,

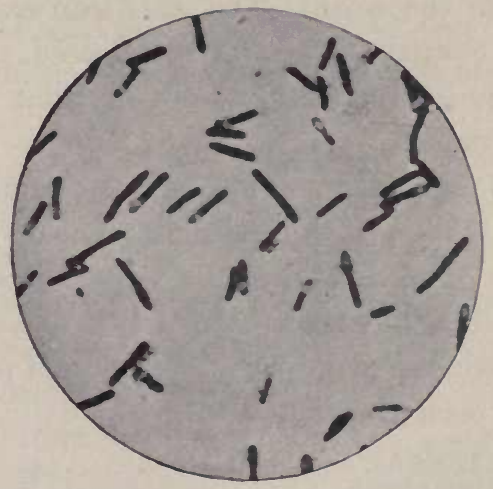

Fig. 154.-Bacillus botulinus (van Ermengem in Kolle and Wassermann).

produces numerous involution forms. Gas is produced from dextrose, but not from saccharose or lactose. Acid, in part butyric, is produced in dextrose media.

Pathogenesis.-Injections of the organism into the body of laboratory animals have revealed the fact that the organism is pathogenic only by virtue of the toxins that are elaborated outside of the body. It does not increase in numbers in the tissues. Probably this may in part be accounted for by its normal optimumgrowth temperature. The toxin produced, on the other hand, is very poisonous, whether injected or ingested. The use of raw or imperfectly cooked animal foods may give rise in man to the symptoms of botulism in the course of twenty-four to thirty-six hours, often with fatal termination. 
Immunity.-The toxin produced by Bacillus botulinus is among the most powerful known- 0.00005 to $0.0001 \mathrm{gm}$. is fatal in three to four days when injected subcutaneously into a guinea-pig, and 0.0001 to $0.0005 \mathrm{gm}$. will destroy a rabbit. A most striking characteristic of this toxin, and one which distinguishes it from those of diphtheria and tetanus, is its ability to produce poisoning when taken into the body by way of the alimentary tract. Guineapigs, and even apes, are killed by the ingestion of 0.01 c.c. of a dextrose broth-culture solution in which the organism has been grown. The toxin is destroyed by exposure to light and air. Heating to a temperature of $80^{\circ}$ renders it non-toxic. Antitoxin has been prepared from the goat and from the horse by gradually increasing doses of the toxin. This antitoxin exerts both a prophylactic and a curative effect when injected. The poisoning by $B$. botulinus is so infrequent, however, that the antitoxin is only of scientific value.

Bacteriological Diagnosis. - This can be accomplished only by isolation and cultivation of the specific organism.

Transmission.- The organism has been isolated, not only from poisonous meat, but from normal swine feces as well. The disease can be produced only by the ingestion of proteins in which the organism has been growing. 


\section{CHAPTER XXXV}

\section{VIBRIO OR CHOLERA SPIRILLUM GROUP}

ONe organism, pathogenic for animals, Spirillum metchnikovi and one pathogenic for man, Spirillum cholerce, and numerous non-pathogenic forms isolated from various sources have been described as belonging to this group.

The organisms of this group are more or less bent rods, usually only a segment of a spiral, rarely showing one or more complete turns. All are motile, aërobic, gram-negative, and without spores.

\section{Spirillum metchnikovi}

Synonyms.-Vibrio metchnikovi; Microspira metchnikovi.

Disease Produced.-Septicemia of fowls.

Gamaléia, in 1888, described this organism from an epizoötic of fowl septicemia which occurred in Russia. What appears to be the same organism was later (1894) isolated by Pfuhl from water.

Distribution.- This organism does not seem to have been isolated from such a disease by any investigator since the original work of Gamaléia. This latter, however, was sufficient to establish its etiologic relation to the disease. It is possible that the disease is more widely spread than the literature would indicate, inasmuch as poultry diseases are in need of careful investigation.

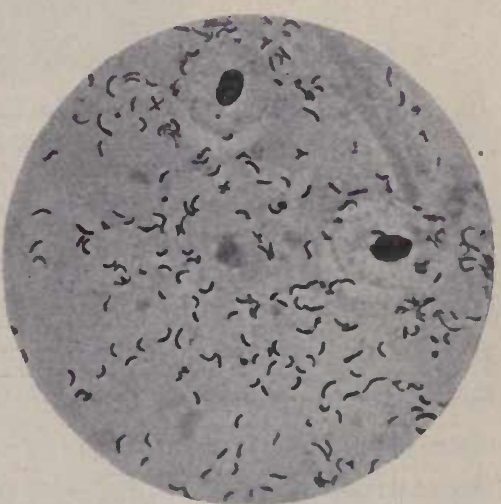

Fig. 155.-Spirillum metchnikoir (Günther).

Morphology and Staining.-It is a curved rod, with rounded ends, or sometimes a spiral filament. It is actively motile by a 
single terminal flagellum, and is about 0.5 by $2 \mu$. Neither capsules nor spores are produced. It stains readily, but is gram-negative.

Isolation and Culture.- The organism may be isolated from the intestinal contents of adult fowls and from the blood of younger fowls by plate cultures in nutrient gelatin. Upon these plates small white, punctiform colonies are developed in the course of twelve to sixteen hours; these enlarge rapidly, cause liquefaction of the gelatin, and are soon to be found in saucer-shaped depressions in the medium. Growth in a stab culture in gelatin is likewise rapid, and the gelatin is quickly liquefied in the form of a funnel. Upon agar slants a yellowish layer is developed. Bouillon is

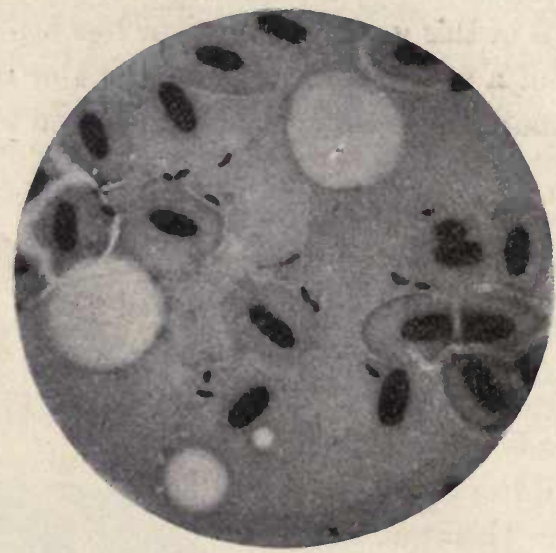

Fig. 156. - Spirillum metchnikovi in the blood of a pigeon $(\times 1000)$ (Fränkel and Pfeiffer).

clouded, and a delicate pellicle may form. Milk is coagulated with acid reaction and without solution of the casein.

Physiology. - The organism is aërobic. It develops almost as rapidly at room-temperature as at blood-heat. The thermal death-point is $50^{\circ}$ for five minutes. It is sensitive to the presence of acids in culture-media, and soon dies in consequence of their production in milk. It produces acid from dextrose and lactose, but no gas. Indol is formed. Gelatinase is developed, but no enzyme which will digest casein.

Pathogenesis.-Experimental Evidence.-Subcutaneous inoculations into the chicken, pigeon, and guinea-pig are quickly fatal; rabbits and mice succumb only to large doses. The disease ap- 
pears as a septicemia. According to Gamaléia, it may be communicated to chickens by feeding pure cultures.

Character of Disease and Lesions.-Chickens affected show many of the same symptoms as those infected with chicken cholera, except that the temperature is little, if at all, elevated. Diarrhea is constantly present. There is a marked hyperemia of the alimentary canal, and a blood-tinged, grayish-yellow liquid is found in the small intestine.

Immunity.-No true toxin has been demonstrated. Agglutin-

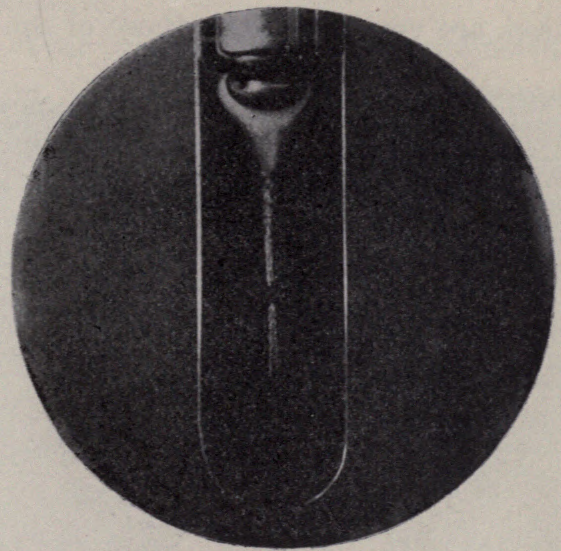

Fig. 157.-Spirillum metchnikovi, gelatin stab (Fränkel and Pfeiffer

ins are present in immune serum. Immunity may be established in animals by repeated injections of killed cultures.

Bacteriological Diagnosis.-This may be made on the basis of microscopic findings and isolation in pure culture.

Transmission.- The disease is probably transmitted by the ingestion of food soiled by droppings from infected fowls.

\section{Spirillum choleræ}

Synonyms.-Spirillum cholerce asiatica; Microspira comma; Vibrio cholerce.

Disease Produced.-Asiatic cholera in man.

Koch, in 1883, discovered the specific cause of Asiatic cholera in the rice-water stools of cholera patients.

Distribution.-The disease is endemic in India and possibly 
parts of China. It has swept in epidemics over Europe several times within the last century.

Morphology and Staining.- The cholera spirillum is a short, slightly curved rod, whence the common designation of " comma bacillus." Longer filaments and involution forms are frequently observed. It is motile by means of a single polar flagellum. Spores and capsules are not produced. It stains readily with the common anilin dyes and is gram-negative.

Isolation and Culture.- It may be readily isolated from the stools of cholera patients by plating upon nutrient gelatin. The cultural characters are very similar to those of $S p$. metchnikovi.

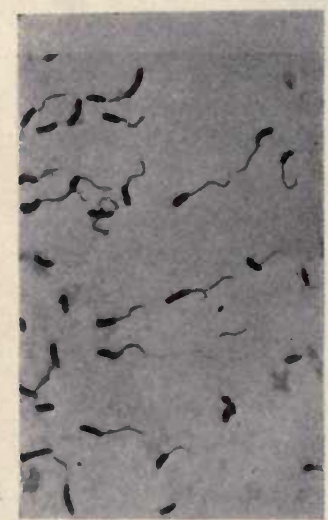

Fig. 158.-Spirillum choleræ (Kühnemann).

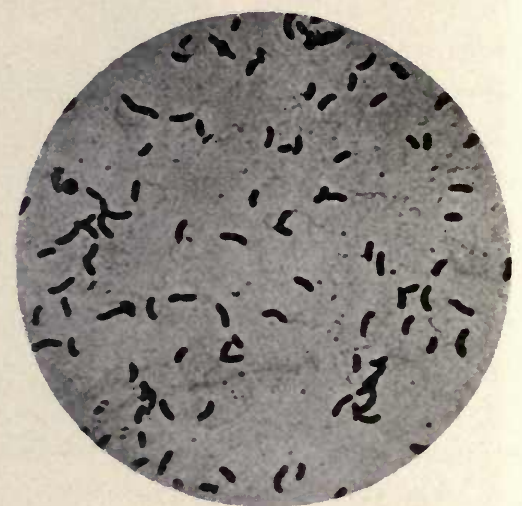

Fig. 159.-Spirillum choleræe, showing flagella (Günther).

Physiology. - It is an aërobic organism. Growth occurs readily at room-temperatures, although the optimum is blood-heat. The thermal death-point is $60^{\circ}$. Desiccation, disinfectants, and sunlight quickly destroy it. Blood-serum and gelatin are liquefied. Milk is not coagulated. Nitrates are reduced to nitrites. Indol is produced. The organism requires a neutral or slightly alkaline medium for its development.

Pathogenesis.-Experimental Evidence.-Asiatic cholera, in the form found in man, usually cannot be transmitted to laboratory animals. The etiologic relation of $S p$. cholerce to the disease, however, has been established by accidental and intentional infection of several laboratory workers. Intraperitoneal injection of the 
guinea-pig results fatally. Ingestion of the organisms by young rabbits may result in the development of the symptoms and lesions of typical cholera as they are observed in man.

Character of Disease and Lesions in Man.-Asiatic cholera is characterized by a severe diarrhea. The intestinal epithelium is desquamated, and gives rise to the appearance known as " ricewater" stools. The intestinal tract shows congestion and sometimes extensive, even diphtheritic, necrosis. The loss of water from the blood results in a considerable, frequently fatal, diminution in blood-pressure.

Immunity.-True toxins have been demonstrated for the cholera spirillum. They are produced under peculiar cultural conditions. Antitoxin has also been produced. Agglutinins and precipitins are found in immune blood, and frequently in the blood of patients. Bacteriolysins may be readily demonstrated; in fact, it is with this organism that the classic demonstration of Pfeiffer's phenomenon was carried out.

Active immunization against Asiatic cholera has been extensively practised. The vaccine consists either of cultures killed at $58^{\circ}$ or of cultures attenuated by growth at $39^{\circ}$.

Bacteriological Diagnosis. - This may be accomplished by an examination of a stained mount from the rice-water discharges, by isolation of the organism, or by the agglutination test.

Transmission.- The disease is transmitted through impure water and food, particularly vegetables, contaminated with the excretions of cholera patients.

\section{Non-pathogenic Spirilla}

Many species of spirilla closely resembling the preceding in morphology and cultural characters, but lacking in pathogenicity, have been isolated from a variety of sources. Such are the Vibrio proteus or Spirillum of Finkler and Prior, isolated from the stools in a case of cholera nostras, Spirillum tyrogenum, or Deneke's spirillum from cheese, Spirillum phosphorescens, isolated from water, and many others. 


\section{CHAPTER XXXVI}

\section{ACTINOMYCES GROUP}

THE members of this group are often called Trichomycetes or thread fungi. In many of their morphological characters they resemble bacteria. Frequently they occur as short rods that cannot be differentiated by examination from true bacilli. Usually, however, they occur in threads, which in some genera may be branched. These threads may show more or less differentiation into parts, and certain portions may develop into conidia or spores. These organisms show a more complex life history, therefore, than do the true bacteria. On the other hand, they can scarcely be grouped with the true molds, as they are much simpler in structure. They may be considered as a group, therefore, related closely to both bacteria and molds, and partaking of the nature of each.

These organisms show such diversity of morphology in the animal body and in culture-media that a satisfactory classification into species and genera is a difficult problem. Many generic names have been proposed. Some of these are valid, but the organisms belonging to them are non-pathogenic, so far as known. Jordan, in his General Bacteriology, has given a fairly satisfactory working classification for the genera of the trichomycetes.

Filaments showing no branching................... Letothrix. Filaments showing false branching. ................ Cladothrix. Filaments showing true branching:

The genus name Streptothrix is also frequently used for the genera given above as Nocardia and Actinomyces. This name, however, was applied to an entirely different genus of plants by Corda in 1839, and was first so used. Its retention as a genus name in this group is, therefore, no longer tenable, in the opinion 
of many investigators, although a committee of the Pathological Society has decided that it be retained.

Organisms belonging to Leptothrix and Cladothrix are not known to produce disease in animals. It seems to the writer that, at the present time, an attempt to draw a distinction between Nocardia and Actinomyces is impracticable. The genera are so imperfectly known, and their life-history in many cases so imperfectly worked out, that it is difficult to know into which of the two genera to place a particular organism. The genus name Actinomyces will be here used to include both.

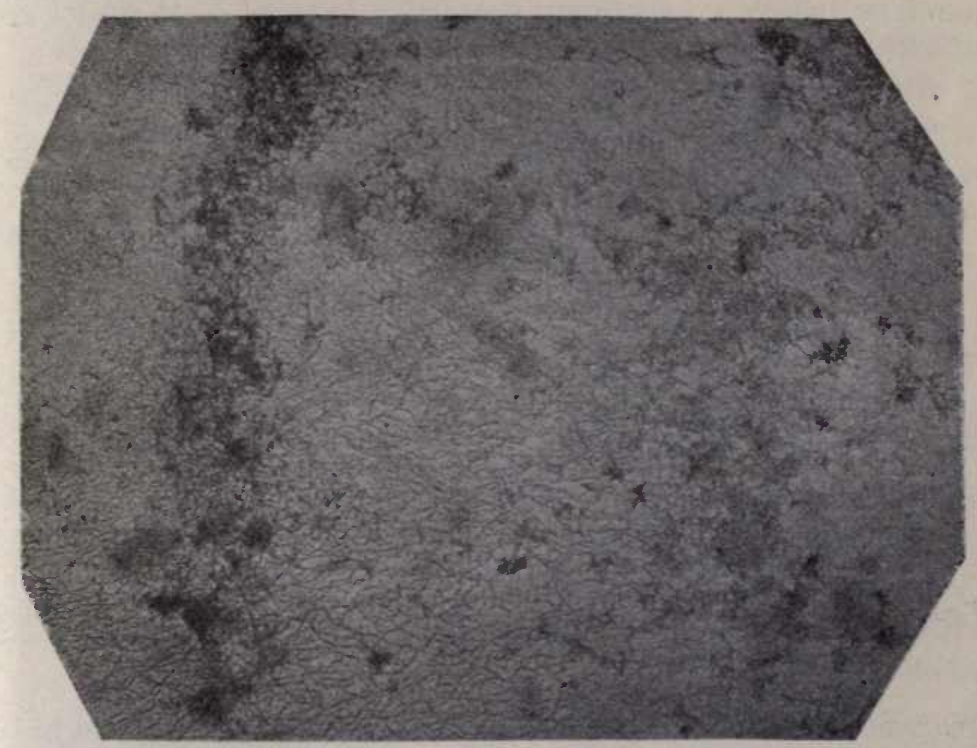

Fig. 160.-Streptothrix (Actinomyces) celicolor, a non-pathogenic trichomycete from the soil. A ring colony on a semisolid medium showing filaments and aërial hyphæ (Müller).

Several organisms are included in this genus, as here discussed, that may be shown to belong to the bacilli and not to the trichomycetes.

Many species of organisms of this group are known from the descriptions of a single author only. It is difficult to determine from these descriptions how many are valid species and how many merely synonyms. The facts seem to be that Actinomyces are widely distributed in nature. They may be isolated in abundance 
from most soils, and may be found to develop upon almost any plate of medium exposed to the air. Only under exceptional conditions are they pathogenic, but it is probable that the species usually described as such are normally saprophytes that can, upon occasion, proliferate in the tissues of the body and produce disease. The fact that cattle become infected through the gums or tongue, where the awns of certain grasses penetrate, that the barley testers, who bite the barley grain to determine its brewing quality, are most frequently infected among men in temperate - climates, that injuries to the feet of natives of certain tropical countries (where no adequate protection is worn on the feet) are

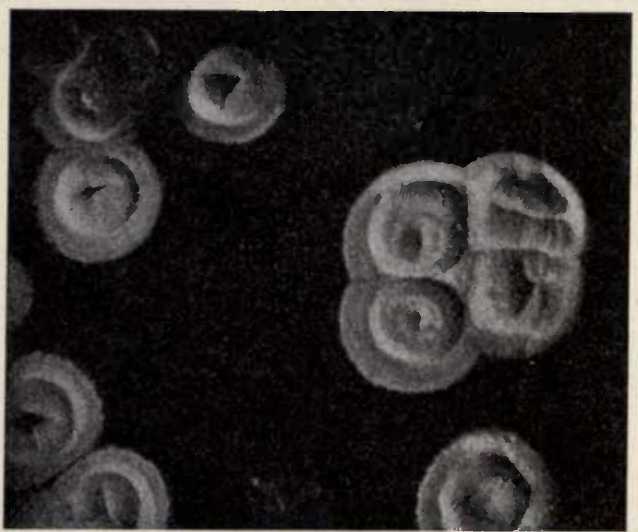

Fig. 161.-Streptothrix (Actinomyces) colicolor. Colony on agar. This colony structure is quite typical of many species (Müller).

frequently followed by local infections, and that Actinomyces have been found causing infections in practically all domestic animals, by one investigator or another is evidence of the wide distribution of the members of the genus. The species to be described are Actinomyces bovis and $A$. nocardii in cattle, A. caprce in goats, A. madure, and A. eppingeri in man.

The group, as a whole, may be characterized as consisting of slender, branching organisms, which may develop into colonies made up not only of threads but rods, cocci, and other cell forms. Frequently, in animal tissues, and sometimes upon artificial media, the ends of the threads may be clubbed. When grown upon the surface of artificial media some forms develop aërial hyphæ, 
which segment into chains of conidia. All species retain the Gram stain to a greater or less degree. Some are aërobic, others facultative, and still others obligate anaërobes. Pigments are produced by some species.

\section{Actinomyces bovis}

Synonyms.-Streptothrix bovis; Cladothrix actinomyces; Streptothrix actinomyces; Discomyces bovis.

Disease Produced.-Lumpy jaw and wooden tongue (actinomycosis) in cattle, and probably related infections in other animals and man.

Harz, in 1878, gave the name Actinomyces to the ray-fungus, which Bollinger, in the preceding year, had found present in the characteristic tumor-like growths in cattle.

Distribution.-The infection is known from Europe and North and South America.

Morphology and Staining.-In the infected tissues the organism forms minute yellowish granules, sometimes large enough to be readily observed by the unaided eye. These granules are made up of compact masses of the organisms. Branched filaments, with a more or less radial arrangement, are to be observed occupying the central portion, commonly mixed with coccus-like degeneration products. The margin of the granule or rosette, when examined in cross-section, is found to consist of club-like enlargements of the threads, showing a marked refractivity to light. The filaments are slender, usually about $0.5 \mu$ in diameter. It is believed that the formation of the clubbed ends is correlated in some way with the resistance of tissue to invasion. They have been variously regarded as degeneration products, involution forms, and as indicating a thickening of the sheath to protect the organism against antibodies produced by the tissues. Young colonies on artificial media consist of interlacing, branched threads, which tend to form compact masses. These commonly break up into bacillus-like segments, in a manner not unlike the formation of certain spores among higher fungi, by segmentation of the hyphal threads. Whether or not these correspond to the oïdial type of spore produced in the higher fungi, or represent spores at all, is not known. The clubbed type rarely develops in artificial media. The organism 
stains readily with the common anilin dyes and is gram-positive. It is not acid-fast.

Isolation and Culture.-The organism is not easily isolated in pure cultures, particularly when it occurs in mixed cultures with pyogenic cocci in the lesions. Wright has described a technic which he found quite uniformly successful. Pus or tissues containing the organism in filamentous rosettes is preferable to that containing only the clubbed type, as in the latter degeneration has gone so far that frequently no growth will oecur. The granules are washed in sterile water, crushed between sterile slides, and inoculated in varying amounts into tubes of melted 1 per cent. dextrose agar, and incubated at $37^{\circ}$. In his experience the

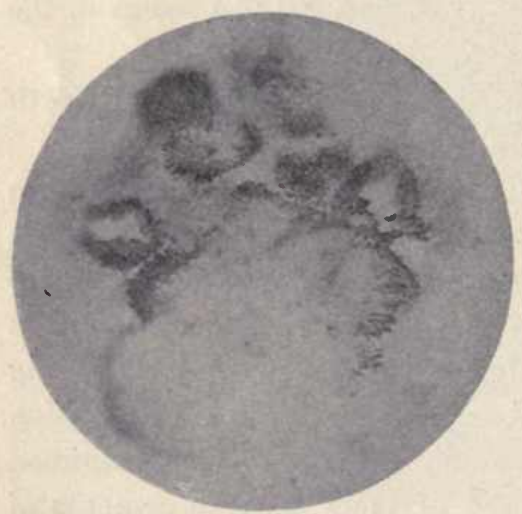

Fig. 162.-Actinomyces bovis, tissue section showing the radial arrangement and the clubbing of threads (Günther). colonies developed characteristically from 5 to $12 \mathrm{~mm}$. below the surface, but others have found them to form quite as well upon the surface of the medium. Isolated colonies may then be transferred to other media. In bouillon the organism forms distinct, solid, spherical, or mulberrylike masses at the bottom of the tube. Growth is secured with difficulty upon the surface of the medium, according to Wright, but other investigators have not experienced the same difficulty. It forms on agar and glycerin agar colonies, which at first resemble tiny drops of amber; these enlarge, and either remain discrete or coalesce to form a distinctly wrinkled, "lichen-like" membrane, which frequently has a dusty appearance. Gelatin is slowly liquefied.

Physiology. - The organism may be regarded as a facultative aërobe, as growth appears to take place best under anaërobic conditions. The optimum growth temperature is $37^{\circ}$. The organism is resistant to desiccation and will live for a long period, probably months, in a dried condition. Gelatin is liquefied. 
There is no gas- or acid-production. A brown to black pigment may be produced.

Pathogenesis.-Experimental Evidence.-In the great majority of cases experimental inoculation is without result. Many animals have been used-cattle, sheep, swine, dogs, cats, rabbits, and guinea-pigs. In relatively a few cases significant lesions have been developed. Musgrave, Clegg, and Polk have produced extensive suppurative lesions by intraperitoneal inoculation of the monkey, the infection terminating fatally in about three weeks. The common lack of pathogenesis may be due to differences in resistance, to a diminution of virulence due to cultivation, or to the manner of inoculation. In cattle it may gain entrance with a grass awn, and this may protect it from the destructive agencies of the tissues until its pathogenicity is well established.

Character of Disease and Lesions Produced.-A swelling or tumor-like mass develops in cattle at the site of infection. This softens and ultimately discharges thick, yellowish pus. The

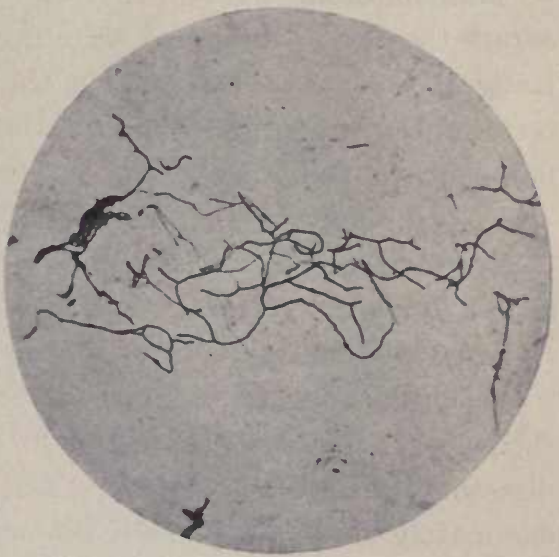

Fig. 163.-Actinomyces bovis (Ntreptothrix actinomyces), stained mount from culture-mędium (Musgrave, Clegg, and Polk, in "Philippine Journal of Science").

discharge after the lesion has opened may become intermittent in character. When the tongue is the primary seat of infection it becomes swollen, indurated, and protrudes from the mouth in some cases. The bones of the jaw are often attacked. The infection is chronic. Animals rarely die from immediate effects. In a few instances metastatic infection of other parts of the body than the head and neck have been reported.

In man the disease usually attacks the softer tissues, progresses more rapidly than in cattle, and is apt to terminate fatally from metastatic infection. Whether or not the organism isolated from human actinomycosis is the same as that found in cattle is uncer- 
tain. The same may be said of the forms that have been isolated from similar infections in other animals, among them the horse, dog, and pig.

Immunity. - No method of immunization against the disease has been developed.

Bacteriological Diagnosis.-A microscopic examination of the unstained pus will usually reveal the characteristic granules, with the radial arrangement of clubs or of tangled bits of branched threads. A film stained by Gram's method will bring the latter out clearly when present in small numbers only.

Transmission.-It is believed that the organism commonly enters the body through a trauma, through carious teeth, or by being carried into the tongue or the gum with the sharp awns of certain grasses and grains. So far as known the disease is wholly non-contagious.

\section{Actinomyces nocardii}

Synonyms.-Streptothrix nocardii; Actinomyces farcinica; Streptothrix farcinica; Nocardia farcinica.

Disease Produced.-Bovine farcy. Farcin du bœuf.

Nocard, in 1888, first described an Actinomyces or Streptothrix from the lesions of cattle in Guadeloupe suffering from a disease termed bovine farcy. The disease itself has not been adequately studied, although the organism has been investigated by several workers. There is no record of its occurrence in the United States.

Morphology and Staining.-The organism is slender, much branched, and interwoven. In culture-media short, plump filaments with branches may occur, and in old cultures many ovoid cells are found. The organism is gram-positive, and many portions, particularly in old cultures, are acid-fast and also alcoholfast.

Isolation and Culture.- It may be isolated in pure culture from lesions directly upon artificial media. The colonies upon agar are small, white, irregular, raised, and opaque. Upon glyeerin agar they are at first discrete, but soon coalesce, and present a moist, meal-like growth. Bouillon is never clouded, but a grayish, flocculent mass forms at the bottom. Milk is unchanged.

Physiology.-The organism is a facultative aërobe. It de- 
velops best at $37^{\circ}$. It is resistant to desiccation, and maintains its virulence when cultivated.

Pathogenesis.-Experimental Evidence.-Guinea-pigs are easily infected by intraperitoneal injections. The organism produces numerous nodules resembling tubercles upon the peritoneum and the abdominal organs, particularly the liver, spleen, and kidneys. Intravenous injection gives rise to a condition resembling generalized miliary tuberculosis. Intraperitoneal injection of the monkey gives rise to similar lesions. Cattle and sheep develop, at the point of a subcutaneous inoculation, an abscess which dis-

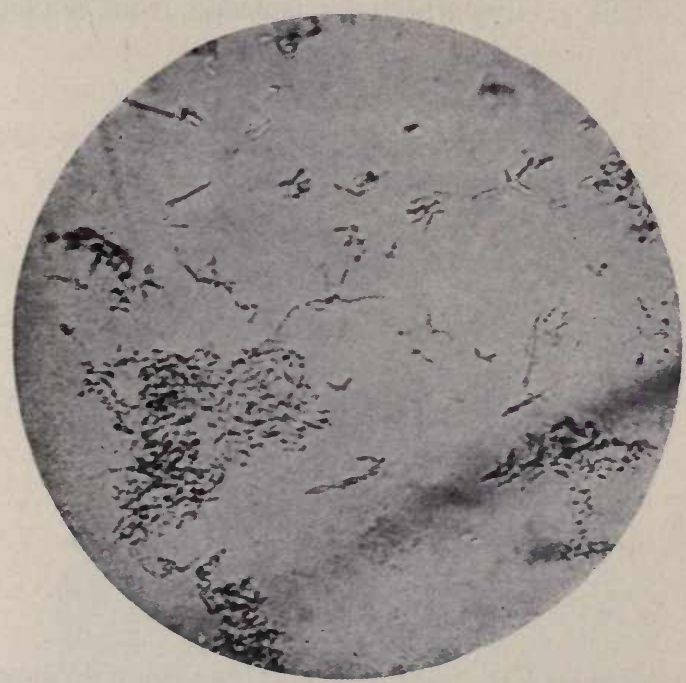

Fig. 164.-Actinomyces nocardii, stained mount from culture (Musgrave, Clegg, and Polk, in "Philippine Journal of Science").

charges, ulcerates, and may disappear, to reappear after an interval.

Character of Disease and Lesions. - The disease in cattle is characterized by an enlargement of the superficial lymph-nodes, which ulcerate and have much the appearance of farcy in the horse. The internal organs may be affected, with a resultant pseudotuberculosis.

Immunity.-Methods of immunization have not been developed.

Bacteriological Diagnosis.-The organism may be recognized in preparations from the lesions, but, for differentiation from other 
Actinomyces or Streptothrices, culture and animal inoculation are necessary.

Transmission.-The disease is probably transmitted by wound infection, but this is not certainly known.

\section{Actinomyces capræ}

Synonyms.-Streptothrix capra and possibly S. canis.

Disease Produced.-Actinomycosis (streptothricosis) in goats, possibly in the dog.

Silberschmidt, in 1899, published a description of an organism belonging to this group, which he isolated from a goat affected

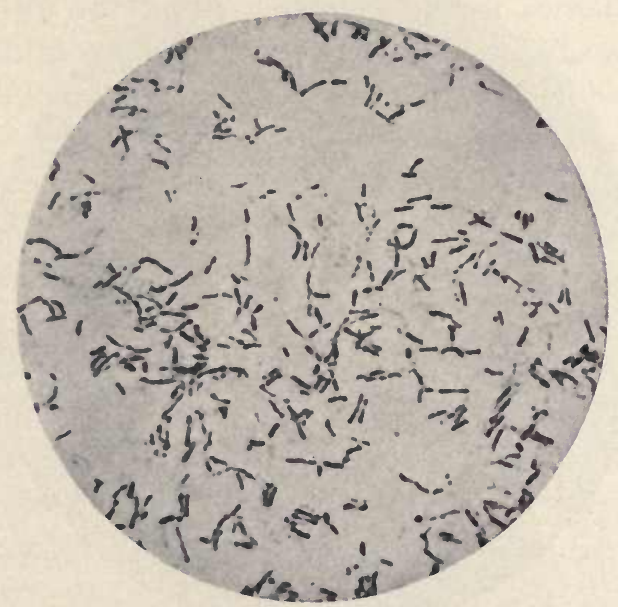

Fig. 165.-Actinamyces capra, stained mount from culture (Musgrave, Clegg, and Polk, in "Philippine Journal of Science").

with a disease which closely simulated tuberculosis. It has been studied by several other investigators, who are in agreement that it should be regarded as a distinct species.

Morphology and Staining.-Morphologically, it resembles the true bacteria more than other members of this group. The filaments are comparatively short, and show little tendency to form tangled masses, but separate easily. Both in culture and in the lesions rod forms and cocci are predominant. It stains with the anilin dyes rather irregularly, and is alcohol and acid-fast.

Isolation and Culture.-The organism grows rather readily upon most of the laboratory media, so that isolation is not a matter 
of difficulty. Upon agar the growth appears in two to three days as small, brownish colonies. It is somewhat more luxuriant upon glyeerin and maltose agar, the colonies coalescing to give the growth a moist, mealy appearance. The colonies are light brown in color. Growth upon potato is similar. In bouillon the colonies develop upon the surface as fine dry disks, and form a pellicle, which finally settles as a sediment, the broth remaining clear.

Physiology. - The organism is a facultative aërobe.

Pathogenesis.-The organism produces tubercle-like lesions in the rabbit, guinea-pig, and monkey upon inoculation. It is not of any considerable economic importance.

\section{Actinomyces maduræ}

Synonym.-Streptothrix madurce.

Disease Produced.-Madura foot, mycetoma, streptothricosis in man.

Vincent, in 1894, cultivated an Actinomyces from cases of mycetoma or Madura foot in man. This disease occurs in certain

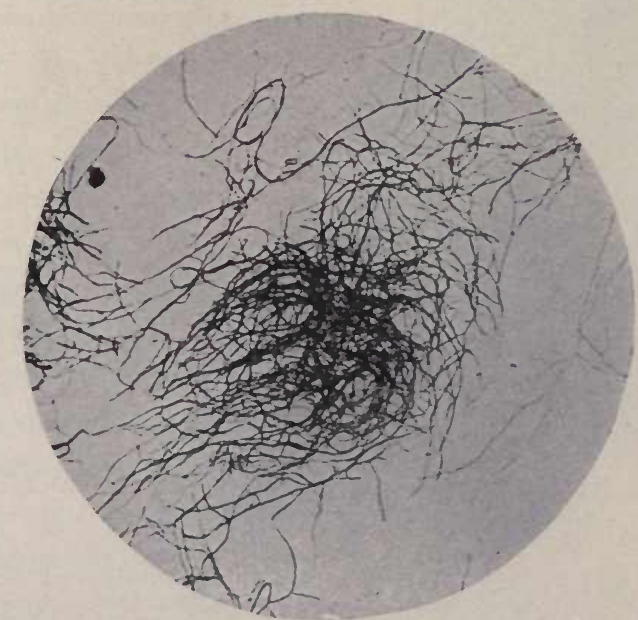

Fig. 166.-Actinomyces madurce, stained mount from culture (Musgrave, Clegg, and Polk, in "Philippine Journal of Science").

tropical countries, as southern Asia and the Philippines. It is undoubtedly a different species from those already described. It is not known to affect animals in nature, but will infect the monkey upon intraperitoneal inoculation. 


\section{Actinomyces eppingeri}

Synonyms. - Streptothrix eppingeri; Streptothrix freeri.

Disease Produced.-Mycetoma, or Madura foot, and other lesions in man.

This organism was described by Eppinger, and has since that time been found in various actinomycotic infections in man. It is pathogenic for the monkey, guinea-pigs, and rabbits, but is not known to produce disease in animals under natural conditions.

\section{ACTINOMYCES OF OTHER INFECTIONS}

Probably about thirty or more other species have been described belonging to this genus. In most cases they have been reported but once or have been incompletely described. As has before been emphasized, careful work is still needed in order to determine the true number of valid species and their relationship to disease. 


\section{CHAPTER XXXVII}

\section{BLASTOMYCETES}

Tне genus name Blastomyces is used to designate a group of pathogenic fungi having many points in common with the members of the genera Saccharomyces and possibly Torula. It is not certainly known that the forms thus classified are closely related among themselves, for it is a well-known fact that many of the Hyphomycetes, when grown in certain culture-media, will assume a form indistinguishable from the yeasts. It is possible, therefore, that some of the forms described as members of the genus Blastomyces may be only growth stages of higher forms. Here, again, as has been emphasized in other groups, there is need still for careful morphological and cultural studies of the various species that have been described, for some of them are very imperfectly known.

An understanding of the morphology of the Blastomyces can best be obtained by a preliminary discussion of the Saccharomyces or true yeasts.

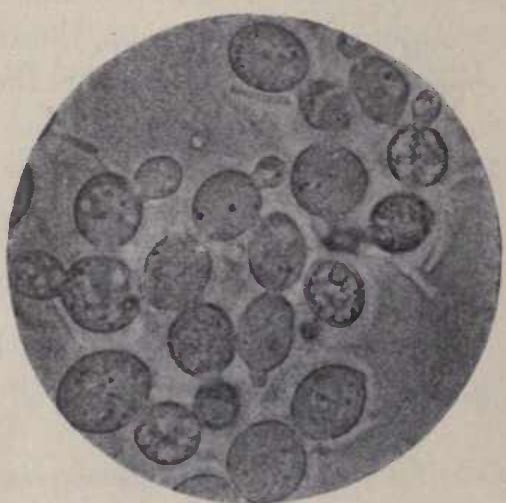

Fig. 167.-Brewer's yeast, Saccharomyces cerevisioe (Günther).

The one character which separates this genus from the Hyphomycetes is the difference in the vegetative method of reproduction. This is accomplished by budding. The mother-cell is usually oval or round, and, at various points on its surface, produces small buds, which enlarge and soon separate as independent cells. Occasionally these cells may remain together and become considerably elongated. By continued budding from the tip, a chain of cells is formed 
simulating a mycelial thread of one of the Hyphomycetes. The cell differs from that of a bacterium by the presence of a definite nucleus, which may be demonstrated by careful staining technic.

Spores are produced by some yeasts when the cells are brought under the right conditions of moisture, oxygen pressure, and temperature. Generally, two, four, or six are produced within a single cell. This type of spore formation relates such forms definitely to the higher fungi, known as Ascomycetes or sac fungi. In these fungi the spores are borne in sacs or asci (singular, ascus), and the cell of the yeast, with its contained spores, is supposed to represent a simple type of ascus. Resting cells, consisting of heavily walled or encapsulated cells filled with protein, glycogen, or oil-granules, are formed by many yeasts. These granules may resemble spores, and have doubtless many times been mistaken for them. When brought under favorable conditions the cell, as a whole, begins again to produce buds, showing conclusively that the granules cannot be regarded as spores.

Among the true yeasts, those which are not known to produce spores are sometimes placed in the form genus Torula. It is not customary to make this distinction among the pathogenic yeasts or Blastomyces, although it has been attempted by some authors. As here used, the term Blastomyces includes all those pathogenic forms which reproduce regularly by budding, and may or may not produce ascospores.

The organisms belonging to this group are Blastomyces farciminosus, B. dermatitidis, and B. coccidioides.

\section{Blastomyces farciminosus}

Synonyms.-Cryptococcus farciminosus; Leishmania farciminosa.

Disease Produced.-Blastopycotic epizoötic lymphangitis or pseudofarcy in the horse.

Rivolta, in 1873 , first described the organism associated with this disease. Tokoshige, in 1897, cultivated the organism and determined its classification. It has been studied since that time by several investigators. Galli-Valerio contends that this organism is a protozoan and not a Blastomyces. There is a clinically similar disease, since described in Europe and the United States 
as due to a member of the mold genus Sporotrichum. The organism described by Tokoshige should be reinvestigated. It is possible that it may prove to be a Sporotrichum also.

Distribution.-The disease is known from Italy, Egypt, Tunis, England, France, northern Europe, Japan, India, the Philippines, and possibly the United States (North Dakota, Iowa).

Morphology and Staining.-The organism as it occurs in tissues does not show budding forms ordinarily, but reproduces by a series of sporulations. In mounts prepared from the tissues it has a double refractive contour, which makes it stand out distinctly from the remainder, even when unstained. It is usually spherical or ovoid, 3 to $4 \mu$ in diameter. The cell contents may be homogeneous or granular. In culture-media the organism consists of hyphal and spherical forms. Cells with buds may be found, identifying the organism definitely with the Blastomycetes. Cells containing granules, and resembling closely the resting cells of the yeasts, are common. It has not been conclusively shown that true sporulation takes place in culturemedia. The organism stains readily with aqueous anilin dyes and is grampositive. The latter method of staining is useful in demonstrating the or-

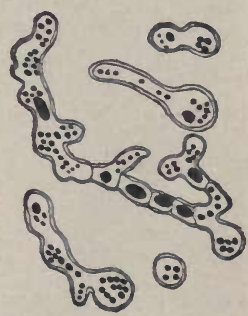

Fig. 168.-Blastomyces farciminosus, cells from culturemedia (adapted from Tokoshige).

ganism in pus or tissues. The alcohol must not remain too long in contact with the organism or it will lose color.

Isolation and Culture.-The B. farciminosus is isolated upon culture-media with considerable difficulty. Several investigators, particularly those holding to the protozoan nature of the organism, deny that it has been accomplished. In view of the success which has attended the cultivation of an essentially similar organism in man, there seems no good reason to deny that Tokoshige and others have succeeded in securing it in pure cultures. A slightly acid medium is said to be more favorable than one which is alkaline. Growth is very slow in any event.

Bouillon finally shows a white, flocculent deposit. Upon the surface of agar, gray-white granular colonies make their ap- 
pearance in the course of a month, and finally attain to a diameter of 1 to $4 \mathrm{~mm}$. The colony is wrinkled, and can be removed only with difficulty. Growth upon gelatin is essentially similar. Potato seems somewhat more favorable, and growth occurs more rapidly, but is of the same character as on agar.

Physiology. - The organism is aërobic. Growth occurs at room-temperature as well as at $37^{\circ}$. It does not liquefy gelatin. Sugars are not fermented with production of either acid or gas.

Pathogenesis.-Experimental Evidence.-Guinea-pigs and rabbits are not easily infected with pure cultures. Typical lesions have been produced in the horse by Tokoshige. They are readily produced by the injection of pus from natural infections.

Character of Disease and Lesions. - The disease in the horse shows a marked superficial resemblance to farcy. The infection progresses through the subcutaneous lymphatics and forms distinct nodules. These may suppurate. Metastatic infection of the internal organs occasionally occurs.

Immunity.- No practicable method of immunization has been developed.

Bacteriological Diagnosis. - The organism may be readily observed in a mount of the pus from a lesion stained by Gram's method.

Transmission. - It is supposed that infection is traumatic, that the organism gains entrance through cutaneous lesions. The disease not highly contagious.

\section{Blastomyces dermatitidis}

Synonyms. - Saccharomyces dermatitidis; Oidium dermatitidis.

Disease.-Blastomycetic dermatitis in man.

Busse, in 1894, first described an organism of this group as the cause of a fatal infection in man. Gilchrist, in 1896, found a similar organism as the cause of a dermatitis in man. Since that time the organism has been repeatedly isolated and studied.

Distribution.-Blastomycotic dermatitis has been reported from the United States, the Philippines, and Europe.

Morphology and Staining.-It is probable that several distinct species have been grouped together; that is, not all cases have shown morphologically identical organisms to be present. They 
have not as yet been sufficiently studied to justify their separation as distinct species, but will be treated rather as one polymorphic form. Careful morphological and cultural studies are still needed.

In the tissues the organisms appear almost invariably as budding forms. The cells are spherical or ovoid, from 10 to $17 \mu$ in diameter. They are distinctly double contoured. Several investigators have observed what they believe to be sporulating forms. The cells are frequently granular or vacuolate, resembling typical yeast cells in this respect. Upon culture-media numerous hyphal threads and budding cells are produced.

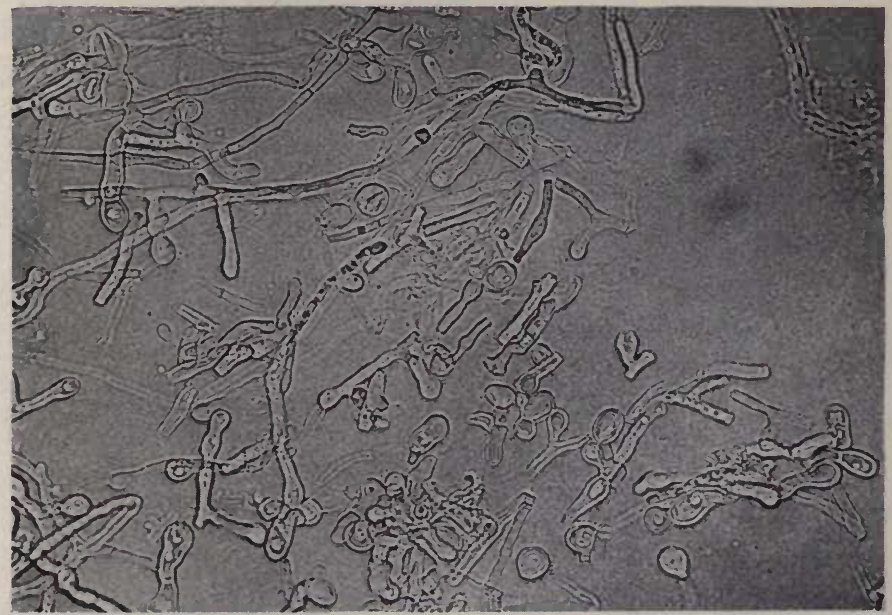

Fig. 169.-Blastomyces dermatitidis. Budding forms and mycelial growth from glucose agar (Irons and Graham, in "Journal of Infectious Diseases").

The organisms do not stain very readily with the aqueous anilin dyes.

Isolation and Culture.-Isolation of the organism is usually attended with considerable difficulty. Blood-serum slants are usually employed and inoculated with material from the lesion. Repeated trials are sometimes necessary before a growth is secured. After once accustomed to growth on artificial media, no difficulty is found in getting the organism to develop upon most of the common culture-media.

Small white colonies showing a mold-like surface, due to the formation of numerous aërial hyphæ, develop upon the surface 
of agar. The addition of dextrose to the medium somewhat increases the luxuriance of the growth. In bouillon a fluffy, moldlike colony or a granular sediment develops without any evidence of the diffuse clouding generally found in yeast cultures. Gelatin is not liquefied. Milk may or may not show coagulation and slight digestion of the casein. Potato is a favorable medium.

Physiology.-Growth occurs at room-temperatures, but somewhat more luxuriantly at $37^{\circ}$. The organism is aërobic and facul-

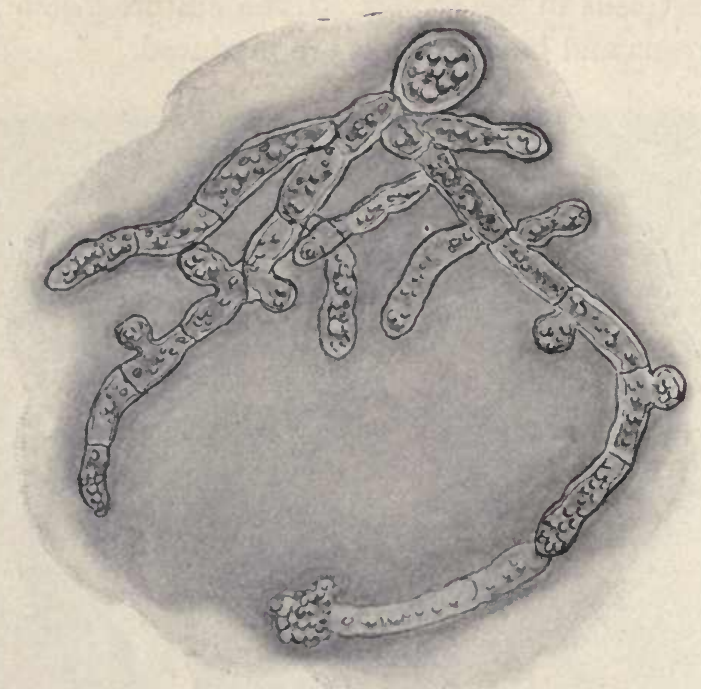

Fig. 170.-Blastomyces dermatitidis (Hamburger, in "Journal of Infectious Diseases").

tative anaërobic. Gas and acids are not produced in carbohydrate media.

Pathogenesis.-Experimental Evidence.-Guinea-pigs and rabbits may be infected, with production of either a local abscess or generalized blastomycosis. The lesions resemble in their essential characters those found in the human body.

Character of Disease and Lesions.-In man a papule generally appears upon one of the extremities, the face, or, more rarely, elsewhere. A viscid pus is exuded, and there is commonly considerable enlargement. Healing with an abundant formation of cicatricial tissue gradually occurs. Usually the lymphatics are 
not involved, the disease differing in this respect from the lymphangitis of the horse. The course of the disease is usually chronic, and it may persist for years, new ulcers appearing successively on various parts of the body. Generalization has been reported in a considerable number of cases. The skin lesions have sometimes been confused with those of syphilis and tuberculosis. Primary infection of the lungs has been shown in several cases.

Immunity.-No method of establishing immunity has been developed.

Bacteriological Diagnosis. - This may be accomplished by direct microscopic examination of the pus. Phalen and Nichols state that the organism may be most easily demonstrated by treating unstained sections with potassium hydrate and mounting in glycerin.

Transmission.--It is supposed that infection sometimes occurs through wounds, but several instances have come to light in which the infection was primarily pulmonary and the skin lesions secondary.

\section{Blastomyces coccidioides}

Synonym.-Oïdium coccidioides.

Disease Produced.-Blastomycosis, so-called coccidioidal granuloma in man.

Posades and Wernecke, in 1892, first reported a case of socalled coccidioidal granuloma from Argentina. In the United States the disease has been recorded principally from California, particularly in the San Joaquin Valley.

Morphology.-This form is of particular interest, because the budding or true blastomyces form very rarely occurs in the tissues, and multiplication is almost wholly through sporulation. The organism in the tissues is spherical and doubly contoured. It may reach a diameter of $30 \mu$ or even more. Budding forms have been recorded from pus. In artificial media the organism resembles a mold, but budding forms may be observed. The method of reproduction in tissues, by the formation of spores within the mother-cell and their liberation by a rupture of the cell membrane, has led some investigators to believe that the organism is really a protozoan. However, sporulation of this general type occurs in the yeasts. The question seems to be definitely settled in 


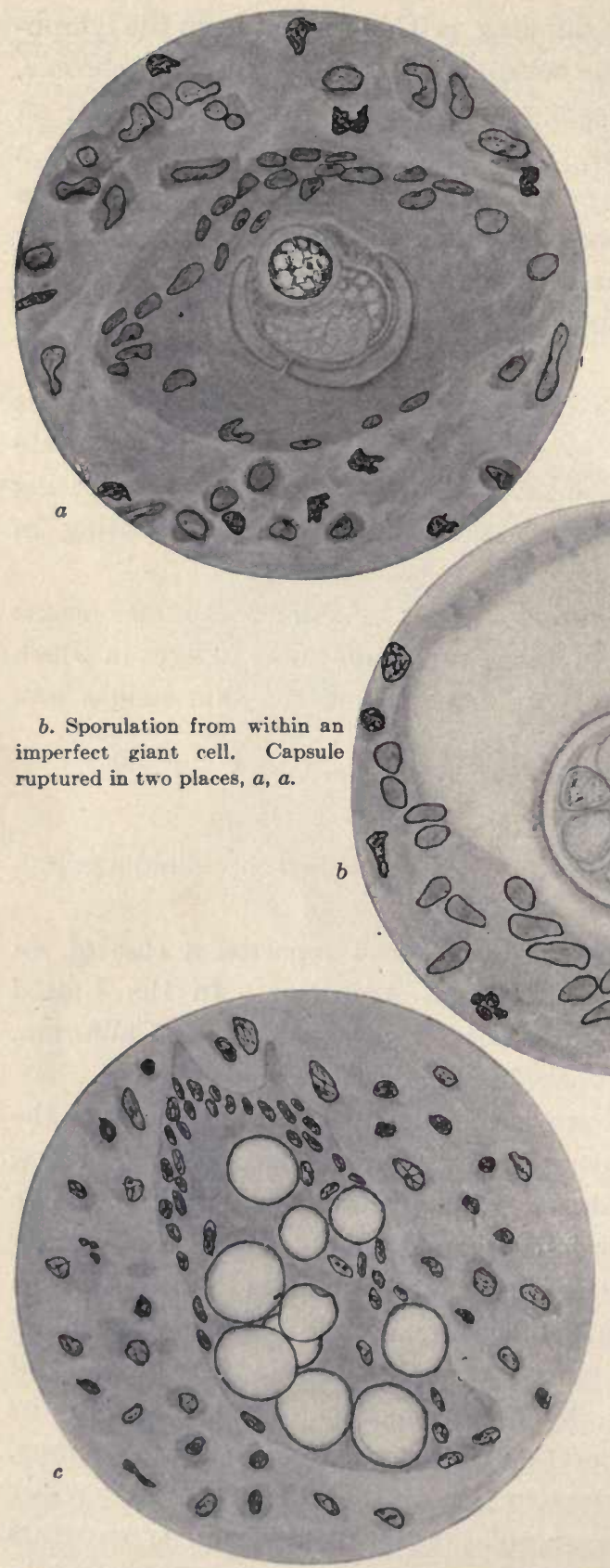

a. Typical large organism with thick hyaline capsule in a giant cell.

c. Giant cell containing a numbcr of organisms without granula cytoplasm. These have apparently recently been liberated by sporulation of their parent organism.

Fig.171.-Blastomyces coccidioides (Evans, in "Journal of Infectious Diseases"). 
favor of the plant hypothesis by the culture forms on artificial media.

Pathogenesis.-Whether this organism should be distinctly separated from the preceding is not certainly known. The disease frequently shows no cutaneous lesions; the infection is systemic and probably always fatal. There is often an involvement of the meninges. 


\section{CHAPTER XXXVIII}

\section{MOLD OR HYPHOMYCETE GROUP}

THE term Hyphomycete, as usually interpreted, is one of convenience only, for within this group are included members of the four great divisions of fungi generally recognized by botanists. The members of the group are many times not closely related. They all resemble each other in having a plant body or mycelium, which consists of threads or hyphoe made up, in the majority of forms, of chains of cells. Reproduction is not generally by budding, although this may sometimes occur. The hyphæ themselves break up into spores, or spores are borne at the tips of hyphæ that have been differentiated for the purpose. The hyphæ may unite to form a more or less solid mass, sometimes tissue-like in appearance. This mass may remain viable when dried for a considerable time, and may function in much the same manner as a resistant spore in tiding the organism over unfavorable conditions. Such a structure is called a sclerotium. The names given to these various types of structures have already been discussed under the heading of Morphology in Section I.

The Hyphomycetes, for the most part, belong to the division of fungi termed Fungi imperfecti by the botanist. The name is derived from the fact that these fungi are not known to produce perfect or sexual spores. Hundreds of genera and thousands of species have been described as belonging to this group. Many of these are doubtless simply developmental stages of forms that are known under other names. The life history of some fungi has been found to be so complex, and consists of so many stages, that five or six names have been applied and the different stages put in different groups of fungi, until it was found that all were the same polymorphic species. Unfortunately, careful morphological study has not been made of the pathogenic members of this group, and there is the greatest confusion in the nomen- 
clature. The pathologists and bacteriologists who have described the organisms have rarely paid any attention to their botanical relationships, and the organisms themselves, for the most part, have been ignored by the botanist in his classification.

As before stated, the possession of a more or less definite mycelium, a more or less "mold-like" growth, and the general production of spores are all that is needed to include an organism in the group. Many of the organisms of the group are very common in nature and are pathogenic only under exceptional conditions, while others have so adapted themselves to a parasitic existence that they may be regarded as obligate parasites. Many, too, have been noted once or twice only in certain pathological conditions, and it is by no means certain that they were more than accidental saprophytes.

The genera of molds containing species of known pathogenicity are-

Aspergillus.

Penicillium.

Fusarium.

Sporotrichum.

Microsporon and Trichophyton.

Achorion.

Ö̈dium or Ö̈spora.

\section{THe Genus ASPERgILluS}

The Aspergilli are widely distributed in nature. They are abundant in the soil and on decaying materials of all kinds. Their spores are common in the air, and cultures may readily be secured in most localities by simple plate exposure. They are not, however, present in such numbers as the genus next to be described, Penicillium. Several hundred species have been described, and by some authors the genus is subdivided into two genera, Aspergillus and Sterigmatocystis.

Aspergillus is placed by the botanists among the Ascomycetes or sac fungi, because at one stage in the life history sexual reproduction occurs, resulting in the formation of sacs filled with spores. This phase of the life history has been worked out in but few species; 
however, it is probable that it occurs in all when grown under the right conditions.

-The mycelium of Aspergillus is colorless and hyaline, muchbranched, penetrating for a short distance into the substratum or medium, and usually sending up aërial hyphæ, which give the colony a floccose or downy appearance. The hyphæ are septate, that is, cross walls are formed and the cells are divided from each other by walls. Asexual reproduction takes place by the forma-

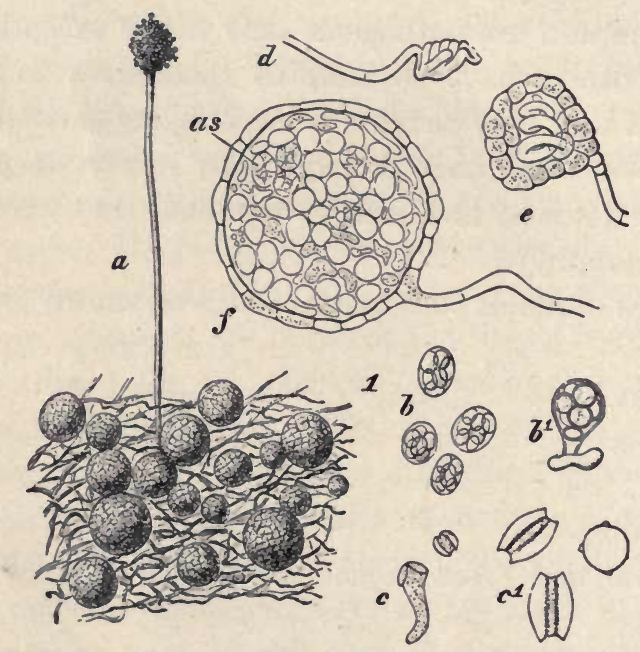

Fig. 172.-Morphology of the Aspergillus glaucus: $a$, Mycelia and perithecia on the surface of the medium, with a single conidiophore; $d$, a very young perithecium; $e$, cross-section through a perithecium, somewhat older; $f$, crosssection through a mature perithecium, showing the asci and the ascospores $(a s) ; b b^{1}$, isolated asci; $c c^{1}$, ascospores ripe and germinating $\left(c b^{1} d e f\right.$ after deBary, $a b c^{1}$ after Wehmer).

tion of enlarged, erect, spore-bearing hyphæ called conidiophores. These conidiophores are inflated at the tip and become covered with papillæ, which develop into short stalks, called sterigmata (singular, sterigma). The sterigmata may branch once or many times, giving rise to bunches of secondary sterigmata, or they may remain unbranched. The species with branched sterigmata are frequently grouped together into a genus Sterigmatocystis. From the tips of these sterigmata spores or conidia are abjointed, and hang together to form long chains. The spore mass at the tip of the conidiophore 
is termed a head. The spores are usually colored green, brown, yellow, or black, or in a few species they are colorless. They are spherical or oval in shape. Their surfaces are not easily wetted; they are easily detached, and are readily carried about by currents of air. This explains the readiness with which birds and some animals become infected in the respiratory tract when fed on moldy grain or fodder. When the spores come under favorable growth conditions, they germinate and reproduce the mold.

If growth conditions are right, careful observation will enable one to discover the sexual stages in the reproduction. Two filaments, somewhat differentiated, begin to twist together until they form a typical cork-screw. The cell contents fuse, and fertilization is effected. A tangled mass of threads arises about this cell, forming a compact layer or covering termed the perithecium. The inclosed cell grows rapidly, and produces a considerable number of enlarged cells, each of which eventually is found to contain spores, usually eight in number. These cells or sacs are called asci (singular ascus), and the spores are termed ascospores. These, like the conidia, when brought under favorable growth conditions, reproduce the mold. An Aspergillus may continue to multiply indefinitely without the sexual stage developing; it is not improbable that some species have altogether lost the power of reproducing other than by means of the conidia.

Several species of Aspergilli have been described as pathogenic. Doubtless, these are normally saprophytes, and only produce disease under exceptional conditions.

\section{Aspergillus fumigatus}

Diseases Produced.-Aspergillosis of birds; pneumomycosis in man and many animals.

The occasional presence of Aspergillus in lung infections has been known since early in the nineteenth century. Probably Mayer and Emmet, in 1815, were the first to note its presence in the lungs of a bird, in this instance a jay. Since that time the organism has been reported many times. In most cases no careful species determination was made, but the probabilities are greatly in favor of Aspergillus fumigatus being the species responsible. Aspergillosis has been reported from the stork, raven, flamingo, 
eider-duck, parrot, pigeon, chicken, hawk, bullfinch, plover, pheasant, bustard, duck, goose, ostrich, swan, and turkey among birds, from the horse, dog, and cow among animals, and from man. It has been reported from Europe and the United States.

Morphology.-In culture-medium it forms greenish or bluish gray or later brownish masses. The conidiophores are abundant, but short. The enlarged tip of the conidiophores is hemispherical, and 8 to $20 \mu$ in diameter, bluish-green, and later brown. The

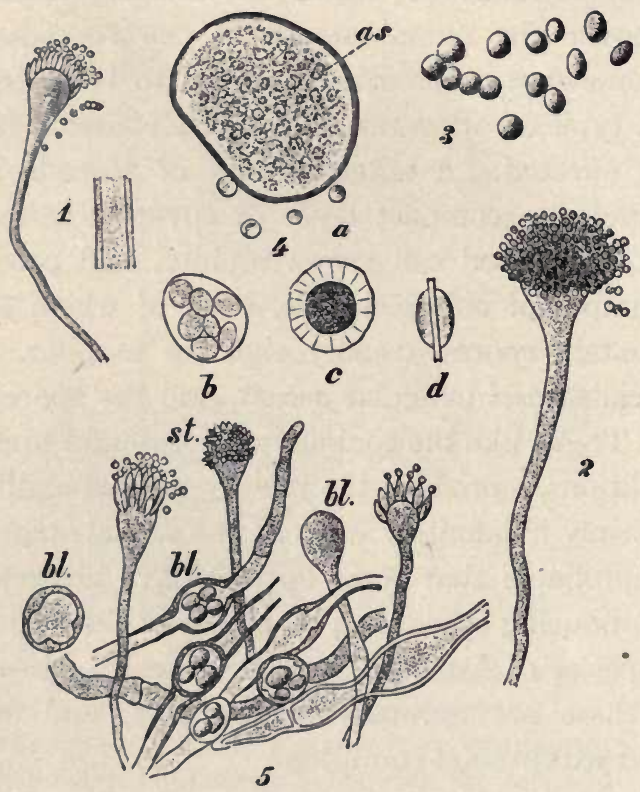

Fig. 173.-Aspergillus fumigatus: 1, Optical section through a conidiophore; 2 , conidiophore and conidia; 3 , conidia; $4, a$, perithecium; $b$, an isolated ascus; $c, d$, ascospores, front and lateral view; 5 , swollen hyphæ, $b l$, and conidiophores (4, $a-d$, after Grijns, remaining after Wehmer).

perithecia with ascospores have been observed in culture-media. In the lung tissues the branching mycelium may be observed on microscopic examination, and the sporophores may be seen projecting into the air-sacs, where the conidia are produced. These spores are never formed except in the presence of oxygen.

Isolation and Culture.-The Aspergillus fumigatus may be readily isolated from the lesions upon almost any of the commonly used artificial media, particularly when spores are produced. For 
the best development the medium should be slightly acid. It develops readily upon potato and bread. Colonies become visible in a day, usually as tiny, white, cottony growths, which, within a few days, turn green, due to the formation of the spores of that color.

Physiology.-The Aspergillus fumigatus is an aërobe. The optimum growth temperature is from $35^{\circ}$ to $40^{\circ}$. According to Mohler and Buckley, growth occurs, but spores do not form below $20^{\circ}$. The spores are resistant to high temperatures. They have been found to survive an exposure of seven hours at $65^{\circ}$.

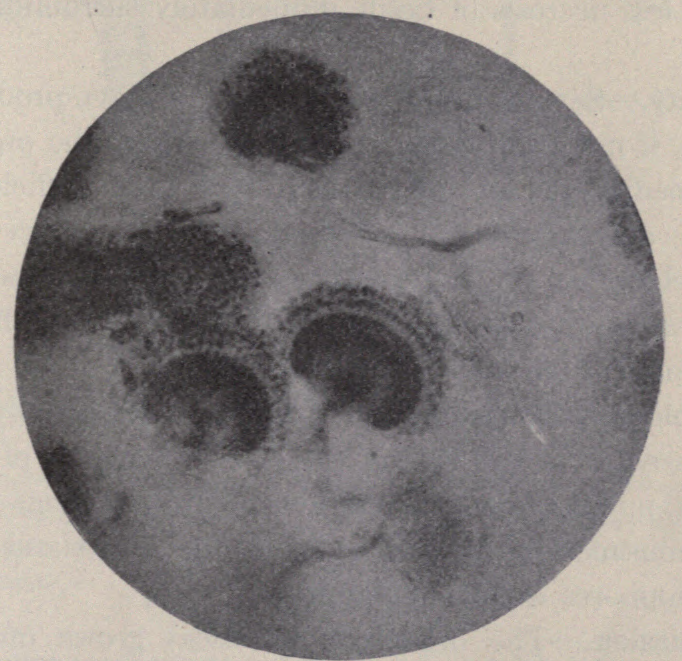

Fig. 174.-Aspergillus fumigatus from a culture on agar (Fränkel and Pfeiffer).

Twelve hours' contact with a 5 ' per cent. solution of phenol is not sufficient certainly to destroy them. They can withstand desiccation indefinitely.

Pathogenesis.-Experimental Evidence.-The organism produces death within a few hours or days when injected intravenously or intrathoracically into the chicken. The pigeon is particularly susceptible to injections. Rabbits and guinea-pigs likewise succumb, usually from a generalized infection. There is sufficient experimental evidence to justify the conclusion that Aspergillus fumigatus may produce a primary and fatal infection in many animals. 
Character of Disease and Lesions Produced.-By far the greatest number of cases of aspergillosis have been reported from birds. The lesions are generally located in the lungs, air-sacs, and hollow bones, where the spores may readily lodge. In man and animals, particularly the horse, the usual picture is an infection of the lungs and air-passages, but occasionally of the mucous membranes of other parts of the body. Metastatic infection of other organs is not infrequent. The organism causes the development of nodules not unlike those of tuberculosis. In the lungs the tubes are frequently occluded by the green fructifications of the fungus. There is more or less necrosis of tissue immediately surrounding the organisms.

Immunity. - Several investigators claim to have produced toxic substances, if not true toxins, by the growth of the organisms in artificial media. These claims have not been sufficiently substantiated, although there is considerable a priori evidence, from the character of the lesions and symptoms, that powerful toxic substances of some kind are produced. No method of successful immunization has been developed.

Bacteriological Diagnosis.-A diagnosis may usually be made by the character of the lesions and the appearance of the green spores. A microscopic examination of the scrapings of the infected mucous membranes should reveal the spores and characteristic conidiophores without difficulty.

Transmission.-The organism doubtless grows on decaying organic matter outside the body. The feeding of moldy grain or fodder may give ample opportunity for infection by inhalation. The preponderance of pulmonary primary infections shows that inhalation probably is the common method of infection.

\section{Aspergillus flavus}

This organism has been described by various investigators, who believed it to be, in part at least, responsible for blind staggers or meningoencephalitis in horses. It occurs in great quantities on moldy corn and other grains. Although the complete data have not been presented, the work of Haslam indicates that it is of some pathogenic significance.

Morphology.-The sterile hyphæ are cobwebby and white. 
The conidiophores are erect. Conidia are 5 to $7 \mu$ in diameter,

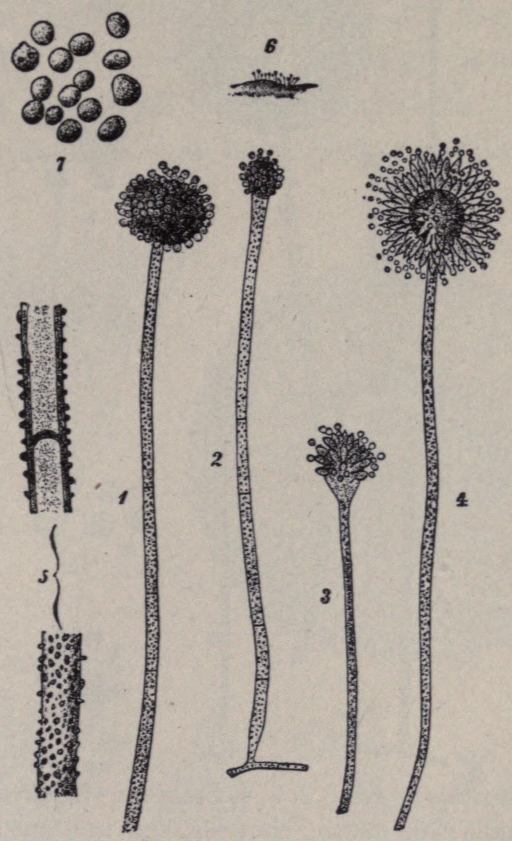

Fig. 175.-Aspergillus flavus: 1, 2, 3, 4, Various stages in the development of conidiophores; 5 , section and surface of a hypha, showing the numerous colorless granules with which it is covered; 6 , natural size of the fungus; 7 , conidia (Wehmer).

globose. Spore masses are yellow and yellowish green. Sclerotia are small and dark.

\section{Aspergillus niger}

This organism occurs under conditions similar to the preceding, and is believed also to be pathogenic to horses and other animals that consume grain infected with it.

Morphology.-The mycelium is at first white, then darker, abundant, and penetrates the medium to a considerable distance. The conidiophores are long and the spores borne up at some distance from the surface of the substratum. The sterigmata are branched. The conidia are 3.5 to $4.5 \mu$ in diameter, roughened. The spore masses ultimately become black, and may be readily differentiated in this manner from the two preceding. This 


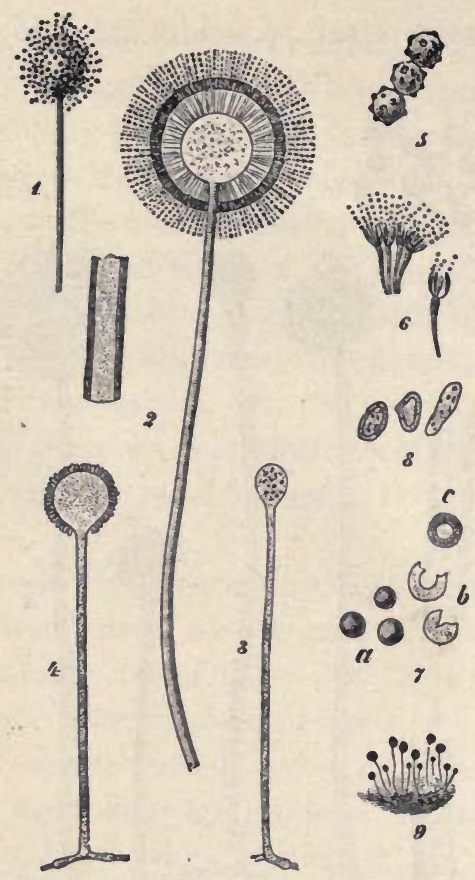

Fig. 176.-Aspergillus niger: 1, 2, 3, 4, Stages in the development of the conidiophores; 5 , conidia; 6 , detail, showing the branched sterigmata; 7,8 , sclerotia; 9 , natural size of the fungus (Wehmer).

organism has also been found in the ear and in lesions in the lungs.

\section{Other Species of Aspergilli}

Several other species of Aspergilli have been reported as pathogenic. Among them are Aspergillus nigrescens, A. subfuscus, and $A$. glaucus. These produce nodular mycotic foci in the internal organs of laboratory animals into which they have been injected. They do not commonly produce infection under natural conditions.

\section{The Genus Penicillium}

Penicillium is closely related to Aspergillus, the principal difference being the manner in which the asexual spores or conidia are borne. The conidiophores are erect, and much branched at the tip, the branches arising in whorls and are not enlarged at the apex. From the end of each ultimate branch a chain of spores is abjointed, 
giving to the organism under the microscope the appearance of being covered with little brooms. The sexual stage is essentially similar to that of Aspergillus. Penicillia are even more common than the Aspergilli. They occur as blue or green molds upon fruit, and upon a great variety of decaying materials. Of the hundreds of species of Penicillium that have been described, the majority
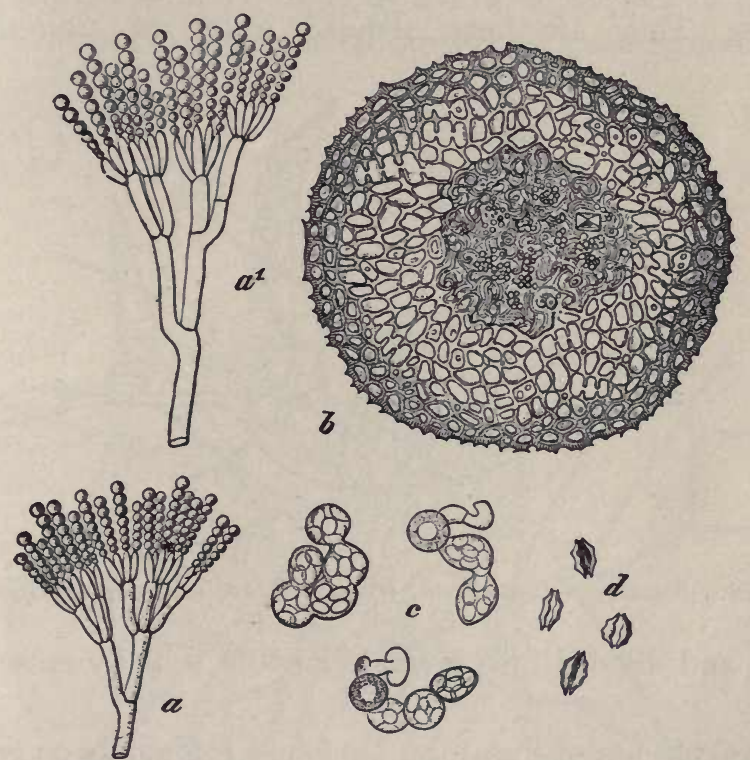

Fig. 177.-Penicillium glaucum: $a, a^{1}$, Tips of conidiophores showing the characteristic method of branching and the chains of spores; $b$, perithecium; $c$, asci; $d$, ascospores (Brefeld).

are green or bluish-green in color, but white, gray, yellow, orange, and brown forms are known.

None of the species of Penicillium are known to be harmful, but their constant presence in moldy silage and grain which has poisoned animals makes it necessary to consider them in any discussion of forage poisoning.

\section{THE GENUS FUSARIUM}

The members of this genus are nearly all saprophytes or plant parasites. Fusarium is included among the Fungi imperfecti, as a sexual or perfect stage is unknown in the life history of most 
of the species. Webber has found an ascus stage in one species, and concludes that the genus Necomospora of the Ascomycetes is the perfect form; in other species it is the genus Gibberetta.

Fusarium is characterized by its loose, spreading, cottony mycelium with numerous cross walls, $i$. e., septate. The conidiophores are not markedly different from the sterile hyphæ, and are usually branched. The conidia are borne at the tips of these branches. They are long, slender, sickle or crescent-shaped

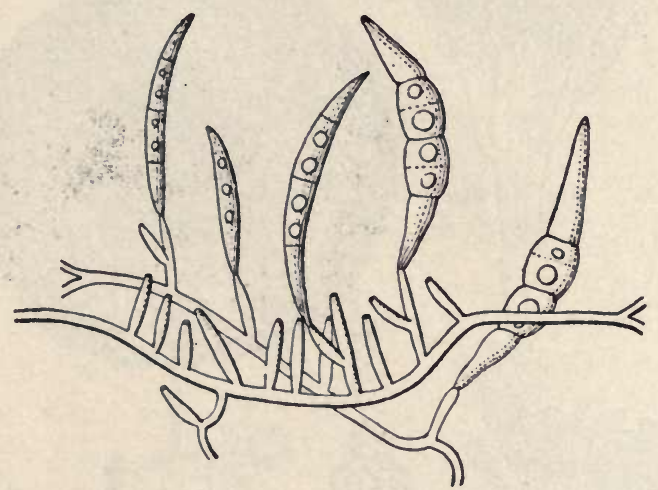

Fig. 178. - Fusarium corallinum, conidiophores and conidia (Saccardo).

usually, and divided into several or many cells by cross walls or septa.

Several species of Fusarium are found commonly on grains and moldy corn. This fungus has been believed by some investigators to be of significance in forage poisoning. It is one of the several forms which must be considered in a determination of the poisonous properties of forage.

One species, the Fusarium equinum, is believed to produce dermatitis in the horse.

\section{Fusarium equinum}

Disease Produced.-Itch disease, associated with sarcoptic dermatitis.

Norgaard, in 1901, noted the presence of a Fusarium in a dermatitis of horses in the State of Oregon, and proposed the name Fusarium equinum for the fungus. Melvin and Mohler later studied the disease in greater detail. The disease has been re- 
ported only from this one locality, but in this instance affected several thousand horses on the Umatilla Indian reservation.

Morphology.-The mycelium upon culture-media is septate and branched. Three forms of spores are produced. The microconidia are small and oval, one- or two-celled. The macroconidia are large, sickle-shaped, three to five septate, and pointed at the ends. They are 25 to $55 \mu$ long by 2.5 to $4.5 \mu$ wide. Chlamydospores are formed in the mycelial threads by a cell rounding up to

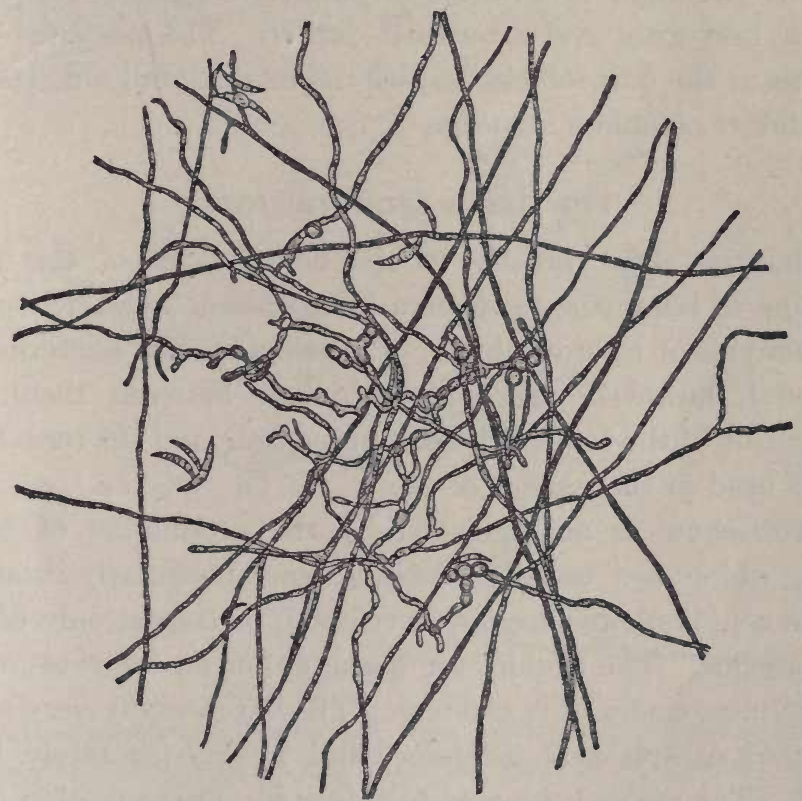

Fig. 179.-Fusarium equinum, mycelium and conidia (Melvin and Mohler, Bureau of Animal Industry).

a diameter of 8 to $15 \mu$ and becoming densely granular. The spores may be recognized in the hair-follicles of the diseased animals.

Isolation and Culture.-No difficulty was experienced in securing a growth of the organism on artificial media. The more favorable media are potato and bread, but good growth will take place on glucose or plain agar. The growth is white and cottony, and the spores are produced in abundance.

Pathogenesis.-Inoculation experiments were unsuccessful, so 
that the evidence of pathogenesis rests entirely upon the constant occurrence of the organism in the disease in question. Itchmites (Sarcoptes equi) were found, but the investigators believe their numbers insufficient to account for the disease. It is entirely possible that the organism is a secondary invader, or produces the disease in a kind of symbiotic relationship with the Sarcoptes. The fungus seems to enter the hair-follicles, penetrates between the epidermal cells, and involves the surrounding skin, causing an intense itching. The body becomes covered with a crust or scurf, at first gray and afterward darker. The presence of the organism in the hair-follicles causes the hairs to fall out, resulting in an almost complete alopecia.

\section{THE GENUS SPOROTRICHUM}

Authorities differ greatly in the delimitation of this genus. According to botanists, the genera Microsporon and Trichophyton are synonyms of Sporotrichum. Pathologists and bacteriologists in general, however, make a distinction between them. The classification of the latter will be adopted here and the term Sporotrichum used in the narrow sense.

Sporotrichum is distinguished by the production of definite hyphæ, which are usually creeping and irregularly branched. Definite conidiophores are not developed, or consist only of small side branches. The conidia are borne either on the sides or ends of the hyphæ, singly or in clusters. They are usually very numerous, ovoid or spherical in shape, and hyaline or rarely lightly colored. The molds belonging to this group are in need of careful study and revision, as there is great uncertainty concerning many of the species.

One, or possibly two, species of Sporotrichum have been shown recently to be of considerable pathogenic significance.

\section{Sporotrichum beurmanni}

Synonym.-Possibly Sporotrichum schenkii.

Disease Produced.- Sporotrichosis in man and animals, one type of epizoötic lymphangitis in horses.

Schenk, in 1898, and Hektoen and Perkins, in 1900, described a species of Sporotrichum causing multiple abscesses in man. 
de Beurmann, in 1903, described similar forms from France. The disease has been reported in man and rats from Brazil, from man in California, Argentina, Germany, and in the horse in the United States and Madagascar. This disease is probably quite wide-spread, but has not been recognized, or has been confused with others, until recently. It is to be differentiated sharply from the true epizoötic lymphangitis of the horse. An excellent discussion of the organism in its relation to disease in the horse was contributed by Page, Frothingham, and Paige in 1910.

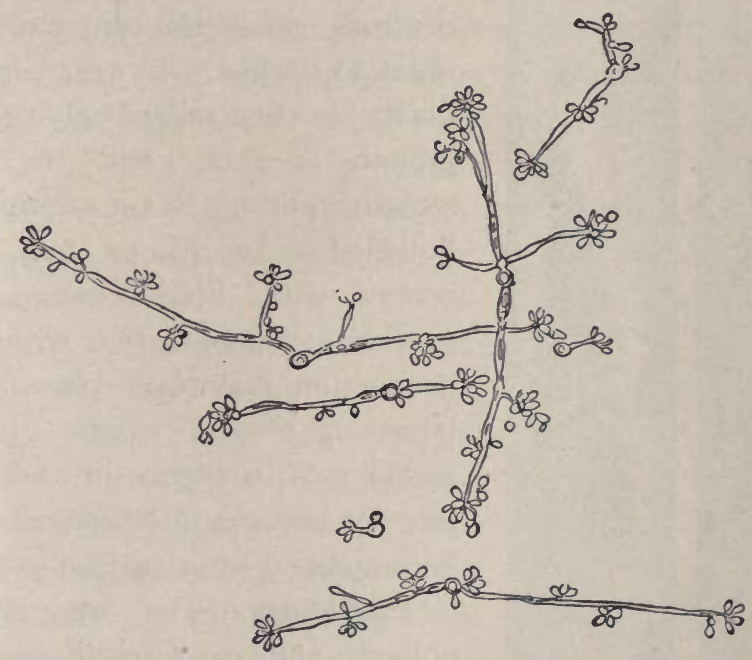

Fig. 180.-Sporotrichum beurmanni, from culture showing the mycelium and spores (Page, Frothingham, and Paige, in "Journal of Medical Research").

Morphology.-The examination of the material from culture is most easily made in a hanging drop. The hyphæ are slender and septate. Spores or conidia are borne at the tips of side branches; usually a number are formed successively and are found then in clusters. The conidia are small, oval or spherical. They frequently bud to some extent, and resemble somewhat the cells of Blastomyces. The hyphæ stain easily with the common anilin dyes and are gram-positive. In using the latter stain the alcohol must not remain too long in contact, otherwise the stain will be removed. Whether or not the organism ever develops a perfect or sexual stage is not known, but it does not seem probable. 
Isolation and Culture.-The organism may readily be isolated from pus from the lesions. Potato is the most favorable medium. Original isolations show at the end of a week, transplants at the end of two or three days, as white, filamentous colonies. These enlarge, become darker at the center, and finally turn dark brown or black, frequently surrounded by a rim of white. The colony becomes wrinkled. Upon gela-
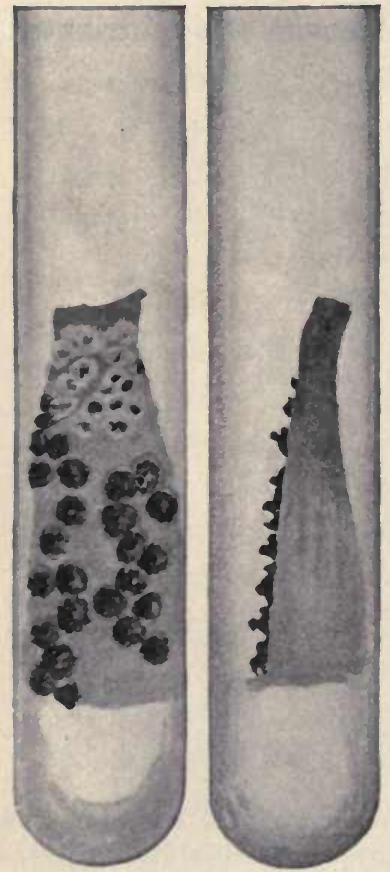

Fig. 181. - Sporotrichum beurmanni, cultures and colonies on potato (Page, Frothingham, and Paige, in "Journal of Medical Research"). tin the growth remains white. Liquefaction begins in from three to ten days or even later. The addition of dextrose causes the center of the colonies to darken. In agar, and particularly in neutralized glycerin agar, growth is good, and the colonies remain white. Blood-serum is not liquefied. In litmus milk growth occurs with little change in the medium, or coagulation without acid production may take place after the lapse of several weeks. In liquid media growth occurs in the form of more or less separated colonies, usually accompanied by a surface pellicle.

Physiology.-The organism is an obligate aërobe. Growth occurs best at $25^{\circ}$ to $28^{\circ}$, but is not prevented at $37^{\circ}$. The spores resist desiccation for considerable periods. Acid is produced from dextrose, but not from lactose, maltose, saccharose, mannite, dulcit, adonit, inulin, or raffinose. Gas is not produced from any sugar. No indol is formed. Gelatin is slowly liquefied. The organism is destroyed at a temperature of $60^{\circ}$ for five minutes.

Pathogenesis.-Experimental Evidence.-There is an abundance of evidence that Sporotrichum beurmanni is pathogenic for man and animals. Accidental laboratory infections have taken place in 
man. Inoculation of pure cultures into mice and white rats gives rise to abscesses at the point of inoculation, and the infection gradually extends. Guinea-pigs and rabbits are infected with greater difficulty. An infection somewhat resembling farcy develops upon inoculation into the horse.

Character of Disease and Lesions Produced.-The infection is usually benign in character in the horse. There is no fever reaction during the course of the disease. Nodules develop which are generally spherical and sharply delineated. These nodules scarcely rupture, but pus accumulates at the center, the skin above is thinned and softened, serum exudes from the surface, the hair is loosened, and a crust holding the hairs together is formed. The ulcers are crateriform, and usually contain a little creamy pus. Healing is accomplished by granulation. Sections of nodules from laboratory animals reveal the organism in the tissues.

Immunity.- No toxins have been demonstrated for this organism. Widal has shown the presence of agglutinins for the spores in the blood of infected individuals. No method of immunization, based upon the organism or its products, has been developed.

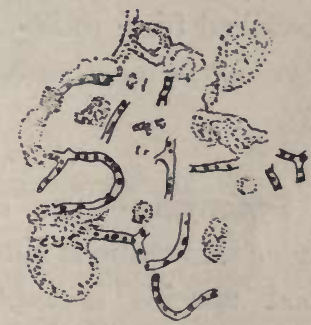

Fig. 182. - Sporotrichum beurmanni, in a section of a mesenteric abscess of a rat (adapted from Fielitz).

Bacteriological Diagnosis. - This may be accomplished by animal inoculation, thus securing the organism in pure culture. Widal claims that the agglutination of spores will take place in dilutions as high as 1:800, but the same reaction takes place in lower dilutions with the blood-serum of individuals having actinomycosis. Bloch found that a bouillon filtrate from an old culture would in man give the von Pirquet cutaneous reaction, as was described in the chapter on Bacillus tuberculosis.

Transmission.- The disease is transmitted by intimate contact usually. It has been found to be transferred from animals to man. Probably the organism usually gains entrance through abrasions of the skin. 


\section{THE GENERA TRICHOPHYTON AND MICROSPORON, ACHORION, AND OÏDIUM}

The organisms belonging to the two genera, Trichophyton and Microsporon, are frequently included together under the single genus Sporotrichum. The two names, Trichophyton and Microsporon, are also used very loosely and interchangeably. A careful study of the relationships of the various forms is needed.

No very clear differentiation of this group from the preceding can be given.

Organisms belonging to these genera are the cause of many skin and hair infections in man and animals. Pityriasis versicolor, or tinea versicolor, in man is caused by Microsporon furfur (Sporotrichum furfur); herpes tonsurans, or ringworm in man and lower animals, by Trichophyton tonsurans. Other species have been described from most of the domestic animals and birds, but they have not in most cases been sufficiently defined and differentiated.

\section{Trichophyton tonsurans}

Synonyms. - The synonymy of the various forms included under this name is almost inextricable. Probably more than one good species is represented. The commoner synonyms are Trichophyton microsporon; Tr. megalosporon; Microsporon adouini; M.equinum; M. carinum; Sporotrichum tonsurans; S. adouini, and many others.

Disease Produced.-Herpes tonsurans, or ringworm, in man, goat, sheep, pig, horse, cat, and dog.

The organism was originally described by Gruby in 1842. In its various forms it is world wide in distribution.

Morphology.-The hyphæ are relatively slender, septate; the spores are numerous in the hairs and scales. They vary in the different types described from 2 to $8 \mu$ in diameter. Chlamydospores are produced in artificial media.

Isolation and Culture.-Pure cultures are secured with difficulty, as the skin and hair are generally filled with bacteria which overgrow the mold. Kral has suggested pulverizing hairs with fine sand or silicon powder and pouring gelatin plates of various dilutions. Kitt has taken advantage of the resistance of the organism to destruction by alkalies by washing the hairs and 
scales from an infected area with a solution of $\mathrm{KOH}$, which removes most of the bacteria without materially injuring the mold spores. Potato is a favorable medium for growth. A rather velvety, wrinkled, relatively heavy, membrane forms which may be white or colored. Gelatin is slowly liquefied.

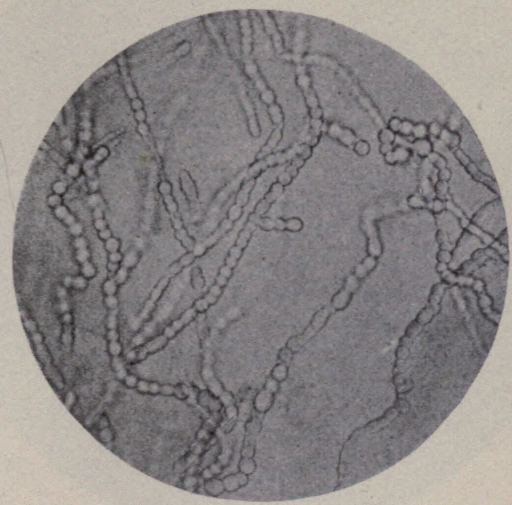

Fig. 183.-Trichophyton tonsurans from agar plate culture (Günther).

Pathogenesis.-The disease in all animals is characterized by the formation of scales, the falling out of hair, with or without suppuration. It is well demonstrated that it can spread from one species of animal to another by contact.

\section{Achorion schoenleinii}

Synonyms.-Ö̈dium porriginis; Oöspora porriginis, and many described species of Achorion. Opinions differ as to whether one polymorphic species or many species are represented.

Diseases Produced.-Favus, tinea favosa, in man, animals, and birds.

The organisms grouped under this name have been separated into a large number of species by some investigators. Doubtless more than one species should be recognized, but they have not been sufficiently differentiated.

Morphology.- The organism is made up of more or less branched hyphæ, 3 to $5 \mu$ in diameter. Spores are formed by the breaking up of the filaments into oval or somewhat cubical spores, 3 to 8 
by 3 to $4 \mu$ in diameter. The mycelium may be quite luxuriant in the skin.

Pathogenesis. - The disease is characterized by the formation

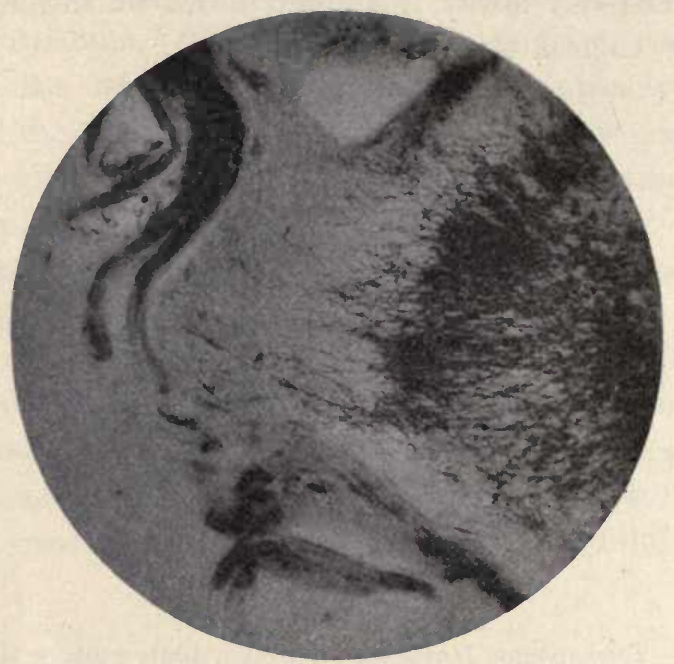

Fig. 184.-Achorion schoenleinii, section showing the hyphæ (Fränkel and Pfeiffer).

of seales upon the skin, often accompanied by a disagreeable odor. It may be communicated from one species of animals to another.

\section{Oïdium albicans}

Synonym.-Monilia candida.

Disease Produced.- Thrush in infants; sometimes in the young of animals.

Berg, in 1840, described this organism as the cause of thrush. It has since that time been repeatedly isolated and cultivated. It is known from most civilized countries.

Morphology.-The mycelium of this organism is poorly developed; frequently the whole growth consists of budding yeastlike cells. These may be spherical, elliptical, oval or cylindrical, the shorter cells about $4 \mu$ in diameter by 5 to $6 \mu$ in length. The hyphal threads are much longer. There ean be little differentiation in many cases between the conidia and the cells of the hyphr, but, on artificial media, the conidia are frequently definitely ad- 
jointed from the tip of the conidiophore. Chlamydospores may form in the hyphæ.

Isolation and Culture.-The organism may be isolated without difficulty from the lesions of the disease. A distinctly acid medium should be used. On most nutrient media it develops superficial, spherical, white, waxy to granular colonies. Gelatin is not liquefied, nor is blood-serum.

Pathogenesis.-The organism, when injected intravenously into rabbits, produces a fatal infection, not unlike a generalized infection with a Blastomyces. Typical thrush has been produced in the mouth of young animals and birds by inoculation. The disease generally occurs in the mouth of sucklings, usually as a benign infection. It is characterized by the formation of white patches on the murcous membrane, varying in size from points to considerable areas. The infection may extend to the pharyngeal or laryngeal mucosæ; rarely metastatic infection of internal organs may occur. 


\section{SECTION V}

\section{PATHOGENIC PROTOZOA}

\section{CHAPTER XXXIX}

\section{STRUCTURE, RELATIONSHIPS, AND CLASSIFICATION OF THE PROTOZOA}

A protozon may be defined as a unicellular organism belonging to the animal kingdom. Protozoa exist throughout their life-history as single-celled individuals, or as colonies of single cells; that is, the cells are not united to form tissues or organs, and never constitute a portion only of a multicellular form.

The protozoa show some forms which intergrade with the bacteria. The group containing the spiral forms, such as the Spirochæta, is at present a questionable one, some investigators believing that it has more bacterial than protozoan characteristics, others taking quite the opposite view. It is difficult, on the other hand, to draw a sharp line of demarcation between the protozoa and the multicellular animals or metazoa. Just when a group of cells ceases to be a mere group of independent units, and becomes a tissue which forms the whole or part of a multicellular form, it is difficult to determine.

Although the protozoa are regarded as the simplest and most primitive of living things, nevertheless many are complex in structure and have the cell divided into specialized parts, sometimes termed organella, somewhat similar in function to the organs of the higher forms. They frequently undergo many changes in form during their life. Their life-history is, therefore, relatively complex as compared with that of the bacteria.

Structure of the Protozoa.-The body substance of a protozoan may be divided into the ectoplasm, or outer layer, which comes into 
contact with the material environment, and the endoplasm, within. Within the endoplasm there is generally a nucleus (in some forms two, a large and a small), and frequently inclusions of other sorts.

The ectoplasm in some cases cannot be differentiated sharply from the endoplasm. These are the exception, however, and not the rule. The ectoplasm may become variously modified, and, by secretion, form shells or a heavy membrane for protection. Many of the pathogenic protozoa become encysted by the formation of a heavy, chitinous wall.

The endoplasm is made up of a very delicate, foam-like or alveolar structure, the density of which varies greatly. It may inclose amorphous granules or crystals of different kinds, green granules or chromatophores, vacuoles, etc.

None of the protozoa are certainly known to be entirely destitute of nuclear material. The nucleus may be devoid of a nuclear membrane or distributed; generally a membrane is present. A single homogeneous nucleus is present in most forms, with the exception of the infusoria, which have, in general, a large or macronucleus and a small or micronucleus. At some stages in the life-history many nuclei may be present in a single cell. This is particularly true just before or during spore formation.

The protozoa with few exceptions are motile, at least during certain stages in the life history. The exceptions are among certain of the parasitic Sporozoa. Special organs of locomotion are frequently found. Pseudopodia are changeable processes of the protoplasm which are thrown out by the cell, the cell contents frequently flowing forward into the pseudopodia. Many or few may be present at one time. They may be short and blunt or long and slender. Usually the endoplasm as well as ectoplasm takes part in their formation. The protozoan flagella are derived from the ectoplasm; are usually unchangeable in shape, long, thin, and pointed; in general, longer than the cell itself. One, two, or many may be present. They propel the cell by a series of undulations or spiral or rotary motions. Cilia, when present, are found in considerable numbers. They are shorter, generally blunt, and, by striking the water in unison, resemble oars in their motion. 
The life histories of the various protozoa show such complexities that they may better be treated under the separate subdivisions.

Classification of the Protozoa.-Authorities are not in entire accord with reference to the principal subdivisions of the protozoa. The classes here used are those given by Calkins in "The Protozoa." The definitions of the groups here given will not hold in all cases for non-parasitic forms.

\section{Classes of ProtozoA}

A. Motile in adult life by means of pseudopodia. Reproduction by simple division and by spore formation. I. Sarcodina or Rhizopoda.

B. Not possessing pseudopodia in the adult form.

(1) Adult motile by means of-

a. Flagella. With one nucleus. II. Mastigophora.

b. Cilia. Two types of nuclei. III. Infusoria or Ciliophora.

(2) Adult forms non-motile. Reproduction by spores. IV. Sporozoa.

Pathogenic organisms belonging to each of the four classes are known. These will be treated under separate chapters. 


\section{CHAPTER XL}

\section{PATHOGENIC PROTOZOA OF THE CLASS SARCODINA (RHIZOPODA) .}

The Sarcodinæ (Rhizopodæ) are protozoa having during adult life movable or changeable processes of protoplasm called pseudopodia. Reproduction is accomplished through simple fission and by spore formation.

Among the hundreds of genera and thousands of species of organisms belonging to this group that have been described there

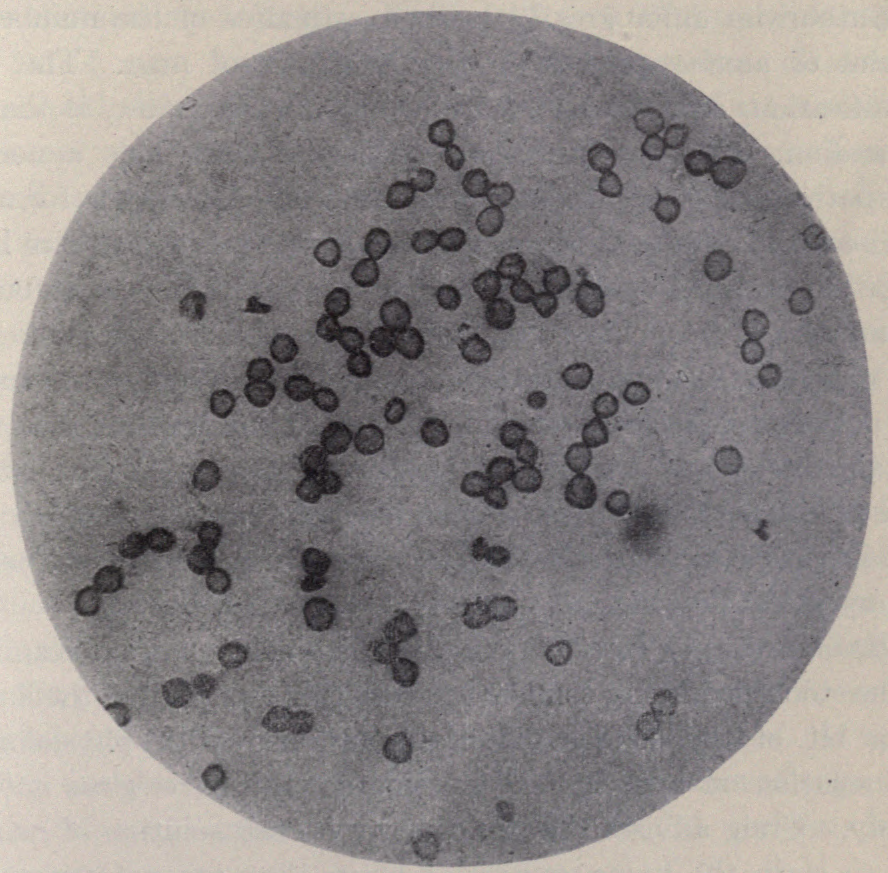

Fig. 185.-Ameba in culture (Schardinger).

is one (possibly two or three) which has been found to be pathogenic. They are certainly known to be pathogenic in man only, 
but the frequent occurrence of the organisms of this genus in the intestines of the lower animals, and the possibility of confusing the adult stage with certain developmental stages of the sporozoa, renders a discussion of these forms advisable in a veterinary text. The possibility of any of the forms being pathogenic for lower animals has not been sufficiently investigated.

\section{THE GENUS ENTAMOEBA}

The normal inhabitant of the intestinal tract of man was first known as Amoba coli. Later, Schaudinn renamed it Entamoba coli, and gave the name Entamaba histolytica to the pathogenic type associated with the amebic dysentery. The genus Entamœba was differentiated from Amœba by the absence of a contractile vacuole and the formation of multinucleated cysts.

Authorities differ greatly in their estimates of the number of species of amebæ present in the intestines of man. The best classification, and the one most commonly used now, is that of Schaudinn. He recognizes two species at least-one a normal non-pathogenic form, Entameba coli, and one pathogenic for man, Entameba histolytica. More recently Hartmann and others have described a third species, E. tetragena, and Koidsumi a fourth, E. nipponica, both from cases of dysentery. The possibility of any of the dysenteries of the lower animals being caused by amebæ has not been sufficiently studied. It was at one time believed that certain diseases of turkeys and other fowls, particularly enterohepatitis, were caused by an ameba termed Amoba meleagridis, but this has been shown to be but a developmental stage in the life history of a Coccidium.

Examination of Living Amebre.-The amebæ may be examined in the stools in a living condition, by placing a portion of the liquid, or a bit of the solider material moistened with physiological salt solution on a slide, and pressing down a cover-glass not too firmly. Craig advises the use of a very weak solution of neutral red to stain the living organisms when they are not present in too great numbers. For the specific determination of the amebæ present an examination of this kind is frequently all that is necessary. The slide must be maintained at about blood heat in order to detect motility. 
Staining Methods.- The organisms stain rather readily with the usual laboratory stains, but these are of little value in the differentiation of the parts of the cell and in separating species. Wright's stain in favorable specimens, if carefully used, gives the best differentiation of the parts of the cell. The organism in tissues is best stained by Heidenhain's iron-hematoxylon or Borrel's stain. The smears should be fixed from fifteen to twenty minutes in alcohol and ether, equal parts, for all stains but Wright's. For the latter no fixation is required.

Methods of Isolation and Cultivation.-Amebæ commonly use bacteria and related organisms as food. A culture of amebæ must provide for the growth of bacteria, but this growth must not be so luxuriant as to overgrow and eliminate the amebæ. The agar medium recommended by Musgrave and Clegg may be used. This contains agar, $20 \mathrm{gm}$.; $\mathrm{NaCl}, 0.03$ to $0.05 \mathrm{gm}$.; beef-extract, 0.3 to $0.5 \mathrm{gm}$.; water, 1000 c.c., made 1 per cent. alkaline to phenolphthalein. Variations in the materials used are sometimes necessary for some specialized saprozoites. This medium is melted, poured into a sterile Petri dish, and allowed to solidify. The surface of the medium is streaked with the material containing the amebæ. The bacteria and amebæ will usually both multiply if the plate be kept at a suitable temperature. Two operations are necessary to secure a culture in which it is known that all of the amebæ are of one species and all of the bacteria of one kind. The mixed culture is placed upon the medium in the center of the Petri dish. Concentric circles of the organism with which it is desired to grow the ameba are placed about this. The amebæ, as they crawl through the successive circles, gradually lose the original organisms with which they started and come to feed on the one kind. After one or more transfers a growth of the amebæ may be secured with the one species of organism desired. It is not always possible to secure growth with every species of organism, as the different amebæ have been found to require various species of bacteria.

In order to secure a culture containing a single kind of ameba, it is necessary to isolate a single individual. Ordinarily this may be accomplished by examination of the surface of an agar culture until an isolated ameba is found, and this is then transferred to a 
fresh plate. Musgrave and Clegg recommend running the tip of the lens against such an organism and removing it, attached to the lens, and inoculating the new medium by running the lens down in contact with it.

\section{Entamoba coli}

Synonym.-A moeba coli.

Disease Produced.-The organism is probably non-pathogenic.

The Entamoba coli was probably seen and recognized by Lambl in 1860 . Since that time it has been repeatedly noted by many investigators. Schaudinn, in 1905, first clearly differentiated the organism and traced its life history. His work has been confirmed and extended by Craig in the United States. The organism is present in a large percentage (50 per cent., according to Schaudinn) of healthy individuals. It is most easily recognized in the feces after the administration of a saline cathartic.

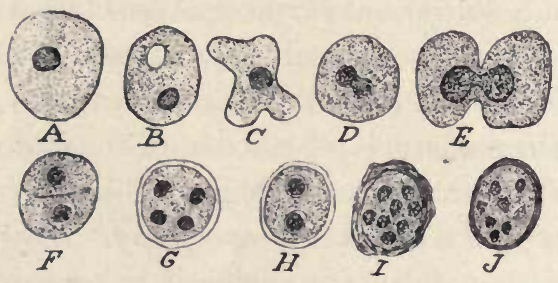

Fig. 186.-Entamœba coli: $A$, Non-motile form; $B$, cell showing pseudopodia; $D, E$, stages in cell division; $F, G, H, I, J$, stages in encystment and sporulation (adapted from Craig).

Morphology.- The $E$. coli is a mass of protoplasm not possessing a definite cell-wall, but with a nucleus containing usually one or more nucleoli. One (rarely more) non-contractile vacuole is occasionally present. The organism varies from 8 to $50 \mu$ in diameter, but in the majority of cases is between 10 and $20 \mu$. When encysted, it is usually between 10 and $15 \mu$. The organism is approximately spherical when not in motion. It is sluggishly motile, and usually is not moving when observed in a hanging drop. In this it is of a dull gray color. The protoplasm cannot be differentiated into endoplasm and ectoplasm when the organism is at rest. When in motion, the ectoplasm may sometimes be seen. This fact is of considerable diagnostic value. The endo- 
plasm is finely granular, and rarely contains more than a single vacuole. The nucleus is definite, spherical, and contains chromatin granules and one or more nucleoli; it is 5 to $8 \mu$ in diameter. When stained by Wright's method, the ectoplasm and endoplasm may be easily differentiated. The ectoplasm stains blue, the endoplasm violet, and the nucleus red.

Multiplication is commonly accomplished in the intestines by simple division. The nucleus divides and the protoplasm constricts to form two individuals. This process is common in the liquid stools, but, when drier and firmer, cystic reproduction is more common. A refractive hyaline cyst forms about the spherical organism, and thickens. The protoplasm becomes homogeneous in appearance and clearer than before. The nucleus then undergoes complicated divisions and recombinations, which ultimately result in the formation of eight nuclei. When the wall is ruptured these nuclei, with bits of the protoplasm, escape and constitute eight young amebæ.

Pathogenesis.-Repeated efforts to produce disease by injection of Entamceba coli into the colon of cats and other animals have failed. It must be regarded as a normal inhabitant of the intestines of man. Similar organisms have been found in the intestines of animals.

Bacteriological Diagnosis.-Entamœba coli may be recognized in the feces by a direct microscopic examination as an ameba showing very slight motility, rounded pseudopodia, little or no observable differentiation between ectoplasm and endoplasm, comparative lack of vacuoles in protoplasm, and by the production of eight daughter-cells from each cyst.

\section{Entamœba histolytica}

Synonym.-A moba dysenterice.

Disease Produced.-Amebic dysentery in man.

Loesch, in 1875, described Amœba coli as the cause of a dysentery in man, and claimed that the rectal injection of feces containing the organisms into dogs produced dysentery. Robert Koch, in 1883, showed the organism to be present in the ulcerations of the intestines. Kartulis firmly established a probable etiological relationship by his studies in Egypt, published in 1886 . 
Councilman and Lafleur studied the pathology of the disease in great detail. Schaudinn gave to the organism its present name of $E$. histolytica, and described its morphology with accuracy.

The disease has been reported from all sections of the world. It seems to be much more prevalent in tropical than in temperate climates, but has been identified repeatedly in the United States.

Morphology.-According to Craig, the morphology of this organism varies so greatly in culture-media that only the forms found in the feces can be regarded as typical. The organism under

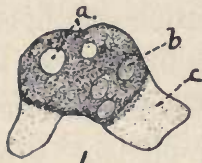

I.

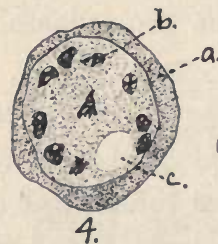

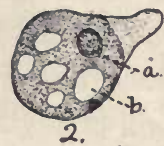

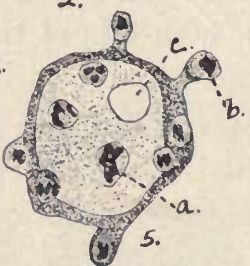

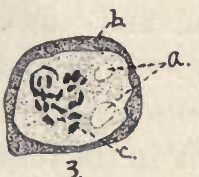

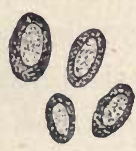

6.

Fig. 187.-Entamceba histolytica: 1, Organism in motion- $a$, Vacuoles; $b$, red blood-cells; $c$, pseudopodium composed chiefly of ectoplasm. 2. Organism showing nucleus $a$, and vacuoles, $b$. 3. Preliminary changes upon beginning sporulation- $a$, Vacuoles; $b$, chromatin masses escaping from the nucleus and scattering through the cell. 4, Chromatin masses scattered through the cell, $b$; $c$, vacuole. 5, Cell budding off spores, the chromatin masses or new nuclei passing through the ectoplasm and escaping as spores. 6, Free spores (adapted from Craig).

these conditions varies in diameter to $50 \mu$ or more, showing it to be larger than $E$. coli. At rest, the organism is spherical or ovoid; when in motion, its shape is extremely variable. It is usually actively motile, throwing out pseudopodia much more rapidly than $E$. coli.

Color is absent, and the organism appears clear, or there may be a greenish tinge, due to the presence of hemoglobin from the blood in the feces and the blood-corpuscles engulfed. In the larger cells, rarely in the smaller, the endoplasm and ectoplasm may be quite sharply differentiated. The latter is hyaline, 
glasslike, and refractive, much firmer than the comparatively delicate membrane of $E$. coli, and the two are relatively easily distinguishable by this means. The ectoplasm apparently comprises about one-third of the protoplasm. One or more vacuoles are always present, as many as ten sometimes being found. The nucleus is faint and difficult to distinguish in the unstained mount. It is about 5 to $6 \mu$ in diameter. The chromatin is relatively sparse. With Wright's stain the ectoplasm stains more deeply than the endoplasm, the opposite of what is true in $E$. coli.

Reproduction is accomplished in two ways. The first consists of a division of the nucleus, followed by a constriction of the cell to form two individuals. This process is essentially the same as that in E. coli. The method of spore formation, gemmation, or budding, is quite different. When conditions arise unfavorable to continued vegetative existence, spores'are produced. The nucleus, by a process of fragmentation, throws out chromatin granules or chromidia, which gradually collect under the ectoplasm, form new nuclei, and are finally thrown off from the exterior, together with some of the protoplasm, as a spore or bud. These spores are round or oval, have a yellowish membrane, and measure 3 to $6 \mu$, usually about $4 \mu$, in diameter. The membrane which forms about these spores is resistant to the penetration and action of stains.

Pathogenesis.-Experimental Evidence.-Schaudinn dried feces of dysentery patients after demonstrating that they contained $E$. histolytica, in the form of spores in large numbers, and that they were free from $E$. coli. These were fed to a kitten, and death resulted in fourteen days, with characteristic ulceration of the intestinal wall. Similar experiments have since been repeated many times. There is little or no doubt of the pathogenicity of the organism, and the disease produced may be considered as a clinical entity.

Character of Disease and Lesions.- The disease produced is a chronic dysentery, marked by intestinal ulceration, and frequently by abscesses in the liver. The presence of the relatively firm ectoplasm is believed to account for the ability of the organism to force its way into the tissues between the cells. 
Immunity.-No method of immunization against the $E$. histolytica has been developed.

Bacteriological Diagnosis.-The $E$. histolytica may be recognized in the feces, and separated from the $E$. coli by its larger size, its distinct differentiation into a hyaline refringent ectoplasm and a more granular endoplasm, the presence of more than one vacuole usually, the common presence of erythrocytes in the protoplasm in the course of digestion, by the less prominent nucleus, and by formation of spores by a process of budding with encystment.

\section{Entamceba tetragena}

Synonym.-Entamoeba africana.

This species was first described by Viereck in dysentery in Africa. Since that time the same organism has been noted by Hartmann, Werner, and others. It has been found capable of producing dysentery in cats. It resembles morphologically the Entamaba coli more closely than the $E$. histolytica, but differs by the formation of four spores instead of eight within the cysts. 


\section{CHAPTER XLI}

\section{PATHOGENIC PROTOZOA OF THE MASTIGOPHORA}

\section{(Exclusive of the Spirochetes)}

THE pathogenic forms of the class Mastigophora differ from the preceding in that they do not possess pseudopodia. In most cases the organism has a relatively definite form. The cells are motile by means of one or many flagella.

This class contains many hundreds of species distributed among many genera and families. Most of these are non-parasitic. Many species are commensals in the intestines of man and animals, and have been suspected of producing intestinal disorders.

The protozoan genera, Spirochæta, Treponoma, and Spiroschaudinnia, probably belong with the Mastigophora, and show some distinct resemblances to the genus Trypanosoma. Their position among the protozoa, however, is challenged by many bacteriologists. They are, therefore, treated as a separate group in the succeeding chapter.

(1) Cell-bodies a flexuous, narrow spiral ......Spirochota (Chapter XLII).

(2) Cell-bodies not as (1):

An undulating membrane and terminal flagellum

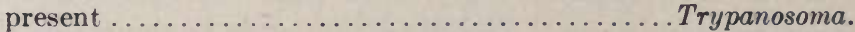
Undulating membrane not present............... Herpetomonas.

\section{THE GENUS TRYPANOSOMA 13 ady}

The first recorded observations of trypanosomes are those of Valentine, who saw them in the blood of a salmon in 1841. Numerous observers found similar organisms in the blood of other fish, reptiles, and batrachia. Lewis, in 1878, observed the first trypanosome of mammalian blood in the rat. Evans, in 1880, noted them in the blood of animals infected with surra, and believed them to be the cause of the disease. Bruce, in 1894, de- 
scribed another form from Africa as the cause of nagana or tsetsefly disease. Since that time the number of known species has increased rapidly. A small proportion only of those described are known to be pathogenic. Among the pathogenic forms, however, are to be found those that are among the most serious hindrances to the development of a live-stock industry, and even to human habitation in certain countries.

Morphology.-Trypanosomes usually are elongated cells, more or less spindle-shaped, rarely almost as broad as long, but always tapering more or less to the ends. Most of the pathogenic forms that have been described are several times as long as broad when observed in the blood. The anterior end of the cell is tipped with a

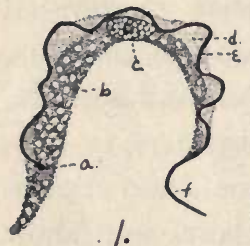

1.
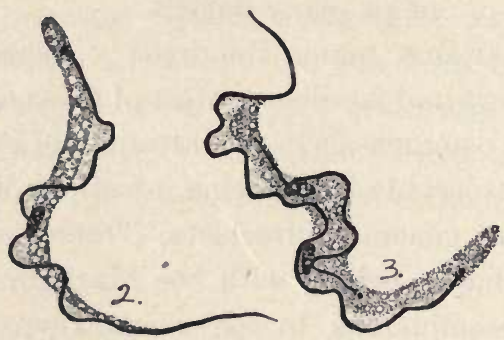

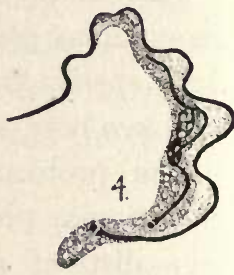

Fig. 188.-Trypanosoma equiperdum, morphology of the trypanosome: 1, A rather thick, short trypanosome- $a$, Blepharoplast; $b$, protoplasm (cytoplasm); $c$, nucleus; $d$, undulating membrane; $e$, flagellum attached to the edge of the membrane; $f$, anterior extension of the flagellum. 2, A longer cell. 3,4 , Trypanosomes in process of longitudinal division (adapted from Gonder and Sieber).

flagellum. Along one side, extending longitudinally on the cell, is a thin membrane. The flagellum extends along this membrane and forms its outer edge. The flagellum finally terminates in the cell-protoplasm near a granule which stains deeply. This granule may be situated in various parts of the cell, but is usually in the posterior portion. Its relative position is one of the characters used in the differentiation of species. It has been called by various names, as micronucleus, kinetonucleus, motor nucleus, centrosome, and blepharoplast. This last name is to be preferred, as it is the one that is most frequently used in the descriptions, and is commonly used for similar structures found in many other flagellated protozoa. The flagellum is, in part, therefore, em- 
bedded in the protoplasm, in part is attached to the edge of the undulating membrane, and in part is free at the anterior end. A nucleus, usually situated near the center or anterior end, may be demonstrated in stained preparations. It is relatively large and granular in structure. The entire body of the trypanosome is mobile, and the organism may vary its shape to some degree. It swims about with the flagellum in front.

Multiplication is accomplished by a preliminary division of the blepharoplast, followed by that of the nucleus, and this by a longitudinal splitting of the cell to form two individuals. In cultures the cells may frequently be observed in the form of rosettes or clusters, with the flagellar ends pointing out. These rosettes do not occur in the blood. Transverse division does not occur. No conjugation or fertilization process in trypanosomes has been certainly detected.

Some investigators have believed that trypanosomes in the animal body may have an ultramicroscopic stage in their development. Bruce and Batemen, in a series of careful experiments, have shown that this does not occur.

The existence of a regular cycle of changes in the life of a trypanosome is at present a somewhat mooted question. Some investigators believe that they have established the existence of a relatively complex life cycle. Kleine, Bruce, and others believe that certain species of insects which transfer the disease must be considered true hosts, and that they do not become infective for some days - in the case of Tr. gambiense about twentyafter biting an infected individual. Rodenwalt and others have found that certain developmental changes take place in the gut of the insect; others have failed to find them. At present it may be concluded that the occurrence of developmental changes has not been satisfactorily demonstrated, although there is good reason to believe that such may occur. Carimi, Schaudinn, and others have recognized what they believe to be an endoglobular stage in the development of the organism in the body. Battaglio claims to have demonstrated for $\operatorname{Tr}$. brucei, Tr. lewisi, and Tr.vespertilionis, a developmental cycle in the blood, which includes sporulation of micro- and macrogametocytes, with formation of micro- and macrogametes. These conclusions have been combated by others. 
Not all trypanosome infections are transmitted through insects. Certain transformations have been noted with some forms in the body itself. There is no evidence that an insect can transfer the organism to its progeny; that is, hereditary transmission through insects plays no part in the life-history. This is in marked contrast to certain other diseases, such as the piroplasmoses.

Cultivation of Trypanosomes.-Novy and MacNeal, in 1903, gave an account of a method which they had successfully used in the cultivation of trypanosomes in artificial media. Equal parts of defibrinated rabbit blood and melted nutrient agar are mixed, and the tubes are slanted and allowed to solidify. The water of condensation is inoculated with a small amount of blood containing trypanosomes. The first culture of trypanosomes frequently develops slowly, but subsequent transfers more quickly. Not all trypanosomes can be cultivated in this manner with equal facility.

Method of Disease Production.-The organisms are found typically in the circulating blood, and to a less degree in the other body-fluids. Anemia and emaciation are frequently associated with the various trypanosome infections. The spleen is quite commonly enlarged.

Examination and Staining Methods.-Usually the examination under a cover-glass of a drop of blood from an infected animal will reveal the organism, particularly if made directly with the lowpower objective of the microscope. The active motion of the organisms reveals their presence by movements of the blood-cells, and they may be thus located and then studied under the higher powers. Centrifugation of blood or body-fluids must be resorted to in some instances to concentrate the cells when they are present in small numbers only. Blood-films stained by Wright's method yield very satisfactory results.

\section{Trypanosoma equiperdum}

Synonym.-Tr. rougeti.

Disease Produced.-Dourine: maladie du coit in horses (horse syphilis).

Rouget, in 1896, first described this trypanosome. Other investigators have conclusively established its etiologic relationship to the disease. It is of particular interest as the only try- 
panosome disease of importance in Europe and in North America.

Distribution.-The disease is known from Germany, Austria, France, and southern European countries, northern Africa, western Asia and India, Chile, Java, and several local epidemics have occurred in North America (Illinois, Nebraska, Wyoming, South Dakota, and northwestern Canada).

Morphology (See Fig. 188).-Moore and Bredini, in a study of this trypanosome as it occurs in artificially infected rats, concluded that it passed through certain developmental stages, finally being converted into rounded bodies with two long delicate flagella. The organism, as it occurs in the lesions and blood of the horse, is a slender cell, usually about 25 to $28 \mu$ in length. There are no particular differentiating characters between this organism and the ones associated with other trypanosomiases of the horse. The blepharoplast is distinct, the membrane considerably folded, the nucleus central, and the free flagellum about $\frac{1}{5}$ to $\frac{1}{3}$ the length of the organism. Protoplasmic granules are never present.

Cultivation.-Thomas and Breinl have succeeded in cultivating the organism in a modified Novy and MacNeal medium in one trial out of nineteen.

Pathogenesis.-Experimental Evidence.-The disease may be transmitted experimentally to the horse, the ass, to fowls, and even to ruminants and apes, according to some observers. The disease occurs naturally only among the equines.

Character of Disease.-The infected animal becomes emaciated, while whitish or chalk-like areas appear in the skin and mucosa of the external genitalia. Ulcers frequently develop, particularly upon the penis. The disease usually runs a chronic course. The animal frequently becomes gradually paralyzed. Recovery is infrequent.

Immunity.-Animals that recover from the disease are thereby rendered immune to a second infection. They are.not, however, rendered immune to infection with another trypanosome, such as that of surra. It appears that an immunity acquired during pregnancy may be transmitted to the offspring. No method of immunization based upon the organism or its products has been developed. 
Bacteriological Diagnosis.-This may occasionally be accomplished by a microscopic examination of the fluids from the lesions and the identification of the characteristic trypanosome in stained mounts. The organisms ean rarely be found in the blood of the general circulation. The blood-tinged fluid secured from the plaques when they first appear is the most favorable material for their identification. They may be found in the blood-stream of artificially infected laboratory animals.

Transmission.- The disease is commonly transmitted from one animal to another through coition. Whether or not the organism can enter through the intact mucosa is not certainly known, but appears probable. Blood containing the organism will infect a rabbit if placed in the conjunctival sac. Sieber and Gonder claim to have succeeded in transmitting the disease through the medium of the fly Stomoxys calcitrans, but this certainly is not the common method. No developmental stages could be observed in the fly.

\section{Trypanosoma evansi}

Synonym.-Spirochota evansi.

Disease Produced.-Surra in horses, eattle, carabou or water buffalo, eamels, dogs, goats, and sheep.

The disease has been known for a long time from southern Asia. The organism was first described from India by Evans in 1880 .

Distribution.-The disease is known from India, China, the Philippines, Africa, and Australia.

Morphology. - The organism as it occurs in the blood is actively motile. It is usually between 20 and $30 \mu$ in length, and from 1 to $2 \mu$ in diameter. It tapers to the anterior end, but the posterior is somewhat blunt. The undulating membrane and the free flagellum are well differentiated. This organism can scarcely be separated from $T r$. brucei on the basis of morphology.

Cultivation.- This organism has been cultivated on Novy and MacNeal's medium, but only after repeated trials.

Pathogenesis.-The disease may be readily transmitted to susceptible animals by the injection of blood containing the trypanosome. The disease itself is characterized in the horse as a relapsing fever, with eruptions, either generalized or localized in the skin. Petechial hemorrhages of the mucosæ are frequent. 
The subcutaneous tissues are infiltrated and edematous. It is practically invariably fatal. Cattle are relatively resistant to the disease, and in these animals recovery usually occurs, but the blood may remain infective for a considerable period. Buffalo frequently succumb. Camels, elephants, and dogs are not infrequently infected.

This disease resembles nagana clinically, and the causal organisms can scarcely be differentiated. Animals immunized against the one disease are susceptible to the other, which would seem to establish specific differences sufficient to separate the organisms as distinct species.

Bacteriological Diagnosis. - The organisms gradually increase in numbers in the blood during the onset of the disease, and have been found as numerous as 350,000 per cubic millimeter. They are frequently not present in the blood between the periods of fever.

Transmission.--Fraser and Symons state that in the Federated Malay States four species of the fly genus Tabanus, particularly T. fumifer, are responsible for the spread of the disease. Probably other flies may carry the organism as well. Experiments seem to show that the transference in this case is merely mechanical, and that there is no. developmental cycle in the intermediate host. Carnivorous animals may be infected by ingestion if there are lesions in the mucous membranes.

\section{Trypanosoma brucei}

Disease Produced.-Nagana or tsetse-fly disease in horses, cattle, camels, buffalo, antelopes, and related wild animals, possibly the elephant.

The fact that this disease follows the bite of the tsetse fly has long been known by African natives, and the early explorers confirmed their belief. Bruce, in 1896, described the trypanosome which causes the disease.

Distribution.-Known only in Africa, particularly in Zulu land.

Morphology.-The organism is sluggishly motile. It is usually between 25 and $30 \mu$ in length and 1.5 to $2.5 \mu$ in width. Granules may generally be observed in the protoplasm. Irregular forms occur in the blood after death, and in the lymphatic glands, spleen, bone-marrow, liver, and lungs during life. Kleine believes, from 
his experiments with fly transmission, that there must be a developmental stage occurring in the insect.

Isolation and Culture.-Novy and MacNeal succeeded in growing the organism of nagana in the medium already described. Only a few tubes out of a large number were found to show growth.

Pathogenesis.-Experimental Evidence.-Inoculation of the mouse, rat, dog, eat, and monkey results in an acute infection; of the rabbit, guinea-pig, equines, and swine, in a subacute infection; and of cattle, goats, and sheep, in a chronic infection.

Character of Disease and Lesions Produced.-The disease is of greatest importance in the equines. The incubation period is from three to twelve days (Theiler). There is a continued or remittent fever and a watery discharge from the eyes and nose. The animal becomes much emaciated before death, which usually

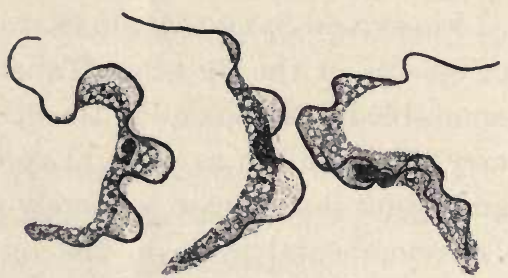

Fig. 189.-Trypanosoma brucei (adapted from Gonder and Sieber).

occurs in from two weeks to three months. Edema of the ventral region is common. Hypertrophy of the spleen is the most constant lesion. The lymph-glands are generally enlarged.

Immunity.- Rodet and Vallet believe that the organism is rapidly destroyed in the spleen. No practicable method of immunizing against the organism has been developed. It has been found that the injection of human serum into laboratory animals at intervals will greatly prolong their life, but will not cure. There is probably some relationship between immunity of man and the trypanicidal character of his serum. Goats, sheep, and cattle show a considerable percentage of cures and are thereafter immune. Their serum, however, has little immunizing power.

Bacteriological Diagnosis.-Stained mounts of the blood from infected animals will generally reveal the characteristic parasites. 
Centrifugation of the blood will frequently result in the collection of the organisms in a layer just at the surface of the corpuscles.

Transmission.- The disease is commonly transmitted from one animal to another by the bite of the tsetse fly (Glossinia morsitans). The herbivorous animals native to sections of the country where the disease is prevalent are almost invariably infected, and render infection of other animals easy. Kleine experimentally showed that another species of Glossinia (G. palpalis) could transmit the disease. He found that the flies did not become infective until eighteen days had elapsed. Other experimenters have found that the fly lost its infectiveness within a day or two after feeding upon an infeeted animal, and have concluded that transmission is wholly a mechanical affair. It seems possible that transmission may occur mechanically in this manner, or there may be a true developmental cycle in the body of the insect.

\section{Trypanosoma equinum}

Synonym.-Tr. elmassiani.

Disease Produced.-Mal de caderas of the horse (Spanish caderas $=$ rump or hindquarter).

Elmassian, in 1901, announced his discovery of the specific trypanosome of this disease in Paraguay. Voges, in Argentina, confirmed this discovery in the following year. The disease is so prevalent in some sections that cattle are used exclusively for riding and driving.

Distribution.-Parts of South America, particularly Brazil, Paraguay, and Argentina.

Morphology. - This trypanosome resembles those of surra and nagana, but the blepharoplast is so inconspicuous that it may be readily overlooked. The cell is usually between 22 and $24 \mu$ in length and $1.5 \mu$ in width. Cells about to divide are somewhat larger. The difference in the blepharoplasts of this and most other forms renders identification easy even in mixed infections.

Pathogenesis.-Experimental Evidence.-Inoculation of the organism causes a fatal infection in the horse; the mule and donkey are somewhat more resistant, as are mice, rats, and other rodents, rabbits, and other laboratory animals. Birds cannot be infected. 
The pig, sheep, goat, and ox may show transitory symptoms, but are highly refractory.

Character of Disease and Lesions. - The disease differs from surra and nagana in the almost complete absence of edema, and is characterized by a paralysis of the hindquarters. There is a progressive emaciation, fever, and the hindquarters become weak; the horse in walking scarcely raises the hoof above the ground. Finally, the animal supports itself by leaning, or falls to the ground. There are no lesions upon the genital organs.

Immunity.- No method of practicable immunization against the organism has been developed.

Bacteriological Diagnosis. - The organism may be found in the blood, particularly during the fever paroxysms.

Transmission.-The disease is evidently endemic in certain parts of South America in rodents or other animals. One of these, the capybara (Hydrochcrus capybara), has been found to be infected, and it is said that stockmen can sometimes foretell an outbreak of the mal de caderas by the death of many of these animals in the vicinity. The method of transmission is not certainly known. Flies have been supposed to act as carriers, but definite proof is lacking.

\section{Trypanosoma dimorphon}

Diseases Produced.-Gambian horse sickness, trypanosomiasis in horses and other equines, cattle, sheep, and goats.

Dutton and Todd, in 1902, reported the discovery of a specific trypanosome in a disease of horses in Senegambia. The same, or very similar trypanosome, has since that time been reported from many African localities in other animals as well.

Distribution.-Various localities in Africa (French Guinea, Zanzibar, Sierra Leone, Mozambique, Zululand).

Morphology. - The organism is characterized by the absence of a free flagellum, the flagellum terminating with the undulating membrane. It is dimorphic, some of the cells being 20 to $25 \mu$ in length, others only about $12 \mu$. Transitional forms between these extremes may be found. The undulating membrane is not well developed. Protoplasmic granules are very rare or are absent in the cell.

Pathogenesis.-Experimental Evidence.-The disease has been 
experimentally produced by the inoculation of the organism into sheep, cattle, goats, rabbits, horses, and white rats.

Character of Disease and Lesions.-The infection is acute in the rat; acute or chronic in the rabbit and dog; and chronic in the $\mathrm{ox}$, sheep, and in equines. It produces a severe anemia with changes in the red blood-cells. In the horse there is progressive emaciation. A marked edema is rarely produced. Death does not occur usually for months after infection. Recovery sometimes occurs.

Immunity.-No practicable method of immunization by means of the organism or its products has been developed.

Bacteriological Diagnosis. - The organism may be found in the blood at certain periods, but repeated examination is sometimes necessary. Inoculation of other animals with the blood will nevertheless show it still to be infective.

Transmission.--Pecaud states that immediate transmission may be due to a fly, Stomoxys. Tsetse flies are found in the region in which the disease is found, and may be responsible for its spread. The exact method of transmission is not certainly known.

\section{Trypanosoma congolense}

Brodin described a disease in the Congo Free State which closely simulated nagana, but the trypanosome resembled rather $T r$. dimorphon. Laveran, as a result of inoculation experiments, has concluded that this is a distinct species. It has been reported from several localities in southern Africa. It is fatal for cattle and sheep. The organisms are 10.5 to $15.5 \mu$ in length and 1.7 to $2.5 \mu$ wide. The flagellum shows no free portion, hence animal inoculations are necessary to differentiate between this and $T r$. dimorphon.

\section{Trypanosoma pecaudi}

Disease Produced.-Baleri or trypanosomiasis in horses, cattle, sheep, and goats.

This organism was described by Laveran from the blood of inoculated sheep brought to Paris by Cazalbou.

Distribution.- The disease is known from the French Sudan.

Morphology.-The organism closely resembles $\mathrm{Tr}$. dimorphon. 
Two forms are described: long slender cells, 25 to $35 \mu$ in length by about $1.5 \mu$ in width, with narrow, undulating membrane and fairly long flagellum, and short broad forms, 14 to 20 by 3 to $4 \mu$, with no free flagellum and a wide, undulating membrane.

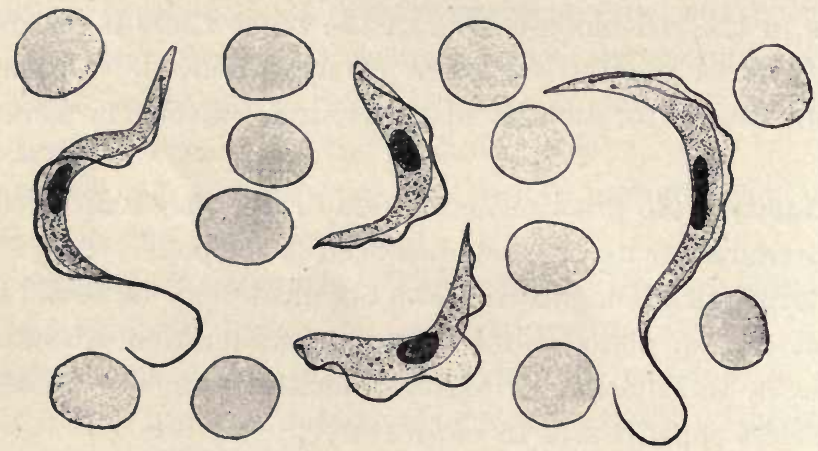

Fig. 190.-Trypanosoma pecaudi (Laveran).

Pathogenesis.-Character of Disease and Lesions.-In the horse the disease is characterized by repeated attacks of a severe fever, swellings in various parts of the body, injection of the conjunctiva, and a considerable degree of emaciation.

\section{Trypanosoma cazalbousi}

Disease Produced.-Souma or soumaya in cattle, sheep, horses, and mules.

Distribution.-Africa, from the French Sudan, French Congo, Upper Nile.

Morphology.-The organism, including its free flagellum, is about 21 by $1.5 \mu$. The oval nucleus is centrally located. The undulating membrane is poorly developed and is little folded. The terminal portion of the flagellum is free. There are no marked characters differentiating the organism from $T r$. evansi.

Pathogenesis.-Experimental Evidence.-Laboratory animals, particularly the rodents, seem to be relatively immune. The infection may be readily transmitted to horses and cattle and the smaller ruminants. Cross-inoculation experiments have shown the disease to be distinet from surra.

Character of Disease.-It attacks cattle generally. The disease leads to a progressive emaciation, the skin is harsh, and there is 
a staring coat. In many individuals the lower surfaces of the body show marked edema. The temperature is variable. The disease generally lasts seven or eight months.

Bacteriological Diagnosis.-The organisms are present in the blood, usually in small numbers only.

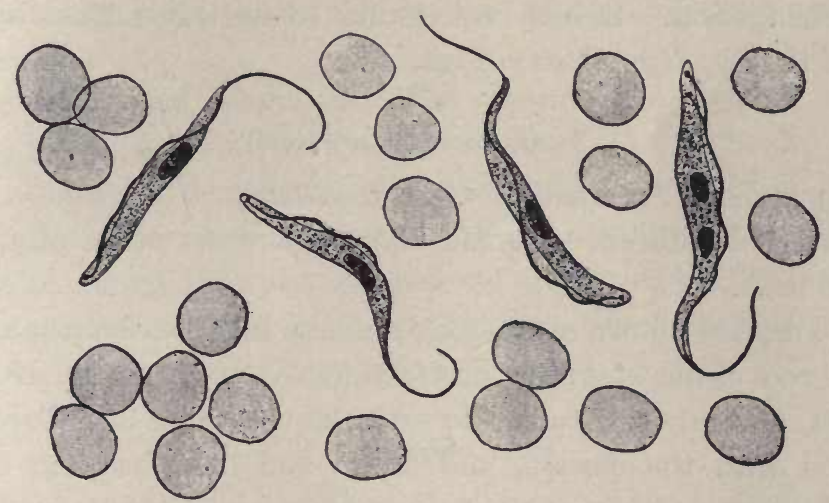

Fig. 191.-Trypanosoma cazalboui (Laveran).

Transmission.-Pecaud concludes that Glossinia palpalis is responsible for the distant transmission of the organism, and that members of the fly-genera Stomoxys and Tabanus may produce immediate transmission.

\section{Trypanosoma theileri}

Disease Produced.-Associated with galziekte or gall-sickness in bovines.

This organism was first noted by Theiler and was described at greater length by Laveran.

Distribution.-A large part of South Africa, possibly also in India.

Morphology.-The organism associated with this disease is of unusual size, 30 to $70 \mu$ in length, and 2 to $5 \mu$ in width. This alone is sufficient to differentiate it from other forms. There is a long, free flagellum. The nucleus is central, but the blepharoplast is a considerable distance from the posterior end. Many protoplasmic granules may usually be seen.

Pathogenesis.-The organism seems to be inoculable only 
into cattle. It resembles the rat trypanosome in being thus limited to a single host. The organism was first described as the cause of galziekte, but the recent investigations of Theiler seem to show it to be a relatively harmless commensal.

Bacteriological Diagnosis.- The organisms are quite common in the blood, but soon diasappear.

Transmission. - It has been found to be transmitted by the bite of the fly, Hypobosca rufipes.

\section{Trypanosoma gambiense}

Synonyms.-Tr. ugandense; Tr. castellani.

Disease Produced.-Human trypanosomiasis, or sleeping sickness in man.

The disease known as sleeping sickness has been known among the negroes of the west coast of Africa for over a century. Dutton, in 1901, had an opportunity to examine the blood of a European infected with the disease, and found and described the causal trypanosome. Other investigators have abundantly confirmed and extended his observations.

Distribution.-The disease is endemic upon the western coast of Africa and in certain of the central portions.

Morphology.-The organism is 17 to 28 by 1.4 to $2 \mu$. Forms undergoing division are somewhat larger. The free flagellum may be one-fourth to one-third the length of the body. Rarely no free portion of the flagellum can be demonstrated. The undulating membrane is narrow. The blepharoplast is near the posterior end. Protoplasmic granules that stain like chromatin are commonly observed.

Pathogenesis.-Experimental Evidence.-The disease, with its characteristic clinical symptoms, may be reproduced by the injection of blood containing the organisms into the monkey. Dogs, jackals, cats, guinea-pigs, and rabbits are readily infected. Mice frequently recover and are thereafter immune. Goats and sheep are relatively refractory, but sometimes succumb. It may produce a mild chronic infection in the horse and in eattle.

Character of Disease.-The disease is insidious in its onset. Two distinct stages may be recognized. These were for a long time supposed to be different diseases. In the first stage the organisms 
appear in the blood; there may or may not be fever. In the second stage pains in the back, tremors, and drowsiness supervene. Finally, the patient dies in a comatose condition. In this second stage the organisms are present in numbers in the cerebrospinal fluid. The disease appears to be always fatal, but may run a chronic course lasting several years.

Immunity.-No practicable method of immunization has been developed.

Bacteriological Diagnosis.-The organisms are usually scanty in the blood, and centrifugation is necessary to find them. They may usually be demonstrated in the fluid secured by a lumbar puncture. They may also commonly be demonstrated by puncturing an enlarged lymphatic gland and examining the fluid secured.

Transmission.- One of the tsetse flies, Glossinia palpalis, has been found to transfer the disease.

\section{Trypanosoma cruzi}

Chagas, in 1909, described this organism as the cause of a disease in man called opilacao, and hitherto confounded with ankylostomiasis. It is transmitted by the bite of a bug (Conorrhinus sp.). This work needs confirmation.

\section{Trypanosoma calmettei}

Mathis and Leger, in 1909, described a non-pathogenic trypanosome from the blood of the domestic fowl in Tonkin. It occurs but rarely.

\section{Trypanosomes in Birds}

Trypanosomes have been described from the blood of a great number of wild birds. They are not known to be pathogenic.

\section{Trypanosoma lewisi}

Chaussat, in 1850, and Lewis, in 1877, noted the presence of a flagellate in the blood of rats. It is so commonly present in the blood of rats in many parts of the world that it has been frequently used in the laboratory for study and demonstration, although its pathogenic properties are almost nil. This trypanosome cannot be transmitted to any other genus of mammals so far as known: even the closely related genera of the rodents are re- 
fractory. It evidently is a highly specialized commensal. The organism, with its flagellum, measures about 24 to $25 \mu$ in length by $1.5 \mu$ in width. Protoplasmic granules are frequently present.

\section{THE GeNUS HERPETOMONAS}

This genus includes certain flagellates that have an essentially trypanosome-like structure, without an undulating membrane. The cell is elongated in the typical Herpetomonas; the closely related genus Crithridia comprises those forms in which the body is much shortened. The flagellum is anterior, the blepharoplast distinct, as in the trypanosomes, and the nucleus centrally located.

Organisms of this genus have been frequently reported from the gut of the mosquitoes and flies. Certain of the trypanosomes sometimes assume shapes that resemble closely the Herpetomonas. The genus assumes pathogenic significance, principally because of the tentative classification of certain protozoa known as the Leishman-Donovan bodies as members of this genus: Three species have been described.

\section{Herpetomonas donovani}

Synonyms.-Leishman-Donovan bodies; Leishmania donovani; Trypanosoma donavani.

Disease Produced.-Kala-azar, eachexial or Dumdum fever in man.

Leishman, in 1900, observed this parasite in smears from the spleen of a patient that had died of Dumdum fever. His account was published in 1903 .

Distribution.-Throughout southern Asia and northern Africa.

Morphology. - The organism as it occurs in the body is commonly intracellular. It is found principally in the spleen, liver, bone-marrow, and lymph-glands. It is oval, spherical, or pearshaped, usually between $2 \mu$ and $3.5 \mu$ in length and 1.5 to $2 \mu$ in width. Two staining granules occur in the interior, the larger spherical, and the smaller, and more deeply staining granule, somewhat elongated. The organisms multiply by a preliminary division of both of the chromatic granules (nucleus and blepharoplast), followed by a constriction of the cell. In cultures typical flagellates are produced. The organism elongates somewhat, 
and a vacuole appears at one side of the blepharoplast, and from this a single flagellum develops. The body finally assumes an elongated form not unlike a trypanosome, without an undulating membrane. This is the Herpetomonas stage. This may now divide longitudinally, frequently unequally, splitting off very slender cells. The systematic position of this organism is still somewhat in doubt. It may be that it should be regarded as belonging to a distinct genus, and the name Leishmania used instead of Herpetomonas.

Pathogenesis.-The disease is characterized by enlargement of the spleen and by fever.

Transmission. - It is believed that the parasite is transferred from the dog to man through some intermediate host.

\section{Leishmania (Herpetomonas ?) infantum}

Nicolle has described an organism similar to the preceding from a disease which he calls infantile kala-azar. The organisms

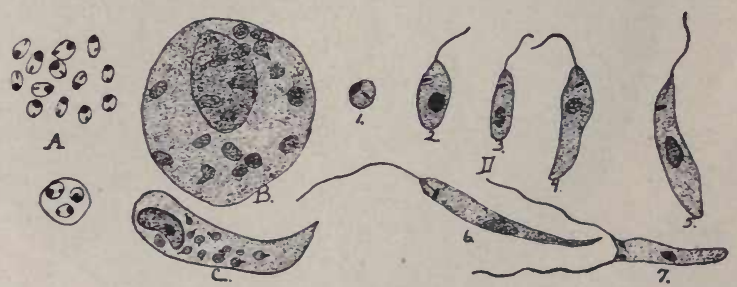

Fig. 192.-Herpetomonas infantum: $A$, Organisms from the spleen of a child; $B$, a mononuclear containing the organisms, and $C$, an endothelial cell from the spleen; $D$, various stages in the development of the Herpetomonas form from the Leishman-Donovan bodies (Nicolle).

resemble the preceding, but are believed to constitute a separate species. The disease is primarily one of dogs, which may be transmitted to children.

\section{Leishmania tropica}

Synonyms.-Ovoplasma orientale; Helcosoma tropicum.

Wright has described a similar organism as the cause of oriental sore or Delhi boil in man. It is probably transmitted likewise by some biting insect. The dog may be infected and show clinical symptoms similar to man. 


\section{CHAPTER XLII}

\section{SPIROCHETE GROUP}

There is probably more confusion relative to the classification of the members of this group of organisms than in any other group of bacteria or protozoa. In the first place, there is by no means an agreement among investigators as to whether these organisms should be included under the heading of bacteria or of protozoa. There seems to be more evidence in recent literature of protozoan rather than of bacterial relationships. Second, it is evident that the group is not homogeneous, and efforts have been made to separate the group into several genera.

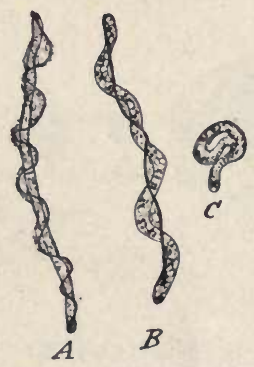

Fig. 193.-Spirochoeta pinno: $A, B$, Cells showing the undulating membrane; $C$, a coiled organism (adapted from Gonder).

In not a single case have we a full and satisfactory knowledge of the life history, particularly in those forms which are transmitted from one animal to another by parasites. Until this is worked out it will be impossible to make a separation of the different types into genera on the basis of true relationships. In the discussion of the group the genus name of Spirochata is retained, the first of the synonyms given being the one which has been suggested by Blanchard in his revision of the group on the basis of protozoan relationships.

The argument advanced for protozoan relationships may be 
summarized as follows. According to several observers, multiplication, frequently, though not invariably, takes place by longitudinal rather than transverse division of the cell. Morphologically, it is believed that these organisms differ from the true bacteria by being in all cases flexible, and swimming with a sinuous motion. In several species, undulating membranes similar to those of the protozoa have been demonstrated. Chromidia-like bodies, resembling the scattered nuclei in some protozoa, have been identified.

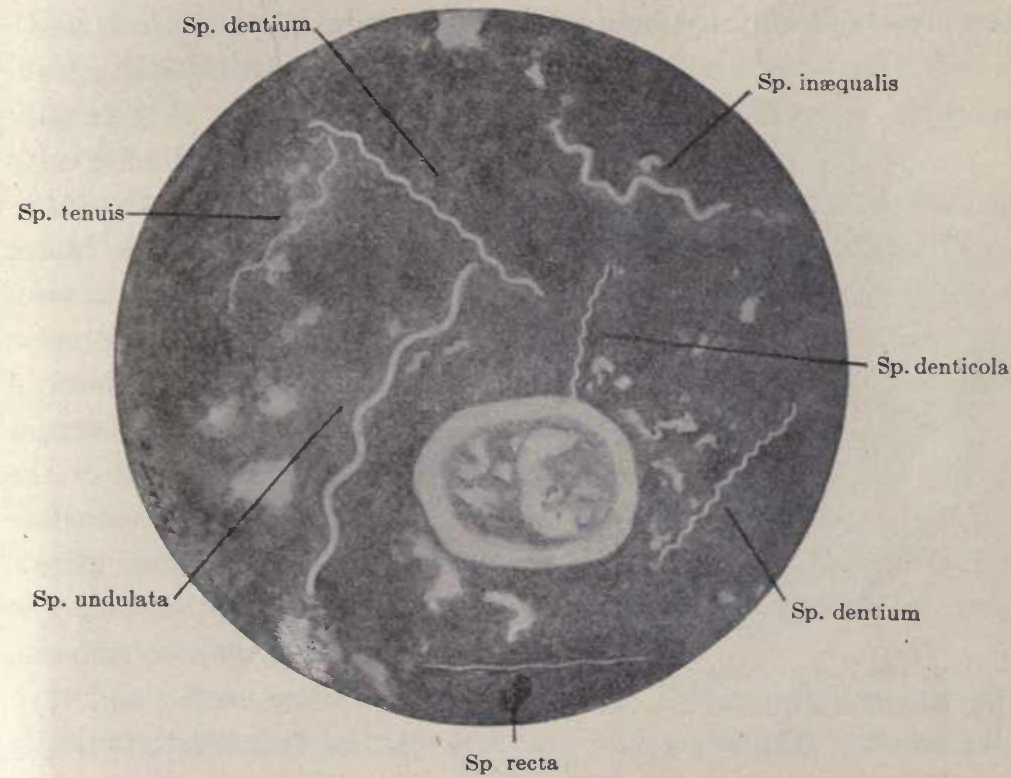

Fig. 194.-Spirochætæ of different species. From a smear from a tonsillar lacuna stained by Burril's India ink method (Gerber).

According to Prowazek, plasmolysis does not take place with salt solutions several times as concentrated as those required for plasmolysis of bacterial cells. Certain spirochetes have been observed to enter red blood-cells, and there assume a coiled condition. A multiplication of the organisms has been observed in the eggs of a tick which transmitted a spirochete disease, as have also certain forms which have been interpreted as stages in a more complex life-history. Leishman has found that certain spirochetes, when ingested by the tick, lose their motility and change 
morphologically, with resultant liberation of small bodies which stain like chromatin. These are of various shapes-rods, cocci, or spirals. They enter the lining cells of the malpighian tubules; they are found in the oviduct, the ovary, and the immature eggs, and in all stages of development of the young tick. Inoculation of material containing these bodies, but not true spirochetes, resulted in the development of tick-fever. The details of this life-history are in present need of elucidation. It has been claimed by Marchoix that the virulence of the spirochete of fowl septicemia can be preserved only by passing through the body of the tick which

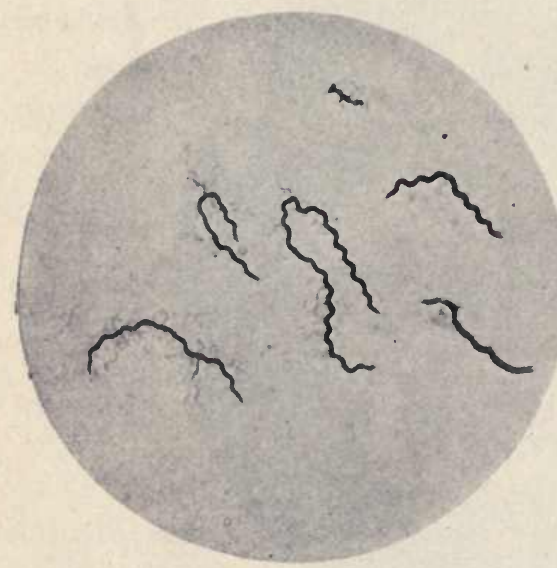

Fig. 195.-Spirochata obermeieri showing flagella distributed over the body of the organism (Fränkel). transmits the disease. Continual transfer of the organism from one fowl to another, without the intermediation of the tick, causes a gradual decrease in virulence. This would seem to indicate that a part of the life cycle of this organism must be passed in the body of the intermediate host or tick. None of this group of organisms may be cultivated uponthe common laboratory media, and they can be induced to multiply in vitro only under very special conditions. All these facts would seem to make out a strong case for those who believe in the protozoan relationships.

There are, on the other hand, investigators who believe quite as firmly that these organisms are bacteria. Novy and Knapp studied with great care a spirochete of relapsing fever. They concluded that division was always transverse, and that the longitudinal divisions reported by others were accidental associations or intertwining of two organisms. Their results with the use of plasmolyzing agents received an interpretation quite the reverse of other investigators. Experiments in immunization, the resistance to heat, stability of form, and staining qualities of 
the flagellum all associated the organism with the bacteria. Bonel, Fränkel, and others claim to have demonstrated the presence of numerous peritrichic flagella on certain forms, a condition which is different from any known protozoan. As before stated, there is so much discordance in the published work of the various investigators that definite conclusions cannot be reached. It has been suggested that these organisms form a group intermediate between the bacteria and the protozoa. This is not as probable as has been sometimes urged, and such a disposition is simply a confession of our lack of definite knowledge. It is by no means improbable that some species of this group will be found to belong to the bacteria and others to the protozoa, and that supposed homologies are only superficial resemblances.

Certain species have been removed from the genus Spirochæta and new genera created for them by certain authors. These names are so common in literature that their meaning should be known. It may here be again emphasized that the name Spirochreta, as used in the discussion of the various species below, includes all of these genera.

Spirochceta (In Narrow Sense).--Organism with an exceedingly slender, spiral, flattened body, with a narrow, undulating membrane that surrounds the entire body in a spiral. No flagella and no spores are produced. Reproduction probably occurs by longitudinal division.

Spiroschaudinnia.-Blood parasites. Minute wavy or spiral threads, with undulating membrane and no flagella. Free motile stage alternates with a stage in which the organism is coiled up in one of the host-cells. Developmental stages have been demonstrated in the intermediate host. The life-history is imperfectly known.

Treponema.-Spiral body, not flattened, tapering at the ends. Flagellum at each pole. No undulating membrane. Multiplication by longitudinal division. Does not stain with common aqueous anilin dyes: special staining methods are required.

The following organisms described as belonging to this group are of sufficient economic importance to warrant their consideration here: Spirochcta obermeieri, Sp. duttoni, Sp. pallida, $S p$. pertenius, in man; $S p$. anserina ( $S p$. gallinarum), in 
geese and other fowls; $S p$. theileri, in cattle; and $S p$. ovna, in sheep.

All the members of this group may be characterized as slender, spiral threads, motile by sinuous movements, incapable of cultivation on ordinary media, and in some cases difficult to stain, requiring special technic.

\section{Spirochaeta obermeieri}

Synonyms.-Spiroschaudinnia recurrentis; Spirillum obermeieri; spirillum recurrentis.

Diseases Produced.-Relapsing fever, recurrent fever, spirillosis in man.

Obermeier, in 1873, published his discovery of a large spiral organism in the blood of patients suffering from relapsing fever. Since that time it has been repeatedly observed, and several similar species have been described infecting man, differing principally in their pathogenicity for small animals, and the fact that immunity to one does not immunize against the other.

Distribution.-The disease is known from Europe, and occurs in isolated cases in many parts of the world.

Morphology and Staining.-Spirochceta obermeieri is a very slender, tapering spiral. It is about $0.4 \mu$ in diameter, and varies greatly in length. It is always many times as long as broad. There are from two to ten spirals or turns in the organism, as commonly observed. Opinions differ as to the presence of flagella and undulating membrane. It is motile, with a very rapid, screwlike motion and a waving motion of the entire organism. The organism may be observed in the living condition. It is best stained by the Romanowsky method or some modification of it.

Isolation and Culture.-The organism has never been successfully cultivated upon ordinary media. Some multiplication may take place in freshly drawn blood, but it does not long continue, and its occurrence has been denied by some investigators.

Pathogenesis.-Experimental Evidence.-The organism is pathogenie for man, monkeys, mice, and rats. The only practicable method of maintaining a culture is by repeated transfers of the organism from one animal to another.

Character of Disease and Lesions. - The disease in man is char- 
acterized by pains in the head and back and by high fever. This is followed by a complete apparent recovery. A second attack, or relapse, occurs usually in about a week, then a third, and even more. The relapses tend to decrease in intensity. The spirochetes are to be found in large numbers during the relapses, though usually in diminished numbers.

Immunity.-No specific toxin has been demonstrated. An attack of the disease confers an active immunity. Repeated injections of blood containing spirochetes result, in the rat, in the

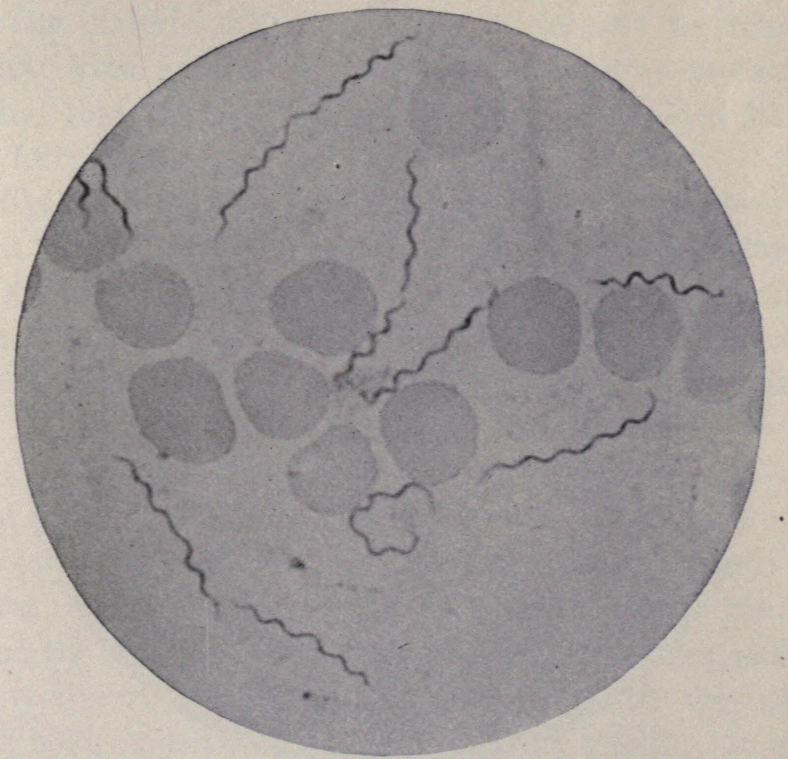

Fig. 196.-Spirocheta obermeieri from the blood of a rat (Novy and Knapp in "Journal of Infectious Diseases"):

development of a hyperimmunity. Immune and hyperimmune blood may be used in conferring a passive immunity. The agencies responsible for the development of immunity are not well understood.

Bacteriological Diagnosis.-The organism may be found in fresh preparation or in stained mounts of the blood during a paroxysm.

Transmission.- The disease is supposed to be transmitted by the bite of an infected bed-bug (Acanthia lectularia), possibly by 
the body louse (Pediculus vestimenti). Whether or not there is a developmental cycle in the body of the parasite is not certainly known.

\section{Spirochæta duttoni}

Synonyms.-Spiroschaudinnia duttoni; Spirillum duttoni.

Disease Produced.-West African tick fever in man.

Ross and Milne, and Dutton and Todd, working independently in 1904, demonstrated the presence of this spirochete in the blood of individuals infected with this disease. Morphologically, it

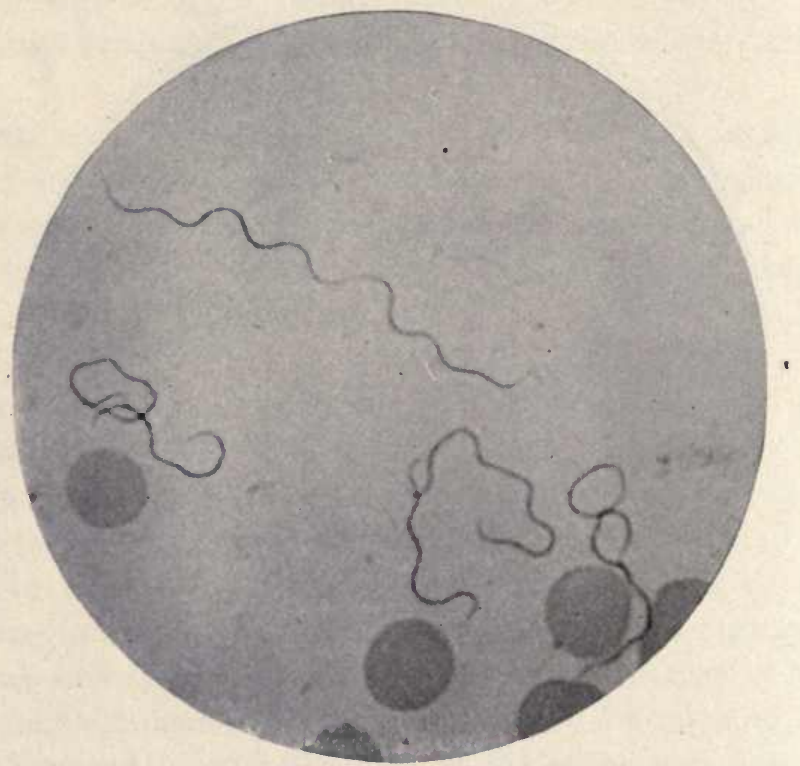

Fig. 197. - Spirochata duttoni from the blood of a rat (Novy and Knapp, in "Journal of Infectious Diseases").

resembles the preceding closely, but is usually longer and more loosely coiled. It is said to possess diffuse flagella. The disease is transmitted by the bite of a tick (Ornithodorus moubata).

Duval, Todd, McGell, and Pong have reported success in the cultivation of the organism outside the body. Many media were used with uniform failure until an egg-yolk preparation was found to be successful. The following is the medium recommended by these investigators. Six mice are skinned and their bodies boiled in 500 c.c. of water. This is filtered and sterilized. Two 
egg yolks are removed under aseptic precautions to a sterile Erlenmeyer flask. One hundred c.c. of the sterile mouse decoction is mixed with these and shaken thoroughly; 5 c.c. of sterile defibrinated mouse blood is then added. The flask is sealed to prevent evaporation, and placed at $37^{\circ}$ for six or eight weeks, during which time the material undergoes autolytic digestion. If properly prepared, the digestion is brought about wholly by autolytic enzymes, and is not due to the presence of bacteria. Examination of the flask at the end of the digestion should show it still to be sterile. The material for inoculation is secured by removing heart blood from an infected mouse, using aseptic precautions. They found that the organism multiplied and retained its virulence for forty days under these conditions.

Life Cycle.-The work of Leishman, Todd, and others indicates that the spirochetes, when taken into the body of the tick, undergo a kind of nuclear fragmentation into chromatin granules, which find their way through the wall of the digestive tract into the various organs, principally to the Malpighian tubules and the ovaries. These same granules may be demonstrated in the eggs of infected females, and the nymphs are able to transmit the disease. Leishman believes that holding the tick at a temperature of $34^{\circ}$, or even blood heat, causes these granules to develop into small spirochetes. They are exuded from the body through the coxal glands and the fluid secretion of the Malpighian tubules, and gain entrance to the wound caused by the tick bite after the tick has loosed its hold, and not through the salivary glands. It is possible that a cycle of changes of this type may account for the relapses that occur in the disease.

Immunity.-Leishman succeeded in establishing an active immunity in a monkey that recovered from the disease by causing infected ticks to feed upon it at intervals.

\section{Spirochæta kochi}

This organism, causing East African tick fever, has been found to be distinct from that causing the West Coast fever. To the former type the name Spirochata kochi has been given. Other related types of organisms 'causing relapsing fever have been described; that described by Novy and Knapp has been called 
Spirochata novyi. It is probable that a disease found in India is caused by still another organism.

\section{Spirochæta anserina (or Gallinarum)}

Synonyms.-Spirillum anserina; Spirochota gallinarum; $S p$. Marchouxi; Sp. nicollei.

Disease Produced.-Spirochetosis, spirillosis, or septicemia in 'geese and domestic fowls.

Sacharoff, in 1890, described the Spirochota anserina as the cause of an acute septicemia in geese, and the same organism was studied by Gabritschewsky in 1898. Marchoux and Salimbeni, in 1903, reported a septicemia or spirochetosis of domestic fowls in Brazil. Since that time similar organisms have been reported from many places. There is considerable difference of opinion as to the identity of the spirochetes isolated from the goose and the domestic fowl, and from the latter in various parts of the world. The peculiarities in virulence are such that the problem can be solved only with considerable difficulty. The arganisms are morphologically identical. They are at least closely related, and are, therefore, grouped together. The name Sp. anserina was the one first used, and, therefore, has priority. The name $S p$. gallinarum, however, is more commonly met with in literature.

Distribution.-The disease has been reported from Russia and the Caucasus, northern central, and southern Africa, southern Asia, and South America. It probably is wide-spread.

Morphology and Staining.-The organism of fowl spirillosis is a tenuous spiral 10 to $20 \mu$ in length, with an average of one spiral per micron in length. It is actively motile. No flagella have been demonstrated. According to Balfour, the organism undergoes changes in the body of the intermediary host, the tick (Argas persicus) corresponding closely to those described above for $S p$. duttoni in the tick (Ornithodorus moubata). The organism produces the same characteristic chromatin granules. Chicks inoculated with material showing these granules, but no spirochetes, are found to develop typical spirochetosis.

The organism may be easily demonstrated when living and motile. Carbol-fuchsin, Leishman, and Giemsa's stains may be used in the preparation of mounts. 
Isolation and Culture.-The organism has not been cultivated upon artificial media.

Pathogenesis.-Experimental Evidence.-Many birds may be infected by inoculation, among them the goose, duck, fowl, guinea fowl, turtle-dove, sparrow, and other birds; usually not the pigeon, although there is disagreement on this point. The rabbit, white mouse, guinea-pig, monkey, horse, and man are not susceptible. Each of the various types described have usually showed the greatest virulence for the species of bird from which it was originally described, and many variations in virulence have been observed.

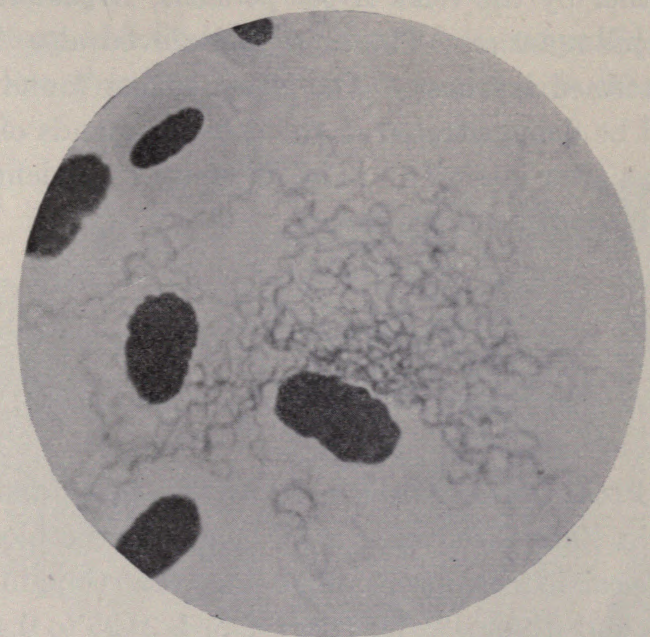

Fig. 198.-Spirochœta anserina (gallinarum). An agglutinated group from the blood of a fowl (Novy and Knapp, in “Journal of Infectious Diseases ").

It is believed that transfer through the intermediary host is necessary for the retention of virulence.

Character of Disease and Lesions.-The disease is characterized as a true septicemia; Levaditi has shown that the organisms also invade the intercellular spaces in various organs. The disease runs an acute course, marked by fever. Young fowls may show relapses, but the adults rarely. In this respect the disease differs from that caused by Spirochota obermeieri in man. The organisms are present in the blood in great numbers during the crisis. They rapidly disappear during convalescence. The mortality varies 
from 80 per cent. or more in some outbreaks to a small percentage in others.

Immunity. - It is probable that agglutinins are formed, but the difficulty of getting suspensions of the spirochete is so great that the question has not been adequately tested. Immunity is developed by an attack of the disease followed by recovery, but to what agencies this is due is not certainly known. Marchoux and Salimbeni heated blood from infected fowls for five minutes at $55^{\circ}$, and succeeded in establishing immunity by its injection.

Transmission.- The disease is commonly transmitted from one fowl to another by the ticks Argas persicus, Argas miniatus, and possibly Argas reflexus. The louse is believed also, by Balfour, to be an intermediary host. The latter author found that spirochetes could be demonstrated in the salivary glands of the tick in fourteen days after injection. The necessity for a definite incubation period has not been shown.

\section{Spirochæta theileri}

Synonyms.-Spirillum theileri; Spirillum ovina; Spirochota ovis; Spirochota equi.

Disease Produced.-Spirillosis in cattle, sheep, and horses.

Theiler, in 1902, discovered a spirochete in the blood of cattle in South Africa. It has been found since that time in Cameroon, East Africa, and Annam. The organism is 0.25 to $0.4 \mu$ by 10 to $30 \mu$. It resembles the preceding morphologically. The disease is a benign infection, and the organisms soon disappear. It is transmitted by the bite of a tick (Rhipicephalus decoloratus). Theiler, in 1904, reported the occurrence of a spirochete similar to Spirochceta theileri in the blood of sheep in the Transvaal. It was later found in northern Africa. Novy and Knapp have proposed the name Spirillum (Spirochata) ovis for this form. The same investigator described a spirochete associated with a disease of the horse in South Africa, and later it was reported from the west coast. Novy and Knapp term this Spirochata equi. Todd and others, by cross inoculations, have demonstrated that these organisms from the horse, sheep, and ox all belong to the same species. 


\section{Spirochrta pallida}

Synonyms.-Spirillum pallidum; Treponema pallidum.

Disease Produced.-Syphilis in man.

Schaudinn and Hoffmann, in 1905, described the organism which is now generally accepted as the cause of syphilis. Prior to that date many organisms had been described as possible causes, but all are now known either to be secondary invaders or commensals.

Distribution.-The disease is widely distributed among all civilized peoples.

Morphology and Staining.-The Spirochoeta pallida is a slender organism, less than $0.5 \mu$ in diameter and 4 to $20 \mu$ in length.

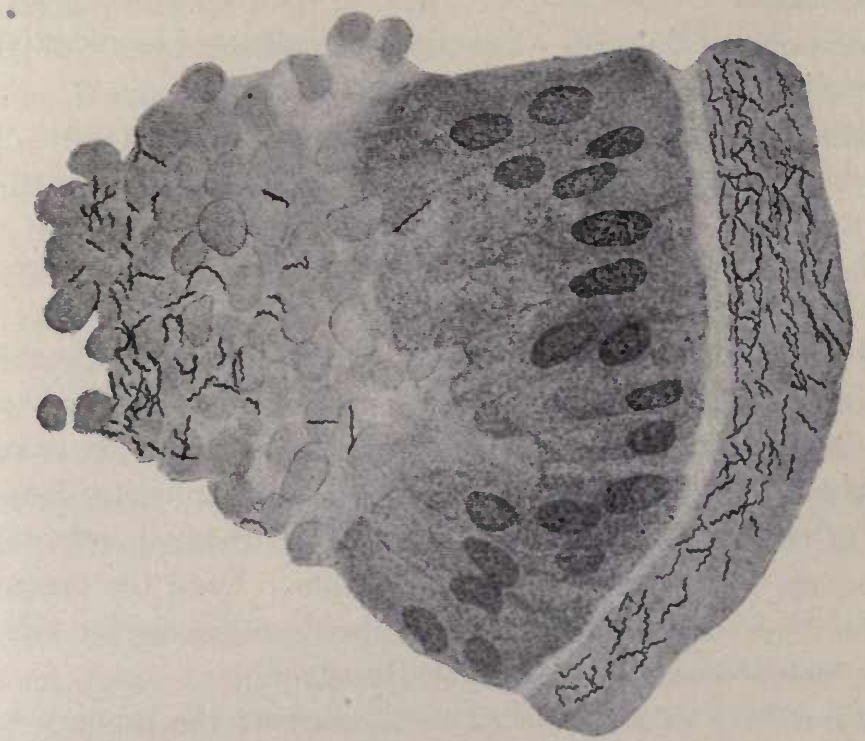

Fig. 199.-Spirochota pallida in the lumen of a bronchus in congenital syphilis (Hedrén).

The spirals are quite regular, and vary in number from three to forty. A flagellum has been detected at each pole. The organism is actively motile. Multiplication is probably by transverse division, although longitudinal division is said to occur. The organism is so slender, and stains with such difficulty, that there 
are many unsettled points relative to its morphology. Whether or not it may pass through a cycle of changes that would mark it as certainly protozoan is not definitely known.

The common anilin dyes used in bacteriological work fail to demonstrate this organism in tissues or in smears. The Indiaink method of demonstrating spirochetes may be used as a simple procedure for showing the organisms in smears. This consists in allowing a thin film of India ink to dry upon the smear. The organisms do not take up the ink, and may be recognized as transparent spirals in the black field. They may also be stained by Giemsa's eosin and azur stains. The stain must be freshly prepared. Very satisfactory results are achieved by impregnation with silver, particularly for the demonstration of the organism in tissues.

Isolation and Culture.-The organism has never been cultivated upon artificial media.

Pathogenesis.-Experimental Evidence.-The organism may always be found in the primary and secondary lesions of syphilis, and has been repeatedly demonstrated in the tertiary as well, although it is much more difficult to find in the latter stage. It may be found in the internal organs of a syphilitic fetus. An infection has been produced in the cornea and the iris of the rabbit, and the organism shown to be present. The primary and secondary lesions of the disease have been produced in the monkey, particularly in the anthropoid apes, and the spirochetes found in each of the stages. The evidence is very strong, therefore, that Spirochceta pallida is the cause of syphilis. Until the organisms can be injected in pure cultures and produce the disease this evidence cannot become indisputable, however.

Character of Disease and Lesions.-In man the primary lesion in the form of a chancre appears in about three weeks after infection, usually on or near the external genitalia. It is followed by invasion of the neighboring lymphaties and by progressive enlargement of the lymph-nodes as the disease progresses. Usually about six weeks elapse between the appearance of the primary and secondary lesions. These latter are probably dependent upon an invasion of the blood, and consist of localized skin eruptions, falling of the hair (alopecia), and the symptoms of generalized 
infection, such as fever. This may last for several years and an immunity be established, which, however, may not be complete enough to prevent gradual sclerosis of blood-vessel walls and degenerations in the parenchymatous organs, and even the appearance of tertiary lesions.

Immunity.-No practicable method of either active or passive immunization against the disease has been developed by the use of the organism or its products.

Bacteriological Diagnosis.-This may be accomplished by direct examination, stained mounts, the Wassermann test, or by chemical recognition of certain changes in the character and composition of the blood-serum. The organisms may be observed in the fluid expressed from fresh tissues by use of dark field illumination. Smears may be prepared and stained with Giemsa's stain, or tissue sections may be used.

The Wassermann test for syphilis has already been described in the discussion of fixation of complement in the section on Immunity. As an antigen, extracts from the organs of a fetus are used, for in these organs the spirochetes are found in the greatest numbers. The blood-serum of the suspected patient is tested for its possible content of specific amboceptor with fresh guineapig serum for complement, sheep red blood-cells, and the serum from a rabbit possessing hemolytic amboceptor for these erythrocytes. The test requires considerable care and must be checked at every step. It has been found in practice to give quite reliable data. The test has been modified in many ways since first proposed.

Various substances, such as 1 per cent. solutions of lecithin, sodium oleate, sodium glycocholate, and taurine have been found to give more or less characteristic precipitates with the blood of syphilitics.

Transmission.-The disease is transmitted usually through sexual congress, rarely through infective drinking vessels, closets, and by direct inoculation, as sometimes happens in surgical work. The disease may be inherited: the organism may possibly enter through the ovum or the sperm, or pass from the circulation of the mother to that of the fetus. 


\section{Spirochæta pertenuis}

\section{Synonym.-Treponema pertenuis.}

Disease Produced.-Yaws in man.

Castellani, in 1905, reported the occurrence of spirochetes in a tropical disease known as yaws. The organism resembles that of syphilis, but is probably distinct, as shown by inoculation experiments and study of specific antigens and antibodies in comparison with those of syphilis.

\section{OTHER SPIROCHETES}

Dodd, in 1906, found a spirochete in a disease of the pig in South Africa. It was associated principally with dark, hemorrhagic lesions of the skin.

Spirochetes may be found in considerable numbers in the mouth, and, under certain conditions, in the intestinal tract, upon the skin, and about the genitalia. They are, for the most part, believed to be harmless commensals. 


\section{CHAPTER XLIII}

\section{SPOROZOA}

The Sporozoa stand alone among the protozoa, in that all the species are parasites. Many are harmless commensals, but a considerable number are pathogenic. The sporozoan cell contains typically a single nucleus, except in the Myxosporidia which are multinucleate. Food is taken in by diffusion through the plasma wall. Gastric and contractile vacuoles are present. The adult form is non-motile; the young forms are frequently actively motile, either ameboid or flagellate. In most of the Sporozoa the differentiation of the protoplasm into ectoplasm and endoplasm can be clearly made out The reproduction of the Sporozoa is the principal character which differentiates this group from others. Spores are always produced in those forms in which the complete life-history is known. The details of spore-formation vary greatly in the different forms, but the essentials are the same.

The cell as a whole, in most forms, divides to form archispores or sporoblasts; each of the archispores forms spores, and each spore then produces one or more sporozoites. Many forms show additional methods of reproduction. Formation of sex cells or gametes, with fusion of like or unlike cells, takes place in many forms, and serves to further complicate the life-history.

Blood-smears may be stained by one of the Romanowsky stains or by Wright's method to demonstrate the protozoa of this group. Considerable care must be exercised in the examination of such blood mounts not to confuse the normal blood contents, such as blood-platelets, with developmental stages of the protozoa.

The class Sporozoa contains many families and genera; only a few of the latter contain species that are of economic importance. The following artificial key will assist in differentiating the various genera. 
A. Sporozoa found in the blood-cells.

1. In the erythrocytes.

a. At some stage occupying a considerable proportion of the interior of the cell.

(1) In mammalian blood.

Well-differentiated, usually pear-shaped bodies, often two in a cell. In animals..................... Piroplasma or Babesia. Ameboid at first, finally filling the cell. In man....... Plasmodium.

(2) In blood of birds......... Proteosoma, Halteridium, Hemoproteus.

b. Forming minute dots, seemingly entirely of chromatin...Anaplasma.

2. In the leukocytes......................... Leukocytozoön. B. Sporozoa in muscles.................. Sarcocystitis and Balbiana. C. Sporozoa usually in membranes (mucous or serous)......... Coccidium.

\section{THE GeNus PIROPLASMa, OR BABESIA}

An organism belonging to this genus was first noted by Babes and called by him Hæmatococcus. Theobald Smith, in 1889, made the first observation which related one of these organisms to Texas fever. He called the organism Pyrosoma. This was later changed to Piroplasma by Patton, and still later by Starcovici to Babesia.

The organisms of this genus occur in the red blood-cells of various mammals and produce several distinct diseases. The lifehistory of all the species has not been satisfactorily worked out.

\section{Piroplasma bigeminum}

Synonyms.-Pyrosoma bigeminum; A piosoma bigeminum; Babesia bigeminum bovis; Hamatococcus bovis; Ixidoplasma bigeminum.

Disease Produced. - Texas fever, or tick fever in cattle-bovine piroplasmosis.

Theobald Smith, in 1889, discovered the cause of Texas fever in cattle. His work was fundamental and remarkably complete. Since that time investigators have found the same organims in many countries.

Distribution.-Southern United States, Australia, Argentina, Europe, India, and Africa.

Morphology. - In the blood of infected animals the organisms are generally in pairs. They are commonly piriform, one end being rounded and the other somewhat pointed. The acute ends are usually pointed toward each other. The organisms vary from 0.5 to $4 \mu$ in diameter. The reproductive stages have not been 
thoroughly worked out. The organism stains readily with such dyes as alkaline methylene-blue and by Wright's method.

Pathogenesis.- The relationship of the organism to the disease has been satisfactorily demonstrated by inoculation experiments. The disease in cattle is characterized by fever and a hemoglobinuria, with considerable destruction of red blood-corpuscles. In acute cases death often occurs in five to eight days after the symptoms are first noted. Those cases in which recovery takes place generally harbor still in their bodies the specific organisms, but remain perfectly well.

Immunity.-As already noted, recovery from disease does not necessarily predicate the disappearance of the organism from the

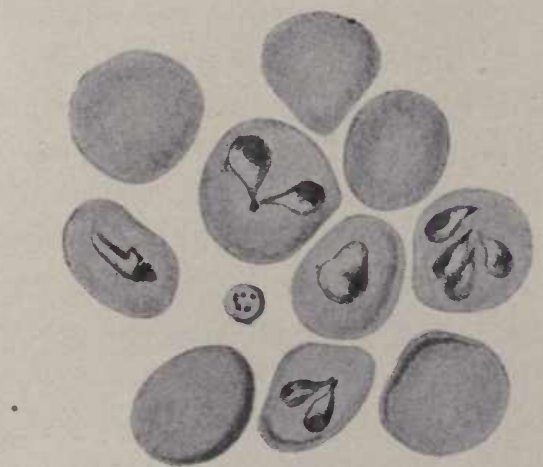

Fig. 200.-Piroplasma bigeminum, infected red blood cells with 1-4 parasites, a blood-platelet in the center (Sieber).

blood, and it may persist for years. It has been found that immunity against a fatal attack of this disease may be conferred by inoculation with the blood of immune animals. This results generally in a mild infection, which immunizes against one of a severer type. Such methods of vaccination are quite widely practised.

Bacteriological Diagnosis.-The organism may usually be demonstrated in the blood when stained with Loffler's methyleneblue or Wright's stain.

Transmission.-Natural infection takes place only through the bite of infected cattle ticks (Rhipicephalus annulatus or Boöphilus bovis) in the United States and closely related forms in other 
countries. The female tick becomes engorged with blood and falls to the ground, where, after a time, eggs are laid. They hatch in from nineteen days to five or six months, depending upon the temperature conditions. The young ticks crawl up the stems of grass and shrubs. They must get upon the body of an animal or die of starvation. The ticks from an infected mother are themselves infective, and may transmit the disease to the animal whose blood they suck.

\section{Piroplasma parvum}

Synonyms.-Babesia parva; Theileria parva.

Disease Produced.-East African coast fever, Rhodesian redwater, Rhodesian tick fever in cattle.

The organism and the disease have been studied by Theiler, Koch, and others. This protozoan is the smallest of the Piroplasmas known. In the red cells it forms a small rod that has a chromatin granule at one end. Frequently ring forms are observed, never the pear-shaped types of $P$. bigeminum. Gonder has worked out in detail the life-history of the organism. This disease is peculiar, in that transference of blood containing the organism from one animal to another does not resu t in the transference of the disease. Repeated inoculations are without effect. It is transmitted by means of the brown tick (Rhipicephalus appendiculatus) and the black pitted tick (Rh. simus). The affected animal shows high fever and swelling of the lymph-nodes. Anemia, icterus, and hemoglobinuria are rare'y observed. Immunity to this disease does not immunize against Texas fever. What is probably the same disease has also been described from southern Russia and in Java.

\section{Piroplasma mutans}

Theiler has established the presence of a third piroplasmosis in southern Africa, due to a protozoan which he has named $P$. mutans. It is smaller than the $P$. bigeminum, and animals immunized against one will contract the other.

\section{Piroplasma equí}

Disease Produced.-Equine biliary fever. Equine piroplasmosis.

Guglienni, in 1899, discovered this organism in Italy, and 


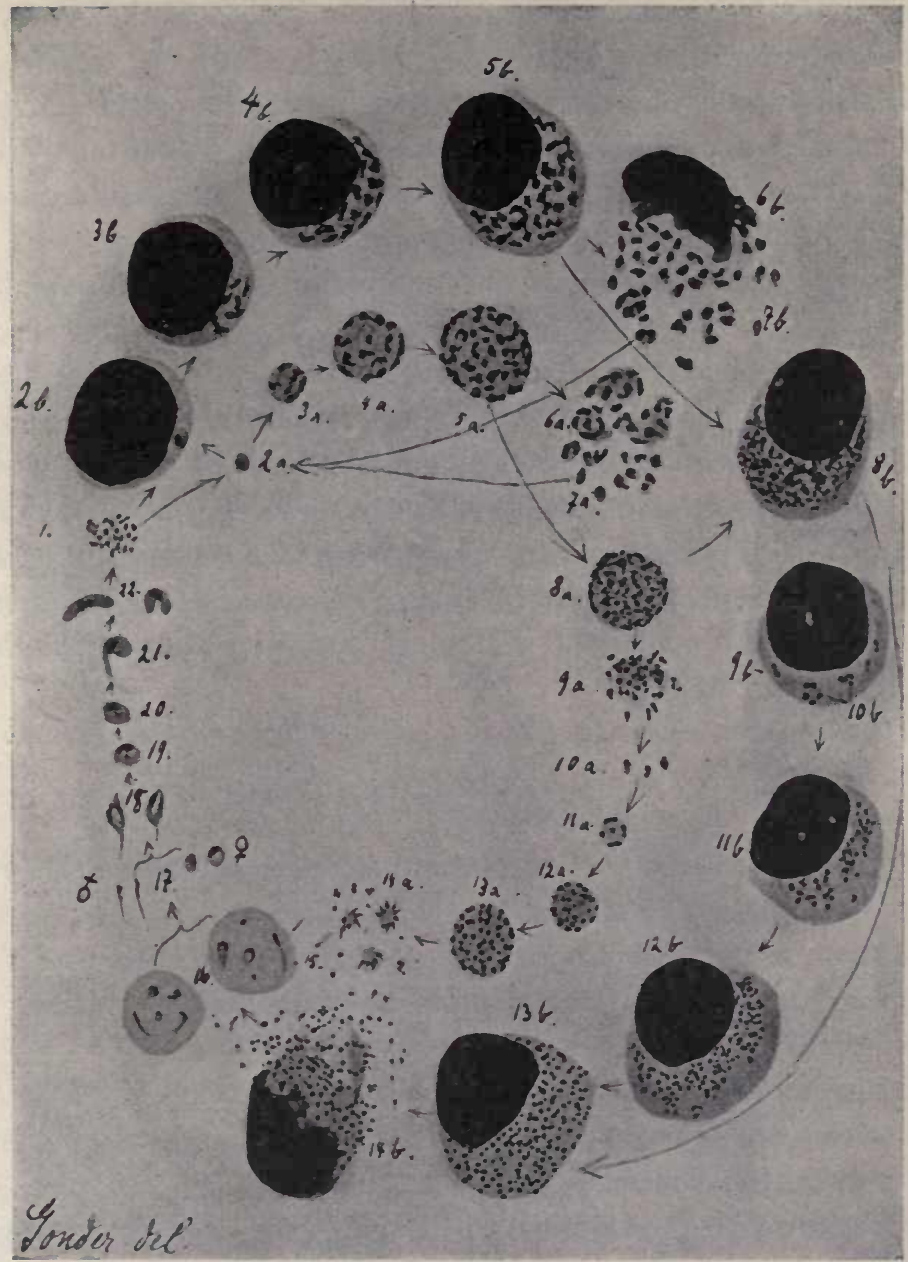

Fig. 201.-Piroplasma parvum, life cycle: 1, Agametes of the first generation (metagametes); $2, a$ and $b$, agamonts with one nucleus; $3, a$ and $b$, agamonts with several nuclei; $4, a$ and $b$, medium-sized agamonts; 5 , $a$ and $b$, large agamonts with numerous nuclei; $6, a$ and $b$, agamonts undergoing schizogony; 7 , $a$ and $b$, agametes; $8, a$ and $b$, reduction forms of agamonts; $9, a$ and $b$, segmentation of reduction forms of agamonts; $10, a$ and $b$, young agamonts; 11 , $a$ and $b$, medium-sized gamonts with several nuclei; 12 and $13, a$ and $b$, large gamonts with numerous nuclei; $14, a$ and $b$, gamonts undergoing schizogony; 15 , free gametocytes; 16 , gametocytes in the red blood-corpuscles; 17 , microand macrogametes in the stomach of the tick; 18, copulation; 19, karyomyxis; 20 and 21 , formation of the oökinetes; 21 , retort forms of oökinete; 22 , oökinete (Gonder, in " Journal of Comparative Pathology and Therapeutics"). 
Theiler later elaborated an account of the disease and the organism as it occurs in South Africa.

Distribution.-The disease has been noted from South Africa, Central Africa, Algeria, Italy, Sweden, Russia, India, and Venezuela. It is evident that further observation may show an extensive distribution

Morphology.-The organism is smaller than P. bigeminum, but resembles it. It occurs singly or in pairs, or rarely in rosettes, in the red blood-cells. Occasionally it is free in the plasm. The disease was at first supposed to be non-transmissible by blood injection, but Theiler succeeded by intravenous injections of virulent blood.

Pathogenesis.-The disease is characterized by jaundice and a high fever. It may run an acute or a chronic course; frequently it is fatal within a few days. The lymph-nodes and the spleen are considerably enlarged. Animals born in infected districts are commonly immune.

Transmission.-The disease is believed to be transmitted by ticks.

\section{Piroplasma ovis}

Disease Produced.-Hemoglobinuria, malarial catarrhal fever, or icterohematuria in sheep.

Babes, in 1892, first noted the parasites in the blood-cells of sheep in Rumania at the time that he made his observations on piroplasmosis of cattle.

Distribution.- It has been noted from Italy, France, Turkey, Venezuela, and the West Indies, South Africa, Rumania, and probably in the United States (Montana).

Morphology. - It is similar to P. bigeminum, but smaller (1 to $1.8 \mu$ in diameter). It is commonly single, sometimes double, in the cells, and frequently occurs in the plasm.

Pathogenesis.- The disease may be transferred by the injection of blood containing the organisms into healthy animals. The incubation period is about eight to ten days. Other animals, including cattle, cannot be infected. The disease is commonly fatal. It is characterized by anemia, icterus, and frequently hemoglobinuria.

Transmission.- The disease is transmitted through the bite of a tick (Rhipicephalus bursa). 


\section{Piroplasma canis}

Disease Produced.-Biliary fever or malignant jaundice of the dog.

Prani and Galli-Valerio, in 1895, first described the blood parasite of canine piroplasmosis.

Distribution.-It has been reported in China, Italy, France, Hungary, South Africa,.East Africa, and possibly from the United States.

Morphology.-The organisms are morphologically almost identical with $P$. bigeminum. They are generally 2 to $4 \mu$ in diameter. They are sometimes found abundantly in the plasma and in a single cell there may be as many as sixteen of the organisms. The free organisms are spherical; those within the corpuscles are pear-shaped or many angled. Multiplication is apparently by direct division.

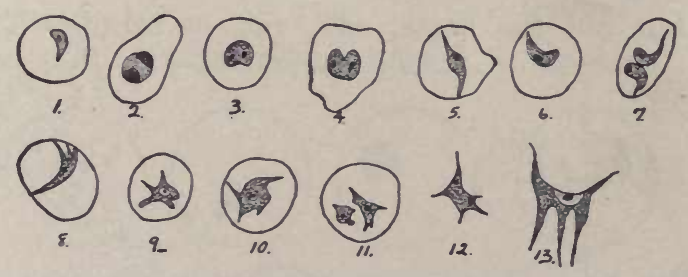

Fig. 202.-Piroplasma canis: 1-11, Organisms in various developmental stages in red blood-cells in culture; 12,13 , organisms free in the plasm (Deseler).

Pathogenesis.- The disease may be readily transferred by the injection of virulent blood. It cannot be transmitted to other species of animals. Nuttall and Graham Smith did not succeed in reproducing the disease in the fox and jackal. The period of incubation is three days or more. There is fever, and sometimes icterus and hemoglobinuria. Anemia is marked. The spleen is greatly enlarged, the gall-bladder is distended, and the kidneys are often ecchymotic. Chronic cases frequently recover. The acute cases are almost invariably fatal. Animals which have apparently recovered retain the parasite in the blood for long periods and retain their infectivity.

Bacteriological Diagnosis.-Stained blood-films will demonstrate the organism if present. 
Transmission.-At least three species of tick, and probably one species of flea, have been found to act as carriers of the organism.

\section{Piroplasma gibsoni}

Patton has described an organism causing piroplasmosis in hounds in the Madras Hunt in India. Later, it was discovered also in the blood of a native jackal. Its relationship to the $P$. canis has not been satisfactorily determined.

\section{Piroplasma commune}

Phillips and McCampbell have described a new species of Piroplasma as the cause of an epizoötic of dogs at Columbus, Ohio. The organisms found were similar to the $P$. canis, but these investigators were able to demonstrate the organism in the blood of guinea-pigs injected with virulent blood. The cat was also infected, but not the horse, cow, rat, or rabbit. This fact of
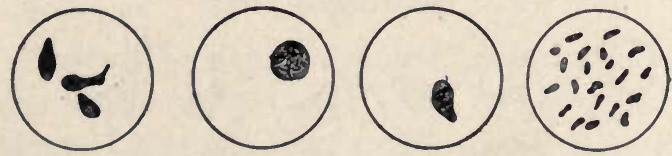

Fig. 203.-Piroplasma commune, organisms in the red blood-cells (adapted from Phillips and McCampbell).

transmissibility led to the tentative adoption of a new specific name, as the true $P$. canis is not known to be transmissible to any other animals. The organisms found were round or pearshaped. The round type were from 0.5 to $1.5 \mu$ in diameter, and the piriform 1.5 by $2.3 \mu$. Considerable pleomorphism was evident.

\section{The Genus Plasmodium}

Malaria in man has been found to be due to three species of protozoa, usually placed in the genus Plasmodium. The organisms pass certain parts of their life-cycle in the blood-corpuscles in man, and the remainder in the gut and tissues of the mosquito. The organisms of malaria were first noted by Laveran in 1880 , and the various types have been differentiated since that time. 


\section{Plasmodium vivax}

Disease Produced.-Tertian malaria in man.

Distribution.-This is the commoner malaria of temperate climates.

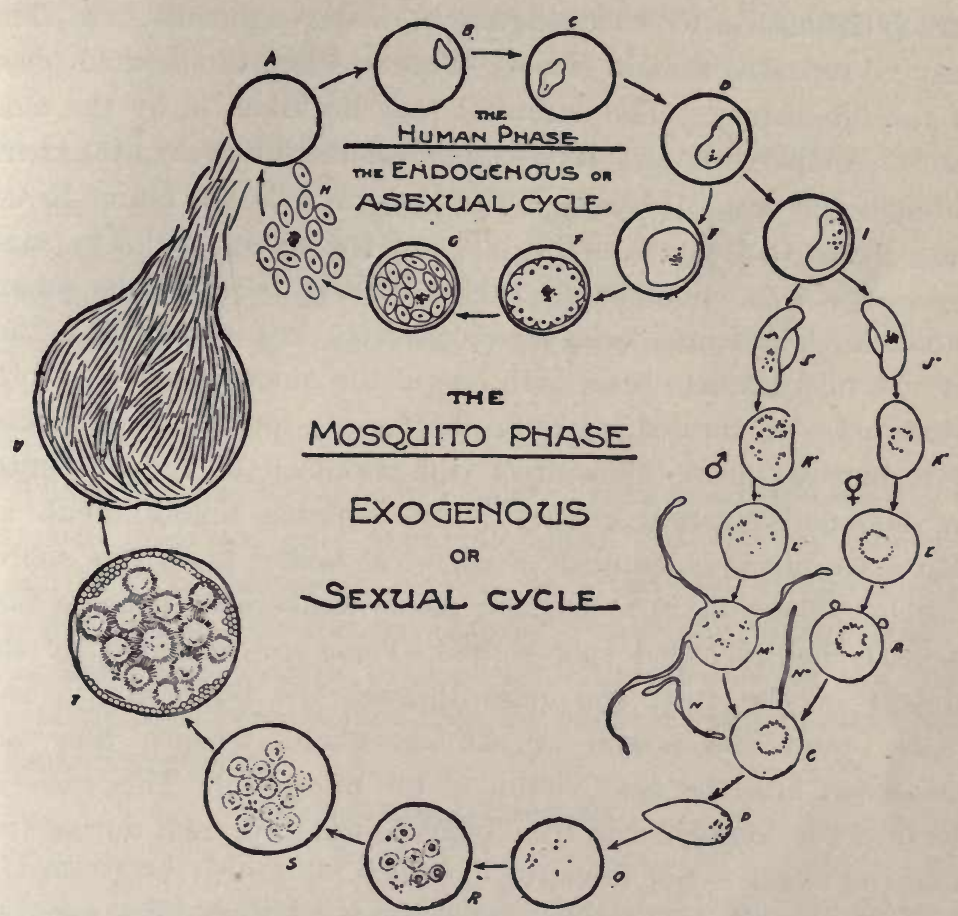

Fig. 204.-Diagram illustrating the life-cycle of the malarial parasite: $A$, Sporozoittes entering a red blood-cell; $B, C, D, E$, the organism in various stages of development; $F, G$, the formation of sporocytes and their division into spores which infect new red blood-cells. The series $A$ to $H$ represents the cycle through which the organism passes in the human body; $I$, infected red cell ingested by a mosquito. The organism may now develop through the series $J^{\prime}, K^{\prime}, L^{\prime}, M^{\prime}$, to form microgametocytes and microgametes or through $J, K, L, M$, to form a macrogamete which unites with a microgamete to form a fertilized ovum; $P$, the organism penetrates the stomach-wall of the mosquito and develops through the stages $Q, R, S, T, U$. From $U$ large numbers of slender spores are liberated into the body cavity. These pass to the salivary glands of the mosquito and are injected when the insect again bites (Rees).

Morphology and Life-history.-The organism when first recognized in the blood is small, with ameboid movements. It penetrates the red blood-corpuscle, and develops until the interior 
of the corpuscle is filled. When full grown, it may double the diameter of a blood-cell. The organism then segments to form a rosette of bodies, which round off to form small spores or merozoïtes. These are freed by the disintegration of the red blood-cell, and attach themselves to other cells and begin development anew. This may be repeated several times. This is called the asexual phase of the life-history. The organism may be taken in by the mosquito (Anopheles), and here completes its life-cycle by passing through the sexual phase. Two types of cells are found to develop from the spores in the body of the mosquito. The male cell (known as microgametocyte) produces five to eight microgametes. The female cells (macrogametes) are larger and granular. A microgamete fuses with one of the macrogametes to form what may be termed a fertilized "egg," copula, or oökinete. This burrows into the wall of the stomach of the mosquito, encysts, and enlarges greatly. The contents finally break up into a considerable number of spherical bodies known as sporoblasts. These in turn produce great numbers of delicate filamentous bodies called sporozoïtes. These are liberated by the rupture of the cyst, and pass through the body cavity, and finally enter the poison or salivary gland, whence they are inoculated into the next victim of the mosquito. This cycle in the insect is completed in from eight to ten days, and during this time the insect is not infective.

Pathogenesis.-The disease is characterized by chills, followed by fever, which occur every forty-eight hours. The infection is usually benign; a fatal termination is very rare. The chills and fever develop at the time of formation of the merozoites and the infection of new cells.

Transmission.- The disease is transmissible only through the bite of the mosquito. The elimination of the possibility of this transfer is the all-important factor in efficient prophylaxis.

\section{Plasmodium malarix}

This organism produces the quartan malaria in which the interval between paroxysms of fever is seventy-two hours, and the asexual cycle is completed in this time. This disease, like the preceding, is benign, and yields readily to quinin treatment. 


\section{Plasmodium immaculatum and falciparum}

This type of malaria is usually tropical. It is malignant, and does not yield readily to treatment. Two types are known, a quotidian, which completes its asexual cycle in twenty-four hours, and a tertian, which requires forty-eight. Whether or not these are distinct species is uncertain, but is probable.

\section{The Genera Proteosoma, Halteridium, and Hemoproteus}

These are genera of sporozoa which produce a malaria-like infection in birds. In some forms a part of the life-cycle is also spent in the body of the mosquito-in this case a Culex. None of the species are of any considerable economic importance.

\section{The GenUS ANAPLASMa}

This genus was created by Theiler in 1910 to accommodate the organism described as "marginal points" in the erythrocytes of cattle. The protozoan consists of a tiny dot of chromatinlike material in the corpuscle, usually near the margin, never more than one-thirtieth to one-twentieth the size of the cell. The name Anaplasma comes from the apparent lack of any cytoplasmic material.

\section{Anaplasma marginale}

Synonym.-Marginal points.

Disease Produced.-Anaplasmosis, Galziekte, or gall sickness in cattle.

This organism, according to Theiler, has been observed by several investigators, among them Smith and Kilborne, in their study of Texas fever. These observers have believed it to be a developmental stage of the Piroplasma (Babesia) bigeminum. Theiler has succeeded in demonstrating the distinction between the organisms, and defines Texas fever as a mixed infection of Anaplasma marginale and Piroplasma bigeminum.

Distribution.-Known with certainty from South Africa, probably widely distributed.

Morphology and Staining.-The organism may be single in the corpuscles, or there may be several within a single cell. The parasites usually lie near the periphery of the corpuscle, rarely free 
in the blood. They are small, spherical, rarely more than onetenth of the diameter of the cell, frequently less. By appropriate

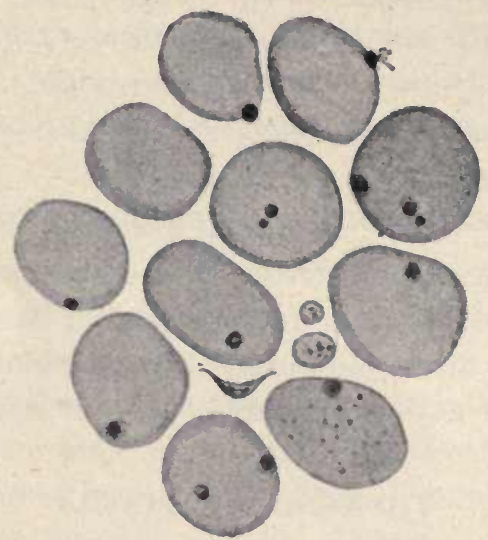

Fig. 205.-Anaplasma marginale in red blood-cells. Note the irregularity in size and in the staining of these cells (Sieber).

staining methods the presence of a central granule surrounded by a less apparent capsule may be demonstrated. Sieber has ob-

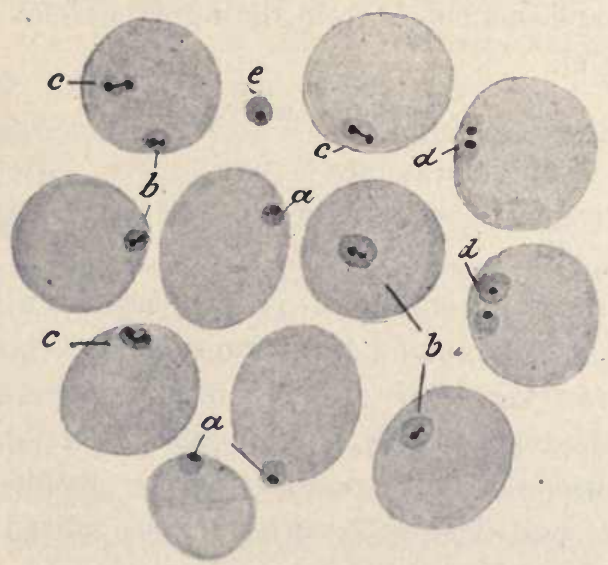

Fig. 206.-Anaplasma marginale, stained by Heidenhain's hematoxylon: $a$, Single parasite; $b$, beginning of division, the diplococcus types; $c$, dumb-bell forms; $d$, completed divisions; $e$, free parasites (Sieber).

served multiplication of the organisms within the blood-cells by a simple type of division. 
The Anaplasma marginale does not stain readily with the usual anilin dyes, but can be demonstrated easily by a stain such as Giemsa's. Heidenhain's iron hematoxylon also gives good results. It may be seen even in the living cells as a refractive marginal granule.

Pathogenesis.-The disease produced has an incubation period of sixteen to sixty days. The specific organisms may be first demonstrated from the spleen; later they become abundant in the blood. As many as 30 per cent. of the cells may be infected. The first evident reaction is irregularity and poikilocytosis of the red blood-cells, followed by more or less polychromasia and fragmentation. The serum does not seem to acquire any hemolytic properties. The febrile periods in the disease coincide with the presence of the greatest number of marginal points in the corpuscles. Cattle are susceptible to artificial infection. It is believed by Theiler and his coworkers that the primary symptoms of disease in Texas fever are due to Piroplasma bigemina, but that the secondary symptoms are due to this Anaplasma marginale, which requires a longer incubation period.

Transmission.-The organism is transmitted through the tick (Boöphilus decoloratus).

\section{THE GENUS LEUCOCYTOZOÖN}

Protozoa somewhat resembling the malarial parasites have been found in the white blood-corpuscles or leukocytes in birds

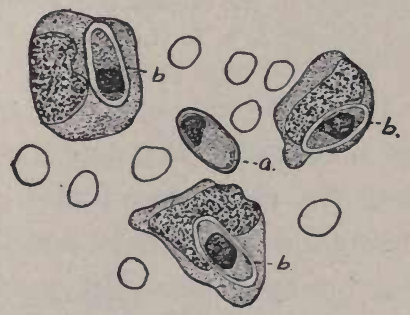

Fig. 207.-Hepatozoön perniciosum, a leucocytozoön from the blood of a rat: $a$, Free parasite; $b$, parasites in the mononuclear leukocytes (adapted from Miller).

by several observers, and in the domestic fowl and the dog in Tonkin by Mathis and Leger. They are not known to be of any economic importance. 


\section{THE GENUS SARCOCYSTIS}

These sporozoa are usually elongated, tubular, oval, or even spherical. Cysts with a double membrane are formed, and in these are produced reniform or sickle-shaped sporozoïtes, with a polar capsule and a projectile thread.

Species of this genus have been described from the muscles of a large number of vertebrates. In most cases the organism does not do any appreciable harm. Recently (1908) Watson has called attention to the prevalence of sarcosporidiosis in western

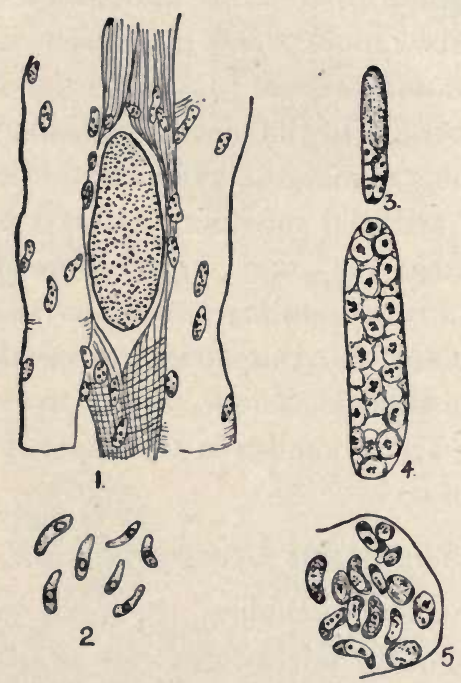

Fig. 208.-Sarcocystis muris in the muscle of a mouse: 1, Mature organism in the muscle; 2 , isolated spores; $3,4,5$, stages in the development of spores (adapted from Negri).

Canada, particularly in animals suspected of loco poisoning or infected with dourine. Six cases were found in cattle and two in horses suspected of being locoed, three in dourine-affected equines, and one in a filly showing cachexia. He concludes that these organisms may sometimes be an important factor in disease. In some cases the entire musculature may be affected with serious and even fatal consequences. A close relationship between loco poisoning and sarcosporidiosis is shown by the autopsy records. Recovery from this affection and from dourine may be prevented or retarded by the presence of the organisms. The species found 
in the horse is Sarcocystis bertrami; in sheep and goats, S. tenella; in swine, S. miescheriana; and in man, S. lendemanni.

\section{THE GenUS Coccidium}

This genus belongs to the sporozoan order Coccidiida. 'This order is characterized by having in the adult an oval or spherical form, not motile. Sporulation takes place within an endocellular cyst. The genus Coccidium is differentiated by the formation of four sporocysts or sporoblasts, each of which contains two sporozoites. The life-history is relatively complex, and varies in some details in different species.

The organism is taken into the body with food in the form of a cyst, which ruptures and allows the escape of the spindleshaped sporozoites. These penetrate the epithelial cells of the intestinal walls or other membranes. The sporozoite on entering the cell rounds up into a sphere, and then grows rapidly in size at the expense of the host cell. These growing organisms are called at this stage schizonts. The nucleus of the mature schizont fragments, and the protoplasm then breaks up into a considerable number of spindle-shaped cells, called merozoïtes, somewhat resembling the sporozoïtes. These break out of the mother schizont and infect new cells. They may then develop as schizonts and repeat the same cycle, or may develop into sexual reproductive cells. Some of these are of considerable size and correspond to an egg; these are termed the macrogametes. Others, called microgametocytes, develop similarly at first, then form a considerable number of very slender, thread-like cells called microgametes. A microgamete fuses with a macrogamete to form the oöcyte. This then continues to enlarge, and secretes a chitinous wall; $i$. e., becomes encysted. When mature, the contents of the cyst divide to form four spherical bodies called sporoblasts. These become somewhat elongated and spindle-shaped. In each of the sporoblasts two still more slender fusiform sporozoïtes develop. The cyst is freed, and upon ingestion by a suitable host the cycle begins again.

Coccidiosis occurs in many of the invertebrates, which do not seem to be seriously affected, but in the vertebrates serious and even fatal disease may be caused by the organisms. 


\section{Coccidium tenellum}

Synonyms. - It is possible that this organism does not differ from that of the rabbit, in which cases the name given would be reduced to a synonym of Coccidium cuniculi.

Disease Produced.-Coccidiosis in domestic fowls and in birds, blackhead or enterohepatitis in turkeys, white diarrhea (at least some types) in chicks, possibly roup in fowls.

These diseases have been studied by a great number of investigators, and many theories of their causation have been developed. Hadley and others have seemed recently to show quite conclusively that they are cases of avian coccidiosis, and the various organisms described by others as causal were secondary invaders or developmental stages of the organism in question.

Distribution.- The disease probably has a very wide distribution over the United States and Europe, but adequate data are not at hand for a determination. It is certainly known from many localities in the eastern States.

Morphology and Life-history.-The life-history is typical for Coccidium as outlined above. The adult coccidial cyst is oval or ellipsoidal. It measures about 14 by $21 \mu$.

Pathogenesis.-A considerable number of infections in the domestic fowls have been ascribed to this organism. A mild infection may not result in marked symptoms. An intestinal and cecal infection in the young chick has been found to be a potent, if not the principal, cause of white diarrhea, which causes such heavy losses in certain localities. A similar infection in adult chickens may also prove fatal. This is particularly true of the turkey, which is unusually susceptible. The principal symptoms are three in number-diarrhea, progressive languor or stupor, and loss of appetite with pronounced emaciation. The disease may be acute or chronic, but is quite generally fatal. Some fowls may harbor the organisms for long periods without any apparent symptoms.

Hadley has also shown that this same organism is probably the cause of roup. In this disease the tissues infected are the mucous membranes of the head. The infection results in the "inflammation of and exudate from the orbital sinus, nasal lachrymal duct, nasal chamber, mouth, pharynx, larynx (some- 
times) esophagus, intestines, and ceca; and terminating fatally in the majority of cases as a result of a series of combined factors,

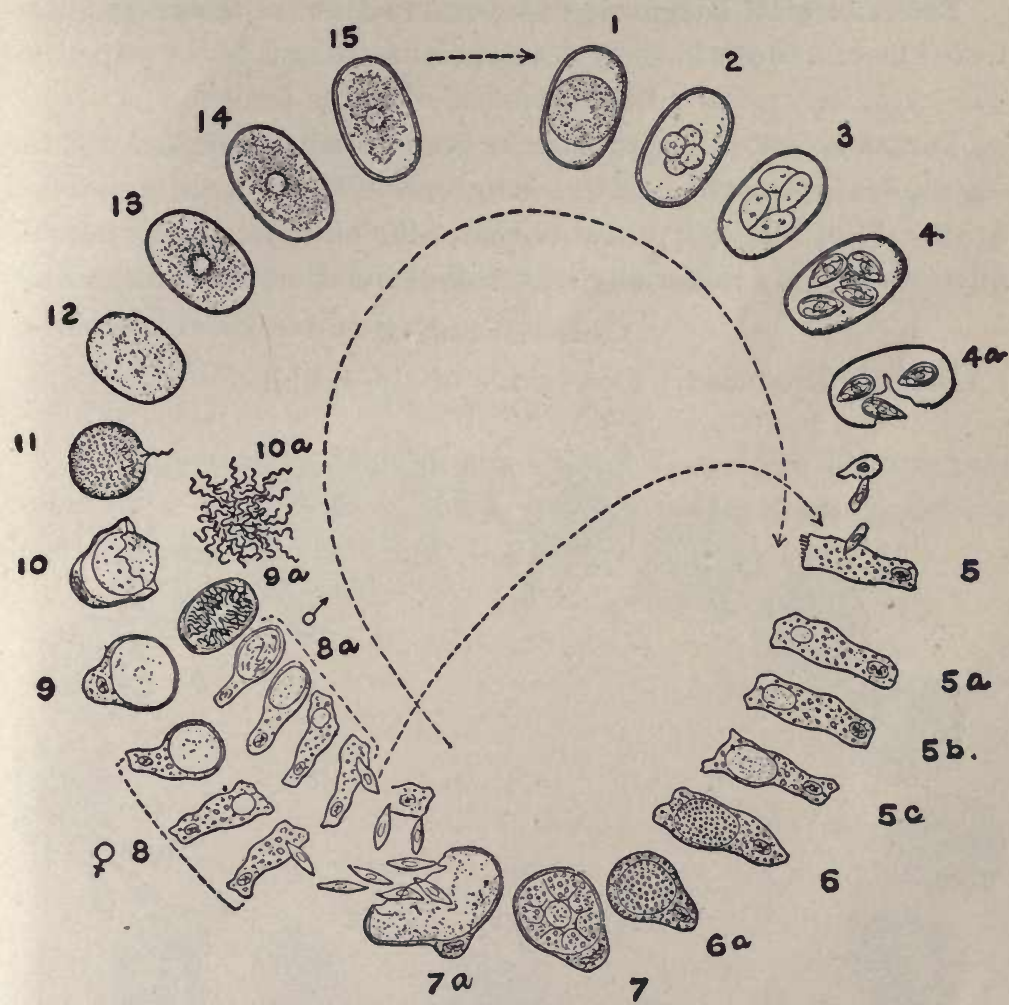

Fig. 209.-Coccidium tenellum, life-cycle: 1, Mature encysted Coccidium; 2, division into four sporoblasts; 3 , sporoblasts elongated and spindle-shaped; 4 , two sporozoïtes have developed in each sporoblast; $4 a$, the cyst ruptured and the sporoblasts and the sporozoites escaping; 5, epithelial cell of the intestinal tract; $5 a, 5 b, 5 c, 6,6 a$, stages in development within the cell, the schizont stage; 7 , schizont dividing to form merozoïtes; $7 a$, cell and schizont ruptured and merozoittes escaping. These again infest the epithelial cells and may repeat the cycle 5-7 $a$. Others produce the sexual stages 8 and $8 a$ to 11 ; 8,9 , infection of a cell with a merozoitte and development of the macrogamete; 10 , cell ruptured, exposing the macrogamete; $8 a$, infection of a cell with a merozoite and development of the microgametocyte; $9 a$, formation of the microgametes; $10 a$, liberation of the microgametes; 11 , fusion of the microgamete with the macrogamete; $12,13,14,15$, development of the mature encysted coccidium (Cole, Hadley, and Fitzpatrick).

including probably the toxic action of microörganisms growing on the mucous membranes, mechanical obstruction to swallowing 
and to respiration, and a progressive marasmus, frequently determined by intestinal complications."

Bacteriological Diagnosis.-An examination of smears from infected membranes will show developmental stages of the organism. The cysts may usually be demonstrated in the feces.

Transmission.-The disease is undoubtedly acquired by the ingestion of cysts which have been given off in the feces of diseased fowls. It is believed probable that wild birds may also become infected, and aid materially in the dissemination of the organism

Coccidium cuniculi

Disease Produced.-Coccidiosis of the rabbit.

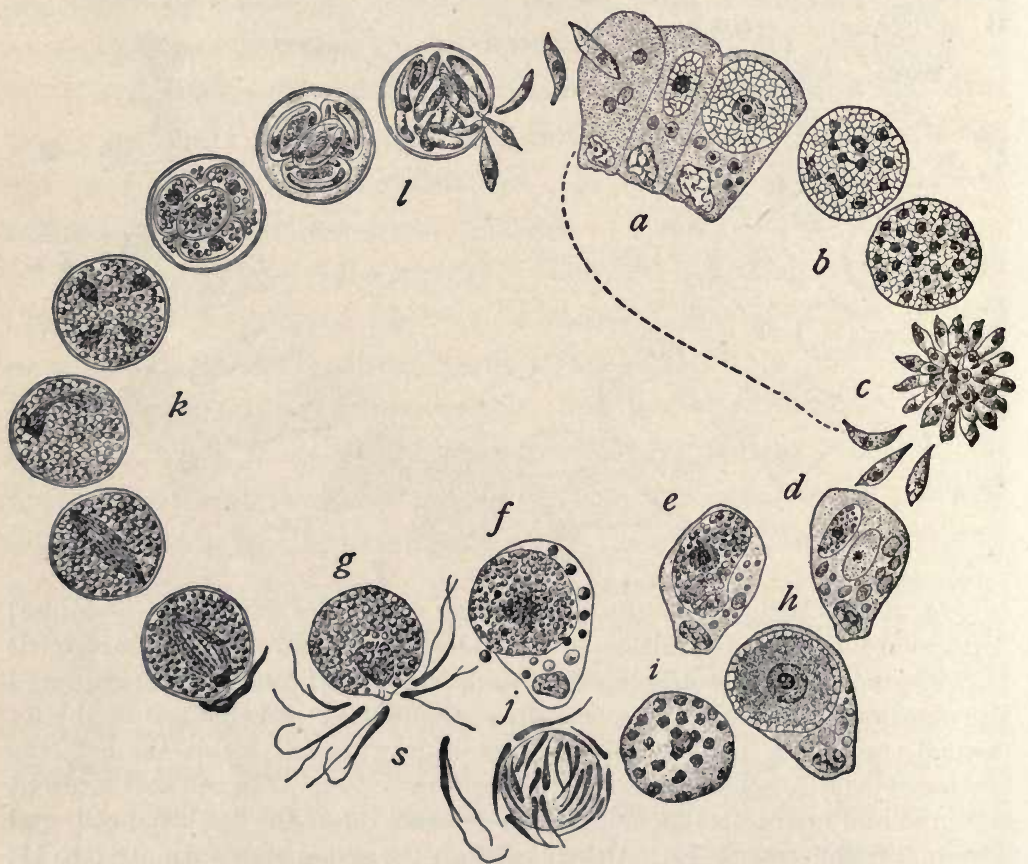

Fig. 210.-Coccidium cuniculi: $a, b, c$, Schizonts, with production of merozoiltes which may repeat the cycle or develop the sexual stage; $e, f, g$, development of the macrogamete; $h, i, j, 8$, development of the microgametocytes and microgametes; $k$, mature coccidium, which encysts and divides to form four sporoblasts; $l$, formation of the sporozoiltes and their liberation by a rupture of the cyst (Schaudinn).

Rivolta, in 1878, first described this organism from the rabbit It occurs in the intestinal epithelium. It may be present without 
evidence of disease, but is undoubtedly the cause of serious epizoötics among tame and wild rabbits. It is possible that this species is identical with the preceding.

\section{Coccidium of Cattle}

Several European investigators have described a Coccidium as the cause of bloody feces, without fever and with progressive emaciation in cattle. The organisms in the stools of infected animals are 18 to 25 by $13 \mu$. Infection experiments have been successful in reproducing the disease.

\section{Coccidium of Sheep}

A number of students in the United States and Europe have reported a coccidiosis of sheep. The symptoms and organisms are similar to the preceding. 


\section{CHAPTER XLIV}

\section{PATHOGENIC PROTOZOA OF THE INFUSORIA}

The Infusoria are differentiated from other protozoa by the presence of cilia at some stage in the life-history, by the presence usually of mouth parts for swallowing or sucking, and by the presence of two kinds of nuclei, micronuclei and macronuclei. Reproduction is usually accomplished by simple fission or by budding. Only a single genus and a single species is known to be pathogenic.

\section{Balantidium coli}

Disease Produced.-A rare fatal enteritis in man.

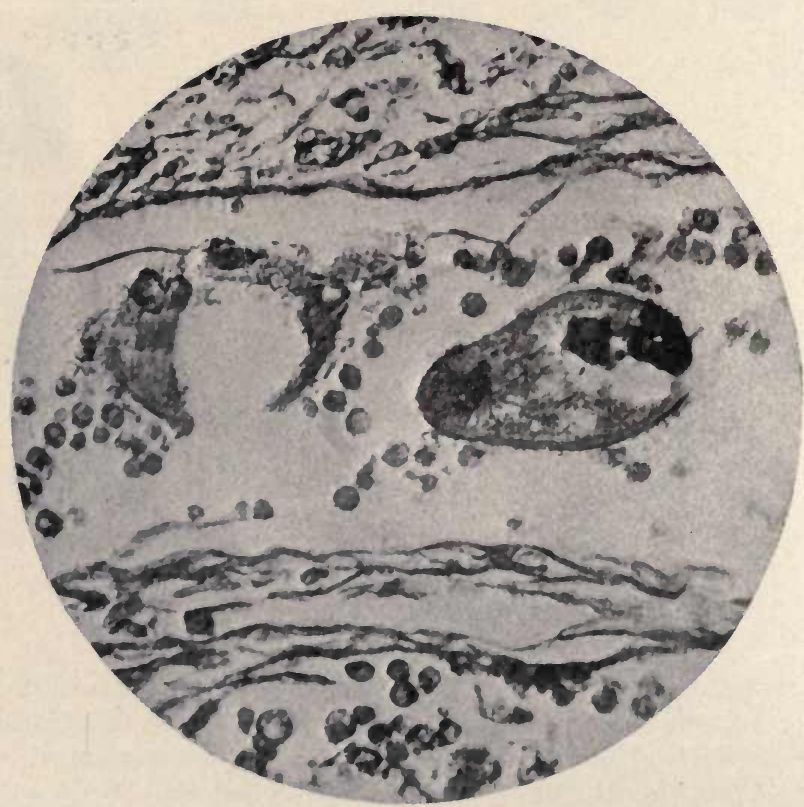

Fig. 211.-Balantidium coli in a blood-vessel of the submucosa of the intestines (Bowman, in "Philippine Journal of Science").

This organism is oval in shape -50 to 70 by 60 to $100 \mu$-and possesses a funnel-shaped peristome which terminates at the mouth. 
Cilia cover the surface. The two nuclei and two contracted vacuoles may commonly be made out. An excretory apparatus is evidenced by the extrusion of waste material at a definite point in the cell surface. The life-history is relatively complex. The cell commonly multiplies by direct division. Conjugation and encystment may occur.

The Balantidium coli appears to be a common inhabitant of the intestinal tract of swine. A large number of instances are recorded in which it has been found associated in man with a severe and even fatal type of diarrhea. The connection of this organism with the disease as a causal agent rather than as a commensal seems to be well authenticated. It appears that infection may follow the ingestion of the cysts produced by the organism. - The disease has been reported from Europe, the United States, and the Philippines. 


\section{SECTION VI}

\section{INFECTIOUS DISEASES IN WHICH THE SPECIFIC CAUSE IS NOT CERTAINLY KNOWN}

\section{CHAPTER XLV}

\section{DISEASES PRODUCED BY ULTRA-MICROSCOPIC ORGANISMS}

Within the last two decades there have been described a number of diseases in which the causal organism is said to be ultramicroscopic. By this is meant that with the best powers of the microscope no definite organism can be distinguished. Such an organism is frequently called a filterable virus, because filtrates passed through fine-pored porcelain filters retain their pathogenicity for susceptible animals.

It is a principle of optics that no object can be clearly differentiated that is smaller than one-half the wave-length of the light in which it is examined. This means that there is an apparently insuperable physical obstacle to the observation of some of these forms, as our best lenses approach moderately near to this limit in their magnification. Our reasons for believing that there are organisms this small will be discussed under the heading of various diseases.

Recently there has come into use an instrument known as the ultramicroscope, which renders visible objects more minute than had heretofore been observed. This instrument enables one to observe objects by making use of the principle worked out by Tyndall in determining the absence of floating dust-particles in the air. He noted that when a ray of a very bright light was admitted to a darkened room or box, this ray could be distinctly seen as long as there were any floating particles, but became invisible when these dust-particles had completely subsided. The motes or 
particles, even when smaller than can usually be seen by the unaided eye, became visible when thus illuminated. This principle is applied to microscopic examination by sending the rays from an are light or similar source, so that they are concentrated in a powerful beam, which is passed through the hanging drop or similar preparation from side to side. Exceedingly minute particles may thus be made visible. The use of this instrument has been found to be less helpful in the fields of biological research than had been hoped. Very few facts concerning the organisms that cause disease, and particularly the ultra-microscopic organisms, have been discovered by its aid.

An attempt has sometimes been made to compare the relative size of ultramicroscopic organisms by the use of porcelain filters of different degrees of density. It has been found that the virus of some diseases will pass through coarse filters, but not through the finer ones. It does not seem to be entirely a matter of the relative size of pores and organisms that may pass through the filter. It is probably a phenomenon analogous to an adsorption quite as much as mechanical filtration that removes the organisms.

\section{Bacterial or Protozoan Relationships of Ultramicroscopic} Organisms.-There is no practicable method telling certainly whether or not an ultramicroscopic virus should be grouped with the protozoa or with the bacteria. There are methods which may sometimes be used that will give inferences, however. It has been found possible in some cases to secure growth in culture-media, such as is used for bacteria. Such organisms are probably bacteria. In others, the type of disease produced may resemble so closely some other infection produced by a known organism that a probable classification into protozoan or bacterial might be made. The type of immunity developed may likewise be of importance. In most instances these differences are not pronounced enough to allow of certainty in the classification.

The more important diseases which have been described as due to ultramicroscopic organisms are contagious pleuropneumonia of cattle, rinderpest or cattle plague, foot-and-mouth disease, hog cholera, horse sickness, dog distemper, fowl plague, equine anemia, fowl pox, yellow fever, and epidemic infantile paralysis. 


\section{Virus of Pleuropneumonia}

Disease Produced.-Pleuropneumonia, peripneumonia, lung plague of cattle and other bovines.

Nocard and Roux described the causal organism in 1898. The disease itself has been known in Europe for several centuries.

Distribution.-The disease is known from Europe, Africa, Australia, Asia, and has been imported into the United States, where, in 1886, it killed 10,000 animals in Illinois alone.

Nature of Virus. - The causal organism is doubtless a bacterium that is just at the limit of visibility. In suitable fluids it may be observed under very high powers as a tiny motile point. Bouillon inoculated with the serous exudate from the pleura or from one of the areas of consolidation in the lungs, sealed in a collodion sac, and placed in the peritoneal cavity of a rabbit for two weeks, will show a slight clouding or opalescence. Transfers to new media similarly treated will likewise result in growth. This material may be shown to be infective. The organism may also be cultivated in a mixture of bouillon and blood-serum outside the animal body. In two to three days it shows a very faint clouding. Agar containing serum develops delicate, transparent, almost invisible, colonies. The optimum temperature is $37^{\circ}$; no growth occurs under $30^{\circ}$.

Pathogenesis.-Injection of pure cultures of the organism into cattle results in infection. Intrapleural injections or inhalations of the organism result in a typical clinical picture of the disease. The disease is characterized by more or less extensive areas of hepatization in the lungs and an inflammation of the pleura, accompanied by a serofibrinous exudate. The amount of fluid which collects may be very considerable.

Immunity.- Recovery from the disease results in a relatively permanent immunity. Immunization against the disease by vaccination with serum from the pleural cavity of infected animals has been practised. The material is injected subcutaneously. Its use is attended with danger, as from 0.5 to 5 per cent. or even more of those vaceinated have been killed by the vaccine. The method in question has been of some use in immunization, but a stamping-out process would appear to be more efficacious.

Nocard and Roux have advised vaccination with pure cultures, 
and claim to have secured more favorable results than by the older method. Nocard has also produced a curative and prophylactic serum by the hyperimmunization of animals by the injection of increasing doses of pure culture until six liters have been used. In doses of 40 c.c. it served as an efficient prophylactic, and, in larger amounts, as a curative agent in the early stages of the disease.

Transmission.-The method of natural spread of the disease is not certainly known. It is probably through inhalation of the causal organism.

\section{Virus of Foot-and-mouth Disease}

Disease Produced.-Foot-and-mouth disease, aphthous fever, Maul- and Klauenseuche in cattle and other bovines, sheep, goats, swine, deer, and occasionally horses, dogs, cats, and man.

The disease has been known for over a century in Europe. Löffler and Frosch, in 1897, Hecker, in 1898, and others since that time have shown that the virus of foot-and-mouth disease may pass through Chamberland and Berkefeld filters, but not through the thicker Kitasato filter.

Distribution.-The disease is known from most of Europe, Asia, and Africa. It has been introduced several times into the United States, but has been stamped out. It has also been reported from Argentina.

Nature of the Virus.-All efforts at observation and culture of the organism have failed. The facts given above show it to be a filterable virus and probably ultramicroscopic.

Pathogenesis.-The disease may be produced by the inoculation of susceptible animals with the filtrate through a porcelain filter. It is characterized by an acute fever, the appearance of a vesicular eruption on the mucous membranes of the mouth, on the feet and between the toes. It is commonly not fatal, but is so contagious, and leads to such losses in flesh and milk, that it is among the most feared of cattle diseases.

Immunity.-Vaccination by intentional infection of animals has sometimes been practised in an effort to "get it over with" as quickly as possible when it breaks out in a herd. An animal recovered is relatively immune. Such methods are attended by 
considerable risk. An efficient and safe method of immunization or vaccination has not been developed.

Transmission.-The organisms gain entrance through contact of healthy animals with the saliva or other secretions of an infected animal. They may be transmitted to young animals or to man in milk.

\section{Virus of Rinderpest or Cattle Plague}

Disease Produced.-Cattle plague, rinderpest, or contagious typhus in eattle, rarely in sheep, goats, and camels.

Nocard, and later Tartakowsky, observed that the body fluids in animals having this disease contained no visible microörganisms, but were infective. Nicolle and Adelbey established that these fluids, if thinned with water, could be passed through the coarser Berkefeld filters, but not through a fine-pored Chamberland, without losing their virulence.

Distribution.-The disease has been reported from a large portion of the area of Europe. It is endemic in southern Asia, is known in the Philippines, and has caused great losses in Egypt and in Southern Africa. It has not gained entrance to the United States.

Character of Virus. - It is both ultramicroscopic and filterable. It has not been cultivated. Blood sealed hermetically in tubes is found to retain its virulence for months. The virus is destroyed by desiccation or by heating to $58^{\circ}$ to $60^{\circ}$. It may survive in putrefying flesh for considerable periods. It is easily destroyed by disinfectants.

Pathogenesis.-The virus is present in all the body tissues and excretions. One one-thousandth of a gram of blood from an infected animal at the height of the disease has been found sufficient to reproduce the disease in a susceptible animal. The infection is an acute, highly fatal fever, in which there are croupous diphtheritic lesions of the intestinal tract. It is typically a cattle disease, but occasionally attacks other animals.

Immunity.-Animals which recover spontaneously from the disease are highly immune, and the blood has some power of passive immunization when injected into another animal. Vaccination with the nasal secretion of sick animals into the tails of 
others has been practised, and has been found in some instances to result in a low mortality. The method has been practically abandoned. Injections of the bile from animals having the disease has been advocated by Koch and extensively practised in South Africa, with good results.

The common method of immunization against rinderpest is that developed by Kolle and Turner. Animals which have recovered spontaneously from an infection, or that have been immunized by injections of virulent blood and gall, are hyperimmunized by repeated injections of virulent blood. The first injection is of a liter of virulent blood. After the subsidence of the reaction an injection of 500 c.c. is given, and later a third injection of a liter. A fourth injection may be made. The blood is drawn from the jugular vein at three intervals, a week apart. Another injection of a liter of virulent blood is given, and later the animal is again bled. The serum, in amounts of 20 c.c., should protect an animal against injection of 1 c.c. of virulent blood. An injection of 50 to 100 c.c. of the serum so secured will protect an animal against infection for a space of 2-4 months usually. A more permanent immunity may be established by the use of what is termed the "serum simultaneous" method. The animal is injected on one side with 8 to 25 c.c. of the immune serum, and on the other with 1 c.c. of virulent blood. Some animals react by a distinct fever, others show no effect. The latter are rendered immune for several months only, while the former for much longer periods. The blood of the animals reacting is infective during the period of fever. The vaccination mortality is about 1 per cent.

Transmission.-The disease is readily transmitted by means of soiled food, water, and by direct contact.

\section{Virus of Hog-cholera}

Disease Produced.-Hog-cholera, Schweinepest, swine fever.

From the time of the researches of Salmon and Smith on this disease, published in 1885, until 1904, the cause of hog-cholera was believed to be the Bacillus cholera suis (B. suipestifer). In the latter year de Schweinitz and Dorset showed the typical hogcholera in the United States to be due to a filterable virus. This has been confirmed by Hutyra, Uhlenhuth, and others in Europe. 
Distribution.-The disease is wide-spread in Europe and North America.

Nature of Virus. - The organism causing hog-cholera is an ultramicroscopic filterable virus. It passes readily through porcelain filters. It has never been cultivated. Fluid material will retain its virulence for a period of ten to fourteen weeks, at least, when kept at room-temperatures. It is killed by exposure to $60^{\circ}$ to $70^{\circ}$ for an hour. Desiccation does not destroy it at once, but only after a lapse of several days. It may be destroyed by disinfectants, but is relatively resistant.

Pathogenesis.-The subcutaneous injection of 1 to 2 c.c. of filtered blood-serum or body fluids results in the production of the disease. The animals may die of a very acute type of the disease, or it may assume a chronic form. The acute cases generally reveal, on autopsy, hyperemia and acute swelling of the internal organs, and hemorrhages on the serous and mucous membranes, and frequently a serous transudate into the pericardium. In the more chronic type ulcerated and necrotic areas are commonly found in the intestines, together with pneumonia.

The disease cannot be transferred to other animal species. The Bacillus cholera suis is probably a secondary invader, but the lesions produced by this organism may in some cases be of the greatest importance.

Immunity.-Animals that have recovered from an infection with hog-cholera are thereafter immune, and it has been shown that their blood has some immunizing power when injected into other susceptible individuals.

Practical methods of immunization were developed through the work of Dorset, McBryde, and Niles in this country. The method devised by them and commonly used is as follows: It is necessary to start with an animal that has recovered from the disease or that has already been immunized. This animal is then hyperimmunized by repeated injections of virulent blood. The latter must be shown to be virulent by actual test before it can be used. About 1 c.c. of the defibrinated virulent blood is injected for each pound of body weight. A week later an injection of two and one-half times as much is made, and after another week an injection of 5 c.c. Subsequent injections are made, preferably 
intravenously. The animal thus hyperimmunized is bled, from the tip of the tail usually, the blood allowed to clot, and the serum used for immunization. It is customary to preserve this serum from consecutive bleedings until a considerable quantity has accumulated, when it is tested for potency. For testing it is customary to use young pigs, weighing from 30 to 60 pounds. A serum of satisfactory potency should protect, in a dose of 15 c.c. or less, one of these animals against an injection of 2 c.c. of virulent blood. The serum injections of 20 c.c. are commonly used to protect pigs against infection. If the animals are exposed to infection, they may have a light attack of the disease, and are thereby rendered permanently immune. Where it is desired to immunize, and exposure to infection is not certain, a much more lasting .immunity is conferred by the use of the serum simultaneous method. In this method virulent blood ( 2 c.c.) is injected at the same time as the immune serum. This results in the development of an active immunity, which is relatively permanent in comparison with the immunity of two to three weeks conferred by antiserum injection alone. The use of this serum has been found to be highly successful in practice.

It is not known what property of the antiserum is thus effective, whether it is antitoxic, opsonic, or bactericidal. There is some evidence that it is the last, but proof is difficult to secure.

Transmission. - The virus may be demonstrated in the blood, the tissues, and the urine of infected animals. It is probable that infection commonly takes place through ingestion.

\section{Virus of Horse Sickness}

Disease Produced.-African horse sickness, or Pferderpest.

This disease, known from southern Africa for more than a century, was first shown by MacFadyean in 1900, and later-in 1901 - by Nocard, to be due to an ultramicroscopic, filterable virus. The disease is characterized as an acute or subacute disease of solipeds, that appears in epizoötics during the hot months of the year. The principal lesions are edematous swellings and hemorrhages of the internal organs. The virus will pass through a Berkefeld or a Chamberland porcelain filter if the serum is diluted with physiological salt solution. 
Immunization against the disease may be brought about by the use of serum from hyperimmunized animals. Koch hyperimmunized horses that had recovered from the disease by three to four injections of virulent blood at intervals of a week, as much as two liters being used for the last injection. Serum simultaneous injections of this hyperimmunized serum and virulent blood into susceptible animals in correctly proportioned doses will immunize.

The disease has been found to be contracted generally at night, and the first frost puts an end to the epizoötic for the year. Considerable quantities of the virus must be fed before an infection is produced, showing that natural infection is probably in some other manner than by ingestion. It is probable that mosquitos, possibly flies, act as carriers. The disease cannot be regarded, therefore, in the strictest sense as contagious.

\section{Virus of Infectious Anemia of the Horse}

Disease Produced.-Infectious anemia, pernicious anemia, mud fever, swamp fever of the horse.

This disease has been known as a clinical entity in Europe for three-quarters of a century. Carre and Villee (1904-1906) and Ostertag and Marek (1907) have demonstrated the disease to be due to a filterable virus. The disease has been studied in North America by several investigators, and the ultramicroscopic nature of the virus has been independently demonstrated. It is not certain that all the infections described under this name are identical, but there is considerable evidence tending to establish such as a fact.

Distribution. - The disease is probably wide-spread, but has not always been clearly differentiated. It is known from Germany, France, Hungary, Switzerland, and Sweden in Europe, and from Saskatchewan, Manitoba, Minnesota, the Dakotas, Nebraska, Kansas, Colorado, Wyoming, Montana, Texas, and Nevada in the United States.

Nature of the Virus.-The causal organism is an ultramicroscopic, filterable virus that cannot be differentiated by staining methods and has not been cultivated. It is found in the blood, the urine, and the feces of infected animals. It is destroyed at a 
temperature of $58^{\circ}$. It will withstand drying for several months, and liquids maintain their infectivity for months, even when decaying.

Pathogenesis.-The virulent blood or blood-serum will infect another animal upon subcutaneous injections of small quantities. The incubation period after injection varies from five to nine days, or even more. The initial symptom is a fever. The disease is more apt to be acute when the organism is introduced by injections than by ingestion. The disease may be characterized as an acute or chronic anemia which has the appearance of a septicemia in which there is a great destruction of blood-elements. The anatomical findings are characteristic. Mack, in his work on cases in Nevada, notes profound cardiac and respiratory disturbances. There is a progressive destruction of the red blood-cells, parenchymatous degeneration of the kidneys and liver, and extensive changes in the vascular system. The spleen is engorged and frequently degenerated, and the bone-marrow undergoes profound degeneration.

Immunity.- No method of immunization has been developed.

Transmission.-European writers are of the opinion that infection arises through the ingestion of food soiled by excretions of infected animals. The mode of dissemination has not been satisfactorily established.

\section{Virus of Dog Distemper}

Disease Produced.-Dog distemper, Hundstaupe.

Bacteria belonging to several different groups, particularly to the colon-typhoid and to the hemorrhagic septicemia, have been described as the cause of dog distemper. Carre, in 1905, attributed the cause to a filterable virus.

Distribution.-Europe and America, probably in other parts of the world.

Nature of the Virus. - Little is known of the virus beyond the fact that it can be passed through a porcelain filter. It has not been cultivated and is probably ultramicroscopic.

Pathogenesis. - The disease is a highly fatal, acute infection of young carnivorous animals, characterized by an acute catarrh of the mucous membrane, and frequently a catarrhal pneumonia. 
In a small percentage of the cases nervous symptoms develop. The discharge from the mucous membranes is highly infective. Secondary infection with bacteria is common, and is believed by some investigators to account for many of the deaths.

Immunity.--Many attempts have been made to prepare an antior immune serum that would be efficacious in preventing or curing the disease. Several have been placed upon the market, but none has been shown to be efficacious. It is possible that success might be attained by the use of hyperimmune blood.

Transmission.- The disease is transmitted by direct or indirect contact with infected individuals.

\section{Virus of Fowl Plague}

Disease 'Produced.-Fowl plague, chickenpest of domestic fowls.

This disease has generally been confused with chicken cholera, which it closely resembles clinically, although Penoncito undoubtedly described it in 1878. Centanni and Savonuzzi, in 1901, showed that the virus could pass through a porcelain filter. This has been amply confirmed by other writers.

Distribution.-The disease is known only from northern Italy, the Tyrol, Germany, and France.

Character of the Virus. - The organism is a filterable virus, and is probably ultramicroscopic, although Rosenthal, Kleine, and Schiffman have described bodies in the nerve-centers that are possibly protozoan in nature. The virus is found in the blood, the nasal secretion, and generally throughout the tissues. The blood retains its virulence for three months when sealed in tubes and kept in a dark place. The thermal death-point is $55^{\circ}$ for thirty minutes or $60^{\circ}$ for five minutes. The dried virus has been found to retain its virulence for two hundred days, and in glycerin and serum mixture for two hundred and seventy days. It is easily destroyed by disinfectants.

Pathogenesis.-Injection of as small amount as $\frac{1}{1,000,(00)}$ c.c. of virulent blood or secretions is sufficient to infect. The virus is pathogenic for many birds besides fowls, but not for mammals. The disease is characterized by the hemorrhages into the serous membranes in acute cases, and in the less acute edema 
of the subcutaneous tissues and of the serous membranes, and the formation of a fibrous exudate upon the latter.

Immunity.-Practicable methods of immunization have not been developed.

Transmission.-The disease is transmitted by the ingestion of food soiled with the infective feces, nasal secretion, or blood of infected birds.

\section{Virus of Epithelioma Contagiosum}

Disease Produced.-Fowl pox, epithelioma contagiosum in domestic fowls, sore head.

Marx and Sticker, in 1902, determined the cause of fowl pox to be a filterable virus. Several other investigators subsequently confirmed their results.

Distribution.-The disease is known to occur in Europe, in the United States, particularly the south, in California, and Hawaii.

Nature of the Virus.-Marx and Sticker showed that when an epithelial nodule was triturated in physiological salt solution that the fluid which passed through a Berkefeld filter was infective. Some investigators have observed tiny spherical granules, less than $0.25 \mu$ in diameter, in the emulsion of the virus, but it is by no means certain that these are the disease-producing organisms. The virus is relatively resistant to unfavorable conditions. The nodules may be dried for weeks without losing their infectivity. It is destroyed by heating to $60^{\circ}$ for eight minutes. Mixed with glycerin, it retains its infectivity for many weeks. It is easily destroyed by disinfectants.

Pathogenesis.-The disease is a chronic, contagious infection, characterized by an initial catarrh of the mucosa of the head, followed by wart-like growths (epithelial hyperplasia) of the skin, especially of the comb and naked skin of the head, sometimes associated with a croupous diphtheritic condition of the mucosa of the head. This latter condition is one of those grouped under the general name of fowl diphtheria. The disease commonly terminates favorably in three to five weeks.

Immunity.-No practicable method of immunization has been devised.

Transmission.-The disease is transmitted by direct contact with infected fowls. 


\section{Virus of the Poxes}

Disease Produced.-Small-pox in man, cow-pox, sheep-pox, horse-pox, swine-pox, goat-pox.

There is much doubt relative to the position of the virus of the various poxes. They are included in this group tentatively, as it is found that the contents of the vesicles of the eruptions may be filtered through a thin, coarse porcelain filter under pressure without losing their infectivity. The causal microörganisms are, at some stages, at least, filterable and probably ultramicroscopic. Certain cell inclusions have been described as being probably of protozoan nature, but the subject cannot be said at present to be completely elucidated. The protozoan parasite has been named Cytorhyctes vaccince in man.

Immunity.- Recovery from an attack of variola is accompanied by a relatively permanent immunity. Vaccination is, therefore, commonly practised, particularly against small-pox in man. The attenuated virus in this instance is secured by passage through an animal, usually a cow. The vaccinating material is the lymph from the vesicles produced on the animals. It is inoculated into the skin by scarification. The virulence is apparently very greatly decreased by this method of inoculation, so that a relatively mild type of disease is produced which terminates in immunity being established. To what this immunity may be due is not known.

\section{Virus of Yellow Fever}

Yellow fever in man has been shown to be due to a filterable virus, probably an ultramicroscopic organism. All efforts at cultivation have failed. The disease is spread only through the bite of mosquitos that have taken virulent blood. The organism evidently undergoes a part of its life-cycle in the blood of the mosquito (Stegomyia), for the latter does not become infective itself for several days. It is evidently more than a mere mechanical transfer of the organism by the mosquito; the latter serves as a true intermediate host.

\section{Virus of Epidemic Infantile Paralysis}

Disease Produced.-Acute poliomyclitis, Heine-Medin disease in children. 
This disease is known from Sweden, Germany, and the United States. Flexner and Lewis, in 1909, have shown the organism to be a filterable, probably ultramicroscopic, virus. The disease may be transferred to the monkey. It probably spreads by ingestion of infected materials.

\section{Virus of Rabies}

Disease Produced.-Rabies in animals. Hydrophobia in man. Lyssa.

The disease has been studied at great length by many investigators, and there is still great disparity of opinion as to the nature of the cause. Remlinger and Riff at Bey, in 1903, showed that the virus could be passed through a porous Berkefeld filter. This has been substantiated since by several workers. As will be seen below, this does not satisfactorily settle the problem, as those who hold to the protozoan nature of certain bodies in the nerve-centers in the disease, as they contend that extremely minute plastic stages in the life-cycle of the organism might easily pass through.

Distribution.-The disease is world wide in distribution.

Nature of the Virus.-Students of the etiology of this disease may be divided into two groups - those who believe in the presence of a specific ultramicroscopic organism, and those who believe in the presence of a protozoan with certain stages of development, when the organism is small enough to pass the pores of the filter. The latter theory has been developed by Negri. The organism has been named Neuroryctes hydrophobice. In 1903 he demonstrated the presence of specific bodies, which have been termed Negri bodies, in the larger ganglia-cells of the Ammon's horn, as well as in other parts of the central nervous system. There is little question but what these bodies are characteristic of the disease; the disputed point is whether they are specific organisms or degeneration products of the cell. Williams and Lowden summarize the evidence of the protozoan nature of these organisms as follows:

"They have definite characteristic morphology; this morphology is constantly cyclic, $i$. e., certain forms always predominate in certain stages of the disease, and a definite series of forms indicating growth and multiplication can be demonstrated; the 
structure and staining qualities, as shown especially by the smear method of examination, resemble that of certain known protozoa, notably of those belonging to the suborder Microsporidia."

The Negri bodies in suitably stained preparations are found to vary in size from less than 0.5 to $25 \mu$. In shape they may be spherical, ovoid, or ellipsoidal. The bodies show a characteristic structure, a smooth hyaline margin, with inclusions of various kinds that resemble chromatin granules.

They may be readily stained by Giemsa's method, or with eosin and methylene-blue.

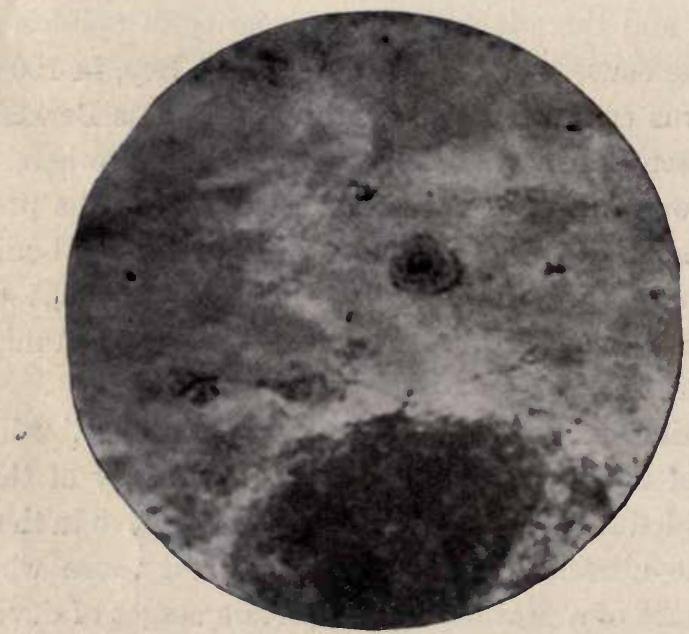

Fig. 212. - A Negri body. Note the circle of chromatoid granules about the central body ( $\times 2000)$ (Williams and Lowden).

Pathogenesis.- The organism enters the body through wounds, usually bites of animals. It then passes slowly along the peripheral nerves to the central nervous system. The portion of this to which these nerves directly lead is the most seriously affected. Characteristic gross anatomical lesions are quite lacking in this disease.

The period of incubation is variable; it is usually several weeks. It probably represents the period necessary for the virus to reach the central nervous system and develop there. The disease is commonly fatal. It affects most mammals, including man, but is primarily a disease of the earnivora, particularly the dog.

Immunity.-The Pasteur method of treatment is essentially a 
method of vaccination at intervals with attenuated virus. The virus is found, on experimentation, to be rather variable in its power to produce disease. The virulence is exalted by repeated inoculations of rabbits until it becomes the "fixed" virus of Pasteur, and will kill rabbits in six to seven days. This is then injected into a rabbit, and upon its death the spinal cord is carefully removed with all aseptic precautions, and suspended in a desiccator over caustic potash. It is kept at a constant temperature of $23^{\circ}$ in the absence of light for two weeks. The vaccine consists of an emulsion of this cord in physiological salt solution.

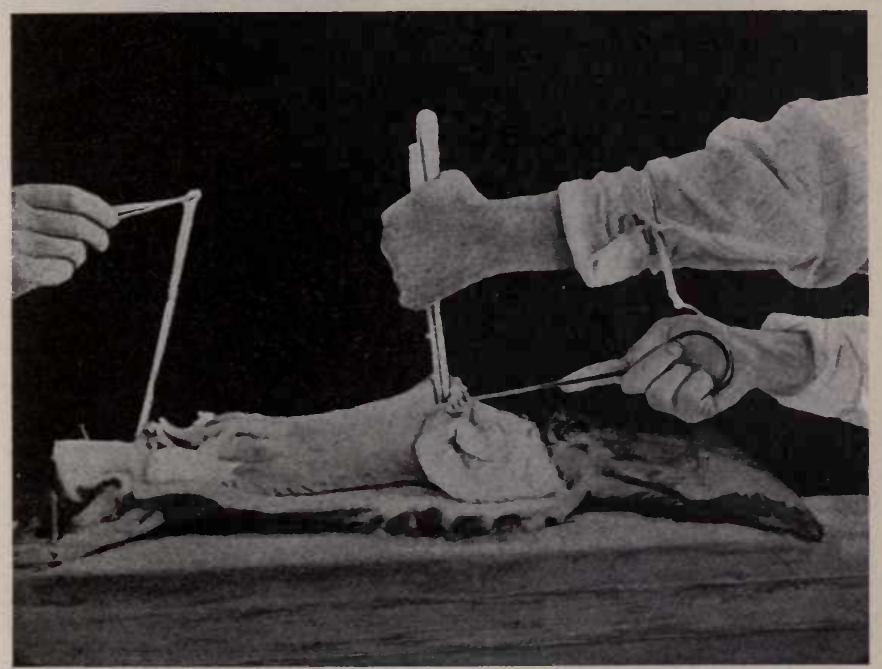

Fig. 213.-Removal of the spinal cord from a rabbit (Stimson, Bull. No. 65, Hygienic Laboratory).

Later, injections are made with a cord that has been dried for a shorter period. Repeated injections are made. The fact that the disease has normally a long incubation period gives an opportunity in the human for the use of this method. The active immunity established by the injection of the attenuated virus is sufficient to destroy the infecting organism. This method of treatment has been highly successful when commenced in time. It is still strictly an active immunity. To what principle it is due is not known.

Bacteriological Diagnosis.-The disease may be diagnosed by 
animal inoculation and by macroscopic examination. For the former it is customary to inject an emulsion from the brain into a rabbit. The inoculation is usually made subdurally. Sections or smears may be made from the brain and stained to show the characteristic Negri bodies. Small portions of the gray substance are removed from the cerebral cortex in the region of the crucial sulcus, the cerebellar cortex, and the hippocampus major. These are crushed on a slide and a smear made by means of a cover-glass. These dried smears may be stained by Giemsa or other stains,

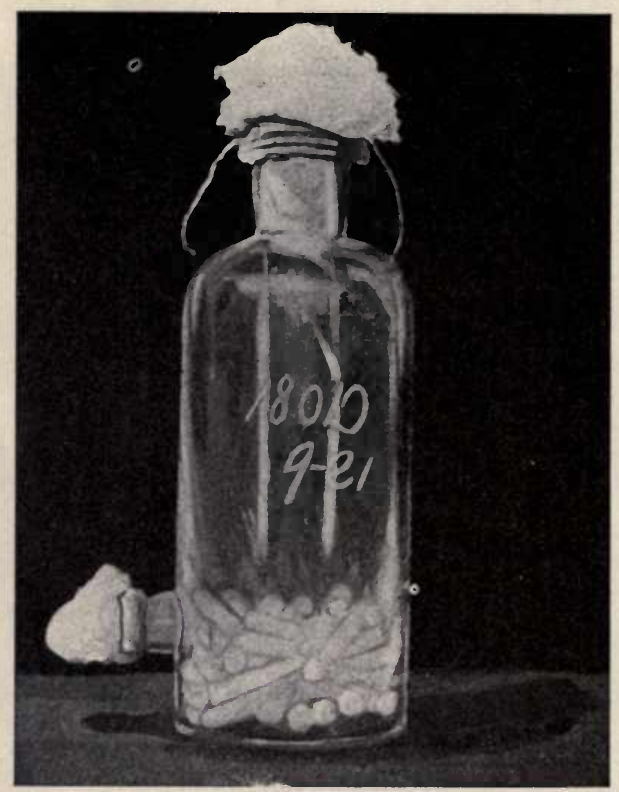

Fig. 214. - Method of drying the spinal cord of a rabbit for the purpose of attenuation (Stimson, Bull. No. 65, Hygienic Laboratory).

perhaps most readily by the method described by Williams and Lowden: "To 10 c.c. of distilled water three drops of a saturated alcoholic solution of basic fuchsin and 2 c.c. of Löffler's solution of methylene-blue are added. The smears are fixed while moist in methyl alcohol for one minute. The stain is then poured on, warmed till it steams, poured off, and the smear is rinsed in water and allowed to dry."

Transmission.- The saliva of diseased animals is found to be infective, and the disease is transmitted commonly through the bite. 


\section{BIBLIOGRAPHICAL INDEX}

Adelberg, 480

Arloing, 355

Arning, 328

Arthus, 176

Ayers, 206

BABEs, 258, 260, 456, 460

Bail, 181, 335, 337

Balfour, 450

Bang, 324, 341, 343, 344, 345

Banzhaf, 142, 143

Barber, 107

Bateman, 425

Battaglio, 425

Behring, 23, 138

Berg, 410

Beurmann, 405

Blanchard, 440

Blencig, 21

Bloch, 407

Bollinger, 302, 375

Bolton, 272

Bowman, 474

Bredini, 427

Brodin, 433

Bruce, 221, 425, 429

Buckley, 269, 270

Bumhall, 302

Bumm, 224

Busse, 386

Calkins, 414

Calmette, 323, 324

Carini, 425

Carre, 484, 485

Castellani, 454

Cazalbou, 433

Centanni, 486

Chagas, 437
Chamberland, 336

Charrin, 238

Chaussat, 437

Clegg, 377, 417, 418

Cohn, 20

Cole, 471

Conradi, 284

Corda, 372

Cornevin, 355

Councilman, 420

Craig, 416, 418, 420

Danman, 210

Danysz, 276

Davaine, 22, 331

de Beurmann, 405

Deneke, 371

Denys, 319

de Schweinitz, 271, 481

Desmon, 158

Dodd, 451

Doerr, 284

Dorset, 95, 271, 272, 481, 482

Douglas, 167

Dutton, 432, 436, 446

Duval, 446

EBERTh, 278

Ehrenberg, 20

Ehrlich, 23, 129, 131, 138, 139, 158

Eichhorn, 256

Elmassian, 431

Emmerich, 263

Emmerlich, 247

Emmet, 395

Engler and Prantl, 76

Eppinger, 382

Escherich, 263, 266

Evans, 22, 423, 428 
Fehleisen, 197

Fernmore, 302

Finkler, 371

Fitzpatrick, 471

Flexner, 220, 282, 489

Foth, 259

Fränkel, 215, 267

Fraser, 429

Friedländer, 215, 267

Frosch, 479

Frost, 97

Frost and McCampbell, 76

Frothingham, 326, 405

Gabritschewsky, 448

Gaffky, 278

Galli-Valerio, 384, 461

Gamaléia, 367, 369

Gärtner, 268

Gerber, 441

Gessard, 228

Gibson, 142

Gilchrist, 386

Gonder, 428

Graham-Smith, 461

Grassberger, 355, 357

Gruby, 408

Guglienni, 458

Guinard, 238

Gwyn, 274

HADLEy, 277, 278, 470, 471

Haffkine, 306

Hansen, 328

Harris, 338, 339, 340

Hartmann, 416, 422

Harvey, 277

Harz, 375

Haslam, 398

Hecker, 212, 479

Heinemann, 204, 205, 206

Hektoen, 203, 204

Henle, 22

Hertel, 298

Hess, 212

Hill, 99

Hirschfelder, 319

Hiss, 282

Hoffinann, 2:37, 451
Hueppe, 293

Hutyra, 481

JoBLING, 220

Johnes, 220, 226, 326

Johnson, 206

Jordan, 338, 339, 340, 372

Kardinski, 200

Kartulis, 419

Kirkpatrick, 278

Kitasato, 303, 349, 350, 355

Kitt, 196, 246, 250, 298, 302, 357, 408

Ǩlebs, 231, 319

Kleine, 425, 429, 431, 486

Knapp, 442, 447, 450

Koch, 99, 248, 309, 319, 331, 359, 369, $419,458,481,484$

Koidsumi, 416

Kolle, 306, 481

Konew, 255

Koram, 284

Krral, 408

Krumweide, 325, 326

Kruse, 204

Kühne, 254

Kumbein, 306

Kutscher, 260

LAFLEUR, 420

Lafosse, 207

Lambl, 418

Landmann, 319

Lange, 247

Laveran, 22, 433, 435, 462

Leclainche, 247

Leeuwenhock, 18, 20

Leger, 437, 467

Leishman, 204, 438, 439, 441, 447

Levaditi, 449

Lewis, 423, 437, 489

Liebig, 21

Lignières, 293, 297, 298, 323

Lister, 24

Loesch, 419

Löffler, 95, 232, 237, 244, 250, 276, $298,345,479$

Lorenz, 247 
Lowden, 489

Lucet, 200

MACFADYEAN, 483

Mack, 210, 485

MacNeal, 426, 430

Mallasez, 238

Manengold, 210

Marchoix, 442, 448, 450

Marck, 484

Marmorek, 203

Marx, 247, 487

Mastbaum, 247

Mathis, 437, 467

Mayer, 215, 298, 395

McBryde, 272, 482

McCampbell, 171, 173, 362, 364, 462

McCampbell and Frost, 76

McFarland, 174

MeGell, 446

Melvin, 402

Metchnikoff, 23, 126, 166, 185

Micellone, 226

Migula, 20, 76

Milne, 446

Mohler, 210, 222, 256, 269, 270, 346, $347,348,402$

Moore, 201, 210, 266, 314, 427

Morse, 277, 346, 348

Müller, F., 20

Murchison, 23

Musgrave, 377, 417, 418

NEGRI, 489

Neisser, 161, 224, 328

Nichols, 389

Nicolaier, 349

Nicolle, 439, 480

Niles, 482

Nocard, 197, 238, 241, 242, 266, 276, $378,478,479,480$

Nörgaard, 210, 238, 402

Novy, 426, 430, 442, 447, 450

Nowak, 341, 344

Nuttall, 154, 461, 467

OBermeier, 444

Ogston, 192, 197
Ostertag, 211, 213, 220, 301, 484

Otho, 283

PAGE, 405

Paige, 405

Park, 325, 326

Parum, 166

Pasteur, 21, 22, 197, 244, 246, 295, 297, 331, 335, 336, 359

Patton, 456, 462

Pecaud, 433, 435

Perkins, 404

Perroncito, 295, 486

Pfeiffer, 157

Pfuhl, 367

Phalen, 389

Phillips, 462

Pirquet, von, 323

Polk, 377

Pollender, 331

Pong, 446

Porrey, 226

Posades, 389

Prani, 461

Prantl and Engler, 76

Preisz, 238

Prettner, 247

Prior, 371

Prowazek, 441

RABE, 226

Raebiger, 212

Redi, 20

Rees, 463

Remlinger, 489

Rettger, 277, 278

Reynolds, 302

Ricketts, 121

Rivolta, 226, 384, 472

Robin, 130

Rodenwalt, 425

Rodet, 430

Roger, 238

Rosenau, 277

Rosenbach, 192, 196, 197

Rosenthal, 284, 486

Ross, 446

Rouget, 426 
Roux, 232, 258, 336, 478

Ruediger, 203

\section{Sacharoff, 448}

Salimbeni, 448, 450

Salmon, 271, 481

Savonuzzi, 486

Schattenfroh, 355,357

Schaudinn, 416, 418, 425, 451

Schenk, 404

Schiffman, 486

Schreiber, 298

Schreuber, 247

Schubert, 247, 256

Schütz, 207, 247, 250, 256, 298, 345 de Schweinitz, 271, 481

Selter, 260

Shiga, 282

Sieber, 428, 457

Silberschmidt, 380

Smith, 271, 299

Smith, T., 312, 314, 351, 456, 481

Sobernheim, 338

Solleysel, 207

Starcovici, 456

Sternberg, 215

Sticker, 487

Stimson, 491

Spitz, 298

Symons, 429

\section{TARTAKOWsky, 480}

Theiler, 430, 435, 436; 450, 458, 465

Thomas, 355), 427

Thuiller, 244, 246

Todd, 209, 284, 432, 446, 447

Tokoshige, 384, 385, 386

Toussant, 331

Trevisan, 293
Turner, 481

Tyndall, 476

UhLENhUth, 155, 481

Uschinsky, 94

VALENTINE, 423

Vallet, 430

Van Ermengem, 364

Veyl, 349

Viereck, 422

Vignal, 238

Villee, 484

Villemin, 309

Vincent, 381

Vladimiroff, 258

Voges, 247, 431

von Behring, 23, 138

von Pirquet, 323

WASHBURN, 222, 347

Wassermann, 230, 301

Watson, 468

Webber, 402

Weichselbaum, 218, 250

Weigert, 22, 133

Weil, 300

Welch, 361

Werner, 422

Werneke, 389

Wesbrook, 233

Wherry, 328

Wichsberg, 161

Widal, 407

Williams, 489

Wilson, 302

Wright, 167, 376, 439

Yersin, 232, 303 


\section{INDEX}

Aвortion bacillus, 341 group, 189, 341 contagious, in mares, 213

Abrin, 130

Abrus precatorius as a source of toxin, 130

Absorption of complement, 164

Acanthia lectularia, 445

Acetic acid fermentation, 64

Achorion, 393, 408 schoenleinii, 409

Acid, acetic, 64 butyric, 64

fermentation, 62

lactic, 63

production, tests for, 96

Acid-fast bacteria, non-pathogenic, 329

group, 188, 308

organisms, staining of, 104

Acquired immunity, 122

Actinomyces, 77, 81, 372

bovis, 374,375

capræ, 374,380

cœlicolor, 374

cuniculi, 345

eppingeri, 374, 382

farcinica, 378

group, 189, 372

maduræ, 374,381

nocardii, 374,378

Actinomycosis of cattle, 375

of dogs, 380

of goats, 380

Active anaphylaxis, 178

immunity, 22, 123

methods of conferring, 123

Addiment, 159

Aërobic, 47
Aërotaxy, 50

African horse sickness, 483

Agar, nutrient, 93

plate cultures, 113

stroke cultures, 10

Agglutination, 128, 147

group, 150

macroscopic test, 153

microscopic test, 152

tests for diseases, 151

Agglutinin, 147

body, 149

chief, 150

coagglutinin, 150

constitution, 148

Ehrlich's theory of production, 148

flagellar, 149

group, 150

hemagglutinins, 153

immune, 147

normal, 147

significance in immunity, 153

somatic, 149

Agglutinogen, 148

Agglutinoid, 149

Agglutinophore, 149

Aggressins, 181

Alcoholic fermentation, 62

Alexin, 158

Algæ, 26

Alkali production, tests for, 96

Alkali-poisoning, 338

Allergin, 177

Alpha-amido-acids, 65

Alt tuberculin, 318, 321

Amanita as source of toxin, 130

Amboceptor, 158

action of, 158

specificity, 158 
Amboceptor, structure, 158, 159

Amebic dysentery, 419

Ameboid colony, 113

Ammonia, oxidation, 69 tests for, 96

Amoba, 416 coli, 416,418 dysenteriæ, 419 meleagridis, 416

Anaërobic, 47 spore-producing group, 189, 340

Anaphylactin, 177

Anaphylaxis, 128, 176 active, 178

bacterial, 178

in tuberculosis, 322

passive, 178

specificity, 178

Anaplasma, 456, 465

marginale, 465

Anaplasmosis, 465

Anilin water, 103

Animal inoculation, animals used, 118 for isolation of pure cultures, 109 methods, 118

reasons for, 117

kingdom, divisions of, 26

Anopheles, 464

Anthrax, 331

group, 188, 331

Anti-abrin, 145

Anti-amboceptors, 159

Anti-anaphylaxis, 178

Antibacterial immunity, 128

Antibiosis, 56

Antibodies as factors in acquired immunity, 127

definition, 126, 127

in anaphylaxis, 177

Anticomplement, 160

Antienzymes, 145

Antiformin, 255, 312

Antigens, definition, 127

Antigonococeus serum, 226

Antipepsin, 145

Antiphthisin, 319

Antirennet, 145

Antiricin, 145

Antiseptic surgery, 191
Antiseptics, 52

Antistreptococcic sera, 203

Antitoxic immunity, 128

Antitoxins as factors in immunity, 127

constitution of, 134

definition, 131

diagrammatic representation, 135

diphtheria, concentration, 142

manufacture, 136

Ehrlich's theory of production, 133 of commercial importance, 136 tetanus, preparation, 143

standardization, 144

Antivenoms, 145

Aphthous fever, 479

Apiosoma bigeminum, 456

Apoplectiform septicemia of fowls, 210

Archispores, 455

Argas miniatus, 450

persicus, 448,450

reflexus, 450

Arnold steam sterilizer, 84,85

Arthritis, 202

Arthrospores, 35, 37

Ascomycetes, 40, 43

Ascospores, 395

of molds, 42, 43

of Peziza, 43

of yeasts, 40

Ascus, 42, 395

of Peziza, 43

Aseptic surgery, 192

Asiatic cholera, 369

group, 189

Aspergillosis, 395

Aspergillus, 393

flavus, 398

fumigatus, 395

glaucus, 394,400

niger, 399

nigrescens, 400

spore production, 43

subfuscus, 400

toxin production, 130

Attenuation of bacteria, 124, 173 methods of, 124

Autoclave, 85, 86

Autocytotoxins, 164 
Autogenic vaccine, 173

from M. aureus, 195

Autolysins, 162

Autolytic enzymes, 60, 61

Avenues of infection, 185

Avian diphtheria, 348

Azotobacter, 70, 71

agilis, 70

ehroococeum, 70

BABESIA, 456

bigeminum bovis, 456

parva, 458

Babesiosis, bovine, 456, 458

Bacillary dysentery, 282

Bacillus abortus, 341

aceti, 63

aërogenes capsulatus, 361

anaërobicus cryptobutyricus, 361

anthracis, 331

symptomatici, 355

avisepticus, 294, 295

of Babes, 260

botulinus, 349 , 364

production of toxins, 131

bovicida, 302

bovisepticus, 294, 302

bulgaricus, 63

butyricus, 64

cadaveris butyricus, 361

eapsulatus mucosus, 267

carrier, 281, 282

chauveaui, 355

chauvei, 349,355

choleræ, 295

gallinarum, 295

suis, $262,271,481$

clavatus, 236

coli communis, 262

isolation from water, 288

reduction of nitrates, 66

cuniculicida, 294, 303

of Danysz, 262, 276

denitrificans, 67

diphtheriæ, 231

production of toxins, 131

toxin, 236

vitulorum, 345

Wesbrook's types, 233
Bacillus dysenteriæ, 262, 278, 282 types of, 283

emphysematis vaginæ, 361

emulsion of Koch, 320

enteritidis, 262, 268

production of toxins, 131

sporogenes, 361

type A, 275

type B, 275

equisepticus, 294, 303

erysipelatis suis, 244

feseri, 355

filiformis, 345

of Flexner, 282

fæcalis alkaligenes, 262, 278

of Gärtner, 268

gastromycosis ovis, 349,359

genus, 77,78

of Hoffmann, 236

of Johnes' disease, 308, 326

of Kutscher, 260

lacti morbi, 331, 338

lactici acidi, 204

lactis aërogenes, 262

lepræ, 308, 328

lymphangitidis ulcerosa, 238, 241

mallei, 250

murisepticus, 244, 248

neapolitanus, 262

necrophorus group, 345

necrosus, 345

of Nicolaier, 349

œdematis, 359

maligni, 359

paratyphosus, 262, 274

pastorianum, 70

perfringens, 361

pestis, 295-303

bubonicæ, 303

of Pfeiffer, 239

phlegmones emphysematosæ, 361

pleurisepticus, 293

pneumoniæ, 262, 267

of Preisz, 238

prodigiosus pigment, 56

pseudodiphthericus, 231, 236

pseudofarcy, 241

pseudotuberculosis, 238

group, 238 
Bacillus pseudotuberculosis murium, 238

ovis, 238

psittacosis, 262, 276

pullorum, 262, 277

pyelonephritidis bovis, 242

pyocyaneus, 228

pigment production, 56

toxins, 131

pyogenes, 266

bovis, 236, 242

foetidus, 262

suis, 228,230

radicicola, 71

renalis bovis, 242

rhusiopathiæ suis, 244

Salmoni, 271

of Selter, 260

septicæmiæ hæmorrhagicæ, 293

shape, 27

of Shiga, 282

of tetanus, 349

smegmatis, 329,330

subtilis group, 331,333

suicida, 298

suipestifer, 271,481

suisepticus, 294, 298

tetani, 349

production of toxins, 131

tuberculosis, 308

typhi, 278

abdominalis, 278

murium, 262, 276

typhosus, 262, 278

welchii, 349,361

Bacteremia, 187

Bacteria, acetic acid, 64

amphitrichous, 34

and disease, 116

arthrospores, 35

atrichous, 34 .

Brownian movement, 35

butyric acid, 64

capsule, 31

cell inclusions, 34

cell-wall, 31

chromogenic, 56

chromoparous, 58

decay, 64, 65)
Bacteria, distribution, 61

ectoplast, 32

endospores, 35

enzymes, $5 \mathrm{~S}$

filamentous, 27

flagella, 34

food preservation, 74

glycogen, 34

grouping of cells, 28

groups of, pathogenic, 187, 1SS

histology of, 31

in retting, 74

in sauerkraut, 74

in silage, 74

in tanning, 74

in tobacco curing, 74

involution forms, 27

iron, 68

lactic acid, 63

legume, 71

lophotrichous, 35

measuring, 101

metachromatic granules, 34

monotrichous, 34

nitrate, 69

nitrite, 69

nitrogen fixing, 70

normal to body, 184

nucleus, 33

of the colon, 184

of the genito-urinary organs, 185

of the intestines, 184

rof the mouth, 184

$\checkmark$ of the skin, 184

of the stomach, 184

of water, 284

oil globules, 34

oxidizing, 67

peritrichous, 35

polar staining, 34

protoplasm, 32

putrefactive, 64,65

reducing, 66

reproduction, 35

rapidity, 35

shape, 27

sheathed, 32

size of, 30

spores, 35 
Bacteria, structure of, 31 sulphur, 67 vacuoles, 34

Bacteriaceæ, 77

Bactericidal action of sera, 157

Bacterins, 173 for M. aureus, 195

Bacteriology, definition, 17 medical, 18 scope of, 17 veterinary, 18

Bacteriolysins, 157, 128 normal, 160, 161

Bacteriolytic immunity, 128 sera, 161

Bacteriopurpurin, 46, 49

Bacterium abortum, 341 aërogenes, 266 anthracis, 331 avicidum, 295 bipolare multicidum, 302 coli commune, 262 diphtheriæ, 231 genus, 78

lepræ, 328 mallei, 250 phosphoreum, 57 tuberculosis, 308 welchii, 361

Bail's aggressin hypothesis, 181

Balantidium coli, 474

Balbiana, 456

Baleri, 433

Bang's abortion bacillus, 341

Barber pipette, 107

Basidiomycetes, 40

Bed-bug, 445

Beef broth, 91

Beerwort, 92

Beggiatoa sp. 67

Biliary fever of dog, 461

Biochemical tests, 96

Bismarck brown, 103

Black death, 305

Blackhead of turkeys, 470

Blackleg, 355

Blastomyces, 82 coccidioides, 384, 389 dermatitidis, 384, 386
Blastomyces farciminosus, 384 group, 189, 383

Blastomycetes, 383 ascospores, 40 cell inclusions, 38, 39 chlamydospores, 40 classification of, 82 cytoplasm, 39 form, 38 glycogen, 39 grouping, 38 morphology, 37 nucleus, 39 oil globules, 39 protoplasm, 38, 39 size, 38 spores, 40 vacuoles, 39

Blastomycotic dermatitis, 386 epizoötic lymphangitis, 384

Blepharoplast, 424

Blood serum as a medium, 94 cultures, 111

medium for B. tuberculosis, 312 recognition of, by precipitins, 155 stain, 106

Blue-green algæ, 26

Boöphilus bovis, 457 decoloratus, 467

Bordet-Gengou phenomenon, 163

Botryomycomata, 227

Botryomycosis, 226

Botryococcus ascoformans, 226

Botulism, 364

Bouillon, 91

Bovine farcy, 378

Bradsot, 359

Braxy, 359

Broth, beef, 91 extract, 91

glycerin, 92

serum, 92

sugar, 92

free, 91

Brownian movement, 35

Bryophytes, 26

Buboes, 305

Büffelseuche, 303

Butter bacillus, 329 
Cachexial fever, 438

Calf diarrhea, 265, 266

Calmette's ophthalmo-reaction, 323

Capsule, 31

bacterial, composition of, 31

Capybara, 432

Carbolic acid as disinfectant, 53

Caseous lymphangitis, bovine, 238

Castor oil bean as a source of toxin, 130

Catalyst, 59

Cattle plague, 480

Cell inclusions in bacteria, 34

glycogen, 34

metachromatic granules, 34

of molds, 40

of protozoa, 44

of yeasts, 38

oil globules, 34

polar granules, 34

receptors, 132

vacuoles, 34

wall of bacteria, 31

Cellulitis, suppurative, 202

Cellulose, 25

Centrosome, 424

Charbon, 331

symptomatique, 355

Chemicals, effect on microörganisms, 50

Chemotaxy, 50

Chemotropism, 52

negative, 50

positive, 50

Chicken cholera, 295

pest, 486

Chief agglutinins, 151

Chitin, 25, 31

chemical composition of, 31

Chlamydobacteriacese, 77, 80

Chlamydospores of chlamydomucor, 43

of molds, 42,43

of yeasts, 40

Cholera bacillus, 295

nostras, 371

spirillum group, 367

Chromogenic bacteria, 56

Chromoparous bacteria, 56
Chronic enteritis of eattle, 326

Cilia, 44, 413

Ciliophora, 414

Cladothrix actinomyees, 375

genus, $77,50,372$

Classification, history, 20

Migula's, 76

of animal kingdom, 26

of bacteria, 76

of microörganisms, 75

of molds, 82

of plant kingdom, 26

of protozoa, 412

of thallophytes, 26

yeasts, 82

Clostridium, 36

pastorianum, 70

Coagglutinin, 150

Coccaceæ, 77

Coccidioidal granuloma, 389

Coccidiosis of cattle, 473

of fowls, 470

of rabbit, 472

of sheep, 473

Coccidium, 456, 469

cuniculi, 472

tenellum, 469

Coccus, 27

Colon bacillus, 262

subgroup, 261, 262

Colon-typhoid group, 261

Columella, 43

Comma bacillus, 369

Commensals, 46, 56

Complement, 158

absorption of, 163

action of, 158

fixation of, 163

specificity, 158

structure of, 163

Complementoid, 159

Complementophilous haptophore, 159

Conidia, 37, 42

of Aspergillus, 43

of Penicillium, 43

Conidiophores, 42, 394

of Aspergillus, 43

of Penicillium, 43

Conjunctival tuberculin reaction, 323 
Conorhinus sp., 437

Consumption, 316

Contact beds, 292

Contagious abortion in cow, 341

in mares, 213

diseases, 183

of cattle, 480

Copula, 158, 464

Corynebacterium diphtheriæ, 231 pseudodiphthericum, 236

Cowpox, 488

Cresols as disinfectants, 53

Crithridia, 438

Cryptococcus farciminosus, 384

Culex, 465

Cultural characters of organisms, 110 media, preparation, 89

Cutaneous tuberculin reaction, 323

Cyanophyceæ, 26

Cytase, 158

Cytolysins, 157

group, 160

Cytophilous haptophore, 159

Cytorhyctes vacciniæ, 488

Cytotoxins, 157, 165

Decay, 64

Delhi boil, 439

Deneke's spirillum, 371

Denitrification, 66

Deodorant, 52

Desiccation, resistance to, by microorganisms, 46

Deuxieme vaccin, 336

Diastase, 59

Differentiation of plants and animals, 25

Diphtheria, 231

antitoxin concentration, 142

manufacture, 136

standardization, 138

avian, 348

group, 188, 231

toxin, manufacture, 136

standardization, 137, 140

Diplococcus, 28, 78

gonorrhœæ, 224

intracellularis equi, 220

meningitidis, 218
Diplococcus lanceolatus, 215

of Neisser, 224

pneumoniæ, 215

Discomyces bovis, 375

Disease, pathogenic theory of, 17

Disinfectants, 52

carbolic acid, 53

efficiency; determination, 99

formaldehyd, 54

lime, 53

mercuric chlorid, 53

phenol, 53

salts, heavy metals, 53

sulphurous acid, 53

Distemper, canine, 485

in equines, 207

Distribution of bacteria, 61

Dog distemper, 485

Dosing chamber, 291

Double serum, 247

Dourine, 426

Drug habituation, 130

Dum-dum fever, 438

Dung bacillus, 329

Dunham's solution, 92 use in indol test, 98

Duration of immunity, 126

Dysentery, amebic, 419 paratubercular, of cattle, 326

EAST African coast fever, 458 tick fever, 447

Eberth bacillus, 278

Eberth-Gaffky bacillus, 278

Eclampsia, puerperal, 179

Ectoplast, bacterial, 32

mold, 42

yeast, 39

Egg as a medium, 95

medium for Bacillus tuberculosis, 312

Ehrlich's humoral theory, 126

lateral-chain theory of immunity, 131

theory of cell nutrition, 131, 132

Electricity, effect of, 50

Elements necessary for cells, 45

Encystment, 413

Endocarditis, ulcerative, 201 
Endogenous infection, 186

Endospores, 35 germination, 36

Entamœba, 416

africana, 422

coli, 416, 418

histolytica, 416, 419

nipponica, 416

tetragena, 416, 422

Enteral introduction of organisms, 176

Enteritidis subgroup, 261, 268

Enteritis, chronic, of cattle, 326

Enterohepatitis, 470

Enzymes, 58

autolytic, 60,61

diastase, 59

extracellular, 58,61

gelatinase, 59

hydrolytic, 59

intracellular, 58,61

invertase, 59

oxidases, 59

oxidizing, 59

pepsin, 59

ptyalin, 59

reducing, 60

rennet, 59

splitting, 59

zymase, 58, 59

Epithelioma contagiosum, 487

Epizoötic lymphangitis, 404

Equine biliary fever, 458

Erysipelas, 201

swine, 244

Eubacteria, 77

Eurythermic bacteria, 48

Exanthema, 187

Exogenous infection, 185

External resistance of body, 121

Facultative bacteria, 47

Farcin du bouf, 378

Farcy, 250

Favus, 409

Fermentation, 58

acetic acid, 64

acid, 62

alcoholic, 62
Fermentation, butyric acid, 64 lactic acid, 63 tubes, 96

Ferments, acetic acid, 64 acid, 62

alcoholic, 62

butyric acid, 64

lactic acid, 63

organized, 58

unorganized, 58

Filterable virus, 476

Filtration, stcrilization by, 87

Fixateur, 158

Fixation of complement, 164

in diagnosis of glanders, 256

Fixed virus, 491

Flagella of bacteria, 34

of protozoa, 44, 413

stain, van Ermengem's, 105

Löffler's, 105

Fluorescin, 229

Fomite, 183

Food relationships of microörganisms, 45

Foot-and-mouth disease, 479

Foot rot of cattle, 348

of sheep, 202

Formaldehyd, 54

Fowl cholera, 295

diphtheria group, 188

plague, 486

pox, 487

septicemia, 367

Friedländer's pneumococcus, 267

Fuchsin, carbol-, 103

phenol, 103

Ziehl's, 103

Fungi, 26

imperfecti, 392

Fusarium, 393, 400, 402

corallinum, $402^{\circ}$

GALL sickness, 435, 465

Gallionella ferruginea, 68

Galziekte, 435, 465

Gambian horse sickness, 432

Gas production, tests for, 96

Gaseous edema, 361 
Gasometer, 97

Gelatin nutrient, 93 plate culture, 112 stab cultures, 111

Gelatinase, 59

Gentian violet, anilin, 103 aqueous, 103

Germicide, 52

Gibberetta, 402

Glanders, 250 group, 188,250

Glossinia morsitans, 431 palpalis, $431,435,437$

Glycerin agar, 93 broth, 92 gelatin, 93

Glycogen in bacteria, 34

Goat pox, 488

Gonococcus, 224

Gonorrhea, 224

Gram's stain, 106

Granular vaginitis in cattle, 211

Granulobacillus saccharobutyricus immobilis, 361

Grass bacillus of Moeller, 329

Groups of pathogenic organisms, 187 abortion bacillus, 189 acid-fast, 188

actinomyces, 189 anaërobic spore-producing, 189 anthrax, 188

blastomyces, 189

diphtheria, 188

fowl diphtheria, 188

glanders, 188

hemorrhagic septicemia, 188

hyphomycetes, 189

intestinal, 188

necrosis bacillus, 189

non-specific pyogenic bacilli, 188

coccus, 188

pseudotuberculosis, 188

specific coccus, 188

spirillum, 189

spirochete, 189

swine erysipelas, 188

Growth temperature range, 48

Gruber-Widal test, microscopic, 151
H正atococcus, 456

bovis, 456

Haffkine's vaccine, 306

Halteridium, 456, 465

Hanging drop, 101

Haptophore, complementophilous, of amboceptor, 159

cytophilous, of amboceptor, 159

of agglutinin, 148

of antitoxin, 134

of enzyme, 145

of precipitin, 154

of toxin, 134

Hautschicht, 39

Healing by first intention, 191

Heine-Medin disease, 488

Helcosoma tropicum, 439

Heliotropism, 52

Hemagglutinins, 153

Hemoglobinuria in sheep, 460

Hemolysins, 157, 162

Hemoproteus, 456, 465

Hemorrhagic septicemia group, 188 293

of birds, 294, 295

of cattle, 294, 302

of horses, 294, 303

of man, 295, 303

of rabbits, 294, 303

of rodents, 295,303

of swine, 294, 302

Hemotoxin, 131

of Bacillus pyocyaneus, 230

Hepatization of lungs, 216

Hepatozoön perniciosum, 467

Herpes tonsurans, 408

Herpetomonas, 423, 438

donovani, 438

infantum, 439

Heterologous, 148

Heterolysins, 162

Hilfkörper, 158

Histology of bacteria, 31

of blastomycetes, 37

of hyphomycetes, 41

of molds, 41

of saccharomycetes, 37

of yeasts, 37,38

Hog cholera, 271, 481 
Hog-cholera subgroup, 261, 268

Homologous, 148

Horse pox, 488 sickness, 483 syphilis, 426

Hot-air oven, 84

Humors' of body in Ehrlich's theory, 126

Hundstaupe, 485

Hydrochærus capybara, 432

Hydrophobia, 489

Hydrotropism, 52

Hyperimmunization, 161

Hypersusceptibility, 176

Hypha, 41, 392

Hyphomycetes, 40, 392

form, 40

group, 189, 392

histology, 41

morphology, 40

reproduction, 42

size, 40

Hypobosca rufipes, 436

IMMUNE body, 158

in anaphylaxis, 177

Immunity, acquired, 122, 123

active, 122,123

definition, 121

duration, 127

history of, 23

individual, 122

natural, 122

passive, 122

racial, 122

specific, 122

theories of, 125

to anaphylaxis, 178

unit of diphtheria antitoxin, 139

of tetanus antitoxin, 144

Immunkörper, 158

Indol, composition, 66 test for, 98

Infantile kala-azar, 439

paralysis, 488

Infection atrium, 185

endogenous, 186

exogenous, 185

mixed, 187
Infection, non-specific, 186 phlogistic, 187

primary, 187

secondary, 187

specific, 186

Infectious anemia, 484

disease, 183

Inflammation, 190

Infusoria, 414, 474

Ingestion, inoculation by, 119

Inhalation, inoculation by, 119

Intermediate subgroup, 261, 268

Intermittent sterilization, 84,85

Internal resistance of body, 121

Intestinal group, 188, 361

Intracardiac injection, 119

Intracranial injections, 118

Intradermal tuberculin reaction, 323

Intra-ocular injections, 119

Intraperitoneal injection, methods, 118

Intrathoracic injection, 119

Intravenous inoculation of rabbit, 118

Invertase, 59

Involution forms of bacteria, 27

Iron bacteria, 68

Isolysins, 162

Itch disease, 402

Ixidoplasma bigeminum, 456

JEQUIRITY bean as source of toxin, 130

KALA-AZAR, 438

infantile, 439

Kinetonucleus, 424

Klebs-Löffler bacillus, 231

Koch's rules, 116

difficulties, 116

statement, 116

Konew's precipitation test for glanders, 255

Lo dose diphtheria toxin, 141

$\mathrm{L}+$ dose diphtheria toxin, 141

Laboratory methods, history, 22

Lactic-acid fermentation, 63

Legume bacteria, 71

Leishman-Donovan bodies, 438

Leishmania donovani, 438

farciminosa, 384 
Leishmania infantum, 439 tropica, 439

Leprosy, 328

Leptothrix genus, $77,80,372$ ochracea, 68

Leukocidin, 194 of Bacillus pyocyaneus, 230

Leukocytozoön, 456, 467

Light, disinfecting action of rays, 49 relationships of microörganisms, 49

Lip and leg ulceration of sheep, 348

Lockjaw, 349

Louse, body, 446

Lumbar puncture, 220

Lumpy jaw, 375

Lung plague, 478

Lupus, 316

Lymphangitis, epizoötic, 384, 404 ulcerative, 241

Lyssa, 489

\section{Macrogametes, 469}

Macronucleus, 44

Macrophages, 166

Madura foot, 381, 382

Mal de caderas, 431

Maladie du coit, 426

Malaria, 463

Malarial catarrhal fever, 460

Malignant carbuncle, 331 edema, 359 jaundice of dog, 461

Malignes œdem, 359

Mallease, 256

Mallein, 258

Malleinum siccum, 259

Malta fever, 221

Mammitis, cattle, 214

Marginal points, 465

Mastigophora, 414, 415, 423

Mastitis, 202 cattle, 214

Maul-und-Klauenseuche, 479

Maximum growth temperature, 48

Meat differentiation by precipitation test, 155

poisoning, 364

due to Bacillus botulinus, 364

due to Bacillus enteritidis, 268
Media, beef-broth, 91 from beef extract, 91

beerwort, 92

blood-serum, 94

Löffler's, 95

bouillon, 91

Dunham's solution, 92

egg, 95

glycerin broth, 92

milk, 92

nutrient agar, 93 gelatin, 93

potato, 94

serum broth, 92

sugar broth, 92

sugar-free broth, 92

synthetic, 92

Uschinsky's solution, 92

Medical bacteriology, 18

Mediterranean fever, 221

Meningitis, 218

human epidemic, 218

Meningococcus, 218

Mercuric chlorid, 53

Merismopedia, 78

Merozoïtes, 469

Mesophilic bacteria, 48

Metachromatic granules, 34

Metastatic infections, 119

Metatrophic bacteria, 46

Metazoa, 26, 43, 412

Methods, staining, 102

Methylene-blue, Gabbett's, 103

Löffler's, 102

Micrococcus albus, 191, 196

toxins, 131

ascoformans, 207, 226

aureus, 191, 192

toxins, 131

botryogenus, 226

bovis, 191, 196

caprinus, 207, 222

cereus albus, 191, 197

flavus, 191, 197

citreus, 191, 196

epidermidis albus, 191, 197

gonorrhœæ, 207, 224

intracellularis equi, 207,220

lanceolatus, 207, 215 
Micrococcus mastitidis, 191, 196

melitensis, 207, 221

meningitidis, 207, 218

ovis, 191,197

pneumoniæ, 207, 215

pyogenes albus, 196

aureus, 192

bovis, 196

citreus, 196

weichselbaumii, 218

Microgametocytes, 469

Micron, 30, 101

Micronucleus of protozoa, 44 of trypanosomes, 424

Microphages, 166

Microscope and its influence, 18

Microspira, 79

comma, 369

metschnikovi, 367

Microsporon, 393, 404, 408

adouini, 408

carinum, 408

equinum, 408

furfur, 408

Milk as a medium, 92

cultures in, 111

litmus, 92

cultures in, 112

sickness, 338

Milzbrand, 331

Minimum lethal dose of diphtheria toxin, 137

of tetanus toxin, 144

temperature, 48

Mist bacillus, 329

Moisture relationships of microörganisms, 46

Mold group, 392

Molds, classification, 82

form, 40

histology, 41

morphology, 40

nitrogen fixing, 71,72

reproduction, 42

size, 40

structure, 41

Monilia candida, 410

Mordant, 102

Morphology of bacteria, 25, 31
Morphology of blastomycetes, 37 of hyphomycetes, 40

of molds, 40

of saccharomycetes, 37

of yeasts, 37

Morve, 250

Morvin, 258

Motor nucleus, 424

Mouse septicemia, 248

Mucin, 32

Mucor, 42,43

sporangium, 43

zygospore, 43

Mud fever, 484

Mycelium, 41, 392

Mycetoma, 381, 382

Mycobacterium diphtheriæ, 231

lepræ, 328

mallei, 250

pseudodiphthericum, 236

pseudotuberculosis, 238

tuberculosis, 308

Mycorrhiza, 72

Myxosporidia, 455

Nagana, 429

Natural immunity, 122

Navel-ill, 191

Necamspora, 402

Necrosis bacillus group, 189, 345

Necrotic dermatitis, 347

metrit is, 348

pox, 347

scratches, 347

vaginitis, 348

vulvitis, 348

Negative phase, 172

Negri bodies, 489

Nephelometer, 174

Nephrolysins, 157

Nessler's solution, 96

Neurocytes hydrophobiæ, 489

Neurotoxin, 131

New tuberculin of Koch, 320

Nitrate bacteria, 69

Nitrification, 69

Nitrites, tests for, 98

Nitrogen cycle, 73

fixation, 70 
Nitrogen, non-symbiotic, 70

symbiotic, 71

Nitroso-bacteria, 69

Nitrosomonas europea, 69 javensis, 69

Nocardia farcinica, 378 genus, $77,80,372$

Nodules in tuberculosis, 316 on roots of legumes, 71

Non-specific pyogenic bacillus group, 188,228

coccus group, 188, 190

Normal solutions, 89

Noxious retention theory of immunity, 126

Nucleus molds, 41

protozoa, 44

yeasts, 39

Nutrient broth, cultures in, 111

Nutrients required by bacteria, 90

(EDEME malin, 359

Oïdium, 393, 408

albicans, 410

coccidioides, 389

dermatitidis, 386

porrigenis, 409

type of spore, 42,43

Oil globules, 34

immersion, objective, 100

optics of, 100

Omphalophlebitis, 201

Oöcyte, 469

Oökinete, 464

Öspora, 393, 408

porrigenis, 409

Ophthalmo-tuberculin reaction, 323

Opilacao, 437

Opsonic index, 169

materials needed, 169,170

McCampbell's modification, 171 method, 171

Opsonins, 128, 166

immune, 168

normal, 168

occurrence, 167

Optimum growth temperature, 48

Organella, 44, 412

Oriental sore, 439
Ornithodorus moubata, 446, 448

Osmotic pressure, adjustment of organisms to, 55

Ovine caseous lymphadenitis, 238

Ovoplasm orientale, 439

Oxidase, 59

Oxidation by bacteria of ammonia, 69 of hydrogen sulphid, 67

of iron, 68

of nitrites, 69

Oxytuberculin, 319

Paracolon bacillus, 274

Paraformaldehyd, 54

Paraphyses, 43

Parasites, 46

Paratrophic bacteria, 46

Paratubercular dysentery of cattle, 326

Paratyphoid, 274

Parenteral injection of organisms, 176

Passive anaphylaxis, 178

immunity, 122, 124

Pasteurella, 293

Pasteurellosis, 293

of birds, 294, 295

of cattle, 294, 302

of horses, 294, 303

of man, 295, 303

of rabbits, 294, 303

of rodents, 295, 303

of swine, 294, 298

Pasteur method of vaccination against hydrophobia, 490

Pasteurization of milk and Streptococcus lacticus, 205

Pathogenic organism, definition, 119

Pearl disease, 316

Pediculus vestimenti, 446

Penicillium, 393, 399

glaucum, 401

spore production, 43

Pepsin, 59

Peptonization, 65

Period of incubation, 130

Peripneumonia, 478

Perithecium, 395

Peritonitis, 201

Perlsuche, 316 
Pernicious anemia, 484

Petri dish, 108

Peziza, 43

Pfeiffer's phenomenon, 157

Pferdepest, 483

Phagocytes, classification, 166 definitions, 126, 166

Phagocytosis, theory of, 126, 166

Phenol as disinfectant, 53

Phenomenon of Arthus, 177 of Theobald Smith, 187

Philocytase, 158

Phlogistic disease, 187

Photogenic bacteria, 57

Phycomycetes, 40

Physiological characters, 115 salt solution, 56

Physiology of microörganisms, 45 antibiosis, 46

antiseptic, 52

chemicals, 50

commensalism, 46

disinfectants, 52

electricity, 50

fermentations, 58

food relationships, 45

light, 49

production, 57

moisture relationships, 46

pigment production, 46

respiration, 47

symbiosis, 46

temperature, 48

Pigments, bacterial, 56

diffuse, 56

Piroplasma, 456

bigeminum, 456

canis, 461

commune, 462

equi, 458

gibsoni, 462

mutans, 458

ovis, 460

parvum, 458

Piroplasmosis, bovine, 456,458

canine, 461,462

equine, 458

ovine, 460

Planococcus genus, 77
Planosarcina, 77

Plant kingdom, divisions of, 26

Plasmodium, 456, 462

falciparum, 465

immaculatum, 465

malariæ, 464

vivax, 463

Plasmolysis, 33,55

Plasmoptysis, 33

Plate cultures, 108

Pleuropneumonia, 478

epizoötic, of equines, 214

Pneumobacillus, 215, 267

Pneumococcus, 215

Pneumomycosis, 395

Pneumonia, 215

traumatic, 201

Polar staining, 34

Poliomyelitis, 488

Pollan in, 145

Pollen as source of toxin, 130

Polyvalent vaccines, 173

Positive phase, 172

Potato as a medium, 94 cultures, 110

Pox, 488

Precipitation, 128, 147 bacterial differentiation, 156 blood stain, differentiation, 155 group, 154

meat differentiation, 155

uses, 154

Precipitin, 147, 154

Precipitogen, 154

Precipitoid, 154

Predisposing factors to disease, 122

Premier vaccine, 336

Preparator, 158

Presumptive test for Bacillus coli, 288

Proteins, decomposition, 65

Proteolysis, 65

Proteosoma, 456, 465

Prototrophic bacteria, 46

Protozoa, form and size, 44

histology, 44

morphology, 43

pathogenic, 412

reproduction, 44

Pseudofarcy, 241, 384 
Pseudoglanders, 241

Pseudomonas æruginosa, 228

genus, 78

pyocyanea, 228

Pseudopodia, 413

of protozoa, 44, 413

Pseudotuberculosis group, 188, 238

Psittacosis, 276

Psychrophilic bacteria, 48

Pteridophytes, 26

Ptomains, 65

Ptyalin, 59

Puerperal fever, 201

Pure culture methods, animal inoculation, 118

dilution, 107

direct isolation, 107

plating, 108

smearing, 107

use of differential antiseptics, 109

Pus, 191

of heat, 109

Putrefaction, 64

Pyelonephritis, 242

Pyemia, 187

produced by Streptococcus pyogenes, 201

Pyocyanin, 229

Pyogenic organisms, 190

Pyrosoma, 456

bigeminum, 456

Pythogenic theory of disease, 23

QUARTAN malaria, 464

Quarter evil, 355

ill, 355

RABIES, 489

Rauschbrand, 355

Reactivation, 157

Receptors, cell, 132

Recurrent fever, 444, 446

Red fever of swine, 244

Reducing enzymes, 60

Reduction of chlorates, 67

of nitrates, 66

of sulphates, 66

processes, 66
Reduction, tests for, 97,98

Relapsing fever, 444, 446

Rennet, 59

Reproduction in bacteria, 35

in hyphomycetes, 41

in molds, 41

rapidity, 35

Respiration of microörganisms, definition, 47

Rheumatism, 202

Rhipicephalus annulatus, 457

appendiculatus, 458

bursa, 460

decoloratus, 450 .

simus, 458

Rhisopoda, 414, 415

Rhodesian red-water, 458 tick fever, 458

Rice-water stools, Asiatic cholera, 369, 371

Ricin, 130

Ricinus communis as source of toxin, 130

zanzibarensis as source of toxin (ricin), 130

Rigor mortis, 60

Rinderpest, 480

Rinderseuche, 302

Ring test for glanders, 255

Ringworm, 408

Rotlauf, 244 doppelserum, 247

Rotz, 250

Rouget, 244

Roup, 470

SaCCHAROMyces, 383

cerevisiæ, 62,82

dermatitidis, 386

genus, 82

Saccharomycetes ascosporus, 40

cell inclusions, 38, 39

chlamydospores, 40

classification, 82

cytoplasm, 39

ectoplast, 39

form, 38

glycogen, 39

grouping, 38 
Saccharomycetes, morphology, 37 nucleus, 39

oil globules, 39

protoplasm, 38

reproduction, 38

size, 38

spores, 40

vacuoles, 39

Salmonella, 271

Salts of the heavy metals as disinfectants, 53

Sand filtration, 292

Sanitary science, 23

Sapremia, 187

Saprophytes, 46 -

Saprozoïtes, 46

Sarcina genus, 77 grouping, 29

Sarcocystis, 456, 468 bertrami, 467

Lendemanni, 469 miescherinia, 469

muris, 468

tenella, 469

Sarcodina, 414, 415

Sarcoptes equi, 404

Sarcoptic dermatitis, 402

Sarcosporidiosis, 468

Sausage poisoning, 364

Scarification as means of inoculation, 119

Schizomycetes, 26

Schizonts, 469

Schizophyces, 26

Schweinepest, 481

Schweineseuche, 298

Sclerotium, 392

Scrofula, 316

Sedimentation, 290

Sensibilisin, 177

Sensibilisinogen, 177

Sensitization, 128

Septic tank, 291

Septicemia, 187

of fowls, 367

gangreneuse, 3.59

produced by Streptococcus pyogenes, 201

Septicidin, 298
Septum, 41

Serum antidiphtheriticum, 138

broth, 92

sickness, 176

Sewage disposal, 291

Sheaths, bacterial, 32

Sheep box, 488

Side-chain, definition, 132

Skatol, 66

Sleeping sickness, 436

Smallpox, 488

Sorehead, 487

Souma, 434

Soumaya, 434

Sources of food for microörganisms, 45

Specific coccus group, 188, 207

infection, 186

Spermatophytes, 26

Spirillacex, 77

Spirillosis of cattle, 450

of fowls, 448

of horses, 450

of man, 444,446

of sheep, 450

Spirillum anserina, 448

cholerx, 367,369

asiaticæ, 369

isolation from water, 288

of Deneke, 371

desulfuricans, 67

duttoni, 446

of Finkler and Prior, 371

genus, 77,79

group, 189, 367

marchouxi, $44 \mathrm{~S}$

metschnikovi, 367

nicollei, 448

obermeieri, 444

ovina, 450

pallidum, 4.51

phosphorescens, 371

shape, 27

theileri, 450

tyrogenum, 371

Spirochxta anserina, 443, 445

denticola, 441

dentium, 441

duttoni, 443, 446

equi, 450 
Spirochæta evansi, 428

gallinarum, 443, 448

genus, $77,80,423,439,443$

inequalis, 441

kochi, 447

novyi, 448

obermeieri, 443,444

ovina, 444

ovis, 443

pallida, 451

perfringens, 443

pertenuis, 454

pinnæ, 440

recta, 441

tenuis, 441

theileri, 450

undulata, 441

Spirochete group, 189, 440

Spirochetosis of fowls, 448

Spirophyllum ferrugineum, 68

Spiroschaudinnia, 443

duttoni, 446

recurrentis, 444

Spirosoma, 79

Splenic fever, 331

Splitting enzymes, 59

Spontaneous generation, 20

Sporangiophore, 42

of mucor, 43

of sporodinia, 43

Sporangium of mucor, 43

of sporodinia, 43

Spore case, 42

Spores, bacterial, 35

germination, 36

of hyphomycetes, 42

of molds, 42

of mucor, 43

of penicillium, 43

of peziza, 43

of sporodinia, 43

of yeast, 40

staining of, 104

Sporoblasts, 455

Sporodinia, 43

Sporotrichosis, 404

Sporotrichum, 385, 393, 404

adouini, 408

Beurmanni, 404
Sporotrichum schenkii, 404

tonsurans, 408

Sporozoa, 414, 455

Sporozoïtes, 455, 469

Stable pneumonia, 214

Staining methods, acid-fast, 104 acid alcohol, 104

Gabbett's method, 104

blood, 106

flagella, 105

Löffler's, 105

van Ermengem, 105

for Bacillus tuberculosis, 104

Giemsa's, 106

Gram's, 106

preparation of mount, 103

protozoan, 106

Romanowsky, 106

spore stain, 104

Hansen, 104

Möller's, 104

Stains, acid, 102

basic, 102

Bismarck brown, 103

carbol fuchsin, 103

Gabbett's, 103

Löffler's methylene-blue, 102

mordants, 102

phenol fuchsin, 103

Stalactite formation of Bacillus pestis, 304

Staphylococcus, 29

aureus, 192

citreus, 196

pyogenes albus, 196

aureus, 192

bovis, 196

citreus, 196

Staphylolysin, 194

Starters, 206

Stegomyia, 488

Stenothermic bacteria, 48

Sterigma, 394

Sterigmata of aspergillus, 43

Sterigmatocystis, 393, 394

Sterilization, 83

at low temperatures, 87

by chemicals, 87

by filtration, 87 
Sterilization by flame, 87

by hot air, 83

by steam under pressure, 85

by streaming steam, 84

intermittent, 84,85

Sterilizer, Arnold steam, 84, 85

Sternberg bulb, 99

Stomoxys calcitrans, 428

Strangles, 207

Strauss' biologic test for glanders, 254

Street virus, 491

Streptobacillus, 29

Streptococcus agalactiæ contagiosæ, 214

articulorum, 197

capsulatus gallinarum, 210

contagious abortion in mares, 213 coryzæ contagiosæ equorum, 207

equi, 207

erysipelatos, 197

gallinarum, 207, 210

genus, 28,77

lacticus, 63, 191, 204

mastitidis sporadic $x, 214$

meningitidis, 218

Ostertag, 211

pneumoniæ, 215

puerperalis, 197

pyogenes, 191, 197

malignis, 197

scarlatinosus, 197

septicus, 197

Streptolysin, 200, 202

Streptothricosis in cattle, 375

in dogs, 380

in goats, 380

in man, 381

Streptothrix, 81, 372

actinomyces, 375

bovis, 375

canis, 380

capræ, 380

colicolor, 374

cuniculi, 345

eppingeri, 382

farcinica, 378

freeri, 382

maduræ, 381

necrophora, 345
Streptothrix nocardii, 378

Structure of protozoa, 412

Subcutaneous inoculation methods, 118

Subdural inoculation, 119

Substance sensibilisatrice, 158

Sulphur dioxid as disinfectant, 53

Sulphurous acid as disinfectant, 53

Suppuration, 190

Surra, 428

Susceptibility, 121

variations in, 122

Swamp fever, 484

Swine erysipelas, 244

group, 188, 244

fever, 481

plague, 298

pox, 488

Symbion, symbiont, 56

Symbiosis, 56

Symptomatic anthrax, 355

Synthetic action of microörganisms, 61

media, 92

Syphilis, 451

TABANUS fumifer, 429

Takosis, 222

Temperature relationships of microorganisms, 48

Tertian malaria, 463

Tetanolysin, 353

Tetanospasmin, 353

Tetanus, 349 . antitoxin, preparation of, 144 standardization of, 144 toxin, preparation of, 144 standardization of, 144

Tetracoccus, 28

Texas fever, 456

Thallophytes, 26 classification of, 26

Theileria parva, 458

Theories of immunity, 125

Ehrlich's humoral, 126

exhaustion, 125

Metchnikoff's, 126

noxious retention, 126

Thermal death-point, 48 
Thermal death-point, conditions governing, 48, 49

method of determination, 99

Thermophilic bacteria, 48

Thiobacteriaceæ, 77

Thiophysa volutans, 67

Thiothrix, 77, 81

Thrush, 410

Tick fever, 446 in cattle, 456 in sheep, 460 Rhodesian, 458

Tinea favosa, 409

Torula, 82, 383, 384

Toxemia, 187

Toxin, tetanus, preparation of, 143 standardization of, 144

Toxine, 129

Toxins as factors in immunity, 127 characteristics of, 129

constitution, 134

definition, 129

diagrammatic representation, 135

manufacture, 136

of pollen, 130

preferential union with body cells, 135

sources, 130 .

specificity, 131

Toxoid, 134

Toxone, 142

Toxophore of toxin, 134

Trembles, 338

Treponema, 443

pallidum, 451

pertenuis, 454

Trichomycetes, 372

Trichophyton, 393, 404, 408

megalosporon, 408

microsporon, 408

tonsurans, 408

Trickling filter, 292

Tropisms, 51

Trypanosoma, 423

brucei, 429

calmettei, 437

castellani, 436

cazalboui, 434

congolense, 433
Trypanosoma cruzi, 437

dimorphon, 432

donovani, 438

elmassiani, 431

equinum, 431

equiperdum, 426

evansi, 428

gambiense, 436

lewisi, 437

pecaudi, 433

rougeti, 420

theileri, 435

ugandense, 436

vespertilionis, 425

Trypanosomes, 423

cultivation, 426

morphology, 424

of birds, 437

Tse-tse fly, 429, 431, 437

Tubercle, miliary, 316

Tuberculin, 317

Alt's, 318, 321

Denys', 319

Hirschfelder's, 319

Klebs', 319

Koch's old, 318, 321

purified, 319

Landmann's, 319

new, of Koch, 320

reaction as anaphylactic reaction, 180

T. O., 319

T. R., 319

tests, anaphylactic, nature of, 322

conjunctival, 323

cutaneous, 323

Calmette's, 323

intradermal, 323

ophthalmo-, 323

subcutaneous injection, 321

von Pirquet's, 323

Wolf-Eisner, 323

Tuberculinum O., 319

R., 319

Tuberculocidin, 319

Tuberculol, 319

Tuberculosis, 308

Turgor, 55

Types of immunity, 122 
Typhoid dysentery subgroup, 261, 278 fever, 278

Ulcerative lymphangitis, 241

Ultramicroscope, 19,476

Ultramicroscopic organisms, 476 virus, 31

Undulating membrane, 424

Univalent vaccines, 173

Uschinsky's solution, 92

Vaccination, definition, 125, 161 to increase opsonins, 172

Vaccines, autogenic, 173 bacterins, 173

polyvalent, 173

preparation, 173

univalent, 173

Vacuoles, 34

in bacteria, 34

Vaginitis, contagious granular, of cattle, 211

Vegetative rod, 36

Verrucose vaginitis of cattle, 211

Vibrio, 79

choleræ, 369

group, 367

metschnikovi, 367

proteus, 371

Vibrion septique, 359

Virulence, definition, 119

Virus, 183

filterable, 31

ultramicroscopic, 31

von Pirquet's cutaneous reaction, 323

WaSSERmann syphilis test, 164

Water, bacteria of, 284

bacterial standards, 287

purification, 284, 289

qualitative examination, 287

quantitative examination, 285

interpretation, 286

self-purification, 289

Weigert's hypothesis, 133

West African tick fever, 446
White scours in calves, 265,266

diarrhea, 470

of chicks caused by Bacillus pulloruin, 277

by Coccidium tenellum, 469

Widal test, 151

macroscopic 153, 281

microscopic, 151, 152, 281

Wildseuche, 302

Wolf-Eisner tuberculin reaction, 323

Wooden tongue, 375

Woolsorter's disease, 331

Wound infection, Streptococcus pyogenes, 200

YAws, 454

Yeast ascospores, 40

cellulose, 38

chlamydospores, 40

classification, 82

spores, 40

Yeasts, cell inclusions, 38, 39

cytoplasm, 39

ectoplast, 39

form, 38

glycogen, 39

grouping, 38

morphology, 37

nucleus, 39

oil globules, 39

protoplasm, 38

reproduction, 38

size, 38

vacuoles, 39

Yellow fever, 488

ZOÖGLEA, 30

pulmonis equi, 226

Zwischenkörper, 158

Zygospore, 42, 43

of mucor, 43

Zymase, 58, 59

Zymophore of agglutinins, 148

of complement, 159

of enzymes, 145

of precipitins, 153

Zymotoxic group of agglutinins, 149 




\section{SAUNDERS' BOOKS}

\section{. \\ Pathology, Physiology Histology, Embryology and Bacteriology}

\section{W. B. SAUNDERS COMPANY 925 WALNUT STREET PHILADELPHIA 9. HENRIETTA STREET COVENT GARDEN, LONDON}

\section{LITERARY SUPERIORITY}

TE excellent judgment displayed in the publications of the house at the very beginning of its career, and the success of the modern business methods employed by it, at once attracted the attention of leading men in the profession, and many of the most prominent writers of America offered their books for publication. Thus, there were produced in rapid succession a number of works that immediately placed the house in the front rank of Medical Publishers: One need only cite such instances as Musser and Kelly's Treatment, Keen's Surgery, Kelly and Noble's Gynecology and Abdominal Surgery, Cabot's Differential Diagnosis, Mumford's Surgery, Cotton's Dislocations and Joint Fractures, Crandon's Surgical After-treatment, Sisson's Veterinary Anatomy, Anders and Boston's Medical Diagnosis, Bonney's Tuberculosis, Gant's Constipation and Obstruction, Jordan's Bacteriology, and Kemp on Stomach and Intestines. These books have made for themselves a place among the best works on their respective subjects.

A Complete Catalogue of our Publications will be Sent upon Request 


\section{Jordan's}

\section{General Bacteriology}

A Text-Book of General Bacteriology. By Edwin O. Jordan, Ph.D., Professor of Bacteriology in the University of Chicago and in Rush Medical College. Octavo of 594 pages, illustrated. Cloth, $\$ 3.00$ net.

\section{THE NEW (2d) EDITION}

Professor Jordan's work embraces the entire field of bacteriology, the nonpathogenic as well as the pathogenic bacteria being considered, giving greater emphasis, of course, to the latter. There are extensive chapters on methods of studying bacteria, including staining, biochemical tests, cultures, etc.; on the development and composition of bacteria ; on enzymes and fermentation-products; on the bacterial production of pigment, acid and alkali; and on ptomains and toxins. Especially complete is the presentation of the serum treatment of gonorrhea, diphtheria, dysentery, and tetanus. The relation of bovine to human tuberculosis and the ocular tuberculin reaction receive extensive consideration.

This work will also appeal to academic and scientific students. It contains chapters on the bacteriology of plants, milk and milk-products, air, agriculture, water, food preservatives, the processes of leather tanning, tobacco curing, and vinegar making; the relation of bacteriology to household administration and to sanitary engineering, etc.

Prof. Severance Burrage, Associate Professor of Sanitary Science, Purdue University.

"I ain much impressed with the completeness and accuracy of the book. It certainly covers the ground more completely than any other American book that I have seen."

\section{Buchanan's}

\section{Veterinary Bacteriology}

Veterinary Bacteriology. By Robert E. Buchanan, Ph.D., Professor of Bacteriology in the Iowa State College of Agriculture and Mechanic Arts. Octavo of 500 pages, with 214 illustrations.

\section{JUST READY}

Professor Buchanan's new work is a comprehensive one, presenting the practical side of bacteriology as applied in veterinary science, discussing thoroughly all bacteria causing diseases of the domestic animals. The author has gone minutely into the consideration of immunity, opsonic index, reproduction, sterilization, antiseptics, biochemic tests, culture media, isolation of cultures, the manufacture of the various toxins, antitoxins, tuberculins, and vaccines that have proved of diagnostic or therapeutic value. Then, in addition to bacteria and protozoa proper, he considers molds, mildews, smuts, rusts, toadstools, puff-balls, and the other fungi pathogenic for animals. Professor Buchanan is a forceful writer, and his book has all the earmarks of a master of his subject. 


\section{Dürck and Hektoen's General Pathologic Histology}

Atlas and Epitome of General Pathologic Histology. By $\mathrm{PR}_{\mathrm{R}}$. Dr. H. DüRck, of Munich. Edited, with additions, by Ludvig HeKtoen, M. D., Professor of Pathology in Rush Medical College, Chicago. I72 colored figures on 77 lithographic plates, 36 text-cuts, many in colors, and 353 pages. Cloth, $\$ 5.00$ net. In Saunders' Hand-Atlas Series.

This new Atlas will be found even more valuable than the two preceding volumes on Special Pathologic Histology, to which, in a manner, it is a companion work. The text gives the generally accepted views in regard to the significance of pathologic processes, explained in clear and easily understood language. The lithographs in some cases required as many as twenty-six colors to reproduce the original painting. Dr. Hektoen has made many additions of great value.

W. T. Councilman, M. D.,

Professor of Pathologic Anatomy, Harvard University.

"I have seen no plates which impress me as so truly representing histologic appearances as do these. The book is a valuable one."

\section{Howell's Physiology}

A Text-Book of Physiology. By William H. Howell, Ph.D., M. D., Professor of Physiology in the Johns Hopkins University, Baltimore, Md. Octavo of 999 pages, 295 illustrations. Cloth, $\$ 4.00$ net.

\section{THE NEW (3d) EDITION}

Dr. Howell has had many years of experience as a teacher of physiology in several of the leading medical schools, and is therefore exceedingly weil fitted to write a text-book on this subject. Main emphasis has been laid upon those facts and views which will be directly helpful in the practical branches of medicine. At the same time, however, sufficient consideration has been given to the experimental side of the science. The entire literature of physiology has been thoroughly digested by Dr. Howell, and the important views and conclusions introduced into his work. Illustrations have been most freely used.

\section{The Lancet, London}

"This is one of the best recent text-books on physiology, and we warmly commend it to the attention of students who desire to obtain by reading a general, all-round, yet concise survey of the scope, facts, theories, and speculations that make up its subject matter." 


\section{McFarland's Pathology}

A Text-Book of Pathology. By Joseph McFarland, M. D., Professor of Pathology and Bacteriology in the Medico-Chirurgical College of Philadelphia. Octavo of 856 pages, with 437 illustrations, many in colors. Cloth, $\$ 5.00$ net; Half Morocco, $\$ 6.50$ net.

\section{THE NEW (2d) EDITION}

You cannot successfully treat disease unless you have a practical, clinical knowledge of the pathologic changes produced by disease. For this purpose Dr. McFarland's work is well fitted. It was written with just such an end in view-to furnish a ready means of acquiring a thorough training in the subject, a training such as would be of daily help in your practice. For this edition every page has been gone over most carefully, correcting, omitting the obsolete, and adding the new. Some sections have been entirely rewritten. You will find it a book well worth consulting, for it is the work of an authority.

\section{St. Paul Medical Journal}

"It is safe to say that there are few who are better qualified to give a résumé of the modern views on this subject than McFarland. The subject-matter is thoroughly up to date."

\section{Boston Medical and Surgical Journal}

"It contains a great mass of well-classified facts. One of the best sections is that on the special pathology of the blood."

\section{McFarland's \\ Biology: Medical and General}

Biology: Medical and General.-By Joseph McFarland, M. D., Professor of Pathology and Bacteriology in the Medico-Chirurgical College of Phila. I $2 \mathrm{mo}, 440$ pages, 160 illustrations. Cloth, $\$ 1.75$ net.

\section{ILLUSTRATED}

This work is both a general and medical biology. The former because it discusses the peculiar nature and reactions of living substance generally; the latter because particular emphasis is laid on those subjects of special interest and value in the study and practice of medicine. The illustrations will be found of great assistance.

\section{Frederic P. Gorham, A. M., Brown University.}

"I am greatly pleased with it. Perhaps the highest praise which I can give the book is to say that it more nearly approaches the course I am now giving in general biology than any other work." 


\section{McFarland's}

\section{Pathogenic Bacteria}

\section{The New (6th) Edition, Revised}

A Text-Book Upon the Pathogenic Bacteria. By Joseph McFarLAND, M. D., Professor of Pathology and Bacteriology in the MedicoChirurgical College of Philadelphia, Pathologist to the Medico-Chirurgical Hospital, Philadelphia, etc. Octavo volume of 709 pages, finely illustrated. Cloth, $\$ 3.50$ net.

\section{FULLY ILLUSTRATED}

This book gives a concise account of the technical procedures necessary in the study of bacteriology, a brief description of the life-history of the important pathogenic bacteria, and sufficient description of the pathologic lesions accompanying the micro-organismal invasions to give an idea of the origin of symptoms and the causes of death. The illustrations are mainly reproductions of the best the world affords, and are beautifully executed. In this edition the entire work has been practically rewritten, old matter eliminated, and much new matter inserted.

\section{H. B. Anderson, M. D.}

Professor of Pathology and Bacteriology, Trinity Medical College, Toronto.

"The book is a satisfactory one, and I shall take pleasure in recommending it to the students of Trinity College."

\section{The Lancet, London}

"It is excellently adapted for the medical students and practitioners for whom it is avowedly written. . . The descriptions given are accurate and readable."

\section{Hill's Histology and Organogiraphy}

A Manual of Histology and Organography. By ChARLes Hill, M. D., formerly Assistant Professor of Histology and Embryology, Northwestern University, Chicago. I $2 \mathrm{mo}$ of 468 pages, 337 illustrations. Flexible leather, $\$ 2.00$ net.

\section{THE NEW (2d) EDITION}

Dr. Hill's work is characterized by a completeness of discussion rarely met in a book of this size. Particular consideration is given the mouth and teeth.

\section{Pennsylvania Medical Journal}

"It is arranged in such a manner as to be easy of access and comprebension. To any contemplating the study of histology and organography we would commend this work." 


\section{GET \\ THE BEST \\ American \\ THE NEW \\ STANDARD \\ Illustrated Dictionary}

Just Ready-New (6th) Edition, Entirely Reset-A New Work

The American Illustrated Medical Dictionary. A new and complete dictionary of the terms used in Medicine, Surgery, Dentistry, Pharmacy, Chemistry, Veterinary Science, Nursing, and kindred branches; with over 100 new and elaborate tables and many handsome illustrations. By W. A. Newman Dorland, M.D., Editor of "The American Pocket Medical Dictionary." Large octavo, 935 pages, bound in full flexible leather. Price, $\$ 4.50$ net; with thumb index, $\$ 5.00$ net.

\section{IT DEFINES ALL THE NEW WORDS-IT IS UP TO DATE}

Dorland's Dictionary defines hundreds of the newest terms not defined in any other dictionary-bar none. These new terms are live, active words, taken right from modern medical literature.

It gives the capitalization and pronunciation of all words. It makes a feature of the derivation or etymology of the words. In some dictionaries the etymology occupies only a secondary place, in many cases no derivation being given at all. In "Dorland," practically every word is given its derivation.

In "Dorland" every word has a separate paragraph, thus making it easy to find a word quickly.

The tables of arteries, muscles, nerves, veins etc., are of the greatest help in assembling anatomic facts. In them are classified for quick study all the necessary information about the various structures.

In "Dorland" every word is given its definition-a definition that defines in the fewest possible words. In some dictionaries hundreds of words are not defined at all, referring the reader to some other source for the information he wants at once.

Howard A. Kelly, M. D., Johns Hopkins University, Baltimore

"Dr. Dorland's dictionary is admirable. It is so well gotten up and of such convenient size. No errors have been found in my use of it."

J. Collins Warren, M. D., LL.D., F.R.C.S. (Hon.), Harvard Medical School

"I regard it as a valuable aid to my medical literary work. It is very complete and of convenient size to handle comfortably. I use it in preference to any other." 


\section{Stengel's}

\section{Text-Book of Pathology}

The New (5th) Edition

A Text-Book of Pathology. By Alfred Stengel, M. D., Professor of Medicine in the University of Pennsylvania. Octavo volume of 979 pages, with 400 text-illustrations, many in colors, and 7 full-page colored plates. Cloth, $\$ 5.00$ net; Sheep or Half Morocco, $\$ 6.50$ net.

\section{WITH 400 TEXT.CUTS, MANY IN COLORS, AND 7 COLORED PLATES}

In this work the practical application of pathologic facts to clinical medicine is considered more fully than is customary in works on pathology. While the subject of pathology is treated in the broadest way consistent with the size of the book, an effort has been made to present the subject from the point of view of the clinician. In the second part of the work the pathology of individual organs and tissues is treated systematically and quite fully under subheadings that clearly indicate the subject-matter to be found on each page. In this edition the section dealing with General Pathology has been most extensively revised, several of the important chapters having been practically rewritten. A very useful addition is an Appendix treating of th technic of pathologic methods, giving briefly the most important methods at present in use for the study of pathology, including, however, only those methods capable of giving satisfactory results. The book will be found to maintain fully its popularity.

\section{PERSONAL AND PRESS OPINIONS}

William H. Welch, M. D.,

Professor of Pathology. Johns Hopkins University, Baltimore, Md.

"I consider the work abreast of modern pathology, and useful to both students and practitioners. It presents in a concise and well-considered form the essential facts of general and special pathologic anatomy, with more than usual emphasis upon pathologic physiology."

\section{Ludvig Hektoen, M. D.,}

Professor of Pathology, Rush Medical College, Chicago.

"I regard it as the most serviceable text-book for students on this subject yet written by an American author."

\section{The Lancet, London}

"This volume is intended to present the subject of pathology in as practical a form as possible, and more especially from the point of view of the 'clinical pathologist.' These subjects have been faithfully carried out, and a valuable text-book is the result. We can most farorably recommend it to our readers as a thoroughly practical work on clinical pathology." 


\title{
Mallory and Wright's Pathologic Technique
}

\author{
Just Ready-New (5th) Edition, Revised
}

Pathologic Technique. A Practical Manual for Workers in Pathologic Histology, including Directions for the Performance of Autopsies and for Clinical Diagnosis by Laboratory Methods. By Frank B. Mallory, M. D., Associate Professor of Pathology, Harvard University; and JAmes H. Wright, M. D., Director of the Pathologic Laboratory, Massachusetts General Hospital. Octavo of 500 pages, with 152 illustrations. Cloth, $\$ 3.00$ net.

\section{WITH CHAPTERS ON POST-MORTEM TECHNIQUE AND AUTOPSIES}

In revising the book for the new edition the authors have kept in view the needs of the laboratory worker, whether student, practitioner, or pathologist, for a practical manual of histologic and bacteriologic methods in the study of pathologic material. Many parts have been rewritten, many new methods have been added, and the number of illustrations has been considerably increased. Among the new matter are the following: Smith's staining method for encapsulated bacteria ; the antiformin method for detection and cultivation of tubercle bacilli; Musgrave's and Clegg's method for the cultivation of amebæ; Wright's method for staining myelin sheaths in frozen sections ; Ghoreyeb's method for spirochetes ; Alzheimer's method for cytologic examination of cerebrospinal fluid; Giemsa's new method for protozoa and bacteria in sections, and the Wassermann-Noguchi tests for syphilis.

\section{PERSONAL AND PRESS OPINIONS}

Wm. H. Welch, M. D.,

Professor of Pathology. Johns Hopkins University, Baltimore.

"I have been looking forward to the publication of this book, and I am glad to say that I find it a most useful laboratory and post-mortem guide, full of practical information and well up to date."

\section{Boston Medical and Surgical Journal}

" This manual, since its first appearance, has been recognized as the standard guide in pathological technique, and has become well-nigh indispensable to the laboratory worker."

Journal of the American Medical Association

"One of the most complete works on the subject, and one which should be in the library of every physician who hopes to keep pace with the great advances made in pathology." 


\section{Heisler's}

\section{Text-Book of Embryology}

\section{Just Ready-The New (4th) Edition}

A Text-Book of Embryology. By John C. Heisler, M.D., Professor of Anatomy in the Medico-Chirurgical College, Philadelphia. Octavo volume of 450 pages, with 212 illustrations, 32 of them in colors. Cloth, $\$ 3.00$ net.

\section{WITH 212 ILLUSTRATIONS, 32 IN COLORS}

The fact of embryology having acquired in recent years such great interest in connection with the teaching and with the proper comprehension of human anatomy, it is of first importance to the student of medicine that a concise and yet sufficiently full text-book upon the subject be available. This new edition represents all the latest advances recently made in the science of embryology. Many portions have been entirely rewritten, and a great deal of new and important matter added. A number of new illustrations have also been introduced and these will prove very valuable. The previous editions of this work filled a gap most admirably, and this new edition will undoubtedly maintain the reputation already won. Heisler's Embryology has become a standard work.

\section{PERSONAL AND PRESS OPINIONS}

\section{G. Carl Huber, M.D.,}

Professor of Embryology at the Wistar Institute, University of Pennsylvania.

"I find the second edition of 'A Text-Book of Embryology' by Dr. Heisler an improvement on the first. The figures added increase greatly the value of the work. I am again recommending it to our students."

William Wathen, M.D.,

Professor of Obstetrics, Abdominal Surgery, and Gynecology, and Dean, Kentucky School of Medicine, Louisville, Ky.

"It is systematic, scientific, full of simplicity, and just such a work as a medical student will be able to comprehend."

\section{Birmingham Medical Review, England}

"We can most confidently recommend Dr. Heisler's book to the student of biology or medicine for his careful study, if his aim be to acquire a sound and practical acquaintance with the subject of embryology." 


\section{Wells' Chemical Pathology}

Chemical Pathology.-Being a Discussion of General Pathology from the Standpoint of the Chemical Processes Involved. By $\mathrm{H}$. Gideon Welts, Ph. D., M. D., Assistant Professor of Pathology in the University of Chicago. Octavo of 549 pages. Cloth, $\$ 3.25$ net.

\section{A PRACTICAL BOOK}

Dr. Wells' work is written for the physician, for those engaged in research in pathology and physiologic chemistry, and for the medical student. In the introductory chapter are discussed the chemistry and physics of the animal cell, giving the essential facts of ionization, diffusion, osmotic pressure, etc., and the relation of these facts to cellular activities. Special chapters are devoted to Diabetes and to Uric-acid Metabolism and Gout.

\section{Wm. H. Welch, M. D.}

Professor of Pathology, Johns Hopkins University.

"The work fills a real need in the English literature of a very important subject, and I shall be glad to recommend it to my students."

\section{Lusk's \\ Elements of Nutrition}

Elements of the Science of Nutrition. By Graham Lusk, Ph. D., Professor of Physiology at Cornell Medical School. Octavo volume of 302 pages. Cloth, $\$ 3.00$ net.

\section{THE NEW (2d) EDITION}

Prof. Lusk presents the scientific foundations upon which rests our knowledge of nutrition and metabolism, both in health and in disease. There are special chapters on the metabolism of diabetes and fever, and on purin metabolism. The work will also prove valuable to students of animal dietetics at agricultural stations.

\section{Lewellys F. Barker, M. D.}

Professor of the Principles and Practice of Medicine, Johns Hopkins University.

"I shall recommend it highly to my students. It is a comfort to have such a discussion of the subject in English." 


\section{Böhm, Davidoff, and}

\section{Huber's Histology}

A Text-Book of Human Histology. Including Microscopic Tech. nic. By Dr. A. A. Böhm and Dr. M. von Davidoff, of Munich, and G. Garl Huber, M.D., Professor of Embryology at the Wistar Institute, University of Pennsylvania. Handsome octavo of 528 pages, with 36 I beautiful original illustrations. Flexible cloth, $\$ 3.50$ net.

\section{THE NEW (2d) EDITION, ENLARGED}

The work of Drs. Böhm and Davidoff is well known in the German edition, and has been considered one of the most practically useful books on the subject of Human Histology. This second edition has been in great part rewritten and very much enlarged by Dr. Huber, who has also added over one hundred original illustrations. Dr. Huber's extensive additions have rendered the work the most complete students' text-book on Histology in existence.

\section{Boston Medical and Surgical Journal}

"Is unquestionably a text-book of the first rank, having been carefully written by thorough masters of the subject, and in certain directions it is much superior to any other histological manual."

\section{Drew's Invertebrate Zoölogy}

A Laboratory Manual of Invertebrate Zoölogy. By Gilman A. DREw, PH.D., Professor of Biology at the University of Maine. With the aid of Members of the Zoölogical Staff of Instructors of the Marine Biological Laboratory, Woods Holl, Mass. I 2 mo of 200 pages. Cloth, $\$ 1.25$ net.

\section{A LABORATORY WORK}

The subject is presented in a logical way, and the type method of study has been followed, as this method has been the prevailing one for many years.

\section{Prof. Allison A. Smyth, Jr., Virginia Polytechnic Institute}

"I think it is the best laboratory manual of zoölogy I have yet seen. The large number of forms dealt with makes the work applicable to almost any locality." 


\section{Norris' Cardiac Pathology}

Studies in Cardiac Pathology. By George W. Norris, M.D., Associate in Medicine at the University of Pennsylvania. Large octavo of 235 pages, with 85 superb illustrations. Cloth, $\$ 5.00$ net.

\section{JUST READY}

The wide interest being manifested in heart lesions makes this book particularly opportune. The illustrations are superb and are faithful reproductions of the specimens photographed. Each illustration is accompanied by a detailed description; besides, there is ample letter press supplementing the pictures. Throughout the book considerable matter of a diagnostic and therapeutic nature has been interwoven, making the work more valuable to the general physician. The subjects treated are endocarditis ; diseases of the aortic, mitral, tricuspid, and pulmonary orifices; pericarditis, hypertrophy, dilatation, aneurism, syphilis, and congenital lesions.

\section{McConnell's Pathology}

A Manual of Pathology. By Guthrie McConnell, M.D., Professor of Bacteriology and Pathology at Temple University, Philadelphia. I $2 \mathrm{mo}$ of 523 pages, with 170 illustrations. Flexible leather, $\$ 2.50$ net.

\section{JUST READY-NEW (2d) EDITION}

Dr. McConnell has discussed his subject with a clearness and precision of style that make the work of great assistance to both student and practitioner. The illustrations have been introduced for their practical value.

\section{New York State Journal of Medicine}

"The book treats the subject of pathology with a thoroughness lacking in many works of greater pretension. The illustrations-many of them original-are profuse and of exceptional excellence."

\section{Hektoen and Riesman's Pathology}

American Text-Book of Pathology. Edited by Ludvig HekToen, M.D., Professor of Pathology, Rush Medical College, Chicago; and David Riesman, M.D., Professor of Clinical Medicine, Philadelphia Polyclinic. Octavo of 1245 pages, 443 illustrations, 66 in colors. Cloth, $\$ 7.50$ net; Half Morocco, $\$ 9.00$ net. 


\section{Dürck and Hektoen's Special Pathologic Histology}

Atlas and Epitome of Special Pathologic Histology. By DR. H. DüRCK, of Munich. Edited, with additions, by Ludvig Hek Toen, M. D., Professor of Pathology, Rush Medical College, Chicago. In two parts. Part I.-Circulatory, Respiratory, and Gastro-intestinal Tracts. I20 colored figures on 62 plates, and 158 pages of text. Part II.-Liver, Urinary and Sexual Organs, Nervous System, Skin, Muscles, and Bones. 123 colored figures on 60 plates, and 192 pages of text. Per part: Cloth, $\$ 3.00$ net. In Saunders' Hand-Atlas Series.

The great value of these plates is that they represent in the exact colors the effect of the stains, which is of such great importance for the differentiation of tissue. The text portion of the book is admirable, and, while brief, it is entirely satisfactory in that the leading facts are stated, and so stated that the reader feels he has grasped the subject extensively.

\section{William H. Welch, M. D.,}

Professor of Pathology, Johns Hopkins University, Baltimore.

"I consider Dürck's 'Atlas of Special Pathologic Histology, edited by Hektoen, a very useful book for students and others. The plates are admirable."

\section{Sobotta and Huber's Human Histology}

Atlas and Epitome of Human Histology. By Privatdocent Dr. J. SовоттA, of Würzburg. Edited, with additions, by G. CARL HubER, M. D., Professor of Histology and Embryology in the University of Michigan, Ann Arbor. With 214 colored figures on 80 plates, 68 text-illustrations, and 248 pages of text. Cloth, $\$ 4.50$ net. In Saunders' Hand-Atlas Series.

\section{INCLUDING MICROSCOPIC ANATOMY}

The work combines an abundance of well-chosen and most accurate illustrations, with a concise text, and in such a manner as to make it both atlas and text. book. The great majority of the illustrations were made from sections prepared from human tissues, and always from fresh and in every respect normal specimens. The colored lithographic plates have been produced with the aid of over thirty colors.

\section{Boston Medical and Surgical Journal} beauty."

"In color and proportion they are characterized by gratifying accuracy and lithographic 


\section{Bosanquet on Spirochaetes}

Spirochrtes: A Review of Recent Work, with Some Original Observations. By W. Cecil Bosanguet, M.D., Fellow of the Royal College of Physicians, London. Octavo of I 52 pages, illustrated. $\$ 2.50$ net.

\section{JUST READY}

This is a complete and authoritative monograph on the spirochrtes, giving morphology, pathogenesis, classification, staining, etc. Pseudospirochætes are also considered, and the entire text well illustrated. The high standing of Dr. Bosanquet in this field of study makes this new work particularly valuable.

\section{Levy and Klemperer's Clinical Bacteriology}

The Elements of Clinical Bacteriology. By Drs. ERnST LEVy and Felix Klemperer, of the University of Strasburg. Translated and edited by Augustus A. Eshner, M. D., Professor of Clinical Medicine, Philadelphia Polyclinic. Octavo volume of 440 pages, fully illustrated. Cloth, $\$ 2.50$ net.

S. Solis-Cohen, M. D.,

Professor of Clinical Medicine, Jefferson Medical College, Philadelphia.

"I consider it an excellent book. I have recommended it in speaking to my students."

\section{Lehmann, Neumann, and Weaver's Bacteriology}

Atlas and Epitome of Bacteriology: INCLUDING A TEXT-BOOK of Special Bacteriologic Diagnosis. By Prof. Dr. K. B. Lehmann and Dr. R. O. Neumann, of Würzburg. From the Second Revised and Enlarged German Edition. Edited, with additions, by G. H. WEAvER, M. D., Assistant Professor of Pathology and Bacteriology, Rush Medical College, Chicago. In two parts. Part I. -632 colored figures on 69 lithographic plates. Part II. - 5 I I pages of text, illustrated. Per part: Cloth, \$2.50 net. In Saunders' Hand-Atlas Series. 


\section{Eyre's Bacteriologic Technique}

The Elements of Bacteriologic Technique. A -Laboratory Guide for the Medical, Dental, and Technical Student. By J. W. H. Eyre, M. D., F. R. S. Edin., Lecturer on Bacteriology at the Medical and Dental Schools, London. Octavo of 375 pages, with I 70 illustrations. Cloth, $\$ 2.50$ net.

\section{American Text-Book of Physiology}

Second Edition

American Text-Book of Physiology. In two volumes. Edited by William H. Howell, Ph. D., M.D., Professor of Physiology in the Johns Hopkins University, Baltimore, Md. Two royal octavos of about 600 pages each, illustrated. Per volume: Cloth, $\$ 3.00$ net; Half Morocco, $\$ 4.25$ net.

"The work will stand as a work of reference on physiology. To him who desires to know the status of modern physiology, who expects to obtain suggestions as to further physiologic inquiry, we know of none in English which so eminently meets such a demand."The Medical News.

\section{Warren's Pathology and Therapeutics Second Edition}

Surgical Pathology and Therapeutics. By John Collins Warren, M. D., LL.D., F. R. C. S. (Hon.), Professor of Surgery, Harvard Medical School. Octavo, 873 pages, I 36 relief and lithographic illustrations, 33 in colors. With an Appendix on Scientific Aids to Surgical Diagnosis and a series of articles on Regional Bacteriology. Cloth, $\$ 5.00$ net; Half Morocco, $\$ 6.50$ net.

\section{Gorham's Bacteriology}

A Laboratory Course in Bacteriology. For the Use of Medical, Agricultural, and Industrial Students. By Frederic P. Gorham, A. M., Associate Professor of Biology in Brown University, Providence, R. I., etc. I 2 mo of 192 pages, with 97 illustrations. Cloth, $\$ 1.25$ net.

"One of the best students' laboratory guides to the study of bacteriology on the market. ... The technic is thoroughly modern and amply sufficient for all practical purposes."-American Journal of the Medical Sciences.

\section{Raymond's Physiology}

New (3d) Edition

Human Physiology. By Joseph H. Raymond, A. M., M. D., Professor of Physiology and Hygiene, Long Island College Hospital, New York. Octavo of 685 pages, with 444 illustrations. Cloth, $\$ 3.50$ net.

"The book is well gotten up and well printed, and may be regarded as a trustworthy guide for the student and a useful work of reference for the generai practitioner. The illustrations are numerous and are well executed."-The Lancet, London. 


\section{Ball's Bacteriology}

Sixth Edition, Revised

EsSENTIALS OF BACTERIOLOGY: being a concise and systematic introduction to the Study of Micro-organisms. By M. V. BALl, M. D., Late Bacteriologist to St. Agnes' Hospital, Philadelphia. I 2 mo of 289 pages, with I 35 illustrations, some in colors. Cloth, \$1.00 net. In Saunders' Question-Compend Series.

"The technic with regard to media, staining, mounting, and the like is culled from the latest authoritative works." - The Medical Times, New York.

\section{Budgett's Physiology}

New (3d) Edition

Essentials of Physiology. Prepared especially for Students of Medicine, and arranged with questions following each chapter. By Sidney P. Budgetr, M. D., formerly Professor of Physiology, Washington University, St. Louis. Revised by Havan Emerson, M. D., Demonstrator of Physiology, Columbia University. I 2 mo volume of 250 pages, illustrated. Cloth, \$1.00 net. Saundcrs' Question-Compend Series.

"He has an excellent conception of his subject. . . It is one of the most satisfactcry books of this class"-University of Pennsylvania Medical Bulletin.

\section{Leroy's Histology}

New (4th) Edition

Essentials of Histology. By Louis Leroy, M. D., Professor of Histology and Pathology, Vanderbilt University, Nashville, Tennessee. r $2 \mathrm{mo}, 263$ pages, with 92 original illustrations. Cloth, $\$ 1.00$ net. In Saunders' Question-Compend Series.

\footnotetext{
"The work in its present form stands as a model of what a student's aid should be; and we unhesitatingly say that the practitioner as well would find a glance through the book of lasting benefit."-The Medical World, Philadelphia.
}

\section{Barton and Wells' Medical Thesaurus}

A Thesaurus of Medical Words and Phrases. By Wilfred M. Barton, M. D., Assistant Professor of Materia Medica and Therapeutics, and WALter A. Wells, M.D., Demonstrator of Laryngology, Georgetowr. University, Washington, D. C. I $2 \mathrm{mo}, 534$ pages. Flexible leather, $\$ 2.50$ net; thumb indexed, $\$ 3.00$ net.

\section{American Pocket Dictionary}

Just Ready New (7th) Edition

Dorland's Pocket Medical Dictionary. Edited dy W. A. Newman Dorland, M. D., Editor "American Illustrated Medical Dictionary." Containing the pronunciation and definition of the principal words used in medicine and kindred sciences, with 64 extensive tables. 6 ro pages. Flexible leather, with gold edges, $\$ 1.00$ net; with patent thumb index, $\$ 1.25$ net.

\footnotetext{
"I can recommend it to our students without reserve."-J. H. Holland, M. D., of the Jefferson Medical College, Philadelphia.
} 




$\frac{j u 2 a}{300}$ nev

IC 88503 
$(4)$

$+4$

$4+2$

1.

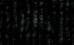

(1)

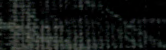

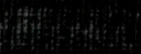

Han

anithit 